$16 r^{\circ}$

, $12+5$

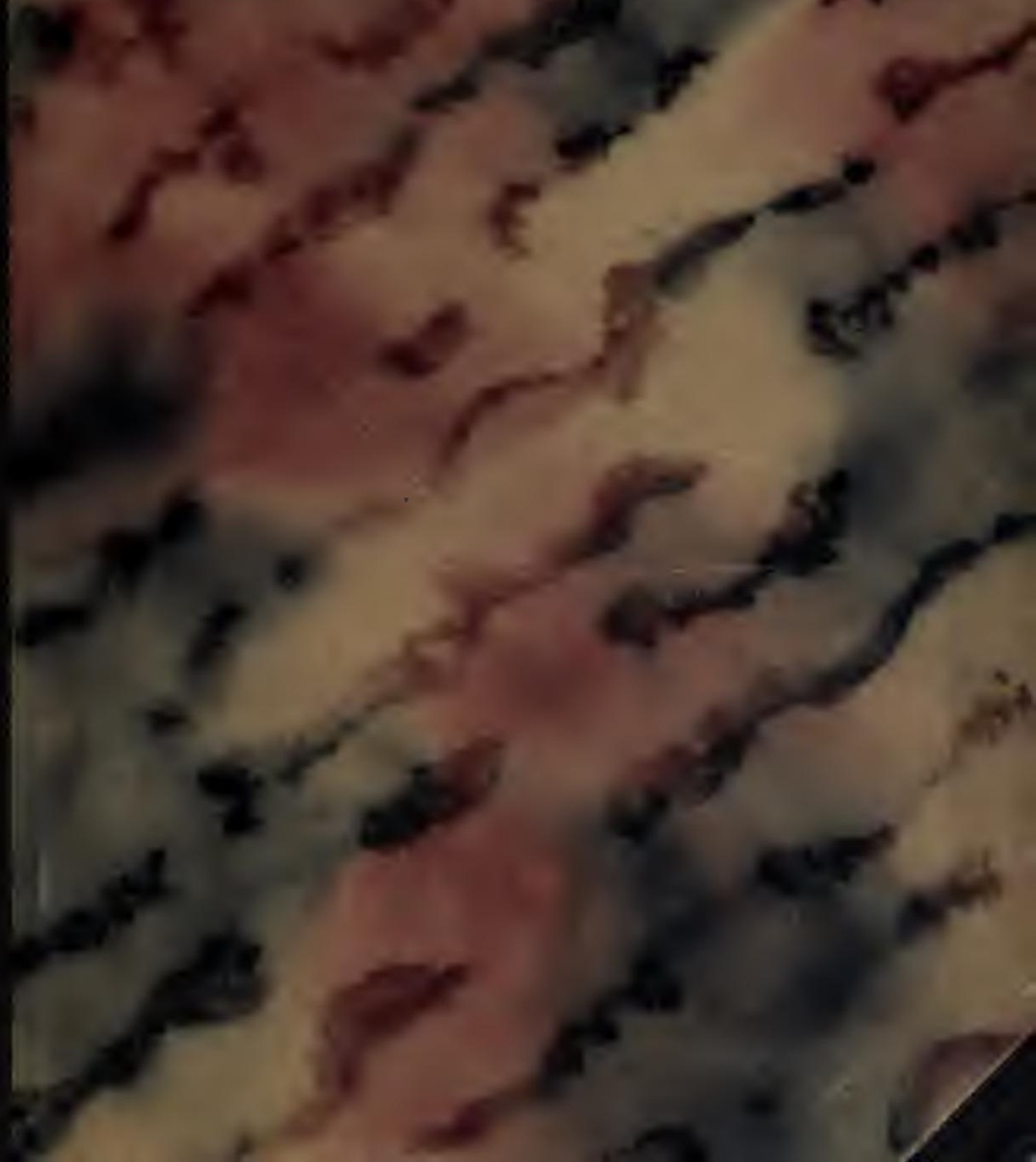





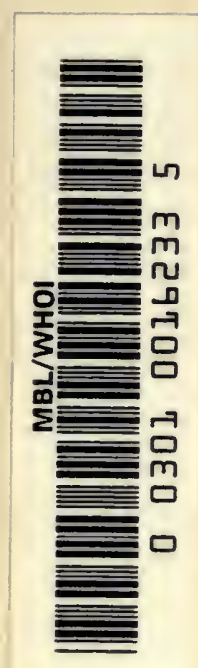






\section{Monographien einheimischer Tiere}

Herausgegeben von

Prof. Dr. H. E. Ziegler, Stuttgart, und Prof. Dr. R. Woltereck, Leipzig

\section{DIE STRUDELWÜRMER (TURBELLARIA)}

Von

\section{Dr. Paul Steinmann}

Naturgeschichtslehrer an der Aargauischen Kantonschule und Privatdozent an der Universität Basel

IIII

Dr. Erinst Bresslau

Profeasor an der Universität StraBburg

Mit 2 Tafeln und 156 Abbildungen im Text

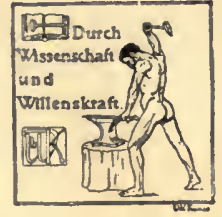

Leipzig 1913

Verlag von Dr. Werner Klinkhardt. 
Drudk von Julius Klinkhardt, Leipzig. 


\section{Dem Altmeister \\ und unermüdlichen Förderer der Turbellarienkunde}

\section{Herrn Hofrat Prof. Dr. L.v. Graff}

in dankbarer Verehrung zugeeignet 



\section{Vorrede}

Der vorliegende Band der „Monographien einheimischer Tiere" ist zwar betitelt: "Die Strudelwürmer (Turbellaria)" will aber in keiner Weise als eine zusammenfassende Bearbeitung aller dieser Formen gelten. Dem Plane der Monographien entsprechend sucht er vielmehr, durch allseitige Schilderung des Baues und der Lebensweise einiger leicht zugänglicher Turbellarienarten die wesentlichen Züge der Gruppe herauszuarbeiten.

In den Vordergrund stellten wir die Süßwassertricladen, die bekannteste einheimische Turbellariengruppe, gleichzeitig die einzige Abteilung der Strudelwürmer, für die eine wissenschaftliche Zusammenfassung bisher fehlt. Hls Vertreter der Rhabdocoeliden wählten wir Mesostoma ehrenbergi, das infolge seiner Größe und Durchsichtigkeit ein besonders günstiges Untersuchungsobjekt darstellt. Diese Formen waren uns durch langjährige Untersuchungen vertraut, und es konnten daher in der Monographie viele bisher unveröffentlichte Beobachtungen über sie verwertet werden. Unser Buch unterscheidet sich in dieser Hinsicht von seinen Vorgängern: Es trägt teilweise den Chararkter einer Originalpublikation. Das gilt besonders für die biologischen Abschnitte.

Dagegen haben wir die übrigen Turbellariengruppen, die Acoelen, Polycladen, Allöocoelen und die maricolen und terricolen Tricladen so weit vernachlässigt, als sich dies mit der Aufgabe vereinigen ließ, dem Laien eine Vorstellung über den Bau, die Entwicklung und die Lebensweise der Strudelwürmer zu vermitteln.

Bei den mannigfachen, für Nicht-Zoologen kaum überwindlichen Schwierigkeiten, die sich einer anatomischen Untersuchung 
unserer Tiere entgegenstellen, haben wir den anatomischen Teil relativ kurz gehalten und dafür den biologischen Abschnitt breiter behandelt. Die dort mitgeteilten Tatsachen können meist ohne spezielle Vorkenntnisse und Hilfsmittel nachgeprüft werden. Ferner haben wir uns bemüht, möglichst einfache und bequeme $\mathrm{Be}-$ stimmungstabellen auszuarbeiten, durch welche auch der Nichtfachmann in Stand gesetzt werden soll, die ihm zugänglichen Strudelwürmer $z u$ bestimmen. So ist unser Buch kein wissenschaftliches Nachschlagewerk, es soll vielmehr lediglich als Einführung in die Turbellarienkunde dienen. Wir haben aus diesem Grunde in unsern Darstellungen Hinweise auf Literatur und Autoren so viel wie möglich unterdrückt. Auch das beigegebene Literaturverzeichnis ist auf das Notwendigste gekürzt und nennt hauptsächlich Werke aus neuerer Zeit, sowie solche, in denen umfassende Literaturverzeichnisse enthalten sind.

Was die Verteilung des Stoffes unter die beiden Autoren anbelangt, so ist $z u$ bemerken, daß alles, was die Tricladen betrifft, von Steinmann, alles was von den Rhabdocoelen handelt, von Bresslau stammt. Für die Einleitung ist Steinmann, für das Kapitel "Entwidklung und Stammesgeschichte der Turbellarien" sind beide Autoren gemeinsam verantwortlich.

Die Vorlagen für die Farbentafel wurden in freundlichster Weise von den Herren Dr. W. Bigler in Basel (Abb. 1, 2 u. 3) und Kunstmaler Leschhorn in Straßburg (Abb. 4 u. 5) hergestellt. Bei der Verfertigung der Textfiguren wurden die Autoren von den Herren Dr. Burr und Dr.v. Voss in Straßburg, Dr.W. Bigler, A. Zuberbühler und Walter Steinmann in Basel, sowie Walter Boveri in Aarau unterstützt; die Bleistiftzeichnungen für Tafel II entwarfen die Herren Dr. W. Bigler (Abb. 1 u. 2) und A. Zuberbühler (Abb. 3, 4 u. 5). Ihnen allen sei auch an dieser Stelle bestens gedankt.

Aarau und Straßburg

Im Juli 1913

Die Autoren 


\section{Inhaltsverzeichnis}

Einleitung .

Seite

Systematische Stellung . . . . . . . . . . . . . . . . 1

Diagnose . . . . . . . . . . . . . . . . . 4

Systematische Ubersicht über die Unterordnungen . . . . . 4

Geschichte der Strudelwurmforschung . . . . . . . . . . . 6

Technische Vorbemerkungen . . . . . . . . . . . . . 8

Tricladida . . . . . . . . . . . . . . . . . 8

Rhabdocoelida . . . . . . . . . . . . 15

Tricladen . . . . . . . . . . . . . . . . 19

Anatomie. . . . . . . . . . . . . . . 19

HuBeres . . . . . . . . . . . . . . 19

Gestalt . . . . . . . . . . . . . 19

Farbe . . . . . . . . . . . . . . . . 21

Körperöffnungen . . . . . . . . . . . . . . . . 23

Sauggrube. . . . . . . . . . . . . 24

Histologie und Organologie . . . . . . . . . . . . 25

Integument . . . . . . . . . . . . . . . 25

Cilien . . . . . . . . . . . . . . . 26

Pharynxintegument . . . . . . . . . . . . 27

Stäbchen . . . . . . . . . . . . . . . 29

Klebzellen. . . . . . . . . . . . . . . . 31

Basalmembran . . . . . . . . . . . 32

Muskulatur . . . . . . . . . . . . . . . . . . 33

Hautmuskelschlauch . . . . . . . . . . . . . . 33

Parenchymmuskeln . . . . . . . . . . . . . . 35

Organmuskeln . . . . . . . . . . . . . . 36

Parenchym . . . . . . . . . . . . . . . . . 37

Drüsen . . . . . . . . . . . . . . . . . . . . 38

Verdauungsapparat . . . . . . . . . . . . . . . 39

Pharynx . . . . . . . . . . . . . . . . . . 42

Darmepithel . . . . . . . . . . 46 
Exkretionssystem .

Genitalapparat . 46

Hoden

Samengänge . . . . . . . . . . . . . . . 54

Kopulationsorgan . . . . . . . . . . . . . . 55

Germarien . . . . . . . . . . . . . 57

Vitellarien . . . . . . . . . . . . . 59

Eileiter . . . . . . . . . . . . . . 59

Gestielter Drüsensadk . . . . . . . . . . . 61

Muskulöses Drüsenorgan . . . . . . . . . . 65

Nervensystem . . . . . . . . . . . . . . . . 70

Histologisches . . . . . . . . . . . . . . . . 70

Allgemeine Morphologie . . . . . . . . . . . 71

Nervensystem der SüBwassertricladen . . . . . . 73

Sinnesorgane . . . . . . . . . . . . 80

Augen . . . . . . . . . . . . . . . . . . 80

Hautsinnesorgane . . . . . . . . . . . 84

Hurikularsinnesorgane . . . . . . . . . . 84

Tentakeln . . . . . . . . . . . . . . . . . 85

Tentakelbläschen. . . . . . . . . . . . . . . 85

Biologie. . . . . . . . . . . . . 86

Bewegung . . . . . . . . . . . . 86

Ernährung . . . . . . . . . . . . . 86

Beutefang . . . . . . . . . . . . 9 90

Nahrungsaufnahme . . . . . . . . . . 92

Verdauung . . . . . . . . . . . . 93

Nahrungsspeicherung . . . . . . . . . . . . . 94

Parasitismus . . . . . . . . . . . . . . . . 95

Commensalismus . . . . . . . . . . . . . . . 95

Hunger . . . . . . . . . . . . 96

Exkretion . . . . . . . . . . . . . . . 98

Geschlechtliche Fortpflanzung durch Eikapseln . . . . . 99

Begattung . . . . . . . . . . . . . . 99

Eikapselbildung . . . . . . . . . . . . . . 101

Zeit der Kapselablage. . . . . . . . . . . . . 104

Hutotomie und ungeschlechtliche Fortpflanzung durch Querteilung. . . . . . . . . . . . . 107

Regeneration . . . . . . . . . . . . . . 115

Unterschiede im Regenerationsvermögen der einzelnen Arten . . . . . . . . . . . . . . . . . . 116

Dauer der Regeneration . . . . . . . . 117 


\section{- IX -}

AuBere Faktoren in ihrem fördernden und hemmenden EinfluB auf den Regenerationsvorgang. . . . . . 117

HuBere Formregulation . . . . . . . . . . . . 118

Doppelbildungen und Heteromorphosen . . . . . . 123

Histologie der Regeneration . . . . . . . . . . 128

Transplantation . . . . . . . . . . . . . . . . 128

Natürliche MiBbildungen . . . . . . . . . . . . . 129

Mehrfachbildungen äuBerer Körperteile und Organe . 129

Polypharyngie. . . . . . . . . . . . . . . . 131

Sinnestätigkeit . . . . . . . . . . . . . . . . . 132

Licht . . . . . . . . . . . . . . . . 133

Temperatur . . . . . . . . . . . . . . . . . 141

Chemische Verhältnisse des Wohnmediums . . . . . 142

Strömung . . . . . . . . . . . . . . . . . 145

Berührung und Erschütterung . . . . . . . . . . 146

Feinde und Parasiten der Tricladen. . . . . . . . . 148

Feinde . . . . . . . . . . . . . . . . . . 148

parasiten . . . . . . . . . . . . . . 149

Oekologie . . . . . . . . . . . . . 149

Aufenthaltsorte. . . . . . . . . . . . . . 149

Verbreitung . . . . . . . . . . . . . . 154

Aktive Verbreitung . . . . . . . . . . . . . 154

Gelegenheitswanderungen . . . . . . . . . 154

Passive Verbreitung. . . . . . . . . . . . 157

Verschwemmung . . . . . . . . . . . . . . . 157

Verschleppung. . . . . . . . . . . . . . 158

Allgemeine Verbreitung . . . . . . . . . . 16!

Verbreitung der Bachplanarien . . . . . . . . . 162

Systematik . . . . . . . . . . . . . . 173

Tricladida maricola . . . . . . . . . . . . . . 174

" terricola . . . . . . . . . . . . . . 176

"paludicola . . . . . . . . . . . . . . . 176

Bestimmungstabelle I . . . . . . . . . . . . . . . 177

Bestimmungstabelle II . . . . . . . . . . . . . . . 180

Speziesdiagnosen . . . . . . . . . . . . . . 183

Rhabdocoelida . . . . . . . . . . . . 202

Anatomie . . . . . . . . . . . . . 202

HuBeres . . . . . . . . . . . . 202

Gestalt . . . . . . . . . . . . . 202

Farbe .. . . . . . . . . . . . 204 
Seite

Histologie und Organologie . . . . . . . . . . . . 207

Integument . . . . . . . . . . . . . . . 207

Cilien . . . . . . . . . . . . . . . . . . 208

Stäbchen . . . . . . . . . . . . . . 209

Nesselkapseln .. . . . . . . . . . . . 211

Hautdrüsen . . . . . . . . . . . . . . 213

Basalmembran . . . . . . . . . . . . . . 214

Hautmuskelschlauch . . . . . . . . . . . . . 214

Körpermuskulatur . . . . . . . . . . . . . . 215

Parenchym . . . . . . . . . . . . . . 219

Verdauungsapparat . . . . . . . . . . 221

Pharynx . . . . . . . . . . . . . . . 222

Darm . . . . . . . . . . . . . . . 228

Exkretionssystem . . . . . . . . . . . . . . 230

Genitalapparat von Mesostoma ehrenbergi . . . . . . 235

Männliche Organe . . . . . . . . . . . 236

Hoden . . . . . . . . . . . . . . . 236

Samengänge . . . . . . . . . . . . 236

Kopulationsorgan . . . . . . . . . . . . 238

Weibliche Organe . . . . . . . . . . . . 239

Germarien . . . . . . . . . . . . . 239

Receptaculum seminis. . . . . . . . . 241

Vitellarien . . . . . . . . . . . . . 241

Ductus communis und Atrium genitale . . . . . 243

Anhangsorgane . . . . . . . . . . . . 243

Uterus . . . . . . . . . . . . . . 243

Bursa copulatrix . . . . . . . . . . . . . 244

Geschlechtsapparat der übrigen Rhabdocoeliden . . . . 244

Nervensystem . . . . . . . . . . . . . . . . 252

Topographie . . . . . . . . . . . . . . 252

Histologie . . . . . . . . . . . . . 257

Sinnesorgane . . . . . . . . . . . . 259

Auge . . . . . . . . . . . . . . . . 259

Statocysten . . . . . . . . . . . . 261

Ubrige Sinnesorgane . . . . . . . . . . . . 261

Hautsinnes- und Tastorgane, Wimpergrübchen . . . 261

Biologie. . . . . . . . . . . . . . 264

Bewegung . . . . . . . . . . 264

Ernährung . . . . . . . . . . . . . 270

Ernährungsweise (Allgemeines) . . . . . . . . . 270

Parasitismus . . . . . . . . . . . 271 
Symbiose mit Algen . . . . . . . . . . . 272

Nahrung von Mesostoma ehrenbergi . . . . . 273

Beutefang . . . . . . . . . . . . . 275

Hunger . . . . . . . . . . . . 278

Defäkation, Exkretion . . . . . . . . . 279

Geschlechtliche Fortpflanzung . . . . . . . . . 279

Begattung . . . . . . . . . . . . . 279

Bildung der Dauereier. . . . . . . . . . . 281

Bildung der Subitaneier . . . . . . . . . . 284

Hufeinanderfolge der Generationen . . . . . . . . 287

Biologische Bedeutung der Subitan - und Dauereier . . 289

Ursachen der verschiedenen Sexualität der Sommer-,

Herbst- und Wintertiere . . . . . . . . 294

Milieueinflüsse und Fortpflanzungsgeschwindigkeit . . 303

Ungeschlechtliche Fortpflanzung durch Querteilung . . . 308

Regeneration . . . . . . . . . . . . . . . . . 311

Mangel des Regenerationvermögens bei Mes. ehrenbergi 311

Natürliche MiBbildungen . . . . . . . . . . . . 313

Sinnestätigkeit . . . . . . . . . . . . . . . . . 314

Feinde und Parasiten der Rhabdocoeliden . . . . 315

Oekologie und Verbreitung . . . . . . . . . . 317

Systematik . . . . . . . . . . . . . 322

Bestimmungstabelle der Gattungen (bzw. Arten) . . . . 329

Entwicklung und Stammesgeschichte der Turbellarien. . 339

Entwicklung . . . . . . . . . . . . . . . . . . . 339

Geschlechtsprodukte . . . . . . . . . . . . 339

Entwicklung der Tricladen . . . . . . . . . . 340

Entwicklung der Rhabdocoeliden . . . . . . . . . . 344

Entwicklung der Polycladen. . . . . . . . . . . . 347

Entwicklung der Acoelen . . . . . . . . . . . . . 348

Stammesgeschichte . . . . . . . . . . . . . . . . 349

Abstammung der Turbellarien . . . . . . . . . . . 349

Verwandtschaftsbeziehungen zwischen den einzelnen Unterordnungen der Turbellarien. . . . . . . . . . . 352

Literaturverzeichnis . . . . . . . . . . . . . 355

Erklärung im Text vorkommender Fachausdrücke . . . . 360

Register . . . . . . . . . . . . . . . . 372

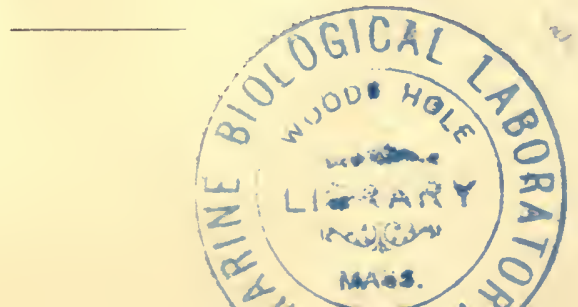





\section{Einleitung \\ Systematische Stellung}

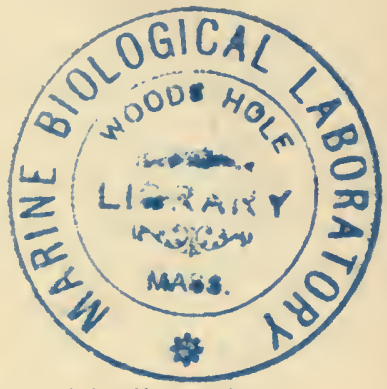

Wenn man von Würmern spricht, so stellen sich die meisten Leute die Regenwürmer vor. Von Band- oder Spulwürmern hat man gelegentlich gehört und gelesen, doch kennt man sie gewöhnlich nicht aus eigener Anschauung. Dagegen bezeichnet das Volk mit dem Namen "Wurm" noch eine stattliche Anzahl bekannter Tiere, so z. B. die vielen Maden und Raupen, die unsere beliebtesten Früchte "wurmig" machen, die garstigen Larven der SchmeiBfliegen und verwandter Zweiflügler, die sich am rohen oder gekochten Fleisch gütlich tun, die Larve des Käfers Tenebrio molitor, "Mehlwurm" genannt, und außerdem zahlreiche blattfressende Raupen der Schmetterlinge und Blattwespen, sowie auch die Mehrzahl der Tausendfüßer, die zufolge ihres langgestreckten Körpers und ihrer schwachen, kaum sichtbaren FüBe tatsächlich eine gewisse Ahnlichkeit mit dem Regenwurm haben. Noch verschiedenartiger sind die Geschöpfe, welche die Bezeichnung "Gewürm“ zusammenfaßt. Selbst gewisse Fische, Schlangen und Eidechsen, deren Körpergestalt an die Würmer erinnert, werden mit diesem Sammelnamen belegt.

Wenn man nun erwägt, daß $\mathfrak{b}$ alle diese Organismen von den Zoologen nicht $z u$ den Würmern, sondern $z u$ ganz anderen Gruppen des Tierreichs, $z \mathbf{u}$ den Gliederfüßern oder gar $z \mathfrak{u}$ den Wirbeltieren gerechnet werden, so könnte man vermuten, der Stamm der Würmer sei wenig umfangreich. Dies wäre jedoch eine Täuschung. Die Zahl der in diese Gruppe zu stellenden

Steinmann - Bressla u, Strudelwürmer. 
Spezies ist vielmehr gegenwärtig kaum zu überblicken, selbst die Artenzahl der Unterabteilungen geht in die Tausende.

Bevor wir daran gehen, dieses Heer zu sichten und zu gruppieren, mag die allgemeine Frage erörtert werden: Welche Eigenschaften kennzeichnen einen Organismus als Wurm?

Die Würmer (Vermes) sind zweiseitig oder bilateral symmetrische Tiere, d. h. ihr Körper kann durch eine Ebene in zwei spiegelbildlich gleiche Hälften geteilt werden. Sie unterscheiden sich dadurch von den gestaltlosen und asymmetrischen (viele Urtiere und Schwämme) sowie von den strahlig gebauten Tieren (Nesseltiere und Stachelhäuter), bei denen zweiseitig symmetrische Formen nur ganz ausnahmsweise auftreten.

Die bilaterale Symmetrie ist jedoch nicht nur für die Würmer charakteristisch, sie kommt auch bei den Weichtieren, GliederfüBern und Wirbeltieren vor. Von diesen großen Abteilungen lassen sich die Würmer leicht abgrenzen, da sie wesentlich einfacher organisiert sind als jene. Vor allem fehlen ihnen wohldifferenzierte Körperanhänge, wie sie der Fuß und der Mantel der Mollusken oder die Extremitäten der Gliederfüßer und der Wirbeltiere darstellen; dagegen besitzen sie ausnahmslos einen ${ }_{n} \mathrm{Hautmuskel-}$ schlauch“, d. h. ein umfassendes, für die Vorwärtsbewegung bestimmtes, unter der Haut gelegenes und mit ihr innig verbundenes Muskelsystem.

Wenn man die Gesamtheit der Tiere überblickt, die auf Grund dieser Eigenschaften im Würmerstamm vereinigt werden, so wundert man sich über die Vielgestaltigkeit ihrer Formen. Man findet hier Tiere von ganz verschiedenem Bauplan miteinander vereinigt. Die Abteilung der Würmer ist also keineswegs wohlumschrieben, sie stellt vielmehr die künstlichste aller Kategorien des Tierreichs dar, und man kann mit einem gewissen Recht sagen: Würmer sind diejenigen Tiere, die in keinem der übrigen Tierstämme untergebracht werden können.

Aus diesen verschiedenartigen Gruppen oder Klassen haben wir eine herauszugreifen: die Plattwürmer (Plathelminthes). Wiewohl auch diese Abteilung noch recht verschiedenartige Formen 
zusammenfaBt, darf sie doch als wohlabgegrenzt bezeichnet werden. Es lassen sich mehrere gute Kennzeichen zu einer Definition für sie zusammenfassen:

Die Plattwürmer sind Würmer von meist abgeplatteter Gestalt, denen eine echte Leibeshöhle (Coelom), d. h. ein zwischen Darm und Körperwand gelegener, von einer eigenen Zellhaut (Epithel) ausgekleideter Hohlraum fehlt. Demgemäß liegen die inneren Organe direkt in einem von Muskelfasern durchsetzten Füllgewebe (Parenchym) eingebettet. Das Hirn der Plattwürmer setzt sich nicht in einen bei andern Würmern, z. B. beim Regenwurm vorkommenden, mit Knoten (Ganglien) ausgestatteten Strang (Bauchmark) fort, sondern entsendet zwei oder mehrere Nervenstämme. Sehr charakteristisch ist auch das aus verzweigten Kanälen mit Endapparaten und Poren bestehende Ausscheidungssystem, der Exkretionsapparat (Protonephridien $=$ ursprünglichste Nieren).

$\mathrm{Zu}$ den Plathelminthen gehören folgende Ordnungen:

die Strudelwürmer Turbellaria,

" Saugwürmer Trematodes,

"Bandwürmer Cestodes,

n Schnurwürmer Nemertini.

Von diesen vier Ordnungen begegnen uns die Trematoden und Cestoden nicht in der freien Natur. Sie leben als Schmarotzer auf oder in andern Tieren. In ihrer Organisation prägt sich die parasitische Lebensweise sehr deutlich aus, so daß sie mit den freilebenden Ordnungen der Nemertinen und Turbellarien nicht leicht verwechselt werden können. Auch die Schnur- und Strudelwürmer lassen sich trotz mancher Ubbereinstimmung ohne Schwierigkeit auseinander halten. Die ersteren kennzeichnen sich durch den Besitz eines Afters und eines Blutgefäßsystems als höhere Tiere. Beides fehlt den Turbellarien, die als die primitivste Ordnung der Plattwürmer aufzufassen sind. Mit den beiden parasitischen Gruppen wird sich unser Buch nicht befassen. Auch die Nemertinen kommen nicht in Betracht, da sie kein Glied der 
einheimischen Fauna bilden. Sie sind vielmehr Bewohner des Meeres, wenn sich auch vereinzelte Vertreter auf das Land oder in unsere süßen Gewässer verirrt haben. Dagegen gehören zahlreiche Arten der Turbellarien unserer einheimischen Tierwelt an. Ihnen wollen wir im Folgenden unser Interesse zuwenden.

Diagnose Die Strudelwürmer (Turbellaria) lassen sich unter Berücksichtigung aller wesentlichen Merkmale durch folgende Diagnose von den andern Ordnungen abgrenzen:

Meist freilebende, mit wimperndem, in der Regel Stäbchen führendem Epithel bekleidete, ungegliederte plathelminthen mit verdauendem Parenchym oder einfachem bis verästeltem, afterlosem Darm. Fast durchweg $Z$ witter mit direkter Entwicklung.

Die Zahl der zurzeit bekannten Turbellarienarten mag etwa 1200 betragen. Sie wird durch spätere Untersuchungen sicher noch bedeutend anwachsen, denn Jahr für Jahr werden aus den verschiedensten Gegenden zum Teil sogar aus seit langer Zeit gut durchforschten Gebieten neue Spezies gemeldet.

Systematische Übersicht Man teilt die Strudelwürmer am über die Unterordnungen besten in vier Unterordnungen ein:

I. Unterordnung: Acoela (= ohne Darm).

Kleine (nicht über $1 \mathrm{~cm}$ große) darmlose Turbellarien, deren Verdauung im Körpergewebe (Parenchym) vor sich geht. Ohne oder mit einfachem, durch Hauteinsenkung entstandenem Schlundrohr. Entwicklung direkt. Durchweg marine, und zwar meist litoral (an der Küste), selten pelagisch (im freien Wasser) lebende Formen. 2 Familien mit 12 Gattungen und ca. 45 Arten.

II. Unterordnung: Rhabdocoelida (= mit Stabdarm).

Kleine Turbellarien mit einheitlichem oder leicht gelapptem Darmsadk und meist zusammengesetztem Schlundrohr. Die Zahl und Lage der Geschlechtsöffnungen wechselt. Hierher gehören ca. 350 Arten, mehr als die Hälfte im Süßwasser (ganz vereinzelt in feuchter Erde), die übrigen marin. 
Die weitere Gruppierung der Rhabdocoelida findet sich in einem spätern Abschnitt (s. Systematik).

1II. Unterordnung: Tricladida (= mit dreiästigem Darm).

GröBere (im Maximum bis $60 \mathrm{~cm}$ lange) Turbellarien mit drei, verzweigte Divertikel tragenden Darmästen, von denen einer kopfwärts, die beiden andern schwanzwärts gerichtet sind. Schlundrohr eingestülpt und vorstreckbar. Der männliche und der weibliche Geschlechtsapparat haben eine gemeinsame Offnung. Etwa 500 meer-, süßwasser- oder landbewohnende Arten (Maricola, Paludicola und Terricola).

Auch diese Gruppe soll in einem besondern Abschnitt weiter eingeteilt werden.

IV. Unterordnung: Polycladida (= mit vielästigem Darm).

Größere (bis zu $15 \mathrm{~cm}$ lange) Arten von meist breiter, blattartiger Körperform. Schlundrohr ähnlich wie bei den Tricladida. Darm aus zentralem Sack und zahlreichen, strahlig abzweigenden Divertikeln bestehend. Männliche und weibliche Geschlechtsöffnung meist getrennt. Etwa 300 marine Arten, die in zwei Sektionen (Acotylea ohne Saugnapf und Cotylea mit bauchständigem Saugnapf) eingeteilt werden, deren jede etwa 5 Familien umfaßt.

Wie sich aus dieser Ubersicht ergibt, sind die Acoelen und polycladen ausschlieBlich Meeresbewohner. Da auch die beiden andern Unterordnungen zahlreiche Vertreter im Meere haben, kann man die Zahl der zurzeit bekannten Meeresstrudelwürmer auf rund 600, also auf die Hälfte der Gesamtzahl beziffern. Von der anderen Hälfte entfallen nahezu 400 auf die Gruppe der fast durchweg exotischen landbewohnenden Tricladen, der Rest auf Süßwasserbewohner. Von den letzteren gehören etwa 140 Arten der Fauna Deutschlands und der umliegenden Gebiete Mitteleuropas an, und zwar etwa 120 Rhabdocoeliden und 20 Tricladen.

Wenn wir trotz der kleinen Zahl die letzteren in unserem Buch in den Vordergrund stellen, so geschieht das, weil die einheimischen Tricladen oft untersuchte, meist leicht erhältliche Tiere sind, während die kleinen Rhabdocoeliden dem Studium weniger 
leicht zugänglich sind. Es werden daher die wichtigeren Tricladen eingehend besprochen, während etwas Ahnliches für die Rhabdocoeliden schon in Anbetracht ihrer großen Artenzahl nicht möglich ist. Die Organisation und Lebensweise dieser Tiere soll daher vorwiegend an einer einzigen, besonders günstigen Form (Mesostoma ehrenbergi) erläutert werden.

\begin{tabular}{|c|c|c|c|}
\hline Geschichte der & Die ersten Arbeiten, in denen Strudel- \\
Strudelwurmforschung & würmer erwähnt werden, stammen aus
\end{tabular} der ersten Hälfte des 18. Jahrhunderts. Aus den kurzen Beschreibungen geht zwar meist mit Deutlichkeit die Strudelwurmnatur der untersuchten Objekte hervor, doch sind die Tiere selbst kaum wiederzuerkennen. Sie wurden von den Autoren als Schnecken, Blutegel oder Leberegel aufgefaßt. Im Jahre 1773 begründete dann O. F. Müller die eigentliche Strudelwurmforschung, indem er gleich 23 Turbellarien beschrieb, und sie gemeinsam mit einigen Schnur- und Saugwürmern mit dem Gattungsnamen Fasciola belegte. Später führte er den heute auf eine kleine Unterabteilung beschränkten Namen Planaria ein, der von da an lange Zeit für alle Strudelwürmer gebraucht wurde. Zahlreiche systematische, später auch anatomische Arbeiten der nächsten Zeit förderten wichtige Erkenntnisse zutage. 1826 entdeckte O. Fabricius die Cilienbekleidung, im gleichen Jahre C. E.v. Baer die Zwitterigkeit. 1828 stellte A. Dugès die Grundzüge des Baues der kleinen rhabdocoelen Turbellarien fest, ohne jedoch die Selbständigkeit dieser Abteilung hervorzuheben.

Ein neues Zeitalter der Strudelwurmkunde eröffnete 1831 Chr. G. Ehrenberg. Von ihm stammt der mit der deutschen Bezeichnung "Strudelwürmer" gleichbedeutende Name Turbellaria, der treffend die strudelnde, bewimperte Körperoberfläche als das vor allem charakteristische Merkmal der ganzen Ordnung hervorhebt, und seit $1845 \mathrm{zu}$ allgemeiner Anerkennung durchgedrungen ist. Zugleich zerlegte er die Ordnung nach dem Bau des Darms (verzweigt oder unverzweigt) in die beiden Abtei-

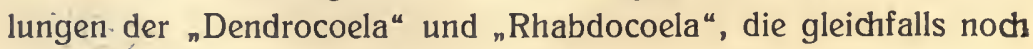


heute in vielen Lehrbüchern der Zoologie einander gegenübergestellt werden. Auf die Ehrenbergschen Arbeiten folgten nacheinander zahlreiche Darstellungen einzelner Strudelwurmarten, sowie systematische und entwicklungsgeschichtliche Untersuchungen. Besonderer Beachtung erfreuten sich die Polycladen und Rhabdocoelen, sowie die Landtricladen, deren Kenntnis z. B. auch durch Ch. Darwin gefördert wurde.

Nachdem im Jahre 1870 W. N. Uljanin die darmlosen Tur bellarien (Acoela) entdeckt hatte, begann eine ganze Serie ausgezeichneter, die Formenkenntnis und Anatomie gleichermaßen fördernder Monographien. Im Vordergrund standen zunächst die Rhabdocoelen, sodann die Polycladen, während die Tricladen, speziell die Süßwasserplanarien weniger Berüdksichtigung fanden. Von besonderer Bedeutung wurden die Arbeiten von A. Lang, vorab die aus dem Jahre 1881 stammende Schrift "Der Bau von Gunda segmentata und die Verwandtschaft der Plathelminthen mit Cölenteraten und Hirudineen " und die Polycladenmonographie von 1884. Ihm gebührt auch das Verdienst, die von Ehrenberg geschaffene, nicht natürliche Abteilung der "Dendrocoelen “ in die ganz abweichend gebauten Unterordnungen der polycladen und Tricladen aufgelöst $z u$ haben. Der Langschen Polycladenmonographie stehen die prächtigen Monographien v. Graffs über Rhabdocoelida 1882, Acoela 1891, und Landplanarien 1899 zur Seite, die neben gewissenhaften Zusammenstellungen des Bekannten eine Menge neuer Tatsachen bringen. v. Graff, dessen Lebenswerk der Erforschung der Strudelwürmer galt und gilt, ist seit langer Zeit die Seele der Turbellarienwissenschaft. Seinen Bemühungen ist es zu danken, daß die Strudelwürmer zurzeit die bestuntersuchte Gruppe der Würmer bilden. Aus der großen Zahl von Arbeiten, die nach dem Erscheinen der Monographien v. Graffs und Langs publiziert wurden, und deren Entstehung zum guten Teil der anregenden Wirkung dieser Fundamentalwerke zuzuschreiben ist, einzelne hervorzuheben, kann hier mit Rücksicht auf den Raum nicht versucht werden, da $z u$ viele es verdienten. 
Wie sehr sich unsere Kenntnisse seit den großen Monographien gemehrt haben, beweist am besten die Tatsache, daß schon jetzt das Bedürfnis nach neuerlicher Zusammenfassung besteht. Als kritische Bearbeitungen dieser Art, verbunden mit vielen neuen Beobachtungen, seien folgende, der neusten Zeit angehörenden Publikationen genannt: Luther, Die Eumesostominen, 1904; v. Hofsten, Studien über die Turbellarien aus dem Berner Oberland, 1907; Böhmig, Tricladenstudien, 1906; Wilhelmi, Tricladenmonographie, 1909. Endlich hat Altmeister v. Graff in zwei gegenwärtig im Erscheinen begriffenen Werken, den "Turbellaria“ in Bronns "Klassen und Ordnungen des Tierreichs" und im "Tierreich “, das gesamte Material noch einmal zu sichten und zusammenzufassen begonnen. In der erstgenannten Publikation wird speziell die Morphologie und Physiologie berücksichtigt. Sie enthält auch ein Literaturverzeichnis von gegen 1500 Nummern und eine historische Einleitung, der wir im vorliegenden Abschnitt teilweise gefolgt sind; das zweite Werk ist speziell der Systematik der Turbellarien gewidmet.

\section{Technische Vorbemerkungen}

Das Sammeln, Untersuchen und Präparieren von Turbellarien bietet bei einiger Ubung in der Regel wenig Schwierigkeiten, doch sind gewisse Winke für den Anfänger unerläßlich.

Da sich bei den Tricladen die Fangmethoden wie auch die Untersuchungspraktik etwas anders gestaltet als bei den Rhabdocoeliden, mögen die beiden Gruppen schon hier getrennt behandelt werden.

\section{Triciadida}

Der Tricladensammler ist an keine Jahreszeit gebunden; er wird die meisten Arten jahraus jahrein in fast gleicher Individuenzahl antreffen. Der Fang ist, sofern man an den richtigen Stellen sucht, sehr einfach. Eine nicht zu kleine weithalsige Flasche (Pulverglas) und ein Malpinsel sind die wesentlichsten Fangrequisiten. Weniger wichtig, aber bisweilen wünschenswert ist ein kleines Handnetzchen zum Herausholen von Schlamm, 
Steinen oder Wasserpflanzen aus dem zu untersuchenden Gewässer. Handelt es sich um einen Bach oder Fluß, so gilt es vor allem, einige überspülte oder umspülte Ufersteine herauszuheben, unter denen sich die Planarien mit Vorliebe aufhalten. Bei sinkendem Wasserstand winkt besonders reiche Beute, da die Würmer infolge ihrer Trägheit dem zurückweichenden Wasserspiegel nur ganz allmählich folgen. Wenig ergiebig wird das Sammeln in einem Bach oder Fluß mit steigendem Wasserstand, da die neubespülten Steine erst nach längerer Zeit von den Planarien besiedelt werden. Man kann sich zur Regel machen, bei Hochwasser auf das Sammeln von Tricladen $z u$ verzichten. Wenn dies aus irgendeinem Grund nicht angeht, so müssen mit einem kräftigen Stangennetz die uferfernen, auch bei Tiefstand bespülten Steine gehoben werden. An den konkaven Erosionsufern hat man, besonders in leicht verschmutzten Gewässern, mehr Aussicht, Planarien zu erbeuten als an den konvexen Sedimentationsufern. In Bächen suche man auch die Auswaschbecken unter Wasserstürzen $a b$; bisweilen ziehen die Tiere ruhigere Partien vor. Besonders günstig wird das Resultat, wenn in kleinen Gebirgsquellen gesammelt wird. Man findet dort nicht selten auch unter Steinen von geringer Größe zahlreiche Exemplare von Planaria alpina, Polycelis cornuta oder Planaria gonocephala. In flieBenden Gewässern mit höheren Pflanzen (Potamogeton, Ranunculus fluitans usw.) trifft man häufig an der Unterseite der Blätter Polycelis nigra und andere Arten, die am besten durch Abspülen in ein weithalsiges Gefäß gesammelt werden. Das gleiche gilt von den Formen des stehenden Wassers, die an Pflanzen sitzen, die übrigen sucht man mit Vorteil unter Steinen des Ufers. Besonders reich sind hier gewöhnlich kiesige Strandpartien besiedelt, an denen eine leichte Brandung spielt, oder aber der Mündungsumkreis der Zuflüsse. Die in der Tiefe im Schlamm lebenden Arten erbeutet man mit Hilfe einer Dredge, deren Stelle auch eine einfache Blechbüchse mit entsprechender Belastung vertreten kann. Besonders zweckdienlich ist ein Gazenetz mit schwerem eisernen Rahmen, der die Form eines gleichseitigen Dreiecks zeigt 
und an den Seiten mit Eisenzähnen bewehrt ist. Diese Netzdregde wird mit Hilfe von drei eisernen Zugstäben, die in einen Ring eingreifen, und mittels Drahtseil dem Boden entlang geschleppt. Sie wirbelt Schlamm auf, filtriert gleichzeitig und bringt bisweilen reichliche Beute an Tricladen aus der Tiefe herauf. Planaria vitta läßt sich hie und da aus Zugbrunnen herausschöpfen oder heraufpumpen, während die Höhlenplanarien in den unterirdischen Gewässern meist steinige Partien aufsuchen. Die landbewohnenden Spezies endlich trifft man gelegentlich in feuchtem Moos, in morschem Holz oder unter Rinde am Fuß alter Baumstämme, einzelne auch in und unter den Blumentöpfen der Gewächshäuser.

Beim Ablösen der Planarien von der Unterlage ist große Vorsicht geboten, da man den weichen Körper leicht verletzt. Der pinsel wird angefeuchtet, flachgedrückt und behutsam unter das loszulösende Tier geschoben. Einzelne Formen lassen sich auch mit Spateln oder sogar mit Taschenmessern abheben.

Soll der Fang lebend transportiert werden, so sorge man dafür, daß sich das Wasser in der Flasche nicht stark erhitzt. Manche Arten ertragen nur ganz geringe Temperaturerhöhungen. Im Sommer verwendet man mit Vorteil eine sog. "Thermosflasche" mit doppelter Wandung. So oft man kann, erneuere man das Wasser. Da sich die Würmer an der Glaswand beim Kriechen ordentlich festheften, genügt ein Ausleeren und Wiederfüllen ohne besondere Vorsichtsmaßregeln.

Die Konservierung geschieht mit Hilfe verschiedener Reagentien, deren Wahl sich nach dem Zweck richtet, den man beim Abtöten verfolgt.

Soll die äußere Körperform möglichst getreu erhalten bleiben, so ist Sublimat-Salpetersäure am Platz. (1 Teil käufliche rohe Salpetersäure, 1 Teil in Salzwasser [5 $\mathrm{g}$ Kochsalz auf $100 \mathrm{ccm}$ Wasser] konzentrierter Sublimatlösung, 1 Teil destilliertes Wasser.) Dies Gemisch kann kalt oder warm verwendet werden. Man bringt die Tiere mit wenig Wasser in eine Glasschale, läßt sie kriechen und übergießt sie im geeigneten Moment mit der Sublimatsalpetersäurelösung. Die meisten Arten strecken sich bei dieser 
Behandlung schön aus, und auch der Kopf erhält eine an das Leben erinnernde Gestalt. Die Flüssigkeit darf jedoch nicht lange einwirken; nach längstens einer Minute werden die Tiere in ein großes Gefäß mit absolutem Alkohol übertragen, wo sie rasch hart werden. ${ }^{1}$ ) - Der Alkohol muß mehrmals gewechselt werden, und nach einigen Stunden sind die Objekte fertig konserviert. Sie werden nun für kurze Zeit zur Entfernung des Sublimates in eine schwache Lösung von Jod in Alkohol zu 95\% gebracht, und endlich wird in reinem Alkohol auch das Jod ausgewaschen. Nach dieser Behandlung eignen sich die Tiere für Totalpräparate und Schnittbehandlung, sowie für einfache Aufbewahrung in Alkohol von $80 \%$ bis $96 \%$.

Gilt es in erster Linie, gute Konservierung des inneren Baues $z u$ erzielen, und braucht auf die Erhaltung der äuBeren Form keine Rücksicht genommen zu werden, so sind folgende Konservierungsmittel zu empfehlen: Zenkersche Lösung, d. h. eine Lösung von $5 \mathrm{~g}$ Sublimat, 2,5 g Kalium bichromicum, $1 \mathrm{~g}$ Natrium sulfuricum in $100 \mathrm{ccm}$ Wasser unter Zusatz von $5 \mathrm{ccm}$ Eisessig. Sublimateisessiggemisch, bestehend aus konzentrierter wässeriger Sublimatlösung, der pro Kubikzentimeter ein Tropfen Eisessig zugesetzt wird. Beide Lösungen werden heiß oder kalt angewandt, das erstere ist meist vorzuziehen. Man läßt die Gemische etwa 10 bis 20 Minuten wirken und überträgt die Objekte dann sofort in eine ausreichende Quantität absoluten Alkohols. Die Entfernung des Sublimates durch Jod erfolgt bei beiden Flüssigkeiten in der gleichen Weise wie nach der Sublimatsalpetersäurekonservierung.

Totalpräparate lassen sich von allen Planarien anfertigen, doch eignen sich in erster Linie die pigmentlosen, hauptsächlich wenn

1) Es empfiehlt sich, als Alkoholbehälter einen Standzylinder $z u$ wählen, der zur Hälfte mit Watte gefüllt ist, damit die aus dem Objekt heraus diffundierenden Stoffe durch die Watte zum Boden des GefäBes gelangen und den umgebenden Hlkohol nicht verdünnen. Je rascher diese Stoffe entfernt werden, um so weniger sind Sdurumpfungen zu befürchten. 
der Darm dunkle Einschlüsse enthält. Meist montiert man die konservierten Tiere ohne vorherige Färbung direkt, indem man sie aus dem (mehrmals zu wechselnden) absoluten Alkohol in ein Vorharz, Xylol, Benzol, Nelkenöl oder Kreosot und von da in Kanadabalsam bringt. Will man färben, so muß der Ưberschuß des Färbemittels (Boraxkarmin oder Hämatoxylin) durch salzsauren Alkohol (ca. 5 Tropfen Salzsäure auf $100 \mathrm{~g}$ Alkohol $70 \%$ ) entfernt werden, da sonst eine Differenzierung der Organe nicht eintritt. Bei pigmentierten Arten gelingen Färbungen kaum, bei pigmentlosen auch nur ausnahmsweise.

Für genaues Studium ist die Zerlegung der Objekte in Mikrotomschnitte unerläßlich. Das Einbetten geschieht nach der hier als bekannt vorauszusetzenden Methode durch Xylol oder Benzol in Paraffin. Besser, wenn auch umständlicher ist eine Doppeleinbettung nach Apáthy und Wilhelmi in Celloidin-Paraffin, die in folgender Handhabung speziell empfohlen sei: Hus dem absoluten Alkohol werden die Objekte, nachdem sie vollkommen entwässert sind, in Ather gebradit. Inzwischen schneidet man aus einem Paraffinblock eine Vertiefung aus, die der Größe des Objektes, bzw. des zukünftigen Schnittblockes entspricht. Diese Vertiefung wird mit Celloidin ${ }^{1}$ ) gefüllt und das Objekt vom Ather direkt oder über eine Mischung von Celloidin und Ather hineingebracht. Nun wird das Celloidin in Chloroformdämpfen gehärtet, indem man den Paraffinblock samt Einschluß gemeinsam mit chloroformgetränkter Watte in ein Glasgefäß bringt. Nach etwa einer Stunde oder, wenn die Celloidinmenge groß ist, auch später, kann der Celloidinblock aus dem umgebenden Paraffin gelöst werden, kommt nun noch für einige Stunden in Chloroform, von da in geschmolzenes Paraffin und wird dann wie ein gewöhnliches Objekt eingeschlossen. Die Vorteile dieser Doppeleinbettung sind eine sehr schöne Erhaltung der innern Organe, speziell des Körpergewebes (Parenchym) und ein angenehmes

1) Celloidinlösung von $4 \%$ in einer Mischung von Ḧther und Alkohol. Sie muB gut verschlossen aufbewahrt werden. 
Schneiden in beliebiger Schnittdicke. Die einzelnen Schnitte haben viel größere Festigkeit als die einfachen Paraffinschnitte, sie brechen nicht und lassen sich mit dem Pinsel oder sogar mit einer Pinzette auf die Objektträger bringen. Zur Befestigung dient Eiweißglyzerin (stark verrieben) und Wasser. Das Glätten welliger Schnitte kann durch Erhitzen bis zum Schmelzpunkt erfolgen.

Soll eine Art gründlich untersucht werden, so fertigt man mindestens drei Schnittserien an. Ein Exemplar wird in sagittale Längsschnitte, ein zweites in frontale Längsschnitte (Flächenschnitte) und ein drittes in Querschnitte zerlegt. Gilt es, nur zu Bestimmungszwecken einen Uberblick über den Bau zu gewinnen, so sind die sagittalen Längsschnitte vorzuziehen. Für Flächenschritte eignen sich nur völlig ausgestreckte Objekte. In günstigen Fällen erhält man jedoch sehr schöne Ubersichtsbilder.

Die Schnitte färbt man mit Hämatoxylin: Delafield, Haemalaun (Mayer), Haemateïn I A (Apáthy) oder nach Heidenhain. ${ }^{1}$ ) Für Anfänger sei das Delafieldsche Hämatoxylin empfohlen. Man bringt die Objektträger, nachdem die Schnitte befestigt sind (das Wasser muß völlig verdunstet sein!), in Xylol; dann nacheinander in Alkohol absolutus, Alkohol von $96 \%, 70 \%, 35 \%$, Wasser, Hämatoxylin. In den Alkoholen bleiben sie je etwa eine Minute, im Wasser etwas länger und im Hämatoxylin je nach Bedürfnis wenige Minuten bis Stunden. Von Zeit zu Zeit überzeugt man sich von dem Stand der Färbung durch kurzes Auswaschen in Wasser und Betrachtung unter dem Mikroskop. Ist überfärbt worden, so zieht man den Uberschuß in Alkohol von $70 \%$ mit ein paar Tropfen Salzsäurezusatz pro $100 \mathrm{~g}$ aus. Die im sauren Alkohol rötlich gewordenen Objekte können durch Behandlung mit Ammoniakalkohol (ein paar Tropfen Ammoniakwasser [Salmiakgeist] auf $100 \mathrm{~g} \mathrm{70 \%}$ Alkohol) gebläut werden und kommen von da für ganz kurze Zeit in eine wässerige Lösung von Orange-G

1) Die Vorschriften für diese Färbemittel sind in Lee und Mayer, Grundzüge der mikroskopischen Technik für Zoologen und Anatomen. Berlin 1898, nachzulesen. 
oder Eosin. Durch diese Farbstoffe werden gewisse Zellen und Gewebe gefärbt, die kein Hämatoxylin aufgenommen haben, so daß man brillante Doppelfärbungen erzielt. Nun müssen die verschiedenen Alkohole rasch passiert werden, damit die durch Alkohol ausziehbaren Farben erhalten bleiben. Vom absoluten Alkohol führt man über Xylol in Kanädabalsam über.

Will man sich über den Bau der Geschlechtsapparate, speziell des Kopulationsorganes Rechenschaft geben, so muß man die Schnitte einzeln in der richtigen Reihenfolge zeichnen, am besten mit Hilfe des Abbéschen Zeichenappartes. Noch leichter gelingt diese Orientierung, wenn man zur plastischen Rekonstruktion schreitet, die Umrisse der Hohlräume und Gänge aus Karton ausschneidet, dem eine der Vergrößerung entsprechende Dicke gegeben wird. Klebt man nun die einzelnen, den Schnitten entsprechenden Kartons übereinander, so kann man sich von den Lagebeziehungen der Organe und Gänge ein Bild machen. Nur Geübte können sich bei einfacher Durchsicht der Schnitte orientieren.

Hat man für eine Bestimmung nur wenige Exemplare zur Verfügung, so mache man nacheinander folgende Untersuchungen:

1. Studium des lebenden Tieres, verbunden mit peinlich genauer Umrißzeichnung des Kopfes und Darstellung der Lagebeziehung der Augen usf.

2. Konservierung, eventuell in etwas gequetschtem Zustand und Aufhellen mit Xylol. In diesem Reagenz treten manche Organe sehr schön zutage, die vor- und nachher fast unsichtbar werden.

3. Einschluß in Celloidinparaffin und Zerlegen in Schnittserien.

4. Färben und Zeichnen der Schnitte.

5. Kombination der Zeichnungen oder plastische Rekonstruktion.

Quetschpräparate der lebenden Tiere geben in der Regel keine zufriedenstellenden Resultate für die topographische Übersicht der Organe, eignen sich aber für das Studium des Wimperschlages. Bei einiger Gewöhnung kommt man rasch dazu, die Tiere nach dem Habitus $z u$ beurteilen und $z u$ bestimmen. 
Rhabdocoelida

Im Gegensatz zu den Tricladen, die fast das ganze Jahr hindurch sowohl in stehenden wie fließenden Gewässern vorkommen, bevorzugt die übergroße Mehrzahl der einheimischen Rhabdocoeliden stehendes Wasser, wobei sich ihre Existenz nur auf wenige Wochen oder Monate der wärmeren Jahreszeit beschränkt. In dieser Zeit beherbergen aber oftmals selbst ganz kleine Wasseransammlungen Tausende von Individuen. Bei der geringen Größe und hohen Durchsichtigkeit der meisten Arten bedarf es allerdings besonderer Aufmerksamkeit, um ihre Anwesenheit festzustellen. Auch sind viele von ihnen rasche Schwimmer und daher nicht so einfach zu erbeuten, als die nur langsam kriechend sich fortbewegenden Tricladen.

Dem Ungeübten, der Rhabdocoeliden sammeln will, ist deshalb $\mathrm{zu}$ raten, damit während des Sommers $\mathrm{zu}$ beginnen, wenn alle nach ihrer Beschaffenheit dazu geeigneten stehenden Gewässer reiches Tierleben und üppig wuchernden Pflanzenwuchs zeigen. An solchen Wasseransammlungen fische man mit einem eng maschigen Tüllnetz - dessen Drahtbügel (von etwa $15 \mathrm{~cm}$ Durchmesser) des bequemeren Transports halber so eingerichtet sein kann, daß er sich vermittest einer Zwinge leicht am Spazierstock befestigen läßt, - vom Ufer aus Proben des Grundes und kleinere pflanzenteile heraus, ziehe dann das Netz ein paarmal rasch durch das Wasser hin und her und entleere schließlich alles Gefangene samt einem gehörigen Wasserquantum in passende Behälter, wozu sich besonders mit gut schließenden Deckeln versehene, etwa $1 / 2$ bis 11 fassende Honig- oder Einmachgefäße eignen. Fischt man an verschiedenen Stellen, so sind selbstverständlich die Fänge getrennt unterzubringen und genau $z u$ etikettieren. $Z u$ Hause angelangt, leere man den Inhalt der Sammelgläser in gewöhn liche, weiße Schüsseln aus, fülle mit Leitungswasser auf und lasse das Ganze einige Zeit ruhig stehen. Sieht man dann nach ein bis zwei Stunden wieder nach, so wird man, falls man an günstigen Orten gefischt hat, zahlreiche tierische Lebewesen am Rande der Schüsseln durcheinander wimmeln sehen, die sich leicht durch ihre Bewegungen unterscheiden lassen. Da hüpfen oder schnellen 
kleine Krebschen verschiedenster Art durch das Wasser, zwischen ihnen schlängeln sich kleine Borstenwürmer oder Fliegenlarven von wurmähnlicher Gestalt. Andere Angehörige des weitverzweigten Arthropodenstammes laufen auf ihren Beinen bald hierhin, bald dorthin. Junge Egel verraten, so klein sie auch sein mögen, ihre Stammesart sofort durch die charakteristischen Spannbewegungen. Sie alle sind nicht mit den Rhabdocoeliden $z u$ verwechseln, die sich, meist ohne daß an ihnen irgendwelche lokomotorische Tätigkeit $z u$ bemerken ist, vollkommen mühelos vorwärts bewegen, bald an der Wand der Schüssel oder am Wasseroberhäutchen dahingleitend, bald frei durch das Wasser schwimmend.

Hat man auf diese Weise einige Ubung im Erkennen der Rhabdocoeliden erlangt, so kann man es unternehmen, sie an ihren Aufenthaltsorten direkt aufzusuchen; dabei ist als Fanginstrument außer dem vorhin genannten, am Stock $z u$ befestigenden Netz noch eine weißemaillierte, mit einem Griff versehene, runde Schale (wie sie in der Küche zum Backen benutzt wird) mitzunehmen. Will man in einem größeren Gewässer auch die fern vom Ufer oder in der Tiefe lebenden Formen, eventuell von einem Boote aus, fangen, so benötigt man dazu noch eines Wurf- oder Planktonnetzes. Alles, was man erbeutet, sei es mit dem Netz, sei es, indem man an verschiedenen Stellen direkt mit der Emailschale Wasser schöpft, wird dann in letzterer, eventuell unter Benutzung einer Taschenlupe, auf Rhabdocoeliden hin durchsucht. Sorgt man dafür, daß nicht zu viel Tiere, Pflanzenteile oder das Wasser trübende Sand- und Schlammpartikelchen in der Schale sind, so wird man bald dahin gelangen, die Würmer, auf die es ankommt, mit raschem Blick zu erkennen. Diese werden dann mit Hilfe einer Pipette in kleinere Sammelgläser übertragen, die man sich zweckmäßig - um die Hände frei zu haben - an Schnüren um den Hals hängt. Auf diese Weise ist es möglich, den Charakter der Rhabdocoelidenfauna eines Gewässers gleich an Ort und Stelle richtig abzuschätzen, und gegebenenfalls dafür Sorge zu tragen, von seltenen oder unbekannten Arten möglichst viele Exemplare zu sammeln. Prüft man 
dagegen, wie vorher empfohlen, die Ausbeute erst zu Hause, so kann es vorkommen, daß man interessante Formen, die man etwa entdeckt hat, bei einer zweiten Exkursion schon nach wenigen Tagen nicht wiederfindet. Irgendein Umstand, sei es eine Temperaturerhöhung oder -erniedrigung, sei es ein Steigen oder Sinken des Grundwasserspiegels oder dergl. kann inzwischen der oft nur kurz befristeten Existenz der Tiere ein Ende bereitet haben.

Die geringe Größe der Rhabdocoeliden nötigt in den meisten Fällen zur Benutzung des Mikroskops, wenn man ihre Artzugehörigkeit bestimmen will; dank ihrer Durchsichtigkeit ist jedoch ihre mikroskopische Untersuchung in der Regel technisch relativ einfach. Man bringe einen der Würmer mit einer Pipette lebend in einem kleinen Wassertropfen auf Objektträger, decke ein mit Wachsfüßchen versehenes Deckgläschen so darüber, daß der Wurm komprimiert, aber nicht zerdrückt wird, sauge etwa überschüssiges Wasser mit einem Fließpapierstreifen auf, und das sog. "Quetschpräparat" ist fertig. In jedem Fall bemühe man sich dann, alles, was von der Organisation des Tieres mit den verschiedenen Vergrößerungen zu erkennen ist, so genau wie möglich zu zeichnen. Oftmals wird das dabei Beobachtete zur Bestimmung ausreichen. Verfügt man über eine größere Zahl von Individuen, so ist es ratsam, das unter dem Mikroskop befindliche Exemplar schließlich durch wiederholten, aber nicht $\mathrm{zu}$ heftigen Druck auf das Deckglas zu zerquetschen. Die für die Artfeststellung besonders wichtigen Organe des Geschlechtsapparates treten dabei nicht selten deutlicher hervor, und besonders die Chitingebilde der Begattungswerkzeuge lassen sich alsdann bisweilen besser mit starken Linsen untersuchen als im intakten Quetschpräpart. Hat man dagegen nur ein Individuum, so verfahre man bei der Lebenduntersuchung möglichst schonend, um nach deren Beendigung das Tier vom Deckglasdruck befreien und für eine etwaige Schnittuntersuchung verwenden zu können. Dauerpräparate von ganzen Tieren anzufertigen, lohnt sich fast niemals. Nur die großen, flachen Arten, wie Mesostoma ehrenbergi geben dabei einigermaßen befriedigende Resultate.

Ste inmann-Bressla u, Strudelwürmer. 
Die Methode der Schnittuntersuchung ist dieselbe wie bei den Tricladen. Zur Konservierung ist vorzüglich das oben erwähnte Sublimat-Eisessiggemisch und die Zenkersche Lösung geeignet. Bei embryologischen Untersuchungen ist außerdem das Kaliumbichromat-Eisessiggemisch nach der Vorschrift von Tellyesniczky $(3 \mathrm{~g}$ Kaliumbichromat $+100 \mathrm{ccm}$ Wasser $+5 \mathrm{ccm}$ Eisessig) zu empfehlen, das kalt oder heiß angewendet werden kann. 1 bis 2 Stunden nach der Konservierung werden die Objekte in mehrfach zu erneuerndem Wasser ausgewaschen und dann allmählich in Alkohol von steigender Konzentration übergeführt. 


\section{Tricladen}

\section{Anatomie}

Nachdem wir im ersten Abschnitt den Bau der Würmer im allgemeinen und der Strudelwürmer im besonderen bereits in den Hauptzügen kennen gelernt haben, mag nun hier eine spezielle Betradhtung der Gestaltungsverhältnisse der Planarien mit vergleichenden Hinweisen auf die übrigen Gruppen folgen.

\section{Ḧußeres}

Gestalt Wenn wir die meer- und süßwasserbewohnenden Arten überblicken, so erhalten wir ein recht einheitliches Bild. Die Form eines länglich-ovalen Blattes wird ziemlich konservativ beibehalten. Der Querschnitt ist in der Mitte am höchsten und nimmt von da nach den beiden Seitenrändern hin kontinuierlich $a b$, so daß diese oft zugeschärft erscheinen. Dabei ist die Bauchfläche meist weniger gewölbt als die Rückenseite. Auch gegen vorn und hinten flachen sich die

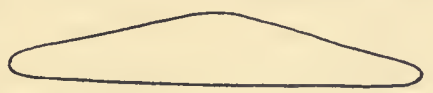

Abb. 1.

Querschnitt durch eine Planaria. Tiere allmählich ab. Besonders scharf, manchmal fast saumartig ist der Körperrand der Dendrocoelumarten entwickelt. Bei dieser Gattung, sowie bei Bdellocephala, beobachtet man während langsamen Kriechens oder vollkommener Ruhe eine Kräuselung der Seitenränder, die verschwindet, sobald sich das Tier ausstreckt und in Bewegung setzt. Andern Arten kommt ein derberer Körperrand zu (Planaria lugubris, torva, 
Polycelis nigra usw.), sie sind weniger schlaff und nachgiebig, ihr Querschnitt demgemäß mehr gerundet; daher sind diese Würmer auch gegen Druck resistenter. Das Hinterende ist in den meisten Fällen zugespitzt oder gerundet, aber niemals deutlich vom Rumpf abgesetzt, so daß der Name Schwanz nur cum grano

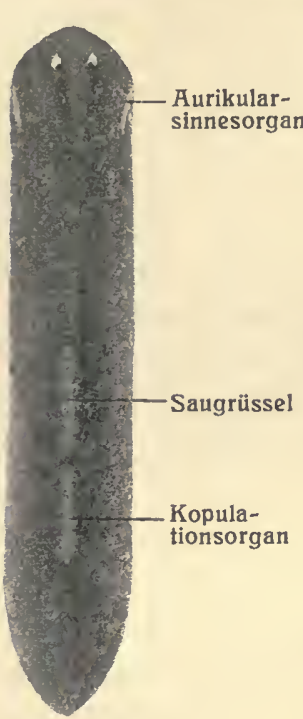

Abb. 2.

Habitusbild von Planaria lugubris. salis zu gebrauchen ist. Die Seitenränder laufen bis in die Nähe des Kopfes ungefähr parallel (Abb. 2).

Unterhalb des Kopflappens findet man bisweilen eine halsartige Einschnürung. Der Vorderrand ist bei den einzelnen Arten recht verschieden und gibt daher ein sehr brauchbares Unterscheidungsmerkmal ab. Neben runden Kopfenden gibt es quer abgestutzte und dreieckige. Die Seitenlappen (Abb. 3) sind besonders beweglich und da und dort zu Öhrchen (Aurikeln) oder Fühlhörnern (Tentakeln) ausgezogen.

Bei Planaria gonocephala (dreieckköpfige Planarie) ist das Vorderende ein mit der Spitze nach vorn gerichtetes Dreieck (Abb.4). Die Kopfform kann übrigens bei ein und derselben Art in ziemlich weiten Grenzen schwanken, je nach dem Alter und Gesundheitszustand der Tierchen. Noch weiter erhöht wird die Mannigfaltigkeit der Form dadurch, daB die Würmer in der Ruhe und in den verschiedenen Phasen der Bewegung ganz verschieden aussehen können.

Beim raschen Kriechen streckt sich der Körper lang, bandförmig aus, der Kopf wird vorgestreckt, die Öhrchen verlängern sich. Setzt sich dagegen der Wurm zur Ruhe, so verkürzt er sich und wird entsprechend breiter, der Kopf zieht sich ein, die Tentakeln werden stumpf, knopfförmig, schwinden wohl auch ganz. Bei der sogenannten spannenden Bewegung der mit Sauggrube versehenen Formen wechselt die Kopfform von Augenblick zu Augen- 
blick (Bdellocephala punctata, Dendrocoelum lacteum u. a.). Die kräftige Muskulatur des Saugnapfes verändert durch ihre Kontraktionen auch den Kopfrand. Im allgemeinen ist das Vorderende dieser Arten quer abgestutzt und trägt seitlich bewegliche,von dem arbeitenden Saugnapf nur wenig beeinflußbareOhrchen. Nach vorn erheben sich zwei fleischige Wülste, die fortwährend zurückgezogen und vorgescho-

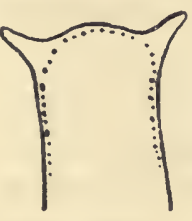

a

Kopfumriß von a Polycelis cornuta, b planaria vitta, c Polycladodes alba. ben werden. Die abgebildeten Umrisse sowie auch die Habitusbilder beziehen sich auf Exemplare in ruhig gleitender Kriechbewegung.

Die Oberfläche ist bei allen Planarien glatt und schleimig. Wir werden davon bei der Betrachtung der Körperbedeckung näheres hören.

\section{Farbe}

Oft kann die Farbe nicht einmal als brauchbarer Artcharakter gelten, indem verschiedene Individuen ein und derselben Spezies bedeutende Differenzen aufweisen können. Dies gilt besonders für die Süßwassertricladen, während in den Abteilungen der Polycladen und Landtricladen die individuellen Unterschiede weniger groß sind.

Es lassen sich unterscheiden Arten mit pigment und pigmentlose Formen.

Die letzteren kann man wiederum nach
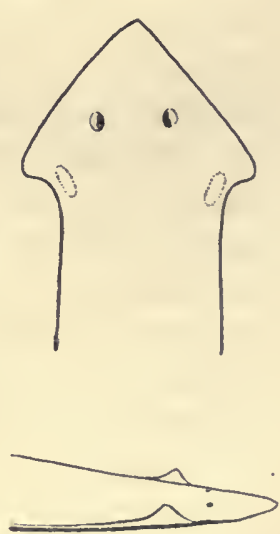

Abb. 4.

Kopf von Planaria gonocephala von oben und von der Seite.

dem Verhalten ihrer Gewebe zum Licht einteilen in durchscheinende bis durchsichtige Arten, deren Körper das Licht mehr oder weniger hindurchtreten läßt und weiße oder weiß- 
liche Formen, deren Körperbedeckung oder Innengewebe das Licht ganz oder zum Teil reflektiert.

Die Pigmente der übrigen sind entweder gelöst oder fest, sie können an sehr verschiedenen Stellen auftreten; in der Haut, in den Parenchymzellen, in beiden, oder aber gelöst in der sog. Perivisceralflüssigkeit.

Bei den SüBwasserplanarien fehlen durchsichtige Formen, höchstens können einzelne Körperbezirke wie die Seitenränder oder der Kopflappen das Licht einigermaßen durchlassen. Daher erscheinen uns die meisten pigmentlosen Arten milchweiß, wenn nicht die im Darm enthaltene Nahrung eine diffuse Gesamtfärbung bewirkt. Von den pigmentierten Formen lassen sich solche Arten leicht unterscheiden, da bei ihnen der Rand unter allen Umständen weiß oder durchscheinend bleibt. Die Mehrzahl der Süßwassertricladen besitzt ein körniges pigment, das unter der Körperhaut liegt. Die Farbe der Körner wechselt in ziemlich weiten Grenzen, ist jedoch vorwiegend braun oder schwärzlich. Selten ist die Gesamtfärbung durch die Farbe der Körnchen allein bedingt, meist spielen zahlreiche andere Faktoren mit. Da und dort mag man geneigt sein, von Farbvarietäten zu sprechen, die für einen Fundort typisch sind. So kommt in einer bestimmten Quelle im Jura eine schwefelgelbe Polycelis cornuta vor, die ihre abweichende Färbung unter den verschiedensten Verhältnissen beibehält. Wer sich aber längere Zeit mit Planarien beschäftigt hat, kennt den geringen Wert der Aufstellung von Färbungsvarietäten. Kommt es doch bisweilen vor, daß unter ein und demselben Stein schwarze, graue, rötliche und weiße Planarien sitzen, die alle $z u$ einer einzigen Art gehören. Als besonders wechselnd in der Färbung seien hier genannt Planaria polychroa, die „vielfärbige“, dann Polycelis nigra und Planaria alpina. Gehen wir den Ursachen dieser individuellen Färbungsdifferenzen nach, so sehen wir, daß junge Exemplare meist pigmentfrei oder doch ganz hell sind. Mit dem Alter scheint die Produktion von Pigmentkörnern zuzunehmen. Man kann daher an der Stärke der Pigmentierung das Alter einer Planarie un- 
gefähr abschätzen. Dabei sind jedoch Trugschlüsse leicht möglich, weil z. B. auch der Hunger das Pigment schwinden macht. Die Pigmentierung ist bei den SüBwassertricladen in der Regel recht gleichmäßig. Daher erscheinen uns kontrahierte Würmer dunkler als ausgestreckte. Durch ungleiche Kontraktion verschiedener Körperstellen kommt gelegentlich eine Art Schedkung oder Streifung zustande. Auch der Druck, den der gefüllte Darm auf die Haut ausübt, kann die Pigmentverteilung modifizieren. Bei schwach pigmentierten Arten kommt auch die Farbe der Nahrung in Betracht, die, durchschimmernd, das Gesamtaussehen ändert. Fast bei allen pigmentierten Planarienarten zeigen sich gelegentlich Individuen mit ungefärbten Stellen. Bisweilen ist der Pigmentmangel auf einzelne Flecken oder Streifen beschränkt. Nicht selten findet man auch ganze Körperteile, Schwänze oder Köpfe, ja ganze Hälften pigmentfrei. Gewöhnlich handelt es sich in solchen Fällen um die Folgen einer Verletzung, respektive Querteilung mit nachfolgender Regeneration. In regenerierten Geweben fehlt nämlich anfänglich das Pigment.

Durch normale Ungleichheiten der Pigmentverteilung bedingte Streifung, Scheckung und Marmorierung, wie sie bei den Landplanarien hăufig vorkommt, ist bei den SüBwasserformen selten. - Bdellocephala punctata, die "punktierte" hat ihren Namen von lichten Stellen auf dunklem Grund. - Dagegen ist die Bauchseite immer heller als der Rücken. Sehr häufig macht sich auch ein dunkler Längsstreif in der Mitte des Rückens bemerkbar (siehe Farbentafel). Pigmentfrei sind meist bestimmte, zu Sinnesorganen gehörige Bezirke am Kopf: ein kleiner Hof um die Augen bei den zweiäugigen Arten und Wimpergruben (Aurikularsinnesorgane) nahe dem Vorderende an den beiden Seitenrändern. Von dieser Grube wird später noch die Rede sein.

Körperöffnungen

a) Der Mund oder die Offnung der Rüsseltasche, durch welche der Saugrüssel vorgestreckt werden kann. 
b) Die Geschlechtsöffnung, durch welche bei der wechselseitigen Begattung der eigene Penis ausgestülpt, der fremde aufgenommen wird. Sie dient gleichzeitig auch zur Ablage der Eier.

Der Mund liegt immer median auf der Bauch-

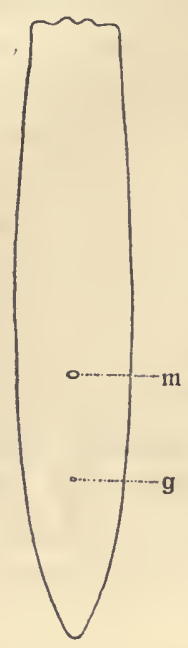

Abb. 5.

Lage der Körperöffnungen bei Dendrocoelum. m Mundöffnung. g Geschlectitsöffnung. seite und zwar nicht am Kopflappen, sondern etwas hinter der Körpermitte. Die Geschlechtsöffnung, ebenfalls ventral gelegen, findet sich noch etwas weiter hinten, etwa in der Mitte zwischen dem Mund und dem Hinterende (Abb. 5).

Sonstige Körperöffnungen können nicht ohne starke Vergrößerung und auch dann meist nur auf Schnitten wahrgenommen werden. Hierher gehören die Offnungen der Wassergefäße und die zahlreichen Ausmündungen der Drüsenkomplexe.

\section{Sauggrube}

Bei der Besprechung des Außern darf auch die Sauggrube nicht vergessen werden, die sich bei einzelnen Arten auf der Unterseite des Kopflappens bemerkbar macht. Bisweilen ist sie in Form einer schwachen Vertiefung entwickelt, an deren Grund zahlreiche Drüsen münden, in anderen Fällen aber gewinnt sie größere Bedeutung und kompliziertere Gestaltung, indem sie bei der Fortbewegung eine Rolle spielt. Sie ist dann mit besonderen Muskeln ausgestattet und gelegentlich sogar von Haftlippen oder Haftwülsten umgeben

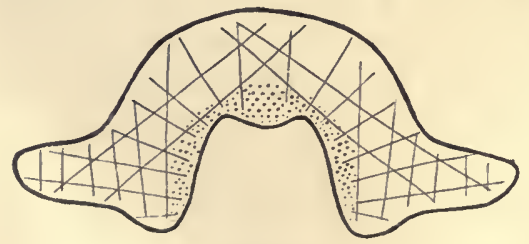

Abb. 6.

Querschnitte durd das Vorderende. Muskelzüge des Saugnapfs von Bdellocephala (nach Ude).
(Bdellocephala $=$ Egelkopf, Dendrocoelumarten). Abb. 6.

Zum Schluß seien noch diejenigen innern Organe aufgezählt, die man schon äußerlich erkennen kann. Durch die Rückenfläche schimmert fast immer der etwa in der Körper- 
mitte gelegene Saugrüssel durch, der sich bei pigmentierten Formen als heller, ovaler Fleck, bei pigmentlosen als ebenso geformte opake, weiße Stelle bemerkbar macht. Bei planaria gonocephala und einigen andern erscheint er als ein kurzer, breiter Zickzackstreif. Das kommt daher, weil er in seiner Tasche schlangenförmig zusammengelegt ist, um Platz zu finden. Bei geschlechtsreifen Formen macht sich meist auch der Kopulationsapparat als eine helle bzw. opake Stelle hinter dem Rüssel geltend. Seltener sieht man von oben die Ovarien als zwei rundliche Flecke hinter den Augen der zweiäugigen und an der entsprechenden Stelle bei den übrigen Arten. Bei unpigmentierten Spezies schimmert häufig, bei pigmentierten nur gelegentlich der Darm in seiner ganzen Ausdehnung durch die Rückenwand (s. Farbentafel).

Durch die Bauchwand pflegt man zu bemerken: Rüssel und Kopulationsorgane, ferner die Eierstöcke und die sogenannten falschen Samenblasen, d. h. die gewundenen vor der Einmündung in das Kopulationsorgan, erweiterten Samengänge, die bei geschlechtsreifen Individuen mit Samen gefüllt sind und daher als weiße oder opake Schlangenlinien $z u$ beiden Seiten des Rüssels sichtbar werden. Dazu kommt meist, auch das Gehirn mit den beiden Marksträngen, deren Lage später erörtert wird.

Von den Augen, die auch als durchschimmernde Organe aufgefaßt werden müssen, weil sie nicht in der Haut sondern im Parenchym liegen, wird im Kapitel über die Sinnesorgane die Rede sein.

\section{Histologie und Organologie}

Wir wenden uns nunmehr zur Betrachtung der einzelnen Gewebe und Organsysteme, und zwar soll uns zunächst das Integument, die Körperbedeckung beschäftigen.

\section{Integument}

Bei allen Strudelwürmern ist der Körper von einer gleichmäßigen einschichtigen Lage von Zellen, einem sog. Epithel umgeben. Diese Epithelzellen besitzen in den meisten Fällen jenes 
sehr feine Wimperkleid, das der Gruppe ihren Namen eingetragen hat. Unter den gewöhnlichen Integumentzellen, den Deckzellen, fallen einzelne durch Abweichungen in Bau und Funktion

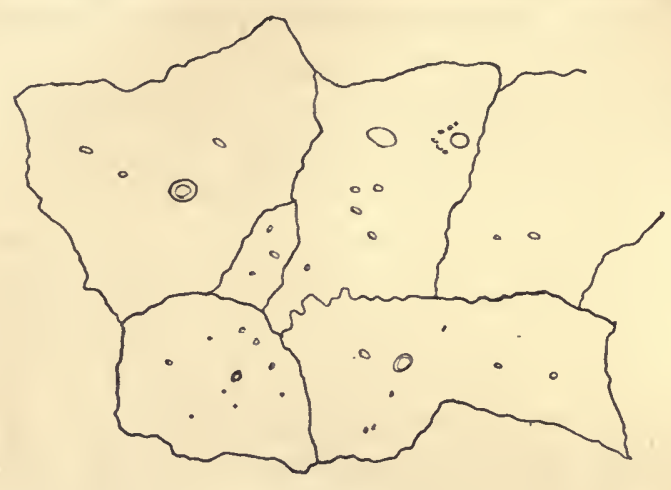

Abb. 7.

Umrisse der Integumentzellen auf Flächenschnitten (nach Sander). auf. Sie können von Drüsengängen durchbohrt sein oder aber mit Nerven in Beziehung treten. Von diesen speziellen Gebilden, den Drüsenund den Sinneszellen, mag später die Rede sein.

BeiSchnitten durch Planarien, die parallel zur Oberfläche gerichtet sind, kann man oft zahlreiche, in der Fläche nebeneinander geordnete Integumentzellen antreffen. Die Einzelzelle zeigt dann eine un regelmäßig polygonale Gestalt (Abb. 7). Auf Querschnitten durch den Wurm haben alle Zellen gleichförmig quadratische oder rechteckige Umrisse (Abb. 8).

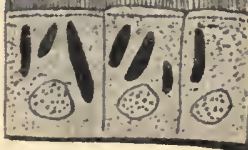

Abb. 8.

Integument im Schnitt mit Rhabditen(schwarz).

Die Einzelzelle hat somit die Gestalt eines prismas mit polygonaler Grundfläche. Ihre Höhe kann im Vergleich zur Breite wechseln. Zwischen den Epithelzellen spannen sich sehr feine Fäden von Protoplasma aus. Durch ähnliche Brücken ist auch die Verbindung zwischen Integument und Körperinnerem hergestellt.

\section{Cilien} Die Wimpern sind außerordentlich feine, nur mit starken Vergrößerungen sichtbare Protoplasmafädchen, die den Zellen in großer Anzahl aufsitzen. Jeder einzelnen Wimper oder Cilie entspricht eine Cilienwurzel im Protoplasmaleib der Zelle, ein äußerst zartes Körperchen (Basalkörperchen), welches mit einem die Zelle durchziehenden Fäserchen in Verbindung steht. Durch 
diese Faserelemente erhalten die Integumentzellen bisweilen eine deutliche Streifenstruktur.

Über den Mechanismus der Cilienbewegung wissen wir nichts. Wir kennen weder die Energiequelle noch das Organ, durch welches die Regulierung des Wimperschlags besorgt wird.

Bei den Süßwasserplanarien ist das Wimperkleid nicht an allen Stellen des Körpers gleich wohl entwickelt. Die Bauchcilien sind überall viel kräftiger, die der Dorsalseite fehlen bei erwachsenen Individuen entweder ganz, oder sind so zart, daß sie beim Abtöten der Würmer verloren gehen. Bei jugendlichen Exemplaren ist dagegen die Bewimperung viel gleichmäßiger. Völlig frei von Cilien sind zwei Streifen an der ventralen Seite, jederseits dicht neben dem Seitenrand, sowie ein ventraler Bezirk vorn und hinten. Es ist das die Zone der Kleb- oder Randdrüsen, die später genauer behandelt werden soll. Umgekehrt besitzen einzelne

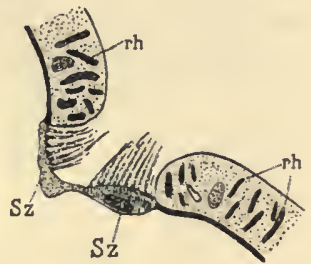

Abb. 9.

Schnitt durch das Integument von Planaria mit Sinneszellen (Sz). rh Rhabditen. Zellen besonders starke Bewimperung, z. B. die Integumentzellen der Fühlhörner und die Sinneszellen (Abb. 9).

\section{Pharynxintegument}

von dem gewöhnlichen Epithel beträchtlich abweichen. Die ganze Außenseite des Rüssels ist von einer zusammenhängenden Schicht polygonaler Zellen bedeckt. Die Oberflächenschnitte rufen das uns vom gewöhnlichen Epithel bekannte Bild (Abb. 7) in Erinnerung. Gelegentlich schieben sich zwischen die großen Zellen kleine ein, die ebenfalls polygonale Gestalt aufweisen. Während aber die gewöhnlichen Epithelzellen kernhaltig sind, lassen sich in den Platten der Pharynxbedeckung keine Kerne nachweisen. Durch komplizierte färberische Methoden gelang es jedoch, den zugehörigen Kern samt seiner plasmatischen Verbindungsbrücke sichtbar zu machen (Abb. 10). Die Kerne finden sich weit von 
der Platte entfernt an der Grenze zwischen der äußeren Muskelschicht und der Mittelzone, und zu jedem Kern führt von der Platte ein Plasmastrang, der die Basalmembran und die Muskelschicht durchbricht. Eine Pharynxepithelzelle (Abb. 11) besteht also aus der Zellplatte und mehreren in die Muskelschicht eindringenden Ausläufern, deren kräftigster die ganze Muskellage durchsetzt, an seinem Ende kolbig anschwillt und den Kern enthält.

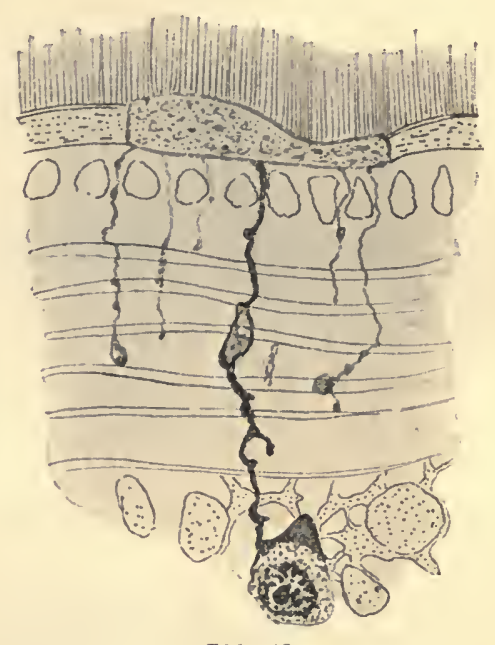

Abb. 10.

Eingesenkte Epithelzelle aus Tricladenpharynx (im Schnitt) nach Jander.

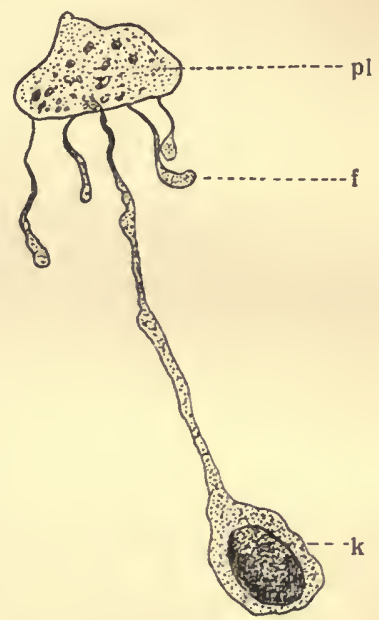

Abb. 11. Epithelzelle des Tricladenpharynx (nach Jander). pl Epithelplatte, f Fortsätze, k Kern.

Ein Epithel, das aus derartigen Zellen besteht, heißt eingesenkt. Eingesenkte Epithelien kommen gelegentlich auch an den Tentakeln und an anderen Körperstellen vor. Bei den Saug- und Bandwürmern ist bekanntlich das gewöhnliche Körperepithel eingesenkt und von einem strukturlosen Häutchen (Cuticula) bedeckt. Das besprochene eingesenkte Epithel kann gewissermaßen als Vorläufer dieser modifizierten Körperbedeckung aufgefaßt werden; es ist eingesenkt, trägt jedoch auf den Platten ein durchaus normales Wimperkleid. Bei den marinen Bdellouriden, die auf den 
Kiemen der Molukkenkrebse leben, ist das ganze Körperepithel der Pharynxbedeckung der andern Tricladen ähnlich.

\section{Stäbchen}

mehrere stabförmige Körperchen, sog. Stäbchen Rhabdoide, die je nach ihrem Bau als Rhabditen (gleichmäßig lichtbrechend), Rhammiten (feinkörniges Mark mit hyaliner Rinde) oder Pseudorhabditen (gleichmäßig granuliert) unterschieden werden).

Uber ihre Natur ist schon sehr viel geschrieben worden. Trotzdem ist manches noch unklar und zweifelhaft. Sehr wahrscheinlich stellen sie festes Sekret dar, das, wenn es mit Wasser in Berührung kommt, aufquillt und sich in eine Flüssigkeit verwandelt.

Die Stäbchen der Süßwassertricladen sind als Rhabditen auf zufassen. Sie können in verschiedener Weise entstehen. Die einen bilden sich in dem Körperepithel selbst und zwar entweder in den gewöhnlichen Deckzellen oder in besondern Rhabditenbildungszellen, die zwischen den andern Epithelzellen eingekeilt sind (dermale Rhabditenbildungszellen). Diese unterscheiden sich von den Nachbarzellen durch einen dunkleren Kern und durch einen größeren Vorrat an Stäbchen, die hier nestartig

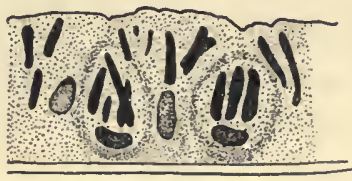

Abb. 12.

Dermale Rhabditenbildungszellen nach Ude. beisammenliegen (Abb. 12). Außerdem können die Stäbchen auch in Bildungszellen des Parenchymes (adenale, d. i. in besonderen Drüsen gebildete Rhabditen) ihren Ursprung nehmen.

In den dorsalen Integumentzellen sind die Rhabditen größer und treten auch zahlreicher auf als in den ventralen Zellen. In der Nähe der Auricularsinnesorgane (s. Abschn. Sinnesorg.), oder wo solche fehlen, in der Nähe der Taststellen und Fühlhörner nehmen die Rhabditen rasch an Zahl und Größe ab; in den eigentlichen Sinneszellen fehlen sie gänzlich, ebenso im Gebiet der Klebzellen (s. unten). 
Was die Funktion der Stäbchen betrifft, so gehen die Meinungen ziemlich weit auseinander. Bei denjenigen Planarien, die sich von kleineren Tieren, Flohkrebsen, Insektenlarven usw. ernähren, dient der zähe Schleim der ausgestoßenen Rhabditen zum Beutefang (s. Biologie).

Bei den Maricolen, deren Nahrung hauptsächlich aus toten Fischen besteht, ist die Bedeutung der Rhabditen weniger klar. Ihr massenhaftes Auftreten verbietet, sie für funktionslose Gebilde $\mathrm{zu}$ halten, die etwa früher, als die Tiere unter andern Bedingungen lebten, eine Bedeutung hatten. Es wurde vermutet, daß es sich um éin Schutzmittel handle. Dem aus den ausgestoßenen Stäbchen entstehenden Schleim wurden giftige Eigenschaften zugeschrieben, die den Angreifer, ein größeres Tier, etwa einen Fisch, vom Verschlingen der Würmer abhalten sollten. In der Tat beobachtet man, daß die Tricladen von vielen Tieren sorgfältig gemieden werden. Ob aber wirklich der Rhabditenschleim diese Wirkung hat, oder ob vielleicht die flüssigen Sekrete der verschiedenen Parenchymdrüsen giftig sind, kann ohne Experiment kaum entschieden werden. Dagegen verdient noch' eine andere Ansicht über die Bedeutung der Rhabditen Erwähnung. Der Stäbchenschleim soll danach zum Verschluß von Wunden dienen, das Eindringen schädlicher Substanzen und Mikroorganismen verhindern, also gewissermaßen antiseptische Funktionen verrichten. Für diese letztere Auffassung sprechen auch einige Beobachtungen: Verletzt man eine Planarie durch einen Schnitt oder durch einen Nadelstich, so werden die Stäbchen in der Nähe der Wunde ausgestoßen. Lebt das Tier sonstwie unter ungünstigen Bedingungen, in $z u$ warmem oder verdorbenem Wasser, so bemerkt man, daß die Stäbchen der ganzen Oberfläche austreten, so daß das Tier von einer zähen Schleimhülle umgeben ist. Bessern sich die Verhältnisse, so kann sich der Wurm aus diesem Zustand befreien; meist aber ist die Ausstoßung der Rhabditen der Anfang vom Ende, und das Tier stirbt bald danach (vergleiche biologischen Teil). 
Gewisse Integumentzellen entbehren, wie wir gesehen haben, sowohl der Cilien als auch der

Rhabditen, sie wurden oben andeutungsweise als Klebzellen bezeichnet.

Sie bilden zusammen einen ventralen, die Körperränder in ungefähr gleichbleibendem Abstand begleitenden Ring und heißen deshalb auch Randzellen.

Der Klebzellenring kann vorn und hinten jederseits auf eine kurze Strecke unterbrochen sein. Er verbreitert sich zuweilen

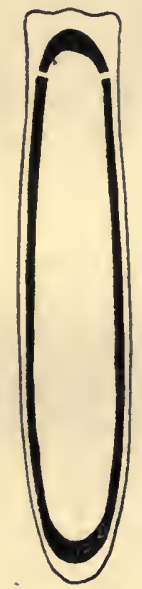

Abb. 13.

Klebzellenring (schemat.) nach Wilhe Imi.

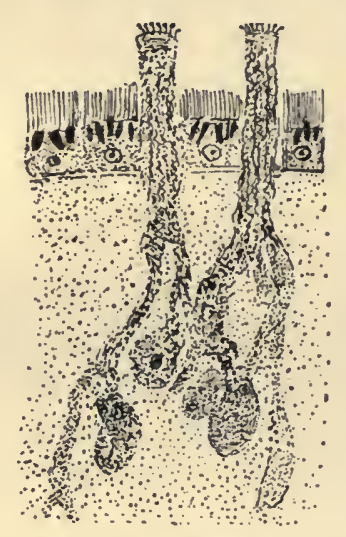

Abb. 14.

Klebzellen und Klebdrüsen (im Parenchym) nach Wilhe Imi.

an beiden Enden zu einem größeren Klebfeld (Abb. 13). Die einzelne Klebzelle ist nicht, wie man vermuten könnte, eine Drüse, sie dient nur zur Ausführung des Sekretes der Klebdrüsen, die im angrenzenden Parenchym gelegen sind (Abb. 14). Wenn man Schnittserien nacheinander in Hämatoxylin und Eosin färbt (blauviolett + rot), so färben sich sowohl die Drüsen als auch die Ausführgänge und somit die Klebzellen hellrot und heben sich so sehr deutlich vom anliegenden blauvioletten parenchymgewebe und Körperepithel ab. Man nennt sie aus diesem Grunde "rot- 
liebend ${ }^{\star}$ erythrophil oder eosinophil, d. h. Eosin liebend. Die zahlreichen, die Klebzellen durchsetzenden Drüsengänge verleihen dem Plasmaleib ein gestreiftes Aussehen. An der Oberfläche tritt das Klebsekret in Form zahlreicher kleinster Stäbchen oder Tröpfchen auf, so daß man von einem kleinen Kamm sprechen könnte (Abb. 14). Oft haben die Sekretpfropfen die Gestalt von Keulen oder gestielten Knötchen. Sie führen in der Literatur auch den Namen Haftpapillen.

Eine Vorstellung über die Wirkungsweise kann man sich nicht leicht bilden, und aus den Resultaten der bisherigen Untersuchungen wird man kaum Gewißheit erlangen. Tatsache ist, daß die Planarien die Fähigkeit besitzen, sich an der Unterlage festzuheften. Sie überwinden dabei nicht nur die Schwere, indem sie sich an senkrechten und überhängenden Flächen anheften, sie trotzen selbst dem heftigsten Wasserstrahl und sind zum Teil im wildbewegten Bergbach gegen das Weggespültwerden gefeit.

\section{Basalmembran}

Alle Elemente des Integumentes, die Deck-, Klebund Sinneszellen sitzen einem bei allen Strudelwürmern mit Ausnahme der Acoelen und einigen Allöocoelen vorkommenden Häutchen, der Basalmembran auf. Sie ist an verschiedenen Körperstellen verschieden dick und scheint sehr dehnbar zu sein.

Zahllose Ausführgänge verschaffen sich Raum, indem sie die Basalmembran durchbohren. Abgesehen von den vielen Löchern, welche die Stäbchen bei ihrem Durchtritt erzeugen, müssen auch Nervenfibrillen und Plasmaausläufer, sowie Drüsengänge hindurchdringen.

Bei den Planarien des süßen Wassers ist die Basalmembran strukturlos und einschichtig. Sie läßt sich durch gewisse Färbemittel sehr deutlich von den angrenzenden Partien abheben.

Die weichen, plastischen Formen, z.B. Dend ro coelu m, besitzen eine dünnere elastischere Basalmembran als die starreren Arten wie. Planaria lugubris. Außerdem hängt die Resistenz des Körpers. von der verschiedenen Entwicklung des Hautmuskelschlauches ab. 
Muskulatur

Der Hautmuskelschlauch, das einzige allgemein gültige Merkmal der Würmer, ist bei allen Turbellarien wohl entwickelt, am besten bei denen, die auf Kriechbewegung angewiesen sind. Allen kommen außerdem Körpermuskeln $\mathrm{zu}$, die entweder durch das Parenchym und, zwischen den einzelnen Or ganen hindurchziehend verschiedene Punkte der Haut miteinander verbinden ( $\mathrm{P}$ a r en ch y m m u skeln), oder von der Haut völlig unabhängig sind und im Dienst bestimmter Organe stehen (Organmuskel n).

Die Muskelfasern bestehen aus einer homogenen bis feinkörnigen Substanz, welche die Fähigkeit besitzt, sich zusammenzuziehen. Sie sind die produkte besonderer Zellen, der Myoblasten, die oft dauernd mit ihren Fasern im Zusammenhang bleiben, indem sie ihnen seitlich als buckelförmige Anhängsel aufsitzen (Abb. 15) oder von ihnen abgerückt sind und nur durch feine, dünne Plasmafäden mit ihnen zusammenhängen (Abb. 16).

Bei den Paludicolen sind die Muskelfasern bald homogen, bald lassen sie ein feinkörniges Mark erkennen. Ihre Enden laufen meist spitz aus, können sich aber auch

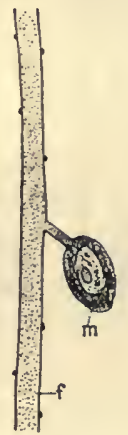

Abb. 16. Muskelfaser (f) mit Myoblast $(\mathrm{m})$ aus dem Pharynx von planaria gonocephala.

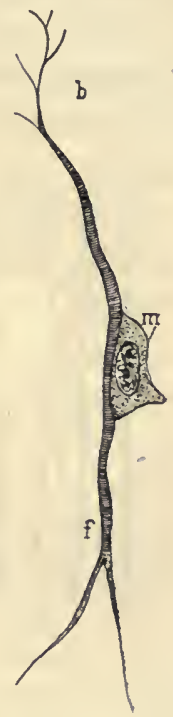

Abb. 15.

Muskelfaser (f) mit anhängendem Myoblast (m) aus dem Hautmuskelschlauch von Planaria gonocephala. b baumför mige Verzweigung. verästeln. Die Form des Querschnittes durch eine Muskelfaser wechselt sehr. Man trifft rundliche, ovale, platte oder kantige Fasern. Ebenso schwankt das Verhältnis der Länge zur Dicke.

Hautmuskelschlauch 
muskelschicht. Bei den meisten Strudelwürmern kommt jedoch dazu eine aus zwei die Medianebene kreuzweise unter $45^{\circ}$ schneidenden Lagen bestehende Diagonalfaserschicht, die sich zwischen die Ring- und Längsmuskelschicht einschiebt. Durch Verdoppelung einzelner Lagen kann die Schichtenzahl steigen (bei den Polycladen auf 5-6).

Wir wenden uns zur Betrachtung der Verhältnisse bei den Süßwassertricladen. Wenn wir den Hautmuskelschlauch einer Planarie von außen nach innen durchdringen, so stoßen wir zunächst

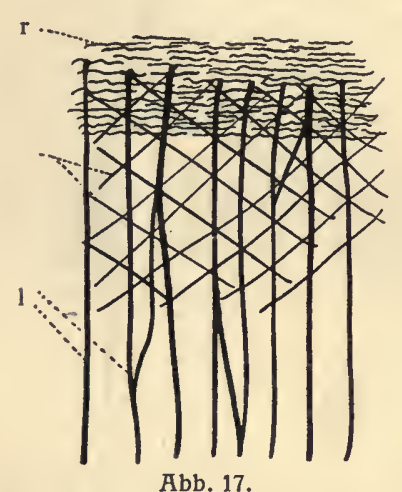

Flächenschnitt durch den ventralen Hautmuskelschlauch einer Planaria. r Ringmuskeln, d Diagonalmuskeln, 1 Längsmuskeln. auf die Ringmuskelschicht (Abb. 17). Die Ringfasern bilden eine einfache Lage, die sich der Basalmembran eng anschließt. Nach innen folgt eine schwache, bisweilen fehlende Schicht von Längsfasern, dann die Diagonalfaserschicht, die bei den plastischen Arten schwächer entwickelt zu sein scheint, als bei den starreren, und also dem Hautmuskelschlauch und damit dem ganzen Tiere Festigkeit verleiht. Die innerste Schicht besteht wieder aus Längsfasern, die meist zu Bündeln zusammengefaßt sind. Diese Lage ist bei weitem die stärkste, sowohl was die Zahi der übereinanderliegenden Fasern, als auch was deren Dicke betrifft.

In den verschiedenen Körperregionen ist das Stärkeverhältnis der Schichten etwas wechselnd. Wir übergehen diese Einzelheiten und beschränken uns auf den Hinweis, daß die Bauchseite, die sog. Kriechsohle, mit viel stärkeren inneren Längsmuskeln ausgestattet ist, als die Rückenseite. Ihnen kommt bei der Kriechbewegung die Hauptaufgabe zu. Durch die Stärke der ventralen Längsmuskeln läßt sich auch eine Erscheinung erklären, die jedem, der Planarien konserviert, unliebsam auffällt. Sobald man die Würmer mit einem der gewöhnlichen Konservierungsmittel, mit Alkohol, 
Formol oder Sublimat übergießt, so kontrahiert sich der ganze Körper. Da aber die Bauchseite die stärksten Längsmuskeln besitzt, krümmt sich das sterbende Tier stark nach dieser Seite ein, rollt sich bisweilen sogar spiralig zusammen. In diesem für die Untersuchung recht ungünstigen Kontraktionszustand erstarrt der Körper. ${ }^{1}$ )

Die Funktion des Hautmuskelschlauches ist sehr kompliziert, indem die verschiedenen Muskellagen sich in ihren Wirkungen ill mannigfaltigster Weise kombinieren. So wird die Planarie zu einem sehr beweglichen Wesen. Bald streckt sie sich mit Hilfe der Ringmuskeln lang aus, im nächsten Augenblick kontrahieren sich die Längsmuskeln, so daß sich der Wurm ruckweise zu einem Klümpchen zusammenzieht. Bald hebt er bei halber Kontraktion den einen oder den andern Körperrand, bald breitet er sich blattförmig aus, um im nächsten Moment wieder den Rücken empor $\mathrm{zu}$ wölben und die Seitenränder zu kontrahieren. Alle diese Bewegungsformen beobachtet man in beliebiger Folge; sie werden in erster Linie vom Hautmuskelschlauch ausgeführt, können aber modifiziert und verstärkt werden durch das System der Körperoder Parenchymmuskeln.

\section{Parenchymmuskeln}

Diese bei allen Strudelwürmern, ja bei allen Plathelminthen auftretenden Elemente sind allseitig von Parenchym umgeben und verlaufen in den verschiedensten Richtungen. Die kräftigsten verbinden meist die Rücken- mit der Bauchseite und heißen daher Dorsoventralmuskeln. Ihre Enden pinseln sich auf und verbinden sich mit der Basalmembran oder mit dem Hautmuskelschlauch. Die Dorsoventralmuskeln sind naturgemäß in ihrem Verlauf abhängig von den Organen des Körperinnern, die sie umgehen müssen. Infolgedessen können sie sich bei den Kontraktionsbewegungen des Darmes betätigen. Da, wo diesem Organ eine Eigenmuskulatur fehlt, können die Dorsoventralmuskeln direkt zu Darmmuskeln

1) Über geeignetere Konservierungsmittel spricht die Einleitung. 
werden, ohne dabei ihre Natur als Parenchymmuskeln zu verleugnen.

Weniger leicht bekommt man anders orientierte Parenchymmuskeln zu Gesicht. Die schräg transversalen, wie die schräg longitudinalen Fasern kann man als $\mathrm{T}$ angentialfasern bezeichnen. Tangentialmuskeln sind hauptsächlich in Tätigkeit, wenn die Würmer das Kopfende hochheben. Sie kommen daher besonders reichlich im Gebiet des Vorderendes vor. Auch das Hinund Hertasten des Kopfes wird zum großen Teil durch diese Muskeln ermöglicht.

In einzelnen Regionen treten die Parenchymmuskeln zu Bündeln und Strängen zusammen. Sie sind dann an ganz bestimmte Funktionen angepaßt. Ein derartiges Muskelsystem hat z. B. die Aufgabe, den herausgestreckten Rüssel wieder in die Tasche zurückzuziehen. Auch die hohe und vielseitige Beweglichkeit der Fühlhörnchen, die gehoben, gesenkt, gedreht und verkürzt werden können, beruht auf einem System von Parenchymmuskeln.

\section{Organmuskeln}

Noch spezialisierter und vom Hautmuskelschlauch ganz unabhängig sind die Organmușkeln, z. B. die komplizierte Muskulatur des Pharynx und die des Genitalapparates, speziell der Penispapille. Diese Organe werden in anderm Zusammenhang besprochen und abgebildet. Daß die Organmuskeln aus Parenchymmuskeln hervorgehen, zeigt uns wohl am schönsten die Saugnapfmuskulatur. $\mathrm{Da}$ nämlich die Saugnäpfe bei den einzelnen Arten der Paludicolen recht verschieden ausgebildet sind, ergibt sich aus der Vergleichung ein Bild der Entwicklung. Im einfachsten Fall scheinen nur einige Tangentialfasern oder Dorsoventralmuskeln eine Vertiefung am Vorderende hervorbringen $\mathrm{zu}$ können. Dadurch, daß die Faserzüge zahlreicher werden, und in verschiedenen Richtungen verlaufen, entstehen kompliziertere Verhältnisse, die zu den ausgeprägten Saugnäpfen mit Wülsten überführen. Die Muskulatur des Saugapparates einer Bdellocephala wird man als Organmuskulatur auffassen müssen (Abb. 6). 


\section{$-37-$ \\ Parenchym}

In den bisherigen Ausführungen wurde schon mehrfach das Parenchym erwähnt. Wir wollen nun auch dieses Gewebe in seinem Bau genauer betrachten.

Das Parenchym, auch Mesenchym genannt, erfüllt das gesamte Körperinnere, soweit dasselbe nicht von Organen eingenommen wird. Es ist bei den verschiedenen Strudelwurmabteilungen sehr verschieden gebaut und meist schwierig zu analysieren.

In einem netzförmigen oder besser schwammartigen Substrate sind viele, sehr verschiedenartige Zellindividuen eingebettet (Abb. 18), am häufigsten sternförmige Zellen, deren Ausläufer sich teils im Grundgewebe (= Reticulum, Netzchen) verlieren, teils gegenseitig umklammern und verfilzen. Daneben trifft man dann und wann spindelige Zellen mit nur zwei Ausläufern. Diese sogenannten bipolaren gehen durch Schwund des einen Fortsatzes in

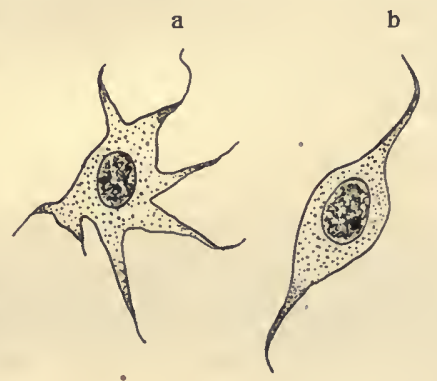

Abb. 18.

Sternförmige (a), bipolare (b) und ruhende (c) parenchymzelle.

unipolare Parenchymzellen über. Am seltensten findet man im normalen Parenchym sogenannte ruhende Zellen mit abgerundetem Plasmahof ohne Ausläufer, die in der Literatur verschiedene Namen, wie Stammzellen, Bildungszellen, embryonale Zellen führen. Man hat ihnen für verschiedene Funktionen des Parenchyms eine wichtige Rolle zugeschrieben. Bis auf weiteres müssen wir aber bekennen, daß über ihre Aufgabe nichts Bestimmtes bekannt ist. Bisweilen trifft man im Körpergewebe der verschiedensten Planarien Stellen, wo die Zellkerne frei im Reticulum liegen, wo also gewissermaßen ein Zerfall in einzelne Zellen noch nicht stattgefunden hat. Ein solches Gewebe wird mit dem Namen Syncytium belegt. 
Das Körpergewebe ist durchaus nicht nur ein Füllgewebe, es kommen ihm vielmehr sehr wichtige Funktionen zu. Von ihm geht die Bildung aller jener Organe aus, die erst im späteren Alter zur Entwicklung gelangen (Genitalapparat). Das Parenchym besorgt den Ersatz verbrauchter Gewebe, sowie den Ausbau anfangs einfacher Organe (Darm, Exkretionsapparat). Ist irgendwo eine Verletzung zu reparieren, ein verlorener Körperteil $z u$ ersetzen, so werden die Zellen des Parenchyms mobil gemacht. Es können sich aus ihnen die verschiedensten Gewebe bilden (Darmepithel, Drüsen, Nerven, Muskeln, Geschlechtsapparat usw.). Außerdem spielen sich im Parenchym die komplizierten Prozesse der Assimilation von Nahrung, der Rückführung oder Reduktion höher differenzierter Elemente in einfachere ab. Es ist somit ein sehr vielseitiges Gewebe.

\section{Drüsen}

Als umgewandelte Parenchymzellen werden oft auch die Drüsen aufgefaßt, die allen Strudelwürmern reichlich zugedacht sind. Hierher hätten wir eigentlich auch die adenalen Rhabditenbildungszellen $z u$ rechnen. Wir beschränken uns aber auf diejenigen Drüsen, welche flüssige Sekrete liefern. Leider wissen wir über die Natur und Funktion dieser Stoffe sehr wenig. Früher hat man zwischen Schleimund Speicheldrüsen unterschieden. $\mathrm{Ob}$ man zu einer solchen Deu tung, wie sie diese Benennung den Sekreten beilegt, berechtigt ist, scheint jedoch sehr zweifelhaft. Wir müssen uns daher damit begnügen, die Drüsen nach ihrem Verhalten gegenüber Farbstoffen einzuteilen, unter Verzicht auf irgendwelche Aussage über die Funktion. Im besten Falle können wir ganz allgemein diejenigen Lebensäußerungen aufzählen, die unter Mitwirkung von Drüsen zustande kommen. Da ist vor allem die Bewegung zu nennen, bei der wahrscheinlich mehrere Drüsenarten beteiligt sind. Einmal ist der Schleimstreifen, den die Planarien wie die Schnecken hinter sich lassen, ein Beweis für die Tätigkeit von Schleimdrüsen. Dieser offenbar zähe Stoff dürfte aber die Bewegung der Cilien stark behindern, muß deshalb vom Sekret anderer Drüsen ver- 
flüssigt werden. Weitere Drüsen mögen Betäubungsmittel für den Beutefang liefern und eventuell die Giftigkeit der Planarien bedingen (s. auch S. 30). Besondere Drüsen besitzt auch der Verdauungs - und der Genitalapparat.

Nach der Gestalt und nach dem Verhalten zu Farbstoffen, wie Hämatoxylin und Eosin, unterscheidet man

1. erythrophile (eosinophile) sich rot färbende Drüsen. Der hierher gehörigen Kantendrüsen haben wir schon im $\mathrm{Ab}$ schnitt über das Integument gedacht. Ihnen schließen sich an die Körnerdrüsen mit körnigem Sekret.

2. cyanophile (sich blau färbende Drüsen). Hierher sind die Kopfdrüsen zu rechnen, deren Ausführgänge als dunkle Züge direkt unter dem Gehirn nach vorn und unten streichen und auf einem scharf umschriebenen Bezirk in der Tiefe der Sauggrube ausmünden. Cyanophil sind auch die vereinzelt auf der ganzen Oberfläche mündenden sog. Schleimdrüsen.

Ubrigens verhalten sich die einzelnen Spezies bezüglich der Färbbarkeit ihrer Sekrete ziemlich verschieden. Wir können es uns deshalb ersparen, näher auf diese Verhältnisse einzugehen.

\section{Verdauungsapparat}

Das Verdauungsystem der Strudelwürmer unterscheidet sich von dem der höheren Tiere ganz beträchtlich. Es liegt hier gewissermaßen ein ganz anderer Grundplan vor. Während man beim Wirbeltier z. B. stets von einem Darmrohr spricht, das zwei Offnungen, Mund und After, besitzt, müssen wir den Darm der Turbellarien als einen Sack bezeichnen. Eine einzige Öfnung dient zur Aufnahme der Nahrung und zum AusstoBen der Uberreste. Selbst in seiner kompliziertesten Form ist der Darm nichts anderes als ein Blindsack. Nur wenige Polycladen, bei denen sekundär die Darmverästelungen dorsal oder lateral nach außen durchbrechen, nehmen hier eine Sonderstellung ein.

Im einfachsten Fall ist nur der vom Integument gelieferte Teil des Verdauungssystems, der Mund und eventuell ein muskulöser 
Pharynx vorhanden. Die Nahrung gelangt direkt in das syncytiumartige Parenchym (Acoelen). Der eigentliche Darm ist sehr einfach bei den Rhabdocoelen, mehr oder weniger kompliziert bei den übrigen, früher als Dendrocoela (mit baumförmigem Darm) bezeichneten Formen, zu denen auch unsere Planarien gehören. Bei ihnen liegt die Mundöffnung immer auf der Bauchseite gewöhnlich über die Mitte nach hinten verschoben (Abb.5). Die sog. äußere Mundöffnung führt zunächst in einen zylindrischen, ziemlich

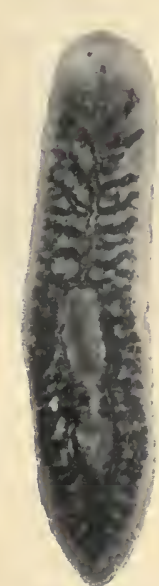

Abb. 19.

Darm von Dendrocoelum lacteum. (Mikrophotographie.) weiten, in der Längsrichtung des Wurmes verlaufenden Hohlraum, Rüsselscheide oder Rüsseltasche genannt. In ihr liegt der vorstreckbare Saugrüssel oder Pharynx, durch den die Nahrung in den eigentlichen Darm gelangt. Der erste Abschnitt des Darmsackes, der Darmmund, d. h. die Stelle, wo die drei großen Blindsäcke zusammenstoßen, schließt sich dicht an die Rüsselwurzel an, seltener ist eine kurze, engere Verbindungsstrecke, ein sog. hinterer Unpaardarm entwickelt. Die Anordnung der drei Hauptstämme ist für die Tricladen ( $={ }_{n}$ mit 3 Darmästen ") sehr charakteristisch und unterscheidet sie deutlich von den übrigen Ordnungen der Turbellarien. Der nach dem Vorderende verlaufende unpaare "Kopfdarm" nimmt die Mitte des Tieres ein, ist also von den Seitenrändern gleichweit entfernt. Er teilt sich in einfach schlauchförmige oder gegabelte, gelegentlich auch verästelte Seitenzweige, die zum Hauptdarm und damit zur Längsachse des Tieres meist senkrecht stehen. Die vordersten Divertikel breiten sich im Vorderende handförmig aus. Ihre und des Hauptdarms letzte Verzweigungen erreichen das Gebiet des Gehirns. Dort endigen sie alle blind. Die beiden zum Hinterende ziehenden Hauptstämme zeigen symmetrische Anordnung zu beiden Seiten des Rüssels. Sie verlaufen zunächst vom Darmmund aus jederseits nach dem entsprechenden Körperrand zu und biegen dann rechtwinklig nach hinten um. Ihre Richtung ist ziemlich genau die des Körperrandes. Daher 
bleiben sie bis in die Gegend des Kopulationsorgans unter sich parallel und konvergieren erst kurz vor der blinden Endigung. In manchen Fällen führt diese Konvergenz zu einer Verschmelzung, zur Bildung eines hintern Unpaardarmes. Dadurch können Verhältnisse geschaffen werden, die an die Alloeocoelen erinnern (Abb. 20). Es muß jedoch betont werden, daß die Vereinigungen der hinteren Darmäste bei den Tricladen stets eine sekundäre Erscheinung ist, die nicht als Verwandtschaftskriterium gelten kann.

Die von den "Schwanzdärmen", wie wir die paarigen Äste im Gegensatz zum ${ }_{n}$ Kopfdarm" nennen wollen, ausgehenden Divertikel sind auf der Außenseite gegen die jeweiligen Ränder zu viel mächtiger entwickelt, haben für ihre Entfaltung auch viel mehr Platz als in der entgegengesetzten Richtung. Hinter dem Pharynx, bzw. bei den geschlechtsreifen Formen hinter dem Kopulationsapparat entwickeln sich innere und äußere Divertikel dem vorhandenen Raum entsprechend gleichmäßig. Zwischen den innern bilden sich dann und wann Anastomosen, indem sich benachbarte Aste berühren und ineinander öffnen. Auch zwischen gleichgerichteten Divertikeln kommen Verbindungen vor (Abb. 20), so daß sich im extremen Fall scheinbar sekundäre Hauptstämme seitlich von den normalen bilden. Die Anastomosenbildung kommt nicht allen Arten

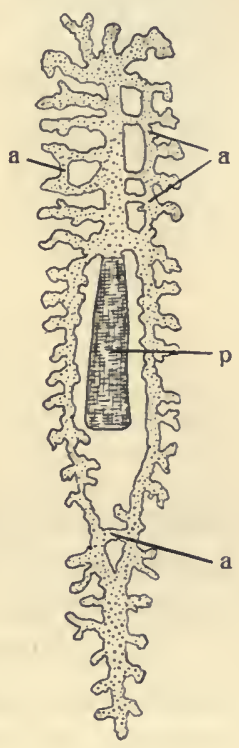

Abb. 20.

Darm mit Anastomosen. a Anastomosen. p Pharynx. $\mathrm{zu}$ und scheint im allgemeinen durch Verletzungen und Teilungsvorgänge mit nachfolgender Regeneration begünstigt $\mathrm{zu}$ werden.

In der ersten Jugend, wenn die Planarie soeben die Eihüllen verlassen hat, ist ihr Darm viel einfacher gebaut. An Stelle der Verzweigungen finden sich plumpe Lappen und Aussackungen (Abb. 21). Erst mit der fortschreitenden Differenzierung und mit dem Zuwachs an Körpersubstanz gliedern sich 
die unförmigen Säcke. Je größer und älter der Wurm ist, um so komplizierter sind im allgemeinen seine Darmäste verzweigt.

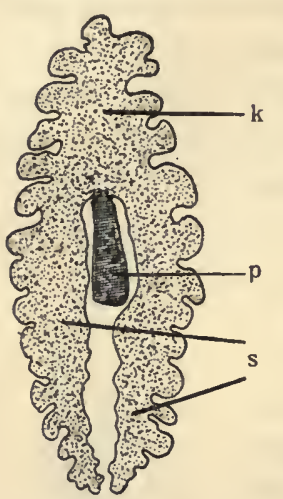

Abb. 21.

Darmtraktus einer jungen PIanaria. p Kopfdarm, p Pharynx. s Schwanzdärme.

Langes Hungern dagegen reduziert gleichzeitig die Körpergröße und die Darmkomplikation.

Wir wenden uns nun zur Betrachtung des feineren Baues der einzelnen Darmabschnitte.

\section{Pharynx}

Der vorstreckbare Saugrüssel ist ein sehr konstantes Merkmal der Tricladen. Seine Form und auch sein mikroskopischer Bau ist geringen Variationen unterworfen. Er stellt ein längliches, zylindrisches Rohr mit sehr starken, muskelkräftigen Wandungen und demgemäß engem Lumen dar. Kleine Differenzen zwischen den einzelnen Spezies ergeben sich aus dem Verhältnis der Rüssellänge zur Länge des Körpers. Relativ groß ist der Rüssel bei Planaria alpina, Polycelis cornuta und Planaria gonocephala, auffallend kurz dagegen bei Planaria torva und Planaria lugubris.

Auch individuelle Schwankungen werden beobachtet: es wechselt das Längenverhältnis mit dem Alter und dem Ernährungszustand. Besonders große Rüssel trifft man bei regenerierenden und hungernden Exemplaren. Merkwürdigerweise harmoniert bisweilen die Größe der Rüsseltasche nicht mit der Länge des Rüssels. Ist die Tasche zu klein, so muß der Pharynx gekrümmt oder schlangenförmig zusammengelegt werden, um Platz zu finden. Ein solches Verhalten ist Regel bei der erwachsenen Planaria gonocephala und kann, wie wir bei Besprechung der durchschimmernden Organe erfahren haben, als äuBeres Kennzeichen für diese Spezies gelten (Tafel Il).

Die Beweglichkeit des Tricladensaugrüssels ist sehr groß. Er kann sich $z u$ einem langen dünnen Rohr ausziehen und $z u$ einem runden Knopf zusammenballen, er vermag sich nach allen 
Richtungen $z u$ dehnen und $z u$ krümmen, er nimmt auch wohl Glockenform an, kräuselt sich und windet sich schraubenartig auf.

Schon durch diese Beweglichkeit verrät sich die Anwesenheit einer komplizierten Rüsselmuskulatur mit eigentümlicher Innervierung.

Beim Studium von Quer- und Längsschnitten durch den Rüssel kann man sich leicht von der Anwesenheit dreier Muskelsysteme überzeugen.

Die Längsmuskeln durchziehen den Rüssel der Länge nach und treten an der Rüsselwurzel ins Parenchym über oder verbinden sich mit den Körpermuskeln, die wir als Rückziehmuskeln des Pharynx bereits kennen gelernt haben. Sie haben außerdem die. Aufgabe den Rüssel zu verkürzen. Ihnen wirken entgegen: Die Ring- oder Zirkulärmuskeln, die gekrümmt, in Ebenen senkrecht zur Längsachse des Rüssels verlaufen und sich dabei in konzentrischen, der Wandung parallelen Ringen anordnen. Sie inserieren an der Basalmembran der äußern Rüsselwandung und beschreiben meist nahezu einen Kreis. Wenn sie sich zusammenziehen, verlängert sich der Rüssel, denn gleichmäßige Verkleinerung des Durchschnittes muß zu einer Verlängerung führen. Damit nun aber der Hohlraum des Rüssels nicht bei jeder Streckung des Rüssels verengert, bei jeder Zusammenziehung erweitert wird, haben besondere, sog. Radiärmuskeln die Aufgabe, die Verengerung und Erweiterung des Lumens zu regulieren. Diese Fasern verlaufen gestreckt, inserieren in der Nähe der innern Wandung und begeben sich direkt zur Basalmembran des äußern Integumentes. Durch ihre Zusammenziehung wird die Lichtung erweitert. Die genannten drei Muskelarten, die Longitudinal-, Radiärund Zirkulärmuskeln treten im Tricladenrüssel in sehr mannigfaltiger Verteilung auf. Stets einzeln trifft man die Radiärmuskeln; die andern dagegen schließen sich meist zu größeren Bündeln und Schichten zusammen. So kann man zunächst bei allen Tricladen zwischen einem innern und einem äußern Schichtenkomplex unterscheiden, die durch eine breite Parenchymlage mit vielen Drüsengängen und Nerven geschieden sind. In jeder Muskelzone 
findet man Längs- und Ringfasern, deren relative Stärke und Lage zum Teil für die einzelnen Arten charakteristisch ist. Zwischen die einzelnen Bündel schieben sich Bindegewebszüge und Radiärmuskeln ein. Bei den meisten Planarien sind die inneren Längsund Ringmuskeln getrennt, bei einigen durchflechten sich die Lagen, so daß ein kompaktes Gewebe entsteht.

Die Mittelschicht, die sich zwischen den beiden Muskellagen befindet, ist in ihrem Bau nicht leicht verständlich. Sie übertrifft an Mächtigkeit die beiden Muskelschichten. Bei Anwendung bestimmter Färbungsmethoden gibt sich ein maschiges Grundgewebe zu erkennen, durch welches Bündel von Drüsenausführgängen und Nerven ziehen. Die in den Kanälen enthaltenen Sekrete sind teils erythrophil teils cyanophil. Sie haben also wahrscheinlich verschiedene Aufgaben zu erfüllen.

Die Pharynxdrüsen liegen nur zum kleinsten Teil im Rüssel selbst, vorwiegend aber in der Nähe der Rüsselwurzel am sogenannten Darmmund. Da ihre Sekrete die Vergiftung der Beute und die Vorbereitung der Nahrung zu besorgen haben, könnte man sie als Gift- und Speicheldrüsen bezeichnen. Leider kennt man aber die Natur der beiden zu wenig, um ihre Aufgaben auseinanderhalten zu können. Man spricht daher auch hier besser einfach von erythrophilen und cyanophilen Pharynxdrüsen. Die Ausführgänge der Rüsseldrüsen treten in den Pharynx meist getrennt ein und verschmelzen dann zu größeren Kanälen, die in Bündeln die ganze Saugrohrwandung durchziehen, um am freien Rüsselrand, der Pharynxlippe auszumünden. Auch in der Anordnung der Drüsengänge ergeben sich einige charakteristische Unterschiede zwischen den einzelnen Tricladenarten.

Der Mittelschicht gehört außer den Drüsenzonen auch ein Nervenplexus an, durch den der komplizierte Mechanismus der Pharynxmuskulatur in Betrieb gesetzt wird. Die bindegewebige, nervenreiche Mittelzone bildet im Verein mit dem soliden Epithel und dessen Basalmembran das elastische Element, das der Kontraktion der Muskeln entgegenwirkt. 


\section{- 45}

Vom Pharynxepithel war schon in den Abschnitt über die Körperbedeckung die Rede. Es mag hier nur der Vollständigkeit. wegen nochmals erwähnt werden, daß der Saugrüssel von einem eingesenkten Epithel bedeckt ist, dessen Platten Wimpern tragen. Unbewimpert ist die Rüssellippe, die überhaupt kein Epithel aufweist. - Dagegen ist das Rüssellumen von einer Cilien tragenden Zellhaut ausgekleidet, die in der distalen Gegend (nahe dem Lippenrand) deutlich eingesenkt ist, proximal aber in ein normales kubisches Epithel übergeht. Eine Basalmembran ist nur unter den Epithelplatten der äußeren Pharynxbekleidung nachweisbar.

Die folgende Abbildung soll das Gesagte noch einmal übersichtlich zusammenstellen (Abb. 22).

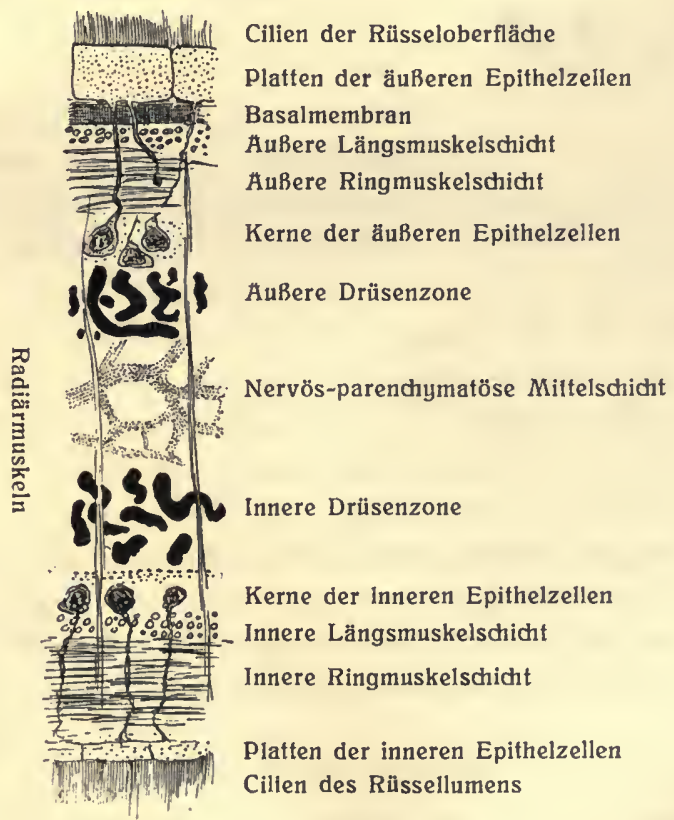

Abb. 22.

Teil eines Querschnittes durch den Tricladenrüssel, schematisiert. 


\section{Darmepithel}

Das Darmepithel ist bei allen Strudelwürmern aus großen, meist unbewimperten Zellen zusammengesetzt. Ob eine besondere Darmmuskulatur vorhanden ist, läßt sich schwer entscheiden. Für die Polycladen ist sie sicher nachgewiesen, für die Tricladen wird ihr Vorkommen zwar ebenfalls behauptet, von andern aber entschieden in Abrede gestellt. Die Epithelzellen des Planariendarmes sind oft kolbig gestaltet und lassen keine scharfen Zellgrenzen erkennen. Zwischen ihnen zeigen sich da und dort, besonders häufig in der Umgebung des Darmmundes, scharf umrissene, keulenförmige Zellen, die gewöhnlich von körnerartigen Gebilden erfüllt sind. Sie heißen nach ihrem Entdecker die Minotschen Körnerkolben (Abb. 23).

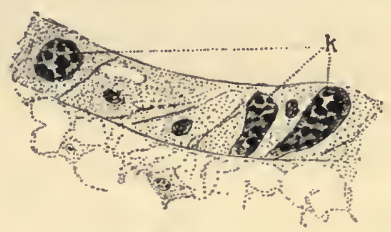

Abb. 23.

Minotsche Körnerkolben (k) aus der Darmwand von Planaria gonocephala.

In Wirklichkeit sind die vermeintlichen Körner Flüssigkeitströpfchen, die sich in Vacuolen befinden. Das sehr dunkel färbbare Sekret der Körnerkolben ist wahrscheinlich ein verdauungförderndes Sekret. Dafür sprechen die Veränderungen, die sich am Darmepithel während des Verdauungsprozesses einstellen. Untersucht man den Darm einer Planarie, die man längere Zeit ohne Nahrung gelassen hatte, so findet man die Darmzellen stark vakuolisiert, die Körnerkolben körnerfrei. Konserviert man aber diese Hungertiere sofort, nachdem man sie wieder gefüttert hat, so kann man konstatieren, daß die Tröpfchen in den Kolben wieder aufgetreten sind, und gleichzeitig zeigen sich einzelne Nahrungsballen in den schwammig gewordenen Darmzellen.

Uber die Nahrungsaufnahme und Verdauung wird der biologische Abschnitt Weiteres zu berichten haben.

\section{Exkretionssystem}

Der Exkretionsapparat (System der Wassergefäße, Protonephridien) ist ein System weitverzweigter Röhren, das in feinste Haargefäße oder Kapillaren ausläuft und dort in den sog. 
Terminalorganen, den Wimpertrichtern, endet. Die Kanäle werden zu zwei oder mehreren in der Längsrichtung verlaufenden Hauptstämmen zusammengefaßt, die durch zwei bis zahlreiche poren nach außen münden. Die Terminalorgane lassen sich ziemlich schwierig beobachten. Sie treten in den Maschen des Parenchyms als trichter - oder birnförmige Erweiterungen der Exkretionskapillaren auf. Den Trichter bildet eine ausgehöhlte Zelle mit stets deutlichem Kern, die am Grunde der Höhlung ein Cilienbüschel, die sog. Wimperflamme, trägt (Abb. 24). Gegen das

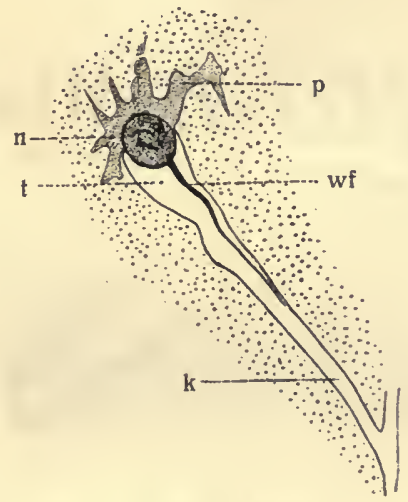

Abb. 24.

Terminalorgan nach Wilhel $\mathrm{mi}$.

p Plasma, n Kern der Exkretionzelle, $t$ Trichter, wf Wimper-

flamme, k Exkretionskapillare.

Parenchym sendet die Terminalzelle Verästelungen aus. Ob zeitweise in dieser Zelle Vakuolen auftreten, ist nicht sicher entschieden; jedenfalls hat man anzunehmen, daß durch Vermittlung der Terminalzelle die Exkretionsstoffe aus dem Parenchym in die Kapillargefäße übergeführt und von dort durch die Wimperflamme weiter befördert werden. Sie gelangen zunächst in kleinere Gefäße und dann in die Hauptstämme,-welche sie durch die Poren nach außen abgeben ( $\mathrm{Abb}$. 25). Die Weite der einzelnen Gefäße schwankt beträchtlich, wohl hauptsächlich infolge der verschiedenen 
Kontraktions- und Füllungszustände. Sie zeigen zahlreiche Biegungen und verästeln sich, um sich nachher wieder $z u$ vereinigen.

Der Tricladenexkretionsapparat ist meist schwierig zu untersuchen. Nur in seltenen Fällen ist es möglich, ihn am lebenden Objekt in befriedigender Weise zu erkennen. Manche Arten eignen sich für solche Untersuchungen gar nicht; andere zeigen oft erst nach langer, mühsamer Beobachtung größere oder kleinere Partien der Wassergefäße, die plötzlich hervortreten können, um bald darauf ebenso schnell wieder zu verschwinden. Sicherer,

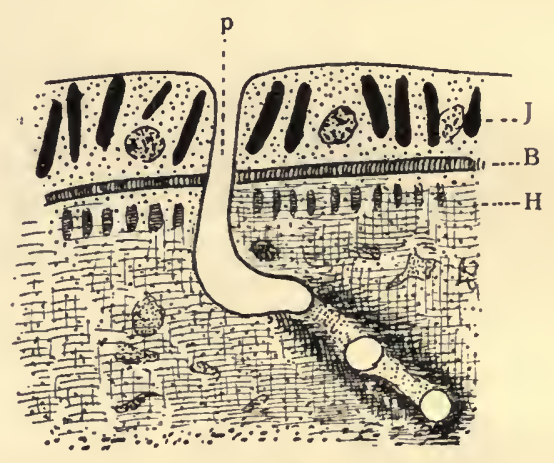

Abb. 25.

Ekretionsporus von Dendrocoelum lacteum nach Wilhelmi.

p Exkretionsporus, J Integument, B Basalmembran, H Hautmuskelschlauch.

wenn auch viel mühsamer, gelangt man mit Hilfe der Schnittmethode zum Ziel. Bei gewissenhafter Durchsicht einer Serie von Querschnitten wird man über den Verlauf der Hauptstämme und über die Zahl und Lage der Poren Aufschluß gewinnen können. Doch läßt auch diese zeitraubende Methode in einzelnen Fällen im Stich. So können z. B. die Exkretionskanäle des Rüssels, die gelegentlich am lebenden Objekt für kurze Zeit mit aller Deutlichkeit zu sehen sind, auf Schnitten nicht oder nur sehr unvollständig beobachtet werden. Daraus erklärt es sich, daß die einzelnen Untersucher verschiedene Angaben machen, und daß vieles zurzeit ganz unklar ist. Wir wollen uns auf diese Streitfragen hier nicht einlassen, 
sondern uns darauf beschränken, das, was gesichert ist, in Kürze zusammenzustellen.

Im einfachsten Fall sind zwei vielfach gewundene, dorsale Längskanäle vorhanden, die den Körperrändern jederseits parallel vom Kopflappen bis etwa zur Grenze zwischen erstem und zweitem Körperdrittel verlaufen, und nur je einen Porus aufweisen (Planaria vruticiana und Anocelis coeca). Beide Formen sind zurzeit nur ungenügend bekannt. Ihre systematische Stellung ist zweifelhaft, da bisher keine geschlechtsreifen Exemplare untersudit werden konnten.

Ein zweiter, genauer untersuchter Typus unterscheidet sich von dem ersten dadurch, daß die beiden Längskanäle nicht auf den Vorderkörper beschränkt sind, sondern jederseits bis in die Schwanzgegend reichen (Abb. 26). Dendrocoelum lacteum, Planaria albissima und die beiden Polycelisarten gehören hierher. Die Zahl der Poren ist auf $8-9$ bei den ersten $z w e i$, auf $15-16$ bei den letzteren erhöht. Dadurch daß die beiden Hauptstämme sich gabeln und auseinander treten, entstehen jederseits zwei Gefäße, ein laterales (äußeres, seitenständiges) und ein mediales (inneres, der Mitte genähertes). Dies trifft $z u$ bei Planaria alpina. Bei planaria polychroa und gonocephala endlich kommen außer den beiden dorsalen paaren noch $z$ wei ventrale vor.

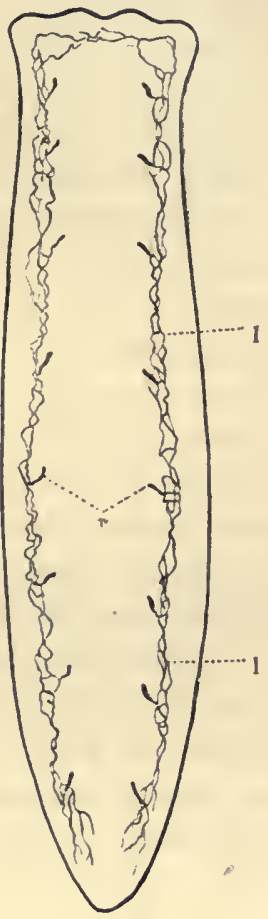

Abb. 26.

Ubersicht über das Exkretionssystem von Dendrocoelum lacteum nach Wilhelmi.

p Poren, 1 Längskanäle. Mit der Vermehrung der Gefäßzahl wächst die

Porenzahl rapid. So werden für Planaria alpina 30 , für Planaria gonocephala 143 und für Planaria polychroa ca. 500 Exkretionsporen angegeben. Die jungen, eben aus den Eikapseln ausgeschlüpften Tiere sollen weniger Poren besitzen als die er Ste inmann-Bres la u, Strudelwürmer. 
wachsenen. Die postembryonale Entwicklung bringt also proportional dem Körperwachstum eine höhere Komplikation des Exkretionsapparates, verbunden mit neuen Porendurchbrüchen. Eine Regel für die Verteilung der Poren auf der Oberfläche läßt sich nicht aufstellen. Am ehesten könnte man bei den 8 poren von Dendrocoelum an segmentale Anordnung denken. Dieses Verhalten braucht jedoch nicht auf ursprünglich metamere Gliederung der Tricladen hinzudeuten, sondern kann sich gewissermaßen aus ökonomischen Gründen ergeben. Der Inhalt der Gefäße wird wahrscheinlich durch Wimperschlag der Lumenauskleidung weitergeleitet. Die Wimpern sind jedoch sehr schwer nachzuweisen. Das Verhalten der Gefäße zu ihrer Umgebung hat zu zahlreichen Auseinandersetzungen geführt. Nach der einen Auffassung sind die Kanäle eigentlich durchbohrte Zellstränge, die Lumina intrazellulär. Richtiger ist die zweite Anschauung, nach welcher die Röhrenwandungen aus Zellen aufgebaut, also epithelial, die Lumina interzellulär sind. Man trifft nämlich bisweilen auf einem einzigen Querschnitt durch die Röhrenwandung zwei Kerne, was mit intrazellulärer Natur der Kanäle unvereinbar ist.

Es sei zum Schluß noch einmal betont, daß unsere Kenntnisse über das Exkretionssystem der Planarien ganz lückenhaft sind, da leider nur wenige Formen in dieser Richtung genauer untersucht worden sind. Auch was die Landtricladen anbelangt, bleibt hier noch viele und schwierige Arbeit zu tun.

\section{Genitalapparat}

Ganz besonders mannigfaltig und oft von erstaunlicher Komplikation ist der Genitalapparat der Strudelwürmer (Abb. 27). Dies hängt von zwei Faktoren ab. Von der Zwitterigkeit und von der Notwendigkeit der Begattung.

Hermaphrodit oder $z$ witterig sind alle Turbellarien mit Ausnahme der Meeresplanarie Sabussowia dioica. Sehr wahrscheinlich ist die Getrenntgeschlechtlichkeit dieser Form kein ursprünglicher Zustand, sondern so zu erklären, daß die Sabussowia 


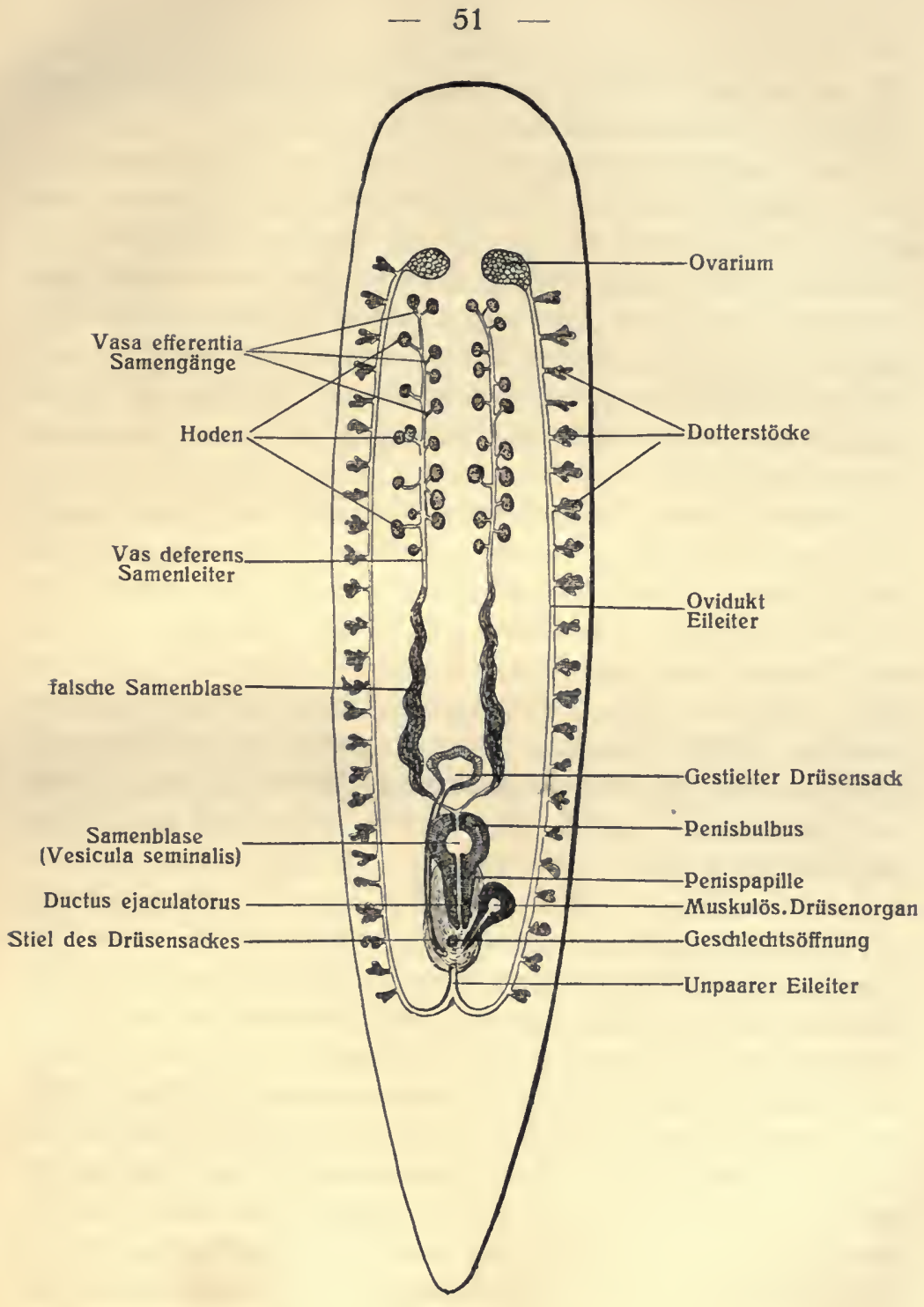

Abb. 27.

Schematische Obersicht über die Geschlechtsorgane einer Planaria. 
sich aus hermaphroditischen Vorfahren durch Reduktion des einen Geschlechts herausgebildet hat.

Der Hermaphroditismus könnte leicht zur Selbstbefruchtung, d. h. zur Befruchtung der Eier mit Samen, die im gleichen Tier erzeugt worden sind, führen. Es ist nun eine bemerkenswerte Tatsache, daB Selbstbefruchtung im Tier- und Pflanzenreich nach Möglichkeit vermieden und nur in seltenen Ausnahmefällen zugelassen wird. Der beste Schutz gegen Selbstbefruchtung ist völlige Trennung zwischen männlichem und weiblichem Genitalapparat mit Ausbildung einer weiblichen und einer männlichen Genitalöffnung.

Tatsächlich sind nun bei den meisten übrigen Strudelwürmern die Geschlechtswege getrennt, entweder völlig, oder bis zum gemeinsamen Geschlechtsraum, der durch einen Genitalporus mit der Außenwelt in Verbindung steht. Auch hier bewirkt jedoch das Kopulationsorgan oder der Penis, der nur in wenigen Fällen fehlt, eine gänzliche Trennung. Indem durch den Genitalporus der eigene Penis aus-, der des Partners eingeführt wird, dient die eine Offnung gleichzeitig zur Aufnahme von fremdem und zur Abgabe von eigenem Samen, ohne daß es zu einer Vermischung kommt.

Da nun die Strudelwürmer einen ziemlich großen Abschnitt ihrer Entwicklung im Ei absolvieren, ergibt sich als weitere Ursache zur Komplikation des Geschlechtsapparates die Notwendigkeit, die Eier mit Reservestoffen und Schutzmitteln auszustatten. Während bei den Acoelen und Polycladen die Reservestoffe in den Eizellen selbst angehäuft werden (endolecithale Eier), findet man bei den Tricladen dotterarme Eizellen, daneben aber sogenannte Dotterzellen, die aus dotterreich, aber entwicklungsunfähig gewordenen Keimzellen hervorgegangen sind. Die Eier werden dann von Dotterzellen umgeben (ectolecithale Eier). Die Kluft, die in dieser Beziehung zwischen Polycladen und Acoelen einerseits und Tricladen andererseits besteht, wird überbrückt durch die Rhabdocoeliden, bei denen sich die allmähliche Differenzierung von Dotterstöcken (Vitellarien) und dotter- 
armen Keimstöcken (Germarien) aus indifferenten Eierstöcken (Ovarien) aufs schönste verfolgen läßt.

Von der Abgrenzung der Geschlechtsorgane gegen das Parenchym ist $z u$ sagen, daß in weitaus den meisten Fällen besondere epitheliale Begrenzungshäute der Keimdrüsen und ebensolche Wandungen der Ausführwege vorkommen. Nur die Acoelen und einige Alloeocoelen machen hier eine Ausnahme. Sehr häufig treten verschiedenartige, zum Teil hinsichtlich ihrer Funktion zweifelhafte Nebenapparate auf, wie Behälter für den eigenen Samen (Samenblasen, vesiculae seminales), Taschen zur Aufnahme des fremden Samens (Samenbehälter, Receptacula seminis), event. besondere Begattungstaschen (Bursae copulatrices) usf. Bisweilen ist der Geschlechtsraum durch eine weit vorspringende Ringfalte oder durch eine kanalartige Verengerung in zwei $A b-$ schnitte geteilt (männliches und weibliches Atrium). Ferner können verschiedenartige Drüsen entwickelt sein, deren Sekrete zum Teil bei der Begattung, zum Teil bei der Eiablage eine Rolle spielen. Alle diese Organe können in verschiedenster Weise kombiniert auftreten. Daher muB man bei der systematischen Einteilung der Strudelwürmer ganz besonders auf den Geschlechtsapparat achten.

Wir wenden uns nun zur Betrachtung des Genitalapparates der Paludicolen.

$\begin{array}{ll}\text { Hoden } & \begin{array}{l}\text { Die männlichen Geschlechtsdrüsen, die Hoden (Testes) } \\ \text { sind kugelige Gebilde, die im reifen Zustand als Bläschen }\end{array}\end{array}$ erscheinen. Sie treten in erheblicher, manchmal in großer Anzahl auf, besonders häufig zwischen den Divertikeln des Darmes. Während sie sich bei Planaria alpina und ihren Verwandten nur im Vorderkörper, etwa zwischen Augen und Rüsselwurzel, somit nur im Bereich des Kopfdarms zeigen, nehmen sie bei den meisten andern auch den Raum zwischen den Zweigen der Schwanzdärme ein. Auf Querschnitten zeigt es sich, daß die Hoden bei einzelnen Arten ventral, bei andern dorsal liegen. Das erstere trifft für Planaria alpina und die Polycelisarten, das letztere 
für Planaria gonocephala und polychroa zu. Bei den Dendrocoelumspezies finden sie sich dorsal und ventral. In den Parenchymbrücken zwischen den Darmdivertikeln, den sog. Sep-

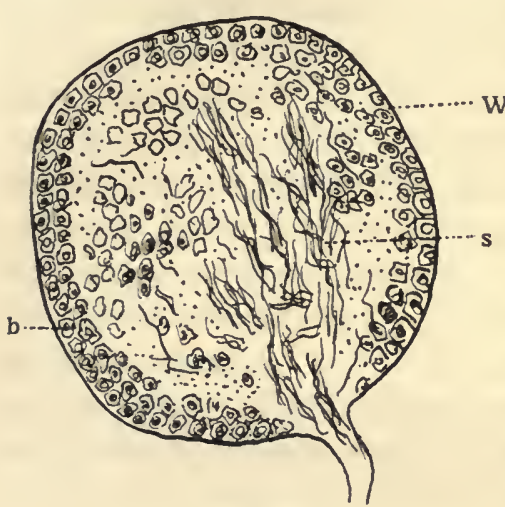

Abb. 28.

Hodenbläschen. W Wandungszellen;

b Samenbildungszellen; s Samenfäden.

ten verbinden einzelne Hodenbläschen die dorsale und die ventrale Schicht. Wahrscheinlich geht die Zahl der Hoden bei den Paludicolen nicht unter 50 herunter, oft ist sie aber wesentlich größer (Planaria alpina ca. 60, Dendrocoelum weit über 100). Die Gestalt der Hoden ist im allgemeinen kugelig, doch kann bei Raummangel Abplattung eintreten, die $z u$ kubischen oder unregelmäßigen, lappigen Deformationen führt. Die Wandung der reifen Hodenbläschen wird aus platten, kernhaltigen Zellen gebildet. Daran schließen sich die Samenbildungszellen, die je nach dem Alter des Bläschens verschieden entwickelt sind. Im Lumen der Hoden findet man in der Regel zahlreiche Samenfäden.

\section{Samengãnge}

Die Hodenblasen sitzen den Samengängen (Vasa deferentia) entweder direkt an oder sind mit ihnen durch besondere, sehr feine Ausführkanälchen (Vasa efferentia) verbunden,die teils selbständig, teils nach Verschmelzung in die Vasa deferentia münden. Letztere sind $z u$ beiden Seiten des Kopfdarms gelege nund verlaufen in der Längsrichtung des Tieres bis in die Gegend des Penis, häufig sogar noch in den Penis hinein. Auf Querschnitten findet man sie ventral meist in der Nähe der großen Längsnerven.

Während im vordersten Abschnitt des Hodenfeldes die Samengänge schwer nachweisbar sind, werden sie weiter hinten sehr deutlich, besonders zu beiden Seiten des Pharynx, wo sie sackartige 
Erweiterungen, die sogenannten falschen Samenblasen bilden. Bei geschlechtsreifen Exemplaren sind diese Strecken der Vasa deferentia prall mit Samenfäden angefüllt, so daß man ihren Verlauf häufig am lebenden Tiere bei Lupenvergrößerung feststellen kann.

Die Wandung der Samengänge scheint die direkte Fortsetzung des Hodenepithels $\mathrm{zu}$ sein, auch sie besteht aus platten Zellen. Hinter dem Pharynx verengern sich die beiden Vasa deferentia, krümmen sich schräg nach oben und innen und streben einander zu. Ihre Wandung hat in diesem verengerten Teil einen Belag von Ringmuskeln erhalten.

So weit stimmen die Paludicolen recht gut miteinander überein. In der Ausbildung des Begattungsorgans aber ergeben sich größere Differenzen.

\section{Kopulationsorgan}

Zunächst verdient hervorgehoben zu werden, daß die größte unter den Paludicolen, Bdellocephala punctata überhaupt keinen Penis besitzt. Das männliche Kopulationsorgan - wenn überhaupt hier von einem

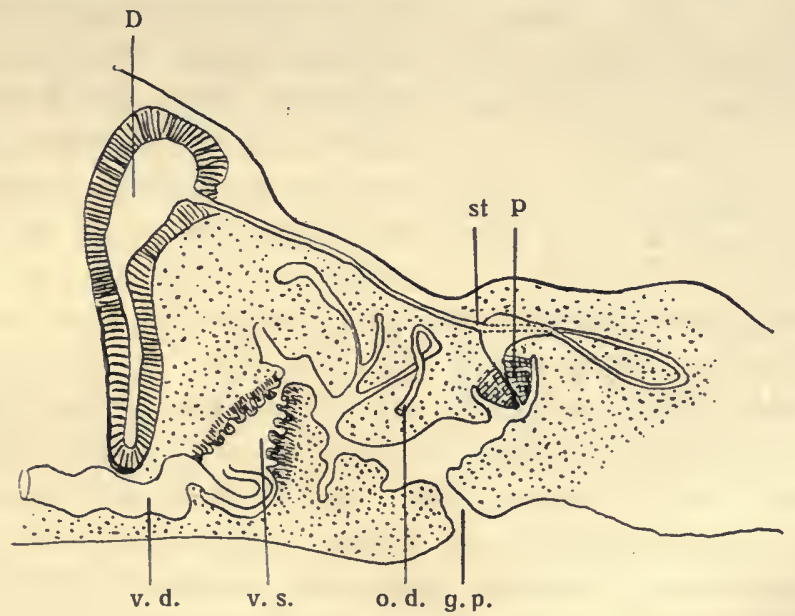

Abb. 29.

Bdellocephala Längsschnitt durch die Gegend der Geschlechtsöffnung. D gestielter Drüsensad; st dessen "Stiel“. p papille an der Ausmündung ins Atrium; v. d. Vas deferens; v. s. Vesicula seminalis; o. d. Ovldukt. G. p. Genitalporus. (Nach Ude.) 
solchen gesprochen werden kann - besteht aus einer Tasche, die mit der Samenblase anderer Formen verglichen werden kann. Am Grunde dieses Hohlraumes münden die beiden Vasa deferentia getrennt. Alle andern Planarien besitzen muskulöse Kopulationsorgane, zapfenartige Penes, die bald sehr ansehnlich sein können (Planaria albissima, torva usw.), bald reduziert erscheinen (Polycladodes, Dendrocoelum).

Am Penis lassen sich meist zwei Abschnitte unterscheiden, der vom Parenchym eingefaßte Penisbulbus und der freie Penis

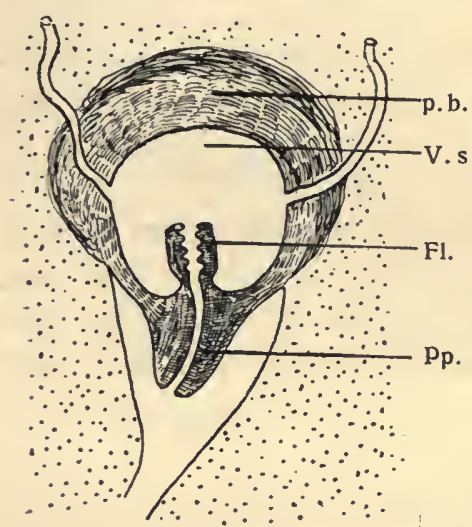

Abb. 30.

Kopulationsorgan von Dendrocoelum infernale im Längsschnitt. p. b. Penisbulbus; V. s. Vesicula se minalis; Fl. Flagellum; Pp. Penispapille. oder die Penispapille. Der Bulbus enthält häufig einen Hohlraum, die Samenblase (Vesicula seminalis), in welche die beiden Vasa deferentia entweder getrennt (Dendrocoelum lacteum, infernale, Pl. vitta usw.) oder zu einem kürzeren unpaaren Gang vereinigt (Dendrocoelum mrazeki, Planaria torva usw.) einmünden. Die Penispapille wird von einem muskulösen Gang, dem Ausspritzkanal, Ductus ejaculatorius durchzogen. Er ist der Ausführgang der Samenblase, oder entsteht, wo diese fehlt, durch den im Bulbusteil erfolgenden Zusammentritt der beiden Samengänge (Planaria cavatica, albissima u. a.). Bei den Arten der Gattung Dendrocoelum kann der Penis durch eine ausstülpbare Ringfalte, das sogenannte Flagellum verlängert werden ( $\mathrm{Abb}$. 30). Das Flagellum ragt im Ruhezustand, eingestülpt in die Samenblase, vor und kann vielleicht als Klappe funktionieren, die den in der Samenblase enthaltenen Samen am Eintritt in den Ausspritzkanal hindert, bis die Kopulation eingetreten ist.

Bei vielen Arten liegt der Penis frei im Geschlechtsraum, in den auch die Eileiter münden (gemeinsames Atrium, A. com- 
mune). Andere (Dendrocoelum, Bdellocephala, Polycladodes und Polycelis) zeichnen sich dadurch aus, daß das Atrium in zwei Räume geschieden ist, indem sich entweder eine Falte trennend einschiebt, wie etwa die Iris die beiden Augenkammern trennt, oder indem die beiden Geschlechtsräume auseinander gerückt und durch einen engen Kanal verbunden sind.

Bei Bdellocephala öffnen sich Samen- und Eileiter in den vorderen (inneren) Teil des Atriums, so daß man bei dieser penislosen Form versucht ist, Selbstbefruchtung anzunehmen. Wir werden auf diese Frage später noch Bezug nehmen. Die Eileiter der übrigen Arten münden meist in den äußeren Abschnitt des Geschlechtsraumes (Atrium femininum $=$ weiblicher Geschlechtsraum), während der Penis im innern Atrium, dem männlichen Geschlechtsraum (Atrium masculinum) liegt. Einen längeren Kanal zwischen den beiden Atriumteilen, eine "Penisscheide", besitzt Polycladodes, deren kleiner Penis bei der Begattung wahrscheinlich kaum bis ins weibliche Atrium reicht (s. Systematik). Eine allerdings viel kürzere Penisscheide kommt auch den Arten des Genus Dendrocoelum zu. Bei Dendrocoelum lacteum öffnen sich die Eileiter in den untersten Teil der Penisscheide nächst der Einmündung ins äußere Atrium.

In den Kopulationsapparat münden meistens die Ausführgänge besonderer sog. Penisdrüsen, deren feinkörniges Sekret dem Samen beigemischt wird.

\section{Weibliche Organe}

Im Gegensatz zum männlichen Apparat, mit seinen komplizierten und von Art zu Art wechselnden Verhältnissen ist der weibliche Teil bei allen Tricladen einheitlich gebaut.

Germarien Allen Land-, Meer- und Süßwasserplanarien kommen zwei Keimstöcke (Germarien), oft auch Eierstöcke, Ovarien genannte, im vordern Abschnitt des Körpers gelegene weibliche Drüsen $\mathrm{zu}$. Sie haben stets kugelige Form und sind von einer Schicht platter Zellen (Randzellen) 
umgeben, von denen Ausläufer ins Innere des Ovariums abzweigen (Abb. 31). Dort treten sie mit den verästelten Zellen in Verbindung, die sich überall zwischen die Eizellen einschieben. Diese sog. Stromazellen sind Stützelemente und dürften außerdem bei der Ernährung der Eier eine Rolle spielen. Die Stromazellen sind modifizierte Eizellen. In den ersten Entwicklungsstadien der Keimstöcke lassen sie sich nicht von den zukünftigen Eizellen

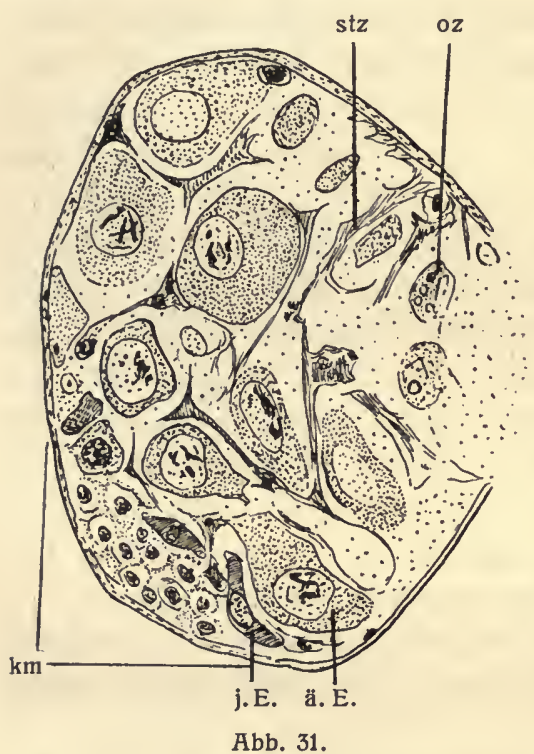

Ovarium von Sabussowia dioica nach Böhmig, $\mathrm{km}$ Keimlager, j. E. jüngere Eizellen, ä. E. ältere Eizellen, stz Stromazellen, oz Oozyten.

i. e. S. oder Oozyten unterscheiden. Die Ovarien stellen vielmehr anfangs Haufen gleichartiger Zellen dar, die als. Oogonien bezeichnet werden, aus ihnen entwickeln sich die Stroma- und Eizellen. Demgemäß ist auch die Zahl der Anlagezellen ungleich größer als die der definitiven Eizellen. Die Reifung des Germariums findet bisweilen in allen Partien gleichzeitig statt. Dies ist der Fall bei Formen mit zeitlich fixierterFortpflanzung. Nach der Ablage der Eikapseln wird in diesem Fall der Keimstock reduziert und, falls das Individuum am Leben bleibt, $z u$ Beginn der folgenden Sexualperiode neu gebildet. Die Keimstöcke anderer Arten, speziell der Maricolen, enthalten jedoch neben reifen immer eine Partie unentwickelter Eier. Diese kleinen Zellen bilden ein sogenanntes Keimlager. Sie enthalten einen stark tingierbaren Kern und liefern später durch Teilung die Eizellen. Germarien mit Keimlager können ununterbrochen Eier abgeben. Sie werden nicht reduziert und neugebildet, sondern in der Intersexualzeit einfach in ihrer Funktion still gestellt. 
Den Keimstöcken in den Anfangsstadien der Entwidklung durchaus ähnlich sind die Dotterstöcke oder Vitellarien, die bei voller Geschlechtsreife einen sehr großen Raum einnehmen. Man findet sie überall zwischen die andern Organe hineingeschoben, am zahlreichsten in den sogenannten Septen zwischen den Divertikeln der Hauptstämme. Ihr Gebiet erstreckt sich von den Ovarien jederseits bis in die Gegend der Geschlechtsöffnung, bisweilen auch noch weiter nach hinten.

Der einzelne Dotterstock entsteht aus einem Zellstrang oder einer Zellgruppe, die anfangs als selbständiges Gebilde auftritt. Die Dotterzelle gleicht zunächst einem Oogonium. Der große, dunkel färbbare Kern ist von einem schwach tingierbaren Zellleib umgeben. Bei der Reife schwillt der letztere mächtig an, umgibt sich mit einer Zellmembran und ist von nun an viel empfänglicher für Farbstoffe. $\mathrm{Er}$ enthält zweierlei Einschlüsse: Dotterkugeln, die zur Ernährung der heranwachsenden Embryonen dienen, und kleine Tröpfchen, die später zur Bildung der Eikapsel Verwendung finden.

Das Vitellarium ist insofern einfacher gebaut als das Ovarium, als in ihm besondere Stromazellen nicht entwickelt sind. Es fehit auch die epitheliale Umhüllung. Somit ist der Dotterstock nichts anderes als ein Haufen gleichartiger Dotterzellen, die einander dicht anliegen. Die Vitellarien entstehen von allen Teilen des Geschlechtsapparates zuletzt. Sie werden umgekehrt am Ende der Geschlechtsreife zuerst zurückgebildet. Welch wichtige Bedeutung die Dotterzellen besitzen, geht daraus hervor, daß unter Umständen Teile der Eierstöcke und der Eileiter in Dotterstöcke umgewandelt werden. Andererseits kann man in diesem Verhalten einen weitern Beweis für die Homologie der Ei- und Dotterzellen - und auch der Eileiterzellen - erblicken.

\section{Eileiter}

Die Eileiter (Ovidukte) werden auch als Eidotter gänge bezeichnet, da sie $\mathrm{Ei}$ - und Dotterzellen in das Atrium zu befördern haben. Sie erstrecken sich jederseits vom Ovarium, bisweilen auch von noch weiter vorn gelegenen

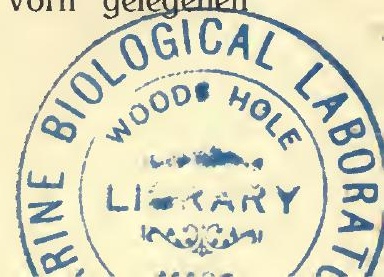


Dotterstöcken bis in die Nähe des Genitalporus und laufen den Vasa deferentia und den ventralen Längsnerven parallel. Die Einmündung ins Atrium kann getrennt erfolgen, meist vereinigen sich aber die beiderseitigen Eidottergänge' zu einem kurzen unpaaren Abschnitt, der an verschiedenen Stellen des Geschlechtsraumes münden kann.

An jedem Ovidukt lassen sich drei Abschnitte unterscheiden: die Tuba, die Region der Dottertrichter und der sogenannte Drüsengang.

Tuba heißt der dem Ovarium anliegende Teil des Eidotterganges, der sich durch besonders hohe Epithelzellen auszeichnet. Die höchsten Zellen sind dem Ovarium am meisten genähert. Die Tuba kann der vorderste Abschnitt des Eidotterganges sein. Bisweilen aber beginnt letzterer, wie wir gesehen haben, noch weiter vorn, so daß die Tuba nur eine nach den Seiten erweiterte Partie des Oviduktes darstellt. Man trifft in ihr häufig Samenfäden. Die Eier werden deshalb wahrscheinlich gleich beim Eintritt in den Eidottergang befruchtet. Der Name Samenbehälter (Receptaculum seminis), der für die Tuba schon vorgeschlagen worden ist, scheint deshalb nicht zutreffend, weil die Tuba keine Tasche, und nicht ausschließlich für den Samen reserviert ist, sondern gleichzeitig als Durchtrittstelle der Eier in den Eidottergang gelten muß. Daß sie bei diesem Vorgang aktiv mithilft, beweist eine dünne Schicht zarter Muskelfasern, die ihr die Ausführung von Schluckbewegungen ermöglichen.

Die an die Tuba sich anschließende Region der Dottertrichter ist, wie der übrige Eidottergang, relativ eng. Kubische, wimperntragende Zellen bilden die Auskleidung, feine zirkuläre und longitudinale Muskelfasern die Umhüllung der Gänge. Mit dem Ovidukt treten die Dotterstöcke in der Regel durch feine Seitenkanälchen, sog. Dottertrichter in Verbindung, die einfache Zweige des Eidottergangs sind, somit auch von den gleichen Wandungen ausgekleidet werden. Oft sind die Dottertrichter so kurz, daß man besser von Öffnungen der Oviduktwandung sprechen könnte. Solange die Dotterstöcke nicht voll entwidkelt 
sind, werden die Dottertrichter durch große Zellen verschlossen, die wahrscheinlich vergrößerte Oviduktzellen sind, und durch deren Rückbildung oder Loslösung die Dottertrichter erst geöffnet werden (Abb. 32). Diese zu Verschlußzellen umgewandelten Wandungselemente tragen durchaus den Charakter von Dotterzellen. Auch darin spricht sich die enge Verwandtschaft des ganzen Organkomplexes aus.

Der dritte Abschnitt der Eileiter, der Drüsengang, beginnt etwa da, wo ihre Umbiegung nach der dorsalen Seite und nach innen stattfindet. An diesen Teil legen sich Drüsen, deren Sekret bei der Schalenbildung eine Rolle spielt. Ihre Ausführgänge münden zwischen den Zellen der Wandung. Der unpaare Teil des Oviduktes, falls ein solcher auftritt, ist ebenfalls mit Schalendrüsen versehen.

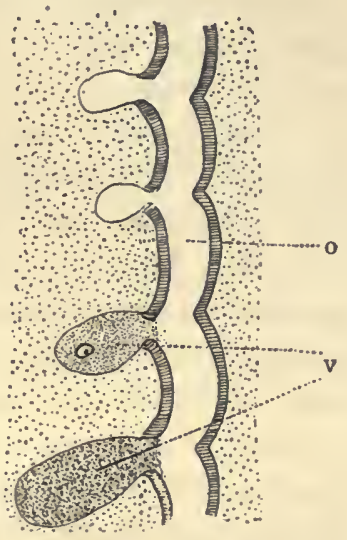

Abb. 32.

Ovidukt: Region der Dottertrichter (nach Jijima).

o Ovidukt; v Verschlußzellen.

\section{Hilfsorgane}

Außer den männlichen und weiblichen Gonaden und deren Ausführgängen findet man bei allen Tricladen noch Nebenorgane von wechselnder Form und oft zweifelhafter Bedeutung.

\section{Gestielter Drüsensadk}

Ein sehr regelmäßig auftretendes Gebilde, dessen Lagebeziehung zum übrigen Genitalapparat sogar systematisch verwertbar ist, stellt seiner Form nach einen ${ }_{n}$ gestielten Drüsensack “ dar. Er ist meist sehr auffällig und wechselt in seiner Gestalt, indem er bisweilen kugelig oder birnförmig, in andern Fällen buchtig-lappig, bei Polycelis nigra sogar H-förmig gestaltet ist. Bei sämtlichen Paludicolen liegt der Drüsensack weiter vorn als die Geschlechtsöffnung, meist sogar dicht hinter der Mundöffnung, sein langgezogener Ausführgang ("Stiel $\left.{ }^{4}\right)$ verfolgt als dorsalster Teil des Geschlechtsapparates 
Längsrichtung; er ist gewöhnlich der Medianlinie genähert, verläuft jedoch bisweilen etwas lateral.

Die sehr verschiedenen Namen, die in der Literatur diesem Organe beigelegt werden, weisen auf Unsicherheit in der Deutung, und wirklich sind bis jetzt kaum alle seine Funktionen einwandfrei festgestellt.

Der gestielte Drüsensadk ist eine Tasche, die mit einem sehr auffälligen Drüsenepithel ausgekleidet ist. Die einzelnen Zellen sind sehr hoch, oft birnförmig und ragen mit dem verbreiterten Teil frei ins Lumen der Tasche, während der basale einer strukturlosen Membran aufsitzt. Das Plasma der Zellen ist im basalen Teil homogen, wird aber gegen innen sehr vakuolenreich und umschließt verschiedene Körperchen, die meist etwas tingiert werden können. Häufig findet man in der Höhlung des Sackes ähnliche Körnchen oder ein homogenes Sekret, das durch Zerfließen der Körnchen (oder Tröpfchen?) entstanden ist. Der "Stiel " ist ein dickwandiger Gang, der von einem kubischen Wimperepithel ausgekleidet und von einem kräftigen Muskelmantel umgeben ist. Die Muskelschicht setzt sich aus longitudinalen und zirkulären Fasern zusammen, die Wimpern sind nach vorn, d. h. gegen die Tasche gerichtet. Bei einigen Arten ist der hinterste Abschnitt des Stieles sackartig erweitert.

Der verbreitetste und älteste, aber ganz unrichtige Name für das Organ heißt "Uterus“. Man glaubte nämlich früher, daß der Stiel mit seiner Mündung aus dem Atrium Eier, Dotter und Samen aufschludke, und sie mit Hilfe der Muskeln nach dem Sack befördere. Dort sollte das gesamte Material in einer Eikapsel vereinigt werden. Die stark drüsigen Wandungszellen dachte man sich als Schalenbildner. Es ist jedoch für verschiedene Formen einwandfrei ermittelt, daß die Eikapselbildung im Atrium stattfindet, und daß die fertigen Kapseln niemals in den Drüsensack zu liegen kommen. Damit fällt aber die Bezeichnung "Uterus“.

Positiv ist festgestellt, daß bei der Begattung der Penis des partners in den Anfangsteil des Uterusganges eingeführt wird, und daß das Sperma von dort durch Wimperschlag oder Muskel- 
kontraktionen in den Sack gelangt. So erklärt es sich, warum man gar nicht selten daselbst Samen antrifft. Nun scheint aber das Sperma meist nur kurze Zeit im Drüsensack zu bleiben und schon wenige Stunden nach der Begattung ins Atrium zurück und in die Eidottergänge hinauf zu wandern, wo es in den Tuben aufgespeichert wird. Nach diesen Feststellungen scheint der Name Begattungstasche, Bursa copulatrix der geeignetste zu sein. Sollte sich jedoch herausstellen, daß das Sperma in der Regel doch längere Zeit im Drüsensack aufbewahrt wird, so wäre die Bezeichnung Samenbehälter (Receptaculum seminis) richtiger.

Über die Bedeutung des vom Drüsensack abgeschiedenen Sekretes wissen wir nichts Bestimmtes. Es ist möglich, daß dieser Stoff "spermienkonservierend " wirkt. $\mathrm{DaB}$ er irgendeine bestimmte, nicht unwichtige Funktion hat, muß in Anbetracht der starken Entwicklung des Drüsenepithels angenommen werden. Vielleicht ist diese Aufgabe sogar der Grund, warum das Sperma gerade dorthin abgegeben wird. Alle diese Fragen können einstweilen nicht beantwortet werden. Zur Vermehrung des Dunkels in dieser Angelegenheit tragen auch die zahlreichen Nachweise von Eizellen und Dotter im Lumen des Drüsensackes bei. Man kann diese Vorkommnisse nicht durch Zufall erklären, es sind ihrer zu viele. Vielleicht ist der Drüsensack auch dazu da, die allfällig im Atrium vorhandenen Eier und Dotterzellen aufzuschlucken und $z u$ geeigneter Zeit portionenweise zu Zwecken der Eikapselbildung wieder ans Atrium abzugeben. Solange wir über all das im unklaren sind, wird es gut sein, das Organ mit dem morphologischen, über die Funktion nichts aussagenden Namen ${ }_{n}$ gestielter Drüsensack" zu bezeichnen.

Während der Drüsensack bei allen Paludicolen ganz ähnliche Verhältnisse aufweist, finden sich bei den übrigen Tricladen verschiedene Abweichungen. Unter den Landplanarien schließen sich die Rhynchodemiden den Paludicolen direkt an, indem bei ihnen der gestielte Drüsensack in Form und Lage dem der Süßwasserformen gleicht. Bei tropischen Landplanarien dagegen kann der Apparat fehlen. Die größten Modifikationen zeigen sich bei den 


\section{- 64}

Maricolen, wo die Eileiter stets mit dem Drüsensack in Verbindung stehen. Bisweilen besitzt der Sadk seine besondere Ausmündung

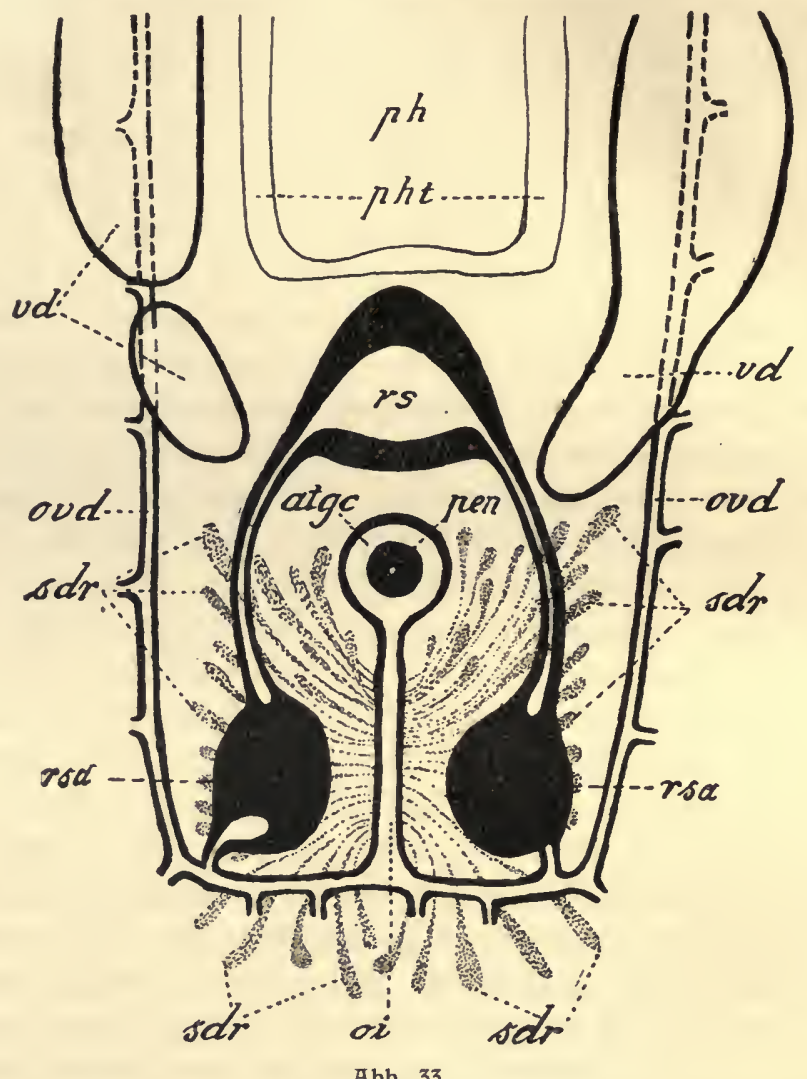

Abb. 33.

Kopulationsapparat von Uteriporus vulgaris, Flächenansicht, schematisiert; nach Bergendahl aus Wilhelmi.

ph Pharynx; pht Pharynxtasche; vd Vas deferens; rs Receptaculum seminis = gest. Drüsensadk; rsa blasenartige Anschwellung derselben; pen Penls; atgc gemeinsames Geschlechtsatrium; ovd Ovidukte; oi unpaarer Eileiter; sdr Schalendrüsen.

(Uteriporus) und hängt durch zwei Verbindungsgänge mit den Ovidukten zusammen ( $\mathrm{Abb} .33)$. An der Einmündungsstelle findet sich jederseits eine blasenartige Erweiterung (akzessorisches Re- 
ceptaculum seminis). Bei andern treten gar zwei selbständig mündende Säcke zu beiden Seiten der Geschlechtsöffnung auf, die mit dem jederseitigen Ovidukt durch einen Gang verbunden sind (Bdellouriden). Die übrigen unterscheiden sich von den Paludicolen vornehmlich dadurch ( $\mathrm{Abb}$. 34), daß bei ihnen der Drüsensack hinter der Geschlechtsöffnung liegt, der Gang somit nach hinten oder schräg nach oben hinten verläuft, ferner, wie schon bemerkt, durch die Einmündung der Eidottergänge in den Stiel des Sackes. Bemerkenswert ist das Verhalten des

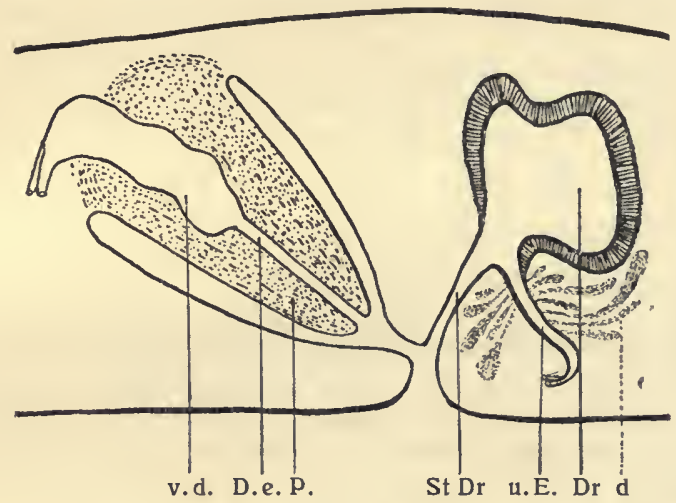

Abb. 34.

Sdhema des Kopulationsapparates von Procerodes lobata nach $\mathrm{Wilhelmi}$.

v. d. Vas deferens, D.e. Ductus ejaculatorius, P. Penispapille, StDr Stiel des Drüsensackes, u. E. unpaarer Eileiter, Dr Drüsensack, d Schalendrüsen.

Drüsensackes bei der getrenntgeschlechtlichen Sabussowia dioica, wo er in beiden Geschlechtern auftritt, somit als ein Anzeichen dafür gelten darf, das Sabussowia sich aus zwitterigen Vorfahren entwickelt hat.

\section{Muskulöses Drüsenorgan}

In ähnliche oder noch größere Verlegenheit bringt uns ein zweiter merkwürdiger Apparat, der jedoch viel weniger konstant auftritt als der Drüsensack. Wir bezeichnen ihn als muskulöses Drüsenorgan.

Was zunächst seine Verbreitung bei den Tricladen anbelangt, so ist $\mathrm{zu}$ sagen, daß es allen Maricolen und den meisten TerriSteinmann-Bresslau, Strudelwürmer. 
colen fehlt. Bei den Paludicolen Planaria gonocephala, albissima, polychroa, lugubris wird es völlig vermißt; Planaria alpina soll das Organ in seltenen Fällen besitzen. Planaria torva zeigt es häufig. Bei ihr soll es im Beginn der Geschlechtsreife besser entwickelt sein als später. Polycelis nigra weist gewöhnlich sogar zwei Drüsenorgane auf, die aber gelegentlich fehlen können. Regelmäßig in der Einzahl findet sich das Organ bei Dendrocoelum lacteum, mrazeki, infernale, planaria vitta, cavatica und Polycladodes alba, in der

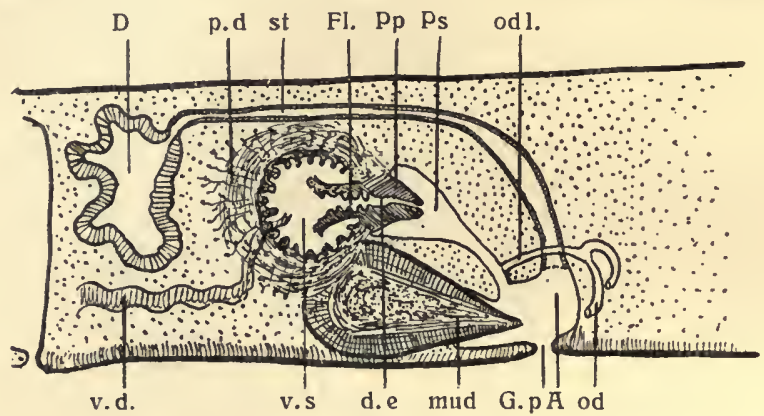

Abb. 35.

Dendrocoelum lacteum. Längsschnitt durch den Geschlechtsapparat.

v.d. Vas deferens, v. $s$ Vesicula seminalis, d. e Ductus ejaculatorlus, mud musk. Drüsenorgan, G.p Genital porus, A Atrium, od Ovidukt, od I unpaarer Ovidukt, Ps Penisscheide. Pp Penispapille, Fl. Flagellum, st Stiel des Driisensackes, p.d Penisdrüsen, D Drüsensadk.

Mehrzahl (2, seltener 4 oder 5) bei Polycel is cornuta. Bei Bdellocephala tritt es, wie wir sehen werden, in modifizierter Form auf.

In allen Fällen sind die muskulösen Drüsenorgane birn- oder flaschenförmig, ihr hinteres, kugeliges Ende steckt im Parenchym, die Spitze (Papille) ragt frei ins Atrium. Dann und wann liegt das Gebilde sogar in einer besonderen Tasche. Die Papille kann oft zum Atrium herausgestreckt werden, so daß mian versucht ist, sie für einen Penis zu halten. In der Regel umschließt der kugelige Teil (Bulbus) einen Hohlraum, der sich gegen die Papille hin zu einem Ausführgang verengert. Bei den beiden Polycelisarten fehlen Hohlraum und Ausführgang, die ganze "Birne" ist solid. Histologisch verhalten sich alle muskulösen Drüsenorgane ähn- 
lich. Der Hohlraum ist, wenn vorhanden, von einem deutlichen Drüsenepithel ausgekleidet. Seine Zellen enthalten zahlreiche, sich schwach färbende Sekrettröpfchen. Diese Stoffe entstehen entweder in den Epithelzellen selbst, oder in besonderen, in den Wandungen des Organs eingebetteten Drüsen, deren Ausführgänge meist mit Sekreten erfüllt und daher leicht sichtbar sind. Die Wandung selbst besitzt im Vergleich zum engen Lumen eine ganz bedeutende Dicke. Sie besteht hauptsächlich aus Muskeln, welche teils der Länge nach verlaufen, teils das Lumen ringförmig umfassen. Die Lagerung der beiden Muskelsysteme ist ziemlich kompliziert, indem sie sich gegenseitig durchdringen. Dazu kommt bei Polycladodes noch eine bindegewebige Schicht als direkte Umkleidung des Innenepithels. Im Lumen ist mehrfach ein Sekret, bisweilen auch Sperma angetroffen worden. Bei Polycladodes, wo das Drüsenorgan den Penis vielmals an Größe übertrifft, enthält es Sekrete und ganz von Körnern erfüllte Zellen, die sich vom Epithel losgelöst haben. Die muskulösen Drüsenorgane der Polycelisarten sind, weil ohne Höhlung, der ganzen Länge nach von zahlreichen Gängen durchzogen, die mit einzelligen, in der Nähe des Organs liegenden Drüsen in Verbindung stehen und an der Papille endigen. Uber die Funktion des Organs wissen wir garnichts. Es sind allerlei Vermutungen ausgesprochen worden, indem man mangels direkter Beobachtung aus der Form auf die Funktion geschlossen hat. Seinem Bau nach eignet es sich jedenfalls zur gewaltsamen Ausspritzung eines in ihm enthaltenen Sekretes. Möglicherweise handelt es sich um ein Reizorgan, das zu Beginn der Begattung in Aktion tritt. Ohne uns auf weitere vage Spekulationen einzulassen, wollen wir hier noch die Schilderung der Verhältnisse folgen lassen, die wir bei Bdellocephala punctata finden. Bei dieser Art fehlt ein selbständiges muskulöses Drüsenorgan. Dagegen findet sich eine muskelkräftige Papille mit zugehörigem Bulbus im hintersten Teil des Atriums (Abb. 29). Während jedoch bei den normalen Drüsenorganen die Bulbushöhle hinten blind endigt, verengert sie sich hier und setzt sich in den Gang des gestielten Drüsensackes fort. Die Recht- 
fertigung für die von uns gezogene Parallele zwischen dem Muskelapparat des Drüsensackstiels und den muskulösen Drüsenorganen wird weiter unten folgen. Die Funktion des Gebildes ist wahrscheinlich die folgende: Da Bdellocephala keinen Penis besitzt, wird die Papille ausgestülpt, in die Geschlechtsöffnung des Partners eingeführt und nun wird mit Hilfe der Bulbusmuskulatur das fremde Sperma aus der Samentasche herausgepumpt. Das Muskelorgan ist also in gewissem Sinne das Gegenteil von einem Penis.

Vergleichen wir nun das Größenverhältnis zwischen muskulösem Drüsenorgan und Penis bei anderen Formen, so ergibt sich, daß die Arten mit sehr starkem Penis kein, die mit sehr kleinem Penis ein besonders großes Drüsenorgan besitzen. Es erhebt sich daher die Frage, ob wir in den beiden Gebilden nicht gewissermaßen vikarierende Apparate zu erblicken haben, in dem Sinn, daß das muskulöse Drüsenorgan, das ursprünglich irgendeine unbekannte oder untergeordnete Rolle spielt, in den Fällen als Begattungsapparat verwendet wird, in denen der Penis für diese Aufgabe zu schwach ist. Am schönsten würde sich an diese Gedankenreihe das Kopulationssystem von Polycladodes anpassen, bei der der Penis so klein und muskelschwach ist, daß er kaum durch die lange Penisscheide ins untere Atrium, geschweige denn durch den Genitalporus herausgelangen könnte. Dafür ist aber das muskulöse Drüsenorgan geradezu riesenhaft entwickelt. Es kann, wie tatsächliche Beobachtungen lehren, ziemlich weit aus dem Körper ausgestülpt werden und liegt, wenn es eingezogen ist, meist so, daß seine Spitze in dem Gang des Drüsensadres steckt. Man ist wohl berechtigt, in diesem Falle auch ohne direkte Beobachtungen sich den Vorgang der Begattung in folgender Weise vorzustellen: Es werden die beiden muskulösen Drüsenorgane wechselweise in die Geschlechtsöffnungen der Partner eingeführt. Ihre Spitze ragt in die enge Penisscheide. Durch Saugwirkung der Bulbusmuskulatur wird das Sperma in die Tasche befördert. Die Tiere trennen sich, die Drüsenorgane werden eingezogen und ihr Inhalt in den gestielten Drüsensack ergossen. 
Bei Dendrocoelum lacteum ist zwar das muskulöse Drüsen organ im Moment der Samenübertragung untätig, bei der großen Verschiedenheit im Bau der Kopulationsapparate nahe verwandter Arten muß man sich aber auf weitgehende Unterschiede im Kopulationsmodus gefaßt machen. Über diese Dinge wissen wir jedoch sehr wenig, da bis heute nur spärliche Arten von Süßwassertricladen (Dendrocoelum lacteum und Planaria gonocephala, lugubris und polychroa) in Kopulation untersucht worden sind.

Sehen wir uns zum Schluß noch bei anderen Turbellarien nach Organen um, die mit den muskulösen Drüsenapparaten der Paludicolen verglichen werden können, so sind zunächst die bei einigen Landplanarien vorkommenden Adenodactylen zu erwähnen, die durchaus als Homologa zu den muskulösen Drüsenorganen der Süßwasserplanarien aufzufassen sind. Treten sie zu Gruppen an einem gemeinsamen Stiel vereinigt auf, so nennt man sie Adenochiren. Über ihre Funktion ist ebenfalls nichts bekannt, dagegen sind diese Gebilde sehr wahrscheinlich von den sog. Giftdrüsen abzuleiten, die bei Polycladen und Acoelen vorkommen. Da es unter den ersteren mit mehreren Kopulationsorganen ausgestattete Arten gibt, die zum Teil mit vasa deferentia versehen sind, zum Teil auch nicht, da sich ferner der Penis und die muskulösen Drüsenorgane gewöhnlich in Form und Bau durchaus gleichen, ist es wohl erlaubt, den Penis selbst aus den Giftapparaten der Polycladen usw. abzuleiten, und anzunehmen, daß er erst sekundär durch Einmündung der Samengänge in den Dienst der Kopulation gezogen worden sei. Das muskulöse Drüsenorgan wäre dann eine rudimentäre Giftblase, oder ein unentwickelter Penis, der je nach Umständen bei den einzelnen Arten regelmäßig oder nur bisweilen reduziert, oder andern Funktionen angepaßt wird. So gut wir aber den Penis durch Hinzutritt der Samengänge aus einem muskulösen Drüsenorgane entstanden denken können, so gut können wir uns auch vorstellen, daß die Papille und der Bulbus an der Einmündung des Drüsensackstieles von Bdellocephala ein speziellen Funktionen (s. oben) angepaßtes muskulöses Drüsenorgan sei. 


\section{Nervensystem}

Nachdem wir nun die vegetativen Organe der Planarien besprochen haben, wenden wir uns zur Betrachtung der animalen, und zwar zunächst des Nervensystems.

Die Strudelwürmer besitzen ausnahmslos ein kompliziertes Nervensystem, das sich aus Strängen (Nerven und Nervenstämmen) und Knoten (Ganglien) zusammensetzt.

\section{Histologisches}

Bei der mikroskopischen Untersuchung des Nervensystems kann man zwei Elemente erkennen: Die Nervenzellen und die Nervenfasern. Die Fasern findet man in den Strängen und in den Knoten zentral gelagert; sie

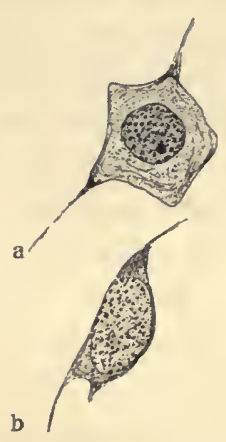

Abb. 36.

Ganglien- (a) und Gilazeile b vom Gehirn von Dendrocoelum infer nale. bilden eine Art Mark. Die dazugehörige Rinde, die mehr oder weniger dick sein kann, besteht aus Nervenzellen. Dieser Zellenbelag kommt jedoch nicht allen Nerven $z u$, man vermißt ihn besonders bei den schwächeren. Unter den Nervenzellen lassen sich zwei Typen auseinanderhalten:

1. Die Ganglienzellen mit schwach tingierbarem Plasma, das in ein, zwei oder mehrere Fortsätze ausläuft und durch sie mit dem Faserelement (Abb. 36) in Verbindung steht, und

2. Gliazellen mit scharfen Konturen und dunkel färbbarem Zellteil, die vorwiegend an den Strängen auftreten, im Gebiet der Ganglien dagegen eher selten sind. Sie bilden durch Verflechtung ihrer zahlreichen Fortsätze eine Art Gerüst, in welchem die Nervenfasern eingebettet sind. Nicht immer ist es möglich, Ganglien- und Gliazellen scharf auseinanderzuhalten.

Die Nervenfasern entspringen an den Ganglienzellen und durchziehen, teils einzeln, teils in Bündeln das Maschenwerk der Gliazellen.

Während an und zwischen den Nervensträngen nur ganz vereinzelte Ganglienzellen auftreten, bildet sich über den Knoten selbst oft ein förmlicher Ganglienzellenbelag. Dazu kommt 
als Charakteristikum der Ganglien noch eine eigenartige, feinkörnige Substanz, die Leydigsche Punktsubstanz, die das Auffinden der Knoten in den Stämmen meist sehr erleichtert.

Die Punktsubstanz ist wahrscheinlich ein Knäuel zartester Fibrillen, deren Durchschnitte als feinste Körnchen erscheinen. Jedenfalls läßt sich ein Zusammenhang zwischen den feinen Fasern, die das Mark der Nerven ausmachen, und der Punktsubstanz nachweisen.

$\mathrm{Ob}$ diese Angaben für alle Strudelwürmer stimmen, muß dahingestellt bleiben, da bis jetzt nur eine beschränkte Zahl von Arten in genügender Weise bekannt sind. Dazu kommt, daß die histologischen Bestandteile des Nervensystems meist sehr schwierig zu untersuchen sind.

\section{Allgemeine Morphologie}

Bisweilen bildet es ein Geflecht von unregelmäßigem Bau, einen sog. Plexus. Bei den Strudelwürmern zeigen immer einzelne Partien des Nervensystems den Chararkter eines Plexus, daneben kommen aber auch schärfer umschriebene, formkonstante Bezirke vor, die an Mächtigkeit den Nervenplexus bei weitem übertreffen, und die meist deutliche Beziehungen zum allgemeinen Körperbau erkennen lassen.

Zunächst tritt bei sämtlichen Turbellarien im Vorderende ein wohlumschriebener Komplex von Nervengewebe, speziell von mit Ganglienzellen überkleideter Punktsubstanz auf, der eine größere oder geringere Zahl von Strängen abgibt. Diese Nervenanhäufung wird als Gehirnganglion oder Zerebralganglion bezeichnet. Die von ihm abgehenden Nerven erstrecken sich nach vorn und hauptsächlich nach hinten, verlaufen also gemäß der meist länglichen Gestalt der Würmer in der Hauptrichtung des Körpers. Die Längsnerven stehen meist unter sich und mit einem unter der Haut gelegenen "Hautnervenplexus " durch Verbindungsstränge (Kommissuren) in Beziehung. Bei drehrunden Formen, z. B. den Acoelen, sind 3-5(6) Paare ungefähr gleichstarker, radiär um 
die Körperhauptaxe orientierter Längsnerven entwickelt (Abb. 37), während sich die Abgeplatteten durch den Besitz eines besonders

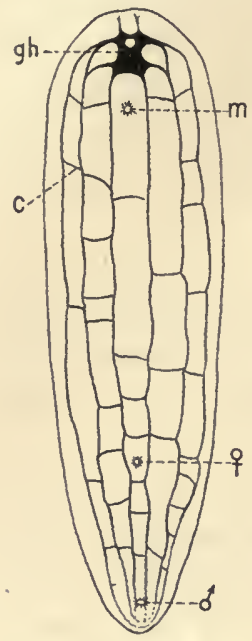

Abb. 37.

Nerven einer Acoele. m Mund, gh Gehirn, o und $\delta^{*}$ Geschlechtsöffnungen. starken, bisweilen einzigen ventralen Paares charakterisieren. Mit der Vervollkommnung der kriechenden Lebensweise und der Ausbildung einer eigentlichen Kriechsohle gewinnt dieses ventrale Nervensystem an Ausdehnung. Es mehren sich die Querkommissuren (Abb. $37 \mathrm{c}$ ), und bei den großen Landplanarien treten außerdem weitere ventrale Längsnerven hinzu, so daß diese ganze Nervenmasse einen starken ventralen Plexus darstellt, in welchem einige Längsstämme dominieren. Stellenweise kann es zur Bildung einer eigentlichen Nervenplatte kommen, in welche sogar das Gehirn mit einbezogen ist (Abb. 38). Man hat jedenfalls in diesem eigenartigen Nervensystem der Landplanarien eine sekundäre Modifikation $\mathrm{zu}$ sehen, die mit dem auf dem Land für so große Arten besonders erschwerten Kriechen zusammenhängt.

Eine andere Entwicklungsreihe führt von Formen mit mehreren gleichwertigen Längsstämmen $\mathrm{zu}$ solchen mit Strickleiternervensystem.

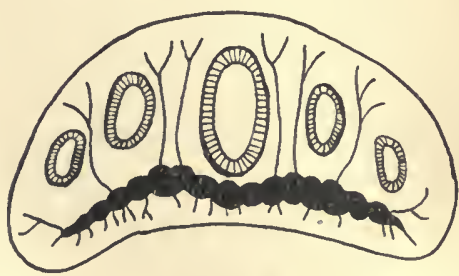

Abb. 38.

Querschnitt durch den Vorderkörper einer Landplanarie mit ventraler Nervenplatte (nach v. Graff).

Bei vielen Rhabdocoeliden dominiert bereits ein ventrales Längsnervenpaar, das in charakteristischer Weise eine starke hinter dem Schlund gelegene Kommissur besitzt. Das übrige Nervensystem kann nun recht verschieden gestaltet sein. Bei einigen Formen sind noch zwei weitere Längsnervenpaare ausgebildet, die Rand - und Dorsalnerven, die sowohl unter sich, als auch mit den großen ventralen Längsstämmen durch Kommissuren verbunden sind. Durch 
Steigerung der Kommissurenzahl zwischen den letzteren entstehen Strickleitern. Am deutlichsten und regelmäßigsten ist die ventrale Strickleiter entwickelt, die bei vielen Formen mit dem Gehirn zusammen als besonderes zentrales Nervensystem dem übrigen entgegengestellt werden kann, indem an der Abzweigungsstelle der Kommissuren Ganglien auftreten. Oft tritt alles übrige vor diesem Strickleiterkomplex so sehr zurück, daß außer den ventralen

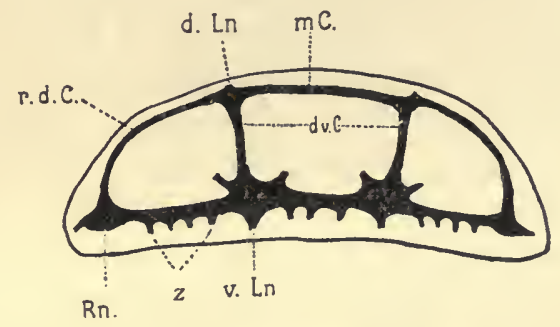

Abb. 39.

Schema des Nervensystems einer Meerplanarie im Querschnitt nach Böh mig.

v. Ln ventraler Längsnerv, d. Ln dorsaler Längsnerv, Rn. Randnerv, r. d. C. Rand-Rückenkommissur, d v. C Dorsoventralkommissur, z Zwelge für den Hautmuskelschlaudh.

Längsnerven keine Nerven von Bedeutung auftreten, daß vielmehr dorsál und in den Randpartien nur diffuse Geflechte vorhanden sind.

Das typische Strickleiternervensystem bildet bekanntlich den Ausgangspunkt für die Ableitung des Nervensystems der Ringelwürmer und Arthropoden, indem aus den ersten Ganglienpaaren der Schlundring (oberes und unteres Schlundganglion) verbunden durch die Schlundkommissuren, aus den übrigen Teilen der Strickleiter durch Verkürzung der Kommissuren und Verschmelzung der Längsnerven das Bauchmark werden kann.

Nervensystem der SüBwassertricladen

Nach diesen allgemeinen Bemerkungen wenden wir uns nun zur Betrachtung des Nervensystems der Süßwasserplanarien. Da bei allen Vertretern dieser Gruppe die ventralen Längsnerven Ganglien aufweisen, 
rechnen wir diese zum zentralen Nervensystem und stellen ihnen und dem Gehirn die übrigen Nerven als peripherischen Teil gegenüber. Um diesen Unterschied zum Ausdruck $z u$ bringen, werden wir die Längsnerven im folgenden Markstränge nennen. ${ }^{1}$ )

Das Gehirn besteht aus mehreren, eng verschmolzenen Ganglien. Es liegt ventral dicht am Hautmuskelschlauch und ist wie auch die Markstränge vom Parenchym umgeben. Seine Unterseite ist flach, während die dorsale Partie etwas gewölbt erscheint. Die eigentliche Gehirnmasse, bald einheitlich, bald deutlich in zwei Lappen zerfallend, ist bilateralsymmetrisch gebaut. Oft erscheinen die beiden Gehirnhälften als die kolbig verdickten, konvergierenden und durch Kommissuren verbundenen Vorderenden der Markstränge. Die Gehirnmasse (Punktsubstanz) umschließt einen parenchymatösen Zellhaufen, die sog. Substanzinsel (Abb. 42, Si). Im Gehirn ist der Faserverlauf sehr kompliziert. Die Brücke, die sich zwischen den beiden Hirnhälften ausspannt, ist bald schmäler, bald breiter, manchmal doppelt und läßt, auch wenn sie äußerlich einheitlich erscheint, auf Schnitten die Zusammensetzung aus mehreren Kommissuren erkennen. Uber die Zahl der an der Bildung des Gehirns beteiligten Ganglienpaare kann man aus dem Studium des Gehirnes selbst keinen Aufschluß erlangen, da die Verschmelzung eine sehr innige ist. Immerhin lassen sich durch Zählung der Brückenkommissuren Anhaltspunkte gewinnen für die Beurteilung der Gehirnzentren. Als Minimalzahl der Ganglienpaare von Planaria alpina, Planaria polychroa und Polycelis cornuta ergibt sich 3, bei Planaria gonocephala dagegen besteht das Gehirn aus 8 Ganglienpaaren.

1) DaB die Markstränge auch physiologisch zum Zentralnervensystem gehören im Gegensatz zu den Längsnerven der Acoelen, Polycladen usw., geht daraus hervor, daß dekapitierte Polycladen mit dem Gehirn auch die Lokomotionsfähigkeit oder doch das Vermögen, sich spontan. d.i. ohne äuBeren Reiz, in Bewegung zu setzen, einbüBen, während man SüBwasserplanarien in mehrere Stücke schneiden kann, die alle munter weiterkriechen, deren Bewegung sogar vom Licht modifiziert wird, die deutlich Thigmotaxis zeigen und somit ohne Gehirn komplizierte, wohlkoordinierte Bewegungen ausführen. 
Die Markstränge bilden die Fortsetzung der Gehirnhälften nach hinten. Eine Grenze läßt sich schwer feststellen. Nach vorn setzen sich die Stränge unter dem Gehirn als dünne, sogenannte

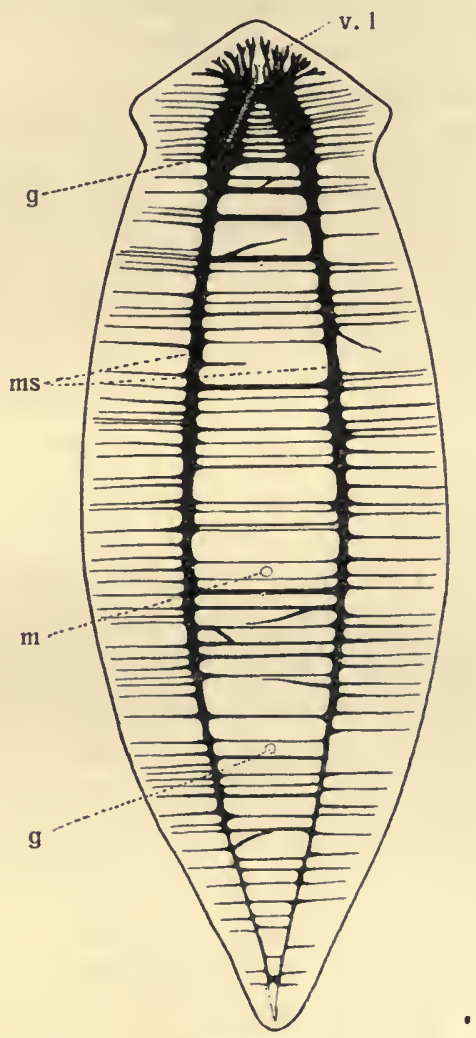

Abb. 40.

Nervensystem von Planaria gonocephala nach Ude. g Gehirn, ms Markstränge, v. 1 vordere ventrale Längsnerven, m Mund, g Genitalöffnung.

vordere ventrale Längsnerven fort, biegen am Vorderrand rückwärts und verschmelzen mit den vorderen dorsalen Partien des Gehirnes. $\mathrm{Ob}$ aber wirklich hier von ${ }_{n}$ Fortsetzen" gesprochen werden darf, ob die vorderen Längsnerven wirklich ursprünglich mit den 
Marksträngen eine Einheit bildeten, ist fraglich. Die direkte sehr starke Verbindung zwischen Gehirn und Marksträngen (Abb. $41 \mathrm{a}$ ) kann kaum sekundär sein. Eher darf man die vorderen Längsnerven und den dorsal entspringenden Nervenast als selbständige Gehirnnerven bezeichnen, die am Stirnrand miteinander verschmelzen (im Sinne von Abb. 41 b).

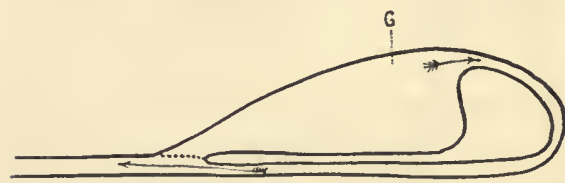

a.

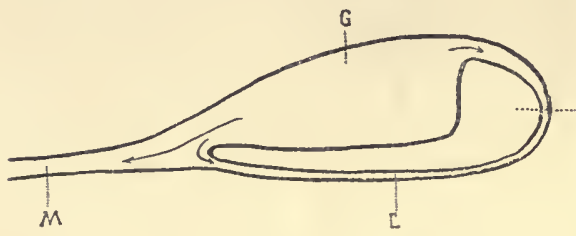

b.

Abb. 41. Sdhemata zur Erklärung d.VerhäItnisses $z$ wischen Gehirn und vordern Längsnerven (L). G Gehirn, $M$ Markstrang.

Die Markstränge schmiegen sich wie das Gehirn dem ventralen Hautmus kelschlauch dicht an und verlaufen, an Stärke allmählich abnehmend, den Seitenrändern parallel nach hinten, wo sie konvergieren und sich entweder ver einigen oder getrennt gegen das Hinterende auslaufen. Im Querschnitt erscheinen die Markstränge rundlich oder oval. Sie bestehen aus mehreren Faserzügen, zwischen die sich das Gliagerüst einschiebt, so daß man auf Längsschnitten oft den Eindruck erhält, die Markstränge seien doppelt. Ganglienzellen trifft man dagegen nur spärlich zwischen den Fasern an; etwas zahlreicher kommen sie im Zellbelage der Ganglien vor; d. h. derjenigen Stellen, von denen die Kommissuren ihren Ursprung nehmen. Man könnte einwenden, daß der Name Ganglion für eine Partie des Stranges, die nicht angeschwollen ist, willkürlich sei. Es zeigen sich jedoch bei einzelnen Arten tatsächlich Anschwellungen und außerdem scheinen sich die Fasern an diesen Stellen nach verschiedenen Richtungen zu durchdringen, so daß man in den Ganglien Punktsubstanz nachweisen kann. Die Zahl der Knoten und damit auch der Kommissuren zwischen 
den Marksträngen ist bedeutenden Schwankungen unterworfen und wechselt bei verschiedenen Individuen einer Art.

Für Planaria gonocephala werden z. B. 47, für Planaria polychroa 70 angegeben. Die Kommissuren sind ungleich stark. Sehr regelmäßig tritt hinter dem Schlund ein besonders kräftiger Verbindungsstrang auf, der wohl der bei Rhabdocoeliden vorkommenden, postpharyngealen Kommissur homolog ist. Eine zweite sehr auffällige Verbindung zeigt sich meist in der Gegend der Geschlechtsöffnung. Die Verstärkung dieser Stränge steht ohne Zweifel mit besonderen Funktionen (z. B. mit dem offnen und Schließen der Mund- und Genitalöffnung) im Zusammenhang.

Peripherisches Nervensystem nennt man bei den Tricladen die Gesamtheit der Gehirn- und Markstrangnerven.

An der Vorderfläche des Gehirns treten mehrere starke Nerven aus, die sich in zahlreiche Aste gabeln, in die Kopflappen ziehen und sich dort förmlich aufpinseln. Andere begeben sich zum Seitenrand des Kopfes oder zum Rücken hinauf und innervieren die Augen und die Aurikularsinnesorgane.

Alle diese Nerven besitzen einen deutlichen Ganglienzellenbelag und können als Sinnesnerven aufgefaßt werden. Sie treten bei verschiedenen Arten in etwas wechselnder Zahl und Anordnung auf. Bei Planaria gonocephala werden drei nach vorn und zwei nach den Seiten abgehende Gehirnsinnesnerven beschrieben, dazu kommen die Sehnerven und 8 doppelwurzelige Nerven, die je dorsal und ventral entspringen.

Etwas anders verhalten sich die Sinnesnerven bei Planaria alpina, wie aus Abbildung 42 entnommen werden kann.

Von den 9 Gehirnnerven dieser Spezies treten 2 (Abb. 42 NI u. N II) mit dem ventralen Strickleiterkomplex in Verbindung, die übrigen innervieren verschiedene Partien des Kopfes, speziell die Tentakeln (N III, IV, V und VI). Sie dürften zum Teil motorisch sein, da die Tentakeln der Alpenplanarie reichliche Muskulatur und große Beweglichkeit besitzen.

Von den Marksträngen gehen in mehr oder weniger regelmäßigen Abständen Seitennerven $\mathrm{ab}$, die als motorische Nerven 
aufzufassen sind, meist an den Ganglien entspringen und zum Körperrand hinziehen. Unregelmäßigkeiten kommen besonders bei Planaria gonocephala (Abb. 40) vor. Bei Maricolen und bei Planaria alpina läuft ein Nerv dem ganzen Körperrand parallel. In diesen Randnerv münden die Seitennerven der Markstränge, wie auch des Gehirnes (resp. der unter dem Gehirn gelegenen sogenannten vordern Längsnerven, von denen schon weiter oben

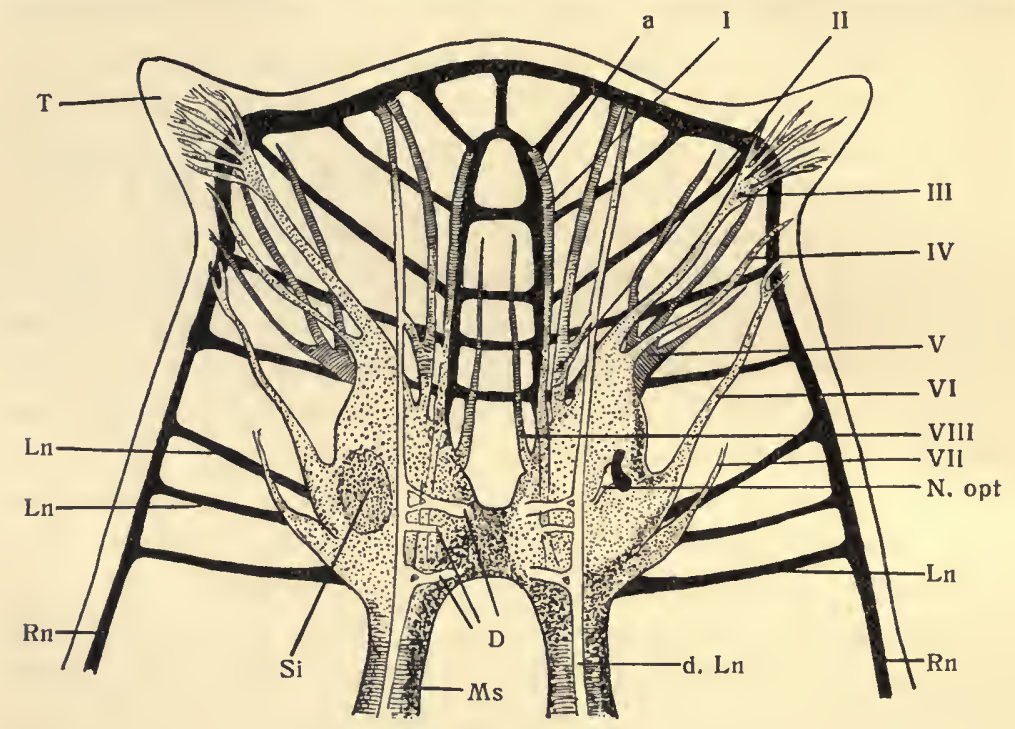

Abb. 42.

Gehirn von Planaria alpina nach Micoletzky.

T Tentakel, a vorderer ventraler Längsnerv, I-VIII Gehirnnerven, N. opt Sehnerv, Ln Seitennerv, Rn Randnerv, Si Substanzinsel, Ms Markstrang, d. Ln dorsaler Längsnerv, D Dorsalnerven.

die Rede war). Außer diesen im ganzen ventral gelegenen Nerven kommt bisweilen ein Paar dorsaler Längsnerven vor, das am vordern Kopfrand jederseits mit dem Randnerv in Beziehung tritt (Planaria alpina und maricole Tricladen). Diese dorsalen Nerven können unter sich, mit dem Randnerv und mit den Marksträngen, resp. im Kopfabschnitt mit dem Gehirn durch Kommissuren in Verbindung stehen, so daß wir im extremsten Fall 
auf Querschnitten Bilder zu Gesicht bekommen können, wie sie in Abbildung 39 angedeutet sind.

Wie wir schon in der einleitenden Ubersicht erfahren haben, kommt bisweilen außer diesem morphologisch konstanten Nervensystem noch ein verwickelt gebauter Hautnervenplexus vor, der jedoch nur vikarierend für die dorsalen Strickleiterbildungen auftritt (Abb. 43). Huch der Randnerv ist oft durch einen Plexus ersetzt; wo er neben einem soldhen auftritt, scheidet er zahlreiche kurze zapfenartige Fortsätze aus, die mit dem plexus zusammenhängen.

Wir hätten also gewissermaßen zwei Extreme. Die Maricolen (z. B. Procerodes), deren gesamtes Parenchym von einem unter dem Muskelschlauch liegenden, regelmäßigen Nervengitter umschlossen wird (drei Längsnervenpaare mit dazugehörigen, ringförmig verlaufenden Kommissuren) einerseits, und andrerseits die Paludicolen Planaria gonocephala, Planaria polychroa und die Landplanarien, spez. Rhynchode-

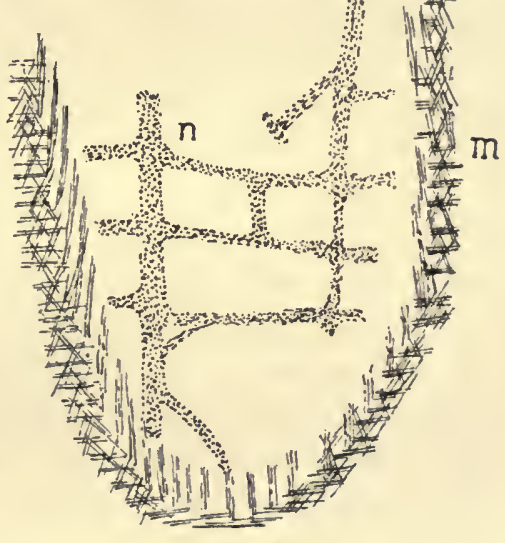

Abb. 43.

Geflecht der Rückennerven. Flächenschnitt. Nach Böhmig.

n Nervengeflecht, m Hautmuskelschlauch.

mus, bei denen an Stelle des Nervengitters ein unregelmäßiger Hautnervenplexus getreten ist, in welchem die dorsalen und die Randnerven nicht hervortreten, während das zentrale Nervensystem, Gehirn und Markstränge mit ihren Kommissuren, besonders kräftig entwickelt ist.

Spezielle, mit dem zentralen Nervensystem zusammenhängende Nervengeflechte besitzt der Saugrüssel (siehe S. 44 u. 45), am Kopulationsapparat konnte derartiges bis jetzt nicht mit Sicherheit beobachtet werden. Es ist jedoch sehr wahrscheinlich, daß dieses Organsystem durch einen besonderen Plexus innerviert wird. 
Sinnesorgane

Augen

Von den Sinnesorganen sind am besten bekannt die Augen. Sie sind in der Regel ohne weitere Hilfsmittel sichtbar. Nur die Polycelisarten lassen ihre Augen erst bei Lupenbetrachtung erkennen. Wir wollen zunächst den Bau des Einzelauges besprechen und dann von der Anordnung bei den einzelnen Arten reden.

Außerlich erscheinen die Sehorgane der Tricladen als schwarze Punkte. Oft sind sie bei dunkel pigmentierten Formen von einem hellen Hof umgeben, der kreisrund, oval oder polygonal sein kann und dadurch zustande kommt, daß an dieser Stelle im Körperparenchym unter der Basalmembran das Pigment fehlt. Die Augenpunkte liegen nicht im Zentrum des Hofes, sie sind dem innern Rande genähert, so daß man bei zweiäugigen Formen den Eindruck eines schielenden Augenpaares erhält.

Auf Schnitten bekommt man AufschluB über die wahre Natur der Augenpunkte, indem sie sich dann als hohle Halbkugeln, als Becher oder Schalen erweisen. Sie sind stets so orientiert, daß ihre Offnung nach außen schaut und daß ihre Achse ungefähr zur Medianlinie senkrecht steht mit geringer Abweichung nach vorn und oben.

Die Pigmentbecher haben mit dem Sehvorgang direkt nichts zu tun, sie dienen nur der optischen Isolation der im Becherhohlraum liegenden, lichtperzipierenden Elemente (Sehzellen). Nur Strahlen, welche ganz oder nahezu in der Richtung der Becherachse einfallen, können wahrgenommen werden, die andern treffen die Außenseite des Pigmentbechers und werden absorbiert.

Bei Polycelis fehlen den zahlreichen Randaugen eigentliche Höfe, doch ist das Körperpigment im Bereich der Augen reduziert. Dies ist sehr wichtig, weil die Augen nicht selten ziemlich tief im Körpergewebe geborgen sind, so daß das Licht zum mindesten Oberhaut, Basalmembran und Hautmuskeln durchdringen muß, um zu den Bechern zu gelangen. Eine Art Beweglichkeit der Augen kommt dadurch zustande, daB die benachbarten 
Muskeln bei ihren Kontraktionen gleichzeitig die Augen verschieben können.

Die Pigmentbecher haben bei verschiedenen Planarien einen etwas verschiedenen Bau (Abb. 44 u. 45). Einmal sind sie um so tiefer, je weniger Sehzellen sie enthalten. Sodann besteht der Becher bei den einen aus einer einzigen Zelle, die in ihrem Plasmaleib sehr zahlreiche Pigmentkörner besitzt, bei den andern aber aus mehreren Zellen. $\mathrm{Zu}$ den ersteren zählen Planaria torva, Planaria alpina, Planaria vitta, die Polycelisarten und Dendrocoelum lacteum, in die zweite Gruppe gehören Bdello-

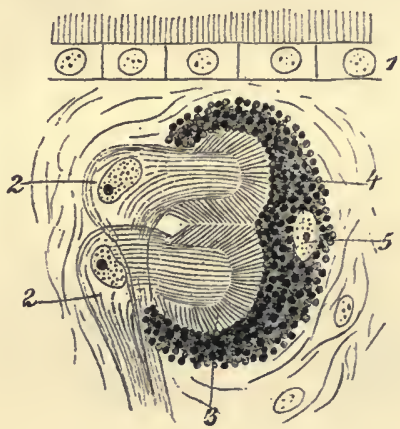

Abb. 44.

pigmentbecherocellus von P lan aria to $\mathrm{rva}$. 1 Integument, 2 Sehzellen, 3 Stiftchensaum, 4 Pigmentzelle, 5 deren Kern (aus Hesse-Doflein).

cephala punctata, Planaria gonocephala, Planaria lugubris und Planaria polychroa.

Der Becher von Planaria gonocephala besitzt eine größte Weite von durchschnittlich $74 \mu$ und eine Tiefe von $42 \mu$. Wesentlich kleiner ist der einzellige Pigmentbecher von Planaria torva (Offung $33 \mu$, Tiefe $20 \mu$ ).

Der wahrnehmende Teil besteht aus Zellen von etwas verschiedener Form und wechselnder Zahl. Danach lassen sich drei Typen von Tricladenaugen unterscheiden:

1. Planaria torva-Typus mit wenigen $(1-4)$ Sehzellen im Augenbecher. Die einzelne Sehzelle besteht aus feinfaserigem Plasma (Abb. 44) und einem großen Kern. Die Fibrillen erstrecken sich

Stein mann-Bresslau, Strudelwürmer. 
bis zum innern, dem Pigmentbecher zugekehrten Ende der Zelle und schwellen dort zu kleinen Stiftchen an, die alle gleich groß sind und dicht stehend eine Stiftchenkappe um den kolbigen Endabschnitt der Zelle bilden.

2. Dendrocoelum lacteum-Typus mit 30 oder etwas mehr Sehzellen, die infolge ihrer großen Zahl im Becherraum nicht Platz finden. Daher zerfällt die Sehzelle in einen kernlosen, im

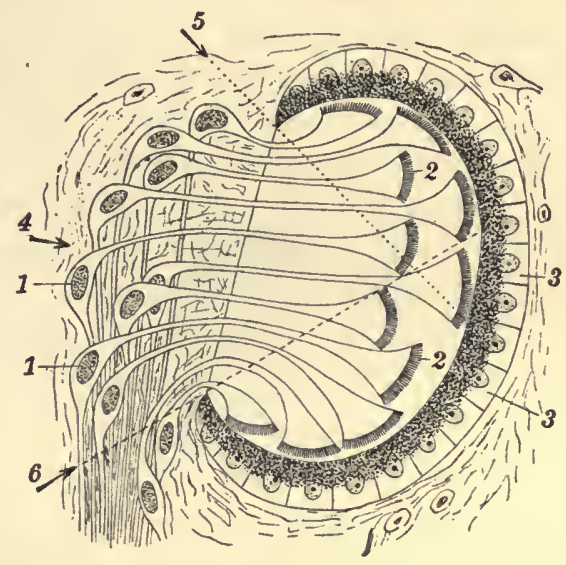

Abb. 45.

pigmentbecherocellus von planaria gonocephala (nach Hesse).

1 Kerne der Sehzellen, 2] Stiftchensaum, 3 Pigmentzellen; Licht, das in der Richtung des pfeiles 4 in den Ocell einfällt, trifft alle Stiftchensäume, Licht von der Richtung des peiles 5 nur diejenigen, die nach unten von der punktierten Linie liegen, solche, aus der Richtung 6 nur die Stiftchensäume oberhalb derselben.

Becher liegenden Teil, den Sehkolben, und einen vor dem Auge gelegenen Abschnitt. Die Verbindung wird durch feine Fasern hergestellt. Die Sehkolben sind deutlich fibrillär gebaut und zeigen einen umfangreichen Saum von Stiftchen, der meist den ganzen Kolben überzieht.

3. Planaria gonocephala-Typus (Abb. 45) mit sehr zahlreichen Sehzellen (über 150). Der Unterschied gegenüber dem vorigen Typus besteht darin, daß die Sehkolben eine andere Form 
haben. Sie können am besten mit einem soliden Trichter oder mit der Brause einer Gießkanne verglichen werden. Die verjüngten, fadenförmigen Abschnitte sind in der Richtung der Lichtstrahlen orientiert, die dazu senkrechte Trichterfläche ist mit Stiftchen besetzt. Somit ergibt sich als Fortschritt gegenüber dem Sehkolben bei Dendrocoelum lacteum, daß die in eine Ebene senkrecht zum Lichteinfall gestellten Stiftchen alle gleichmäßig vom Licht getroffen werden können. Im übrigen gleichen die Sehzellen von Planaria gonocephala denen von Dendrocoelum lacteum, indem auch hier die zu Fäden verjüngten Teile der Sehkolben schließlich zum kernhaltigen Abschnitt der Sehzelle führen.

Ohne Zweifel handelt es sich hier um drei Komplikationsstufen; das Planaria torva-Auge ist das primitivste, das von planaria gonocephala das höchststehende.

Bei der Entstehung der komplizierten Augen sind Stadien mit nur wenigen Sehzellen zu durchlaufen. Bisweilen findet man auch Teilungsprodukte von Augen, die dann meist eine reduzierte Sehzellenzahl aufweisen. Hierbei handelt es sich in der Regel um sekundäre Prozesse, die zum Teil durch äußere Einflüsse, wie Hunger, bedingt sind. Die vieläugigen Arten unterscheiden sich im Bau ihrer Augen kaum von den zweiäugigen, in dem die Vertreter der Gattung Polycelis sich dem Dendrocoelum lacteum-Typus, Polycladodes alba eher bei planaria torva einreihen läßt.

Sehen wir uns zum Schluß die Anordnung der Augen bei den einzelnen Arten an, so ist hervorzuheben, daß es einige augenlose Formen gibt (Planaria cavatica, Dendrocoelum mrazeki, Dendrocoelum infernale, Anocelis coeca, Planaria anophtalma), daß ferner auch sehende Arten bisweilen in blinden Standortvarietäten auftreten können (Planaria alpina in der Tiefe der Seen).

Unter den Sehenden ist der zweiäugige Typus am stärksten vertreten, indem er allen sehenden Arten der Gattung Planaria und Dendrocoleum zukommt. Er gilt auch für die Terrikole Rhynchodemus, sowie für die marikolen Tricladen ohne Aus- 
nahme. Vieläugig sind Polycelis und Polycladodes. Die Arten der ersteren Gattung besitzen zahlreiche Augen längs dem Vorderrand des Kopflappens, sowie auch längs den Seitenrändern, zuweilen bis gegen die Körpermitte. Polycladodes entspricht in der Augenanordnung den asiatischen Planarien-Genus Sorocelis und einigen Polycladen, indem am Kopflappen jederseits eine Augenansammlung von 5 bis 40 Stück auftritt. Bei einigen Terricolen können Tausende von Augen beobachtet werden.

\section{Hautsinneszellen}

Als Sinnesorgane sind auch die in das Körperepithel eingelagerten, vereinzelten Sinneszellen (Abb. 9) aufzufassen, die mit dem Hautnervenplexus in Verbindung stehen. Sie sind modifizierte Epithelzellen und liegen bisweilen inmitten normaler Integumentzellen, von denen sie sich nur durch ihre und ihres Kernes Größe, durch den Mangel an Stäbchen, sowie durch lange, ziemlich dicke Cilien auszeichnen. Manchmal erscheint das Plasma der Sinneszellen streifig; die Streifen gehen gegen den Körper in sehr feine Fäserchen über, welche die dünne Basalmembran durchsetzen und mit dem Nervenplexus in Verbindung treten. Bei Planaria gonocephala treten die Sinneszellen meist einzeln, seltener in kleinen Gruppen (3-4 nebeneinander) auf; sie gehören fast ausschließlich der dorsalen Seite an, sind regelmäßig zerstreut, gegen den Rand zu aber viel zahlreicher als in der Rückenmitte. Während die Sinneszellen bei marinen Arten selten eingesenkt sind, finden sie sich bei Planaria gonocephala stets in Vertiefungen. An einem Exemplar wurden 280 Sinnesgruben gezählt. Über die Bedeutung der Zellen wissen wir nichts, ebensowenig kann ihre Verbreitung bei den Tricladen erörtert werden, da unsere Kenntnisse darüber noch sehr mangelhaft sind.

Hurikularsinnesorgan

Als Gruppen von Sinneszellen sind auch die noch wenig bekannten sog. Aurikularsinnesorgane aufzufassen, die als pigment- und rhabditenfreie Streifen zu beiden Seiten des Kopfes auftreten (Bdellocephala, 
Planaria torva, polychroa, Ingubris und die meerbewohnende Procerodes ulvae), oder unregelmäßigere ovale bis polygonale Flecke bilden: Planaria gonocephala. Die Aurikularsinnesorgane können wegen ihrer verschiedenen Gestalt und Lage als bequeme systematische Kennzeichen gelten.

Tentakeln

Zusammengesetzte Sinnesorgane sind die Tentakeln, oder ihre stellvertretenden Organe die Aurikeln und Tastlappen. Ihre Integumentzellen sind durch Pigmentarmut oder völligen Pigmentmangel, sowie durch Fehlen der Rhabditen ausgezeichnet. Dafür tragen sie besonders starke Wimpern, die bisweilen einen vom übrigen Wimperkleid unabhängigen Schlag erzeugen, so daß um die Ohrchen ein Kreisstrudel entsteht (Abb.46).
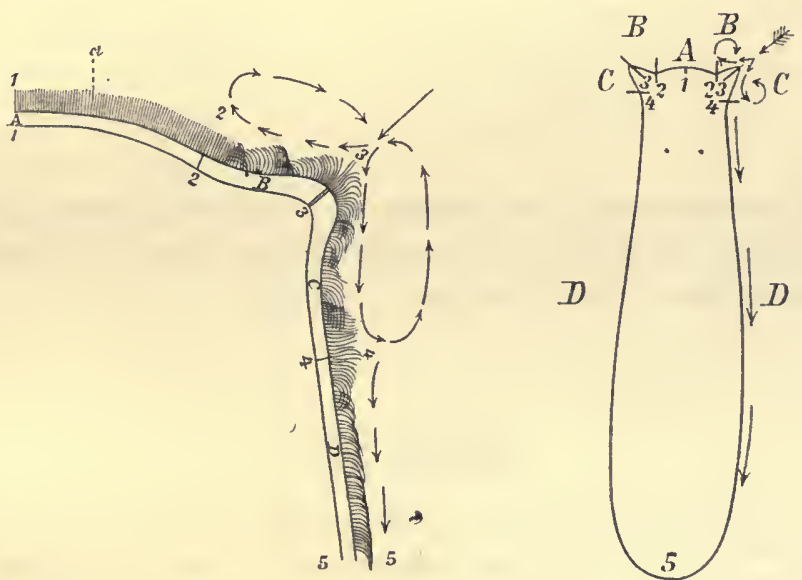

Abb. 46.

Schema der Wimperbewegung von Procerodes ulvae.

Nach Wilhelmi.

$1,2,3,4,5$ Wellenberge; $A, B, C, D$ Wellentäler.

Tentakelbläschen

Einigen Arten fehlen die Aurikularsinnesorgane.

$\mathrm{Zu}$ ihnen gehören Planaria alpina und ihre Verwandten, die polypharyngealen Abarten. Diese Gruppe besitzt jedoch in den Tentakeln oder an derem Grunde je ein blasiges 
Gebilde mit einem homogenen Körper (Abb. 47, 48). Sehr wahrscheinlich handelt es sich um ein Sinnesorgan. Leider wissen wir

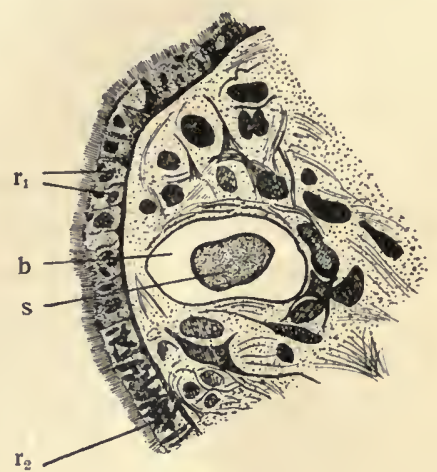

Abb. 47.

Schnitt durch den Tentakel von Planaria teratophila.

$r_{1}$ rhabditenarme Integumentzellen, $r_{2}$ normale Integumentzellen, $b$ Tentakelblase, s EinschluBkörper.

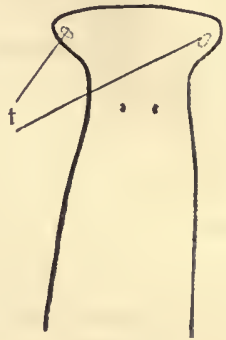

Abb. 48.

Die Tentakelblasen $(t)$ bei Planaria alpina nach einem Totalpräparat.

über die Wirksamkeit der Tentakeln, sowie der Aurikularsinnesorgane und Tentakelbläschen sehr wenig. Einige Vermutungen werden im biologischen Teil ausgesprochen.

\section{Biologie}

Bewegung

Das Kriechen der Planarien, wie übrigens auch die ähnliche Bewegungsweise der Schnecken, pflegt den Laien jeweilen in Erstaunen zu setzen. Man ist gewohnt, das Kriechen als etwas Mühsames zu betrachten, das mannigfaltige Muskelkontraktionen und Krümmungen erfordert. Eine kriechende Planarie aber schwebt sanft und gleichmäßig, scheinbar ohne jegliche Mühe und wie von unsichtbaren Kräften getrieben, dahin. Die Kriech- oder Gleitbewegung ist denn auch oft studiert worden, ohne daß es bis jetzt gelungen wäre, alle Einzelheiten aufzuklären. Ohne Zweifel kommt den auf der Bauchseite sehr stark 
entwickelten Wimpern lokomotorische Bedeutung zu. Diese feinsten Fäden werden nämlich mit großer Energie rückwärts geschlagen, aber relativ langsam vorgezogen. Sie kommen daher als vorwärtstreibende Organe in Betracht. Außerdem macht die Kriechsohle ähnlich wie bei den Schnecken wellenartige Bewegungen, indem die Längsmuskeln in regelmäßigen Abständen abwechselnd gestreckt und kontrahiert werden (Abb. 49a). Die Wellen beginnen vorn und laufen bis zum Schwanzende weiter. Sie haben wohl doppelte Bedeutung. Einmal bringen sie den Körper direkt wie bei den Schnecken vorwärts, sodann können an den Stellen, die von der Unterlage abgehoben sind, an den Wellentälern, die Wimpern besser spielen.

Von großer Wichtigkeit ist ferner der Drüsenapparat, dessen Sekret die Unterlage schlüpfrig ma-

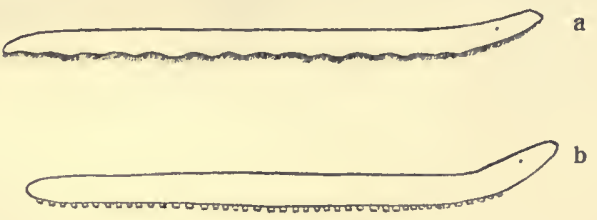

Abb. 49.

Schema der Kriectibewegung nach Wilhelmi. chen und so die Reibung aufheben muß. Da nun dieser Schleim die Wimpern behindern könnte, so wird er nur an den Rändern des Körpers und am Schwanz durch die sog. Kantendrüsen abgesondert. Während man früher dem Kantendrüsensekret Klebfunktion zuschrieb, hat Wilhelmi für Seetricladen überzeugend dargetan, daß es nicht für die Anheftung, sondern im Gegenteil für die Ortsbewegung von Bedeutung ist.

Die Kanten- oder Haftzellen bilden in ihrer Gesamtheit eine Leiste und stehen durch den an ihnen ausgeschiedenen Schleim mit der Unterlage in Kontakt (Abb.49b). Das Sekret, das an der Bauchseite zwischen den Wimpern austritt, verhält sich gegen Farbstoffe ganz anders als das der Kantendrüsen, hat also wahrscheinlich auch andere Bedeutung; vermutlich schützt es die Wimpern vor Verschleimung, indem es das Kantendrüsensekret verflüssigt. Eine besondere Rolle kommt den sog. Haftpapillen der Kantendrüsen zu. Diese sehr feinen kolbigen Gebilde stellen die Verlängerung der Drüsenkanälchen dar. Sie wirken wohl ähnlich wie 
die Polsterkissen an den Füßen kletternder Insekten, indem sie den Körper an die Unterlage anheften. Soweit unsere bisherigen Kenntnisse eine Zusammenfassung erlauben, könnte man die Planarienbewegung als ein Gleiten auf den schlittenschienenartigen Seitenrändern bezeichnen. Der Schleim der an ihnen austritt, macht die Bahn schlüpfrig und bleibt wie bei den Schnecken als Schleimspur zurück. Als vorwärtstreibende Momente kommen in Betracht die von vorn nach hinten fortschreitenden Wellen der
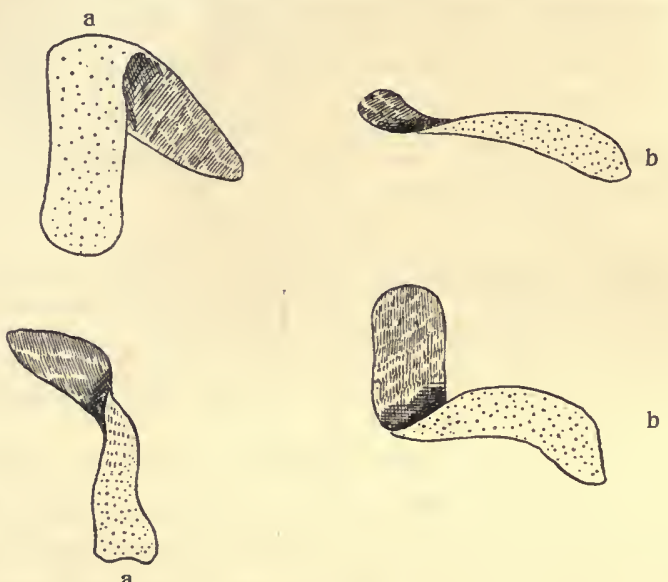

$\mathrm{Abb} .50$.

a Ưbergang vom gewöhnlichen Kriechen zum Kriechen an der Wasseroberfläche;

b das umgekehrte. Nach Originalzeichnungen von Bresslau.

ganzen Kriechsohle, bedingt durch Kontraktionen der Längsmuskeln und ferner der Schlag der Bauchwimpern, die durch das Sekret der cyanophilen Drüsen vor Verschleimung und Verklebung bewahrt bleiben.

Weder von den sehr rasch verlaufenden, wenig ausgiebigen, aber sehr zahlreichen Kontraktionen, noch von der Wimperbewegung kann man ohne starke Vergrößerung etwas bemerken; daher geht die Gleitbewegung der Tricladen scheinbar in so rätselhaft müheloser Weise vor sich.

Neben dieser gewöhnlichsten Fortbewegungsweise kommen noch andere vor. 
Einmal ist die Gleitbewegung auch an der Wasseroberfläche möglich. Durch die Oberflächenspannung wird die oberste Wasserschicht gewissermaßen zu einem zähen Häutchen, dessen Festigkeit so groß ist, daß man dünne Blechstückchen (Stanniol), also Körper, die spezifisch schwerer sind als Wasser, auflegen kann, ohne ein Untersinken befürchten $z u$ müssen. An diesem Häutchen könnten sich die Planarien, den Rücken nach unten gekehrt, aufhängen, und es dient gleichzeitig als Unterlage für die Gleitbewegung (Abb. 50). Ahnliches kann man bekanntlich bei Wasserschnedken beobachten. Eine andere Lokomotionsart zeigen mehrere Planarien, wenn man sie beunruhigt, starkem Licht, extremen Temperaturen aussetzt, oder mit Chemikalien und durch Berührung reizt. Sie besteht in einem "Spannen" wie bei Blutegeln (Abb. 51). In der ersten Phase wird der Körper lang ausgestreckt, während sich das Hinterende der Unterlage fest anheftet, in der zweiten Phase preßt sich der Kopf dem Boden an, der

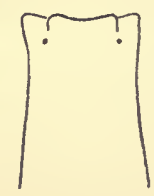

a

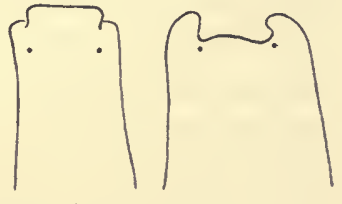

b

Abb. 51.

Spannende Bewegung von Dendrocoelum lacteum. a erste, b zweite, c dritte Phase.

Hinterleib läßt los und wird durch Kontraktion des ganzen Körpers nachgezogen. 'Diese Bewegungen lösen sich in kurzen Intervallen $a b$, so daß die Lokomotion rascher vonstatten geht als bei der einfachen Gleitbewegung. Meist dauert das Spannen nur kurze Zeit und geht allmählich in ruhiges Gleiten über.

Besonders $\mathrm{zu}$ dieser Bewegung geneigt sind die Dendrocoelumarten, Bdellocephala und Polycladodes, bei denen sich an der Unterfläche des Kopfes sogar eine eigentliche Sauggrube findet (s. S. 24). Bei Planaria alpina, die bisweilen Andeutungen von Haftnäpfen zeigt, kann man nicht selten die spannende Bewegung beobachten. Demnach scheint dieses Organ tatsächlich in erster Linie der Lokomotion $z \mathbf{u}$ dienen. Daneben allerdings scheint es zur Festheftung während der Ruhe bestimmt zu sein. Die für die genannten Formen sehr charakteristischen Kopfkon- 
traktionen zeigen, daß die Sauggruben auch nach Einstellung der Bewegung in Tätigkeit sind.

Bei stark gereizten, speziell bei dekapitierten Exemplaren kann man dann und wann heftige, krampfartige Krümmungen sehen, die fast den Eindruck von Schwimmversuchen machen, ohne daß sie die Tiere jemals vom Ort bewegen könnten.

Nur selten dürfte es gelingen, eine weitere Bewegungsart $\mathrm{zu}$ beobachten: das Herablassen von der Oberfläche des Wassers an einem Schleimfaden. In der Regel fallen die Süßwassertricladen, die man beim Kriechen an der Oberfläche stört, direkt herunter

Ist ein Tier im Begriff sich zur Ruhe zu setzen, so verlangsamt es sein Kriechen, der Rumpf, der in voller Gleitbewegung relativ lang und schmal war, verbreitert sich. Bei manchen Arten kräuseln sich die Seitenränder (Dendrocoelum, Bdellocephala) und nun verharren die Würmer stunden- ja tagelang in starrer Bewegungslosigkeit, bis sie der Hunger oder ein äußerer Reiz weckt.

\section{Ernährung}

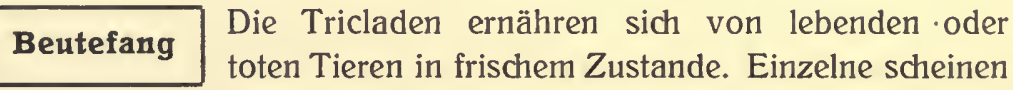
im Notfall auch pflanzliche Stoffe zu sich zu nehmen. Transportiert man in einem Glas mit Planarien gleichzeitig ein paar Flohkrebse oder Insektenlarven, so findet man diese zu Hause entweder überhaupt nicht mehr vor, oder sie krabbeln mit gelähmten Beinen, von zähem Schleim umhüllt, mühsam einher. In diesem Zustand fallen sie den Planarien leicht zum Opfer. Woher stammt der Schleim, der die Beutetiere gefangen hält? Es kann das Sekret, das beim Kriechen abgesondert wird, die Schleimspur, in Betracht kommen. Außerdem beobachtet man, daß Schleim aus dem Rücken der Planarie austritt, so oft ein Gammarus im Vorbeischwimmen den Wurm berührt. Das sind die Rhabditen, die ausgestoßen werden und sich im Wasser sofort zu zähem Schleim auflösen (vergl. S. 30). Kleinere Beutetiere können durch dieses Sekret förmlich festgeklebt werden, während größere in der Regel 
loskommen und nach mehrmaligem Kontakt die Verschleimung zeigen, von der oben die Rede war. Nehmen wir nun an, ein Gammarus liege gelähmt, aber noch lebend am Boden eines Gefäßes, in das wir eine Planarie gesetzt haben. Je nach dem Witterungsvermögen, das bei verschiedenen Arten sehr verschieden ist, werden die Planarien, die zufällig an der Beute vorbeischwimmen, aus größerer oder kleinerer Distanz auf den Krebs aufmerksam und kriechen direkt an den Ort ihrer Wünsche, indem sie den erhobenen Kopf tastend hin und her wenden. Die Bewegung ist eher langsamer als gewöhnlich. Manchmal hört das Tasten in der Nähe der Beute sogar auf, und der Wurm gleitet ganz ruhig vorwärts. Man wird unwillkürlich an eine Katze erinnert, die eine Maus beschleicht. Bei Dendrocoelum lacteum wurde sogar beobachtet, daß im letzten Moment der Kopf ruckartig vorgeschnellt wird und sich dem Opfer anheftet. Andere Planarien suchen so rasch als möglich einen großen Teil der Bauchfläche mit dem Beutetier in Berührung zu bringen, damit ein Abschütteln nicht mehr möglich ist. Nicht alle Arten stellen sich beim Beschleichen der Opfer gleich geschickt an, einzelne müssen nach mehreren Mißerfolgen ihr Vorhaben aufgeben. Sehr gut verstehen sich auf Beutefang Dendrocoelum lacteum und Planaria gonocephala, wenig geübt erscheint das Benehmen von Planaria lugubris. - Ist das Opfer ein Wurm oder eine Schnecke, so verfahren die Planarien ähnlich; sie verhalten sich auch im Wesentlichen gleich, wenn es sich um einen toten Nahrungsbrocken, etwa um ein Stück Regenwurm, eine Portion Fleisch usw. handelt. Uber die Unvollkommenheit des Spürsinnes, der häufig nur alarmiert und erst in ganz geringer Distanz des Beutetieres orientierend wirkt, werden wir weiter unten zu sprechen haben. Nicht selten kriechen selbst ausgehungerte Exemplare dicht neben den fettesten Speisestücken vorbei, indem sie zwar wie schnuppernd den Kopf heben und drehen, aber nicht imstande sind, die Herkunft der Witterung zu merken. 


\section{Nahrungsaufnahme}

Ist die Nahrung, z. B. ein Gammarus, aufgefunden, so wird sie allseitig untersucht, indem sich das Kopfende wiederholt eng an den Speisebrocken anschmiegt. Besonders eifrig bewegt sich dabei der Vorderrand, der zahlreiche Sinneszellen enthält und offenbar die chemische Beschaffenheit der Nahrung zu prüfen hat. Während dieses Geschäftes tritt der Rüssel aus und beginnt sofort, sich abwechselnd $\mathrm{zu}$ strecken und $\mathrm{zu}$ verkürzen. Ist eine schwache Stelle am Chitinkleid des Krebses gefunden, so wird der Lippenrand fest angepreßt. Kurz darauf bemerkt man, daß der Chitinpanzer durchbrochen ist und daß der Rüssel im Körperinnern des noch zuckenden Opfers zu wühlen beginnt. Wahrscheinlich erfolgt der Durchbruch durch die Haut des Krebses nicht nur durch die mechanische Wirkung des Saugnapfes, sondern es helfen lösende, verdauende Sekrete des Rüssels mit. Nachdem der Pharynx sich einen Durchtritt verschafft hat, kann man das Auftreten von peristaltischen Kontraktionsbewegungen beobachten, die am Lippenrand beginnen und sich nach der Wurzel hin fortpflanzen. Hierdurch werden wohl kräftige Saugwirkungen erzielt, denn man sieht, wie die Gewebe des rasch absterbenden Tieres portionenweise losgerissen und in die Planarie übergeführt werden. Der Rüssel drängt sich überall zwischen den Geweben durch und streckt sich bisweilen zu einem langen dünnen Gebilde aus. Es scheint fast unmöglich, die rasche und gründliche Ausräumung des Beutetieres bis auf das Skelett nur durch die Saugarbeit des Pharynx zu erklären. Die kräftige Muskulatur eines Gammarus könnte sicher länger Widerstand leisten, wenn sie nicht gleichgleichzeitig durch die Sekrete der Pharynxdrüsen aufgeweicht, resp. aufgelöst oder mazeriert würde. Die Frage, ob die Nahrung der Planarien auBerhalb des Körpers (extrakorporell) durch die ausgespieenen Säfte der Rüsseldrüsen vorverdaut wird oder nicht, ist zurzeit strittig, doch scheint mir schon die Anwesenheit so kräftiger und ausgedehnter Drüsen und Drüsengänge für eine wesentliche Funktion der Sekrete beim Verdauungsakt zu sprechen. Nur durch extrakorporelle Verdauung wird wohl auch die Tat- 
sache verständlich, daß die Planarien an größeren Stücken frischen Fleisches fressen können. Man mag die Saugkraft des Pharynx sehr hoch bemessen, zu einem Losreißen von Muskelfasern aus ihrem Verband, kann sie nicht als ausreichend angenommen werden. Es wäre noch etwa die Frage aufzuwerfen, warum die Sekrete der Pharynxdrüsen sich gegenüber Farbstoffen ganz verschieden verhalten. Man könnte hier an zwei verschiedene Funktionen denken in dem Sinne, daß die cyanophilen Drüsen Gift oder Betäubungsmittel, die erythrophilen aber Verdauungssäfte liefern oder umgekehrt.

Ist Sättigung eingetreten, oder ist der Nahrungsbrocken völlig aufgezehrt, so tritt der Rüssel wieder in seine Tasche zurück, die Planarie kriecht träge von dannen und setzt sich bald zur Ruhe.

\section{Verdauung}

Die Assimilation der aufgenommenen Nahrung kann mehrere Wochen in Anspruch nehmen, doch können inzwischen wieder weitere Rationen vertilgt werden. Der Prozeß wird eingeleitet durch eine gleichmäßige Verteilung der Nahrung in die Darmäste vom Kopfdarm aus, verbunden mit einer "Vorverdauung “ im Darmraum. Uber diesen letzteren Vorgang weiß man noch wenig; doch ist nachgewiesen, daß Fett im Darmlumen durch die Wirkung der von Darmdrüsen (Körnerkolben) ausgeschiedenen Säfte verändert und in einen Zustand übergeführt wird, der sich für direkten Übergang in die Zellen der Darmwand eignet (extrazelluläre Verdauung).

Die Hauptverdauung aber spielt sich, wie bei den meisten Strudelwürmern, innerhalb der Darmepithelzellen ab. Nach der Fütterung wird der Darmraum stark verengert, indem sich die Zellen verlängern und überall zwischen die Nahrungsteilchen einschieben. Sie nehmen die noch geformte Nahrung direkt auf. Man kann sie daher als Freßzellen oder Phagozyten, ihre Tätigkeit als Phagozytose bezeichnen.

Die Phagozyten bewegen sich wie Wechseltierchen (Amöben) und können gelegentlich miteinander verschmelzen. Die Aufnahme von Nahrungsteilchen erfolgt durch Aussendung von scheinfüßchen- 
artigen Fortsätzen. Nach der einen Auffassung wird ohne Wahl alles aufgenommen, was fein genug zerteilt ist. Richtiger dürfte die Ansicht sein, daß den Phagozyten ein Wahlvermögen zukommt. Sobald die Speiseteilchen in das Plasma der Freßzellen übergegangen sind, erscheinen daselbst Blasen (Vakuolen), deren Inhalt auflösende Wirkung hat. Nun erfolgt die Verdauung, die meist längere Zeit in Anspruch nimmt, bisweilen auch schon nach wenigen Stunden vollendet ist. Das Aufgelöste wird in flüssiger Form in das Parenchym abgegeben; das Unverdauliche kann noch eine Zeitlang in den Vakuolen bleiben und tritt dann ins Darmlumen zurück.

Die Entleerung des Kotes (Defäkation) erfolgt in größeren $Z$ wischenräumen. $Z u$ diesem $Z$ weck macht die Planarie einige Krampfbewegungen, die den ganzen Körper umfassen, der Darminhalt kommt in kräftige Bewegung. Man ist versucht, diesen Vorgang mit einer Ausspülung zu vergleichen. Nun tritt der Rüssel aus, und durch seine Mündung werden die Fäzes unter Krämpfen ausgestoßen. Aus der Schnelligkeit, mit der die Kotbestandteile ausgespritzt werden, kann man auf die große Energie schließen, die für die Defäkation aufgewendet wird.

\section{Nahrungspeicherung}

Bei wohlgenährten Individuen findet man aufgespeicherte Nahrungssubstanzen in den Darmzellen und im Parenchym. Die Phagozyten zeigen Reserve einschlüsse in Form von Eiweißkörnchen und Fettröpfchen; außerdem können auch Nahrungspartikel in halb- oder unverdautem Zustand gespeichert werden. Im Körpergewebe trifft man nicht selten ebenfalls Nahrungsbestandteile, besonders Fett. Somit haben wohl auch die Parenchymzellen die Fähigkeit, solche Stoffe zu phagozytieren und $\mathrm{zu}$ assimilieren.

\section{Spezielle Ernährungsformen}

Nur anhangsweise sollen hier einige Ernährungsarten erwähnt werden, die teils vorübergehend, teils dauernd bei einigen Spezies vorkommen. Sie dürften sich wahrscheinlich aus dem normalen Verhalten herausgebildet haben. 
Parasitismus

Ist das zu überwältigende Beutetier klein, so wird es völlig ausgesaugt und getötet, erreicht es aber eine gewisse Größe, so kann sich die Planarie an seinem Blute sättigen, ohne ihm den Tod zu bringen, sie wird also nach einiger Zeit von ihrem Opfer ablassen. Hier könnte man bereits von einem AuBenschmarotzer sprechen, da aber diese Ernährungsform niemals Regel wird, ist wohl der Ausdruck Gelegenheitsparasitismus am Platz. Bei marinen Tricladen scheint diese Art der Lebensweise nicht gerade selten zu sein, indem die vorzugsweise in grobem Sand lebenden Arten häufig Fische, die sich im Sand eingraben, anfallen und, falls ihre Haut nicht standhält, verletzen, ansaugen, ja sogar derart schwächen, daß der Tod eintritt. In einem Fall wurde ein junger Aal von etwa 30 Seetricladen der Gattung Procerodes angefallen. Die letzteren lösten sich später nicht los, sondern kapselten sich in eine Schleimhülle ein. Dieser Vorgang kann nach reichlicher Ernährung beobachtet werden.

Als wirklicher Außenschmarotzer ist unter den Tricladen einzig die auf Rochen lebende, wenig bekannte Micropharynx parasitica zu nennen. Eine sogenannte Planaria unionicola, die in der Mantelhöhle der Muschel Unio gefunden wurde, dürfte sich zufällig verirrt haben. Daß letzteres möglich ist, zeigt ein Fall, der kürzlich beobachtet wurde. Aus der Lunge eines frisch geschlachteten Molches wurde eine Süßwasserplanarie heraus präpariert, die sich als ein normales Exemplar von Polycelis nigra auswies.

\section{Commensalismus}

Als falsche Schmarotzer oder Commensalen müssen die an Limulus, dem Pfeilschwanzkrebs vorkommenden Tricladen der Familie der Bdellouriden aufgefaßt werden. Diese Formen sind so sehr an ihr Wirtstier angepaßt, daß sie sich, nachdem sie künstlich von Limulus entfernt worden sind, nur kurze Zeit in Zuchtbecken halten lassen, und, trotzdem sie Nahrung annehmen, eingehen. Ein feiner Geruchsinn ermöglicht die Auffindung des Limulus. Der Aufent- 
haltsort der Bdellouriden sind die Kieferfüße oder die Kiemenblätter des Krebses. Sie nähren sich jedoch niemals von ihrem Wirt, sondern nehmen lediglich an dessen Mahlzeiten teil, indem sie Abfälle der aus Fischen bestehenden Nahrung des Limulus fressen. Trotz dieser in keiner Weise parasitischen Ernährungsart, erweisen sich die Bdellouriden durch ihre Haftapparate, durch die Rückbildung ihrer Rhabditen, sowie durch das Fehlen der negativen Phototaxis als spezialisierte Formen, die sich vom Typus der freilebenden wesentlich entfernen.

\section{Hunger}

Das Hungervermögen ist bei den Tricladen ganz außerordentlich entwickelt. Zu verschiedenen Malen sind Planarien monatelang, ja bis zu einem Jahr in Zuchtgläsern gehalten worden, ohne daß ihnen während dieser langen Zeit irgendwelche Nahrung zur Verfügung stand. Selbst in destilliertem Wasser lassen sich die Hungerkulturen bei genügender Durchlüftung wochenlang halten. Die Planarien bleiben dabei nicht nur am Leben, sondern zeigen selbst nach Monaten noch große Beweglichkeit und ausgesprochene Fähigkeit, auf Reize $z u$ reagieren. Sogar eben ausgeschlüpfte Junge, die noch keine Nahrung zu sich genommen haben, halten monatelanges Hungern aus.

Trotzdem hat der Hunger mannigfache Degenerationserscheinungen zur Folge. Es nimmt die Körpergröße bedeutend $a b$, so daß ein hungerndes Tier nach 3 Vierteljahren kaum mehr ein Viertel seiner ursprünglichen Länge besitzt.

Für Planaria alpina stellt Stoppenbrink diese Größenabnahme durch Hungerwirkung übersichtlich zusammen:

\begin{tabular}{|c|c|c|c|c|c|c|c|c|}
\hline \multirow{3}{*}{ Datum } & \multicolumn{4}{|c|}{ Gefütterte Gruppe } & \multicolumn{4}{|c|}{ Hungernde Gruppe } \\
\hline & \multicolumn{2}{|c|}{ GröBtes Tier } & \multicolumn{2}{|c|}{ Kleinstes Tier } & \multicolumn{2}{|c|}{ GröBtes Tier } & \multicolumn{2}{|c|}{ Kleinstes Tier } \\
\hline & Länge & Breite & Länge & Breite & Länge & Breite & Länge & Breite \\
\hline & \multicolumn{2}{|c|}{$\mathrm{mm}$} & \multicolumn{2}{|c|}{$\mathrm{mm}$} & \multicolumn{2}{|c|}{$\mathrm{mm}$} & \multicolumn{2}{|c|}{$\mathrm{mm}$} \\
\hline 6. März 1903 & 13 & & 10 & $: 1$ & 13 & : 2 & 10 & 1 \\
\hline 15. Juni 1903 & 17 & 2,5 & 12 & : $11 / 3$ & 10 & $: 11 / 3$ & 6 & $2 / 3$ \\
\hline 15. September 1903 & 17 & 2,5 & 13 & : 2 & & $: 1$ & 4 & $1 / 2$ \\
\hline 15. Dezember 1903 & $17:$ & 2,5 & 14 & $: 2$ & $3^{1 / 2}:$ & : $1 / 2$ & $21 / 2$ & $1 / 3$ \\
\hline
\end{tabular}


Weitere äußerlich erkennbare Hungerdegenerationszeichen sind allmählicher Schwund des Pigmentes, Auftreten weißlicher Flecke, Kleinerwerden der Augen, die bei einzelnen Arten zunächst geteilt werden und sich dann in feinste Pünktchen auflösen. Bei Polycladodes hält umgekehrt die Reduktion des Augenpigmentes mit der durch Hunger bedingten Verringerung der Körpergröße nicht Schritt, so daß gerade Hungerexemplare relativ große Augen besitzen.

Hand in Hand mit der äußern Rückbildung geht eine Degeneration der innern Organe. In erster Linie wird an den legefertigen Kokons gespart, die immer kleiner werden und eine immer kleinere Zahl von Embryonen enthalten. Dann hört die Kokonablage überhaupt auf.

Nun beginnen die Dotterstöcke zu schwinden, es zerfließen die Kerne der Dotterzellen, die Dotterkugeln wandern in die umgebenden Gewebe und werden resorbiert. Sind diese Stoffe aufgebraucht, so werden der Penis, die Penisscheide und die andern Teile des männlichen Kopulationsapparates angegriffen. Die Muskeln zerfallen, indem zunächst die Fasern, später die Myoblasten zugrunde gehen. Epithelien, Muskeln, Drüsen, alles wird verflüssigt und aufgezehrt, so daß nach einiger Zeit vom ganzen komplizierten Begattungsapparat nichts mehr übrig ist.

Endlich werden auch die Hoden und Ovarien desorganisiert. In den Geweben eines ausgehungerten Individuums sind überhaupt keine Sexualorgane mehr $\mathrm{zu}$ finden. Interessant ist die Reihenfolge der schwindenden Organe, indem diejenigen zuerst degenerieren, die zuletzt ausgebildet worden waren. Es ist das eine Bestätigung des Satzes, nach welchem die entbehrlichen und weniger wichtigen Organe zuerst und am stärksten angegriffen, und die entnommenen Substanzen als Nährmittel für die wichtigeren Organe verwandt werden. Damit stimmt auch überein, daß die Hungerdegeneration nach und nach alle übrigen Organe erfaßt, den Darm, das Parenchym, das Exkretionssystem, die Hautmuskeln und die Körperepithelzellen. Nur das für den Nahrungserwerb in erster Linie wichtige Nervensystem hält sehr lange stand und ist 
die Ursache der unproportionierten Form einer Hungerplanarie, deren Kopf im Vergleich zum Rumpf viel zu groß ist.

Eben dadurch erhalten Hungerindividuen eine große Ahnlichkeit mit jungen Exemplaren. Beide wachsen bei normaler Fütterung rasch und bilden nach und nach die Geschlechtsorgane, nachdem sie eine bestimmte Größe erreicht haben.

Sehr auffällig ist die Tatsache, daß stark ausgehungerte Planarien noch ein großes Regenerationsvermögen besitzen, auch wenn man ihnen während der Regenerationszeit nichts zu fressen gibt. Selbst das scheinbar ganz reduzierte Gewebe kann sich noch mehr zurück-, resp. umdifferenzieren.

Übrigens ist die Wirkung, die ein umfangreicher Regenerationsprozeß auf die Gewebe ausübt, dem Hungereinfluß durchaus gleich. Man kann also durch Einleitung eines Regenerationsgeschehens die Gewebe in typischen Hungerzustand versetzen.

\section{Exkretion}

Bald nach der Nahrungsaufnahme setzt die Exkretion in verstärktem Maße ein, die wahrscheinlich ununterbrochen vor sich geht und nur insofern von der Verdauung abhängig ist, als durch letztere die Menge der Exkretionsprodukte gesteigert wird.

Der Prozeß ist physiologisch wenig bekannt. Er besteht im Wesentlichen darin, daß die im Mesenchymgewebe vorhandenen Exkretionsstoffe sich in den Wimpertrichtern ansammeln, von den schlagenden Wimperflammen in die Exkretionskapillaren und von dort in die Hauptstämme getrieben werden, wo sie sich sammeln, um durch den nächsten Exkretionsporus nach außen entleert zu werden. Bei Seetricladen beobachtete Wilhelmi nach reichlicher Fütterung zahlreicher Exemplare in relativ kleinem Zuchtgefäß, daß das Wasser einen scharf säuerlichen Geruch bekam, und daß die Würmer in Menge den Versuch machten, die Glaswand empor aus dem Wasser herauszuklettern. Als Ursache dieser Erscheinungen dürften die Exkretionsprodukte der vielen Planarien in Betracht kommen. Ahnliches kann man auch bei übermäßig er- 


\section{$-99$}

höhter Temperatur im Zuchtglas beobachten. Vielleicht darf man daraus schließen, daB durch Wärme der ExkretionsprozeB beschleunigt und verstärkt wird.

\section{Geschlechtliche Fortpflanzung durch Eikapseln}

\section{Begattung}

Alle Wasserplanarien und auch die Terricolen pflanzen sich durch Eikapseln fort. Der Kokonablage geht eine Begattung voran. Sie ist bei den Land- und Süßwassertricladen wechselseitig, indem jeder Partner zugleich
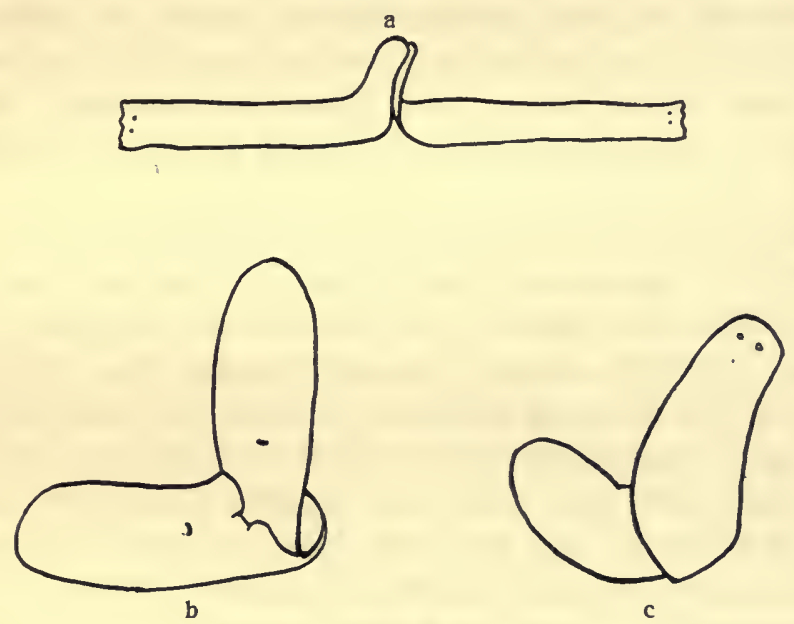

Abb. 52.

Kopulationsteilung a von Dendrocoelum lacteum. b Planarla lugubris. c Planaria polychroa. Nach Burr.

aktiv und passiv ist. Da der Penis jedes der beiden Kopulanten in die Geschlechtsöffnung des andern eingeführt werden muß, liegt dieses Organ bisweilen asymmetrisch, etwas nach der Seite verschoben. Wo dies nicht der Fall ist, wird entweder die Begattungsstellung so gewählt, daß sich die beiden Kopulationsorgane gegenseitig nicht hindern, indem die Kopulanten miteinander einen rechten Winkel (Abb. 52, b) bilden, oder die Penes winden sich umeinander. Ihre Spitze ragt in die Mündung des gestielten Drüsensackes. 
Der gewöhnlichste, bei Dendrocoelum lacteum (Abb. 52, a), Planaria lugubris, Planaria polychroa, Planaria gonocephala und Procerodes dohrni beobachtete Kopulationsmodus ist der folgende: Die beiden Tiere sitzen mit abgewandten Vorderenden auf einer Fläche beisammen und pressen die rechtwinklig emporgerichteten Schwänze fest aneinander. In dieser Stellung verharren sie kürzere oder längere Zeit $\left(1 / 2\right.$ Minute bis $1 \frac{1}{2}$ Stunde). Das Sperma tritt durch den eingeführten Penis in den Stiel und von dort ins Lumen des Drüsensackes (Receptaculum seminis). Nachdem sich die Tiere getrennt haben, scheint das Sperma bald wieder in das Geschlechtsatrium zurückzuwandern und von dort die Eileiter hinauf bis $z u$ den Tuben $z u$ gelangen. Die Eier werden somit gleich nach ihrem Austritt aus dem Ovarium befruchtet.

Was die näheren Umstände und Vorbedingungen der Begattung anbelangt, so scheinen sich verschiedene Arten ziemlich verschieden $z u$ verhalten. Über die Zeit, die zwischen der Begattung und der Eiablage verstreicht, liegen fast keine Angaben vor. Eine Kopulation soll für 2 bis 3 Eikapseln ausreichen. Die Kopulanten brauchen durchaus nicht gleiche Größe und Färbung zu zeigen. Nicht selten findet man sogar sehr ungleiche Paare. Vor der Vereinigung benehmen sich die Tiere aufgeregt, sie kriechen lebhaft übereinander hin, indem sie das Kopfende wie beim Beutefange tastend bewegen. Dabei sieht man gelegentlich auf kurze Zeit den Penis austreten. Eines der Individuen scheint aktiver $z u$ sein als das andere, sucht dessen Bauchseite zu gewinnen und sich anzupressen. Dabei spielen zur Befestigung der Tiere aneinander und an der Unterlage die Haftzellen und Haftpapillen eine wichtige Rolle, wie auch der während der Begattung reichlich abgesonderte Schleim. Die Kopulationen können sich in kurzer Zeit mehrmals wiederholen. Der Trieb zur Begattung ist stärker als die Phototaxis. Wenigstens scheint das Licht die Würmer nicht von der Begattung abzuhalten.

Selbstbefruchtung ist bei den Tricladen nicht mit Sicherheit nachgewiesen worden. Eine bei den Maricolen Procerodes 
dohrni beobachtete, eigentümliche Einkrümmung des Hinterendes (Abb. 53) wird von Wilhelmi als Selbstbefruchtungsstellung gedeutet. Dem gleichen Forscher gelang es, ein Exemplar dieser Art, dessen Hinterende mit dem ganzen Kopulationsapparat abgeschnitten worden war, und das man hierauf 16 Wochen lang ganz isoliert gehalten hatte, nach erfolgter Regeneration zur Eikapselablage zu bringen. Es ist nicht anzunehmen, daß

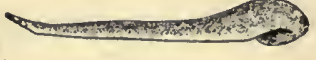

Abb. 53.

Selbstbegaitungsstellung von Procerodes lobata nadi Wilhelmi. sich in diesem Individuum noch Sperma einer vor der Operation stattgehabten Begattung vorfand, daher ist hier Selbstbefruchtung in hohem Grade wahrscheinlich.

Ein sehr merkwürdiger Begattungsmodus besteht darin, daß der Penis des einen Tieres sich an irgendeiner Stelle in den Körper des Partners einbohrt, und daß das Sperma klumpenweise direkt ins Körpergewebe abgegeben wird. Die Spermatozoen gelangen von dort durch die Parenchymlücken in die Eileiter. Diese von Lang bei den Polycladen beobachtete Erscheinung konnte für die Seetricladen bestätigt werden. Die in Frage kommenden Arten weisen einen harten, chitinbewaffneten Penis auf, der zum Durchdringen der Haut geeignet ist.

Eikapselbildung

Eier und Dotterzellen durch die Eileiter gelangen. Das Durchwandern dieses Ganges geschieht entweder aktiv, indem die Dotterzellen amöbenartige Bewegungen machen oder passiv durch Kontraktionsbewegungen, des Eileiters. Nachdem eine genügende Menge Eier und Dotter beisammen ist, setzt die Schalenbildung ein. Die Schalendrüsen, die im unpaaren Teil des Eileiters und im Gang des gestielten Drüsensackes gelegen sind, beginnen, vielleicht durch den Druck der Ei- und Dottermassen veranlaßt, mit der Sekretion eines homogenen Stoffes. Unterdessen sind aus den Dotterzellen kleine Kügelchen oder Tröpfchen ausgetreten, die nach der Oberfläche der zukünftigen Kapsel ge- 
langen und von der Grundsubstanz aufgenommen werden. Sie ordnen sich hier in der Weise an, daß die größern nach außen,

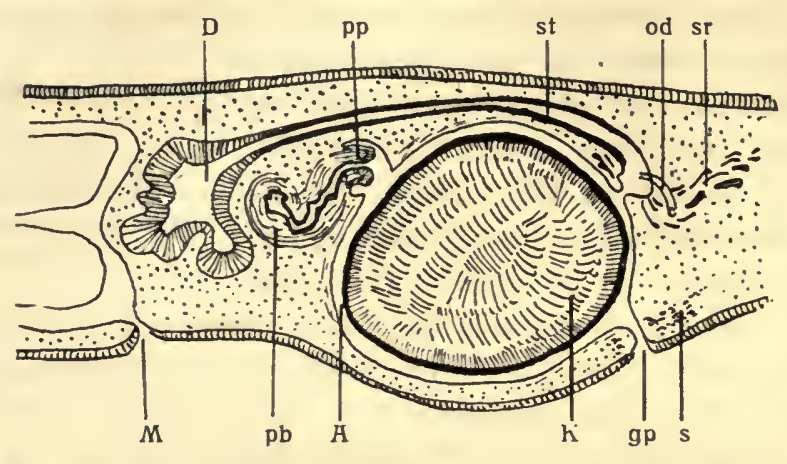

Abb. 54.

Längsschnitt durch Planarla polychroa mit Eikapsel nach Burr.

D Drüsensad, pp Penispapille, st Stiel des Drüsensadkes, od Ovidukt, sr Schalendrüsen, s Drüsen, gp Genitalporus, für die Anheftung der Kapseln, K Eikapsel, A Atrium, $\mathrm{pb}$ Penis bulbus, $M$ Eingang in die Rüsselhöhle.

die kleinern nach innen zu liegen kommen. Nun setzt ein Prozeß ein, der am besten als Auflösung der Schalenkügelchen durch die
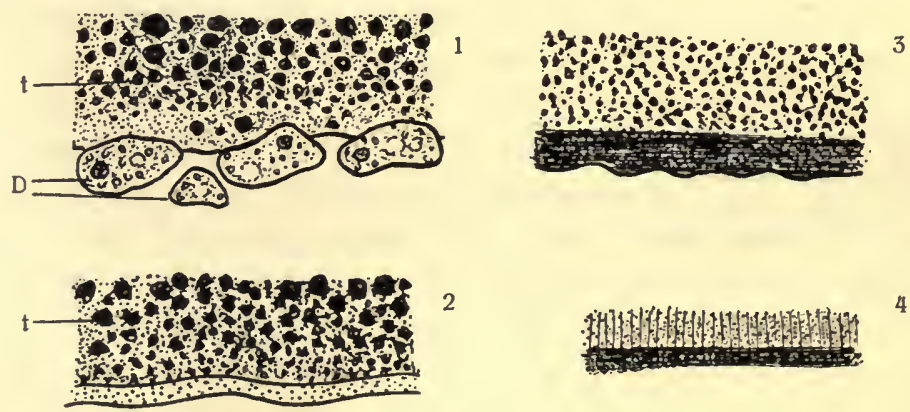

4

Abb. 55.

Querschnitte durch dle in Bildung begriffenen Eiskapselschalen von Dendrocoleum lacteum $(1,2)$. 3 dasselbe von Planaria gonocephala. 4 definitives Aussehen der Kapselschale von Planaria gonocephala. Nach Burr.

t Schalentröpfen, D Dotterzellen.

hyaline Schalensubstanz aufgefaßt wird. Die anfangs grobkörnige Masse der Schale wird innen allmählich hell und homogen, 
während sie außen dunkel und porös erscheint. Die fertige Kapselschale ist somit zweischichtig. Sie ist gegen Austrocknung ziemlich widerstandfähig. Ihre Farbe ist im Moment der Ablage ein helles Gelb, verwandelt sich aber nach wenigen Stunden in ein dunkles Braun oder Schwarz, die Zwischenstadien sind orange, rot oder rotbraun.

Während Planaria alpina und Polycelis cornuta ihre Kapseln frei ins Wasser ablegen, wo sich dieselben in Ritzen und Spalten des Untergrundes verlieren und daher sehr schwer zu finden sind, pflegen die übrigen Arten sorgfältiger vorzugehen, indem sie die Kokons an Blättern und Steinen befestigen. Ihre Lichtscheu hat zur Folge, daß die Ablage stets an dunklen, geschützten Orten erfolgt. Zur Anheftung dient ein weißlicher Schleim, der im Wasser erstarrt. Bei einigen Arten (z. B. auch bei Planaria lugubris, Abb. 56) hängen die Eikapseln durch einen dünnen Stiel mit der Unterlage zusammen. Die Substanz für dieses Gebilde wird von der Geschlechtsöffnung selbst geliefert, d. h. von Drüsen, die in der Umgebung des Genitalporus im Körpergewebe liegen, und deren Sekret sich in die Offnung ergießt. Der Stiel besteht somit nicht aus Schalensubstanz, er ist ein Gebilde für sich, das mit der Kapsel verkittet wird. Nach Burr soll dem Stiel keine Klebkraft zukommen. Er wird mit Hilfe einer zähen klebrigen Masse festgeheftet. Dieses Klebsekret dürfte dem Schleim entsprechen, der andern Arten zur Anheftung ihrer ungestielten Kapseln dient. Als Bildungsstätten kommen kolbige Drüsenzellen rings um die Geschlechtsöffnung in Betracht.

Das weitere Schicksal der Eikapseln wird im Abschnitt über die Entwicklung besprochen. Das Bemerkenswerteste an ihrer Bildung scheint die doppelte Herkunft der Kapselschale zu sein, die einerseits von den Schalendrüsen, andererseits von den Dotterzellen stammt. DaB diese letzteren auch bei andern Platoden- 
gruppen mit der Eischalenbildung in Beziehung stehen, ist schon wiederholt nachgewiesen worden. So entstehen die Schalen der Saugwürmereier aus kleinen Tröpfchen, die sich in den Dotterzellen bilden. Während aber nach der Ansicht einiger Trematodenkenner die Dotterzellen bei dieser Gruppe keine andere Bedeutung als die der Schalenbildung haben, kann davon bei den Planarien nicht die Rede sein. Die wichtige Rolle, welche diesen Elementen beim Heranwachsen der Embryonen in der Eikapsel zukommt, soll später gewürdigt werden.

\section{Zeit der Kapselablage}

Uber die Zeit der Kokonablage liegen nicht sehr viele zuverlässige Meldungen vor. - Wir haben im Abschnitt über Hungererscheinungen bereits erfahren, daß der Geschlechtsapparat von allen Organen am spätesten entwickelt wird, und daß ein bestimmtes Alter Voraussetzung für den Eintritt der Geschlechtsreife ist. Außerdem haben wir vernommen, daß als weitere Vorbedingung die Ernährung in Betracht kommt, indem hungernde Exemplare keine Geschlechtsorgane ausbilden, ja sogar etwa bereits vorhandene wieder zurückbilden.

Als weiteren bedingenden, fördernden oder hemmenden Faktor der Geschlechtsdifferenzierung haben wir jetzt die Temperatur kennen zu lernen.

Man hat die Planarienarten nach dem geschlechtlichen Verhalten im Lauf des Jahres einzuteilen in

1. Formen mit andauernder, ununterbrochener Sexualität,

2. $n n$ unterbrochener Sexualität.

Letztere zerfallen wieder in

a) Arten, die im Sommer die Geschlechtsorgane zurückbilden (Winterlaicher).

b) Arten, die im Winter die Geschlechtsorgane zurüdkbilden (Sommerlaicher).

So klar nun diese Einteilung scheinen mag, und so gut sie sich mit dem Verhalten der Planarien in manchen Gegenden ver- 
tragen wird, so ist doch $\mathrm{zu}$ betonen, daß die Planarien sich nicht an die Jahreszeiten, sondern lediglich an die Temperatur halten.

So darf es nicht verwundern, wenn der Winterlaicher Planaria alpina in sehr gleichmäßig temperierten Quellen ununterbrochen geschlechtlich differenziert, bleibt, wenn umgekehrt eine gewöhnlich während des ganzen Jahres Kokons produzierende Art wie Dendrocoelum lacteum in den Laboratoriumsaquarien während der hier warmen Wintermonate erhöhte Geschlechtlichkeit zeigt, dafür aber im Sommer die Geschlechtsorgane, vielleicht aus Erschöpfung, zurückbildet.

Stoppenbrink hat die Zahl der in seinen Laboratoriumskulturen abgelegten Kokons für mehrere Arten zusammengestellt. Er findet, daß Polycelis cornuta ununterbrochen geschlechtsreif bleibt, während Planaria alpina und noch viel deutlicher Dendrocoelum lacteum im Sommer die Kokonablage einstellt. $\mathrm{Zu}$ diesen Winterlaichern steht im schroffen Gegensatz der Sommerlaicher Planaria gonocephala, dessen Kokonablage nur vom Mai bis September dauert. Seine Befunde stehen teilweise zu denen des Verfassers in direktem Gegensatz:

Bdellocephala punctata konnte nur in den kälteren Monaten Dezember, Januar und April nachgewiesen werden, dann aber jeweils in voller geschlechtlicher Differenzierung zusammen mit frisch abgelegten Kokons. Sie soll während des Sommers in den tieferen Schlammschichten eine Art Sommerschlaf abhalten und nur im Winter zum Vorschein kommen, um sich fortzupflanzen.

Planaria alpina findet man vom Oktober bis zum Mai häufig geschlechtsreif, in kalten Quellen dagegen und im gesamten Alpengebiet scheint sie ihre Geschlechtlichkeit gar nicht zu unterbrechen.

Dendrocoelum lacteum kann z. B. im Rhein bei Basel jahraus jahrein in Fortpflanzung angetroffen werden.

Planaria lugubris und Planaria gonocephala scheinen dagegen im Sommer oder Frühling fruchtbarer zu sein als während der kältesten Zeit, wenn auch die Fortpflanzung niemals ganz ruht. 
Weniger lückenlos sind die Beobachtungen, die über die Kokonablage der andern Arten vorliegen. Im ganzen ergibt sich, daß die Verhältnisse von Ort zu Ort wechseln, daß eine scharfe Einteilung nicht möglich ist, indem eben die speziellen Temperaturbedingungen jedes einzelnen Wohngewässers und nicht unmittelbar der allgemeine Jahreszeitenwechsel maßgebend sind.

Sehr wahrscheinlich ist es ferner, daß nicht einmal die Temperatur direkt die sexuelle Differenzierung bedingt, sondern auch sie wirkt nur mittelbar, indem sie den Stoffwechsel und die Lebenstätigkeit fördernd oder hemmend beeinflußt. $\mathrm{DaB}$ sich in dieser Hinsicht die einzelnen Arten ganz verschieden verhalten, ist schon in einem früheren Abschnitt betont worden. Wir dürfen daher im allgemeinen sagen, daß die eurythermen Formen durch Temperaturwirkung in ihrer Sexualität wenig beeinflußt werden, und somit im allgemeinen während des ganzen Jahres geschlechtsreif bleiben. Unter den Stenothermen werden die Kältetiere durch Wärme ungünstig beeinflußt, werden also im ganzen Winterlaicher sein, während umgekehrt die stenothermen Wärmeformen ihre Fortpflanzungszeit auf den Sommer verlegen.

Mit diesen theoretischen Ableitungen stimmen die spärlichen, statistischer Behandlung noch nicht zugänglichen Daten recht gut überein.

Uber die Laichzeit mariner Tricladen ist wenig positives bekannt. Sie scheinen im großen und ganzen sich wenig an den Jahreszeitenwechsel zu kehren. Dies entspricht ihrem eurythermen Verhalten.

Noch wählerischer als in der Zeit sind die Süßwasserplanarien im Ort der Eiablage. Man trifft daher die Eikapseln stets nur unter Steinen, Blättern, in Spalten oder sonstwie an dunklen geschützten Orten. Damit stimmt die Tatsache, daß bis jetzt eine Kokonablage bei Tag in belichteten Zuchtaquarien noch niemals beobachtet worden ist, daB dagegen in verdunkelten Gläsern die Kapseln zu jeder Tageszeit abgegeben werden. 
Autotomie und ungeschlechtliche Fortpflanzung durch Querteilung

Wer in einem kleinen Gefäß eine Anzahl Planarien bei höherer Temperatur transportiert, wird sich häufig wundern, daB er, zu Hause angekommen, in seinem Glas halbe Würmer oder aber nur noch Schleimfetzen findet. Gelingt es ihm, die Planarien in gesundem Zustand in ein Glas zu setzen, und läßt er sie dann längere Zeit stehen, so daß das Wasser anfängt faulig zu werden, so kann er gewöhnlich die gleichen Beobachtungen madhen. Manchmal wird man auch in ganz gesunden Kolonien einzelne Fälle von Querteilung konstatieren können und endlich gibt sich nicht selten die Gelegenheit, in der freien Natur ganze Teilungsepidemien nachzuweisen.

Bevor wir zur Schilderung der Autotomie übergehen, wollen wir kurz die Vorgänge beschreiben, die sich abspielen, wenn etwa Planaria alpina oder Planaria gonocephala infolge zu hoher Temperatur oder anderer Faktoren allmählich zugrunde geht.

Wir setzen in eine Schale einige Planarien und lassen das direkte Sonnenlicht darauffallen. Zunächst werden die Tiere unruhig kriechen, den Kopf nach allen Seiten wenden, den Versuch machen, mit der Bauchseite nach oben an die Oberfläche des Wassers zu gelangen. Dann treten Krämpfe ein, die Planarien krümmen sich rinnenartig ein, schlagen mit dem Schwanzteil auf und nieder, strecken sich lang aus und ziehen sich dann wieder zusammen. Während dieser Bewegungen tritt am ganzen Körper reichlich Schleim aus. Die Krämpfe werden heftiger; oft findet man das Vorderende lang ausgestreckt und das Hinterende kontrahiert oder umgekehrt. Nun entsteht auf der Rückenfläche, in der Rüsselgegend ein Riß, durch den weißes Körpergewebe austritt, sehr häufig drängt sich auch der Rüssel durch diese Wunde und trennt sich ganz von der Planarie los. Die Krämpfe hören auf, die Wunde klafft immer weiter und bald wird der ganze Körper gallertartig. Ein schwaches Schütteln und das ganze löst sich zu einem schleimigen Brei auf - die Tiere sind tot. 
Ganz ähnlich verläuft nun bei mehreren Planarienarten anfangs die Autotomie. Wir wollen Planaria gonocephala als Paradigma wählen (Abb. 57).

Wenn sich die dreieckköpfige Planaria zur Selbstteilung anschickt, so hört sie zu kriechen auf. Sie kauert zusammengezogen an einer dunklen Stelle des Gefäßes und sondert reichlich Schleim ab.

Dann treten Krampfzustände ein mit abwechselnder Streckung und Zusammenziehung, es erscheint ein dunkler Pigmentfleck in

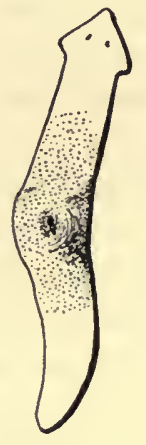

a

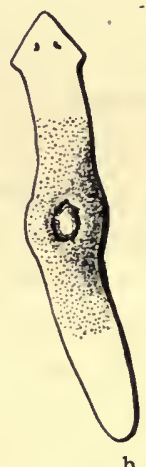

Abb. 57.

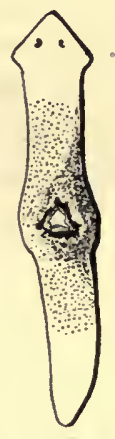

c

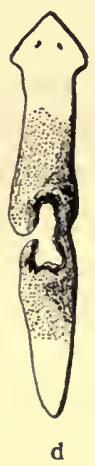

d

Selbstteilung von Planaria gonocephala. a Beginn. b nach 4 Stunden. c nach 7 Stunden. d nach 9 Stunden.

der Mitte der Rückenfläche, der sich bald in einen Riß oder in ein rundliches Loch verwandelt. Indes scheint der Wurm unter seinem Zustand nicht stark zu leiden, er beginnt sogar gewöhnlich wieder zu kriechen. Dabei kann man deutlich beobachten, daß der Körper in der Gegend des Loches kontrahiert und daher relativ breit ist. Aus der Offnung tritt weißer Schleim und gewöhnlich auch der Rüssel, der in der Regel abgeschnürt wird. Um die Rückenwunde herum erscheint bald ein ganz dunkler Ring. Die zerrissenen Hautmuskeln krampfen sich zusammen und wahrscheinlich wandert auch das Pigment nach dem 
Wundrand. Inzwischen wird das Loch immer größer, die Selbst. teilungszone krampft sich immer mehr zusammen und schließlich reißt erst der eine, dann der andere Wundrand nach den Seiten aus. Das Hinterende löst sich ganz los und setzt nun kopflos seinen Weg auf eigne Rechnung fort. Die Dauer des ganzen Prozesses kann bei Planaria gonocephala sehr verschieden sein. Meist verfließen bis zur vollen Loslösung des Schwanzteiles Stunden, in andern Fällen genügen einige Minuten. Mehrmals konnte die Beendigung der Autotomie erst nach einigen Tagen konstatiert werden.

Der WiederergänzungsprozeB spielt sich genau so $a b$, wie bei der künstlichen Querteilung, eine „vorzeitige " Regeneration vor der Querteilung läßt sich bei unserer Art in keiner Weise beobachten.

Das Vorderende zieht sich nach vollbrachter Spaltung mehrmals heftig zusammen, wie man das auch bei künstlicher Durchtrennung beobachtet, bald aber kriecht es ruhig weiter, sucht einen dunklen Platz und pflegt der Ruhe. Schon nach wenigen Tagen hat sich eine deutliche, weiße Regenerationsknospe und ein kleiner Rüssel gebildet, der sich an der Grenze zwischen altem und neuem Gewebe befindet. Das Hinterende bewegt sich viel langsamer oft ruckweise und ohne jede Orientierung im Gefäß herum, es setzt sich irgendwo zur Ruhe. Nicht selten beschreibt es eine kreisförmige Bahn. Dies geschieht, wenn der Querriß nicht genau wagrecht verlief. Solche schief abgestutzte Hinterenden beschreiben um so kleinere Kreise, je schneller sie sich bewegen. Schließlich geht ihre Bahn bei ständig abnehmender Bewegungsgeschwindigkeit in Spiralenform über, dann tritt völlige Ruhe ein. Normalerweise bleiben die Tierchen dann tagelang ruhig, bis die Regeneration tüchtig eingesetzt hat, und bis wieder Augenpunkte am Regenerat auftreten.

In zahlreichen Fällen wird die bereits begonnene Querteilung nachträglich wieder rückgängig gemacht. Die Rißwunde schließt sich und vernarbt, der ausgestoßene Rüssel wird neu gebildet. 
Bei anderen Tricladen geht der Prozeß in etwas anderer Weise vor sich. Planaria alpina z. B. teilt sich selten genau an der gleichen Stelle wie PI. gonocephala. Manchmal liegt
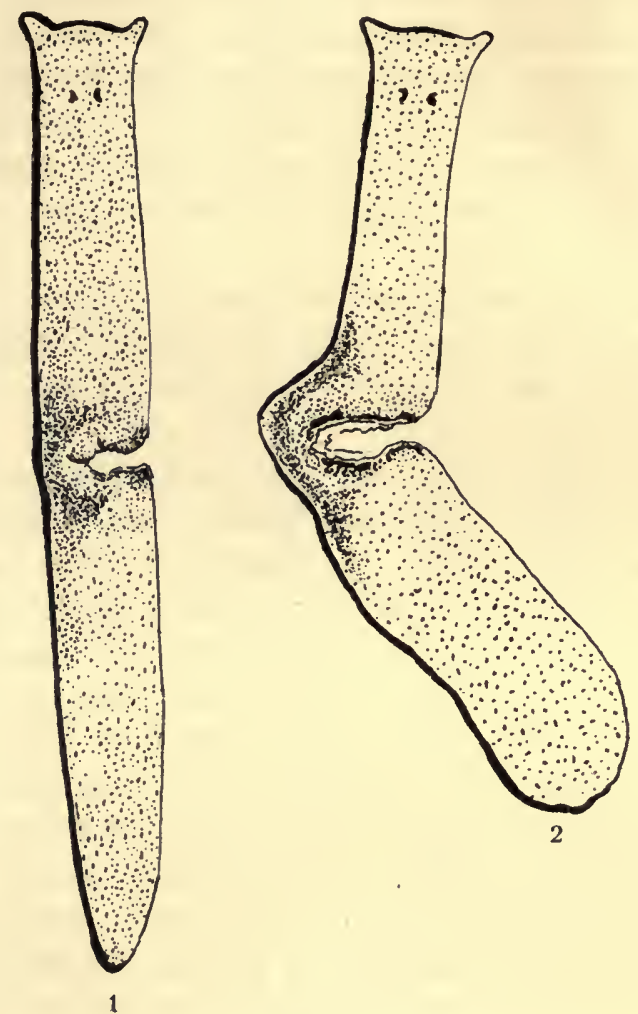

Abb. 58.

Hutotomie von Planaria alpina präpharyngeal mit seltllchem Beginn. (Nach dem Leben gezelchnet.)

1. Früheres Stadium.

2. Späteres Stadium.

hier die Fissionsebene vor dem Rüssel, so daß das hintere Stück dieses wichtige Organ behält, in anderen Fällen schnüren sich die Würmer hinter dem Rüssel durch. Bei der Fission der Planaria alpina (Abb. 58) und ihrer nächsten Verwandten Planaria 
teratophila beginnt die Einschnürung an einem der Seitenränder und die Lochbildung der Mitte unterbleibt. Der Prozeß dauert nie so lange wie bei Pl. gonocephala. Man trifft relativ häufig Exemplare mit vernarbten seitlichen Einrissen, die wahrscheinlich auf frühere Teilungsvorgänge mit nachträglicher Unterdrückung zurückzuführen sind.

Auch Polycelis cornuta teilt sich vor und hinter dem Rüssel. In einem Fall konnte ich Platzen der Rückenwand und Austreten des Rüssels konstatieren. Die Selbstteilung bei Polycelis cornuta dürfte daher ähnlich vor sich gehen wie bei Planaria gonocephala. Die Teilungsebene scheint jedoch bisweilen auch sehr weit hinten zu liegen, wie aus der Figur 59 hervorgeht.

Demnach ist die Autotomie bei den Planarien eine verbreitete Erscheinung. In dieser Ansicht wird man bestärkt, wenn man in der freien Natur $z u$ verschiedenen Jahreszeiten Planarien sammelt. Teilungsstadien und regenerierende Spalthälften habe idh bei folgenden einheimischen Planarien gefunden: Bdellocephala punctata, Polycladodes alba, planaria alpina, Planaria gonocephala, Planaria vitta, Planaria lugubris, Polycelis cornuta.

Bei anderen Formen ist das Vorkommen der Autotomie mehr oder weniger zweifelhaft. Dagegen darf bestimmt behauptet werden, daß das Fissionsvermögen bei Dendrocoelum lacteum und bei den marinen Tricladen fehlt. Zufällig anzutreffende Regeneranten dieser Spezies haben die fehlenden partien durch Verletzungen, nicht aber durch Autotomie eingebüBt. Bemerkenswert ist die Korrelation, welche zwischen Fissionsfähigkeit und Regenerationsvermögen besteht. Autotomierende Tricladen regenerieren nämlich viel prompter als selbstteilungsunfähige.

Fragen wir nach der Bedeutung der Autotomie, so müssen, da die Meinungen über diesen Punkt sehr geteilt sind, zunächst einige Vorfragen erledigt werden. 

ein?

1. Unter welchen Umständen tritt die Selbstteilung

Es scheint, als ob zur Lösung dieser Frage das Experiment das geeignete Forschungsmittel sein müsse, und doch sind die
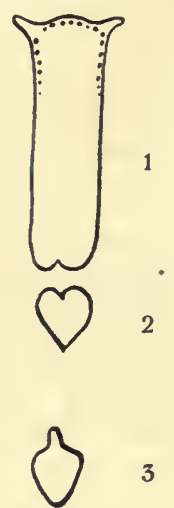

Abb. 59.

Polycelis cornuta in ungeschl. Fortpflanzung nach Volz.

Teilungsebene postpharyngeal. 1 vorderes, 2 hinteres Teilstück, 3 dasselbe, nachdem die Regeneration eingesetzt hat. auf diesem Wege erzielten Resultate keineswegs unzweideutig.

Planaria alpina kann gelegentlich in überhitzten Tümpeln und Gräben der Hochalpen in Teilung angetroffen werden, sie teilt sich häufig in Transportgefäßen, in denen die Temperatur stark steigt. Das gleiche gilt für Planaria gonocephala und Polycel is cornuta. Für die erstere scheint weniger die hohe Temperatur als vielmehr der Sauerstoffmangel ausschlaggebend $z u$ sein. Pla naria alpin a reagiert hauptsächlich auf raschen Temperaturwechsel durch Querteilung. Sie teilt sich auch nach plötzlicher Abkühlung des Wassers. In allen Fällen wirkt reichliche $\mathrm{Er}$ nährung fördernd. Hungernde Exemplare, die bereits deutliche Organrückbildungen zeigen, scheinen die Fähigkeit, zu autotomieren, verloren $z u$ haben. Bei alledem muß betont werden, daß es nicht möglich ist, jedes Individuum durch entsprechende Versuchsbedingungen zur Autotomie zu zwingen. Höchstens kann man eine Art Teilungsepidemie heraufbeschwören. Bei Planaria gonocephala gelingt das noch am ehesten. So konnten von 15 großen Exemplaren, die in engem Versuchsgefäße ohne Wasserwechsel 6 Tage belassen wurden, 10 zur Fission gebracht werden.

Auffälligerweise scheinen sich Planarien der gleichen Spezies in verschiedenen Gegenden ungleich $z u$ verhalten, indem Voigt und Stoppenbrink in Aquarien nur sehr selten, Zacharias im Riesengebirge niemals Autotomie bei Planaria alpina fest"stellen konnte. 
Einige Arten schreiten auch bei normalen Außenbedingungen regelmäßig zur Teilung, die besonders durch reichliche Ernährung gefördert wird. Hierher gehören Planaria vitta und die ausländischen Tricladen Planaria maculata und Planaria fissipara.

2. Wie spielt sich der Fissionsvorgang ab?

Bei verschiedenen Arten recht verschieden. Planaria alpina teilt sich (Abb. 58) rasch und unregelmäßig, oft findet ein förmliches Zerreißen statt. Die Reißfläche kann, wie wir gesehen haben, vor oder hinter dem Rüssel liegen und ist nicht selten mehr oder weniger schief. Oft autotomieren unfertige, noch in Regeneration begriffene Individuen neuerdings. Eine Wiederverheilung nach eingetretenem Teilungsprozeß kommt relativ häufig zur Beobachtung.

Polycelis cornuta (Abb. 59) weist ebenfalls keinen streng fixierten Teilungsmodus auf; doch findet die Autotomie stets prompte und glatte Erledigung. Schräge Teilungsflächen sind nicht beobachtet worden.

Bei Planaria gonocephala (Abb. 57) geht der Prozeß nicht sehr rasch vor sich. Die Wundränder haben Zeit, sich einzuziehen, so daß nach erfolgter Trennung die Teilstücke schnell vernarbende Trennungsflächen aufweisen.

Bei Planaria vitta ist dies Verhalten noch deutlicher $z u$ beobachten. Die Autotomie trifft hier nur gesunde, ausgewachsene Individuen. Die Dauer der Selbstteilung ist festgelegt, die Lage der Selbstteilungsebene fixiert, indem die Durchschnürung stets hinter dem Rüssel vor sich geht.

planaria fissipara endlich bildet vor der Durchschnürung die fehlenden Teile neu. Ahnliches ist für die unsichere Art planaria subtentaculata von $Z$ acharias beschrieben worden. Sofern dieses Tier, wie vermutet werden muB, mit Pl. gonocephala identisch ist, dürfte es sich um einen Zufallsfund handeln, wohl um eine unvollständige Teilung mit partieller Doppelbildung, indem ja bei dieser Form die Autotomie mehrfach beobachtet und beschrieben worden ist, ohne daß man jemals Anzeichen einer vorzeitigen Regeneration hätte nachweisen können.

Steinmann-Bresslau, Strudelwürmer.

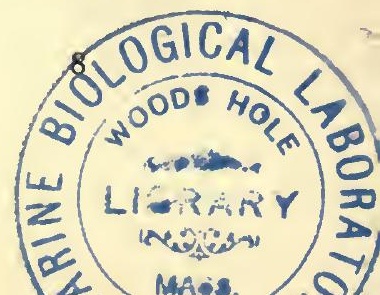


3. Welches sind die Folgen der Autotomie für die Teilstü cke?

Planaria alpina und zum Teil auch Polycelis cornuta geht an den Folgen der Querteilung häufig zugrunde.

Voigt gibt an, daß er in seinen Kulturen eines der beiden Teilstücke regelmäßig eingehen sah. Nicht selten sterben sogar beide Spalthälften; es bildet die Autotomie die Einleitung zur völligen Auflösung des Körpers.

Bei Polycelis cornuta scheint sich dieser Fall nur ganz ausnahmsweise $\mathrm{zu}$ ereignen. Die Teilstücke von Planaria gonocephala befinden sich in der Regel wohl; sie regenerieren bei günstigen Lebensverhältnissen fast immer anstandslos die ihnen fehlende Hälfte. Infolgedessen mag die Selbstteilung da und dort eine Vermehrung der Art zur Folge haben.

Die Fission von Planaria vitta (noch mehr von Planaria maculata und fissipara) endlich muB direkt als ein Fortpflanzungsmodus aufgefaßt werden, indem die Teilstücke vorzüglich gedeihen und in kurzer Zeit $z u$ normaler Größe heranwachsen. Diese Vermehrungsart kann schließlich die geschlechtliche Fortpflanzung mehr oder weniger zurückdrängen oder ersetzen.

Hus der Beantwortung unserer 3 Fragen ergibt sich, daß die Teilung für die verschiedenen Planarienarten eine ganz verschiedene Bedeutung hat:

Sie fehlt einigen Spezies völlig, bei andern tritt sie als Vorzeichen beginnenden Absterbens auf, als Reaktion auf ungünstige Bedingungen, wie extreme Temperaturen und eventuell Sauerstoffmangel.

Eine weitere Gruppe kann zeitweilig, jedoch nur bei besonderen Bedingungen eine zur Vermehrung führende Selbstteilung aufweisen, die aber sehr wahrscheinlich auch umgekehrt den Bestand schädigen kann.

Endlich können wir bei einzelnen Arten direkt von Fissiparität oder Teilungsfortpflanzung sprechen, indem sich die Spezies 
das ganze Jahr hindurch mittelst Selbstteilung vermehrt oder höchstens eine kurze Sexualperiode zwischen langdauernde Fissionszeiten einschiebt.

\section{Regeneration}

Die Planarien sind überaus dankbare Objekte der Regenerationsforschung. Eine Reihe fundamentaler Fragen konnten an ihnen geprüft und der Lösung nähergebracht werden, so daß die gewonnenen Resultate über das Gebiet der Tricladenkunde hinaus allgemeinste Beachtung verdienen.

Nachdem im Jahre 1740 Abraham Trembley an Hydra experimentiert, die Regeneration dieser Form entdeckt und eingehend studiert hatte, folgte eine Zeit eifrigster Untersuchungen über diese merkwürdige Erscheinung. Als Objekte dienten zunächst Regenwürmer, Salzwasserpolypen, Seesterne, Süßwasseranneliden, Tritonen, Kaulquappen, Land- und Wasserschnecken. Erst relativ spät wurde man auf die Planarien aufmerksam. Die ältesten Experimente, von Pallas im Jahre 1778 publiziert, wurden anfangs kaum beachtet. Nur Dugès nimmt 50 Jahre später darauf Bezug. Wir geben hier eine Stelle des interessanten alten Werkes wieder, das mehrere, später völlig vergessene Tatsachen enthält $(z . B$. auch die erste Beschreibung des Amphioxus):

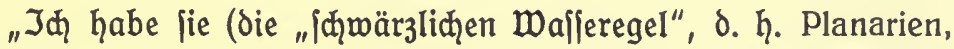
vielleicht Planaria torva) öfters überquer zer[đnitten oder aud zerriffen, allein zufällige lumitände hinderten miđ ftets, den Anwad̨s des ver|tümmelten Thieres anhaltend зu beobađ̆ten. Daß fich das Dordertheil der zer|đ̧nittenen Egel ergänze, davon habe id einigemaḩl proben gejehen. Einmahl jahe id an einem folḑen fajt auf die দqälfte verftümmelten Thier nach Der= flieffung mehrerer Tage, dấ ein vollkommenes Gintertheil wieder gewahjen war, welḑes bis an den Sđ̆nitt viel zarter

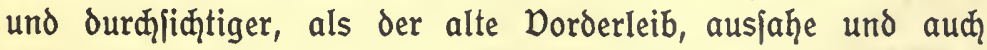
eine 3eit lang 10 verblieb. An abgejđ̄nittenen Ginterleibern habe iđ̆ nie den geringiten Anjąein zur wiederergänzung be: 
merkt. Solḑe Theile lebten oft viele Tage, ohne fid reḑt $3 u$ vernarben oder aus der Wunde einigen Anwad, zu zeigen, und kamen allemahl um."

Schon durch diese ersten Untersuchungen ist die große Regenerationfähigkeit der Planarien festgestellt. Die vorderen Spalthälften regenerieren leichter als die hinteren, ein Verhalten, das für Planaria torva gilt. Spätere Autoren, wie Shaw 1791, Draparnauld 1800, Dalyell 1814 und andere fanden das gleiche wie Pallas und erweiterten unseren Erfahrungsbereich durch zahlreiche Versuche mit origineller Fragestellung. Erst sehr spät (1881) begann man sich für die histologischen Vorgänge bei der Regeneration $z u$ interessieren (Carrière), und der neuesten Zeit (vor allem der amerikanischen Schule seit 1897) blieb es vorbehalten, die äußeren und inneren Bedingungen der Planarienregeneration systematisch und im Zusammenhang mit der Histologie zu erforschen. Die folgenden Ausführungen sollen die wichtigsten Ergebnisse unzähliger Experimente aus allen Perioden der Tricladenregenerationsforschung kurz zusammenstellen.

\begin{tabular}{|l|l}
\hline $\begin{array}{l}\text { Unterschiede im Regenerations- } \\
\text { vermögen der einzelnen Arten }\end{array}$ zeigen sehr ungleiche Regene- \\
zeinen - Arten
\end{tabular} rationsfähigkeit. Während der Körper der einen (z. B. Pl. lugubris, gonocephala, alpina) sich kreuz und quer in zwei und mehr, ja in zahlreiche Stücke teilen läßt, die sich alle wieder zu normalen Individuen ergänzen, - ein Verhalten, das Dalyell treffend als "Unsterblichkeit unter der Schneide des Messers" charakterisiert, - gewinnt man bei andern, wie Dendrocoelum lacteum, Planaria torva usw. den Eindruck, als könnten gewisse Teile des Körpers schwieriger als andere ersetzt werden. Speziell bereitet die Neubildung des Kopfes große Beschwerden und dauert, wenn sie überhaupt zustandekommt, unverhältnismäßig viel länger als der Ersatz des abgeschnittenenen Schwanzes.

In den folgenden allgemeinen Erörterungen wird von Planarienregeneration schlechthin die Rede sein. Dabei werden wir die gut regenerierenden Spezies planaria lugubris, gonocephala, 
maculata usw. ausschließlich im Auge haben, ohne daß bei den einzelnen Experimenten das Versuchstier jedesmal angegeben wird.

\section{Dauer der Regeneration}

Die Dauer des Regenerationsvorganges hängt $a b$ von der Spezies, von der Größe des entfernten Stückes und von den äußeren Bedingungen. Im allgemeinen geht der Prozeß rasch vor sich. Schon Draparnauld hat gefunden, daß eine in der Symmetrieebene geteilte Planarie sich in 20 Tagen zu zwei symmetrischen Individuen ergänzt. Von Bedeutung ist wohl auch das Alter der Versuchstiere, und zwar scheinen merkwürdigerweise junge Exemplare langsamer zu regenerieren als alte. Je größer das entfernte Stück, um so umfassender das Regenerationsgeschehen und um so langsamer der Prozeß.

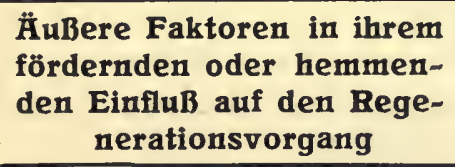

Daß die Bedingungen des umgebenden Mediums auf den Regenerationsverlauf modifizierend wirken, war in Anbetradht der Ahnlichkeit

zwischen Regeneration und Wachstum von vornherein zu vermuten. Die Temperatur des Wassers ist ein solcher Faktor, der. von allergrößter Bedeutung sein kann. Bei Planaria torva (?) ist als unterste Grenze für das Regenerationsgeschehen $3^{\circ} \mathrm{C}$ ermittelt worden, sinkt das Thermometer noch tiefer, so vernarben die Wunden, ohne daß neues Material gebildet wird. Auch hohe Wärmegrade über $33^{\circ}$ verhindern die Wiederergänzung und bewirken rasches Absterben der Teilstücke. Dagegen liegt bei $29^{\circ}$ ein Optimum, indem bei dieser Temperatur der Ersatz verloren gegangener Teile am promptesten erfolgt.

Die Ernährung des regenerierenden Wurmes ist auffälligerweise nicht Vorbedingung für die Regeneration. Auch hungernde Planarien ersetzen amputierte Körperteile. Selbst auf die Dauer des Ergänzungsvorgangs übt die Ernährung nicht in allen Fällen einen deutlichen Einfluß aus. Planarien, die vor der Operation einige Zeit gehungert haben, regenerieren sogar durchschnittlich 
etwas rascher als frisch gefütterte. Spaltet man eine Planarie durch einen medianen Längsschnitt in zwei. Hälften, so verkleinern sich beide und bilden erst einen Streifen von Regenerationsgewebe und dann einen neuen Rüssel. Läßt man nun die eine Hälfte hungern, während man die andere füttert, so sieht man, wie die hungernde immer kleiner wird, wie aber trotzdem das Regenerat wächst. Letzteres vergrößert sich also auf Kosten des alten Gewebes. Später bleibt dann das Hungerregenerat hinter dem der gefütterten Hälfte deutlich zurück, so daB also der Futtermangel mit der Zeit doch hemmend auf den Regenerationsprozeß wirkt. Daher sind die beiden Würmer nach beendeter Regeneration sehr ungleich groß.

Durch Licht und Schwerkraft wird das Regenerationsgeschehen weder in positiver noch in negativer Richtung beeinflußt. Die Planarien ersetzen die fehlenden Teile im Hellen und im Dunklen gleich gut, und ebensowenig kommt es darauf an, ob sie während dem Ergänzungsvorgang mit dem Rücken oder mit dem Bauch nach unten oder an senkrechten Wänden mit dem Kopf oder mit dem Schwanz nach oben sitzen.

Dagegen können Veränderungen im Chemismus der Umgebung die Regeneration weitgehend beeinflussen. Versuche an einer marinen Form (Procerodes segmentata) ergaben, daB durch Verminderung des Salzgehaltes (Zusatz von destilliertem Wasser zum normalen Seewasser) die Regeneration gefördert, durch Erhöhung der Konzentration dagegen gehemmt wird. Von ganz untergeordneter Bedeutung ist der Kalkgehalt des Wohngewässers, wie sich aus Parallelzuchten in kalkarmem und kalkreichem Wasser ergab.

\section{Ḧußere Formregulation}

Schneidet man eine Planarie dicht vor dem Rüssel quer entzwei, so bildet sich am hintern Teilstück ein kurzer, weißlicher Regenerationszapfen, der sich bald zu einem Kopf differenziert. Damit ist aber der Prozeß keineswegs beendet, denn die entstandene Planarie ist zu kurz, ihr Kopf liegt dicht vor dem Rüssel. Es tritt also zu- 
nächst eine Wachstumszone hinter dem neugebildeten Kopf auf, die Zellwucherungen schieben den Kopf immer weiter vom Rüssel weg, bis die normalen Formverhältnisse erreicht sind. Dabei ist das alte Gewebe an dieser Umformung aktiv beteiligt. Noch schöner zeigt sich die allmähliche Formregulation an kurzen Querabschnitten des Körpers, die am vordern Schnittende einen Kopf, am hintern einen Schwanz erzeugen (Abb. 60). Während nämlich die beiden Regenerate heranwachsen und sich differenzieren, verschmālert sich das alte Stück oft auf die Hälfte und darüber und
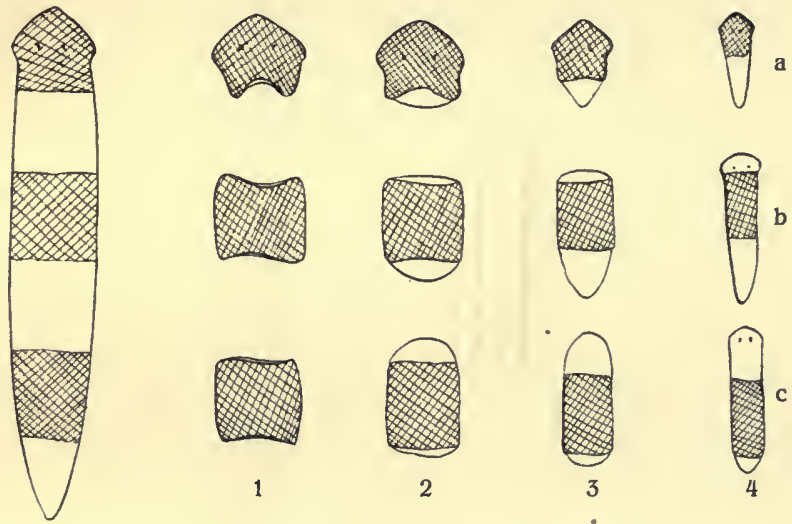

2
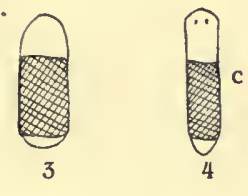

Abb. 60.

Regeneration dreier Querabschnitte von Planaria go noce $\mathrm{phala}$ : a Kopf; b präpharyngealer; c postpharyngealer Abschnitt: $1,2,3,4$ die vier aufeinanderfolgenden Stadien. Der präpharyngeale Hbschnitt $b$ bildet einen kleinen Kopf und einen großen Schwanz, der postpharyngeale Abschnitt c einen großen Kopf und einen kleinen Schwanz.

gliedert sich so in den neuen stark verkleinerten Wurm ein. Bei einigen landbewohnenden Tricladen kann es ohne Neubildung zur Verwandlung eines Querabschnittes in einen ganzen Wurm kommen (Abb. 61). Man bezeichnet diese Art von Regeneration als Morphallaxis im Gegensatz zur Epimorphose, der Regeneration durch Auswachsen neuen Materials. Bei den Süßwasserplanarien tritt Morphallaxis neben der Epimorphose auf.

Interessant sind die Formregulationen an Teilstücken mit schrägen Schnittflächen. Schneidet man durch einen schiefen 
Schnitt einer Planarie den Kopf $a b$, so bildet sich längs dem ganzen Wundrand Regenerationsgewebe. Bald aber entsteht nicht in der Mitte des Schnittrandes, wie man erwarten sollte, sondern am vordern Teil ein Kopf, dessen Axe anfangs senkrecht zur Schnittfläche steht (Abb. 62). Im weiteren Verlauf des Prozesses wird dann durch ungleiches Wadhstum des Regenerates und durch Umwandlung des alten Stückes die Symmetrie wieder-

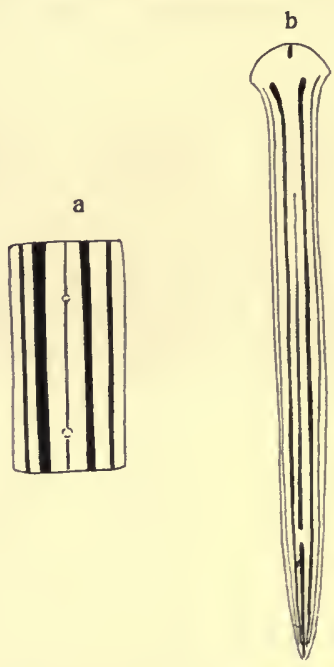

Abb. 61.

Regeneration einer Landplanarie aus einem Querabschnitt a durch Morphallaxis nadh Morgan.

Die Mittellinie ist durch zwei Nadelstiche verletzt; die entstandenen Lüdken zeigen beim regenerierten Wurm b die bedeutende Streckung, die eingetreten ist.

hergestellt. Ein ähnlich gerichteter Schnitt, der nur eine Kopfhälfte entfernt ( $\mathrm{Bbb} .63)$, zieht meist nur die Bildung eines halben Kopfes nach sich. Doch können gelegentlich auch Doppelköpfe entstehen. Analoge Vorgänge spielen sich ab bei der Regeneration eines Schwanzes von einer schrägen Schnittfläche aus, sowie bei der Wiederergänzung eines schmalen Streifens vom Seitenrand.

Sehr auffällig ist das ganz verschiedene Regenerationsgeschehen 
an gleich großen Querabschnitten aus verschiedenen Körperregionen. Teilt man eine Planarie durch Querschnitte in zahlreiche Stücke, so werden die vorderen Querabschnitte einen kleinen Kopf und einen großen Schwanz, die hintern umgekehrt einen großen Kopf und einen kleinen Schwanz regenerieren,

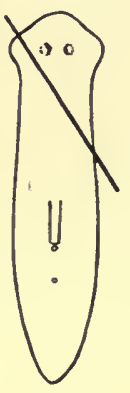

1

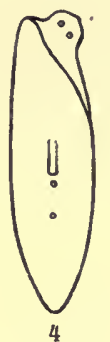

4

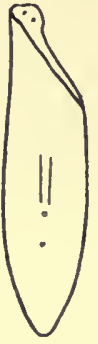

2

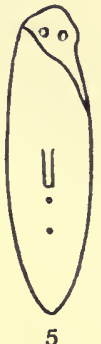

5

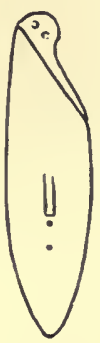

3

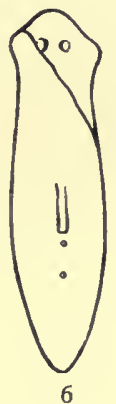

Abb. 62.

Formregulationen an schrägen Schnittflächen. Regeneration eines schief abgeschnittenen Kopfes. 1 Schniltrichtung, 2-5 Regenerationstadien, 6 nach erfolgter Regeneration (nad Morgan).

während die der Mitte entstammenden Querabschnitte vom vordern und hintern Schnittrand etwa gleich viel Material erzeugen werden (Abb. 60). Damit stimmt die Lage des Rüssels, der im ersten Fall weit hinten, im zweiten vorn und im dritten in der Mitte gelegen ist. 
Mehrere Experimente beschäftigten sich mit der Frage nach dem Minimum der für die Regeneration notwendigen Substanzmenge. Dugès glaubte, daß Stücke, die kleiner als $1 / 10$ des ursprünglichen Tieres sind, keine Regeneration mehr zeigen. Bei

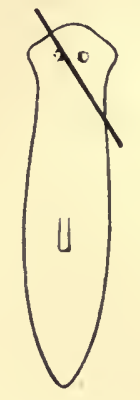

1

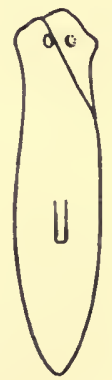

4

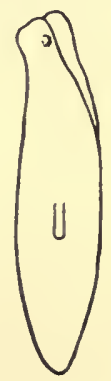

2

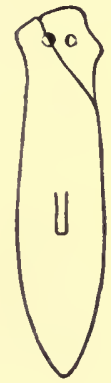

5

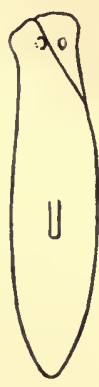

3

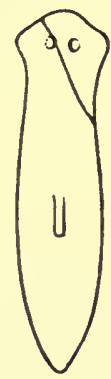

6

Abb. 63.

Formregulationen von schrägen Schnittflächen. Regeneration eines schief abgeschnittenen Halbkopfes. 1Schnittrichtung, 2-5 Regenerationsstadien, 6 nach vollendeter Regeneration (nach Morgan).

amerikanischen Arten, sowie bei Planaria gonocephala und planaria lugubris sind jedoch auch wesentlich kleinere Teile noch regenerationsfähig. Das "Minimum" scheint keine genau fixierte Größe zu sein und schwankt jedenfalls bei verschiedenen Arten sehr bedeutend. Eine Ursache für die Regenerations- 
unfähigkeit kleinster Stücke kann bis jetzt nicht angegeben werden. Mit Ausdrücken wie "Mangel an hinreichendem Baumaterial", "zu große Oberflächenspannung im Vergleich zum Volumen“ ist die Frage nur umschrieben, keineswegs erklärt.

Doppelbildungen und

Heteromorphosen
$\mathrm{Zu}$ den rätselhaftesten Erscheinungen auf dem rätselreichen Gebiet der Regeneration gehören die Fälle, in welchen nicht das, was entfernt worden ist, sondern etwas Anderes erzeugt wird. Man kann diese Bildungen Heteromorphosen nennen. Neuerdings pflegt man von

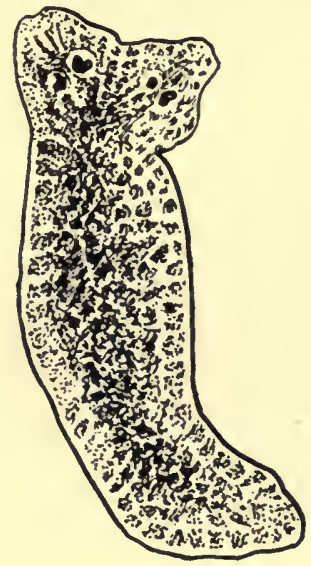

Abb. 64.

Doppelkopfplanarie nach van Duyne.

den eigentlichen Heteromorphosen die Fälle, in welchen nach teilweiser Spaltung Organverdoppelungen usw. entstehen, abzutrennen und als "Mehrfachbildung " $z u$ bezeichnen.

Spaltet man das Vorderende einer Planarie durch einen medianen Einschnitt, so ergänzt sich jede Kopfhälfte auf eigene Faust, und es entsteht ein Monstrum mit zwei Köpfen und einem Leib (Abb. 64).

Durch einen Längsschnitt, der am Schwanzende beginnt, kann 
man ein zweischwänziges Geschöpf erzeugen (Abb 65). Reicht der Einschnitt sehr tief, so kann im Schnittwinkel merkwürdigerweise ein kleiner, nach hinten gerichteter Kopf entstehen (Abb. 65, b) oder es entstehen sogar zwei kleine Vorderenden (Abb. 65, c).
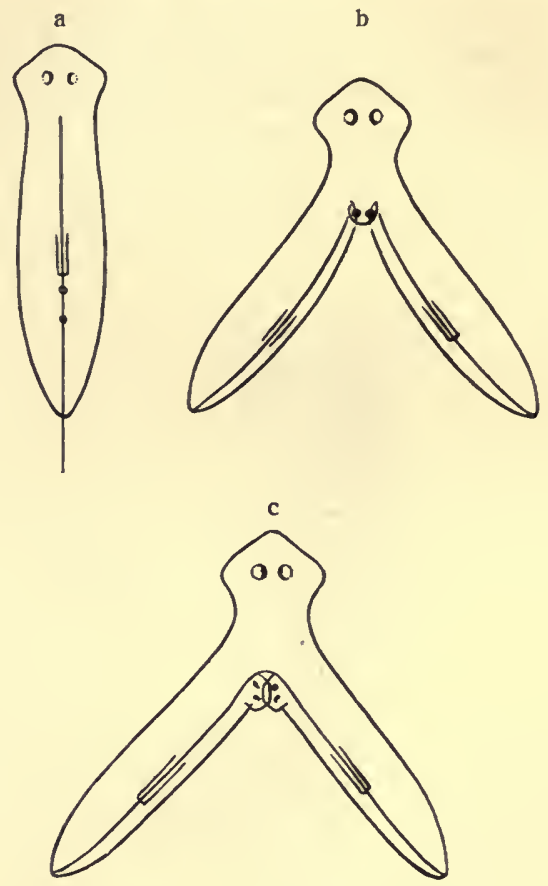

Abb. 65.

Bildung von Doppelplanarien bei medianer Spaltung des Schwanzes. a Schnittrichtung; b und c zwei verschiedene Arten der Wiederergänzung (nach Morgan).

Mehrere Längsschnitte liefern Individuen mit entsprechender Zahl von Schwänzen und Köpfen.

Schneidet man in der Mitte des Seitenrandes wagerecht bis gegen die Körpermitte, so entsteht am vordern - nach hinten gerichteten - Schnittrand ein Schwanz, am hintern - nach vorn gerichteten - ein Kopf. 
Bei wagerechter Schnittrichtung zeigt das Regenerat, wenn es einheitlich ist, Kopfcharakter, sofern die Verletzung im vordern Teil angebracht wurde, Schwanzcharakter, falls sich die Wunde hinter dem Rüssel befindet.

Schiefe Einschnitte liefern, sofern sie nach hinten gerichtet sind, überzählige Köpfe (Abb. 66), falls sie von hinten nach vorn verlaufen, Schwänze.

Auch kombinierte Quer- und Längsschnitte ergeben Doppelbildungen.

Sehr auffällig ist die Abhängigkeit der doppelten Partien von dem gemeinsamen Stück.

Die 2 Köpfe einer durch mediane Längsspaltung erzeugten Doppelplanarie sind um so größer, je tiefer der Einschnitt reichte, je kleiner also das gemeinsame Stück im Vergleich zu den Spalthälften ist. Ohne Zweifel wirkt der gemeinsame Rumpf und Schwanz hemmend auf die Kopfbildung. Das ergibt sich auch aus dem Vergleich der alten und neuen Augen. Die letzteren bleiben an kleinen Doppelköpfen sehr klein. Der Unterschied wird jedoch um so geringer, je tiefer der Spaltschnitt reicht.

Schneidet man einer zwei-

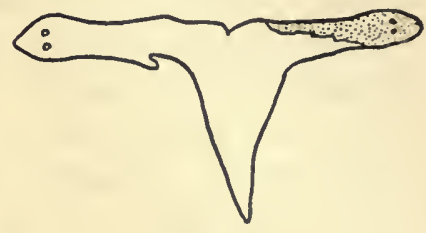

Abb. 66.

Doppelplanarie, punktiert, der regenerierte Abschnitt. Nach van $D$ uyne. Die Doppelbildung ist hervorgegangen aus einen schräg von vorn nach hinten und innen gerichteten Einschnitt.

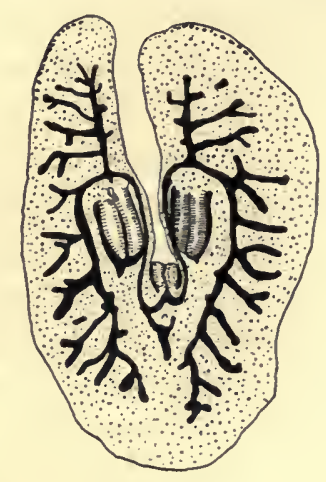

Abb. 67.

Doppelbildung bei polycelis nigra. Flächenschnitt kombiniert. Man sieht, daB der Kopfdarm nicht in der Medianlinie der Vorderenden liegt, und die beiden Rüssel ebenfalls stark gegen die Mitte verschoben sind. Rätselhaft ist das Huftreten eines dritten unpaaren nach vorn gerichteten Rüssels. köpfigen Planarie den einen Kopf $a b$, so wird er in der Regel sofort regeneriert. Entfernt man beide Köpfe durch einen einheitlichen Schnitt an der Verzweigungsstelle, so entsteht ein einziger Kopf. 
Amputiert man einer Doppelplanarie mit tiefer Spaltung den einen Kopf, so wird er durch einen Schwanz ersetzt. Daran kann offenbar nur der stehengebliebene Kopf schuld sein.

Ein auffallendes Verhalten ist noch vom Pharynx der Doppelplanarien zu berichten. Reichte der Spaltschnitt so weit nach hinten, daß jeder Spaltkopf seinen besonderen Rüssel erhält, so liegt nach der definitiven Ausgestaltung des Regenerates der Pharynx jederseits nicht in der Symmetrielinie der Doppelköpfe, sondern er wird nach innen zu verschoben (Abb. 67). Die Verschiebung ist um so geringer, je selbständiger die Spalthälften sind.

Aus diesen Einzelresultaten darf für die Planarien der Schluß abgeleitet werden, daß die Regeneration qualitativ und quantitativ weder durch die angeschnittenen Zellen (GröBe der Wunde) noch durch die im Schnittrand freiliegenden Gewebe und Organe bestimmt wird, sondern durch die Gesamtheit des Regeneranten.

Sehr auffällig sind die erstmals von Morgan im Jahre 1898 erzeugten, sogenannten polaren Heteromorphosen, an die sich ebenfalls wichtige theoretische Fragen knüpfen. Schneidet man eine Planaria lugubris dicht hinter den Augen quer durch, so bildet naturgemäß der Rumpf seinen Kopf neu; der entfernte Kopf aber erzeugt nicht, wie man erwarten sollte, einen Rumpf, sondern einen zweiten, nach hinten gerichteten Kopf; es entsteht ein unglaubliches Monstrum, das nur aus zwei Köpfen besteht, dem also alle übrigen Körperteile fehlen (Abb. 68, 1). Ein derartiges Geschöpf ist natürlich auf die Dauer nicht lebensfähig, es hält sich aber immerhin tage- und wochenlang und stirbt schließlich infolge der Unfähigkeit, Nahrung aufzunehmen. Später wurde gezeigt, daß man polare Heteromorphosen in analoger Weise an äußersten Schwanzstücken erzielen kann. Die betreffenden Geschöpfe bestehen dann nur aus zwei an der Wurzel miteinander verwachsenen Schwänzen.

$\mathrm{DaB}$ es sich dabei nicht etwa bloB um undifferenzierte Regenerationszapfen, sondern um wirkliche Schwänze handelt, beweist ein Fall von doppelter Anlage der Geschlechtsorgane mit 
2 selbständigen Öfnungen, einer im alten Stück und einer im Regenerat.

Mehrere Fälle von polarer Heteromorphose wurden an ganz schmalen Querabschnitten des Planarienkörpers beobachtet; entstammt ein solcher schmaler Streifen der Gegend vor dem Rüssel, so werden in der Regel die beiden Regenerate zu Köpfen (Abb. 68, 2). Querabschnitte der Schwanzregion dagegen liefern an beiden Schnittenden Schwänze.

Die polare Heteromorphose erscheint besonders geeignet für die Erklärung der sogenannten Polarität, eines schwierigen, aber sehr wichtigen Begriffes der Regenerationswissenschaft. Wenn wir beobachten, daB stets an hintern Schnittenden quergeteilter Tricladen Schwänze, an vordern Köpfe entstehen, so müssen

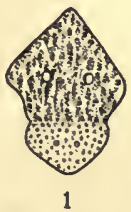

1

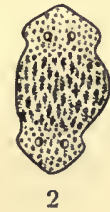

2

1 Ein abgeschnittener Kapf bildet statt des fehlenden Hinterleibes einen nach hinten gerichteten Kopf.

2 An einem kurzen Querabschnitt der vordern Körperregion entwickelt sich nach vorn und hinten je ein Kopf.

Abb. 68.

Polare Heteromorphosen von Planaria maculata nach Morgan.

wir hier eine Gesetzmäßigkeit annehmen, die man mit dem Namen Polarität bezeichnet hat. So wie bei einem in Stücke geschnittenen Magnetstab jedes Segment wieder ein kleines Magnet ist und seinen positiven und negativen Pol besitzt, so hat jeder Querschnitt einer Planarie einen Kopf- uud einen Schwanzpol, wenn der Ausdruck erlaubt ist. Am Schwanzpol entsteht normalerweise ein Schwanz, am Kopfpol ein Kopf. Uber das Wesen der Polarität weiß man nichts Sicheres. Man vermutet, daß es sich um den Ausdruck einer graduellen Schichtung der chemischen Substanzen von vorn nach hinten handle (wobei zu bemerken ist, daß die Kopf-Schwanz-Polarität nicht die einzige zu sein braucht). Trifft das $z u$, so könnte man erwarten, daß die Polarität sich um so deutlicher Geltung verschaffen könne, je verschiedener die Substanzen vorn und hinten sind; mit andern Worten: längere 
Querabschnitte werden stärkere, kürzere dagegen schwächere Polaritätswirkung zeigen. Da nun bei den polaren Heteromorphosen die Polarität offenbar nicht zur Geltung kommt, und da andrerseits diese Erscheinung sich ausschließlich an kurzen Querabschnitten zeigt, dürfen diese Tatsachen als Stützen der Hypothesen von der Schichtungspolarität betrachtet werden, wenn auch zugegeben werden muß, daß damit für die Erklärung dieser seltsamen Vorgänge und Kräfte wenig gewonnen ist.

Histologie der Noch ganz ungenügend bekannt sind die VorRegeneration gänge, die sich während der Regeneration in den Zellen und Geweben abspielen. Wir können uns daher kurz fassen. Der regenerierende Wurm befindet sich in einem Zustand, der am besten mit demjenigen hungernder Individuen verglichen werden kann (S. 96). Im alten Gewebe finden wichtige Umbildungen, sogenannte Reduktionen, Rückführungen differenzierter Elemente auf primitive, gewissermaßen embryonale Stadien statt. Aus solchen einfachen Zellen, die auch im normalen Parenchym eine gewisse Rolle spielen (S. 37), bildet sich das Regenerationsgewebe, das durch Reichtum an Kernen und durch zahlreiche, 1 bis 2 Ausläufer tragende Zellen ausgezeichnet ist. Dieses Gewebe vergrößert sich durch rasch aufeinanderfolgende Zellteilungen und differenziert sich später $z u$ den verschiedenartigsten Geweben. Darmepithel, Muskeln, Drüsen, der ganze Pharynx, wahrscheinlich auch das Nervensystem und die Augen können daraus hervorgehen.

\section{Transplantation}

Die Zahl der an Planarien angestellten Transplantationsversuche ist relativ gering, wohl infolge der bedeutenden Schwierigkeiten, die sich einer Vereinigung der weichen Wundränder entgegenstellen. L. V. Morgan hat gezeigt, daß kleine Stücke in verschiedener, auch inverser Stellung in Wunden einer Planarie einheilen und sich mit dem Versuchstier so innig vereinigen, daß ein ganz einheitlicher Wurm entsteht. Manchmal werden aufge- 
pfropfte Stücke ziemlich weit verlagert. Ein der Körpermitte entnommenes Stück kann in der Kopfgegend einheilen und dann wieder schwanzwärts wandern bis in die Gegend, in der es ursprünglich saß. Bei dem sehr bedeutenden Regenerationsvermögen der Versuchsobjekte erscheint das Einheilen der Pfropfstücke nicht besonders merkwürdig, wohl aber die weitgehenden Regulationen und Umdifferenzierungen, die sich nach der Transplantation einstellen.

\section{Natürliche Mißbildungen}

\section{Mehrfachbildungen äuBerer Körperteile und Organe}

Als Mißbildungen können die schon oben beschriebenen, sogenannten polaren Heteromorphosen betrachtet werden, die jedoch nur im Laboratorium künstlich zu erzeugen sind und in der freien Natur niemals vorkommen dürften.

Dagegen trifft man beim Planariensammeln gar nicht selten auf Monstrositäten, natürliche Mißbildungen, von denen hier noch einige kurz besprochen werden sollen.

Manchmal geradezu häufig treten Individuen mit Doppelaugen auf. In der Regel ist das eine Auge kleiner und scheint sich durch Teilung von dem Hauptauge losgetrennt zu haben. Dabei kann es sehr vollkommen organisiert sein, seinen normalen Pigmentbecher, sowie seine Sehzellen aufweisen, selbst der pigmentfreie Hof kann wohl entwickelt sein. Manchmal ist die Augenverdoppelung beidseitig, öfters dagegen bleibt sie auf das eine Auge beschränkt. Es sind auch schon Individuen mit Augenverdreifachung zur Beobachtung gekommen. Starke Augenanomalien zeigt besonders die tiefenbewohnende Varietät von Planaria alpina aus dem Genfer See. Ganz vereinzelt ist auch schon bei Hungerexperimenten einseitiger Schwund der Augen konstatiert worden.

Relativ häufig trifft man auch Exemplare mit Doppelschwänzen. Dabei scheint eine Verletzung, z. B. eine partielle Spaltung zur Doppelbildung geführt zu haben. Je nach der Tiefe der letzteren 
zeigen die Hinterenden größere oder geringere Selbständigkeit. Sie können ihren eigenen Rüssel und Kopulationsapparat be-

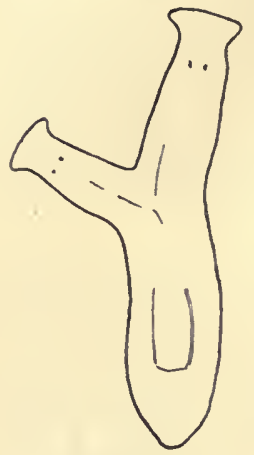

Abb. 69.

Natürliche Doppelbildung v. Planaria alpina nach einem Präparat. sitzen. Sehr eigenartig gestalten sich dann die Beziehungen dieser doppelt angelegten hinteren Teile des Geschlechtsapparates zu den einfach ausgebildeten des Vorderstückes.

Oft sind die beiden Schwänze ungleichwertig, der eine ist als ein seitlicher Körperanhang $\mathrm{zu}$ betrachten, der aus einem Querriß hervorgesproßt ist.

Seltener trifft man Individuen mit 3 Schwänzen, oder solche mit schwanzartigen Auswüchsen in den mittleren Körperpartien. Dagegen ist es schon dann und wann geglückt, mehr oder weniger tiefgespaltene Doppelkopfplanarien in der freien Natur zu beobachten (Abb. 69). Diese Individuen zeigen die gleichen Eigentümlichkeiten in der Anordnung der äußeren und inneren Organe, wie die künstlichen Doppelköpfe.

\section{Polypharyngie}

Ein sehr merkwürdiges Vorkommnis, das unser Interesse aus verschiedenen Gründen verdient, ist das Auftreten mehrerer Rüssel, das bei manchen Planarienarten gelegentlich $\mathrm{zu}$ beobachten ist, und das in einigen Fällen merkwürdigerweise erblich auftritt und zum Artcharakter wird. Man bezeichnet die Erscheinung als Vielrüßligkeit oder Polypharyngie. Die Vielrüßligen oder Polypharyngealen stehen mit einer normalen Art in engster verwandtschaftlicher Beziehung, so daß diese Monstrosität jedenfalls als ein sekundärer Erwerb gelten muß. Die Polypharyngealen besitzen in der Jugend nur wenige Rüssel. Eine Art, die in Montenegro nachgewiesene Planaria anophthalma (augenlose Pl.), kommt zeitlebens nicht über 3 Pharynge hinaus, bei andern Formen, wie Planaria gracilis aus Amerika, Planaria montenigrina aus Montenegro und Planaria teratophila aus Süditalien vergrößert sich die Rüssel- 
zahl während dem Heranwachsen rasch, so daß das geschlechtsreife Tier deren 12, 14, ja 20 bis 30 aufweist. Die Rüsseltasche ist in ebensoviele Nebentaschen zerklüftet, als Pharynge existieren. Der erste unpaare ${ }_{n}$ Hauptrüssel" entspricht dem normalen Tricladenrüssel. Er nimmt die Längsrichtung des Tieres ein, mündet an der Vereinigungsstelle der drei Darmäste und ist der älteste. Die sekundären, jüngeren sind kleiner und sitzen den beiden Schwanzdarmästen seitlich an. Je weiter hinten ein Rüssel liegt, um so kleiner ist er, und um so später entsteht er. Die Rüsselzahl schwankt von Individuum $\mathrm{zu}$ Individuum und scheint gelegentlich auch im spätern Alter erhöht zu werden. Man findet nämlich nicht selten geschlechtsreife Exemplare einer Art, welche die mittlere Rüsselzahl noch nicht erreicht haben.

An die Erscheinung der Polypharyngie knüpfen sich zahlreiche Fragen von allgemeiner Bedeutung, auf deren Diskussion wir uns hier nicht einlassen können. Nur auf einige sei kurz hingewiesen.

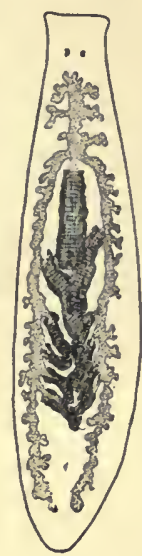

Abb. 70.

Dle vielrüsselige Planaria teratophila. (Nach einer Mikrophotographie.) Da jeder Einzelrüssel seine besondere Mundöffnung und seine eigene Innervierung besitzt, konkurrieren die Pharynge bei der Nahrungsaufnahme, trotzdem sie in einen Darm führen. Wiewohl die Rüsseltaschenöffnung sehr dehnbar ist, kann sie nur eine beschränkte Anzahl von Pharyngen gleichzeitig austreten lassen. Sobald mehr als vier ausgestreckt sind, wird das Fressen erschwert oder unmöglich, da die Rüsselbasis durch die Taschenöffnung eingeschnürt wird. Wer eine Polypharyngeale bei der Nahrungsaufnahme beobachtet, muß den Eindruck bekommen, daß ein einzelner Rüssel besser und schneller funktionieren könnte, daß die Polypharyngie somit etwas durchaus unpraktisches und verfehltes sei. Dazu kommt, daß bei Exemplaren mit 20 und 30 Pharyngen die Mehrzahl derselben überhaupt nicht ausgestoßen werden kann. Nun haben wir aber gesehen, daß sich die polypharyngealen aus einrüßligen Arten entwickelt haben. Wir stehen 
also vor der bemerkenswerten Erscheinung, daß sich ein unzweckmäßiges Merkmal aus einem zweckmäßigen heraus entwickelt hat.

Die Vielrüsseligkeit verdient auch vom morphologischen Standpunkt aus Interesse. Mehrfachbildungen von Organsystemen sind ja im Tierreich recht selten. Es mag hier daran erinnert werden, daß man in der Mehrfachentwicklung des Geschlechtsapparates bei den Bandwürmern eine gewisse Parallele hat, und ferner gibt es Medusen mit mehreren Mundröhren. Bemerkenswert ist die Tatsache, daß wir in der Kettenbildung des Bandwurms eine Art unvollkommener Teilung $z \mathrm{u}$ sehen haben und daß auch die polypharyngealen Medusen sich durch Teilung vermehren. Es ist wohl kaum zufällig, daß die als Stammformen der Polypharyngealen in Betradıt kommenden einrüsseligen die Fähigkeit der Querteilung zeigen. Im übrigen kann die Entstehung der Polypharyngie noch nicht als allseitig geklärt betrachtet werden. Durch die sehr eigentümliche inselartige Verbreitung der Polypharyngealen - Montenegro - Bulgarien - Süditalien und Amerika - erhält das Problem auch eine tiergeographische Seite. Endlich kommt der Biologie die Aufgabe zu, den Bedingungen nachzuforschen, die zur Fusbildung des teratologischen Merkmals der Polypharyngie geführt haben.

\section{Sinnestätigkeit}

Als freilebende Tiere, die ihre Nahrung selbst suchen, meist sogar lebend fangen müssen, sind die Tricladen mit gut funktionierenden Sinnesorganen ausgestattet. Auf verschiedene äußere Reize reagieren die Würmer meist sehr prompt durch Anderung der Schnelligkeit oder Richtung der Bewegung, etwa auch durch erhöhte Sekretion. Mit diesen Antwortreaktionen, soweit sie zurzeit analysiert sind, sollen sich die folgenden Zeilen befassen.

Als Reize kommen zunächst in Betracht: das Licht, die Temperatur, Anderungen im Chemismus des Wohnmediums, Wasserbewegungen, Erschütterung und Berührung. 
Licht

Allgemein wird den Tricladen große Lichtscheu zugesprochen. Sie leben in finstern Winkeln, unter Steinen und Blättern, in Ritzen und im groben Sand, zum Teil steigen sie in die lichtlosen Tiefen der Seen, in die Grotten und Höhlen, in die tiefen Brunnen.

$\mathrm{DaB}$ man unter Lichtempfindung nicht etwas Psychisches im menschlichen Sinn verstehen darf, mögen die folgenden Erörterungen zeigen.

Bringt man eine Schale mit Planarien ins Dunkel, etwa in einen gut schließenden Schrank, so nimmt ihre Bewegungsschnelligkeit rasch $a b$, sie setzen sich bald völlig zur Ruhe. Umgekehrt beginnen sie bei plötzlicher Belichtung sofort zu kriechen. Steigert man allmählich die Belichtungsintensität, so kann eine Zunahme der Kriechgeschwindigkeit beobachtet werden, man bekommt den Eindruck, als ob das Licht beunruhigend wirke, das Kopfende macht tastende Krümmungen und oft tritt spannende Bewegungsweise ein.

Umgekehrt wirkt Abnahme der Lichtstärke beruhigend.

Am schönsten läßt sich diese Reaktion bei plötzlicher Ver änderung der Lichtintensität nachweisen, doch ist sie auch bei allmählichem Wechsel unverkennbar. Man nennt die Reizbarkeit, die diesem Verhalten zugrunde liegt, Unterschiedsempfindlichkeit. Sie kommt bei verschiedenen Organismen vor, z. B. in umgekehrtem Sinne bei Medusen, die sich nach plötzlicher Verdunklung in Bewegung setzen, oder bei Röhrenwürmern, die bei Beschattung ihres Tentakelkranzes mit einem Ruck in ihre Röhre zurückschnellen.

Genaue Beobachtung plötzlich belichteter Planarien lehrt aber noch etwas anderes. Wir kommen hier zu der widhtigen Feststellung, daß die Tricladen nicht nur auf Intensitätsunterschiede, sondern auch auf Lichtrichtung in ganz bestimmter charakteristischer Weise reagieren, daß ihnen neben der Unterschiedsempfindlichkeit noch eine phototaxis zukommt.

Belichtet man ein Gefäß mit ruhenden Planarien plötzlich einseitig, so beginnen alle Tiere augenblicklich der lichtabgewandten 
Seite zuzuwandern, sie stellen ihren Körper in die Ridhtung der einfallenden Lichtstrahlen und behalten diese Orientierung bei, respektive sie kehren nach kleineren oder größeren Abweichungen immer wieder in diese Richtung zurück. Da der Kopf stets der lichtabgewandten Seite zugekehrt ist, spricht man hier von negativer Phototaxis (Abb. 71).

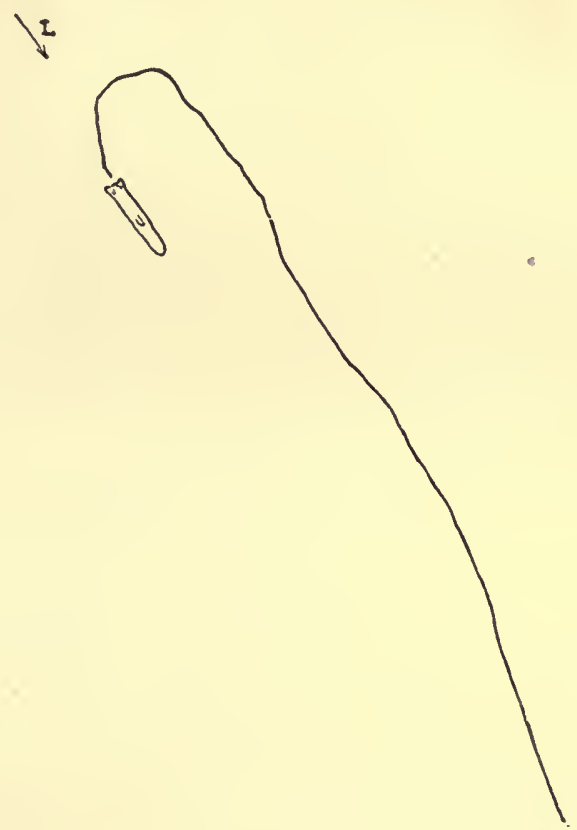

Abb. 71.

Kriechbahn einer gegen das Lidht $\mathrm{L}$ gestellten Polycladodes alba.

Bei längerem Aufenthalt im hellen Licht verliert sich, wohl infolge von Blendung (d. h. Uberreizung) oder Adaption die Phototaxis. Die Würmer wandern ziellos im Gefäß umher und kommen schließlich infolge der ständig wirkenden Unterschiedsempfindlichkeit an den dunkelsten Stellen zur Ruhe. Bringt man kleine Steinchen ins Versuchsgefäß, so sammeln sich die Würmer an deren Unterseite oder in deren Schatten an. Enthält die Schale 
keine schattenwerfenden Objekte, so gelangen die Planarien an verschiedenen Stellen zur Ruhe, je nach der Form und Belichtung des Gefäßes. Bei Glasschalen von zylindrischem Querschnitt ist die lichtabgewandte Seite infolge des Reflexes relativ hell. Die Tiere stellen daher auf der linken und rechten Seite des Gefäßes (bezogen auf den Lichteinfall) das Kriechen ein, da dort die Lichtintensität am geringsten ist (Abb. 72). Wieder anders verhalten sie sich in schwarzen Photographenschalen. Dort sammeln sie sich an der lichtabgekehrten Seite, oder, falls die Ränder Schatten werfen, im Bereich der letzteren an ( $\mathrm{Abb}$. 73).

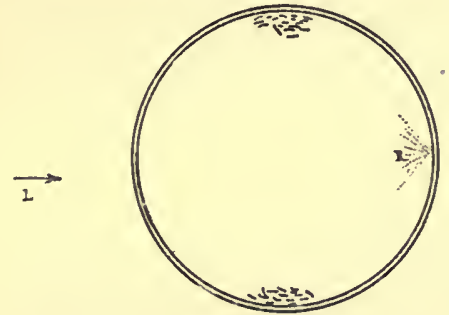

Abb. 72.

Ruheplatz der Planarien in einseitig belichteter Glasschale mit reflektierenden Wänden. $\mathrm{R}=$ Reflex. $\mathrm{L}$ Lidhteinfall.

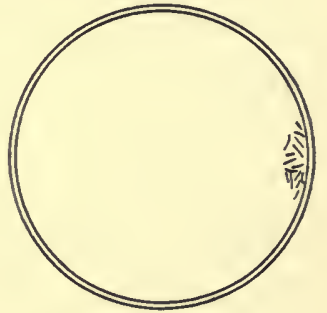

Abb. 73.

Ruheplatz der planarien in einseitig beleuchteter, nicht reflektierender Schale.

L Lidhteinfall.

Dieses Experiment gelingt so unfehlbar, daß man Planarien direkt zur Ermittlung der dunkelsten Stellen in irgendeinem Gefäß verwenden kann.

Wir haben nun $z u$ untersuchen, mit welchen Organen die Lichtreize perzipiert werden, und in welcher Art die Antwortreaktionen zustande kommen.

Die hohe Bedeutung des Lichtes für den Stoffhaushalt in der Natur ist allgemein bekannt, ebenso der beträchtliche Einfluß auf chemische Vorgänge. $\mathrm{DaB}$ das Licht auch den tierischen Stoffwechsel stark beeinflußt, geht schon daraus hervor, daß sehr viele Organismen bei intensiver Belichtung absterben. Durch diese Feststellung dürfte wohl die Unterschiedsempfindlichkeit der Planarien dem Verständnis näher gebracht sein. Intensiveres 
Licht bewirkt umfangreichere chemische Umwandlungen im Körper als schwächeres. Als eine Folge dieses Unterschiedes kann man die schnellere oder langsamere Kriechbewegung auffassen. Wahrscheinlich liegen allerdings die Dinge wesentlich komplizierter. Die durch das Licht erzeugten Stoffveränderungen könnten das Nervensystem und dieses wiederum die Muskulatur beeinflussen. Endlich könnten sich die chemischen Vorgänge nicht im ganzen Körper, sondern nur an bestimmten Stellen, z. B. in den Augen oder in der pigmentierten Haut abspielen und durch Beeinflussung des Nervensystems die Bewegungsorgane regulieren.

Für mehrere Planarien ist festgestellt, daß die Unterschiedsempfindlichkeit von den Augen nicht abhängig ist. Blendung durch Ausstechen der Augen mit heißen Nadeln und auch $\mathrm{Ab}$ schneiden des ganzen Kopflappens mit samt dem Gehirn raubt ihnen ihre Unterschiedsempfindlichkeit nicht. Diese Eigenschaft geblendeter und kopfloser Individuen ist bis jezt nur für pigmentierte Arten festgestellt worden und wird für mehrere unpigmentierte entschieden verneint. Man könnte also hier daran denken, daß das Pigment der Haut für die Unterschiedsempfindlichkeit von Bedeutung sei.

Selbstverständlich folgt aus dem Nachweis, daß es. Unterschiedsempfindlichkeit ohne Augen gibt, noch niçht, daß die Augen unterschiedsunempfindlich sind; im Gegenteil muß angenommen werden, daß bei denjenigen Arten, die ihre Unterschiedsempfindlichkeit durch Blendung einbüßen, die Augen die Reizrezeption besorgen.

Ohne Zweifel sind die Augen Organe der negativen Phototaxis, indem geblendete Würmer jegliche Fähigkeit, sich in der Richtung der Lichtstrahlen einzustellen, verlieren.

Wollen wir also die Vorgänge, die zur Flucht in der Rich tung des einfallenden Lichtes führen, verstehen, so müssen wir uns den Bau und die Anordnung der Augen ins Gedächtnis zurückrufen (s. S. $80 \mathrm{ff}$ ). Die Pigmentbecherzellen bewirken eine Isolierung bestimmt gerichteter Lichtstrahlen. Jedem Auge kommt ein Gesichtsfeld zu. Strahlen, die von einem Punkte außerhalb 
des Gesichtsfeldes ausgehen, können nicht in die Offnung des Bechers hineingelangen und die lichtempfindlichen Sehzellen erregen, sie treffen die Außenseite und werden vom Pigment absorbiert.

Betrachten wir zuerst den einfachsten Fall, eine Planarie mit 2 Augen. Der jedem Auge zugeordnete Lichtkegel ist so orientiert, daß seine Axe in bezug auf die Planarie von vorn, außen und oben einfällt. Die beiden Gesichtsfelder sind also ganz unabhängig voneinander (Abb. 74).

Wie wirkt nun dieser Sehapparat? Bei der geringen Zahl von Sehzellen in einem Ocellus ist ein "Bildsehen“, ja sogar ein "Bewegungssehen" so gut wie ausgeschlossen. Das Auge wird höchstens Intensitätsunterschiede wahrnehmen, seine Funktion wird ein "Hell-Dunkelsehen " sein. Bringt man nun in das Gesichtsfeld einer ruhig kriechenden Planarie einen hellen Gegenstand oder besser: läßt man, um den Erschütterungsreiz $\mathrm{zu}$ vermeiden, den Wurm an hellen Gegenständen vorbeikriechen, so bemerkt man, daß das Tier nach der entgegengesetzten Seite ausbiegt. Wählt man umgekehrt einen

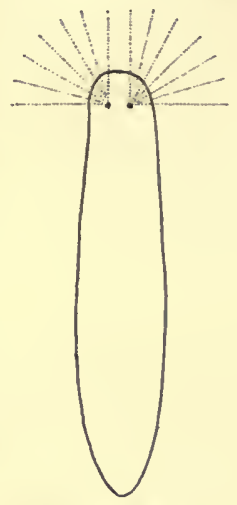

Abb. 74.

Die Gesichtsfelder einer Planaria. dunklen Gegenstand, d. h. verdunkelt man das Gesichtsfeld, so kehrt sich die Planarie nach der Seite des verdunkelten Auges.

Die Umbiegung geschieht, wie man leicht nachweisen kann, durch Kontraktion der Längsmuskeln auf der Biegungsseite. Es scheint also, daß jeweilen bei Belichtung des einen Auges die gegenteilige, bei Beschattung die gleichseitige Längsmuskulatur sich kontrahiert.

Nun ist aber Belichtung des einen oder Beschattung des andern dem Effekt nach identisch, indem durch beide Vorgänge das gleiche Auge stärker gereizt wird; somit braucht man sich nicht $\mathrm{zu}$ wundern, daß auch der Erfolg der gleiche ist.

Man darf also die Sache auch folgendermaßen formulieren: Ist das eine Gesichtsfeld einer Planarie stärker belichtet als das andere, so krümmt sich die Planarie nach der Seite des 
verdunkelten Auges, indem sich die dortige Längsmuskulatur kontrahiert.

Wird nun ein Wurm einem einseitig einfallenden Lichte ausgesetzt, so dreht er sich vom Lichte weg nach dem Dunkel. Die Drehung wird dann aufhören, wenn die beiden Gesichtsfelder gleichstark beleuchtet sind, d. h., wenn die Planarie mit abge-

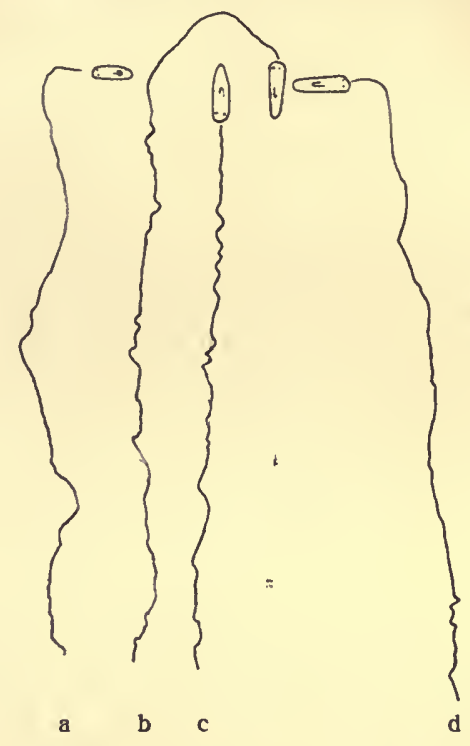

Abb. 75.

Planaria lugubris, ein Exemplar $4 \mathrm{mal}$ in der Mitte einer einseitig beleuchteten Schale aufgestellt (schwarze Cuvette). 32 Kerzen Osram in $10 \mathrm{~cm}$ Abstand. $\mathrm{a}, \mathrm{b}, \mathrm{c}, \mathrm{d}$ die vier Kriechbahnen.

wandtem Kopf von der Einfallsrichtung des Lichtes weg orientiert ist. Sollte die Krümmung weitergehen, so wäre das entgegengesetzte Gesichtsfeld stärker beleuchtet, und dadurch müßte durch Kontraktion der entgegengesetzten Muskulatur eine Zurückziehung eintreten.

Eine in der Richtung der einfallenden Lichtstrahlen wegwandernde Planarie wird also ihre Richtung ständig korrigieren und daher pendelnde oder schlangenlinienartige Bewegungen ausführen (Abb. 75). Bei der Schnelligkeit, mit der die korrigierende 
Reaktion erfolgt, ist davon allerdings nicht viel $\mathrm{zu}$ sehen, doch kann man ein Pendeln des Kopfes bei den phototaktischen Wanderungen nicht selten beobachten.

Diese Funktion der Augen konnte durch einige weitere Experimente bestätigt werden:

Entfernt man mit heißer Nadel das eine Auge, so wird man, wenn der Wundreiz nachgelassen hat, finden, daß die einseitig belichtete Planarie im Kreise $z u$ wandern beginnt, und zwar bleibt die Seite des vernichteten Auges, die dem noch funktionierenden Ocellus zugeordnet ist, in ständiger Kontraktion. Der Radius des beschriebenen Kreises ist um so kleiner, je stärker die Belichtung ist. $\mathrm{DaB}$ es sich dabei nicht um eine rein mechanische, durch einseitige Wundkontraktion bedingte Kreisbewegung handelt, zeigen folgende Kontrollversuche:

1. Verletzt man auch den entgegengesetzten Körperrand und zwar durch einen Einschnitt, der oberhalb des Auges gelegen ist, so daß das Auge weiter funktioniert, so wird dadurch die Kreisbewegung nicht sistiert.

2. Bei starker einseitiger Belichtung, z. B. in direktem Sonnenlicht, werden die Kreise, in denen sich die einseitig geblendete Planarie bewegt, allmählich seitlich verlegt, und zwar bei rechtsgeblendeten nach der Rechten, bei links-geblendeten nach der Linken bezogen auf den Einfall des Lichtes.

Die Erklärung für dieses merkwürdige Verhalten ergibt sich am natürlichsten aus den obigen Ausführungen über das Zustandekommen der Phototaxis.

Die Kreisbahn einer einseitig, sagen wir rechts-geblendeten Planarie, die von links belichtet wird ( $\mathrm{Abb}$. 76), kann in einen lichtzugekehrten Halbkreis $A B$ und einen lichtabgewandten $B A$ eingeteilt werden. Bewegt sich die Planarie auf dem lichtzugewandten Bogen $A B$, so wird ihr Auge von den vollen Sonnenstrahlen getroffen. Das hat zur Folge, daß die Kontraktion verstärkt, der Körper mehr gekrümmt, daher der Radius des Bogens verkleinert wird. Die Planarie wird infolgedessen nicht so weit nach links (bez. auf den Lichteinfall) gelangen, wie sie bei diffusem 
Licht gelangt wäre. Nun hört aber der starke Reiz des Sonnenlichtes auf und der lichtabgewandte Bogen hat infolge schwächerer Krümmung des Wurmes einen gröBeren Radius. Infolgedessen gelangt die Planarie nicht zu ihrem Ausgangspunkt zurück, sondern nach $A^{1}$. Nun wiederholt sich der gleiche Vorgang, und der Wurm kommt schließlich am rechten Rand des Versuchsgefäßes an, bezogen auf den Lichteinfall. Genau das Umgekehrte erfolgt, wenn die Planarie links geblendet ist, wie aus der Abbildung ohne weiteres hervorgeht. Natürlich sind die Kreise bisweilen ziemlich un-

I.

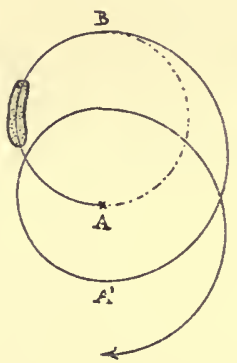

Abb. 76.
I1.

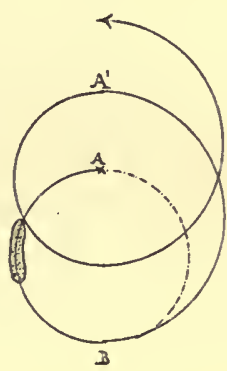

Verhalten einseitig geblendeter Planarien bei einseitiger Belichtung.

I. Kriechbahn der rechts geblendeten, Il. der links geblendeten Planarie (schematisch).

regelmäßig, und streng genommen dürften es gar keine Kreise sein, da ja der Lichtreiz auf der ganzen Wegstrecke AB nicht gleich stark ist, er nimmt zu bis zur Mitte von $A$ und B, d. h., bis die Axe des Augenbechers mit der Richtung der Lichtstrahlen zusammenfällt und dann wieder $a b$, bis er in B ein Minimum wird. Diese Einzelheiten ändern aber nichts an dem Endresultat. Wir dürfen nach diesen Erfahrungen wohl den Schluß ziehen, daß die negative Phototaxis der Planarienarten durch die Wirksamkeit der Augen und der mit ihnen in Beziehung stehenden seitlichen Längsmuskeln zustande kommt. Anatomisch ist diese 
Beziehung nicht besonders merkwürdig, indem ja die eine Gehirnseite mit dem Längsnerven (Markstrang) der gegenüberliegenden Seite durch Fasern in Verbindung steht.

Bei Polycelis und Polycladodes haben wir statt zwei zahlreiche Pigmentbecherocellen, die aber im großen und ganzen ebenfalls symmetrisch gelegen, und deren Öffnungen auch nach vorn und nach der Seite gerichtet sind. So wirken die Augen einer Seite wie ein einziges Auge, auch sie sind Organe der negativen Phototaxis.

Man braucht daraus noch nicht zu schließen, daß alle Augen vom Bau und von der Anordnung der Planarienaugen phototaktisch sein müssen, gibt es doch sogar unter den Tricladen Formen ohne Phototaxis (Bdellouriden, die Commensalen des Limulus, s. S. 175). Auch die durchweg phototaktischen Süßwassertricladen sind nicht alle gleich empfindlich und ferner kann ein und dasselbe Individuum $z u$ verschiedenen Zeiten verschieden stark reagieren. Es kommt hier offenbar noch eine gewisse "Stimmung" in Betracht, die von verschiedenen Faktoren, wie Ernährungszustand, Temperatur usw. abhängig sein dürfte. In dieser Hinsicht bleibt noch manches aufzuklären.

\section{Temperatur}

Auch gegenüber den Temperatureinflüssen zeigen die Tricladen eine Art von Unterschiedsempfindlichkeit. Kälte wirkt im allgemeinen beruhigend, während Wärme ausgiebigere Bewegung auslöst. Sehr tiefe Temperaturen werden allen Planarien verderblich, ebenso sehr hohe. In beiden Fällen wird die Bewegung eingestellt, es tritt reichlich Schleim aus der Haut, Krampfzustände und Selbstverstümmelung leiten den Tod ein. Die meisten Arten zeigen eine mehr oder weniger große Anpassungsfähigkeit: sie halten sich auch bei Temperaturen, die hoch über ihrem Optimum liegen, ganz leidlich, vorausgesetzt, daß die Erhöhung eine allmähliche ist. Plötzlicher Ubergang $z u$ relativen hohen Wärmegraden von tiefen und umgekehrt bringt sofortigen Tod. Eine Orientierung kriechender Würmer durch Wärme- oder Kälteströmungen scheint nicht vorzukommen. Die 
Frage, ob die Wärme mit Hilfe besonderer Sinnesorgane wahrgenommen wird, muß verneint werden. Die Temperatur scheint eben auf den gesamten Organismus $z u$ wirken. Daraus läßt sich die bewegungshemmende Wirkung der Kälte und die anregende der Wärme erklären. Stoffwechselerscheinungen dürften auch schuld sein an den bei bestimmten Temperaturen auftretenden Autotomieprozessen (s. S. 107), und endlich mögen auch die Fälle, in denen die Ausbildung der Geschlechtsorgane an bestimmte Wärmegrade gebunden ist, sich auf ähnliche Ursachen zurückführen lassen, indem z. B. hohe Temperatur den Stoffwechsel steigert, so eine Art Hungerzustand des Organismus bedingt und die nur bei reichlicher Ernährung zustandekommende Ausbildung der Sexualorgane verhindert (vergleiche den Abschnitt über Hungerzustand und Organreduktion, S. 96).

Chemische Verhältnisse des Wohnmediums
Auf Anderungen im Chemismus des Wohnmediums reagieren die meisten Planarien sehr prompt. Salzlösungen, Säuren und alle möglichen Chemikalien wirken störend, ja verderblich auf die Würmer. Daher bewohnen die meisten Planarien nur ganz reines Wasser. Planaria gonocephala kann $z$. B. im Rhein als Leittier unverschmutzten Wassers gelten. In Flußstrecken, die irgendwie verunreinigt sind, fehlt die Planarie, und wo sie unterhalb wieder auftritt, da ist anzunehmen, daß der Selbstreinigungsprozeß die Abfallstoffe bereits beseitigt hat. Kalkhaltiges Wasser ziehen einige Arten dem kalkarmen vor. Andere verhalten sich umgekehrt. Einzelne sind sehr sauerstoffbedürftig, andere dagegen können auch in fauligem Wasser eine Zeitlang ihr Dasein fristen.

Auch hier handelt es sich um Einflüsse, die das Wohnmedium auf den Stoffwechsel ausübt. Das Verhalten der Tricladen groben Verunreinigungen gegenüber gleicht durchaus dem, das die Tiere beim Eintritt ungünstiger Temperaturbedingungen zeigen. Während jedoch die Wärme und Kälte nicht mit besonderen Sinnesorganen wahrgenommen werden, besitzen alle Tricladen Apparate, mit Hilfe deren sie chemische 
Reize rezipieren können. Es sind das die Organe der Witterung und des Geschmackes. Falls die Reize in die Ferne wirken, pflegt man etwa auch von Geruch zu sprechen, doch handelt es sich hier nur um in Wasser gelöste Stoffe, um Flüssigkeiten, während die Geruchsorgane der Lufttiere gasförmige Stoffe als Reize empfinden.

Die Planarien reagieren auf chemische Reize in doppelter Weise: einmal durch Anderung der Bewegungsgeschwindigkeit und dann auch durch Anderung der Bewegungsrichtung (Chemotaxis).

Legt man unter einen Stein im Bett eines Baches ein Stück Fleisch, so bemerkt man, daß nach kurzer Zeit alle Planarien unterhalb des Köders zwischen den Steinen hervorkriechen und bachaufwärts zu wandern beginnen. Oft bedeckt sich nach einiger Zeit die ganze Oberfläche des Köders mit Planarien. Für den Fang zahlreicher, speziell jüngerer Tricladen ist diese Ködermethode mit großem Erfolg $z u$ verwenden.

Was hat sich von der Zeit des Ködersetzens bis zur Ankunft der Planaria beim Fleisch abgespielt? Vom Köder sind Stoffe, wie Blut und Salze, ins Wasser gelangt und bachab gespült worden. Sie müssen es gewesen sein, welche die Würmer aus ihrer trägen Ruhe aufweckten. Die Stoffe haben somit als Reize gewirkt. Eine Planaria wird "aufgeregt" , d.h. beschleunigt ihre Bewegungen, sobald sie Beute wittert. Bei der Anderung der Geschwindigkeit bleibt es jedoch nicht, sondern der Wurm verfolgt bei seinem Kriechen eine ganz bestimmte Richtung, er wandert der Strömung entgegen auf den Köder zu. Wir werden in kurzem zu erörtern haben, daß eine Bachplanarie fast immer gegen die Strömung kriecht, ob eine Lockspeise vorhanden ist, oder nicht. So kann uns also dieses Experiment die orientierende Wirkung der vom Köder ausgehenden Stoffströmung nicht erklären. Die Chemotaxis läBt sich also am besten im stehenden Wasser verfolgen, wo die Kombination mit der Rheotaxis (s. unten) wegfällt.

In Aquarien ohne Wasserzirkulation verhalten sich verschiedene Planarien dem Köder gegenüber ziemlich ungleich. Einzelne 
sind nicht imstande, das Fleisch aufzufinden, wenn sie nicht zufällig ganz nahe daran vorbeikriechen. Sie machen zwar fortgesetzt tastende Bewegungen mit dem Kopf, lassen die Fühlhörner spielen und krümmen sich manchmal sehr auffällig. Sie wittern also ohne Zweifel die Beute, doch fehlt ihnen die Fähigkeit, zu erkennen, aus welcher Richtung die Riechstoffe kommen. Andere Arten dagegen wittern die Nahrung von ferne und kriechen direkt auf sie zu. Dabei scheinen sie sich nach den feinen Strömungen zu orientieren, welche durch Diffusion der Stoffe des Köders entstehen. Die Einstellung in die Richtung des Köders geschieht in ähnlicher Weise wie bei der Phototaxis mittels abwechselnder Krümmung, bewirkt durch einseitige Kontraktion der Längsmuskeln. Als Organe der Chemorezeption dürfen vielleicht die Sinneszellen und -zellgruppen des Vorderendes in Anspruch genommen werden, speziell die Aurikularsinnesorgane. Es ist zwar zurzeit über die Funktionsweise dieser Apparate noch nichts bekannt; doch kann man leicht zeigen, daB die Chemotaxis mit dem Verlust des vordern Körperabschnittes verloren geht, daß also die Organe der Chemorezeption tatsächlich am Kopf liegen müssen. Andererseits vermögen die abgeschnittenen Köpfe den Köder zu wittern, ja sogar bei den entsprechenden Spezies ihn aufzufinden, trotzdem ihnen das wenig nützt, bevor sie den pharynx regeneriert haben. Sehr schön lassen sich die chemotaktischen Erscheinungen an Planaria lugubris beobachten. Das hängt wahrscheinlich damit zusammen, daß diese Art besonders hoch entwickelte Aurikularsinnesorgane besitzt. Die symmetrische Anordnung dieser Organe $z u$ beiden Seiten des Kopfes deutet darauf hin, daß es sich um einen richtungsbestimmenden Apparat handelt. Einige Experimente, die in dieser Hinsicht unternommen wurden, sind nicht ganz eindeutig ausgefallen; doch darf schon jetzt behauptet werden, daß das Kriechen in der Richtung der Beute durch die Aurikularsinnesorgane bewirkt wird; denn Exemplare, denen man sie durch Wegschneiden der Seitenränder am Kopflappen entfernt hat, verlieren die Fähigkeit, sich nach dem Köder zu orientieren. 


\section{Strömung}

Wir haben schon weiter oben auseinandergesetzt, daß die Planarien auch gegen Wasserbewegung empfindlich sind. Plötzliche Anderungen der Strömungsintensität werden von einer kriechenden Planarie durch Kontraktion des Körpers registriert, ruhende Tiere veranlassen sie bisweilen, sich in Bewegung zu setzen. Außerdem gibt es aber eine orientierende Wirkung der Strömung, eine sog. Rheotaxis. In Bächen und Flüssen, in denen man Tricladen in Bewegung beobachten kann, wird man sich leicht überzeugen, daß die Tiere stromaufwärts kriechen. Nur selten ist das Gegenteil der Fall. Die Erscheinung ist schon ziemlich lange bekannt, jedoch unrichtig gedeutet worden. Man glaubte, daß die immer in gleicher Richtung kriechenden Tiere periodische oder Gelegenheitswanderungen ausführen, auf denen sie durch ein oberwärts im Bach liegendes Beutetier chemotaktisch orientiert würden. Demgegenüber ist festzustellen, daß die meisten Planarien auch ohne Witterung der Strömung entgegenkriechen:

Läßt man über eine schräg gestellte Platte von oben einen Wasserstrahl fließen, und setzt man am unteren Ende oder irgendwo in der Mitte der überfluteten Fläche Planarien an (z. B. Planaria gonocephala oder Dendrocoelum lacteum), so stellen sich diese, falls sie sich überhaupt halten können, alsbald so, daß ihr Kopfende nach oben gerichtet ist. Sie wandern der Strömung entgegen bis dahin, wo die Gewalt des aufprallenden Wassers ihnen den Halt entzieht. Wenn dies nicht eintritt, so können sie sogar den Wasserschlauch erreichen und durch die offnung bis in die Wasserleitung hineinkriechen.

Sehr demonstrativ ist auch ein anderer Versuch: Ein rundes Glasgefäß mit senkrechten Wänden (Krystallisierschale) wird mit Wasser gefüllt. Man setzt einige Planarien hinein und läßt einen starken Wasserstrahl von schräg oben gegen die Wandung prallen. Es entsteht so eine kreisförmige Wasserströmung, deren Verlauf man durch hereingeworfene Sandkörnchen verdeutlichen kann. Die Planarien wandern nicht im Sinne der Strömung, sondern in entgegengesetzter Richtung. Ihr Zug begegnet den mitgerissenen Sandkörnchen.

Steinmann-Bresslau, Strudelwürmer. 
Gräbt man in eine Holztafel zwei Rinnen, die oben und unten in eine zusammenlaufen und bringt man in den untern, gemeinsamen Abschnitt Planarien, so werden diese beim Aufwärtswandern denjenigen Arm benützen, der die stärkere Strömung zeigt. Mehrfach wurde eine Umkehrung dieser Verhältnisse dadurch zu erzielen gesucht, daß man einen zerschnittenen Regenwurm als Köder in den schwächer fließenden Arm brachte. Der Erfolg war negativ. Daraus geht mit Sicherheit hervor, daß die in Frage stehenden Arten (es wurde mit Planaria gonocephala und Planaria alpina experimentiert) durch die Strömung und nicht durch die Witterungsreize orientiert wurden. Köpfe verhielten sich wie ganze Planarien, Rümpfe zeigten keine Rheotaxis. Daher müssen die Organe, welche die Strömungsrichtung wahrnehmen, am Kopf gelegen sein. Durch Wegschneiden der Tentakel einer Planaria alpina oder der Aurikel einer Pl. gonocephala raubt man den Tieren die Fähigkeit, sich nach der Strömung $z u$ orientieren. Amputation der Kopfspitze oder des Lippenrandes dagegen ändert nichts an der Reaktion.

Verschiedene Arten sind übrigens sehr ungleich empfindlich. Die Bachbewohner Pl. alpina und gonocèphala, ferner Dendrocoelum lacteum und Polycladodes alba sind deutlich rheotaktisch, während die Tümpelbewohner Pl. torva, lugubris usw. und merkwürdigerweise auch die rheophile Polycelis cornuta schwache oder gar keine Reaktion auf Strömung zeigen.

\section{Berührung und Erschütterung}

Erschütterungsreize, rasche Wasserbewegung, etwa von einem vorbeischwimmenden Gammarus erzeugt, oder Erschütterung des Gefäßes werden augenblicklich bemerkt und gewöhnlich durch Kontraktionen der Längsmuskeln beantwortet. Daraufhin setzt die Bewegung energischer ein, als zuvor. Auf Berührung erfolgt ebenfalls plötzliche $\mathrm{Zu}$ sammenziehung. Werden die Seiten des Kopfes getroffen, so kontrahiert sich die entgegengesetzte Seitenmuskulatur, der Kopf wird dem Bereich des berührenden Instrumentes entzogen. Wiederholt man diese Manipulation mehrmals, so wird die Reaktion 
sehr viel schwächer, die Tiere werden abgestumpft und unempfindlich und können schließlich berührt werden, ohne daß sie ausweichen. Dieser Umstand ist sehr wertvoll für Regenerationsexperimente, indem man bei Amputationen das Versuchstier erst operiert, nachdem es auf die beschriebene Art unempfindlich gemacht ist. Gegen Berührungsreize ist der ganze Körper empfindlich, am meisten der Kopf, nach ihm die Seitenränder, die sie sich bei Kontakt einziehen.

Als Thigmotaxis oder Stereotaxis kommt in Betracht die Erscheinung, daß Planarien, die man auf den Rüdken legt, sich sofort umdrehen. $\mathrm{DaB}$ es sich dabei nicht um Reaktion auf die Wirkung der Schwerkraft, um "Geotaxis" handelt, geht daraus hervor, daß Planarien häufig unter Steinen sitzend angetroffen werden, wobei sie die Rückenseite dem Boden, die Bauchseite dem Steine zukehren, und daß sie in ähnlicher Stellung an der Wasseroberfläche kriechen.

Wie Thigmotaxis wirkt, kann man sich vergegenwärtigen, wenn man in ein Glas mit Planarien Objektträger bringt, die man einseitig etwas emporhebt. Sobald die Planarien bei ihrem Kriechen von oben her einen Berührungsreiz empfangen, ziehen sie sich zusammen und machen eine schraubenartige Drehung, so daß sich die Bauchseite dem aufliegenden Glas anlegt. Das Gleiche spielt sich $a b$, wenn ein Exemplar mit einem hohl aufliegenden Stein in Berührung kommt, oder wenn es zufällig auf den Rücken fällt. Die Thigmotaxis ist nicht an bestimmte Stellen gebunden, sie zeigt sich auch an gehirnlosen Rümpfen, sogar an wenig umfangreichen Abschnitten der verschiedensten Körperregionen. Schneidet man eine Planarie der Länge nach in zwei Hälften, so beobachtet man schraubenartige Bewegungen, die den thigmotaktischen durchaus entsprechen. Wahrscheinlich handelt es sich um eine Ausfallserscheinung, deren Ursachen nicht bekannt sind. 
Die Sinnestätigkeit einer Planarie ist nach dem Gesagten sehr kompliziert und hochstehend. Wir können zum mindesten Phototaxis, Chemotaxis, Rheotaxis und Thigmotaxis unterscheiden.

Interessant sind die Fälle, in denen die eine Reaktionsweise über die andere siegt. So kann z. B. eine Planarie durch Licht oder Strömungswirkung vom Weg nach der gewitterten Beute abgebracht werden. Sie kann z. B. auch rheotaktisch gegen das Licht oder phototaktisch mit der Strömung wandern. Ob die eine oder die andere Reaktionsweise vorherrscht, hängt von der momentanen ${ }_{n}$ Stimmung ${ }^{~} a b$, in der sich die Tiere befinden. Bei Hunger wandern die Planarien hellem Sonnenlicht entgegen, nach Uberfütterung setzen sie sich trotz Strömung und Licht zur Ruhe. Auch Berührungsreize werden verschieden beantwortet je nach der Stimmung des Versuchsobjektes. Letztere ist denn auch ein recht unbequemes Moment für den Experimentator und macht manche Resultate undeutlich, die $z \mathfrak{u}$ anderer Zeit und unter anderen Nebenumständen mit aller nur wünschbaren Klarheit $\mathrm{zu}$ erlangen sind.

Feinde und Parasiten der Tricladen

\begin{tabular}{|l|l} 
Feinde Die Sinnesorgane scheinen den Tricladen ausschließlich \\
zum Nahrungserwerb und zur Flucht vor schädigenden
\end{tabular} Einflüssen des umgebenden Mediums dienlich zu sein; sie sind keine Mittel zum Schutz gegen Fein de. Das erklärt sich hauptsächlich aus der sehr geringen Zahl turbellarienfressender Tiere. Die schleimige Körperbeschaffenheit, vielleicht auch übelriechende oder giftige Körpersekrete verbunden mit der Fähigkeit, sich an der Unterlage sehr fest anzusaugen, erschwert etwaigen Feinden den Fang von Planarien in dem Maße, daß das Gefressenwerden für die Planarien nur eine seltene Gefahr darstellt. Man hat schon verschiedenen Tieren, wie Tritonen, Salamanderlarven, Stichlingen, Insektenlarven, z. B. den gefräBigen Aeschna- und Dytiscuslarven Planarien vorgeworfen. Gelegentlich konnte das Fehlen einiger Würmer festgestellt werden, mehrmals aber war das 
Gegenteil des Erwarteten eingetreten; das Versuchstier, das die Planarien hätte fressen sollen, war ihnen selbst zum Opfer gefallen. Für Seetricladen konstatierte Wilhelmi ähnliches, wenn es ihm andrerseits auch gelang, Fische zum Fraße zahlreicher Tricladen $\mathrm{zu}$ bewegen.

\section{Parasiten}

Von Parasiten kommen in erster Linie in Betracht die Sporozoen, von denen mehrere meist ganz ungenügend bekannte Arten im Darm, andere auch im Mesenchym der Süßwassertricladen vorkommen. Über ihre Entwicklung und die Umstände ihrer Übertragung wissen wir nichts. Sehr häufig kommen Sporozoen im Darmlumen und in den Darmepithelzellen der Landtricladen vor. Auch im Mesenchym und in den Hoden kann man die Parasiten nachweisen. Ahnliches gilt für die Polycladen.

$\mathrm{Zu}$ den Wimperinfusorien sind $\mathbf{z u}$ zählen entoparasitische Darmbewohner, die sich besonders gern im Rüsselinnern sowie in der Rüsseltasche aufhalten. $\mathrm{Ob}$ die auf Turbellarien mehrfach beobachteten Trichodinen nur als Commensalen Nahrungsabfälle genießen oder den Wirtstieren, wie von anderer Seite angenommen wird, die Cilien abfressen, ist nicht sicher $\mathrm{zu}$ entscheiden.

Bandwurmköpfe, die sich an marinen Tricladen festsaugten und sich daselbst tagelang hielten, konnten einmal beobachtet werden. Es dürfte sich dabei nur um einen Zufallsfund handeln.

Dagegen sind ziemlich häufig kleine Fadenwürmer im Prüssel von Süßwasserplanarien und in allen möglichen Organen und Körperbezirken der Landplanarien nachgewiesen worden.

\section{Oekologie}

\section{Hufenthaltsorte}

Aus den Erörterungen über die Sinnestätigkeit der Planarien ist bereits hervorgegangen, daß die Ansprüche, welche die einzelnen Arten stellen, die Lebensbedürfnisse, recht verschieden sind, 
und somit haben wir zu erwarten, daß auch verschiedene Aufenthaltsorte bezogen werden, daß sich die Planarien demnach auch nach ökologischen Gesichtspunkten gruppieren lassen.

Da haben wir zunächst die Landbewohner, die auch systematisch von den Wassertricladen scharf getrennt sind. Sie müssen sich gegen Trockenheit und grelles Licht schützen, leben daher an feuchten schattigen Orten, unter Baumstämmen in Spalten morschen Holzes oder saftreicher Pilze, unter abgefallenem Laube, im Moos und in Erdlöchern; sie führen eine nächtliche Lèbensweise und halten sich während der trockenen Zeit versteckt. Die bekannteste einheimische Landplanarie Rhynchodemus terrestris scheint Kalkboden $\mathrm{zu}$ bevorzugen und wird besonders in den Monaten September und Oktober gefunden; sie liebt also wohl kühle Temperaturen. Umgekehrt ziehen andere, so die bei uns in Gewächshäusern vorkommende, meist eingeschleppte Art Bipalium kewense höhere Temperaturen vor. Viele Landplanarien, darunter auch die letztgenannte, können bei sehr verschiedenen Wärmegraden existieren.

In zweiter Linie haben wir die Süßwasserplanarien zu betrachten. Sie zeigen innerhalb ihres Mediums wenig beschränkte Verteilung und bewohnen die verschiedenartigsten Gewässer. Im großen See beleben einzelne Formen die Ufersteine und den groben Sand, die phanerogamen Uferpflanzen, wie die Charawiesen, sie steigen zum Teil aber auch in die größten Tiefen hinunter, halten sich bei über $200 \mathrm{~m}$ in den Rasen der Tiefenbryozoen auf und nähren sich von verschiedenen profunden Organismen. Im kleinen Teich mit schlammigem Untergrund, in dessen Pflanzen, vorzugsweise aber unter den schlammfreien Steinen, im Waldtümpel und Sumpf, ja sogar in seichten Pfützen trifft man Tricladen, aus dem tiefen Sodbrunnen lassen sie sich heraufpumpen, und in allen möglichen fließenden Gewässern, vom Waldquell und Sturzbach bis zum breiten Strom oder bis zum trägen Wassergraben und Kanal, in den unterirdischen Quelladern, in Tropfbecken der Tropfsteinhöhlen, überall können Planarien leben; nur die Planktonregion bleibt ihnen versagt, da sie nicht schwimmen können. 
Wir wollen zwei Gruppen unterscheiden:

I. Die Rheophilen, die Bewohner flieBender Gewässer, die nie oder doch nur ausnahmsweise im stehenden Wasser angetroffen werden.

Hierher sind zu zählen die Bewohnerin der Brunnen, des Grundwassers und der Quellen, Planaria vitta, und die Berg-. bachplanarien Pl. alpina und Polycelis cornuta, rheophil sind auch Planaria gonocephala und Polycladodes alba. Ferner sind hierher zu rechnen die beiden Höhlentricladen $\mathrm{Pl}$. cavatica und Dendrocoelum infernale. Nur selten wird man diese Arten in unbewegtem Wasser finden, einzelne verlangen sogar starke Strömung, während andere sich in langsam fließenden Gewässern wohlfühlen.

II: Die Limnadophilen, die Bewohner der ruhigen Teiche, Sümpfe und Seen. Sie kommen wohl gelegentlich auch in bewegtem Wasser vor, können sogar, wie Dendrocoelum lacteum, unter Umständen in die Sturzbäche hinaufsteigen; doch bleibt ihr Hauptverbreitungsgebiet das stehende Wasser.

Hierher zählen die tentakellosen, braunen Planarien: Pl. lugubris, torva und polychroa, dann Dendrocoelum lacteum, Bdellocephala punctata und Polycelis nigra. Unter den hier aufgeführten Spezies hat jede wieder ihre besonderen Liebhabereien. Dendrocoelum lacteum hält sich hauptsächlich unter Steinen auf, Polycelis nigra liebt Wasserpflanzen, Bdellocephala punctata pflegt sich im Schlamme zu verkriechen.

Besondere Erwähnung verdienen die Dunkelbewohner, die teils zu den rheophilen (Pl. cavatica, Dendrocoelum infernale, Pl. vitta, Pl. alpina ex parte) teils zu den limnadophilen (Dendrocoelum lacteum var. bathycola) gehören.

Die Tiefe der Seen scheint bei uns keine besonderen Spezies zu beherbergen, sondern nur Varietäten litoral lebender Arten. Dabei wirkt die besondere Lebensweise auf die Organisation, es entstehen Kümmerformen mit gesteigerter Fruchtbarkeit bei reduzierter Körpergröße, verkleinertem Darm und rüdkgebildetem Pig- 
ment. Selbst die Augen pflegen sich in einzelne Punkte aufzulösen; sie können sich verkleinern, je sogar ganz fehlen.

Uber das Verhalten gegenüber Temperatureinflüssen haben wir schon in anderem Zusammenhang berichtet und auf die sehr großen Verschiedenheiten aufmerksam gemacht, die zwischen den einzelnen Arten bestehen. Die einen verlangen konstante Wärmegrade, ertragen weder hohe noch tiefe Temperaturen und sind besonders empfindlich gegen raschen Temperaturwechsel. Man hat diese Formen als stenotherm bezeichnet. Ihnen stehen die Eurythermen gegenüber, anpassungsfähige Arten, denen Temperaturwechsel nicht viel anhaben kann und die auch bei extremen Kälte- und Wärmegraden noch leidlich gedeihen können.

Aus diesen Bedürfnissen ergibt sich die Verteilung der einzelnen Arten in die verschiedenen Kategorien von Gewässern. Die stenothermen Arten werden an gleichmäßig temperierten Orten in Höhlen, Quellen, Brunnen, Sturzbächen, in den Seen der Hochgebirge, in der Tiefe großer Seen leben, während die eurythermen nicht wählerisch sind und mit verschiedenartigen Wohnstätten vorlieb nehmen, vorausgesetzt, daß sie die übrigen $\mathrm{Be}-$ dingungen ertragen. Den eurythermen Sumpfbewohnern sollte der Weg in den gleichmäßig temperierten Bach offen stehen, es fehlt ihnen aber an Mitteln, der heftigen Strömung zu trotzen. Die eurytherme planaria gonocephala ist, wahrscheinlich wegen ihres großen Sauerstoffbedürfnisses auf fließendes Wasser angewiesen, sie kann aber in der kalten Quelle wie im Wiesenbach mit seiner inkonstanten Temperatur ausdauern.

$\mathrm{Da}$ die Ansprüche an die Reinheit des Wassers, sowie an den Gehalt an Kalk und anderen Stoffen verschieden sind, geht daraus hervor, daß es Reinwasser- und Schmutzwasserplanarien, kalkliebende und kalkfliehende Formen usw. gibt.

Reinwasserformen sind die Bachplanarien, besonders $\mathrm{Pl}$. gonocephala. Als Schmutzwasserorganismus kann stellenweise Dendrocoelum lacteum aufgefaßt werden, wenngleich auch sie starke Verschmutzung meidet. In Kalkwasser scheint 
Planaria alpina besser zu gedeihen als Polycelis cornuta, in kalkarmem ist das Umgekehrte der Fall.

Sehr widerstandsfähig gegen Sauerstoffentzug sind, wie uns Experimente von Bunges zeigen, die limnadophilen Planaria torva und Dendrocoelum lacteum. Diese Formen bleiben nämlich, in abgekochtem Teichwasser über Quellwasser abgegesperrt, 1-2 Tage am Leben.

Andererseits gehen Planaria gonocephala und die übrigen Bachtricladen, ja wohl alle Rheophilen sehr leicht an Sauerstoffmangel zugrunde. Sie lassen sich, selbst wenn es sich um stenotherme Arten handelt, in flachen Becken leicht, in enghalsigen Flaschen schwer züchten, halten in einer Uhrschale mit wenig Wasser tagelang aus, sterben aber in einer Tube mit der gleichen Wasserquantität rasch ab.

Im Bradkwasser oder gar im Meerwasser selbst können sich nur wenige, anpassungsfähige Süßwassertricladen halten, die bekanntesten sind Dendrocoelum lacteum und Planaria torva. Bei Greifswald sollen diese beiden Formen zeitweise geradezu massenhaft im Brack- und Seewasser auftreten.

Von diesen Salzwasser bewohnenden Süßwassertricladen sind scharf $\mathrm{zu}$ trennen die anatomisch wohl charakterisierten, streng marinen Seetricladen, die in nicht sehr großer Anzahl, aber oft sehr individuenreich an den Küsten auftreten. Die meisten ziehen den groben Sand allen anderen Wohnorten vor, einzelne leben unter Steinen der Brandungszone; der an den Pfeilschwanzkrebs gebundenen Bdellouriden ist schon an anderer Stelle gedacht worden. An marinen Algen, wie Ulva, scheinen nur gelegentlich Tricladen vorzukommen, sehr selten verlassen sie die Uferzone und wandern in die Tiefe. Auch für die Maricolen scheint luftreiches Wasser, wie es in der Brandungszone zur Verfügung steht, Lebensbedingung $z u$ sein. Daß sich marine Tricladen in flachen Gläsern ohne Durchlüftung halten können und auch in feuchtem Sand ausdauern, spricht nicht für die Widerstandskraft gegen Sauerstoffmangel, indem ja Wasser, das mit größerer Fläche die Luft berührt, recht sauerstoffreich ist, auch ohne Durchlüftung. 


\section{Verbreitung}

Die Verbreitungsmöglichkeiten sind für die Tricladen nicht besonders mannigfaltig infolge ihrer geringen Lokomotion und ihrer versteckten Lebensweise. Man kann auseinanderhalten 1. die aktive Verbreitung durch Wanderung und 2. die passive durch Verschwemmung und Verschleppung. Im folgenden Abschnitt wollen wir zu zeigen versuchen, welche Bedeutung den beiden zukommt.

\section{Aktive Verbreitung}

Als aktive Verbreitung kommen alle Ortsveränderungen in Betracht, die das Individuum vollzieht, andererseits aber auch jene allmählichen Verschiebungen der Wohnbezirke, bei denen die kleinen individuellen Wanderungen eine untergeordnete Rolle spielen, bei denen in erster Linie Vermehrung, Ubervölkerung an der Grenze neu zu besiedelnder Gebiete und auf Aussterben und Degeneration an der Grenze der zu verlassenden Gebiete ausschlaggebend sind. Diese letztere Verbreitungsweise läßt sich nur selten direkt beobadhten, denn meist handelt es sich um Prozesse, die sehr langsam verlaufen, um Verschiebungen, die sich in Zeiträumen von Jahrtausenden unter der Einwirkung von Klimaveränderungen vollziehen. Ein so unsicheres Gebiet, das nur durch indirekte $\mathrm{Be}-$ weise aus der Planarienverbreitung benachbarter Gebiete erschlossen werden kann, ist ein geeigneter Nährboden für verschiedene Hypothesen, und so erfreut sich denn auch das Thema Planarienverbreitung einer besonderen Beliebtheit bei Hydrobiologen und Tiergeographen. Wir werden davon später hören.

Gelegenheits- $\mathrm{DaB}$ seeuferbewohnende Planarien in die Tiefe wanderungen auswandern, beweisen uns die Tiefenvarietäten von Dendrocoelum lacteum und Planaria alpina, die unzweifelhaft nächste Verwandte der litoralen Formen sind. Hier muB also eine Besiedelung durch aktive Wanderung stattgefunden haben. Einige Beobachtungen über das ständige Auftreten von 
Planarien an den eben noch bespülten Steinen des Wasserrandes in Seen mit schwankendem Wasserstand legen die Vermutung nahe, daß die Planarien, dem Wasserrand folgend, seewärts oder landwärts wandern; doch bleiben nach eingetretenem Hochwasser die Ufersteine bisweilen noch einige Zeit unbevölkert. Umgekehrt findet man bei sinkendem Wasserstand unter den trocknenden Steinen oft große Mengen von Strudelwürmern dicht beieinander, die dem Untergang geweiht sind, wenn sie sich nicht noch im letzten Moment zur Auswanderung bequemen. Da bei diesen, den Wasserstandsschwankungen folgenden Wanderungen neues Gebiet nicht bevölkert wird, haben sie für die Verbreitung kaum eine Bedeutung.

Auch in Flüssen und Strömen lassen sich Wanderungen beobachten, die durch das Steigen und Fallen des Wasserspiegels bedingt sind. Sie verlaufen weniger träge als in stehenden Gewässern und sind wohl stets mit rheotaktischen Wanderungen kombiniert. Durch sie erhalten wohl gelegentlich tote Flußarme, die während dem Hochwasser wieder mit dem Strom Kontakt gewinnen, Planarienzufuhr.

Eine wichtigere Rolle spielen, wie wir gesehen haben, die Wanderungen, welche durch ins Wasser gefallene Beute bedingt sind. Bei Bachplanarien haben sie häufig eine dauernde Verlegung des Wohnortes zur Folge. Bei dieser Auswanderung werden die Würmer, wie uns der Abschnitt über Rheotaxis gezeigt hat, in erster Linie durch die Strömung orientiert. Jede Störung, die ruhende Planarien zum Kriechen veranlaßt, Temperaturwechsel, Anderung der Strömungsverhältnisse, Trübung des Wassers durch Regengüsse hat ein Wandern gegen den Strom zur Folge. Daraus müßte sich aber im Lauf der Zeit eine Auswanderung sämtlicher Planarien eines Flußggebietes nach den Quellen ergeben. Nun wird aber wohl jede Planarie im Laufe ihres Daseins einmal oder mehrere Male von der Strömung erfaßt und flußabwärts getrieben, vielleicht sehr weit abwärts, so daß der Ort, wo es ihnen gelingt, sich wieder anzuheften, viel weiter unten liegt als ihre Geburtsstätte. Vermutlich kommt der bei allen Tieren des fließenden 
Wassers in mehr oder weniger deutlichem Grade entwickelten Rheotaxis die Bedeutung zu, die Gefahr, durch wiederholtes Fortgespültwerden aus dem Wohngewässer vertrieben $z \mathbf{u}$ werden, $z \mathbf{u}$ kompensieren. Durch das Bestreben stets gegen die Strömung $z u$ kriechen, gelingt es den rheophilen Tieren, sich trotz wiederholten Verschwemmungen $\mathrm{zu}$ behaupten; die verlorenen Gebiete werden im Lauf der Zeit durch aktive Wanderung wiedergewonnen. Somit hätten also auch diese Gelegenheitswanderungen für die Verbreitung keine Bedeutung - vorausgesetzt, daß die Planarien dauernd in Gewässern oder Flußabschnitten verbleiben, in denen die verschwemmende Wirkung der Strömung und der Grad der Rheotaxis sich genau die Wage halten.

Aus diesen flußaufwärts gerichteten Gelegenheitswanderungen dürften sich einige scheinbar unverständliche Tatsachen der Planarienverbreitung zwanglos erklären lassen.

Die wilden Gletscherströme enthalten sehr wenige oder gar keine Tricladen. Man hat vermutet, daß der Chemismus der Gletschermilch oder die allzutiefe Temperatur hierfür verantwortlich zu machen sei. Die Temperatur ist jedoch oft höher als in dichtbesetzten, kleinen Seitenquellen, kann leicht $6-10^{\circ}$ betragen, während die firngespeisten Seitenadern oft wenig über $0^{0}$ warm sind. Jedenfalls wäre der Talstrom gleichmäßiger temperiert, müBte also schon aus diesem Grunde den Tricladen besser zusagen als die Seitenadern mit ihren unterwärts stark schwankenden Wärmeverhältnissen. Andere Bergströme, die nicht von Gletschern gespeist werden, bei denen das Wasser also normale Zusammensetzung hat, verhalten sich hierin gleich, wiewohl sie mit ihren zahlreichen Eintags- und Köcherfliegen, mit ihren Perliden und Gammariden ein wahres Eldorado für die Planarien darstellen könnten.

Es ist nicht einzusehen, daß der auffallende Reichtum an Planarien in kleinen konstanten Rinnsalen der Alpweiden, in Brunnen und Quellen und das fast völlige Fehlen der Tiere im Talstrom anders erklärt werden kann, als durch gestörtes Verhältnis zwischen Rheotropismus und verschwemmender Kraft des Stromes. Über- 
wiegt der erstere, so sammeln sich die Tiere in den Quellen, im umgekehrten Fall werden sie aus dem Gewässer fortgespült.

Vielleicht wird auf diese Weise auch das Vorkommen der sonst sehr rheophilen Planaria alpina in Hochgebirgseen verständlich, in welche sie aus allzu heftig bewegten Zuflüssen immer wieder eingeschwemmt wird.

$\mathrm{Da}$ nun alle Gewässer im Oberlauf wasserärmer werden und schließlich bergwärts meist in sanftfließende Quellbäche übergehen, könnte sich im Lauf der Zeit sehr wohl das Verbreitungsgebiet der Planarien durcht die rheotaktisch orientierten Gelegenheitswanderungen flußaufwärts verschieben.

Uber gesellige Wanderungen infolge eines angeborenen Wandertriebes weiß man nichts Sicheres. Mehrere Autoren berichten von großen, lange dauernden Wanderzügen stromaufwärts, die durch Jahreszeit oder durch Witterungseinflüsse bedingt sein sollen. Vermutlich handelte es sich jedoch um Gelegenheitswanderungen von der oben gekennzeichneten Art, wenigstens konnte eine Bestätigung dieser Angaben bis zur Zeit nicht erbracht werden.

\section{Passive Verbreitung}

\section{Verschwemmung}

Passiv werden Planarien häufig durch das strömende Wasser verbreitet. Schon oft hat man im Unterlauf von Bächen vereinzelte Exemplare von Planarien angetroffen, die sonst nur in der Quellregion heimisch sind. Wohl stets ist daraus auf passive Verbreitung, auf Verschwemmung geschlossen worden. Über das Schicksal solcher Schiffbrüchiger wissen wir wenig. Wahrscheinlich geht das Individuum infolge der Ungunst der Bedingungen bald zugrunde, jedenfalls kann es nicht zu einer dauernden Ansiedelung kommen, wie denn auch zahlreiche, oft wiederholte Nachprüfungen solcher Lokalitäten späterhin ein Fehlen der Art ergeben haben. Als Ursachen der Verschwemmung kommen verschiedene Zufälligkeiten in Betracht. Leichte Verschiebungen im Bachbett, wie sie das Hochwasser mit 
sich bringt, bewirken, daß zahlreiche Würmer loslassen und, vom Strudel erfaßt, bachabwärts treiben. Geringe Mengen Salz haben eine ähnliche oder noch intensivere Wirkung. DaB die Verschwemmung zur Besiedelung von Alpenseen durch sturzbachbewohnende Arten führen kann, ist schon oben angeführt worden.

\section{Verschleppung}

Als zweite Form der passiven Verbreitung kommt die Verschleppung durch Tiere in Betracht. Leider liegt nicht ein einziger Fall vor, bei welchem diese Verbreitungsweise einwandfrei bewiesen wäre. Noch niemals sind Planarien oder Eikapseln von solchen an den Füßen von Wasservögeln gefunden worden. Somit müssen wir uns damit begnügen, rein theoretisch die Möglichkeit der Verschleppung durch Tiere zu zeigen und darauf hinzuweisen, daß einzelne Fälle von Planarienverbreitung am einfachsten durch passive Ubertragung erklärt werden können.

Bei Planarien des stehenden und fließenden Wassers könnten etwa Rehe oder andere Säugetiere als Verbreiter in Frage kommen. In den Hufspalten oder zwischen den Zehen eines den Bach durchquerenden Tieres könnte eine Planarie oder eine Eikapsel haften bleiben und in einem benachbarten Gewässer wieder abgespült werden. Für Planarien des stehenden Wassers dürfte besonders auch die Möglichkeit bestehen, an den Füßen eines Wasservogels weggetragen und beim nächsten Aufenthaltsort des Vogels wieder abgegeben $z$ werden.

Die Wahrscheinlichkeit ist jedoch eine recht geringe, daß eine Planarie einen längeren Transport durch die Luft unbeschadet durchmacht. Nach Versuchen mehrerer Autoren geht die Planarie (Pl. alpina, gonocephala oder Polycelis cornuta), nachdem sie sich etwa 15 Minuten an der Luft aufgehalten hat, zugrunde. Nur ganz ausnahmsweise wird ein Wasserentzug von ca. 30 Minuten überstanden. Bei der Austrocknung, die mit einem Transport durch Vögel infolge des Luftzugs verbunden wäre, w.ürde sicher der Tod noch viel rascher eintreten. Dazu kommt, $\mathrm{da} B$ die Planarien sich nur sehr ungern an Gegenständen ansetzen, 
die sich selbst frei im Wasser bewegen. Wer etwa versucht hat, frei herumkriechende Planarien mit Löffeln oder Blättern zu fangen, wird sich erinnern, daß die Tiere in dem Augenblick, wo der Gegenstand, auf dem sie sitzen, in Bewegung kommt, loslassen und so dem Sammler große Schwierigkeiten bereiten. Das gleiche dürfte sich aber ereignen, wenn sich eine Ente, an deren Fuß eine Planarie sitzt, zum Wegflug anschickt.

Für die Fluß- und Bachplanarien gelten natürlich alle diese Bedenken in gleichem Grade wie für die Bewohner des stehenden Wassers. Dazu kommt noch, daß die einsamen, unter Gebüsch versteckten Quellen und Quellbäche kaum je von Vögeln besucht werden, so daß für die passive Verbreitung der rheophilen, speziell der torrenticolen, d.h. bergbachbewohnenden Tricladen der Wasservogel als Vehikel nicht von Bedeutung ist. Daß etwa ein Frosch oder eine Kröte auf ihrem feuchten Rücken eine Planarie von einem Gewässer zum andern trägt, mag vielleicht eher vorkommen; doch dürften derartige Fälle äußerst selten sein, da die Frösche sich auf ihren Wanderungen über Land meist reichlich Zeit lassen, mehr.als den Planarien, ihren Passagieren, zuträglich sein dürfte.

Vielleicht eignen sich die Kokons mit ihren festen Hüllen besser für den passiven Transport als die Tiere selbst. Letzteres gilt jedoch nicht für die kugelrunden, glatten Eikapseln von Planaria alpina und Polycelis cornuta, die frei zwischen die Steine des Baches abgegeben werden und in irgendwelche Ritzen und Löcher zu liegen kommen.

Eikapseln dagegen, die mit Hilfe von Stielen an Blätter und Stengel von Wasserpflanzen angeheftet sind, oder durch Schleimbänder an Steinchen haften, haben eher Aussicht, durch Tiere, vielleicht sogar durch den Wind verschleppt $z u$ werden. Immerhin stehen auch solche Fälle unter dem Zeichen des Zufalls und dürften sich selten ereignen, noch seltener wirklich zur Besiedlung neuer Gebiete führen.

Auf eine Erscheinung darf in diesem Zusammenhang noch hingewiesen werden, auf die Fähigkeit der Enzystierung, die bis- 
her nur bei Planaria vitta und außerdem bei meerbewohnenden Tricladen beobachtet worden ist. Bei den letzteren handelt es sich nach Wilhelmi um eine Schleimzyste, die nicht imstande ist, die Tiere vor Eintrocknung $z u$ bewahren. Für Planaria vitta dagegen darf angenommen werden, daß die Eintrockung mit Hilfe des Zystenstadiums überstanden wird. Da die betreffende Form oft in ephemeren, vom Grundwasser gespeisten Waldpfützen auftritt; dürfte die Fähigkeit der Enzystierung mit diesen Lebensgewohnheiten zusammhängen. Natürlich wäre die Planarie in en zystiertem Zustand zu passiver Verbreitung sehr geeignet und es ist möglich, daß wir ihr sporadisches Auftreten nicht ausschließlich durch subterrane Lebensweise mit gelegentlicher Verschwemmung, sondern durch passive Ubertragung im Zystenzustand $\mathrm{zu}$ erklären haben.

Passive Ubertragung ist schon häufig zur Erklärung isolierter Vorkommnisse der Bergbachplanarien herangezogen worden. Kleine Wasserstürze, die rasch versickern, Bäche, welche sich in abflußlose Bergseen, wie die Eifelmaare ergießen, sollen ihre Planarien nicht durch aktiven Zuzug, sondern durch passive Verbreitung erhalten haben. Da nun aber Planarien nicht selten unterirdisch angetroffen worden sind, so ist sehr wohl möglich, daß die Tiere ihren Weg durch Spalten und unterirdische Rinnsale gefunden haben und so, aktiv wandernd, wenn auch auf unsichtbaren Wegen in die isolierten, mit dem tiefer gelegenen System der Gewässer nicht sichtbar zusammenhängenden Wasserläufe gelangt sind.

Direkt gegen passive Verbreitung spricht der Umstand, daß man nicht selten in benachbarten Quellen ganz verschiedene Planarien findet. Im Kaiserstuhl z. B. gibt es nach Bornhauser Quellen, die, trotzdem sie nahe beieinander sind, ganz verschiedene Planarien - die eine Planaria alpina, die andere Polycelis nigra - enthalten. Die durch passive Úbertragung $\mathrm{zu}$ bewerkstelligende Faunenmischung ist trotz der geringen Distanz nicht eingetreten. 


\section{Allgemeine Verbreitung}

Nachdem wir nun die Verbreitungsmöglichkeiten gegeneinander abge-

wogen und dabei die überwiegende Bedeutung des aktiven Wanderns kennen gelernt haben, stellen wir die Frage nach der allgemeinen Verbreitung.

Für die Landplanarien ist die Antwort nicht schwer zu geben: Die wenigen in Europa vorkommenden Formen, speziell die bei uns im Freien beobachteten Rhynchodemus terrestris und bilineatus dürften als weitverbreitete autochthone Bewohner Europas zu betrachten sein. Sie würden sicher noch vielerorts gefunden, wenn sie eine weniger versteckte Lebensweise führten, oder wenn das Augenmerk der Forscher mehr auf sie gerichtet wäre. Über die Verbreitung von Microplana humicola, die in Böhmen entdeckt wurde, wissen wir nichts. Die Seetricladenverbreitung ist noch $\mathrm{zu}$ wenig studiert, um allgemeine Schlüsse zuzulassen. Dagegen sind wir über die Verteilung der Süßwassertricladen zum Teil recht gut unterrichtet, dank der eifrigen Arbeit von Voigt, der zahlreiche andere Zoologen zu ähnlichen Untersuchungen angeregt hat.

In erster Linie nennen wir einige sehr allgemein verbreitete Formen, deren Bezirk wahrscheinlich über die Grenzen Europas hinübergreifen dürfte, wiewohl Angaben über die Vorkommnisse europäischer Tricladen in andern Erdteilen sehr mit Vorsicht aufzunehmen sind. Wir werden uns also auf das Gebiet von Europa beschränken.

Dendrocoelum lacteum, die bekannteste und häufigste Triclade, ist in ganz Europa gemein, kommt sogar in der Ostsee vor. Sie paßt sich auch dem Leben in großen Seetiefen an und nimmt dann neue Charaktere an, sie wird zu einer besondern Varietät. Planaria torva, lugubris und wohl auch polychroa, sowie Polycelis nigra scheinen ebenfalls weiteste Verbreitung zu genießen. Über ihre Herkunft und die Zeit ihrer Einwanderung in Europa läßt sich nichts aussagen. Ebensowenig wissen wir über die Geschichte der sehr seltenen Formen, die bisher nur von einzelnen Fundorten bekannt geworden sind.

Ste inmann-Bresslau, Strudelwürmer. 
Dagegen dürte es sich verlohnen, die Verbreitung von Planaria gonocephala, Polycelis cornuta, Planaria alpina in erster, Planaria cavatica und Pl. vitta in zweiter Linie eingehender $z u$ betrachten, da wir hier einige Kenntnis über die Einwanderungsgeschichte besitzen.

\section{Verbreitung der Bachplanarien}

Planaria alpina, Polycelis cornuta und planaria gonocephala gehören $z u$ den regelmäßigsten Bewohnern der Bergbäche, sie treten oft in großen Mengen auf. Planaria gonocephala ist auBerdem das Charaktertier unverschmutzter Flüsse und Ströme, in denen sie mit Dendrocoelum lacteum zusammen anzutreffen ist. In die Seitenbäche pflegt letztere Form nicht zu wandern. Sie bleibt in den Flüssen zurück, während in der Regel Planaria gonocephala in den Nebengewässern noch häufiger wird. Verfolgen wir nun einen solchen Zufluß oder gehen wir dem Hauptfluß nach bis zur Quelle, so machen wir die Entdeckung, daß im Mittellauf auf einmal eine neue Planarienart auftritt, zunächst mit Planaria gonocephala gemeinsam, weiter oben aber das ganze Bachbett beherrschend: Polycelis cornuta. Damit noch nicht genug. Wenn wir uns der Quelle nähern, so wiederholt sich die Erscheinung, es tritt neben Polycelis cornuta eine neue Form, Planaria alpina, auf, die in der Quelle selbst meist allein zu Hause ist.

Diese charakteristische Verbreitung ist nicht etwa nur auf einen einzelnen Bach beschränkt, sie wiederholt sich überall; es darf geradezu als Regel bezeichnet werden, daß Planaria gonocephala den Unterlauf, Polycelis die Mitte und Planaria alpina das Quellgebiet bewohnt und daß sich zwischen diese, von nur je einer Art besiedelten Gebiete relativ kurze Strecken einschieben, an denen eine Mischung stattfindet.

Demnach hätten wir in einem typischen Gebirgsbach fünf Abschnitte zu unterscheiden:

I. Die Quellregion enthält Planaria alpina allein,

II. Abschnitt " Planaria alpina und Polycelis cornuta gemeinsam, 
1II. Abschnitt enthält Polyceylis cornuta allein,
IV.
n Polycelis cornuta und Planaria gono- cephala gemeinsam,
V. " " Planaria gonocephala allein.

Bachabwärts schließt sich dann häufig noch ein weiterer $A b$ schnitt an, der durch gemeinsames Vorkommen von Planaria gonocephala und Dendrocoelum lacteum ausgezeichnet ist.

Diese überraschende Feststellung verlangt Aufklärung. Wir stellen uns die Frage: Warum kommt Planaria gonocephala nur im Unterlauf oder Planaria alpina nur im Oberlauf vor. Warum sind die Verbreitungsbezirke der Bachplanarien getrennt? Hätten die drei Arten genau die gleichen Bedürfnisse, so wäre kein Grund für das Fehlen der einen im Gebiet der andern einzusehen. Alle drei könnten den Bach von der Mündung bis zur Quelle gemeinsam bewohnen. $\mathrm{DaB}$ sie es nicht tun, beweist uns, daß sie verschiedene Ansprüche an ihr Wohngewässer stellen.

Vergleichen wir die Bedingungen, die der Oberlauf eines typischen Baches seinen Bewohnern bietet, mit denen des Unterlaufs, so fallen uns sofort einige Unterschiede auf. Die Quelle ist wasserärmer als der Unterlauf, bleibt aber dafür jahraus jahrein fast gleichstark, zeigt also geringe Schwankungen des Wasserstandes, während im Unterlauf jeder ordentliche Regenguß ein Anschwellen zur Folge hat. Das Gefälle wird meist im Quellgebiet größer sein als im Unterlauf, doch sind hier keine Regeln aufzustellen. Dagegen läßt sich über die Temperatur das gleiche sagen wie über den Wasserstand. Die Quelle ist konstant temperiert und zwar im allgemeinen kühl, während der Unterlauf sich im Sommer stark erhitzt, im Winter dagegen in gleichem Maße abkühlt. Der Mittellauf nimmt gemäß seiner räumlichen auch eine thermische Mittelstellung zwischen Quelle und Unterlauf ein und ähnlich verhält es sich mit den Wasserstandsverhältnissen.

Untersuchen wir nun auf experimentellem Wege die Unterschiede im biologischen Verhalten der drei Arten, so finden 
wir, daß Planaria alpina ihre Genossen an Empfindlichkeit gegen Temperaturwechsel bei weitem übertrifft. Sie ist ausgesprochen stenotherm und geht zugrunde, wenn sie plötzlichem Temperaturwechsel ausgesetzt ist. Im Eiswasser läßt sich das Tier längere Zeit halten; bringt man es dann aber plötzlich in $12^{\circ}$. warmes Wasser, so kontrahiert es sich und stirbt unter reichlicher Schleimabsonderung. Der gleiche Versuch mit Planaria gonocephala angestellt, gefährdet die Versuchstiere keineswegs, der Temperaturunterschied kann sogar noch wesentlich größer sein, er kann $30^{\circ}$ betragen, bis der Tod der Planarie eintritt. Durch langsames Erwärmen von Eiswasser läßt sich allerdings Planaria alpina an hohe Wärmegrade gewöhnen, sie bleibt bei $21^{\circ}$ noch lebensfähig, Planaria gonocephala aber erträgt selbst Temperaturen von $34^{\circ}$, wenn die Angewöhnung langsam erfolgt.

Es ergibt sich also, daß die stenotherme Planaria alpina gegen schroffen Wechsel sehr empfindlich, die eurytherme Planaria gonocephala dagegen sehr unempfindlich ist.

Planaria gonocephala schreitet vorzugsweise bei Temperaturen von über $12^{\circ}$ zur Fortpflanzung, ihre Geschlechtlichkeit dauert den ganzen Sommer vom Frühling bis zum Herbst, erleidet aber während der kalten Jahreszeit eine Unterbrechung, die je nach Umständen mehrere Monate dauern kann. Immerhin sind die Grenzen der Temperaturen, bei denen Planaria gonocephala sich geschlechtlich fortpflanzt, ziemlich weit. Planaria alpina dagegen pflanzt sich im Winter fort und bildet die Geschlechtsorgane zurück, sobald die Temperatur über $10^{\circ}$ steigt. In Gewässern, in denen dies nicht stattfindet, bleibt sie dauernd geschlechtsreif. Polycelis cornuta ist auch in dieser Beziehung ein Mittelglied, sie steht aber Planaria alpina viel näher als Planaria gonocephala, sie ist ein stenothermer Winterlaicher wie die erstere, kann aber auch bei Temperaturen von ca. $13^{\circ}$ geschlechtsreif sein.

Halten wir nun die physikalischen Eigenschaften der Bachabschnitte und die Eigentümlichkeiten der Planarien in biologischer 
Hinsicht nebeneinander, so finden wir, daß jede Art denjenigen Bachabschnitt bewohnt, dessen Bedingungen ihr am meisten zusagen.

Das scheint vielleicht auf den ersten Blick nicht besonders merkwürdig. Wenn wir aber bedenken, daß die vielen tausend Bachabschnitte, in denen z. B. Polycelis cornuta vorkommt, völlig voneinander getrennt sind, indem das Mündungsgebiet wohl fast überall von Planaria gonocephala besetzt ist, wenn wir uns ferner die großen Schwierigkeiten vor Augen stellen, die einer passiven Ubertragung der Planarien von Bach zu Bach im Wege stehen, so müssen wir uns sagen, $d a B$ die heutigen Verhältnisse auf eine komplizierte Geschichte hindeuten.

Eine Annahme ist in ganz besonderem Maße geeignet, auf die Entstehung der heutigen eigenartigen Verbreitung Licht zu werfen, die Annahme, daß das ganze System der Gewässer ursprünglich von Planaria alpina bewohnt gewesen sei, daß diese Art dann im Lauf der Zeit im Unter - und Mittellauf den Platz geräumt und nur in den kalten Quellen sich erhalten habe. Hierauf wanderte Polycelis cornuta in das Gebiet ein und belebte die Bachstrecken, die ihr von Planaria alpina überlassen wurden. Später mußte auch Polycelis den Unterlauf räumen und ihre Stelle wurde von der dritten Planarie, die in das Gebiet einwanderte, von Planaria gonocephala eingenommen.

$\mathrm{DaB}$ durch die Hypothese die Verbreitung der Planarien erklärt wird, ist wohl nicht $\mathrm{zu}$ bezweifeln; dagegen verlangt sie selbst noch eingehende Begründung. Eine große Reihe von Fragen muß gelöst werden, bevor wir ihre Berechtigung aner kennen dürfen.

Welche Anhaltspunkte haben wir z. B. dafür, daß Planaria alpina einst das ganze Flußsystem beherrscht hat?

$\mathrm{DaB}$ sie bei den heutigen Bedingungen und gemäß ihrem heutigen biologischen Charakter dazu nicht mehr befähigt ist, geht aus ihrer großen Empfindlichkeit gegen Temperaturwechsel und aus ihrem tiefen Temperaturoptimum hervor.

War die Alpenplanarie aber von jeher ein stenothermes Kalt- 
wassertier, oder hat sie sich diese Eigenschaft erst erworben, seif sie die konstant temperierten Quellbäche bewohnt? Mit andern Worten: Ist die Verbreitung eine Folge des biologischen Verhaltens oder das biologische Verhalten eine Folge der Verbreitung? Im zweiten Falle hätten wir die heutige Verbreitung nicht der Stenothermie, sondern anderen Faktoren zuzuschreiben. Da es nun nicht wahrscheinlich ist, daß solche Faktoren an all den weit auseinanderliegenden Orten, an denen Planaria alpina vorkommt, in ganz analoger Weise wirken - man denke an Skandinavien, Balkan, Pyrenäen, Atlas usw. - so hat die erstere Auffassung mehr für sich. Wir nehmen also an - bewiesen ist es nicht daß die alpine Planarie schon von alters her stenotherm war, lange bevor die heutigen Verbreitungsverhältnisse gegeben waren.

Diese Annahme erfordert aber, falls wir im Sinne unserer Hypothesen ursprüngliche allgemeine Verbreitung von Planaria alpina in unsern Gewässern postulieren, eine weitere Voraussetzung: eine Zeit, zu welcher unsere Gewässer gleichmäßig tief temperiert waren. Als eine solche Epoche darf nun die Eiszeit angesehen werden.

Die Annahme, Planaria alpina habe zur Eiszeit alle Gewässer des im Bann des Glazialphänomens stehenden Gebietes allein bewohnt, ist nicht unberechtigt. Es geht dies hauptsächlich daraus hervor, daß das Tier in den Alpen und in Skandinavien noch heute derartige Verbreitung zeigt; wo also das eiszeitliche Regime bis zum heutigen Tage weiterdauert, da haben wir heute noch in allen Bächen von der Quelle bis zum Strom, ja selbst in kleinen Tümpeln und Seen die Alpenplanarie.

Somit dürfen wir den Schluß ziehen:

Die von alters her stenotherme Planaria alpina war am SchluB der Eiszeit in allen Gewässern allein und gleichmäßig verbreitet.

Warum ist sie heute im Tal und in den Unterläufen der Mittelgebirgsbäche ausgestorben? 
Nach dem bereits Besprochenen kann die Antwort nur die sein, daß infolge der Temperaturerhöhung, des stärkeren Hervortretens der jahreszeitlichen Unterschiede die genannten Gewässerabschnitte für die Alpenplanarie unbewohnbar wurden.

Hohe Temperatur und schroffer Wechsel rufen nämlich, wie wir gesehen haben, bei Planaria alpina Selbstverstümmelung durch Querteilung hervor. Regenerierende Tiere bilden die Geschlechtsorgane zurück und zeigen häufig Degenerationserscheinungen. Hohe Temperatur verhindert aber auch den Eintritt der Geschlechtsreife. Diesen Schwierigkeiten ist Planaria alpina nicht gewachsen, sie räumt den Platz. An Stellen, wo sie allein ein Bachsystem bewohnt, wie auf Rügen und in einzelnen Bächen der Mittelgebirge, fehlt sie dem Unterlauf, der infolgedessen überhaupt keine Planarien enthält. Ahnliches berichtet v. Hofsten von den alpinen Planarien Skandinaviens, die in von Moorwasser gespeisten Bächen fehlen. Moorabflüsse zeigen sehr starke Tem peraturschwankungen.

Die untere Verbreitungsgrenze von Planaria alpina mag außerdem bedingt sein durch den oben besprochenen Rheotropismus (s. S. 145).

Im ferneren wird diese Grenze verschoben durch die Konkurrenz von seiten der nachrückenden Polycelis cornuta, die sich in ganz gleicher Weise ernährt wie Planaria alpina und ihr daher in solchen Gewässerabschnitten, in denen sie sich wegen der Ungnnst der Bedingungen sowieso kaum mehr halten kann, verderblich wird. Von manchen Autoren wird dem sogenannten Aushungern eine groBe Bedeutung zugemessen. Voigt stellt sich vor, daß Polycelis cornuta so weit im Bach emporsteige, als die für sie immer ungünstiger werdenden Temperaturverhältnisse es erlauben; sie dezimiert im Mittellauf die Planaria alpina, deren Fortpflanzungs - und Ernährungsbedingungen dort infolge von ungünstigen Temperaturbedingungen schlecht sind, sie wird aber in dem Maße selbst von Planaria alpina dezimiert, als die Bedingungen sich für letztere verbessern. Das Dezimieren geschieht dadurch, daß sich die ver- 
drängende Art reichlicher vermehrt als die verdrängte und daß somit ein Aushungern stattfindet.

So plausibel diese Ausführungen klingen, so machen sie doch eine Voraussetzung, die nur in beschränktem Maße gültig ist: Aushungerung kann nur da stattfinden, wo die Nahrung völlig aufgezehrt wird. Wer nun Planarien sammelt, wird sich leicht überzeugen, daß in verschiedenen Gewässern die Zahl der Planarien sehr stark wechselt und daß die Menge von Nahrungstieren, Gammariden und Insektenlarven in gar keinem Verhältnis steht zur Individuenzahl ihrer Vertilger. Ich kenne Quellen, unter deren Steinen man Dutzende von Planarien finden kann, ohne daß es möglich wäre, eine nur einigermaßen entsprechende Zahl von Flohkrebsen u. dgl. nachzuweisen. Dieser Zustand bleibt aber jahrelang bestehen und beweist uns das bekannte, sehr geringe Nahrungsbedürnis unseres Tieres. Umgekehrt kann man oft Gammariden zu Hunderten beobachten in Bächen, in denen die Planarien sehr spärlich sind. Zugegeben, daß die Planarienverbreitung nahrungsarmer Bäche durch Aushungern modifiziert werden kann, in Gewässern mit NahrungsüberschuB ist an einen Einfluß des Hungers nicht $z u$ denken und im ganzen scheinen die nahrungsreichen Bäche vorzuherrschen.

Aus dem Besprochenen ergibt sich als zweiter SchluB:;

planaria alpina starb im Laufe des Postglazials aus, und $z$ war räumte sie umso größere Strecken, je mehr sich die thermischen Verhältnisse von denen der Eiszeit entfernten. Dabei spielten noch weitere Faktoren mit, speziell das Nachrüdken eines Nahrungskonkurrenten.

Was hat es nun $z u$ bedeuten, daß unterhalb des Verbreitungsbezirks der alpinen Plenarie in den Bächen aller Gebiete derjenige von Polycelis cornuta folgt?

Die einfache Erklärung für diese Verhältnisse ist die: es erfolgte eine Einwanderung in die Bäche im Postglazial, eine all- 
mähliche Besiedelung der von Planaria alpina freigelassenen Bachabschnitte durch Polycelis cornuta. Da die Stenothermie bei Polycelis weniger ausgeprägt ist als bei Pl. alpina, vermag die erstere auch Gewässer zu beleben, die für die letztere unbewohnbar sind; ihr Temperaturoptimum ist aber so gelegen, daß die Quellenregion für ihre geschlechtliche Vermehrung $z u$ tief temperiert ist, sie bleibt daher im Mittellauf und überläßt die Quelle der alpinen Planarie, deren Optimum tiefer liegt. Auch hier mag in nahrungsarmen Bächen der Wettbewerb um die Nahrung die Grenzen mitbestimmen, indem z. B. die alpine Planaria die obersten Vorposten von Polycelis auf dem für letztere ungünstigen Boden erfolgreich aushungern kann.

Polycelis hat also ihre Einwanderung zu einer Zeit vollzogen, wo Planaria alpina anfing, den Platz zu räumen. Auch sie hat wohl anfangs das ganze Gebiet der Ebene nach und nach bevölkert und ist von dort aus in die Bäche hinaufgestiegen, soweit es ihr die Temperaturbedingungen gestatteten.

Was sich kurz nach der Eiszeit mit Polycelis cornuta ereignete, vollzieht sich jetzt vor unseren Augen mit der eurythermen Planaria gonocephala, die in breiter Front aus den großen Strömen in die Flüsse und Nebenflüsse bis in die Bäche hinaufsteigt, das von Polycelis cornuta im Laufe der Zeit geräumte Gebiet $\mathrm{zu}$ besiedeln. Auch sie, die große, kräftige Form, drängt stellenweise wohl polycelis vor sich her, indem sie deren letzte Nadızügler aushungert; doch ist auch an der Verbreitungsgrenze zwischen polycelis cornuta und Planaria gonocephala die Temperatur ausschlaggebend. Der Sommerlaicher, die Ebenenform Planaria gonocephala kann nur im Unterlauf der Bäche mit der kälteliebenden Polycelis erfolgreich konkurrieren. Die tiefe Temperatur gebietet ihr zunächst Halt.

Was die Zeit anbelangt, die seit dem Vordringen von planaria gonocephala verstrichen ist, so ist in zahlreichen Fällen, wo durch Gebäude, Stauwehre usw. der Verbreitung von planaria gonocephala ein Riegel vorgeschoben worden ist, 
zur Genüge erhärtet, $\mathrm{da} B$ der Prozeß sich in historischer Zeit vollzogen hat. Jedenfalls darf als gesichert gelten,

daB Planaria gonocephala in geologisch gesprochen allerjüngster, ja in historischer Zeit, aus den Strömen und Flüssen in die Bäche vorzudringen begonnen hat.

In der Schweiz ist ihr dies erst in ganz bescheidenem Maße gelungen, in den deutschen Mittelgebirgen hat sie zum Teil schon recht bedeutende Erfolge zu verzeichnen. Ihre obere Verbreitungsgrenze ist gegeben durch ihr relativ hohes Temperaturoptimum. Eine untere Grenze scheint nicht zu existieren, da Planaria gono cephala gleichzeitig eine Bewohnerin der großen Ströme ist.

Es bliebe noch darzutun, daß ganz besonders die Ausnahmen, die abweichenden Verbreitungsarten die Hypothese stützen, wenn sie uns andererseits auch zeigen, daß die Komplikation doch größer ist, als man ursprünglich annahm.

Es kommt zunächst vor, daß Planaria alpina in einer Quelle fehlt und durch Polycelis cornuta vertreten ist, ja daß sogar die Gewässer eines ganzen Gebirges wie des Hundsrück diese Eigentümlichkeit zeigen. Geht man den einzelnen Fällen nach, so findet man, daß die Quellen meist in entwaldetem Gebiet liegen, wo sie den Sonnenstrahlen so sehr ausgesetzt waren, daß Planaria alpina sich nicht $z u$ halten vermochte, sondern der weniger empfindlichen Polycelis den Platz räumte. Daß dies nicht von Anfang an der Fall war, beweisen ganz vereinzelte Pl. alpina-Funde in Quellen des Nordhanges des genannten Gebirges. Umgekehrt kann es vorkommen, daß in einzelnen Bächen Polycelis fehlt. Dies ist in den Gewässern des Taunus der Fall. Die Tatsache, daß auch dort in vereinzelten Fällen Polycelis cornuta zwischen den Verbreitungsgebieten der beiden Planaria-Arten noch in spärlichen Exemplaren vorkommt, zeigt, daß hier ebenfalls eine sekundäre Modifikation vorliegt; daß Polycelis gewissermaßen zwischen ihren beiden Konkur renten erdrückt worden ist. Den Grund dieser Erscheinung erblickt Voigt in den speziellen Verhältnissen des Taunus, der kalte, raschfließende Quellen besitzt, während beim Austritt des 
Baches aus dem Walde sofortige Erwärmung eintritt, so daß der Oberlauf für Polycelis gewissermaßen zu kalt, der Unter- lauf zu warm wurde.

Ein besonders lehrreiches Beispiel von Planarienverbreitung im Schweizer Jura bei Bärschwyl sei hier als Ergänzung besprochen (Abb. 77).

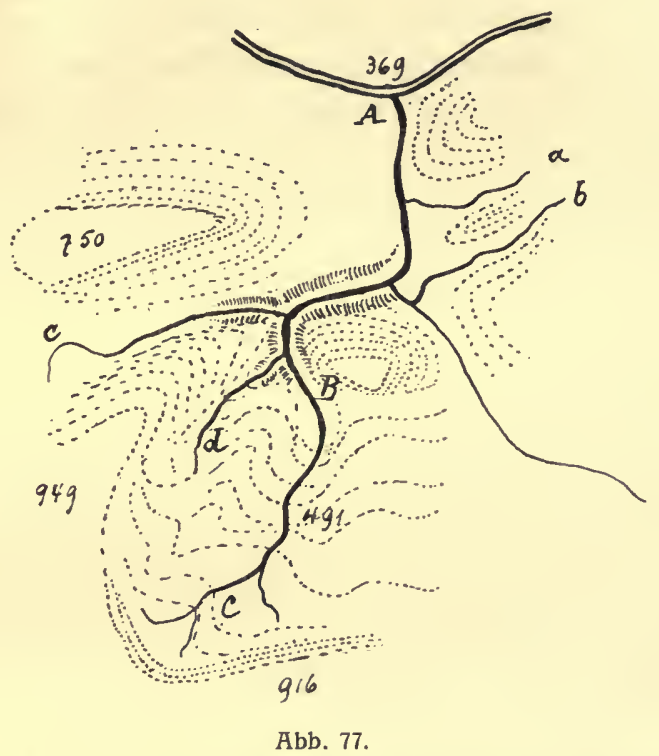

Kartenskizze des Bergbaches von Bärschwyl im Jura.

B A Hauptbach, C dessen Quellgebiet; a, b Seitenbäche mit Südwestexposition, c, d Seitenbäche mit Nordostexposition.

Der betreffende Bach entspringt in Wiesengelände, nimmt sumpfige Nebenrinnsale auf und erwärmt sich daher im Sommer sehr stark.

Die Quelle enthält keine Planarien, ein einziges Mal konnte eine Planaria vitta nachgewiesen werden (bei $C$ Abb. 77). Einige hundert Meter unterhalb findet man bereits Planaria gonocephala, die von hier an den ganzen Oberlauf als einzige Planarie charakterisiert. Weiter unten bildet der Bach eine enge Schlucht, deren Hänge mit Wald bekleidet sind; der eine ist 
ungefähr nach Südwesten, der andere nach Nordosten exponiert. Von beiden Seiten kommen kalte Nebenbäche herunter, in welche Planaria gonocephala nur wenig weit eindringt.

Auffälligerweise enthalten nun die Bäche des nach Südwest exponierten Hanges (a und b) ausschließlich Polycelis cornuta, selbst in der Quelle konnte keine Planaria alpina gefunden werden. Die nach Nordost orientierten Seitenbäche (c und d) dagegen enthalten ebenso ausschließlich Planaria alpina. Im Unterlaufe des Hauptbaches (BA) trifft man neben Planaria gonocephala ziemlich häufig Polycelis cornuta, die aus den Nebenbächen verschwemmt, sich in dem durch die Zuflüsse abgekühlten Wasser zu halten vermag. Im Oberlauf des Hauptbaches waren sicher ursprünglich alle drei Planarien vertreten. Die speziellen Bedingungen haben aber einzig planaria gonocephala übrig gelassen.

Dieser Fall kommt relativ häufig in der Umgebung von Basel vor. Bornhauser nennt aus diesem Gebiet 31 Quellen, in denen Pl. gonocephala, 78, in welchen Pl. alpina vorkommt, während auf Polycelis cornuta 71 Quellen entfallen.

Daß die Temperatur nicht allein maßgebend ist, zeigt uns das spärliche Auftreten oder völlige Fehlen von Polycelis in Kalkgebirgen. Kalkhaltiges Wasser verändert die Chancen der beiden Planariaarten zu ungunsten von Polycelis, die umgekehrt in kalkarmen Gebirgen relativ große Bachstrecken bevölkert und oft Planaria alpina aus Quellen vertrieben hat, in denen letztere normalerweise der Temperatur wegen hätte leben können. Als weiteren die Planarienverteilung modifizierenden Faktor kommt die Nähe großer Flüsse in Betracht, aus denen planaria gonocephala reichlich Nachschub erhält. Sie soll dadurch instand gesetzt sein, Quellbäche mit kurzem Lauf ganz zu erobern, deren Temperaturverhältnisse an sich den stenothermen Planarien nicht verderblich geworden wären.

Zum Schluß sei daran erinnert, daß in den Quellen hin und wieder, und zwar an weit auseinander gelegenen punkten, planaria vitta beobachtet worden ist (Montpellier, Böhmen, Odenwald, Württemberg, Rügen, Basel, Genf). Durch systema- 
tische Quelluntersuchungen gelang es, allein für die Umgebung von Basel 10 Vorkommnisse dieser Planarie festzustellen. Man hätte nach alledem das Recht, die Frage aufzuwerfen, ob dieses merkwürdige, auf Quellen und Höhlen beschränkte Tier nicht gewissermaßen eine Vorgängerin von Planaria alpina gewesen sei, die von letzterer in die Quellen und ins Erdinnere verdrängt worden sei, wie es jetzt mit Planaria alpina geschieht (auch sie ist schon mehrfach subterran gefunden worden). $\mathrm{Ob}$ es sich mit der in der Schweiz mehrfach nachgewiesenen blinden Form Dendrocoelum infernale, mit dem böhmischen Dendrocoelum Mrazeki und der in Schwaben sowie auch anderwärts gefundenen, ebenfalls augenlosen Planaria cavatica ähnlich verhält, muß einstweilen dahingestellt bleiben. Erst wenn ihre Verbreitung in weiteren Gebieten gewissenhaft festgestellt ist, können diese ganz isolierten Formen, die vielleicht eine ältere Faunenschichte repräsentieren, in das allgemeine Verbreitungsbild und in die geographische Diskussion einbezogen werden.

\section{Systematik}

Nachdem wir bereits in der allgemeinen Einleitung (S. 4) eine systematische Übersicht über die Unterordnungen der Turbellarien gegeben haben, handelt es sich hier um Gruppierung der Tricladen und um Hervorhebung einiger besonders wichtiger Formen. Leider sind unsere Kenntnisse über die Tricladen, speziell über die Süßwasserbewohner noch so lückenhaft, daß die hier $z u$ gebende Einteilung als eine vorläufige betrachtet werden muß.

Wiewohl es sonderbar erscheinen mag, daß man heutzutage noch bei der systematischen Einteilung die Lebensweise resp. den Aufenthaltsort in den Vordergrund stellt, haben zurzeit die drei Hauptgruppen der Tricladen: See-, Süßwasser- und Landplanarien auch anatomisch Berechtigung. Und zwar scheint 
es sich nicht um gestaltliche Abweichungen zu handeln, die auf die verschiedene Lebensweise zurückzuführen wären, sondern um wirkliche phylogenetische Unterschiede. Wir wollen daher diese bequeme Einteilung auch hier vornehmen.

\section{Tricladida maricola, Seetricladen oder Meerestricladen}

Kleinere, rein marine Tricladen, mit einer Ausnahme (augenlose Micropharynx parasitica) zweiäugig. Gestielter Drüsensack über oder hinter dem Penis liegend, bisweilen mit besonderer Offnung. Fortpflanzung nur geschlechtlich durch Kokonablage. Die Seetricladen bewohnen das Meer, wo sie freilebend an den Küsten mit besonderer Vorliebe im groben Sand der Brandungszone vorkommen. Eine Familie (nicht europäisch) lebt auf den Kiemen der Pfeilschwanzkrebse als Kommensalen: Bdellouriden. Die wenig bekannte Micropharynx parasitica findet sich als Dauerparasit auf Rochen.

Die Tricladida maricola werden in 6 Familien 10 Gattungen mit etwa 30 Arten eingeteilt.

1. Familie: Procerodidae. Vorderende mit Tastlappen, bisweilen mit Tentakeln.

Beispiel: Procerodes lobata (O. Schmidt) $=$ Gunda segmentata, bekannt durch die Untersuchungen von Lang, zeichnet sich durch große Regelmäßigkeit in der Anordnung der Darmdivertikel, der dazwischen liegenden Hoden und anderer Organe aus. (Pseudometamerie $=$ Scheinbare Segmentierung). - Mittelmeer. (Abb. 78).

2. Familie: Uteriporidae mit zwei Geschlechtsöffnungen, einer vordern Ausmündung des Drüsensackes, sog. Uterus und einer hinteren, die in das Geschlechtsatrium führt. ( $A b b .33$ ).

Die Familie wird nur durch eine Art repräsentiert:

Uteriporus vulgaris Bergendahl. Nördliche Meere, Weißes Meer, Skandinavien. 

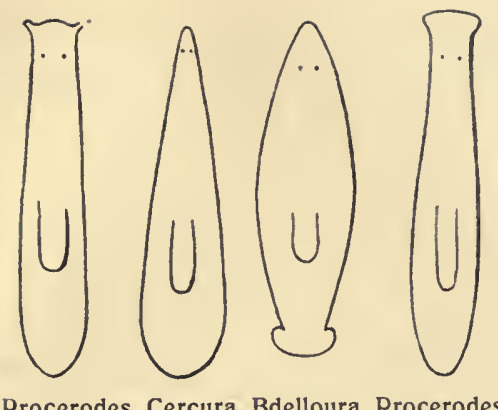

ulvae

Cercyra Bdelloura
hastata candida

rodes

Abb. 78.

Habitusbilder mariner Tricladen (nach Wilhelmi).

\section{Familie: Cercyridae.}

Mit schmalem Kopf und breitem rundlichen Hinterende.

Cercyra hastata $O$. Schmidt, mit langem, spitzem chitinisierten Penis. Mittelmeer.

In diese Familie gehört auch die einzige getrennt geschlechtliche Triclade Sabussowia dioica (Claparède). Mittelmeer, Normandie, England.

4. Familie: Bdellouridae. Hinterende mit Saugnapf, drei Geschlechtsöffnungen, indem jederseits vom Kopulationsapparat ein besonderer Drüsensack (Receptaculum seminis?) ausmündet. Kommensalen auf Limulus.

Bdelloura candida (Girard): Nordamerika; verwandt Syncoelidium Wheeler, durch Verschmelzung der Schwanzdärme hinter dem Geschlechtsapparat charakterisiert.

5. Familie: Micropharyngidae.

Blattförmig, augenlos, am Hinterende eine Haftscheibe.

Einzige Art: Micropharynx parasitica Jägerskiöld parasitisch auf Rochen, Kattegatt.

6. Familie: Synsiphonidae. Synsiphonium Hallez. 
Tricladida terricola, Landtricladen

Meist größere bis sehr große Tricladen (bis $60 \mathrm{~cm}$ lang), von wechselnder Form, Augenzahl und Anordnung sehr verschieden, an der Bauchseite meist eine Kriechleiste. Geschlechtsöffnung einfach; Fortpflanzung geschlechtlich, selten ungeschlechtlich.

Die Landtricladen leben in feuchter Erde und kommen vorwiegend im tropischen und subtropischen Gebiet vor. Sie umfassen etwa 400 Arten, die in 5 Familien und 17 Gattungen eingeteilt werden.

Da es sich hier hauptsächlich um Exoten handelt, wollen wir nur die einheimischen Formen aufzählen:

Bipalium kewense Stimpson aus der Familie der Bipaliidae ist ein Kosmopolit und in Europa nicht selten beobachtet worden, zeichnet sich durch hohes Regenerationsvermögen aus.

Europäisch sind mehrere der im Bau den Süßwassertricladen nahe stehenden Rhynchodemiden. Rhynchodemus terrestris (Müll) und Rh. bilineatus (Darw.) mehrfach in Deutschland beobachtet. Microplana humicola Vejd., nur $6 \mathrm{~mm}$ lang, in Böhmen.

\section{Tricladida paludicola, SüBwassertricladen}

Die Systematik dieser Abteilung liegt noch im Argen. Ohne Zweifel müßten die etwa $80 \mathrm{zu}$ ca. 12 Gattungen $z \mathrm{u}$ sammengefaßten Arten in mehrere Familien gruppiert, einzelne Genera, 'speziell die Gattung Planaria in mehrere selbständige Genera aufgelöst werden. Zurzeit müssen wir uns darauf beschränken, die Genera ohne weitere Zusammenfassung nebeneinander $\mathrm{zu}$ stellen. Auch eine Abteilungsdiagnose ist zurzeit schwer zu geben, da gerade die abweichendsten Formen, die großen Tricladen des Baikalsees ganz ungenügend bekannt sind.

Charakteristisch ist jedenfalls die Lage des gestielten Drüsensackes, der sich zwischen Pharynx und Penis findet und dessen Stiel somit in der Längsachse des Wurmes verläuft und dann etwa rechtwinklig gegen das Atrium abbiegt. Das Vorderende ist recht verschieden gestaltet, die Augenzahl und Anordnung 
wechselt ebenfalls. Neben der geschlechtlichen Fortpflanzung durch Eikapseln kommt dann und wann ungeschlechtliche vor.

Aufenthalt: Stehendes und fließendes Süßwasser, wenige Arten gelegentlich im Brack- oder Seewasser. -

Da wir uns in diesem Buch vorwiegend an die einheimischen Süßwassertricladen gehalten haben, sollen hier zwei Bestimmungstabellen mit anschließenden Diagnosen der wichtigsten Formen folgen. Der Leser soll dadurch in Stand gesetzt werden, die Tiere zu bestimmen. Diese Arbeit wird sehr leicht sein, wenn es sich nur um Unterscheidung der Genera handelt. Auch die Arten sind zum Teil wohl charakterisiert; bisweilen aber kann die Speziesbestimmung nur dann erfolgen; wenn die Tiere in Mikrotomschnitte zerlegt und gefärbt werden. Diesem Umstand sollen die beiden folgenden Bestimmungstabellen Rechnung tragen, von denen die eine für vorläufige Orientierung mit der Lupe, die andere für feinere Untersuchungsmethoden bestimmt ist. Am sichersten wird man gehen, wenn man beide Tabellen nacheinander benützt.

\section{Bestimmungstabelle $I^{1}$ )}

A. Ohne Augen:

I. Ohne Tentakeln; Stirnrand in der Mitte eingebuchtet; Farbe weiß; hintere Darmschenkel verschmolzen:

Anocelis coeca Dugès. (S. 200.)

II. Mit Tentakeln oder beweglichen Seitenlappen des Kopfes:

1. Mittlerer Teil des Stirnrandes konvex; hintere Darmschenkel verschmolzen:

Dendrocoelum mrázeki Vejd. (S. 187.)

2. Mittlerer Teil des Stirnrandes konkav; von zwei kleinen Wülsten flankiert:

a) hintere Darmschenkel verschmolzen; Tentakel schräg nach vorn und nach der Seite gerichtet:

Planaria cavatica Fries. (S. 196.)

1) Die mit Hilfe dieser Bestimmungstabelle mit genügender Sicherheit $\mathrm{zu}$ determinierenden Arten sind mit einem * ausgezeichnet.

Steinmann-Bresslau, Strudelwürmer. 
b) hintere Darmschenkel nicht verschmolzen, keine eigentlichen Tentakel, nur stumpfe bewegliche Seitenlappen am Kopf:

Dendrocoelum infernale (Steinmann). (S.188.)

B. Mit Augen:

I. Zwei Augen am Kopflappen (gelegentlich akzessorische, kleinere Nebenaugen, selten Augen völlig geteilt):

1. Mit pfriemenförmigen Fühlhörnern, Pharynx lang, Kopulationsorgan kugelig, bei geschlechtsreifen Exemplaren als runder, weißer Fleck hinter dem Rüssel äußerlich sichtbar:

* Planaria alpina (Dana). (S. 190.)

2. Ohne pfriemenförmige Tentakeln:

a) Seitenlappen des Kopfes beweglich:

$\alpha)$ Kopf dreieckig, die eine Ecke nach vorn gerichtet, die anderen als aufrichtbare Ohrchen (Aurikeln) entwickelt. Farbe grau, braun, olivengrün, bisweilen fast schwarz, hinter den Aurikeln ein heller Fleck (Aurikularsinnesorgan):

* Planaria gonocephala Dugès. (S. 192.)

$\beta)$ Kopf quer abgestuzt, Stirnrand horizontal bis konkav, Körperrand in der Ruhe gekräuselt:

a) Farbe milchweiß; Darminhalt oft verschiedenartig gefärbt, durchschimmernd;Kopf des kriechenden Tieres nicht viel schmäler als der Rumpf: *Dendrocoelum lacteum (Müll). (S. 184.)

$\beta$ ) Farbe braun, oft mit dunklen Flecken, Kopf viel schmäler als der Rumpf; Saugnapf groß. Größte europäische Art:

*Bdellocephala punctata (Pallas).

b) Seitenlappen des Kopfes nicht abgesetzt, unbeweglich:

a) Stirnrand horizontal oder wenig konvex, daher seitlich am Kopf stumpfe Ecken: 
c) milchweiß gefärbt:

$\left.a^{\prime \prime}\right)$ Stirnrand wenig konvex, Augen der Mittellinie sehr genähert:

Planaria vitta Dugès. (S. 193.)

$\left.\beta^{\prime \prime}\right)$ Kopf mehr gerundet als bei der vorigen Art, Augen weiter auseinander:

Planaria albissima Vejd. (S. 197.)

$\left.\beta^{\prime}\right)$ Nicht milchweiß gefärbt, große braune Form, $z \mathfrak{u}$ beiden Seiten des Kopfes streifenförmige Aurikularsinnesorgane, die zur Hauptsache vor den Augen gelegen sind:

* Planaria torva $M$. Schultze.

$\beta$ ) Kopf gerundet, ohne stumpfe Ecken an den Seiten: (i) Augen liegen vor der breitesten Stelle des Kopfes:

Panaria lugubris O. Schm. (S. 194.)

$\left.\beta^{\prime}\right)$ Augen liegen an oder hinter der breitesten Stelle am Kopf; von der vorigen sehr schwer $\mathrm{zu}$ unterscheiden. Übergangsformen!

Planaria polychroa O. Schm. (S. 195.)

Hierher auch die unsichere Art Planaria fusca (Pallas), deren Stirnwand in der Mitte in ein kleines Spitzchen ausgezogen sein soll, sowie Planaria vruticiana Vejd.

II. Zahlreiche Augen:

1. Augen in zwei unregelmäßigen Haufen, rechts und links von der Medianlinie verteilt. Farbe mildhweiß, Kopfende abgestutzt, mit beweglichen Seitenlappen und terminaler Haftgrube :

* Polycladodes alba Steinmann. (S. 189.)

2. Augen reihenweise dem Stirn- und Seitenrand entlang angeordnet:

a) Kopf mit pfriemenförmigen Tentakeln und leicht konvexem Stirnrand. Hinter dem Mundporus noch zwei 
ventrale Geschlechtsöffnungen (nur bei geschlechtsreifen Individuen):

*Polycelis cornuta Johns. (S. 199.)

b) Kopf mit stumpfen, wenig beweglichen Seitenlappen, median häufig in eine stumpfe Spitze ausgezogen, nur ein Genitalporus:

*Polycelis nigra (Ehrbg.). (S. 198.)

\section{Bestimmungstabelle II}

(Berüdksichtigung der äuBern und der innern Anatomie)

A. Ohne Penis. Große, braune, oft gefleckte Form mit großem Saugnapf und relativ schmalem Kopf:

Bdellocephala punctata (Pallas). (S. 183.)

B. Mit Penis:

I. Penis mit Flagellum, Haftgrube am Vorderende deutlich, etwas ventral verschoben. Kopf quer abgestutzt mit beweglichen Seitenlappen; muskulöses Drüsenorgan vorhanden:

Genus Dendrocoelum.

a) Mit 2 Augen, Flagellum trompetenförmig, bisweilen ausgestülpt und dann in seiner Form schwer kenntlich, Farbe weiß:

Dendrocoelum lacteum (Müll.). (S. 184.)

b) Ohne Augen:

1. Mittlerer Teil des Stirnrandes konvex, hintere Darmschenkel verschmolzen. Vasa deferentia münden dicht nebeneinander ins Penislumen (Samenblase). Uterusgang nicht sackartig erweitert, Farbe weiß:

Dendrocoelum mrázeki (Vejd.). (S. 187.)

2. Mittlerer Teil des Stirnrandes konkav, von zwei kleinen Wülsten flankiert, hintere Darmschenkel nicht verschmolzen; Vasa deferentia weit getrennt, von der Seite her in die Samenblase mündend; Uterusgang sackartig erweitert. Farbe weiß:

Dendrocoelum infernale (Steinmann). (S. 188.) 
II. Penis ohne Flagellum:

A. Ohne Augen:

1. Milchweiße, große Höhlenform mit quer abgestutztem Kopf und beweglichen Seitenlappen. Penis ohne Samenblase. Muskulöses Drüsenorgan vorhanden, Penisscheide fehlt. Exkretionsapparat durchzieht den ganzen Körper

$$
\text { Planaria cavatica Fries. (S. 196.) }
$$

2. Stirnrand median konkav; Seiten des Kopfes abgedacht. Exkretionsapparat nur im vordersten Körperabschnitt:

$$
\text { Anocelis coeca (Dugès). (S. 200.) }
$$

B. Mit Augen:

1. Mit zwei Augen, gelegentlich akzessorische Nebenaugen:

a) Muskulöses Drüsenorgan vorhanden, Kopf quer abgestutzt mit leicht konvexer Krümmung des Stirnrandes:

a) Farbe weiß, Augen der Mittellinie sehr genähert; Aurikularsinnesorgan nicht sichtbar:

Planaria vitta (Dugès). (S. 193.)

$\beta$ ) Farbe braun bis schwärzlich, Augen etwa um ein Drittel der Kopfbreite voneinander entfernt; Aurikularsinnesorgane streifenförmig zu beiden Seiten des Kopfes, nicht immer deutlich:

Planaria torva M. Schultze. (S. 195.)

b) Muskulöses Drüsenorgan fehlt, Kopf verschieden gestaltet:

$\alpha$ ) Mit pfriemenförmigen Tentakeln, Pharynx lang, Kopulationsorgan aus muskulösem, kugeligem Bulbus und dünnem Penis bestehend. Farbe verschieden, häufig grau bis schwarz:

Planaria alpina (Dana). (S. 190.)

$\beta$ ) Ohne pfriemenförmige Tentakeln:

$\left.\alpha^{\prime}\right)$ Kopf dreieckig, die eine Ecke nach vorn gerichtet, die andern als aufrichtbare Ohrchen (Aurikeln) 
entwickelt, Farbe grau, braun, olivengrün, bisweilen fast schwarz, hinter den Aurikeln ein heller Fleck (Aurikularsinnesorgan). Vesicula seminalis vorhanden. Ductus ejaculatorius in zwei durch eine Erweiterung getrennte $\mathrm{Ab}$ schnitte zerfallend:

Planaria gonocephala Dugès. (S. 192.)

$\left.\beta^{\prime}\right)$ Kopf nicht dreieckig:

$\left.a^{\prime \prime}\right)$ Farbe weiB, Kopf quer abgestutzt mit stark konvexem Stirnrand. Penis in GröBe und Form fast dem Pharynx entsprechend; Stiel des Drüsensadkes in seinem untern Abschnitt sackartig erweitert; Vereinigung der Vasa deferentia an der Wurzel des Penis; Samenblase fehlt:

Planaria albissima Vejd. (S. 197.)

$\left.\beta^{\prime \prime}\right)$ Farbe braun bis schwarz, Kopf gerundet:

$\left.\alpha^{\prime \prime}\right)$ Augen liegen an oder hinter der breitesten Stelle am Kopf, Aurikularorgan streifenförmig am Körperrand, in Augenhöhe. Penis ziemlich spitz. Bulbus in eine vordere und hintere Partie zerfallend; dazwischen ein kanalartiger Abschnitt:

Planaria polychroa O. Sch. (S. 195.)

$\left.\beta^{\prime \prime \prime)}\right)$ Augen liegen vor der breitesten Stelle am Kopf. Aurikularsinnesorgan ähnlich wie bei voriger Art, doch im Vergleich zu den Augen etwas weiter hinten, Penis stumpfer, Bulbus nicht deutlich in zwei Abschnitte zerfallend, Ductus ejaculatorius nimmt zahlreiche Drüsengänge auf:

Planaria lugubris O. Sch. (S. 194.)

Uber Planaria fusca (Pallas) und Planaria vruticiana Vejd. s. die Bemerkung S. 179. 
2. Mit zahlreichen Augen;

a) Augen in zwei Haufen zu jeder Seite des Kopfes, Kopfende abgestutzt, mit beweglichen Seitenlappen und terminaler Haftgrube. Muskulöses Drüsenorgan sehr groß:

Polycladodes alba Steinmann. (S. 189.)

b) Augen dem Körperrand entlang in einer Reihe geordnet: Genus Polycelis.

a) Kopf mit pfriemenförmigen Tentakeln und leicht konvexem Stirnrand. Zwei hinter einander gelegene Geschlechtsöffnungen, die hintere in eine Höhlung führend, in welcher zwei oder mehr muskulöse Drüsenorgane liegen; gestielter Drüsensack nicht $\mathrm{H}$-förmig:

Polycelis cornuta Johns. (S. 199.)

$\beta$ ) Mit stumpfen, wenig beweglichen Kopflappen. Stirnrand median häufig in eine kleine Spitze ausgezogen, nur eine Geschlechtsöffnung. Muskulöse Drüsenorgane (fakultativ) im gemeinsamen Geschlechtsatrium; H-förmiger gestielter Drüsensack:

Polycelis nigra (Ehrbg.). (S. 198.)

\section{Speziesdiagnosen $\left.{ }^{1}\right)$}

Bdellocephala punctata (Pallas). (Abb. 5, Tafel II; Abb. 6, 29)

Körperlänge 32-40 mm; Breite 6-6,5 mm. In kontrahierem Zustand Länge 13-16 mm; Breite 10-12 mm; Köperrand gewöhnlich gefältelt.

Kopfende verschmälert abgestutzt, vom Rumpf durch eine Art Hals getrennt. Mund ungefähr in der Körpermitte. Geschlechtsöffnung dem Mund viel näher als der hinteren Körperspitze. Färbung: braun, etwas ins rötliche spielend, mit dunkleren Streifen und Flecken. Gelegentlich fehlen die Flecken oder sie sind

1) Unter Benützung der Böhmigschen Diagnosen in Brauers ${ }_{n} \mathrm{SüB}$ wasserfauna ". 
heller als die Grundfarbe und von einem dunklen Rand umsäumt. Am Kopflappen kann man dunklere Längsstreifen unterscheiden; dazwischen liegen helle Partien, in denen die Augen eingebettet sind, die Tentakeln (seitl. Kopflappen), besitzen eine geringe Beweglichkeit und tragen die streifenförmigen, hellen Aurikularsinnesorgane. Sehr stark entwickelt und auch auf der dorsalen Seite bemerkbar ist die Haftgrube mit ihren muskulösen Wülsten.

Darmdivertikelschema $\left.{ }^{1}\right) .10-12,2$ (9-10), 10-12.

Atrium genitale durch Falten eingeengt ( $\mathrm{Abb}$. 29), in $2 \mathrm{Ab}$ schnitte zerfallend; in das vordere Atrium mündet das männliche Kopulationsorgan, das nicht papillenartig vorspringt, sondern sackförmig gestaltet ist. Wände des Sackes muskulös. Etwas weiter hinten öffnet sich in dem vordern Atriumteil der unpaare Ovidukt. Der hintere Abschnitt des Vorraumes nimmt den auf einer Papille ausmündenden Gang des gestielten Drüsensackes auf. Letzterer ist wenig ausgebuchtet. Sein Ausführkanal erstreckt sich weit gegen den Schwanz, biegt dann um, erweitert sich sackartig und durchsetzt schließlich die Papille als enger Gang. Eikapseln kugelig (3-4 ${ }_{1}^{1 / 4} \mathrm{~mm}$ im Durchmesser), enthalten 9-24 Junge.

Lebensweise: In schwach bewegtem oder stehendem Wasser, scheint gewöhnlich im Schlamm zu leben.

\section{Dendrocoelum lacteum (Müll.).}

(Abb. 3, Tafel I'; Abb. 19, 25, 26. 35, 51, 52, 55)

Körperlänge $26 \mathrm{~mm}$; Breite bis $6 \mathrm{~mm}$. Kopfende abgestutzt, mit beweglichen, breiten Seitenlappen, ventraler Sauggrube und 2 dem Vorderrand ziemlich genäherten Augen, deren gegenseitiger Abstand die Distanz von jedem Auge zum entsprechenden Körperrand übertrifft. Mund zirka doppelt so weit vom Vorderende als vom Hinterende entfernt. Genitalöffnung dem Munde näher als der Schwanzspitze. Körperrand in Ruhe gefaltet. Farbe milchweiß. Darm oft rötlichbraun oder schwarzgrau usw. durchschim-

1) Das Darmdivertikelschema enthält die folgenden Angaben: Zahl der Divertikel am linken Schwanzdarm, 2 mal Zahl der Divertikel am Kopfdarm, Zahl der Divertikel am rechten Schwanzdarm. 

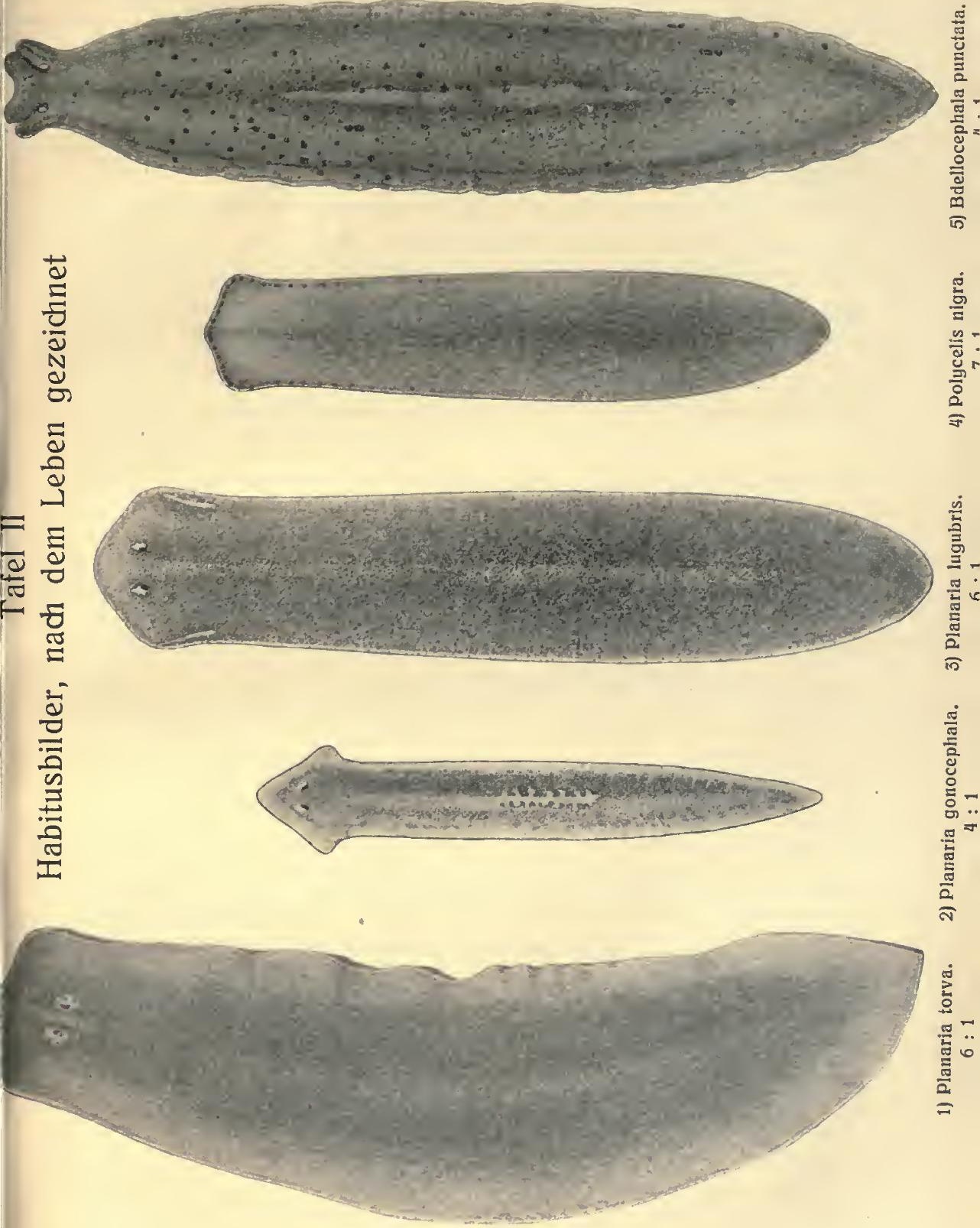

mernd. Die hintern Darmschenkel können der Gegend des Kopulationsorganes zustreben und vereinigen sich häufig.

Schema für die Divertikel: $16-19,2$ (10-15), 16-19.

Kopulationsapparat (Abb. 35) mit Flagellum, kugeligem Penislumen (Vesicula seminalis), das durch ein zottenbildendes Epithel ausgezeichnet ist. Einmündung der Vasa deferentia seitlich. Atrium masculinum verengert sich zur Penisscheide. Ovidukte, zum unpaaren Ovidukt verschmolzen, münden in die Penisscheide. Muskulöses Drüsenorgan birnförmig, liegt etwas schwanzwärts vom Penis. Gestielter Drüsensack mäßig groß, meist gefaltet. Sein Stiel mündet ins Atrium, ohne sich vorher sackförmig zu erweitern. Kokons kugelig, messen $2-3 \mathrm{~mm}$ im Durchmesser und enthalten 5-42 Embryonen.

Lebensweise: In stehendem und fließendem Wasser. Im Rhein kommt sie auch an stark verschmutzten Stellen, z. B. in der Nähe von Abführkanälen der Schlachtanstalt Basel vor. Sie geht stellenweise auch in Bäche mit stärkerer Strömung, bleibt aber daselbst immer vereinzelt. Sie scheint während des ganzen Jahres geschlechtsreif werden und Kokons ablegen zu können. Fortpflanzung durch Querteilung fehlt ihr. Dementsprechend ist auch das Regenerationsvermögen gering.

Dendrocoelum mrázeki (Vejd.). (Abb. 79)

Kopfende abgestutzt mit beweglichen Seitenlappen, die tentakelartig zugespitzt sind. Stirnrand median konvex. Augen fehlen. Hinter dem Kopf eine halsartige Einschnürung. Ventrale Sauggrube schwach entwickelt, bei konservierten Exemplaren in Form eines Längsspaltes. Mund etwa doppelt so weit vom Vorderende als vom Hinterende entfernt. Genitalöffnung dem Mund ziemlich näher als der Schwanzspitze. Farbe weiß. Die hinteren Darmschenkel vereinigen sich zu einem unpaaren Stamm.

Schema für die Divertikel: $12-14,2(11-12)$, $\begin{gathered}\text { Abb. } 79 . \\ \text { Dendrocoelum }\end{gathered}$ $12-14$.

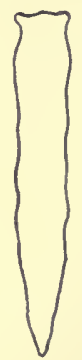
mrazeki (nach Vejd.). 
Im Kopulationsapparat an Dendrocoelum lacteum anschließend, Vasa deferentia münden jedoch dicht nebeneinander in die Samenblase. Penisscheide langgestreckt. Ovidukte öffnen sich ins gemeinsame Atrium. Stiel des Drüsensackes außerordentlich lang, nicht sackartig erweitert. Muskulöses Drüsenorgan ziemlich klein, in eine Aussackung des gemeinsamen Atriums mündend.

Lebensweise: In den Anfangspartien kalter, sehr klarer Waldbäche (Böhmen).

Dendrocoelum infernale (Steinmann). (Abb. $30,36,80,81$ )

Körperlänge bis $13 \mathrm{~mm}$; größte Breite bis $3,5 \mathrm{~mm}$. Kopfende abgestutzt, mit beweglichen, breiten Seitenlappen und ventraler Sauggrube. Augen fehlen. Mund zwischen dem 3. und 4. Fünftel der Körperlänge. Genitalöffnung in der Mitte zwischen Mund und Schwanzende. Körperrand in der Ruhe gefaltet. Farbe weiß.

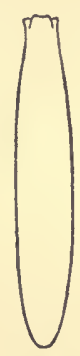

Abb. 80.

Dendrocoleum infernale.

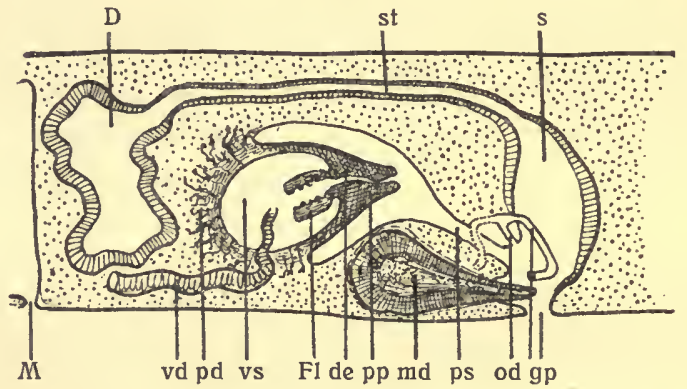

Abb. 81.

Dendrocoelum infernale. Kopulationsapparat.

D Drüsensad, st dessen Stiel, s sackartige Erweiterung, vd Vas deferens, pd Penisdrüsen, vs Vesicula seminalis, F1 Flagellum, de Ductus ejaculatorius, pp Penispapille, md muskulöses Drüsenorgan, ps Penisscheide, od Ovidukt, gp Genitalporus, $M$ Mund.

Darm gewöhnlich sehr schwach durchschimmernd. Die hintern Darmschenkel (Schwanzdärme) bleiben fast immer völlig getrennt. Schema für die Divertikel: $15-18,2$ (12-15), 15-18 (vor läufig; schätzungsweise nach 3 präparaten).

Kopulationsapparat mit Flagellum, dessen Rand nicht nach außen gebogen ist. Penislumen (Vesicula seminalis), kugelig, ohne 
zottenbildendes Epithel. Einmündung der Vasa deferentia in die Vesicula seminalis seitlich. Atrium masculinum verengert sich zur Penisscheide. Ovidukte zu einem unpaaren Ovidukt vereinigt, der in der Nähe der Penisscheidenöffnung ins Atrium mündet. Das muskulöse Drüsenorgan nicht auf gleicher Höhe wie der Penis, birnförmig, ventral. Gestielter Drüsensack mäßig groß, sackförmig. Sein Stiel erweitert sich im letzten Abschnitt sackartig und mündet selbständig ins Atrium.

Lebensweise: Dendrocoelum infernale ist ein Dunkeltier von vorzugsweise subterraner Lebensweise. Im Hölloch bei Schwyz kommt sie in nicht geringer Individuenzahl in einem Höhlenbach vor, der erst nach stundenlangem Vordringen erreicht werden kann.

Polycladodes alba Steinmann (Abb. 1, Tafel I; Abb. 3, 71, 82, 83)

Körperlänge bis $25 \mathrm{~mm}$; Breite 3,5 mm (bei ruhigem Kriechen im lebenden Zustand gemessen). Kopfende abgestutzt, mit breiten, beweglichen Seitenlappen. Sauggrube am Vorderrand. Haftwülste schwach entwickelt. Augen zahlreich in zwei Haufen verteilt (Gehirnhofaugen), mit von Individuum zu Individuum schwankender Augenzahl (5-37). Mund vom Kopfende fast gleich weit entfernt wie vom Schwanzende. Der Pharynx ist $1 / 7$ so lang wie der Körper und liegt, wie aus den eben angegebenen Verhältnissen ersichtlich, relativ weit vorn. Körperrand in der Ruhe gefaltet.

Farbe milchweiß. Darm rötlich, oft auch ganz schwarz oder grünlich durchschimmernd. Die hintern Darmäste neigen zu Verschmelzung.

Schema für die Divertikel 15-24, 2 (9-15), $15-24$.

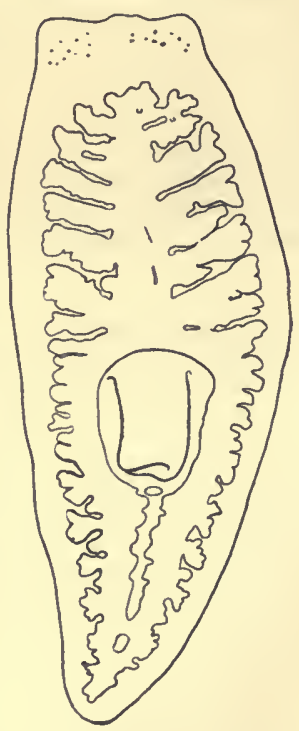

Abb. 82.

Polycladodes alba (nach einem Totalprä parat). 
Kopulationsapparat durch ein sehr großes, muskulöses Drüsenorgan ausgezeichnet, das vollständig hinter dem Penis liegt und den letzteren an Größe wesentlich übertrifft (Gattungscharakter!). Aus demselben Grunde ist die Penisscheide sehr langgestreckt und verengert sich zu einem Gang von geringem Durchmesser. Der Penis ist von einem Atrium masculinum umgeben

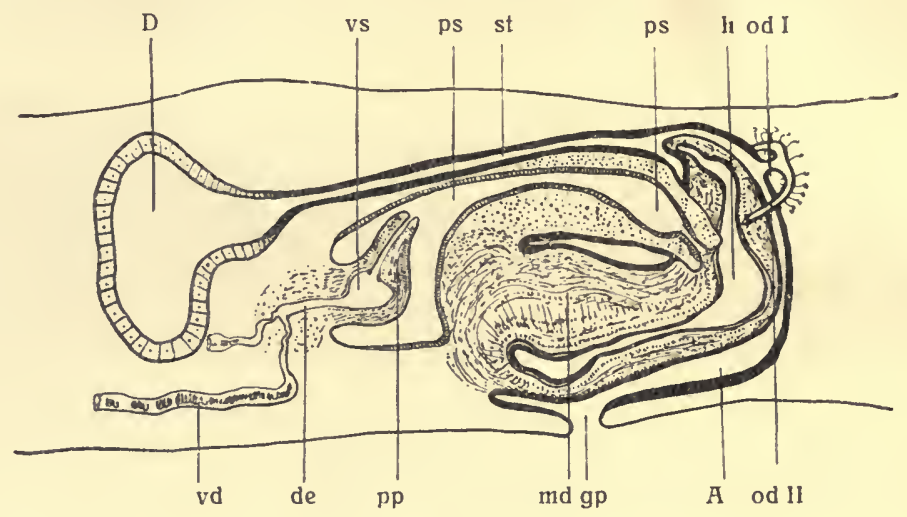

Abb. 83.

Polycladodes alba, Kopulationsorgan.

D Drüsensadk, vs Vesicula seminalis, ps Penisscheide, st Stiel des Drüsensadkes, h Lumen des muskul. Drüsenorg., od I unpaarer Ovidukt, od II paarige Ovidukte, A Geschlechtsatrium, gp Genitalporus, md muskul. Drüsenorgan, pp Penispapille, de Ductus ejaculatorius, vd Vas deferens.

und enthält eine Vesicula seminalis, in welche ein unpaares Vas deferens (verschmolzen aus den paarigen Vasa deferentia) und aus welcher ein Ductus ejaculatorius führt. Stiel des Drüsensackes links, letzterer groß, birnförmig. Die Ovidukte münden gemeinsam in den untersten, etwas erweiterten Teil des Uterusganges. Kokons kugelig, schwarz, ungestielt.

Lebensweise: Quellentier, möglicherweise auch subterran.

Planaria alpina (Dana). (Abb. 42, 48, 69, 84, 85)

Körperlänge bis $16 \mathrm{~mm}$. Breite bis $5 \mathrm{~mm}$. Kopf quer abgestutzt, trägt zwei bewegliche, zirka $1 \mathrm{~mm}$ lange, horizontal ausgestreckte Tentakeln. Die beiden Augen sind vom Stirnrand ziem- 
lich weit entfernt und einander gegen die Medianlinie zu genähert. Eine ventrale Sauggrube scheint inkonstant $\mathrm{zu}$ sein, ist jedenfalls immer nur in geringer Ausbildung vorhanden. Die Färbung variiert in sehr weiten Grenzen. Am häufigsten ist Planaria alpina schiefergrau. Sie kann aber auch völlig schwarz (besonders viele alpine Fundstellen), braun, rötlich, grünlich, gefleckt, ja sogar weiß sein. Die Bauchfläche ist auch bei sehr dunklen Invividuen hellgrau. Der Mund befindet sich am Ende des dritten Körperviertels, der Genitalporus liegt ziemlich weit hinten. Der

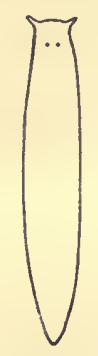

Abb. 84.

Planaria alpina.

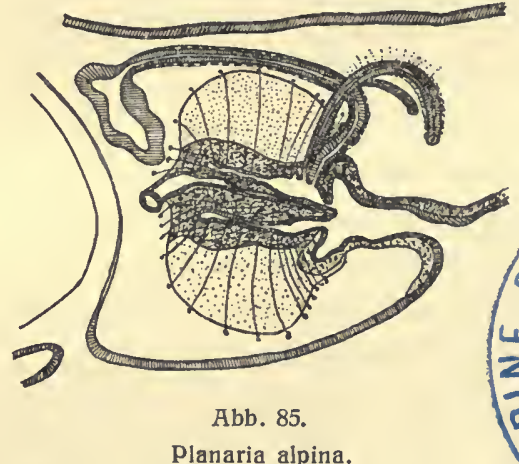

Schema des Kopulationsorganes, die starke Muskulatur des Bulbus zeigend (nadh Böhmig u. Micoletzky).

Pharynx ist demgemäß relativ groß. Durch die Dorsalwand des Körpers schimmert bei geschlechtsreifen Exemplaren deutlich das Kopulationsorgan.

Schema für die Divertikel $16-20,2$ (8-10), 16-20.

Hoden nur präpharyngeal, ventral. Für Planaria alpina und ihre nächsten Verwandten ist sehr charakteristisch die sehr starke, in halbmondförmigen Längsbündeln angeordnete Muskulatur des Penisbulbus. Penis selbst sehr dünn. Am Penisbulbus sind zu unterscheiden eine äußere Schicht, zusammengesetzt aus den eben erwähnten, radiär gestellten Platten und eine nach innen sich anschließende fibrilläre, von Sehnenzügen durchsetzte Lage. Im engen Bulbuslumen befindet sich der Penis. Gestielter Drüsen- 
sack klein. Muskulöses Drüsenorgan fehlt. Kokons kugelig, werden nicht befestigt. Durchmesser 1,6 mm, mit 15-30 Embryonen.

Lebensweise: Bach- und Quellenbewohner, im Hochgebirge auch in stehenden Gewässern... Fortpflanzung im Gebirge und in konstant tief temperierten Gewässern während des ganzen Jahres, an anderen Stellen nur im Winter und im ersten Frühling. Gelegentlich, besonders bei ungünstigen Temperaturverhältnissen, tritt «Fortpflanzung» durch Teilung, besser vielleicht Selbstverstümmelung ein. Regenerationsvermögen gut entwickelt.

\section{Planaria gonocephala Dugès}

(Abb. 2, Tafel II; Abb. 4, 15, 16, 23, 40, 45, 55, 57, 60)

Körperlänge bis $25 \mathrm{~mm}$; Breite bis $6 \mathrm{~mm}$. Kopfende zugestutzt, mit beweglichen, seitlichen Öhrchen, welche als Ecken jederseits am Kopf vorspringen (dreieckköpfig!). 2 Augen, deren Distanz ungefähr gleich der Distanz jedes Auges zum entsprechenden Körper rand. Die Augen liegen vor der breitesten Stelle am Kopf. Mund

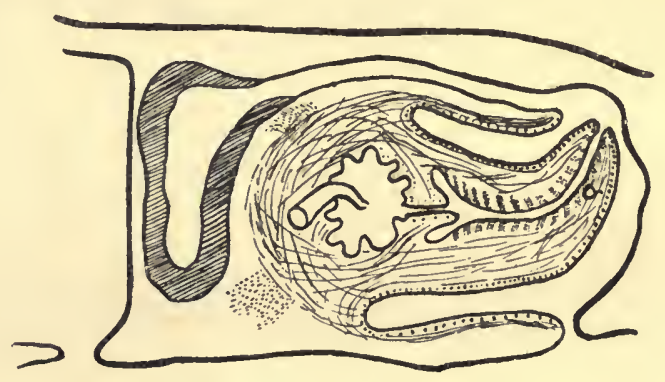

Abb. 86.

planaria gonocephala.

Schema des Kopulationsorganes (nach Böhmig u. Ude).

etwas hinter der Körpermitte. Geschlechtsöffnug dem Munde etwas näher als der Schwanzspitze. Farbe braun bis grau, oft schwärzlich oder auch ins Olivengrün spielend, zuweilen mit dunkleren Längsstreifen. Pharynx schimmert durch die Rückenwand. In zurückgezogenem Zustand wird er gewöhnlich etwas gefaltet, daher erscheinen seine Konturen als 2 Wellenlinien. Bauchseite stets heller. 
Schema für die Darmdivertikel: $13-15,2$ (10-12), 13-15.

Penis groß; Bulbus mit Muskeln, enthält eine Vesicula seminalis mit gefalteten Wandungen. Ductus ejaculatorius in zwei durch eine Erweiterung getrennte Abschnitte zerfallend. Die beiden Ovidukte münden selbständig ins Atrium. Muskulöses Drüsenorgan fehlt. Gestielter Drüsensack groß, mit sehr hohen Drüsenzellen. Stiel nicht erweitert. Kokon kugelig, gestielt an Blättern, Steinen usw. befestigt.

Lebensweise: Rheophil, in Strömen und Bächen. Gegen Wasserverunreinigung äußerst empfindlich. «Leittier» für reines Wasser. Fortpflanzung hauptsächlich im Spätfrühling und Sommer.

\section{Planaria vitta Dugès (Abb. 3,87 )}

Körperlänge 10-15 mm. Körperränder fast völlig parallel. Breite nur etwa $1 / \mathrm{s}$ der Länge, Kopf gerundet, eher etwas breiter als der übrige Körper. Stirnrand variabel (vergl. Abb. 3 u. 87). Augen klein. Ihr gegenseitiger Abstand beträgt ungefähr ein Fünftel der Körperbreite. Vom Stirnrand sind sie ziemlich weit entfernt. Der Mund liegt etwas hinter der Körpermitte. Farbe rein weiß.

Schema für die Divertikel: $18-19,2$ (11), 18-19.

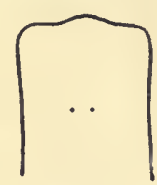

Abb. 87.

planaria vitta. Vorderende.

Genitalapparat dem Verf. unbekannt, da das Tier, wie es scheint, sehr selten geschlechtsreif wird. Vejdovsky und Böhmig geben folgende Diagnose des Geschlechtsapparates:

Penis langgestreckt, keulenförmig, in einen Bulbus und eine schlauchförmige Papille zerfallend, letztere, wie es scheint, vom übrigen Penis durch eine Furche getrennt. Vasa deferentia münden getrennt ins Penislumen. Ovidukte $z u$ einem unpaaren Ovidukt zusammentretend. Muskulöses Drüsenorgan vorhanden mit Lumen. Gestielter Drüsensack birnförmig.

Lebensweise: Planaria vitta ist ein Schlammbewohner und lebt normalerweise subterran. Sie zieht Brunnen und Quellen mit etwas Strömung vor. Sie besitzt ein ausgeprägtes 
Selbstteilungsvermögen und regeneriert sehr leicht und und schnell. Gegen Temperaturerhöhung ist sie empfindlich, dagegen läßt sie sich auch längere Zeit züchten,

Planaria lugubris O. Sch. (Abb. 3 , Tafel II; Abb. 2, 52, 56, 75, 88)

Körperlänge bis $20 \mathrm{~mm}$. Breite $3-4 \mathrm{~mm}$. Kopfende gerundet, etwas verbreitert, in der Form wechselnd («herzförmig, stumpfdreieckig»), in der Regel rund. Die Augen liegen vor der breitesten Stelle am Kopf. Die Aurikularsinnesorgane beginnen in Form von langen, dem Körperrand ungefähr parallel verlaufenden Streifen ohne Pigment, erst eine Strecke weit hinter den Augen. Farbe graubraun bis schwarz. Mund etwa doppelt so weit vom Vorder- als vom Hinterrand entfernt. Geschlechtsporus in der Mitte zwischen Mund und Schwanzspitze.

Schema für die Darmdivertikel: $12-16,2$ (8-11), 12-16.

Penisbulbus in zwei Abschnitte geteilt; der innere enthält die Vesicula seminalis und nimmt die seitlich einmündenden Vasa

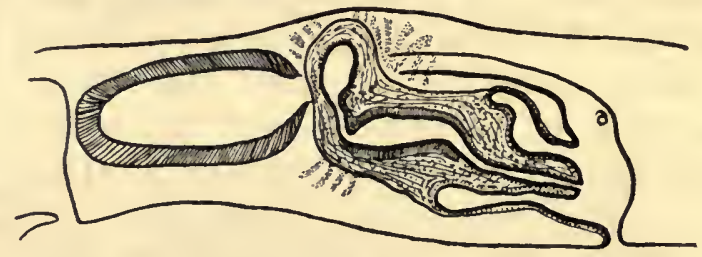

Abb. 88.

Planaria lugubris.

Schema des Kopulationsapparates (nach Böhmig).

deferentia auf. Er liegt ziemlich dorsal und steht daher mit dem zweiten, mehr ventral gelegenen Teil, durch einen Gang von dorsoventralem Verlauf in Verbindung. Diese Knickung des samenführenden Ganges scheint mir nach meinen Präparaten das charakteristischste Unterscheidungsmerkmal der Planaria lugubris von ihrer sehr nahe verwandten Genossin, Planaria polychroa zu sein. Gestielter Drüsensack meist sehr groß.

Lebensweise: Planaria lugubris bevorzugt stehendes und langsam fließendes Wasser, scheint weder gegen Temperaturen noch 
gegen chemische Verunreinigungen empfindlich zu sein, regeneriert leicht und schnell und besitzt die Fähigkeit der Selbstteilung.

$$
\text { Planaria polychroa O. Sch. (Abb. } 52,54,89)^{1} \text { ) }
$$

Körperlänge $16-20 \mathrm{~mm}$. Breite $3-4 \mathrm{~mm}$. Kopfende etwas verbreitert, gerundet. Augen etwas weiter hinten als bei der vorigen Art. Aurikularsinnesorgane daher unmittelbar hinter den Augen. Färbung: Die von mir (Steinmann) beobachteten Exemplare zeigten Fleischfarbe und waren mit braunen Tüpfchen sehr fein gesprenkelt. Die Färbung war sehr wenig haltbar, so daß man sich an die am lebenden Tier gemachten Beobachtungen halten mußte.

Schema für die Darmdivertikel (nach Böhmig): 13-15, 2 (7-8), 13-15. Die Zahl scheint nach Angaben Ijimas in noch weiteren Grenzen schwanken zu können.

Am Genitalapparat scheint charakteristisch, daß das Stück des Ductus ejaculatorius, das die Vesicula seminalis mit der erweiterten, in dem innern Bulbusteil gelegenen Partie des Aus-

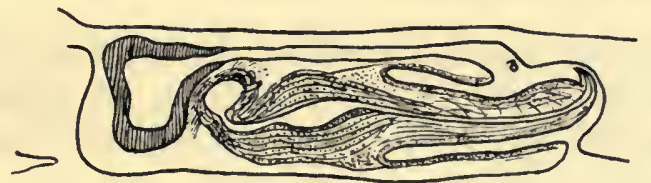

Abb. 89.

Planaria polychroa.

Schema des Kopulationsorganes (nach Böhmig).

spritzungskanales verbindet, in der Längsrichtung verläuft, daß somit das innere Bulbuslumen gegen das äußere nicht rechtwinklig abgeknickt erscheint. Der gestielte Drüsensack ist weniger groß als bei der vorigen Art.

Lebensweise: Wie bei Planaria lugubris.

planaria lugubris und polychroa stehen sich sehr nahe. Die Unterschiede sind fast nur quantitativer Natur. In der Bildung

1) Eine erst während des Druckes erschienene Arbeit über Planaria polychroa: Lang, P., Beiträge zur Anatomie und Histologie von Planaria polychroa, Zeitschr. f. wiss. Zool. 1913 konnte hier nicht mehr berücksichtigt werden, siehe Literaturverzeichnis. 
des Kopfes können sie völlig übereinstimmen. Die Lage der Aurikularsinnesorgane kann ebenfalls nur als sehr zweifelhaftes Kriterium gelten. Die neuesten eingehenden Beschreibungen von Pl. polychroa durch Lang (s. Literatur) können sich fast alle audh auf Pl. lugubris beziehen.

Planaria torva M. Schultze (Abb. 1, Tafel II; Abb. 44)

Bis $20 \mathrm{~mm}$ lang. Vorderende gerundet, Stirnrand jedoch mit stumpfen Ecken in den Seitenrand übergehend. Seitenlappen des Kopfes nicht abgesetzt. - Augen mit ziemlich großem pigmentfreien Hof von Stirnrand ziemlich weit entfernt. Die streifenförmigen, hinten etwas verbreiterten Aurikularsinnesorgane beginnen noch etwas vor den Augen, sind jedoch nicht immer deutlich. Färbung braun bis schwarz, auf der Bauchseite heller.

Mund zirka in der Mitte des dritten, Geschlechtsöffnung am Beginn des letzten Körperviertels.

Schema der reich verzweigten Divertikel: $12-15,2$ (5-8), 12 - 15.

Hintere Darmschenkel bisweilen Anastomosen bildend.

Am Geschlechtsatrium zwei Abschnitte, ein größerer, der den Penis umschließt und den langen unpaaren Endabschnitt der Ovidukte aufnimmt, und ein kleinerer, seitlich gelegener, in den sich der Stiel des Drüsensackes und das eiförmige muskulöse Drüsenorgan öffnen, das zur Längsachse des Tieres fast senkrecht steht. Es kann bisweilen fehlen. Penispapille groß, Bulbus klein. Die Vasa deferentia durchsetzen den Bulbus und vereinigen sich an der Wurzel der Papille zu einem kurzen unpaaren Stück, das in den erweiterten Anfangsteil des Ductus ejaculatorius (vielleicht als Samenblase anzusprechen) mündet.

Eikapseln elliptisch 1,5 zu $1 \mathrm{~mm}$ groß. 7-14 Embryonen enthaltend.

Lebensweise: Stehendes und leicht fließendes Wasser.

Planaria cavatica (Fries). (Abb. 90)

Körperlänge $20-35 \mathrm{~mm}$. Breite $5-10 \mathrm{~mm}$. Kopfende abgestutzt. Stirn eingebuchtet, von zwei seitlichen Längswülstchen 
flankiert. Tentakel mäßig groß, sçräg nach vorn und seitwärts gerichtet. Sauggrube wohl entwickelt. Augen fehlend. Färbung milchweiß.

Schema für die Darmdivertikel nach Böhmig: $18-22 ; 2$ (14-17), 18-22.

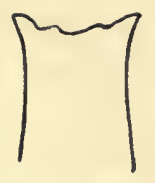

Abb. 90.

Planaria cava. tica. Umriß des Vorderendes (nach Enslin). als vom Schwanzende. Kopulationsorgan mit großer Papille ohne Samenblase, frei im Atrium. Die Vasa deferentia durchsetzen die Peniswand in schräger Richtung und vereinigen sich erst in der Nähe der Bulbusspitze zu einem ganz kurzen Ductus ejaculatorius.

Ovidukte zum unpaaren Eileiter verschmolzen. Muskulöses Drüsenorgan auf gleicher Höhe wie der Penis, ist nach eigenen Untersuchungen betrãchlich kleiner als der Penis, soll dagegen nach Böhmig-Enslin fast die Größe des Penis erreichen.

\section{Planaria albissima (Abb. 91, 92)}

Körperlänge bis $10 \mathrm{~mm}$; Breite bis $1,5 \mathrm{~mm}$. Kopf quer abgestutzt mit deutlich konvexem Rand, ohne Tentakeln, Seitenlappen gerundet; 2 Augen, nicht sehr nahe beieinander; ihr Abstand soll etwas schwanken. Mund etwa doppelt so weit vom vordern als vom hintern Ende entfernt.

Schema für die Divertikel: $17-20,2(6-8)$, $17-20$.

Uber den Kopulationsapparat schreibt Böhmig: ${ }_{n}$ Der zylindrische, stumpf zugespitzte Penis steht an Größe wenig hinter dem Pharynx zurück. Die Vasa

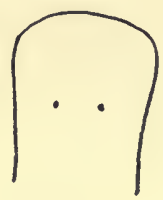

Abb. 91.

Planaria albissima.

Vorderende. deferentia vereinigen sich sofort bei ihrem Eintritt in den sehr kleinen Penis bulbus zum Ductus ejaculatorius, der in ganzer Länge von einer dicken Schicht von Ringmuskeln umgeben wird. Von noch größerer Mächtigkeit ist die äußere Ringmuskelschicht, des Penis im engern Sinne; das mesenchymatöse Gewebe, welches diese beiden Muskelschichten trennt, wird von Radiär- und Längsmuskeln durchsetzt, von denen die letztern zum Teil - und dies gilt auch für die Ringmuskeln - in die Muskulatur des Atriums, 
zum Teil in die des Penis bulbus übergehen. In den vordersten Abschnitt des Ausspritzungskanales münden die Ausführgänge von Drüsen, die selbst in der Umgebung des Bulbus gelegen sind; das Sekret eines Teiles dieser Drüsen färbt sich mit Eosin lebhaft rot, das anderer bleibt ungefärbt. Der Uterus [= gestielle Drüsensack] ist von geringer Größe. Der Uterusgang [Stiel des Drüsensackes] verläuft anfänglich oberhalb des Penis nach rückwärts, kommt alsdann seitlich von diesem $z u$ liegen und wendet

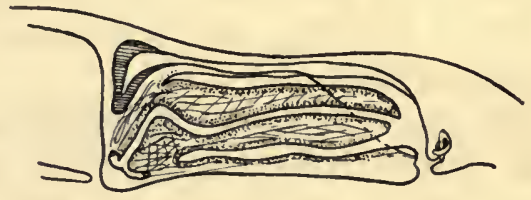

Abb. 92.

Planaria albissima.

Schema des Kopulationsorgans (nach Böhmig).

sich schließlich mit einer ziemlich scharfen knieförmigen Biegung der Ventralseite $z \mathbf{u}$, wobei er sich zugleich sackartig erweitert. Die Wandung dieses erweiterten Teiles ist sehr muskulös und besitzt infolgedessen eine bedeutende Dicke. Die Ovidukte vereinigen sich hinter dem Atrium genitale zu einem unpaaren Gange, der dicht oberhalb des Genitalporus in den Vorhof mündet."

Lebensweise: In Tümpeln, Bächen und Quellen (Böhmen und Steiermark). Das Tier tritt bisweilen in groBer Zahl auf und verschwindet dann plötzlich.

Polycelis nigra (Ehrenbg.). (Abb. 4, Tafel II; Abb. 67)

Länge bis $12 \mathrm{~mm}$. Breite 1,5 mm. Kopf vorn abgestutzt, median in einen ganzen stumpfen Winkel ausgezogen. Die seitlichen Kopflappen sind stumpf und wenig beweglich. Der Kopf ist jedoch die breiteste Partie des Körpers. Die Färbung ist sehr variabel, grau, braun, schwarz, auch grünlich, rotbraun bis schwefelgelb, bisweilen ein dunkler Rückenstreifen. Mund hinter der 
Körpermitte. Genitalporus dem Munde etwas näher als der Schwanzspitze.

Schema für die plumpen Divertikel: $12-16,2(4-6), 12-16$ :

Penis in ein Atrium masculinum eingeschlossen, das sich zur Penisscheide verengert, enthält einen weiten, unregelmäßig ausgebuchteten Ductus ejaculatorius und nimmt zahlreiche Penisdrüsen, sowie die seitlich mündenden Vasa deferentia auf. Ovidukte, zu einem relativ langen, unpaaren Stück verschmolzen, münden direkt ins Atrium commune, in welches auch $1-2$, zuweilen fehlende, muskulöse Drüsenorgane vorragen. Letztere sind birnförmig und sitzen mit dem verbreiterten Hinterende im Parenchym. Da ein Lumen fehlt, münden die Drüsen direkt am freien, kegelförmigen Teile des Apparates. Der gestielte Drüsensack ist dadurch, daß er jederseits nach vorn und nach hinten Blindsäcke aussendet, H-förmig gestaltet, jedoch in seiner Form mannigfaltigen Schwankungen unterworfen. Der Stiel entspringt am queren Verbindungsstück des $\mathrm{H}$ und erweitert sich nicht, er mündet nahe der Genitalöffnung ins Atrium. Kokons ellipsoidisch bis kugelig, zirka $1 \mathrm{~mm}$ groß.

Lebensweise: Sehr resistente Form stehender und flieBender Gewässer von nicht zu starker Strömung. Leicht zu züchten. Scheint sich gerne an Pflanzen aufzuhalten. Ablage der Eikapseln im Frühjahr.

Polycelis cornuta (Johnson). (Abb. 2, Tafel I; Abb. 3,58)

Länge bis $18 \mathrm{~mm}$. Kopf mit zwei pfriemenförmigen Tentakeln. Stirnrand leicht nach vorn ausgebuchtet und Kopf ziemlich breit. Färbung sehr variabel, grau und schwarz, etwas in Grünliche spielend, aber auch rötlich, gelb, hellgrau, ja fast farblos. Mund ziemlich weit hinten, etwa doppelt so weit vom Vorderrande entfernt als vom Hinterrande.

Pharynx lang. Hinter der Mundöffnung 2 Genitalpori, ein vorderer dem gewöhnlichen Porus der Tricladen homolog und ein hinterer, akzessorischer, der in einen blind endigenden, die 
(2-5) muskulösen Drüsenorgane enthaltenden Hohlraum führt. Divertikel $13-15,2(4-6), 13-15$. Penis in einem Atrium masculinum, das sich ohne eine Penisscheide zu bilden, in das, Atrium commune öffnet. Bulbus und Papillenteil am Penis nicht scharf getrennt. Ductus ejaculatorius weit, mit Einengungen. Gestielter Drüsensack nicht H-förmig, einfach. Stiel den Kopulationsapparat im Bogen umgreifend, ganz ventral, nächst dem Genitalporus von hinten her ins Atrium auslaufend. Zeigt nach Böhmig an der Umbiegungstelle Muskelverstärkungen in Form eines Ringwulstes.

Eikapseln kugelig, nicht gestielt, werden im Wasser nicht befestigt.

Lebensweise: Rheophil und stenotherm. Speziell massenhaft in gewissen Quellbächen, aus denen Planaria alpina verschwunden ist.

\section{Anocelis coeca (Dugès). (Abb. 93)}

Bis $9 \mathrm{~mm}$ lang. Kopfende ohne bewegliche Seitenlappen.

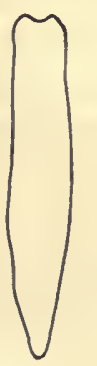
Stirnrand median konkav. Seiten des Kopfes abgedacht. Augen fehlen. Farbe weiß. Die vordersten Verzweigungen des Darmes sind auffallend klein. Die Schwanzdärme verengern sich zu einem unpaaren Stamm.

Schema für die Divertikel 16, 2 (12), 16.

Exkretionsapparat auf die vorderste Körperregion - vor dem Darm - beschränkt. Nur zwei

Hbb. 93. Exkretionsporen und zwei Hauptexkretionskanäle, Anocelis coeca von denen je 4 sekundäre Aste ausgehen, die sich (nach Böhmig u. Vejdovsky). weitergabeln. Die hinteren Äste des dritten Paares bilden ein Netzwerk anastomosierender Kanälchen. Genitalapparat unbekannt.

Lebensweise: Fließendes Wasser (nur 1 Fundort). 
In dieser Zusammenstellung sind von europäischen Tricladen weggelassen:

Planaria macrocephala Fries.

Planaria subtentaculata Draparnauld.

Planaria fusca (Pallas).

Planaria vruticiana (Vejd.).

Alle vier sind nach den vorliegenden lückenhaften Beschreibungen nach meiner Ansicht nicht wieder zu erkennen. Für Planaria subtentaculata ist wahrscheinlich Identität mit Planaria gonocephala anzunehmen.

Von den obigen Arten wurden Dendrocoelum mrazeki und Anocelis coeca nur nach vorliegenden Beschreibungen charakterisiert unter spezieller Anlehnung an die Böhmigsche $\mathrm{Zu}$ sammenstellung in Brauers Süßwasserfauna. Die übrigen wurden nach eigenen Präparaten unter Vergleich mit der Originalliteratur beschrieben, wobei sich zahlreiche, zum Teil wesentliche Differenzen und Widersprüche ergaben. Hoffentlich bringt uns die nächste Zeit die so dringend notwendige Revision der Süßwassertricladen. 


\section{Rhabdocoeliden}

\section{Hnatomie}

\section{Ḧußeres}

Gestalt Uberblidkt man die Gesamtheit der Rhabdocoeliden, so zeigt ihre Körpergestalt viel weniger Einheitlichkeit als die der Tricladen. Neben blattartigen Formen (s. die Tafelfiguren von Mesostoma ehrenbergi), deren Breite in einzelnen Fällen die Hälfte der Länge erreichen kann, finden sich sowohl im Meer (Monocelis u. a.) wie im süBen Wasser (Prorhynchus, Stenostomum) Arten, die, um ein vielfaches länger als breit, feinen Fäden gleichen, und zwischen diesen Extremen vermitteln zahlreiche Ubergänge. Dem Wechsel der äußeren Gestaltverhältnisse entsprechend erscheint der Körperquerschnitt bald trikladenähnlich abgeplattet, bald mehr der Form eines Kreises genähert, bisweilen aber auch viereckig, indem zu den beiden Seitenkanten des Körpers noch je eine kielartige Kante auf der Rücken- und auf der Bauchseite hinzukommt, oder indem statt einer auf jeder Seite zwei Kanten vorspringen, die sich sogar $\mathrm{zu}$ flossenartigen Leisten ausziehen können ( $\mathrm{Abb} .94,95)$. Bei den in unseren süßen Gewässern heimischen Arten überwiegen weitaus die gestreckten Formen von kreisrundem oder nur schwach abgeplattetem Querschnitt. Unsere größten und schönsten Arten dagegen zeigen ausgesprochene Blattform, so vor allem das wundervoll durchsichtige Mesostoma ehrenbergi oder das vierflossige Mesostoma tetragonum (Abb. 94). Vorder- und Hinterende können beide ab- 
gestumpft oder zugespitzt sein, es kann aber auch das eine Körperende spitz, das andere stumpf zulaufen. Bei manchen Formen entsteht dadurch, daß sich das im ganzen breite Hinterende plötzlich verschmälert, ein kleines Schwanzspitzchen (s. die Abb. von Mesostoma ehrenbergi).

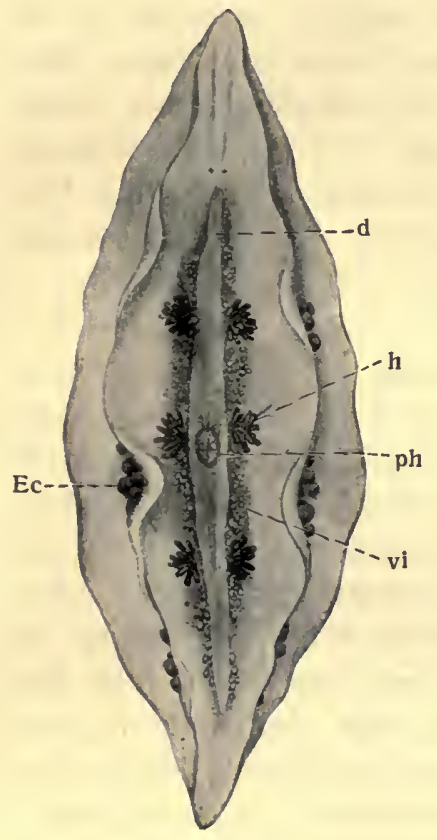

Abb. 94.

Mesostoma tetragonum von oben gesehen. d Darm; Ec Dauereier; h Hoden; ph Pharynx; vi Dotterstock (nach Braun).

Wie bei den Tricladen bildet auch bei den Rhabdocoeliden das Vorderende vornehmlich den Sitz der Tastempfindungen. Doch sind nur ganz wenige Arten mit den dort so verbreiteten Ohrchen oder Tentakeln ausgestattet. Statt dessen ist häufig das ganze Vorderende zu einem durch hohe Beweglichkeit aus-

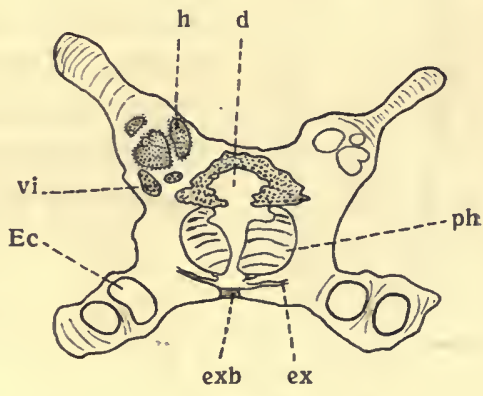

Abb. 95.

Querschnitt durch Mes. tetragonum. ex ExkretionsgefäBe; exb Exkretionsbecher; tubrige Bezeichnungen wie Abb.94 (nach Braun).

gezeichneten Tastapparat umgebildet, der bisweilen fernrohrartig eingestülpt werden kann, wie bei Rhynchomesostoma rostrat um (Abb. 96), öfters aber noch einen dauernd in eine besondere Scheide eingeschlossenen Tastrüssel darstellt (in der Gruppe der Kalyptorhynchia). Wir werden bei der Besprechung der Körpermuskulatur (s. S. 216 ff.) darauf zurüdkkommen. 
Von der ektoparasitischen Gattung Genostoma abgesehen tragen die Rhabdocoeliden niemals an ihren Vorderende Saug-

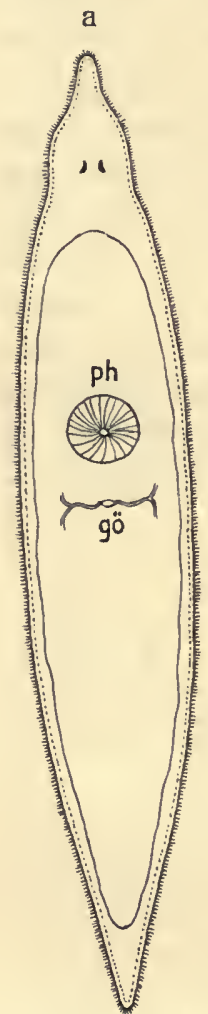

Abb. 96.

Rhynchomesostoma rostratum. a das ganze Tier mit ausgestrecktem, b das Vorderende mit eingezogenem Tastrüssel. ph Pharynx; gö Geschlechtöffnung mit den darein mündenden Exkretionskanälen. anzeigen.

Farbe

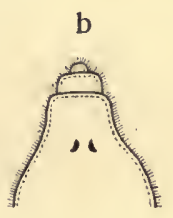
einrichtungen, wie sie die Tricladen besitzen. Sehr vielen Formen fehlt überhaupt die Fähigkeit, sich am Boden oder auf irgendeiner Unterlage festzuheften. Wo dies möglich, geschieht es fast immer nur durch das Sekret besonderer Hautdrüsen (Klebzellen), die vorwiegend am Hinterende ihren Sitz haben und ihr Vorhandensein nicht selten durch kleine papillenartige Vorwölbungen (Haftpapillen) des Körperumrisses

Mannigfaltig wie die äußere Körperform ist auch die Färbung der Rhab-

docoeliden. Manche Arten sind wasserklar durchsichtig. Andere, die ebenfalls ganz oder nahezu pigmentfrei sind, erscheinen weißlich, da ihre Körpergewebe den Durchtrilt des Lichtes hindern. Zahlreicher aber noch sind die Formen, die in-

folge der Anwesenheit von Pigmenten eine bestimmte Färbung besitzen. Sie bilden in ihrer Farbenmannigfaltigkeit einen Gegensatz $z u$ den Tricladen, die vorwiegend düstere Töne zeigen: gelb, orange, grün, rot, braun in allen Schattierungen bis $z u$ einem bräunlichen Schwarz ist vertreten; selbst bläulich grüne und lila Töne kommen vor. Haben die Pigmente ihren Sitz in der Haut oder im Darmepithel, so pflegen sie über diese Organe gleichmäßig verteilt $\mathrm{zu}$ sein und eine mehr oder minder einheitliche Färbung hervorzubringen. Sind sie dagegen im Körperparenchym enthalten, so können sie bei unregelmäßiger Speicherung 
verschiedenartige Zeichnungen in Gestalt von Quer- und Längsbinden, Netzen oder Flecken bedingen. Dabei schließt das Vorhandensein von Pigmenten nicht notwendig die Transparenz der Tiere aus. Besonders Formen, deren Farbstoffe in der Perivisceralflüssigkeit gelöst sind, können sich vollkommene Durchsichtigkeit bewahren. Ein ausgezeichnetes Beispiel hierfür bildet das schön rosarote Rhynchomesostoma rostratum. Reichliche Einlagerung von Pigmentkörnern oder -stäbchen in Haut und Parenchym bewirkt dagegen, wie z. B. im Falle des kaffeebraun bis schwarz gefärbten Bothromesostoma personatum, absolute Undurchsichtigkeit.

Wenn auch die meisten der gefärbten Rhabdocoeliden die pigmente, denen sie ihr Aussehen verdanken, selbst produzieren, so gilt dies keineswegs für alle. Über zwei Dutzend schmücken sich vielmehr mit fremden Farben, die ihnen pflanzliche Organismen - kleine einzellige Algen, die in das Parenchym der Würmer eindringen und sich mit ihnen zu gemeinschaftlicher Existenz ("Symbiose. ${ }^{4}$ ) vergesellschaften - als Mitgift bringen. In den meisten Fällen handelt es sich um chlorophyllhaltige Algen, sog. Zoochlorellen, und der bekannte grüne Pflanzenfarbstoff verleiht dann auch den Würmern, durch deren Gewebe er durchschimmert, eine lebhaft grüne Färbung. Oder aber die Algen sind gelb bis braun gefärbt (sog. Zooxanthellen) und rufen dann eine dementsprechende Färbung ihrer Symbionten hervor. Auch bei den Acoelen gibt es zahlreiche Arten, die sich zur Symbiose mit Zoochlorellen oder Zooxanthellen verbunden haben, wie denn überhaupt diese Art des Gemeinschaftslebens unter den niederen Tieren nicht selten ist ${ }^{1}$ ). Oft ist in diesen Fällen schwer $z u$ entscheiden, ob beide Teile von dem Zusammenleben einen Nutzen haben - wie es der Begriff der Symbiose im Gegensatz zum Parasitismus eigentlich voraussetzt. Um so bedeutsamer ist

1) So rührt z. B. auch die Färbung des grünen SüBwasserpolypen (Hydra viridis) von Zoochlorellen her; vgl. O. Steche, Hydra und die Hydroiden. Diese Monographiensammlung, Bd. 3, 1911, S. $14 \mathrm{f}$. 
es, daß sich bei manchen Acoelen interessante Einblicke in die Art des Verhältnisses zu ihren Zoochlorellen tun lassen. Wir werden uns später noch etwas näher damit zu beschäftigen haben.

Den hohen Grad von Durchsichtigkeit, den manche Rhabdccoeliden erreichen, veranschaulichen wohl am besten die $\mathrm{Ab}-$ bildungen von Mesostoma ehrenbergi auf unserer Farbentafel. In den Gewässern, in denen es lebt, ist es für unser Auge völlig unsichtbar, und junge Exemplare, vor voller Entfaltung des Geschlechtsapparates, entziehen sich selbst dann noch dem nicht durch längere Übung geschärften Blick, wenn sie bereits in der oben (s. S. 16) beschriebenen Sammelschale gefangen sind. Leichter bemerkbar sind ältere Individuen von Mes. ehrenbergi, deren Geschlechtsorgane, Darm und Hirn mitsamt den davon ausstrahlenden Nerven infolge größerer Dichtigkeit des Gewebes als weißliche Partien in dem transparenten Körper hervortreten. Bei gut genährten Exemplaren erscheint zudem der Darm häufig gefärbt, indem die Nahrung durch seine Wandungen durchschimmert. Auffällig werden die Tiere aber erst, wenn sie mit der Bildung ihrer erst leuchtend weißen, dann gelblich und schließlich rotbraun gefärbten, hartschaligen Eier beginnen und ihre Eihälter mehr und mehr damit anfüllen (Abb. 4 der Farbentafel).

Dank dieser vollendeten Durchsichtigkeit und Größe läßt somit Mesostoma ehrenbergi schon bei Lupenvergrößerung alle wesentlichen Züge seiner Organisation erkennen. Nimmt man das Mikroskop zu Hilfe, so enthüllen sich an den lebenden Tieren Einzelheiten ihrer Struktur, die bei weniger transparenten Organismen, etwa bei den Tricladen, nur nach ihrer Abtötung und nach mühsamer Präparation sichtbar gemacht werden können. Wenige Formen unter den vielzelligen Tieren dürften so geeignete Objekte zum Studium des feineren Baues der lebenden Zellen aller möglichen Gewebsarten oder der Vorgänge bei der Zellund Kernteilung abgeben wie gerade Mesostoma ehrenbergi. Ihm ähnlich verhalten sich viele andere Rhabdocoeliden. 


\section{Histologie und Organologie}

Integument

Die Haut der Rhabdocoeliden ist gleich der der Tricladen im allgemeinen recht zart und wenig widerstandsfähig, eine Eigenschaft, von der sich jeder, der diese Tiere lebend im Quetschpräparat untersucht, gar oft zu seinem Schaden überzeugen muß. Nur wenige Arten - vorzugsweise die rüsseltragenden Formen - vertragen einen stärkeren Deckglasdruck, ohne beschädigt zu werden. Meist platzt bald die Haut, und der Wurm geht rasch zugrunde.

Bei ihrer zarten Beschaffenheit besitzen die Wimperzellen der Rhabdocoelenhaut zugleich einen hohen Grad von Plastizität. Man kann daher am lebenden Tier leicht beobachten, daB die Dicke des Epithel bei Anderungen im Kontraktionszustande des Körperteils, zu dem es gehört, beträchtlich schwankt, oder sich unter dem Druck des Deckgläschens verändert. Trotzdem bleibt aber die Höhe der Epithelzellen fast durchweg erheblich hinter ihrer Breite zurück, sie bilden also in ihrer Gesamtheit ein typisches "Plattenepithel“. Bei Mesostoma ehrenbergi $z$. B. beträgt die Höhe der Epithelzellen ca. 0,004-0,008 mm, während ihr Breitedurchmesser 0,1 mm erreichen kann. Von der Oberfläche gesehen erscheinen die Zellen hier polygonal. Sie enthalten einen großen,

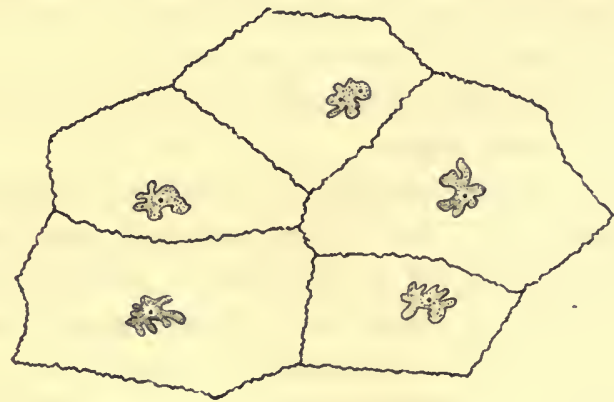

Abb. 97.

Verband von 5 Epithelzellen von Mesostoma ehrenbergl, Oberflädnenansidht. Im Innern die amoeboidgelappten Kerne. 
in sehr verschiedener Weise gelappten, oft auffällig amoebenartig aussehenden Kern mit einem oder mehreren Kernkörperchen. (Abb.97). Nadh außen sind sie durch den Saum der Cilienwurzeln begrenzt, der in früheren Zeiten fälschlich für eine Cuticula angesehen wurde.

\section{Cilien}

Das Wimperkleid ist bei den Rhabdocoeliden im allgemeinen gleichmäßig über die ganze Körperfläche ausgebreitet, wenn es auch bisweilen - so z. B. bei älteren Exemplaren von Mes. ehrenbergi - dorsal im Vergleich zur Bauchseite etwas abgeschlissen erscheint. Fälle, wo es auf größere Strecken ganz in Wegfall geraten ist, sind dagegen recht selten, und es ist wohl kein Zufall, daß gerade solche Formen davon betroffen sind, die sich zugleich durch Besonderheiten ihrer Lebensweise auszeichnen. So fehlen die Wimpern auf dem Rücken der im groben Sand der Meeresufer wohnenden Otoplana intermedia und von Prorhynchus hygrophilus, einer der wenigen Rhabdocoelenarten, die das Wasserleben aufgegeben und mit dem Aufenthalt in feuchter Erde vertausdht haben. Noch weiter geht die Rückbildung des Wimperkleides bei den Vertretern der ektoparasitisch an Krebsen lebenden Gattungen Didymorchis und Genostoma, wo nur noch ein Teil, in letzterem Genus sogar nur ein kleines mittleres Feld der Bauchseite bewimpert. ist. Daß es sich hier gerade um Schmarotzer handelt, verdient besonders im Hinblick auf die den Turbellarien nahe verwandten, durchweg parasitischen Saug- und Bandwürmer, die bekanntlich der Cilien ganz entbehren, Interesse.

Wo das Wimperkleid gut ausgebildet ist, stehen die Cilien außerordentlich dicht beieinander, und ihre Zahl geht bereits auf der Fläche von $1 \mathrm{~mm}^{2}$ in die Millionen. Ihre feinere Anordnung ist daher am lebenden Tiere nicht $z u$ erkennen; man sieht vielmehr auch bei den ganz durchscheinenden Formen nur ein undeutliches Wogen des Wimperkleides, und selbst am Körperrande sind die einzelnen Cilien oft schwer zu unterscheiden. Durch Untersuchung von Präparaten, auf denen die Cilienwurzeln durch 
besondere Färbung (Eisenhämatoxylin) sichtbar gemacht worden sind, läßt sich jedoch feststellen, daß die Wimpern in feinen Längs reihen angeordnet stehen, ähnlich wie man dies bei den Infusorien schon während des Lebens beobachten kann. Allerdings ziehen sich die Längsreihen nicht so regelmäBig über den ganzen Körper hin, wie dort, sondern gehen stets nach längerem oder kürzerem Verlauf ineinander über (Abb. 98); doch setzen sie sich dabei ohne Rücksicht auf die Zellgrenzen lkontinuierlich von einer Zelle auf die andere fort. So wenig man auch von dem Mechanismus der Wimperbewegung weik, so kann man doch vermuten, daß diese Anordnung der Cilien für die Regelung ihrer Schlag folge von einiger Bedeutung ist, und $\mathrm{da} B$ insbesondere die direkte Fortsetzung der Längsreihen von einer Zelle auf die andere das

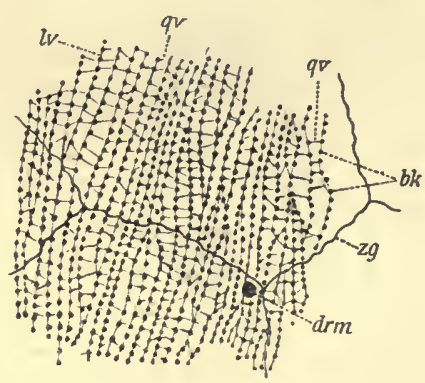

Abb. 98.

Anordnung der Cilienwurzeln (Basalkörperchen, bk) bei Mesostoma ehrenbergi. Iv Längs-, qv Querverbindungen $z$ wischen Cilienwurzeln; $z g$ Grenzen der Epithelzellen; drm Drüsenmündung (nach Luther). ununterbrochene Fortschreiten der

Wellen des Wimperschlages vom einen zum anderen Körperende erleichtert. Möglicherweise spielen auch bei der Fortleitung der die Wimperbewegung veranlassenden Reize, feine fadenartige Differenzierungen des Zellplasmas eine Rolle, die alle Cilienwurzeln einer Längsreihe miteinander verbinden und sich auch, wenngleich unregelmäBiger verteilt, zwischen den Basalkörperchen je zweier benachbarter Längsreihen ausspannen. Es ist aber ebenso gut auch denkbar, daß diese intrazellulären Fasern nur ein Gerüstwerk bilden, das die Cilienwurzeln innerhalb der Epithelzellen fester verankert.

\section{Stäbchen}

Die für die Haut der Strudelwürmer charakteristischen Stäbchen finden sich bei den Rhabdocoeliden in der ganzen Mannigfaltigkeit der oben (S. 29) beschriebenen Aus- 


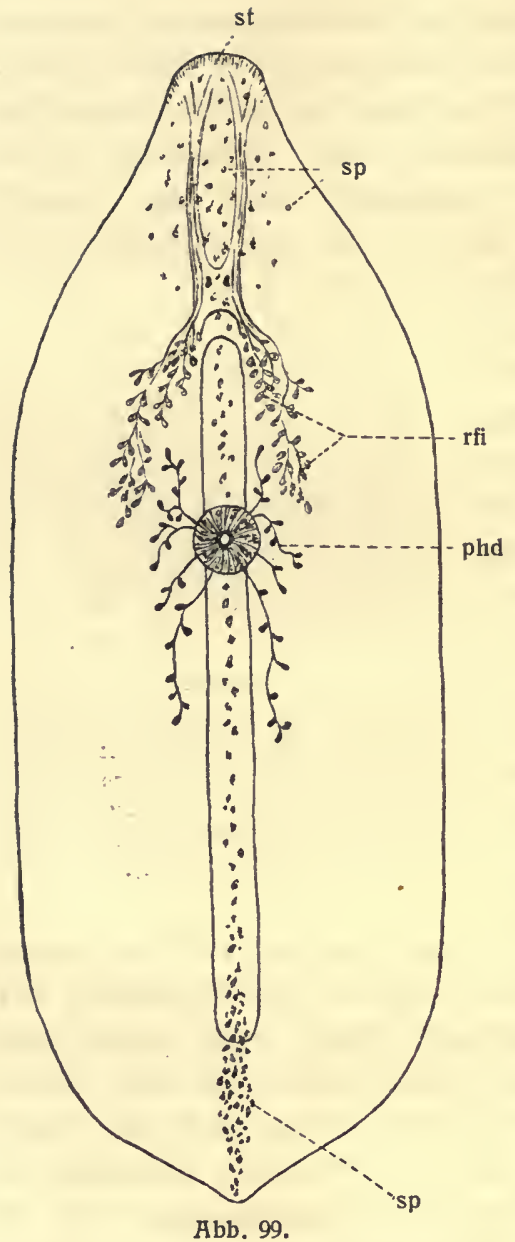

Anordnung der Rhammitenbildungsdrüsen (rh), Splnndrüsen (sp) u. extrapharyngealen Speicheldrüsen (phd) bel Mesostoma ehrenbergi; st dermale Rhabditen des Vorderendes. bildungsformen. Viele Spezies besitzen sogar mehrere Stäbchensorten nebeneinander, seien es Rhabditen und Rhammiten, wie z.B. die Mesostoma-, oder Rhabditen und Pseudorhabditen, wie manche PlagiostomumArten. Umgekehrt können aber auch bisweilen die Stäbchen gänzlich fehlen, so bei vielen Vertretern der Microstomiden, bei Gyratrix hermaphroditus und bei der Mehrzahl der parasitisch lebenden Arten.

Die Stäbchen der Rhabdocoeliden zeichnen sich durch glasartige Beschaffenheit aus, die ihnen auch den Namen

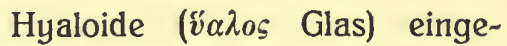
tragen hat. Zugleich ist ihr Lichtbrechungsvermögen von dem des Plasmas der sie einschließenden Zellen nur wenig verschieden. Dank diesen beiden Eigenschaften beeinträchtigen dieStäbchen die Durchsichtigkeit der Tiere im allgemeinen nicht, selbst wenn sie in großer Zahl vorhanden sind. Erst, wo sie sidh so stark anhäufen, daß eins dicht neben dem andern liegt, wird die Transparenz etwas herabgemindert. Dies ist $\mathrm{z}$. B. im Vorderende der Mesostomeen der Fall, wie Abbildung 4 unserer Farbentafel von Mes. ehrenbergi veranschaulicht. Der Vorderrand des auf dunkler Unterlage 
kriechenden Tieres erscheint hier nämlich deshalb weißlich, weil sein Eేpithel dicht von kleinen dermalen Rhabditen erfüllt ist und außerdem massenhaft große adenale Rhammiten enthält, die ihm von den im Parenchym gelegenen Stäbchendrüsen zugeführt werden. Diese finden sich bei allen Mesostoma-Arten im Vorderende weit zahlreicher als im übrigen Körper. Speziell bei Mes. ehrenbergi ist die Hauptmasse der Rhammitenbildungszellen in zwei Paaren traubiger Komplexe zwischen Gehirn und Pharynx angehäuft ( $\mathrm{Abb} .99 \mathrm{rh}$ ), deren Ausführungsgänge in vier sich eng den Hauptnervenstämmen anschmiegenden Strängen zum Vorderende ziehen. Die älteren Forscher pflegten diese Ausführungsgänge als "Stäbchenstraßen“ zu bezeichnen, ein Name, der auch heute noch ganz passend erscheint, da sie stets zahlreiche Rhammiten enthalten, die auf der Wanderung zur Körperoberfläche begriffen sind (vgl. auch Abb. 108, 109 rhdr). Rhabditen und Rhammiten unterscheiden sich, von ihrem Bau abgesehen, auch bedeutend durch ihre Größe. Erstere sind außerordentlich klein und erreichen bei Mes. ehrenbergi eine Länge von kaum $0,004 \mathrm{~mm}$, während letztere bis $0,06 \mathrm{~mm}$, also $15 \mathrm{mal}$ so lang werden können.

\section{Nesselkapseln}

Besonderes Interesse verdient noch eine weitere Sorte von Epitheleinschlüssen in Gestalt von Nesselkapseln (Nematocysten), die bei verschiedenen Meer- und Süßwasserturbellarien, besonders aber bei Vertretern der in unsern Binnengewässern so häufigen Gattung $M$ i crosto m u m ( $M$. li neare, giganteum) $z \mathbf{u}$ beobachten sind. Diese Nesselkapseln gleichen vollkommen den Nematocysten, wie sie die Hydroidpolypen besitzen und wie sie außerdem noch in den Rückenpapillen gewisser Meeresnacktschnecken (Aeolididae) vorkommen, wurden aber früher ganz allgemein für Bildungen nach Art der Stäbchen gehalten, obwohl es von jeher Verwunderung erregt hat, daB so eigenartige Gebilde in 3 so sehr verschiedenen Stämmen des Tierreiches, wie es die Cnidarier, Würmer und Mollusken sind, gleichermaßen zur Entstehung gelangt sein sollten. In neuerer Zeit hat 
sich indessen herausgestellt, daß die Verhältnisse hier ganz anders liegen. Weder die Turbellarien noch die Aeolidier erzeugen nämlich ihre Nesselkapseln selbst. Diese rühren vielmehr aus den Leibern gefressener Hydroidpolypen her, was natürlich ihre scheinbar so merkwürdige Ubereinstimmung auf das einfachste erklärt. Bei Microstomum lineare z. B. ließ sich zeigen, daß die Zahl seiner Nesselkapseln individuell beträchtlich schwankt, und am größten bei Exemplaren aus solchen Gewässern ist, wo auch Hydra in Massen lebt, daß ferner die Nematocysten genau die gleichen 3 Typen unterscheiden lassen, die für unsere Süßwasserpolypen charakteristisch sind. ${ }^{1}$ ) Weiter konnte bei Individuen, die Hydren verzehrt hatten, festgestellt werden, daß die Nesselkapseln einige Zeit nach der Mahlzeit aus dem Darmlumen durch das Darmepithel in das Parenchym gelangen. Hier werden sie von amoeboiden Zellen umfaßt, die sie zum Integument befördern und daselbst derart orientiert absetzen, daß ihr Entladungspol senkrecht zur Körperoberfläche gerichtet ist. Es gelang sogar nach Fütterung von Micostomum mit Hydren, deren Nesselkapseln vorher durch Methylenblau gefärbt worden waren, unter der Haut der Würmer die blaugefärbten Nematocysten wiederzufinden. Ferner konnte die fremde Herkunft der Nematocysten dadurch experimentell erwiesen werden, daß man zur Fütterung der Würmer Hydroiden - wie z. B. Cordylophora lacustris - verwandte, deren Nesselkapseln einen von den Hydra-Nematocysten abweichenden Bau besitzen. Auch in diesen Fällen konnten dann die verfütterten Nesselkapseln in der Haut der Versuchstiere wiedergefunden werden.

Nach alledem kann an der Fremdkörpernatur der Nesselkapseln von Microstomum - und also wohl auch aller andern Turbellarien, wo solche vorkommen - nicht mehr gezweifelt werden, zumal da dasselbe auch für die Nematocysten der Heolidier erwiesen ist. Mit den "Stäbchen" haben sie also nichts $z u$ tun. Wir stehen hier vielmehr vor der eigenartigen Erscheinung,

1) Vgl. die Hydra-Monographie von Steche, S. 24. 
daß gewisse Tiere Organe der von ihnen verzehrten Beutetiere, anstatt sie zu verdauen oder als unverdaulich auszuscheiden, ihrem Körper einverleiben und sich so zu eigen machen, als ob es von ihnen selbst erzeugte Organe wären. $\mathrm{Da}$ es sich dabei gerađe um Nesselkapseln handelt, ist zugleich deswegen bemerkenswert, weil auch noch Vertreter anderer Tierstämme es verstanden haben, sich den wirksamen Schutz dieser den Cnidariern eigentümlichen Bildungen nutzbar zu machen. Es gilt dies z. B. für manche Fische (Carangiden), die sich in ihrer Jugend zwischen den Mundarmen und Tentakeln von Quallen (Chrysaora) aufhalten, oder für die zahlreichen Korallenfische aus den Familien der Labriden, Scariden, Pomacentriden usw., die sich ganz an das Leben zwischen den buntfarbigen Polypen der Korallenriffe angepaßt haben und bei jeder Gefahr unter deren nesselkapselbewehrte Fangarme flüchten. Aus demselben Grunde verbinden sich die Einsiedlerkrebse bekanntlich regelmäßig mit gewisssen Aktinienarten zu gemeinsamem Leben; andere Crustaceen wie z. B. die Krabbe Melia tesselata, pflegen sogar mit den Scheren ihres ersten Gehfußpaares kleine Seeanemonen zu erfassen und dauernd als Waffen und Beutefangapparate mit sich herumzutragen. Ahnlicher Vorteile erfreuen sich auch Microstomum und seine Genossen, nur daß sie sich auf viel radikalere Weise in den direkten Besitz der Nesselkapseln bringen.

\section{Hautdrüsen}

Von den Hautdrüsen, die bei den Rhabdocoeliden vorkommen, sind die Stäbchendrüsen schon oben erwähnt worden. Außerdem finden sich unmittelbar unter dem Hautmuskelschlauch cyanophile "Schleimdrüsen " über den ganzen Körper verbreitet, aber meist in ziemlich lockerer Anordnung. Nur das Vorderende pflegt größere Massen von ihnen zu enthalten. Besonders kräftig entwickelte Schleimdrüsen bestimmter Körperabschnitte bilden bei manchen Arten die sog. "Spinndrüsen“" große, oft unregelmäßig gelappte Drüsenzellen mit langgestreckten, dünnen Ausführungsgängen. Mesostoma ehrenbergi, bei dem sie zuerst entdeckt wurden (A. Schneider 1873), besitzt sie in großer 
Zahl längs einer mittleren Zone der Bauchseite, die vom Vorderende bis zur Schwanzspitze reicht. Vorn ist diese Zone relativ breit und die Drüsen stehen in ihr sehr weitläufig verteilt; von der Gehirngegend an bildet sie dagegen einen schmalen Streifen mit einer charakteristischen Anschwellung am Hinterende, wo sich die Drüsen überaus dicht anhäufen ( $A b b .99$ sp). Der Schleim, den die Spinndrüsen aussondern, dient zum Spinnen von Fäden, an denen sich die Tiere, wie wir später. noch genauer hören werden, von der Wasseroberfläche herablassen und frei im Wasser schwebend halten können. Eine dritte Sorte von Hautdrüsen sind die erythrophilen "Klebdrüsen“ der Microstomiden, Dalyelliiden und anderer Arten, deren Sekret den Tieren gestattet, sich ziemlich fest an der Unterlage anzuheften. Im übrigen sind aber die bei den Rhabdocoeliden vorkommenden Hautdrüsenarten noch verhältnismäßig wenig untersucht. Schon die rein topographischen Namen: Kopf-, Schwanzdrüsen usw., unter denen sie in der Literatur beschrieben werden, zeigen an, daß ihre Funktion noch ganz unklar ist; meist kennt man nicht einmal ihr färberisches Verhalten genauer.

\begin{tabular}{|c|c|c|c|c|c|}
\hline $\begin{array}{c}\text { Basalmembran } \\
\text { Hautmuskelschlauch }\end{array}$ & Basalmembran und Hautmuskulatur bieten \\
bei den Rhabdocoeliden wenig Besonder-
\end{tabular} heiten. Nur ist die Längsfaserschicht des Hautmuskelschlauchs nicht überall gleichmäßig entwickelt. Zahlreiche Arten zeigen zwar das gleiche Verhalten wie die Tricladen, derart daß die als Kriechsohle dienende Bauchseite mit stärkeren Längsmuskeln ausgestattet ist als die Rückenseite. Andere Formen aber, z. B. Mesostoma productum, besitzen gerade dorsal eine stärker entfaltete Längsfaserschicht; wieder andere, wie Mes. ehrenbergi zeichnen șich dadurch aus, daß die Längsmuskeln in der Mitte von Bauch und Rücken kräftiger ausgebildet sind als an den Seiten. Bisweilen stellen die Ring- und Längsfasern starke, breite Bänder dar (Kalyptorhynchia), was dem Hautmuskelschlauch dieser Arten eine verhältnismäßig große Festigkeit verleiht. 
Körpermuskulatur

Im Vergleich $\mathrm{zu}$ den Tricladen ist die Körpermuskulatur der Rhabdocoeliden relativ schwach entwickelt. Bei vielen Formen ist sowohl die Zahl als auch die Dicke der Fasern, die man auf Schnitten durch die Tiere antrifft, auffällig gering. Unter den Mesostomiden tritt bei den Arten, deren Körper im Querschnitt viereckig oder in flossenartige Säume ausgezogen ist, die Dorsoventralmuskulatur so weit zurück, $\mathrm{daB}$ sie außer im Vorder- und Hinterende fast ganz verschwindet. Die Körpermuskulatur wird daher im wesentlichen durch Tangentialfasern gebildet, die auf Querschnitten in Gestalt einer rhombischen Figur erscheinen ( $\mathrm{Abb} .100$ a) und bisweilen, wenn sie zahl-

a
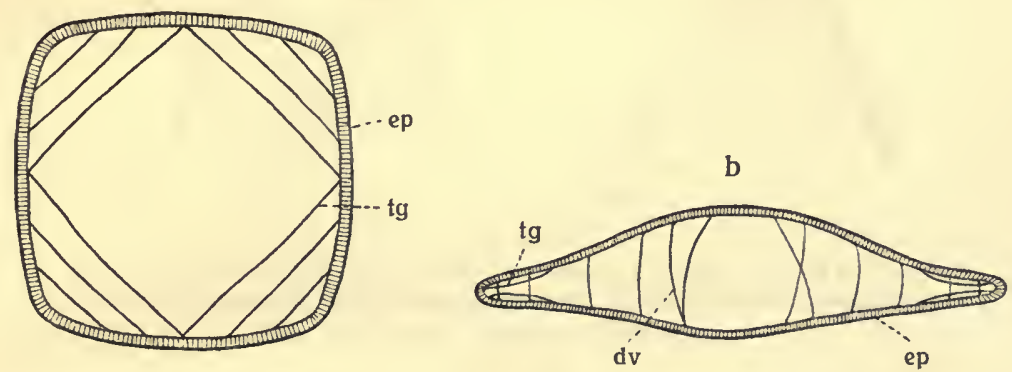

Abb. 100.

Anordnung der Körpermuskulatur (schematisch) : a bei Mesostoma lingua; b bei Mes. ehrenbergi. dv Dorsoventralfasern; ep Epithel; $t g$ Tangentialfasern (nach $\mathrm{L}$ uther).

reicher vorhanden sind, den Darm mit einer Art Muskelmantel umhüllen. Es ist ohne weiteres verständlich, daß sie es sind, die die vierkantige Gestalt der Würmer oder die Abflachung der Flossensäume herbeiführen (vgl. Abb. 95, S. 203). Gerade umgekehrt verhalten sich Mes. ehrenbergi und die anderen abgeplatteten Arten. Hier sind die Tangentialfasern von geringer Bedeutung und nur die Dorsoventralmuskeln, die die Abflachung des Körpers bewirken, einigermaßen entwickelt. Erst bei genauem Suchen findet man in den lateralen Abschnitten des Körpers spärliche, zarte den Tangentialfasern entsprechende Muskeln, die vielleicht bei der Bewegung der Seitenränder eine Rolle spielen (Abb.100 b). 
Eine besondere Ausbildung der Muskulatur zeigt häufig das Vorderende des Körpers, das, wie bei den Tricladen, erhöhte Beweglichkeit aufweist und zugleich hauptsächlich den Sitz des Tastvermögens darstellt. Bei Mesostoma ehrenbergi, das sich seines Vorderendes, wie wir noch sehen werden, auch zum Fangen und Festhalten der Beute bedient, und damit außerordentlich geschickt $\mathrm{zu}$ manövrieren versteht, wird die stärkere Kontraktilität dieses Körperteils lediglich durch die kräftige Entfaltung und den besonderen Verlauf einer Anzahl Dorsoventralfasern ermöglicht, die,
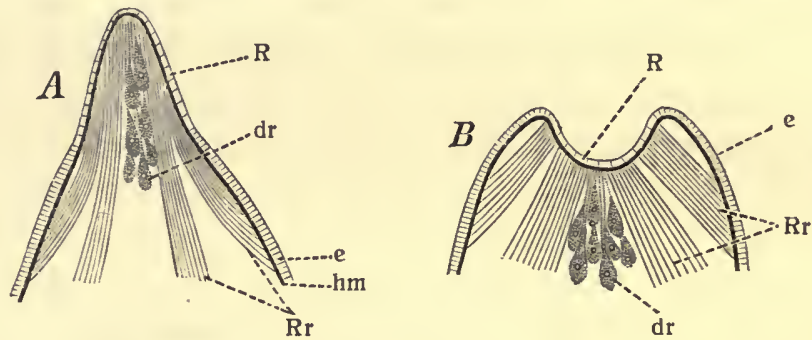

Abb. 101.

Astrotorhyndus bifidus. Vorderende ausgestredkt (A) und eingezogen (B), dr Kopfdrüsen, e Körperepithel, hm Hautmuskelschlaudh, R Rüssel, Rr Rüsselretraktoren (nach v. Graff).

statt senkrecht, in schräger Richtung von der Rückenseite nach vorn zur Bauchseite ziehen. Durch ihre Zusammenziehung muß daher das Vorderende eingebogen werden. Denkt man sich den Verlauf dieser Fasern allmählich immer schräger und schräger werdend, so müssen daraus schließlich Muskeln entstehen, die das Vorderende zurückziehen oder gar in den Körper einschließen können. Dies ist $z$. B. bei Mesostoma lingua der Fall und noch stärker bei Astrotorhynchus bifidus, dessen Vorderende einen deutlich abgesetzten Tastrüssel bildet (Abb. 101).

Noch weiter differenziert ist der Tastrüssel von Rhynchomesostomå rostratum (Abb. 102). Hier fehlen der äußersten, kegelförmig gestalteten Spitze des Vorderendes außer den schwachen Fasern des Hautmuskelschlauchs die muskulösen Elemente gänzlich. Dagegen setzen sich im Umkreise dieses Endkegels und etwas 
dahinter eine Anzahl starker Retraktoren an, die von hier rückwärts bis etwa in die Gegend des Schlundes ziehen, wo sie sich an der Körperwand befestigen. Die Folge dieser Anordnung der Muskelfasern ist, daß der vordere Endkegel selbst nicht eingestülpt, wohl aber als Ganzes fernrohrartig in den Körper zurückgezogen oder ausgestreckt in äußerst geschickter Weise hin- und herbewegt werden kann (vgl. audı Abb. 96, S. 204). Das lebhafte, zierliche Spiel des Tastrüssels von Rhynchomesostoma rostratum bietet daher einen überaus reizvollen Anblick dar. Seine höhere
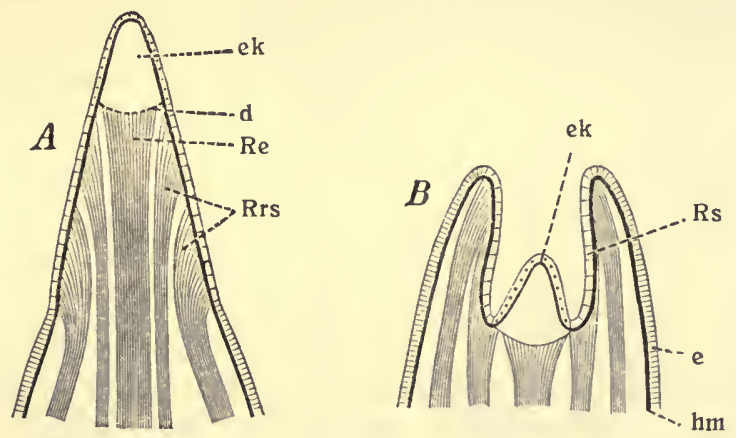

Abb. 102.

$\mathrm{Rhynchomes}$ ostoma rostratum. Vorderende ausgestredkt $(A)$ und elngezogen (B), d muskul. Diaphragma, e Körperepithel, hm Hautmuskelschlauch, ek einstiilpbarer Endkegel, Re Retraktor des Endkegels,

Rrs Retraktoren des einstülpbaren Teils (Rs) (nach v. Graff).

Organisation prägt sich übrigens auch in der histologischen Differenzierung der Retraktormuskelfasern selbst aus. Diese zeigen nämlich im Gegensatz zu den einfachen "glatten "Fasern der übrigen Körpermuskulatur eine Zusammensetzung aus 2 abwechselnd hintereinandergeschichteten Substanzen, was sich unter dem Mikroskop in einer deutlichen Querstreifung zu erkennen gibt, ähnlich wie in den willkürlich bewegbaren "quergestreiften " Muskelfasern der höheren Tiere.

Seine höchste Ausbildung erreicht der Tastrüssel aber erst bei den zahlreichen Arten der unter dem Namen Kalyptorhynchia 
zusammengefaßten Rhabdocoelenfamilien (Abb. 103). Hier ist der Endkegel des Rüssels, der bei Rhynchomesostoma rostratum bloß zeitweilig in den Körper zurückgezogen wird, im Ruhezustand dauernd in eine Scheide eingeschlossen, die durch eine enge Offnung am Vorderende oder etwas dahinter an der Ventralfläche mündet. Außerdem wird der Endkegel nicht bloß passiv durch
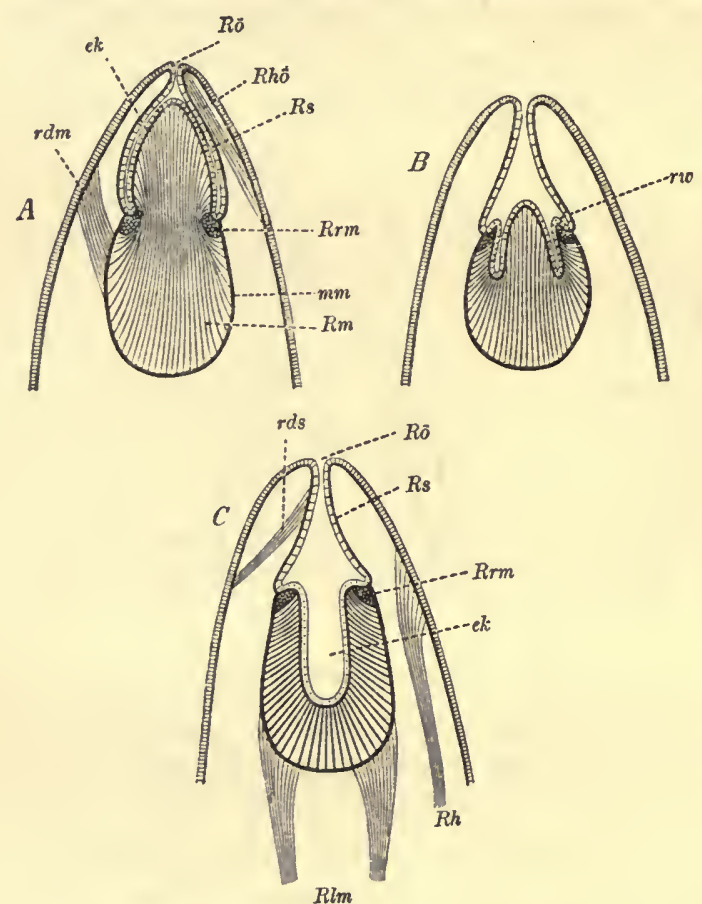

Retraktoren bewegt, sondern enthält eine bei den verschiedenen Arten mehr oder minder komplizierte Eigenmuskulatur, die ihn zu mannigfaltigen Gestaltveränderungen befähigt. Bisweilen besorgen ferner besondere, als Protraktoren bezeichnete Muskelbündel das Vorstoßen des Rüsselkegels, sog. Dilatatoren eine Erweiterung der Rüsselscheidenöffnung. So entsteht ein Apparat von auBerordentlich hoher Beweglichkeit, umsomehr, da alle zu ihm gehörigen Muskelelemente Querstreifung zeigen können.
Abb. 103.

Acrorhyndus sophiae.

Rüssel im Ruhezustand $(A)$, mit halb(B) und ganz

(C) in den Muskelzapfen eingestülptem Endkegel, ek Endkegel, mm Muskularis des Muskelzapfens, rdm Protraktoren desselben, rds Retraktoren der Rüsselscheide, Rh Retraktoren des Integumentes, Rhö Dilatatoren der Rüsselöffnung, Rhm lange Rüsselretraktoren, $\mathrm{Rm}$ sog. Radiärmuskeln, Rö Offnung der Rüsselscheide, Rrm Ringmuskel, Rs Rüsselscheide, rw Ringwulst (nach v. Graff). 


\section{Parenchym}

Das Parenchym der Rhabdocoeliden ist im allgemeinen weniger dicht und massig als das der Tricladen und Polycladen, ein Umstand, der wesentlich dazu beiträgt, daß sie meist zarter und daher gegen Druck weniger widerstandsfähig sind als jene. Es gilt dies besonders für die Mesostoma-Arten, deren Parenchymelemente einen verhältnismäßig plasmaarmen Zelleib besitzen, in dem der Kern gelegen ist, dafür aber nach allen Richtungen zahlreiche verzweigte Fortsätze aussenden. Diese sind häufig faserartig ausgezogen oder $z \mathbf{u}$ Lamellen verbreitert und anastomosieren reichlich untereinander. So entsteht ein mehr oder weniger weitmaschiges Netzwerk, dessen Hohlräume miteinander kommunizieren und von einer Art Lymphe, der sog. perivisceralen Flüssigkeit, erfüllt sind. Außerdem können sie Drüsen, Myoblasten, Zoochlorellen und vereinzelt auch freie Bindgewebszellen enthalten. Die periviscerale Flüssigkeit ist nicht selten gefärbt; oft sind aber auch die Parenchymzellen selbst, sei es in ihrem Zellkörper, sei es in ihren Ausläufern, Träger von Farbstoffen. Sogar bei Mesostoma ehrenbergi pflegen die Plasmafortsätze der $\mathrm{Pa}$ renchymzellen schon frühzeitig kleine Anhäufungen grünlich-gelber Pigmentkörnchen oder -schollen zu führen, wenn auch meist nur in so geringen Quantitäten, daß die Durchsichtigkeit der Tiere dadurch nicht gestört wird. Unter ungünstigen Verhältnissen, bei kranken oder alten Individuen, kann sich aber das Pigment rasch vermehren, so daß die sonst so schön wasserhellen Tiere schmutzig gelbgrün oder braungelb erscheinen. Es ist nicht unmöglich, daß diese Pigmentkörner von Mes. ehrenbergi in den Parenchymzellen gebildete, feste Exkretionsprodukte darstellen, die nur in pathologischen Fällen reichlicher zur Abscheidung gelangen. Bewiesen ist diese Annahme aber keineswegs.

Ahnlich wie bei den Mesostomeen ist das Parenchym auch noch in einigen anderen Familien gebaut. AuBerdem kommen aber unter den Rhabdocoeliden noch mehrere, in höherem oder geringerem Grade davon abweichende Bindegewebstypen vor. Die Verhältnisse sind indessen hier noch zu wenig erforscht, als daß 
sich eine nähere Besprechung lohnte. Erwähnt seien bloß die Allöocoelen, deren Parenchym meistens nur spärliche Hohlräume enthält; es ist daher im allgemeinen ziemlich dicht und nähert sich somit in seinem Aussehen dem der Tricladen.

Ganz besondere Zustände finden sich bei den Acoelen. Da hier Darm und Exkretionsorgane fehlen, spielen sich alle Stoffwechselvorgänge ausschließlich im Parenchym ab (Abb. 104). Dieser

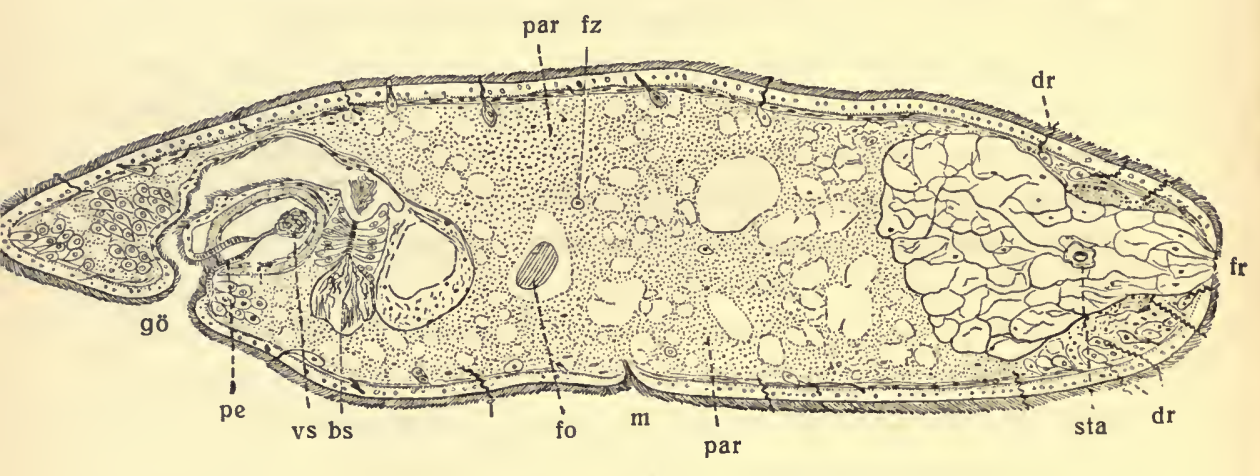

Abb. 104.

Medianschnitt durch eine Acoele (Otocelis rubropunctata). bs Bursa seminalis; dr Schleimdrïsen; fo Fraßobjekt; fr Frontalorgan; fz FreBzelle; gö Geschlechtsöffnung; $m$ Mund; par Parenchym; pe Penis; sta Statocyste; vs Samenblase

(nach v. Graff aus Winterstein).

Mannigfaltigkeit der Leistungen entspricht aber durchaus nicht etwa überall eine besonders komplizierte Struktur. In seiner einfachsten Form besteht hier das Parenchym vielmehr aus zusammenhängenden, nur spärliche Vakuolen führenden, syncytialen Plasmamassen, in die massenhaft Kerne und verästelte oder amöboid bewegliche, freie Zellen (sog. Freßzellen) in wechselnder Zahl eingelagert sind. Bei höherer Organisation macht sich eine Sonderung in ein dichteres Rand- und ein lockereres Zentral- oder Verdauungsparenchym bemerkbar. Letzteres kann dann bisweilen (manche Convoluta-Arten) so deutlich von dem peripherischen Stützgewebe geschieden sein, daß ihm zum "Darm“ nichts fehlt als das Lumen und die Aufteilung seiner syncytialen Plasmamasse in einzelne epithelial angeordnete Zellen. 


\section{Verdauungsapparat}

In dem Namen Rhabdocoelen finden wir auBer dem von dem griechischen xoikos $=$ hohl abgeleiteten, auf die Darmhöhle hindeutenden Stamm ${ }_{n}$ coel $^{\text {“ dasselbe Wort } \varrho \alpha ́ \beta \delta o s ~}=$ Stab wieder, nach dem die Stäbchen Rhabditen heißen. Rhabdocoelen besagt also Stabdarmwürmer, und in der Tat charakterisiert diese $\mathrm{Be}$ zeichunng unsere Tiere sehr gut. Bei allen ihren Arten durchzieht der Verdauungskanal den Wurm fast in seiner ganzen Länge als ein stabförmig gestreckter, langzylindrischer Sack (Abb. $94 \mathrm{~d}$ und Tafelfig. 4 und 5), dessen Wandungen allerdings nicht immer ganz geradlinig begrenzt erschienen, sondern häufig unregelmäßige Ausbuchtungen zeigen. Weit weniger prägnant ist der auf eine abweichende Darmbeschaffenheit hindeutende Name der mit den Rhabdocoelen zur Unterordnung Rhabdocoelida verbundenen

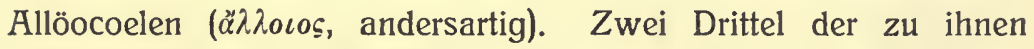
gehörigen Arten besitzen nämlich einen durchaus rhabdocoelenartigen Darm, und nur das übrigbleibende Drittel von Formen macht seinem Namen Ehre. Im Grunde genommen beruht aber auch hier die andersartige Beschaffenheit des Darmes nur darauf, daß jene Ausbuchtungen der Darmwand, die bereits bei den Rhabdocoelen $z u$ beobachten sind, gröBere Dimensionen angenommen haben und zahlreicher geworden sind. Sie verändern jedoch das Aussehen des Darmes in der Tat so, daß von der Ahnlichkeit mit einem Stabe nichts mehr übrig bleibt, beson ders dort, wo sie längere Divertikel bilden (Abb. 105) und eine regelmäßige, annähernd symmetrische Anordnung zeigen oder sich gar selbst wieder verzweigen und Nebendivertikel tragen. Wird hierdurch der Darm einzelner Formen direkt polycladenähnlich, so erinnert seine Konfiguration bei anderen Arten mehr an die Tricladen, indem hier die hintere Hälfte des Darmes durch den Pharynx durchbrochen und in 2, erst am Schwanzende sich wieder miteinander verbindende Schenkel zerlegt wird (Abb. 106).

Noch manigfaltiger als die Ausbildung des Darmes ist die Verschiedenheit in der Topographie und Entfaltung der anderen 
Organe des Verdauungsapparates. Nirgendwo sonst im Tierreich zeigt der Mund eine so wechselnde Lage wie gerade bei den

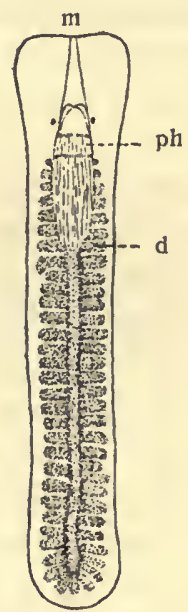

Abb. 105.

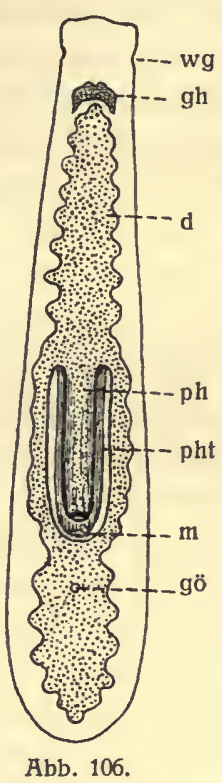

Abb. 105. Prorhynchus applanatus. d Darm;

m Mund; ph Pharynx (nach Kennel).

Abb. 106. Euporobothria bohemica; d Darm; gh Gehirn; gö Geschledıtsöffnung; $m$ Mund; ph Pharynx; pht pharyngealtasche; wg

Wimpergrübchen (nach Vejdovsky).

Rhabdocoeliden, wo er an allen Punkten der ventralen Mittellinie, vom Vorder- (Abb. 105, m) bis zum Hinterende, $z u$ finden sein kann. Nur noch die Polycladen kommen ihnen in dieser Beziehung einigermaßen nahe. Nicht minder variabel ist der Bau des Pharynx, der - häufig noch durch Vermittlung eines kurzen Ösophagus - die Kommunikation zwischen Mund und Darm herstellt.

Nach der ausführlichen Beschreibung, die der Bau des Tricladensaugrüssels erfahren hat, kann hier wohl darauf verzichtet werden, die verschiedenen Pharynxformen der Rhabdocoeliden in gleich eingehender Weise zu schildern. Eine kurze Charakterisierung derselben ist jedoch schon deshalb nicht zu umgehen, weil der Tricladenpharynx nur einen Spezialfall der bei den Rhabdocoeliden vorkommenden Typen bildet.

\section{Pharynx}

Man unterscheidet zunächst 2 Hauptkategorien des Pharyngealapparates: den einfachen und zusammengesetzten Pharynx (Ph. simplex und compositus). Ersterer, der die hauptsächlich für die Acoelen charakteristische Pharynxform darstellt und unter den Rhabdocoeliden nur bei einigen Gattungen der Hysterophora vorkommt, ist streng genommen weiter nichts als eine durch Einstülpung der ventralen 
Leibeswand entstandene kurze Röhre, in deren Bereich der Hautmuskelschlauch eine Verstärkung erfahren hat (Abb. 107 A, 108). Demgegenüber zeichnet sich der $\mathrm{Ph}$. compositus dadurch aus,
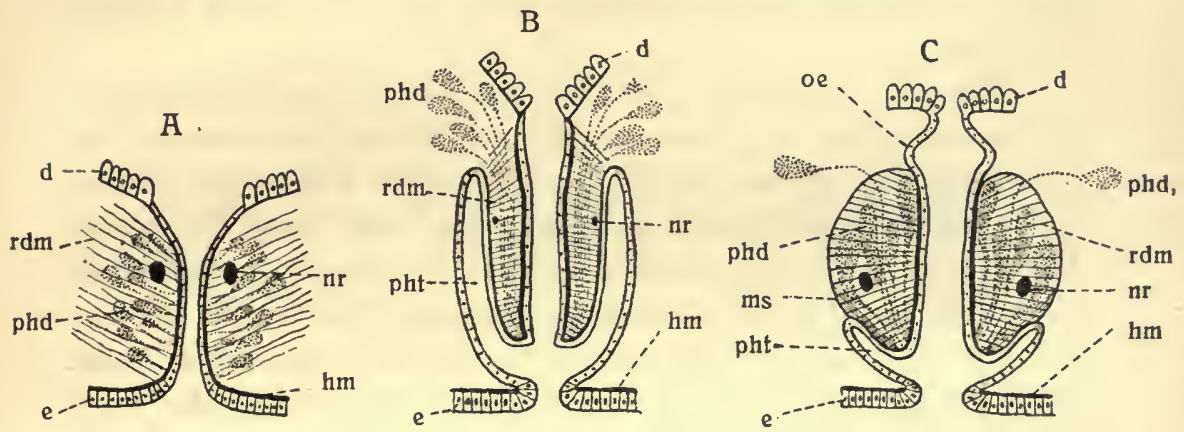

Abb. 107.

Sdiematische Längssdınitte durch den Pharynx simplex $(A)$, plicatus $(B)$ und bulbosus $(C)$. d Darm; e ventrales Epithel; hm Hautmuskelschlauch; ms Muskelseptum; nr Nervenring; oe Oesophagus; $\mathrm{phd}, \mathrm{phd}_{\mathfrak{}}$ Pharyngealdrüsen; pht Pharyngealtasche; rdm radiäre Muskelfasern.

daß sich im Innern dieser Röhre eine Ringfalte vorgewulstet und, durch sehr bedeutende Ausbildung ihrer Muskulatur zum eigentlichen Schlundkopf (Pharynx s. str.) geworden, gegen den übrigbleibenden, als Schlund - oder Pharyngealtasche bezeichneten Teil der Röhre differenziert hat. Bleibt dabei die Ringfalte des Schlundkopfes in offenem Zusammenhang mit dem Körperparenchym (Abb.107 B), so spricht man von einem Pharynx

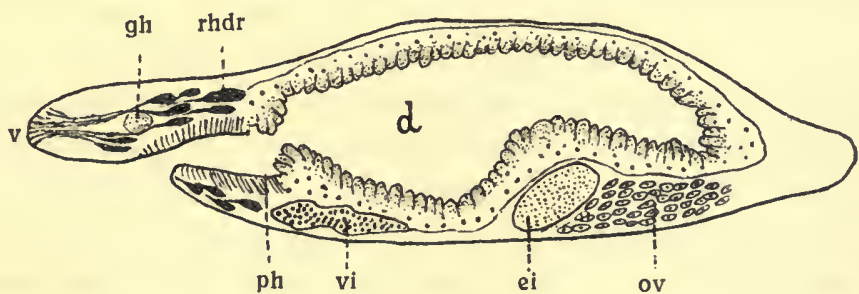

Abb. 108.

Sagittaler Längsschnitt durch Macrostomum appendiculatum. d Darm; ei relfes Ei; gh Gehirn; ov Ovar; ph Pharynx simplex; rhdr Stäbchendrüsen; v Vorderende; vi Dotterstock (nach v. Graff). 
plicatus (plicare, falten), setzt sie sich aber durch eine muskulöse Scheidewand (ms) scharf dagegen ab (Abb.107 C), so daß der Schlundkopf gleichsam zwiebelartig in einer besonderen Schale stedkt, so spricht man von einem Pharynx bulbosus (bulbus, Zwiebel).

Aus dem Gesagten ergibt sich, daß der Tricladenschlundrüssel in die Kategorie des Pharynx plicatus gehört, und ebenso der Pharyngealapparat der Polycladen. Unter den Rhabdocoeliden ist dieser Schlundrüsseltypus dagegen relativ selten vertreten (einige Allöocoelen), vielmehr ist meist ein bulböser Pharynx vorhanden. Funktionell ist für den $\mathrm{Ph}$. plicatus charakteristisch, daß er weit aus der geräumigen Schlundtasche hervorgestreckt werden kann. Beim Pharynx bulbosus ist dagegen die Pharyngealtasche meist klein und der Schlundkopf gar nicht oder doch nur wenig vorstülpbar.

Je nach der Gestalt des Schlundkopfes und nach seiner Lage im Verhältnis zum Darm lassen sich nun wiederum mehrere Typen des Pharynx bulbosus unterscheiden. Von diesen ist unter den Rhabdocoelen am weitesten die Pharynxform verbreitet, die sich bei Mesostoma ehrenbergi und den übrigen Typhloplaniden findet. Der etwas vor oder in der Gegend der Körpermitte (Mesostoma $=$ Mittelmund) gelegene Schlundkopf hat hier etwa die Gestalt einer Kugel und die Axe des ihn durchbohrenden Pharyngealkanals steht ungefähr senkrecht zur Bauchfläche und zur Längsaxe des Darmes (Abb. 109). Bei der abgeplatteten Gestalt von Mesostoma ehrenbergi ist ein Bild, wie es Abbildung 109 von Bothromes. personatum zeigt, aber nur aus Schnitten zu gewinnen. Im Quetschpräparat erhält man dagegen eine ganz andere Ansicht (Abb. 99, S. 210), die den Pharyngealkanal im Zentrum des muskulösen Schlundkopfes zeigt. In letzterem treten dabei die Radiärmuskeln überaus deutlich hervor, und zwischen ihnen liegen die Pharyngealdrüsen gruppenweise ${ }_{n}$ wie Blütenblättchen ${ }^{*}$ so regelmäßig angeordnet, daß v. Graff dafür mit vollem Recht den Namen Pharynx rosulatus vorgeschlagen hat. Bei einer Anzahl Pharyngealdrüsen liegt der Zell- 
leib außerhalb des Schlundkopfes (Abb. 107 C, phd, Abb. 99). Ihre Ausführungsgänge durchbohren daher das diesen umschlieBende Muskelseptum, um in den Pharynx einzutreten.

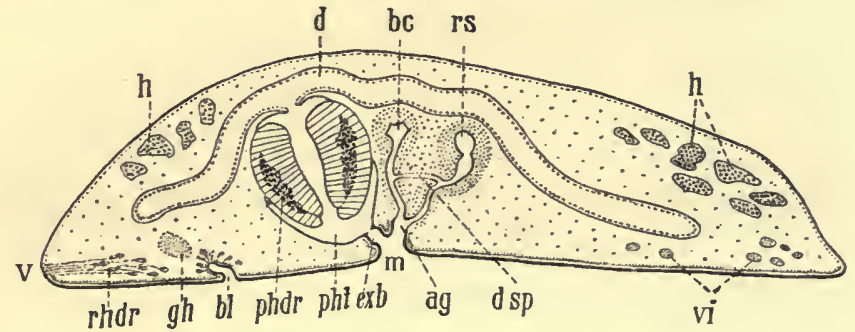

Abb. 109.

Sagittaler Längsschnitt durch Bothromesostoma personatum. ag Atrium genitale; bc Bursa copulatrix; bl Blindsadk; d Darm; dsp Ductus spermaticus; exb Exkretionsbecher; gh Gehirn; h Hoden; $m$ Mund; phdr Pharyngealdrüsen; pht Pharyngealtasche; rhdr Stäbchendrüsen; rs Receptaculum semin is; v Vorderende; vi Dotterstock.

Die Pharyngealtasche umfaßt bei Mes. ehrenbergi und vielen anderen Arten nur etwa das der Bauchseite zugekehrte Drittel des Schlundkopfes. Es kann daher bloß dieses kurze Stück des Pharynx als "Greifwulst" dienen. Nach außen mündet die Schlundtasche hier nicht, wie es sonst die Regel ist, direkt, sondern erst durch Vermittlung eines kurzen, die Endstämme der Nierenkanäle aufnehmenden sog. Wassergefäß oder Ex kretionsbechers (Abb. $95 \mathrm{exb}$ ), den man sich - wie sein mit der äußeren Haut übereinstimmender Bau und seine Entwicklung lehrt - durch eine sekundäre Einsenkung der Mundöffnung und des sie umgebenden, die beiden Exkretionsporen enthaltenden Hautbezirkes entstanden $z \mathfrak{u}$ denken hat. Betrachtet man beim lebenden Mes. ehrenbergi den Pharyngealapparat von der Ventralseite, so kann man unter günstigen Umständen 5 Öffnungen übereinander beobachten, die sich bei den Schluckbewegungen in regelmäßigem Wechsel ausdehnen und verengern (Abb. 110): Die Mündung des Exkretionsbechers (1), den eigentlichen Mund (2), den Pharynxmund (3), den Ösophaguseingang (4) und den Darmmund (5). Auf die Ausdehnung der Exkretionsbecheröffnung folgt 
die des eigentlichen Mundes. Während noch diese beiden weit geöffnet sind, erweitert sich der Pharynxmund unter gleichzeitigem Zurückziehen des Schlundkopfes und bewirkt ein Hereinstürzen

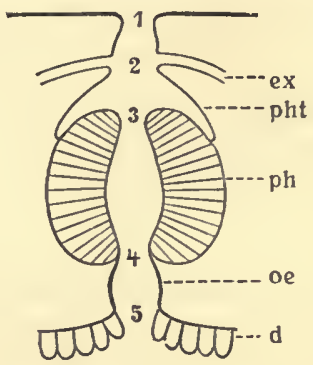

Abb. 110.

Gemeinsame Ausmündung von Exkretions- $\mathbf{u}$. pharyngealapparat bei Mesostoma ehrenbergi. (Schematischer Längsschnitt, Bauchseite nach oben). d Darm; ex Nierenendkanäle; oe Oesophagus; ph Pharynx; pht pharyngealtasche. Erklärung der Zahlen im Text (nach v. G raff).

des Wassers. Dann schließen sich die beiden erstgenannten Offnungen, während sich gleichzeitig der Pharynx wieder vorschiebt, das in der Pharyngealtasche enthaltene Wasser schludkt und den Pharynxmund schließt. Im folgenden Moment gewahrt man eine in der Richtung gegen den Darm fortschreitende Ausdehnung der Pharynxlichtung und Einpressung des ihn erfüllenden Wassers in den Ösophagus und Darm, natürlich unter Erweiterung ihrer Eingänge. Während diese noch ausgedehnt sind, ist bereits wieder der Exkretionsbecher geöffnet und damit ein neuer Schluckakt eingeleitet. So geht das Spiel abwechselnder Ausdehnung und Zusammenziehung fort, solange die Wasseraufnahme dauert, - in entgegengesetzter Reihenfolge verläuft es, wenn der Darminhalt nach außen entleert wird.

Hinsichtlich der Verbreitung des Pharynx rosulatus ist $\mathrm{zu}$ merken, daß gleich Mesostoma ehrenbergi auch alle übrigen Angehörigen der artenreichen Typhloplanidenfamilie damit ausgestattet sind, ebenso die Byrsophlebidae, Proxenetidae und die überwiegende Mehrzahl der rüsseltragenden Rhabdocoelenarten (Kalyptorhynchia). Häufig, aber keineswegs immer, findet sidh zugleich die oben beschriebene Kombination des Mundes mit dem Exkretionsbecher. Bei den Olisthaneilini unter den Typhloplaniden z. B. und bei den Kalyptorhynchia münden die Nierenkanäle ganz unabhängig von der Mundöffnung nach außen. 


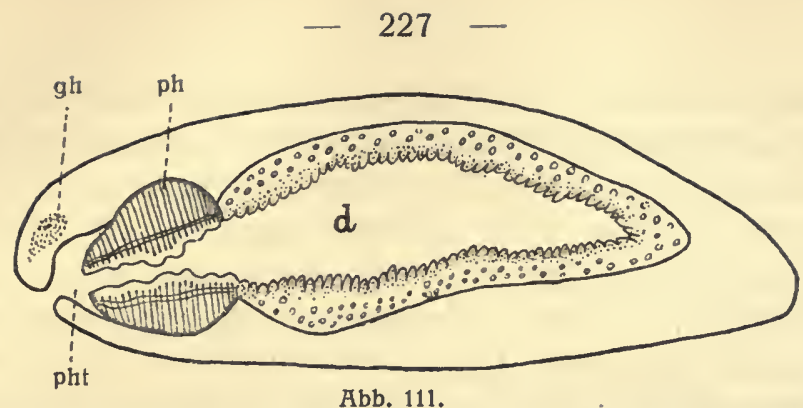

Sagitlaler Längsschnitt durch eine Dalyellia. d Darm: gh Gehirn; ph Pharynx; pht Pharyngealtasche.

Eine zweite Form des bulbösen Pharynx ist der hauptsächlich für die große Familie der Dalyelliiden charakteristische tonnen förmige Pharynx ( $\mathrm{Ph}$. doliiformis). Sein Name kennzeichnet treffend seine Gestalt, die im allgemeinen einer Tonne, bisweilen einer mehr gestreckten Röhre entspricht. Da er zudem meist am Vorderende, seltener am Hinterende des Darms (Gattung Opistomum), und zwar so befestigt ist, daß seine Längsachse mit der des Darmes zusammenfällt (Abb. 111) oder nur einen stumpfen Winkel bildet, erhält man im Quetschpräparat ein ganz anderes Bild (Abb. 112) als beim $\mathrm{Ph}$. rosulatus, das ihn auf den ersten Blick davon unterscheiden läßt. In dieser Ansicht treten am Schlundkopf nicht die Radiär-, sondern die Längsund Ringmuskelfasern überaus deutlich zutage, und ihre regelmäßige Anordnung verleiht ihm häufig ein sehr charakteristisches "gegittertes" Aussehen. Weitere Unterschiede gegenüber dem Pharynx rosulatus bestehen in einem etwas andersartigen Bau des Pharyngealepithels und in dem Fehlen extrapharyngealer Speicheldrüsen.

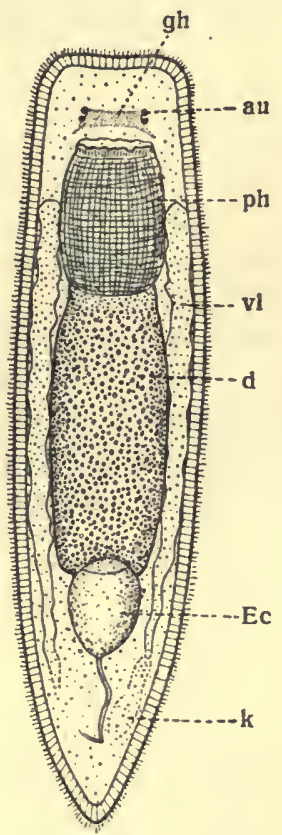

Abb. 112.

Castrella truncata (leidht gequetscht) Ubersicht der Organisation. au Augen; d Darm; Ec Eikapsel mit Stiel ; gh Gehirn; k Keim.stodk; ph Pharynx dolilformis; vi Dotterstock. 
Dem tonnenförmigen Pharynx bisweilen recht ähnlich ist endlich eine dritte Modifikation des Pharynx bulbosus, die bei der Mehrzahl der Allöocölen vorkommt, so weit diese nicht mit einem $\mathrm{Ph}$. plicatus versehen sind. Hauptkennzeichen dieses Pharynxtypus ist eine hohe Veränderlichkeit der Gestalt, die ihm daher den Namen Ph. variabilis eingetragen hat. Bald kann hier der Schlundkopf bedeutende Länge erreichen, bald sehr klein und muskelschwach sein; aber auch bei dem gleichem Individuum ist sein Aussehen den verschiedenen Kontraktionszuständen entsprechend fortwährendem Wechsel unterworfen. Histologisch betrachtet beruht diese Unbeständigkeit der Gestalt auf dem Fehlen jener Regelmäßigkeit in der Anordnung der Muskelfasern, die dem $\mathrm{Ph}$. rosulatus und $\mathrm{Ph}$. doliiformis die Konstanz ihres Aussehens verleiht.

\section{Darm}

Da die verschiedenen Formen des Darms der Rhabdocoeliden schon oḅen besprochen wurden, seien hier nur noch einige speziellere Mitteilungen über die Beschaffenheit des Verdauungskanals vom Mesostoma ehrenbergi angefügt.

Der Ösophagus, der den eigentlichen Darmsack mit dem Pharynx verbindet, ist ein kurzes, dünnwandiges Rohr, dessen Epithel eine direkte Fortsetzung der inneren Auskleidung des Schlundkopfes bildet und gleich dieser wimperlos ist. Er kennzeichnet sich dadurch als Teil des Pharyngealapparats. Dasselbe lehrt auch seine Entwicklung, die ohne jede Beziehung zum Darm erfolgt und ihn einfach als eine "innere Pharyngealtasche" erscheinen läßt.

Der Darm ist ein an beiden Enden blindgeschlossenes Rohr, das bei Mesostoma ehrenbergi durch die Verbindung mit dem Schlunde etwa im Verhältnis $1: 3$ in einen prä- und einen postpharyngealen Abschnitt geteilt wird. Ersterer endigt vorn in einiger Entfernung vom Hirn. Der postpharyngeale Abschnitt reicht hinten nicht ganz bis zur Schwanzspitze, sondern endigt etwa ein Sechstel der Körperlänge von dieser entfernt. Beim hungernden oder schwadhgefütterten Tier ist die Lichtung des 
Rohres sehr eng und auch das Darmepithel recht niedrig, durch reichliche Nahrungsaufnahme kann sich der Darm aber beträchtlich erweitern und bei stark gemästeten Tieren sogar sein Aussehen in höchst bemerkenswerter Weise verändern. Erscheint nämlich der Darm in der ersten Zeit nach der Fütterung bloB angeschwollen und nach wie vor ungefähr geradlinig begrenzt, so beginnt er am zweiten oder dritten Tage der Mästung zahlreiche kleine Ausbuchtungen hervorzutreiben, bis er schließlich in seiner ganzen Länge mit ziemlich regelmäßig angeordneten Seitendivertikeln besetzt ist (Abb. 113). Der einfache Stabdarm läBt sich also durch gesteigerte Inanspruchnahme zur Ausbildung von Seitenästen bringen, was mit Rücksicht auf die viel umstrittene, später noch näher zu erörtende Frage nach den gegenseitigen Beziehungen der verschiedenen Turbellariengruppen und ihrer wechselnden Darmverhältnisse von besonderem Interesse ist.

Histologisch unterscheidet sich das Darmepithel der Rhabdocoeliden nur wenig von dem der Tricladen (s. S. 46). Doch ist

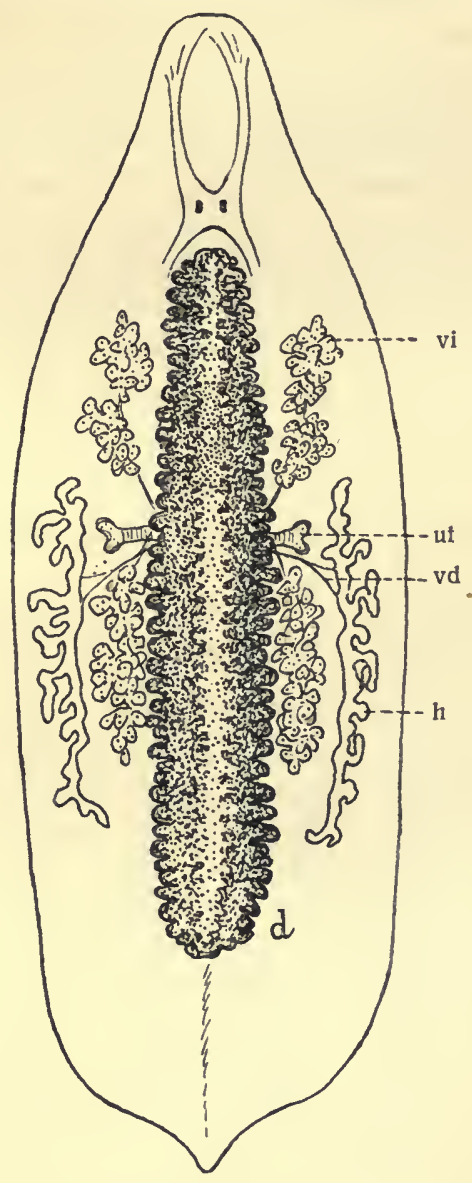

Abb. 113.

Mesostoma ehrenbergi nach Mästung. d der mit Divertikeln besetzte Darm; h Hoden; ut_Uterus; vd Vas deferens; vl Dotterstodk. es bei manchen Hysterophora (Microstomum, Macrostomum) lang bewimpert. Dieselben Formen zeichnen sich auch durch den 
Besitz einer eigenen Darmmuskulatur aus. Bei allen übrigen Rhabdocoeliden ist dagegen das Darmepithel cilienlos.

\section{Exkretionssystem}

Im Gegensatz zu den Tricladen, die der Untersuchung der Protonephridien im Leben große Schwierigkeiten entgegensetzen,

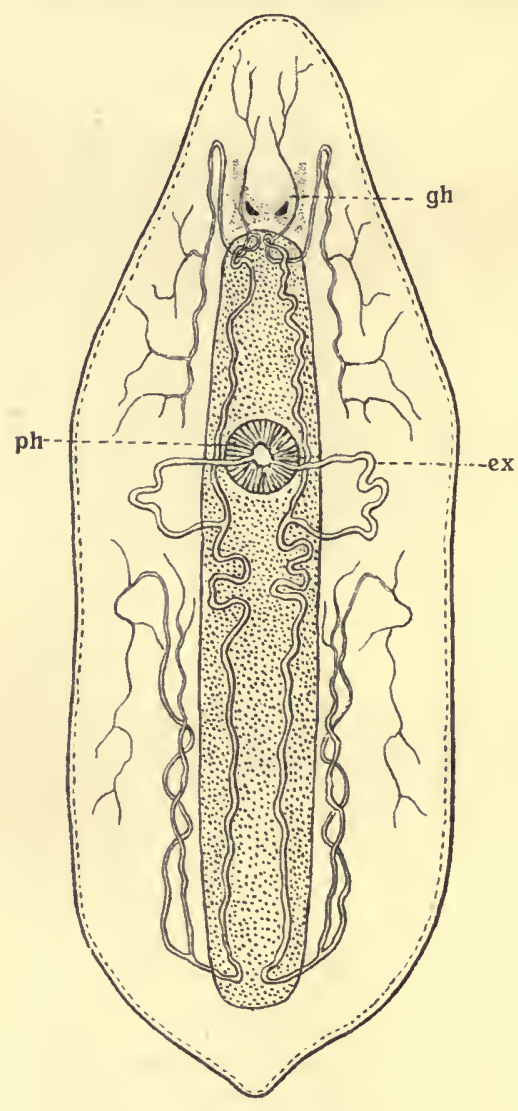

Abb. 114.

Ubersicht über den Exkretionsapparat von Mesostoma ehrenbergi, von der Bauchseite gesehen. ex Endstamm; gh Gehirn; ph Pha rynx (nach L e uds art, ergänztu. abgeändert). genügt bei vielen Rhabdocoelen schon ein Quetschpräparat des lebenden Tieres, um den allgemeinen Verlauf der Wassergefässe zur Anschau ung $z u$ bringen. Daß die durchsichtigen Formen für das Studium der in Rede stehenden Organe besonders günstig sind, liegt auf der Hand; wir wollen daher zunächst die Verhältnisse bei Mesostoma ehrenbergi kennen lernen, diesem klassischen Objekt für die Untersuchung der Protonephridien. Nachher wird die Besprechung der abweichenden Formen folgen.

Wenn wir - der bequemeren Beschreibung halber den Exkretionsapparat von seiner Mündung an zum Ursprung verfolgen (Abb. 114), so sehen wir ihn mit dem sog. Exkretionsbecher beginnen, von dem schon im vorigen Kapite! (s. S. 225) die Rede war. Von hier entspringen rechts und links in 
querer Richtung die beiden Endstämme, kehren dann aber bald, etwa auf halbem Wege zwischen Seitenrand und Mittellinie des Körpers um und teilen sich in einen vorderen und hinteren Hauptstamm. Beide Hauptstämme verlaufen nun jederseits dorsal und unverzweigt in der Längsrichtung des Tieres, der eine bis zum Gehirn, der andere etwa bis zum hinteren Ende des Darmes. Der vordere bildet dicht hinter und über dem Hirn eine der Körpermitte zugekehrte Schlinge, die sich der von der anderen Seite kommenden oft fast bis zur Berührung nähert; hier schickt er einen Nebenast zum vorderen Körperende und zieht dann, sich vielfach verzweigend, parallel dem nach vorn gerichteten, unverzweigten Teile wieder rückwärts, mit seinen feinsten Verästelungen ungefähr bis in die Pharyngealgegend reichend. Der hintere Hauptstamm wendet am Darmende nach vorne um und teilt sich in zwei Aste, die ihre Ausläufer bis etwa zu der Spaltunçsstelle der Endstämme entsenden.

Bei den übrigen Typhloplaniden finden wir im wesentlichen die gleiche Anordnung der Exkretionskanäle. Wichtige Unterschiede bestehen jedoch hinsichtlich der Art ihrer Ausmündung: bei den Olisthanellini fehlt der Exkretionsbecher, so daß die beiden Endstämme sich durch getrennte Exkretionsporen nach außen öffnen; bei Rhynchomesostoma rostratum andererseits ergießen sich die Exkretionskanäle in das Genitalatrium (Abb. 96 a, S. 204). Bei den erstgenannten Formen können die Poren entweder der Mundöffnung mehr oder minder benachbart sein (Gattung Typhloplanella, Abb. 115), oder aber von ihr entfernt, nach hinten in die Nähe der Geschlechtsöffnung bisweilen sogar noch darüber hinaus verschoben liegen (Gattung Olisthanella, Abb. 116). Die verschiedenen Spezies der Olisthanellini veranschaulichen dabei eine ganze Reihe von Übergangsformen, die-allmählich von dem in Abbildung 116 gezeichneten Zustande zu dem Ausmündungstypus hinführen, wie er bei Mesostoma ehrenbergi vorliegt. Ebenso läßt sich von diesem oder einem ähnlichen $\mathrm{Zu}$ stande auch das Verhalten bei Rhynchomesostoma rostratum ableiten. Denn es darf mit größter Wahrscheinlichkeit ange- 
nommen werden, daß hier die Kombination der Nierenöffnungen mit dem Geschlechtsvorraum, ebenso wie ihre Verbindung mit dem Munde bei Mesostoma ehrenbergi, durch eine sekundäre Einstülpung des die Exkretionsporen tragenden Hautabschnittes veranlaßt wurde.

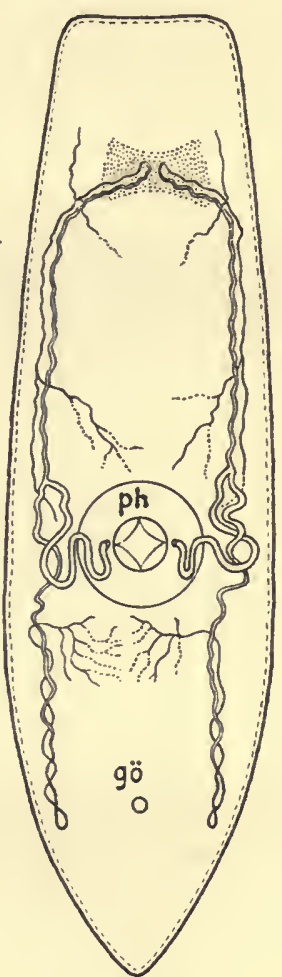

Abb. 115.

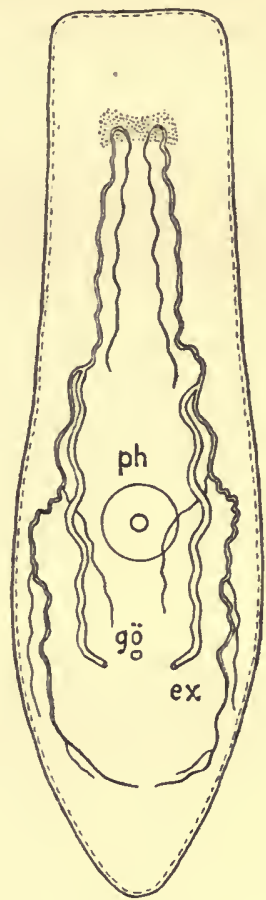

Abb. 116.

Abb, 115. Obersicht über den Exkretionsapparat von Typhloplanella bresslaui.

Abb. 116. Desgl. von Olisthanella truncula. ex Exkretionsporus; gö Geschlechtsöffnung; ph Pharynx (nadh Sekera).

Dem Olisthanellatypus steht auch - wenigstens soweit bis jetzt bekannt - der Exkretionsapparat der Dalyelliiden nahe, und ebenso der der meisten Kalyptorhynchia. Nur liegen bei den letzteren die beiden Nierenöffnungen dem Hinterende noch mehr 
genähert. Unter den wenigen im süßen Wasser vorkommenden Arten der Kalyptorhynchia zeigt dies Gyratrix hermaphroditus, die sich dank ihrer großen Transparenz nicht minder gut zum Studium der Protonephridien eignet als die durchsichtigen Mesostomeen. Zwei weitere Süßwasservertreter der rüsseltragenden Rhabdocoelen, Polycystis goettei und Phonorhynchus lemanus haben dagegen wiederum einen sekundären Exkretionsbecher ausgebildet; er steht aber natürlich wegen der für die Kalyptorhynchia typischen Lage der Exkretionsporen im Schwanzende weder zum Munde noch zur Geschlechtsöffnung in Beziehung. Vielmehr bildet er eine in der Nähe des Hinterendes gelegene, ziemlich geräumige Blase (Abb.117 eb), deren Auskleidung entsprechend ihrer Entstehung aus einer Hauteinstülpung einfach eine Fortsetzung des Körperepithels darstellt; nur fehlen ihr die Stäbchen.

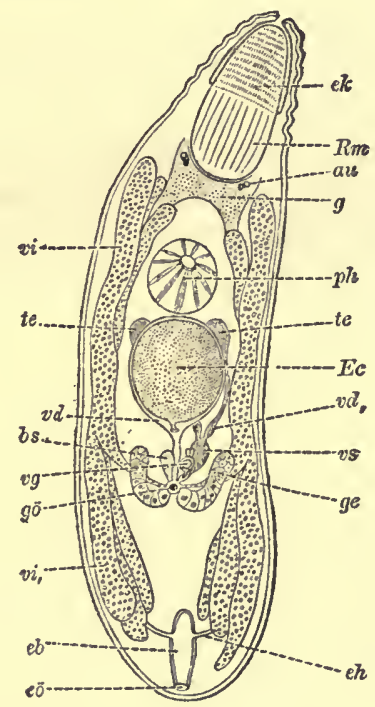

Abb. 117.

Polycystis goettei, Ventralansicht, Darm weggelassen.

au Augen; bs Bursa seminalis; eb Exkretionsblase; Ec Eikapsel ; eh Ekretionshauptstämme; ek Endkegel des Tastrüssels; eö Exkretionsöffnung ; gh Gehirn; ge Keimstock; gö Geschlechtsöffinung; ph Pharynx; $\mathrm{Rm}$ Muskelzapfen des Rüssels; te Hoden; u Uterus; vd Vas deferens; vg Vesicula granulorum; vi, vi $i_{1}$ Lappen der Dotterstöcke; vs Vesicula seminalis.

AuBerordentlich wechselnd ist der Bau des Exkretionsapparates bei den hysterophoren Rhabdocoelen. Zwar zeigen die Microstomumarten noch eine den bisher besprochenen Formen 
im allgemeinen ähnliche paarige Anordnung der Hauptstämme; die beiden Exkretionsporen liegen hier aber ganz im Vorderende, noch vor dem Pharynx. Ebenfalls in der vorderen Körperhälfte, jedoch unmittelbar hinter dem Pharynx, münden die beiden Endstämme bei Macrostomum, der weitere Verlauf der Nierenkanäle ist hier aber noch nicht genügend bekannt. Bei Prorhynchus stagnalis gehen von den beiden querlaufenden, etwas hinter dem ersten Körperdrittel sich nach außen öffnenden Endstämmen jederseits zwei Hauptäste nach vorn und hinten $a b$, so daß der Körper also von einem System von vier Längskanälen durdızogen wird, die sich zugleich durch starke Schlängelung auszeichnen. Eine Reduktion der Zahl der Nierenkanäle zeigen dagegen die Catenuliden. Ihr in unseren süßen Gewässern häufigster Vertreter, Stenostomum leucops, läßt schon bei mäßig starker Vergrößerung im Quetschpräparat erkennen, daß nur ein einziger Hauptstamm vorhanden ist; dieser verläuft in der Mittellinie des Körpers über dem Darm von dem am Hinterende gelegenen Exkretionsporus aus in leichten Wellen nach vorn, biegt vor dem Gehirn um und zieht, feiner und feiner werdend, unter Abgabe zahlreicher Seitenästchen wieder nach hinten.

Mit den besprochenen Fällen sind die bei den Rhabdocoeliden vorkommenden Typen des Exkretionsapparates noch keineswegs erschöpft. Wir können aber auf ihre Beschreibung um so eher verzichten, als sie bei Süßwasserformen nur selten $z u$ beobachten, vielfach auch noch nicht genau genug bekannt sind. Erwähnt sei nur noch, daß bei den mit je einer Art (Plagiostomum lemani und Otomesostoma auditivum) auch im Süßwasser vorkommenden Alläocoelenfamilien der Plagiostomidae und Monocelididae die Hauptgefäßstämme (vier bei Plagiostomum, sechs bei Otomesostoma) sich durch zahlreiche dorsolaterale oder dorsal und ventral gelegene Exkretionsporen nach außen öfnen. Diese Art der Ausmündung verdient deshalb Interesse, weil sie an die von den Tricladen her bekannten Verhältnisse erinnert.

In histologischer Beziehung gilt für den Exkretionsapparat 
der Rhabdocoeliden im wesentlichen das für die Tricladen Gesagte. Wir brauchen daher hier nur einige Besonderheiten zu erwähnen, durch die er sich auszeichnet. So sitzen die Terminalorgane (Abb. 118 t) nicht nur den Capillaren, sondern häufig auch direkt den kleineren oder größeren Sammelgefäßen, ja sogar (z. B. bei Stenostomum) dem Hauptstamme auf. Den Terminalorganen ähn lich gebaute "Wimperorgane s. str." sind in den Verlauf der Hauptstämme eingeschaltet; es sind das Cilienbüschel, die auf einem in das Lumen des Gefäßes vorspringenden Wulst sitzen und

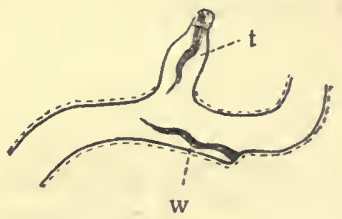

Abb. 118.

Exkretionssammelgefäß von Mesostoma ehrenbergi mit Terminalorgan ( $t$ ) und diesem gegenüberliegenden "Wimperorgan" (w). durch ihren Schlag die Exkretstoffe in der Richtung zum Exkretionsporus befördern helfen ( $A b b .118$ w). Kurz vor der Mündung der Haupt- oder Endstämme finden sich bisweilen ampullenartige Erweiterungen dieser Gefäße, die jedoch inkonstant zu sein scheinen und vielleicht nur bei Stauung der Sekretflüssigkeit auftreten.

Zum Schluß sei noch bemerkt, daß, ähnlich wie den Acoelen, auch einigen entoparasitischen Rhabdocoeliden ein typisches Exkretionssystem zu fehlen scheint; vermutlich wird es bei ihnen durch ein blasiges Bindegewebe mit amöboiden „Excretophorenzellen" ersetzt. Bei den Acoelen werden die im Parenchym zur Ausscheidung gelangenden flüssigen Stoffe wahrscheinlich gleich den festen Fäkalmassen durch die Mundöffnung nach außen entleert.

\section{Genitalapparat}

Bei Besprechung des Genitalapparats der Tricladen ist oben (S. 52) schon die Morphologie der keimbereitenden Organe und der zugehörigen Anhangsgebilde und Ausführwege für die Strudelwürmer im allgemeinen geschildert worden. Diese Übersicht kann auch als Einleitung zu dem folgenden Kapitel dienen, das die Geschlechtsorgane der Rhabdocoeliden behandeln soll. Dabei er- 
scheint es praktisch, auch hier zunächst den Bau des Genitalapparates von Mesostoma ehrenbergi genauer $z$ betrachten, da er alle für die Rhabdocoeliden wesentlichen Teile dieses Organsystems erkennen läßt.

\section{Männliche Organe}

Hoden

Die Hoden sind bei Mes. ehrenbergi langgestreckte, im lebenden Tier leicht weißlich erscheinende Drüsen, die jederseits dem Rande des Körpers genähert liegen und sich, bei voller Entwicklung schon mit bloßem Auge erkennbar (Tafel I Abb. 4), etwa vom hintern Ende des Darmes bis in die Gegend des Pharynx erstrecken. Während sie nach der Körpermitte zu einen im wesentlichen glatten Umriß besitzen, bilden sie lateralwärts eine wechselnde Zahl von Ausbuchtungen oder Follikeln, die bruchsackähnlich hervortreten und manchmal nur durch eine sehr schmale Basis mit dem innern Hauptteil in Verbindung stehen (Abb. $113 \mathrm{~h}, 124 \mathrm{D}$ ). Bisweilen kommt es sogar - was noch viel ausgesprochener bei anderen Arten $z u$ beobachten ist (Abb. 94 h, 124 E) - zu einem Zerfall der Hoden in zwei oder mehrere Lappen, die untereinander nur noch durch die das ganze Organ umschließende Tunica propria zusammenhängen.

\section{Samengänge}

Die Ableitung des in den Hoden erzeugten Spermas zum männlichen Kopulationsorgan erfolgt durch Vasa deferentia, die an der medianen Seite jedes Hodens und zwar etwas hinter der Mitte mit doppelter Wurzel aus seiner Tunica propria entspringen (Abb. $113 \mathrm{vd}$, S. 229). Ihre Wandung stimmt daher histologisch vollkommen mit der Umhüllungsmembran überein. Beide Samenleiter ziehen in leichtem Bogen median und etwas vorwärts in die Gegend des Begattungsapparates, der ungefähr einen Pharynxdurchmesser hinter dem Munde gelegen ist (Abb. 119). Hier münden sie, vorher öfters noch $z u$ sog. falschen Samenblasen anschwellend, durch Vermittlung eines kurzen Ductus seminalis in die Vesicula seminalis des männlichen Kopulations- 
organs oder Penis. Manche Beobachter geben an, daß die Vasa deferentia getrennt in den Penis eintreten. Ihre Vereinigung zum Ductus seminalis scheint daher nicht bei allen Individuen zustande

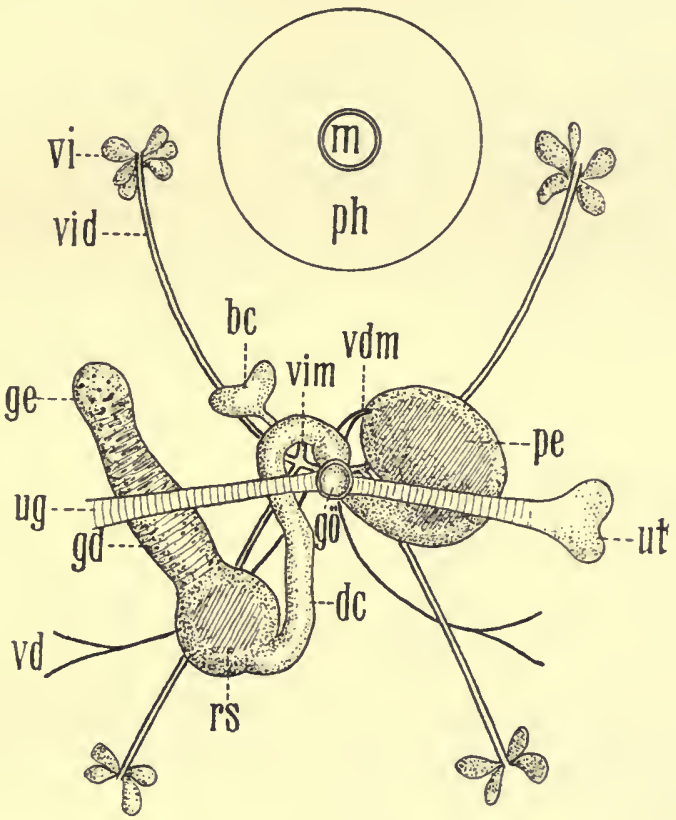

Abb. 119.

Ubersicht über den Genitalapparat von Mesostoma ehrenbergi, von der Baudhseite gesehen. Die Hoden sind fortgelassen, von den Dotterstöcken ist nur der Anfangsteil (vi) gezeidnet. Man kann aus der Figur erkennen, wie sich die verschiedenen Organe gegenseitig überlagern. bc Bursa copulatrix; dc Ductus communis; gd Germidukt; ge Germarium; gö Genitalöffung; m Mund; pe Penis; ph Pharynx; rs Receptaculum seminis; ug Uterusgang; ut Uterus; vd Vas deferens; vdm Mündung der Vasa deferentia in den Penis; vid Vitellodukt; vim Mündung der Vitellodukte in den Ductus communis.

zu kommen, wie denn überhaupt selbst nahe verwandte Arten in dieser Beziehung starke Verschiedenheiten zeigen. Da der Penis auf der linken Körperseite liegt ${ }^{1}$ ), ist der rechte Samenleiter stets ein wenig länger als der linke.

1) Bei Betrachtung von $A b b .119$ ist $2 u$ beachten, daB es sich um eine Ansicht von der Ventralseite handelt, daB also die linke Körperseite hier rechts erscheint. 
Der Penis von Mesostoma ehrenbergi und seiner Verwandten kann passend mit einer Retorte verglichen werden ( $\mathrm{Abb} .119 \mathrm{pe}$ ), nur daß der Hals dieser "Retorte" bedeutend stärker eingebogen ist, als es sonst bei solchen Gefäßen der Fall zu sein pflegt. Bei diesem Vergleich entspricht dem Kolben der Retorte der stark erweiterte Teil des Penis (Penisbulbus), der die schon erwähnte, zur Aufbewahrung des Spermas dienende und bei älteren Individuen

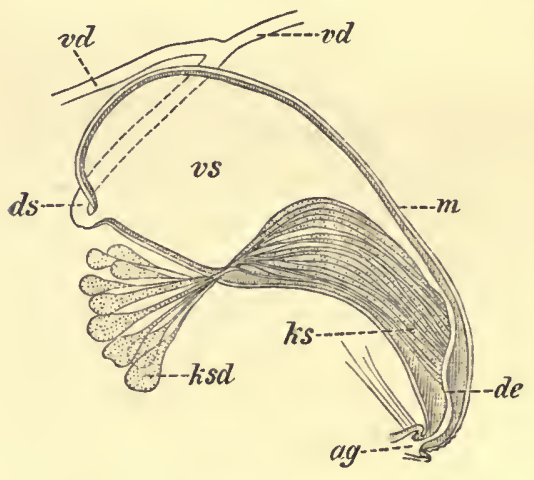

Abb. 120.

Schematischer Längsschnitt durch den Penis von Mesostoma lingua. ag Htrium genitale; de Ductus ejaculatorius; ds Ductus seminalis; ks Kornsekret; ksd Körnerdrüsen; $m$ Muskelmantel; vd Vas deferens; vs Vesicula seminalis (nach L uther). stets prall damit angefüllte Vesicula seminalis (Abb. 120 vs) enthält. An die Vesicula seminalis schließt sich der den Samen abführende Ductus ejaculatorius an, zunächst stark eingeengt durch Sekretmassen, die von außerhalb des Penis gelegenen sog. Körnerdrüsen produziert werden und längs einer Furche in den Muskelmantel des Peniskolbens eindringend den gesamten, in letzterem noch verfügbaren Raum ausfüllen. Der Ductus ejaculatorius selbst erhält das Kornsekret, das wahrscheinlich eine nutritive Bedeutung für die Spermien besitzt, durch feine Poren zugeführt und zieht sodann als einfaches Rohr, den Retortenhals bildend, zum Atrium genitale, in dessen Lichtung er in Gestalt einer kleinen Papille vorspringend ausmündet. Vielfach wird nur dieser letzte Teil des Kopulationsorgans als Penis s. str. bezeichnet.

Entsprechend seiner Bedeutung als Kopulationsorgan besitzt der Penis stark muskulöse Wandungen. $Z u$ äußerst finden sich Längsfasern, nach innen 2 Lagen spiralig angeordneter Muskelzüge, die eine Verengung der Vesicula seminalis bewirken, ohne dabei, 
wie das Ringmuskeln tun würden, zugleich eine Verlängerung des Penisbulbus herbeizuführen. Die Spiralmuskeln reichen nur bis in die Gegend, wo die Kornsekretgänge in den Ductus ejaculatorius münden. Von da an werden sie durch Ringfasern abgelöst. Außerdem setzen an den Penis noch eine Anzahl Muskelfasern an, die von der Wand des Atriums und aus dem Körper her an ihn herantreten und jedenfalls seine Bewegbarkeit erhöhen.

\section{Weibliche Organe}

Germarien Im Gegensatz zu den schon makroskopisch erkennbaren, paarigen Hoden ist die Bereitungsstätte der weiblichen Keime, der Keimstodk (Germarium), ein unscheinbares, unpaares Organ, dem Penis gegenüber auf der rechten Körperseite gelegen (Abb. $119 \mathrm{ge}$ ). Seine Gestalt ist etwa fingerförmig, seine Beschaffenheit kompakt. Das eine Ende des Keimstocks, der von einer dünnen Tunica propria überzogen wird, endigt frei, das andere Ende steht mit dem Keimleiter oder Germidukt in Verbindung.

An seinem freien Ende ist das Gewebe des Keimstockes syncytialer Natur, d. h. hier liegen in einer gemeinsamen, noch unzerklüfteten Protaplasmamasse eine Anzahl Kerne, die Kerne der späteren Ureier oder Oogonien. Mitotische Figuren, die hier - entgegen den Angaben älterer Autoren - regelmäßig anzutreffen sind, weisen darauf hin, dal3 sich die Kerne innerhalb dieser Zone durch Teilung vermehren. Zugleich wachsen sie, und mit ihrem Größerwerden grenzt sich um jeden von ihnen eine Plasmaportion $a b$, wodurch die Oogonien als distinkte Zellen sichtbar werden. Weiteres Wachstum läßt sie bald darauf solche Dimensionen annehmen, daß sie den ganzen Querdurchmesser des Germariums ausfüllen. Zugleich werden sie durch die nachdrängenden, neugebildeten Eizellen geldrollenförmig zusammengepreßt, was dem Keimstock hier ein sehr charakteristisches Aussehen verleiht.

An diesen Abschnitt des Germariums schließt sich nun direkt 
der Germidukt an, der seiner Funktion entsprechend selbstverständlich nicht kompakt ist, wie der Keimstock, sondern eine Röhre darstellt, wegen seines eigenartigen Baues aber letzterem äuBerlich so ähnlich sieht, daß er lange Zeit für eine Fortsetzung desselben gehalten wurde. Auch in ihm liegen scheinbar geld-

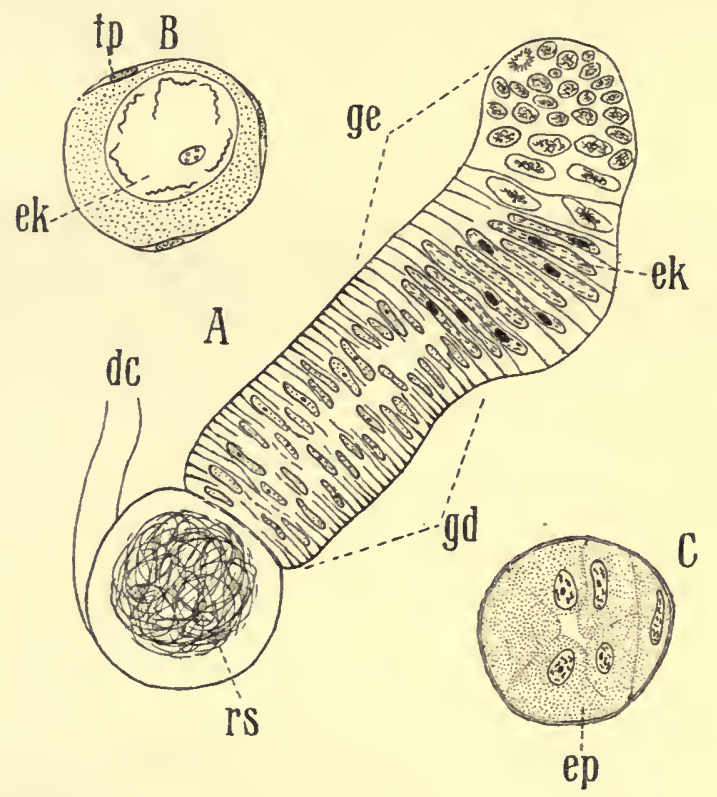

Abb. 121.

A Lăngsschnitt durch Germarium und Keimleiter von Mesostoma ehrenbergi. B? Querschnitt durch den Keimstock in der Zone der fertigen Oogonien. C Querschnitt durch den Germidukt. de Ductus communis; ek Kern der Oogonie; gd Germidukt, ge Ger marium; tp Kern in der Tunica propria.

rollenförmig, aber noch stärker abgeplattet, flache Zellen dicht hintereinander. Betrachtet man indessen nicht Totalpräparate (Abb. $119 \mathrm{gd}$ ) oder Längs- (Abb. $121 \mathrm{~A}$, gd), sondern Querschnitte ( $\mathrm{Abb} .121 \mathrm{C}$ ), so zeigt sich, daß hier mehrere sehr hohe Epithelzellen einen äußerst feinen Kanal umschließen, dessen Inneres von einem feinkörnigen Gerinsel erfüllt wird. Die Epithelzellen sitzen auf einer starken Basalmembran auf, von der lamellen- 
artige Fortsätze entspringen und zwischen die einzelnen Zellen hineinreichen, wodurch sich der Eindruck der geldrollenförmigen Anordnung noch erhöht. Nach außen von der Basalmembran wird der Germidukt von inneren Ring- und äußeren Längsmuskeln umgeben.

\section{Receptaculum seminis}

An seinem dem Keimstock entgegengesetzten Ende erweitert sich der Germidukt zu einer kugeligen Blase, dem Receptaculum seminis, das zur Aufbewahrung der Samenfäden dient. Müssen die Spermien jedoch längere Zeit bis zu ihrer Verwendung hier verweilen, so kann man beobachten, daB sie in das Epithel des Germidukts eindringen, und dieses allmählich aufzehren. Dabei finden sie an den hohen Epithelzellen des Keimleiters reichliche Nahrung und werden außerdem durch die hohen lamellenartigen Vorsprünge der Basalmembran an allzu raschem Vordringen gehindert. Erst wenn, was nur sehr selten geschieht, alle Germiduktzellen von den Spermien ausgefressen sind, wird auch der Keimstock von ihnen verzehrt. Für gewöhnlich jedoch wird das Germarium durch den Keimleiter - und das erklärt seinen auffallenden Bau - vor solchem Geschick bewahrt.

\section{Vitellarien}

Die Dotterstöcke (Vitellarien) sind bei Mesostoma ehrenbergi in bestimmter Lebensperiode, nämlich zur Zeit der Dauereibildung, die weitaus auffälligsten Organe des Tieres, indem sie das Licht nicht hindurchlassen, sondern reflektieren. Sie erscheinen daher, wenn die Tiere auf hellem Grunde kriẹchen, dunkel, auf dunklem Grunde aber auffällig weiß (Tafel I. Abb. 4). Sie liegen nach einwärts von den Hoden und reichen nach hinten etwa gleich weit wie diese, nach vorn dagegen beträchtlich weiter, bis in die Gegend der vorderen Darmspitze. $\mathrm{Zu}$ andern Zeiten, vor oder während der Subitaneierbildung, sind die Vitellarien dagegen gleich den übrigen Organen des Körpers transparent, und oft recht unscheinbar. So bilden sie einen vortrefflichen Indikator für die jeweilige sexuelle Disposition der Tiere. 
In der zuletzt genannten Periode haben die Dotterstöcke das Aussehen zarter, schlanker, durchsichtiger Schläuche (Sammelgänge) mit einer Anzahl kleiner Seitenpapillen (Abb. 122 a), deren

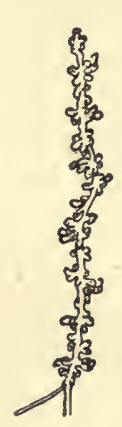

a

Abb. 122.

Dotterstöcke von Mesostoma ehrenbergi. a zur Zeit der Subitan -, b zur Zeit der Dauereibildung.

Zellen fast völlig homogen erscheinen und in ihrem Plasma nur spärliche Tröpfchen oder Körnchen einer das Licht wenig brechenden Substanz enthalten. Bei voller Entfaltung (Abb. $122 \mathrm{~b}$ ) sind dagegen ${ }^{\circ}$ die anfangs so kleinen Seitenpapillen mächtig ausgewachsen, so daß schließlich die Sammelgänge ganz von stark entwickelten Papillenbüscheln bedeckt sind, in deren Zellen sich zahlreiche stark lichtbrechende, zum Teil bräunlich-gelb gefärbte Kugeln von verschiedener Größe angehäuft haben. Umhüllt werden diese dotterbereitenden Teile von einer Tunica propria, die auch die Wandung der ausführenden Gänge bildet.

Während bei den übrigen Mesostomeen die Sammelgänge die Tiere in ihrer ganzen Länge durchziehen, soweit die Dotter stöcke überhaupt reichen, ist dies bei Mesostoma ehrenbergi nicht der Fall. Vielmehr ist hier auf jeder Seite ein vorderer und ein hinterer Abschnitt des Dotterstockes zu unterscheiden, zwischen denen etwa in der Höhe der Genitalöffnung eine Lücke besteht (Abb. 113 vi, Tafel I, Abb. 4). Man kann also, wie schon früher behauptet, in neuerer Zeit aber wieder bestritten wurde, bei Mesostoma ehrenbergi mit einem gewissen Recht von einem vierfachen Dotterstock reden. Es zeigt sich dies auch in der Anordnung der Ausführungsgänge, indem jede dieser $4 \mathrm{Ab}$ teilungen von ihrem Sammelgang aus einen schräg verlaufenden Dottergang in der Richtung nach dem Genitalatrium entsendet (Abb. 119 vid). $Z u$ einer getrennten Einmündung der Vitellodukte kommt es jedoch nicht, vielmehr vereinigen sich zu nächst rechts und links die beiden Dottergänge einer Seite zu einem querverlaufenden Gang und sodann diese beiden Gänge 
zu einem kurzen unpaaren Endgang, der in den sog. Ductus communis (Abb. $119 \mathrm{ds)}$ mündet. Dieser, der früher für den Germidukt gehalten wurde, trägt seinen Namen, weil sich hier die Produkte von Germarien und Vitellarien vereinigen; außerdem wird ihnen noch das Sekret von ebenfalls hier mündenden sog. Schalendrüsen beigemengt.

\section{Ductus communis und Atrium genitale}

Der Ductus communis stellt eine direkte Fortsetzung des Receptaculum seminis dar und führt von diesem in S-förmigem Bogen zum Atrium genitale, in das, wie wir schon gesehen haben, auch die männlichen Organe münden. Das Atrium ist bei Mesostoma ehrenbergi einheitlich, d. h. es zeigt nicht, wie bei anderen Arten eine Teilung in einen proximalen, männlichen und einen distalen, weiblichen Abschnitt. Es liegt genau in der Medianebene, etwa einen Pharynxdurchmesser hinter dem Munde, und besitzt eine aus inneren Ring- und äußeren Längsfasern bestehende Muscularis. Außerdem ziehen von ihm zur dorsalen Körperwand starke Retraktoren. Nach außen öffnet es sich durch den Genitalporus, der durch einen kräftigen Sphincter verschlieBbar ist.

\section{Anhangsorgane}

Das Genitalatrium nimmt aber nicht nur die Mündungen der männlichen und weiblichen Organe in sich auf, sondern trägt als Anhangsorgane noch den Uterus und eine Bursa copulatrix.

\section{Uterus}

Der Uterus oder Eihälter ist bei Mesostoma ehrenbergi paarig: nach rechts und links hin.entsteht durch Wucherung der Atriumwand eine Ausstülpung, die zunächst in querer Richtung einfach stabförmig auswächst, dann aber, in dem Zwischenraum zwischen Hoden und Dotterstöcken angelangt, in rechtem Winkel $z u$ der bisherigen Wachstumsrichtung zwei Zipfel aussendet, einen nach vorn, einen nach hinten (Abb. 113, 119 ut). So bleibt die Anlage, bis die Bildung der 
Eier beginnt. Diese dehnen dann in den Uterus übertretend jene Zipfel in der Körperlängsachse mehr und mehr aus, so daß beide Uteri zusammen schließlich eine $\mathrm{H}$-förmige Figur bilden.

Bursa copulatrix

Ebenfalls als Ausstülpung des Atrium genitale ist die Bursa copulatrix aufzufassen, eine gestielte Blase, die ungefähr in der Medianebene liegt und bei der Begattung zur Aufnahme des Penis des kopulierenden Partners und des aus diesem ergossenen Spermas dient. Hier verbleiben jedoch die Spermatozoen nicht lange, sondern werden durch peristaltische Kontraktionen der slarken Bursa- und Stielmuskulatur in den auf der gerade gegenüberliegenden Seite des Atriums mündenden Ductus communis und das an diesen anschließende Receptaculum seminis getrieben. Die Bursa enthält bei praller Füllung einen ziemlich geräumigen Hohlraum. Ungefüllt zieht sich ihre Lichtung $z \mathfrak{u}$ einem zweizipfligen Spalt $z u-$ sammen (Abb. 119 bc).

Geschlechtsapparat der übrigen Rhabdocoeliden

Nachdem wir bis jetzt ausschließlich den Bau des Geschlechtsapparates von Mesostoma ehrenbergi betrachtet haben, wollen wir nun noch einen kurzen Blick auf die Ausbildung dieses Organsystems bei den übrigen Rhabdocoeliden werfen. Es kann sich dabei für uns nur darum handeln, einige besonders wichtige Verhältnisse kennen zu lernen, vor allem solche, die mit Rücksicht auf die Systematik, für die Bestimmung der verschiedenen Formen bemerkenswert sind. Eine erschöpfende Darstellung ist hier unmöglich, da gerade in der Gruppe der Rhabdocoeliden die Organisation des Genitalapparates, sowohl was die Anordnung und Kombination der ihn zusammensetzenden Teile, als auch was deren strukturelle Gestaltung betrifft, eine erstaunliche Mannigfaltigkeit beobachten läßt. Nicht nur die einzelnen Familien und Genera, sondern oft selbst die Arten derselben Gattung zeigen in dieser Hinsicht bedeutende Unterschiede. 
Als erstes sei hervorgehoben, daß Mesostoma ehrenbergi hinsichtlich der Topographie seiner Geschlechtsdrüsen, besonders was die laterale Lage seiner Hoden anbelangt, nur einen Spezialfall darstellt, der sich aus seiner abgeplatteten Gestalt erklärt. Alle Formen mit rundlichem Körperquerschnitt, auch die der Gattung Mesostoma, verhalten sich dagegen wesentlich anders. Bei den meisten Rhabdocoelen ist die Anordnung so, daß die Hoden mehr oder minder über dem Darm, dorsal von den Vitellarien gelegen sind. Hierauf deutet auch bei Mes. ehrenbergi noch die dorsale Lage der Vasa deferentia im Vergleich $\mathbf{z u}$ den Dottergängen hin (Abb. 119). Einzelne Gattungen, z. B. die Typhloplanini und viele Allöocoelen zeigen jedoch gerade das umgekehrte Lageverhältnis von Hoden und Vitellarien.

Von weit größerer Bedeutung ist, daß nicht bei allen Rhabdocoeliden jene Scheidung der weiblichen Gonaden in Keimund Dotterstöcke durchgeführt ist, die wir bei Mes. ehrenbergi und ebenso auch bei den Tricladen antrafen. Zahlreiche Arten, nämlich alle Hysterophora unter den Rhabdocoelen und die Halleziiden unter den Allöocoelen besitzen vielmehr, gleich der Mehrzahl der übrigen Tiere Ovarien oder Eierstöcke, in denen Eizellen erzeugt werden, die allen zu ihrer Entwicklung nötigen Nahrungsdotter in sich selbst enthalten. Im einfachsten Falle (Stenostomum) geschieht die Aufspeicherung des Dotters direkt, ohne daß die Eizellen dabei besondere Nährzellen verarbeiten. Bei den übrigen Hysterophora und bei den Halleziiden gelangen dagegen nicht alle Eizellen, die sich im Eierstock anlegen, zur Entwicklung, sondern ein Teil von ihnen wird von seinen Nachbarn zum Zwecke der Bereitung von Nahrungsdotter verzehrt. An diese Formen schließen sich die Vertreter der Gattungen Paravortex, Pseudostomum u. a. an, bei denen äußerlich scheinbar einheitliche Gonaden vorhanden sind. Innerhalb derselben besteht aber bereits eine Sonderung, indem die später zur Entwicklung gelangenden eigentlichen Keimzellen und die zur Dottererzeugung dienenden "abortiven Keim- oder Dotterzellen " in verschiedenen Abschnitten der Geschlechtsdrüsen erzeugt werden. 
Von dem Zustand solcher als Germovitellarien bezeichneten Gonaden ist es nur ein Schritt bis zu dem uns bereits bekannten Typus, wo auch die äußerliche Scheidung der innerlich bereits

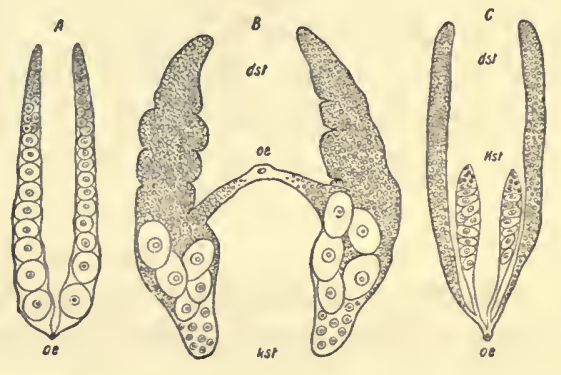

Abb. 123.

Weibliche Geschlechtsdrüsen von Aphanostoma (A), Pseudostomum (B) und Provortex (C). A Ovarien, B Keimdotterstödre C Keim- und Dotterstöcke. dst Dotterstodk; k Keimstodk; oe Geschlechtsöffnung (nach v. G r aff und Korschelt-Heider).

getrennten Abschnitte, also die Sonderung von Keim- und Dotterstöcken (Germarien und Vitellarien) durchgeführt ist (Abb. 123).

Wir finden somit bei den Rhabdocoeliden noch heute alle Stadien einer kontinuierlichen Entwidklungsreihe der weiblichen Geschlechtsdrüsen verwirklicht, wie sie durch die nachstehend aufgestellten Etappen gekennzeichnet wird:

1. einfache Ovarien ....... Stenostomum

2. Ovarien mit Nährzellen ... übrige Hysterophora, Halleziidae

3. Germovitellarien ........ Paravortex, Pseudostomum u. a.

4. Germarien und Vitellarien . . übrige Rhabdocoeliden. getrennt

Wir können daraus schließen, in welcher Weise sich im Laufe der Stammesgeschichte die eigenartige Differenzierung der weiblichen Gonaden herausgebildet hat, die wir bei den Tricladen und bei Mes. ehrenbergi kennen lernten. Um den hohen Wert solcher Entwicklungsreihen recht schätzen zu lernen, überlege man für einen Augenblick, wie die Situation sein würde, wenn die unter 2. und 3. genannten Entwidklungsstufen nicht existierten, etwa deshalb, weil die sie repräsentierenden Arten ausgestorben wären. Die Bedeutung der Dotterstöcke als abgespaltene und 
umgewandelte Teile ursprünglich einheitlicher Eierstöcke würde dann viel weniger klar zutage treten.

Der unter 4. angeführte, in Abbildung $123 \mathrm{C}$ veranschaulichte Zustand bildet aber noch nicht das letzte Ende jener Reihe von Umwandlungen, die den keimbereitenden weiblichen Apparat der Rhabdocoelidenso mannigfaltig gestalten. Allerdings besitzen zahlreiche Arten gleich Provortex neben paarigen Vitellarien auch paarige Germarien. Bei vielen Formen, besonders Süßwasserbewohnern, kommt jedoch noch eine weitere $\mathrm{Ab}$ änderung hinzu, indem einer der beiden Keimstöcke reduziert wird. So erst erklärt sich der Befund, den wir vorher bei Mes. ehrenbergi ermittelten, vollständig. Der linke Keimstock ist hier verschwunden und nur noch das rechte Germarium als unpaare Bildung übriggeblieben. Das Vorhandensein der beiderseitigen Vitellarien weist aber klar auf die ursprüngliche Paarigkeit des ganzen Systems hin.

Was das Aussehen der
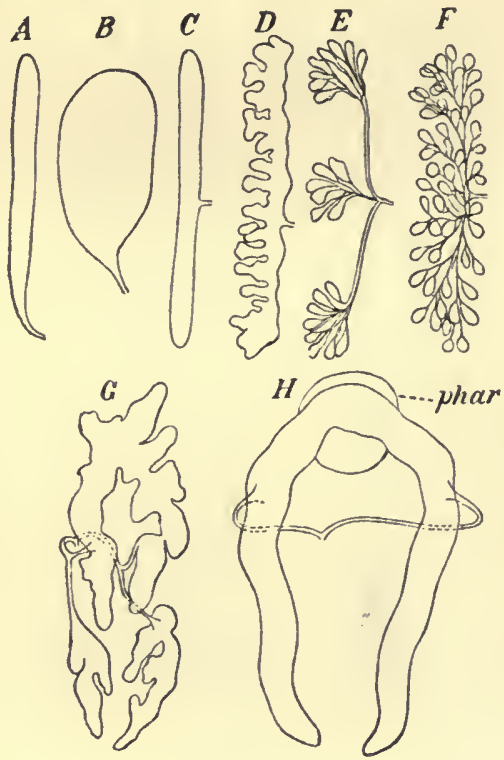

Abb. 124.

Schemata der Hodenformen von: A Olisthanella nassonoffi, B Typhloplaninl, C Olisth. halleziana, D Mesostoma ehrenbergi, EMes. telragonum, F Bothromesostoma, G Mes. lingua, $\mathrm{H}$ Mes. craci. phar Umriß des Pharynx (nach Luther). Geschlechtsdrüsen betrifft, so sind die Keimstöcke in ihrem Habitus denen von Mes. ehrenbergi meist sehr ähnlich, die Dotterstöcke und Hoden aber außerordentlich vielgestaltig (Abb. 124). Größte Mannigfaltigkeit zeigen ferner die verschiedenen bei der Begattung eine Rolle spielenden Organe.

Am männlichen Apparate ist besonders das eigentliche Kopu lationswerkzeug, der Penis, in seinem Bau höchst variabel und 
vielfach mit charakteristischen Chitingebilden ${ }^{1}$ ) bewehrt. Diese zeigen häufig die Gestalt von Stacheln, die bald gerade oder gekrümmt, solid oder hohl sein können: daneben kommen aber auch höchst komplizierte und bizarre Strukturen vor (Abb. 125). Verschiedene Arten bilden Spermatophoren, d. h. mehr oder

B
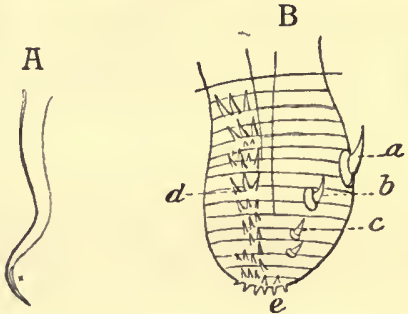

D

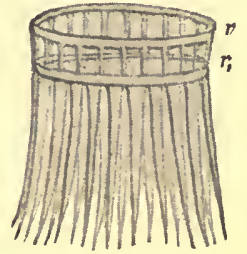

Abb. 125.

Chitinbewaffnung der Kopulations organe verschiedenerRhabdocoelen. A Chitinpenis von Microstomum lineare mił schlifzförmiger Offnung $x$. B Vorgestiilpter Ductus ejaculatorius von Phaenocora anophthalma mil Stacheln $\mathrm{a}-\mathrm{e}$, von der Seite betrachtet. C Chitinpenis von $\mathrm{Ca}$ strella truncata. D Desgl. von Dalyellia expedita, $r$ und $r_{1}$ Reifen, an denen ein Kranz dolchartiger Stacheln sitzt (nach Schltze, Vejdovksy, v. Hofsten aus v. Graff).

minder festwandige, die Samenfäden umschließende Kapseln, die bei der Begattung in die Bursa copulatrix des Partners übertragen werden (Abb. $126 \mathrm{spph}$ ). Über die Entstehung der Kapseln sind direkte Beobachtungen noch nicht angestellt worden. Für manche Typhloplaniden (besonders die Gattung Castrada) wird angenommen, daß die Spermatophorenhülle nichts anderes darstellt, als die Chitinauskleidung des den Penis durchsetzenden

1) Mit dem Ausdruck "Chitingebilde" ist hier nur gemeint, daß die Substanz der Stacheln nach Aussehen und Festigkeit eine gewisse Ahnlichkeit mit der Chitinsubstanz zeigt, die für die Hautskelette der Gliedertiere charakteristisch ist. In chemischem Sinne liegt hier jedoch kein Chitin vor. 
Ductus ejaculatorius (Abb. $126 \mathrm{cde}$ ), die bei der Begattung mit ausgestülpt werden soll und demgemäB nach jedem Geschlechtsakt wieder regeneriert werden müßte. Eine andere Möglichkeit wäre die, daß das Kornsekret das Material zur Bildung der Kapseln liefert, wenigstens bei den Spermatophoren der DalyelliaArten, deren Ausspritzungskanal keine Chitincuticula besitzt.

An Stelle von Bursa copulatrix und Receptaculum seminis, die wir bei Mes. ehrenbergi fanden, ist bisweilen ( $z$. B. bei Gyratrix hermaphroditus) nur ein einziges Organ vorhanden, eine Begattungstasche, die zugleich dauernd als Samenbehälter dient und zum Unterschied von beiden den Namen Bursa seminalis führt. Sowohl die Bursa copulatrix wie die Bursa seminalis können mit Chitingebilden ausgestattet sein, die nicht selten bei nahe verwandten Arten verschiedenes Aussehen und verschiedene Anordnung zeigen und daher systematisch von Bedeutung sind. Unter

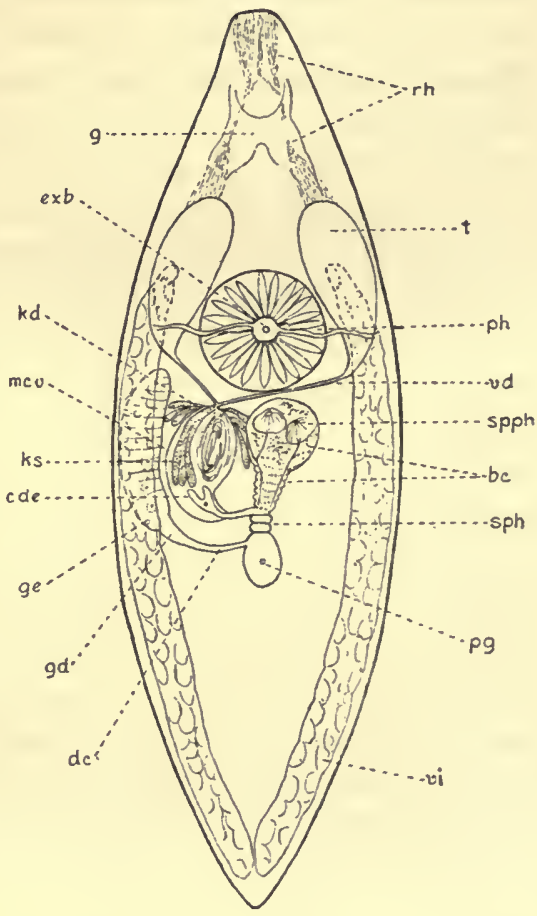

Abb. 126.

Castrada hofmanni, Obersicht der Organisation, Darm fortgelassen. bc Bursa copulatrix; cde Cuticulare Auskleidung des Ductus ejaculatorius; dc Ductus communis; exb Exkretionsbecher; g Gehirn; gd Germiduct; ge Germarium: kd Körnerdrüsen; ks Kornsekret; mco Männl. Copulationsorgan; pg Genitalöffnung; rh Stäbdhenstraßen; sph Sphincter des Atrium copulatorium; spph Spermatophore; t Hoden; vd Vas deferens; vi Dotterstock (nach v. Hofsten).

den Bewohnern unserer süßen Gewässer gilt das besonders für die zahlreichen Vertreter der Gattung Castrada. Einige Spezies 
(z. B. die Arten der Gatt. Bothromesostoma) befördern die bei der Begattung in die Bursa copulatrix aufgenommene Samenmasse nicht auf demselben Wege in das Receptaculum seminis wie beim Hintransport, d. h. durch den Bursastiel und das Genitalatrium, sondern durch einen besonderen, beide Organe verbindenden Gang, der als Ductus spermaticus bezeichnet wird (Abb. 109 dsp). Bei anderen Arten dagegen dienen umgekehrt separate Kanäle, die von der Geschlechtsöffnung (Anoplodium, Syndesmis) oder von der freien Körperoberfläche und zwar vom Rücken her (Gyratrix) in die Bursa seminalis führen, zur Hineinbeförderung des Spermas in die Begattungstasche unter Umgehung der gewöhnlichen Geschlechtswege. Diese Bildungen können also nach ihrer Funktion den Namen Vagina oder Scheide tragen. Gelegentlich (Phaenocora) steht endlich das Receptaculum seminis mit dem Darm durch einen sog. Ductus genito-intestinalis in Verbindung, der möglicherweise die Aufgabe besitzt, im Ubermaß vorhandene Spermamassen dem Verdauungsapparat zur Assimilation zu übermitteln. Alle diese Kanäle sind natürlich nur bei sehr gründlicher Untersuchung wahrzunehmen und können eingehender allein auf Schnitten studiert werden. Vergleichend-anatomisch besitzen aber besonders die beiden letzteren hohes Interesse, weil auch am Geschlechtsapparat anderer Turbellariengruppen (Polycladen, Landtricladen), sowie der Saug- und Bandwürmer Kanäle von ähnlichen Lagebeziehungen $\mathrm{zu}$ beobachten sind. Ihre Bedeutung hat daher $\mathrm{zu}$ vielfachen Diskussionen Anlaß gegeben.

Daß die Gestaltung des Genitalatriums bei den verschiedenen Rhabdocoeliden außerordentlich wechselt, ist nicht verwunderlich, wo sich so zahlreiche, in der verschiedensten Weise miteinander kombinierte Organe darein öffnen. Bald ist es als Atrium commune ausgebildet wie bei Mes. ehrenbergi, bald zerfällt es dadurch, daß die männlichen und weiblichen Geschlechtswege räumlich gesonderte Abschnitte des Geschlechtsvorraums zur Ausmündung benutzen, in ein Atrium masculinum und femininum. Manche Typhloplaniden (Gattungen Rhynchomeso- 
stoma, Tetracelis, Castrada) zeichnen sich dadurch aus, daß dorsal ein Teil ihres Genitalatriums durch einen ringförmigen Schließmuskel (Abb. $126 \mathrm{sph}$ ) als besonderes, bisweilen noch mit blindsackartigen Ausstülpungen und Chitinstacheln versehenes Atrium copulatorium abgetrennt ist, in das der Penis und die Bursa copulatrix münden ( $\mathrm{Abb} .127 \mathrm{ac}$ ). Wieder andere Ver -

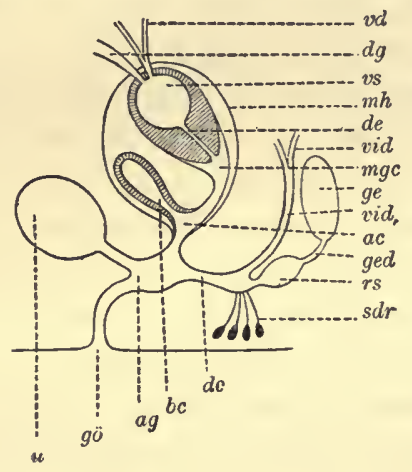

Abb. 127.

Schema der in das Genitalatrium mündenden Organe von Castrada. ac Atrium copulatorium; ag Genitalatrium; bc Bursa copulatrix; dc Ductus communis ; de Ductus ejaculatorius; dg Korn* sekretgang; ge Keimstock; gd Germiduct; gö Geschlechtsöffnung ; mgc männlicher Geschlechtskanal; mh Das Atrium copulatorium samt Bursa copulatrix und Penis umhüllenderMuskelmantel; rs Receptaculum seminis; sdr akzersorische Drüsen; u Uterus; vd Vasa deferentia; vid Vitelloduct; vs Samenblase des penis (nach $L$ uther aus v. Graff).

hältnisse zeigen diejenigen Arten, deren männliche und weibliche Organe sich unabhängig voneinander nach außen öffnen; zum Unterschied von den als Atrium masculinum und femininum bezeichneten Unterabteilungen des einfachen Genitalatriums spricht man alsdann von einem Antrum masculinum und femininum. Selbstverständlich ist je nachdem auch die Zahl der Genitalporen verschieden. Im ersteren Falle haben wir nur eine Geschlechtsöffnung, im letzteren deren zwei, wobei die männliche bald vor, bald hinter der weiblichen gelegen sein kann. In der Regel findet sich die einfache oder doppelte Geschlechtsöffnung auf der Bauchseite hinter dem Munde. Eine Ausnahme machen jedoch $z$. B. die Stenostomum-Arten, deren männlicher Porus sich dorsal öffnet.

Bemerkenswerte Abweichungen entstehen ferner dadurch, daß die gemeinsame oder eine der beiden getrennten Geschlechtsöffnungen mehr oder minder nahe an den Mund heranrücken und bisweilen ganz mit ihm verschmelzen kann. Es läßt sich 
dies sehr schön bei unsern Mesostomeen verfolgen. Die Geschlechtsöffnung von Mes. ehrenbergi ist, wie wir gesehen haben, noch etwa um Pharynxbreite von dem Munde entfernt. Viel näher schon sind sich beide Offnungen bei Mes. lingua gerückt; nur noch eine ganz schmale Epithelbrücke scheidet sie hier voneinander. Bei Mes. productum und den Bothromesostoma-Arten endlich ist auch dieser letzte trennende Wall verschwunden, und nur noch eine äußere Offnung für Mund und Genitalapparat vorhanden (Abb. $109 \mathrm{~m}$, S. 225). Da bei den letzteren Arten auch der Exkretionsbecher dem Munde aufgesetzt ist, hat hier eine Konzentration der Öfnungen aller inneren Organsysteme stattgefunden, wie sie intensiver nicht gedacht werden kann. Sehr eigenartig liegen auch die Verhältnisse in der Gatt. Prorhynchus, wo der männliche $\mathrm{Ge}$ schlechtsporus mit dem am Vorderende sich öfnenden Munde kombiniert und der kräftig muskulöse Penisbulbus mit einem Chitinstachel ausgerüstet ist, der nach Lage und Gestalt an das Angriffsstilett des Nemertinenrüssels erinnert. Es ist daher kein Wunder, daß die zuerst aufgefundene Art, der im Schlamm unserer Gewässer nicht seltene Prorhynchus stagnalis, von seinem Entdecker als Nemertine beschrieben wurde, zumal da auch seine langgestreckte, fadenförmige Gestalt ihn diesen Würmern ähnlich erscheinen läßt.

\section{Nervensystem}

Topographie Wie schon früher ausgeführt wurde (S. $70 \mathrm{f}$.), haben wir an dem Nervensystem der Rhabdocoeliden einen zentralen Abschnitt, das Gehirn, und die davon abgehenden peripheren Nervenstämme mit ihren Kommissuren und Verzweigungen $z \mathbf{u}$ unterscheiden. Außerdem kommt ein Hautnervenplexus vor, der sich mit Hilfe geeigneter Methoden bei Mesostoma ehrenbergi leicht nachweisen läßt (Abb. 128).

Wir wollen wiederum die Verhăltnisse bei dieser Art als Grundlage für unsere Besprechung wăhlen. 
Neben Darm und Geschlechtsorganen gehört das Hirn mit einer Anzahl der von ihm ausstrahlenden Nerven zu den Organen, die man am lebenden Tier schon mit bloßem Auge oder

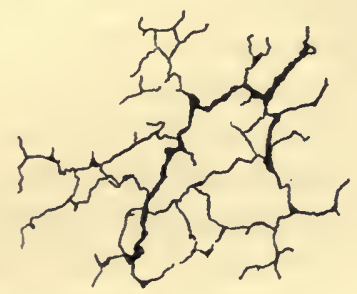

Abb. 128.

Mesostoma ehrenbergi, Stüik des Hautnervenplexus (nach einem mit Hilfe der GolgiMethode behandelten Totalpräparat, s. Anm. 1 auf S. 13).

bei schwacher Lupenvergrößerung wahrnehmen kann (Tafel I, Abb. 4 und 5). Wenn man den vorderen Körperabschnitt ins Auge faßt, so erblickt man in ihm zwei weißliche Stränge, die von dem vorderen Darmzipfel an in leicht geschwungener Linie zur Kopfspitze ziehen, dabei aber dicht vor dem Darm durch einen breiteren und in der Mitte leicht eingeschnürten, queren Strang miteinander in Verbindung stehen und also zusammen die Figur eines $\mathrm{H}$ bilden. Der quere Strang ist das Hirn, zwei mit der Lupe leicht wahrnehmbare schwarze Punkte in ihm bezeichnen die Augen. Die nach vorn ziehenden Balken des $\mathrm{H}$ entsprechen einem vorderen Hirnnervenpaare, die nach hinten ziehenden den ventralen Längsnerven.

Wendet man stärkere Vergrößerungen an, so werden zwar eine Reihe weiterer Details sichtbar. Im großen und ganzen aber werden jetzt die nervösen Bildungen, die unter der Lupe so scharf geschnitten hervortraten, nicht soviel besser unterscheidbar, wie man wohl erwarten könnte. Einmal besitzen die nervösen Organe der Strudelwürmer, wie wir bereits wissen, keine besondere Hülle, die sie gegen das umgebende Parenchym abgrenzt. Vor allem aber stört der Umstand, daß jetzt auch alle die Muskelfasern, Drüsenschläuche und Stäbchenstraßen sichtbar werden, die gerade das Vorderende in so reichem Maße durchziehen. Bei der unvergleichlichen Transparenz der Tiere oflenbart sich so dem Beobachter ein dichtes Geflecht von Faser- 
massen, das leichter verwirrt, als daß es sich entwirren läßt Um die Topographie des Nervensystems zu ermitteln, muß man daher unbedingt Totalpräparate ${ }^{1}$ ) und Schnittserien zu Hilfe nehmen.

Es ergibt sich dann zunächst (Abb. 129), daß die vorderen

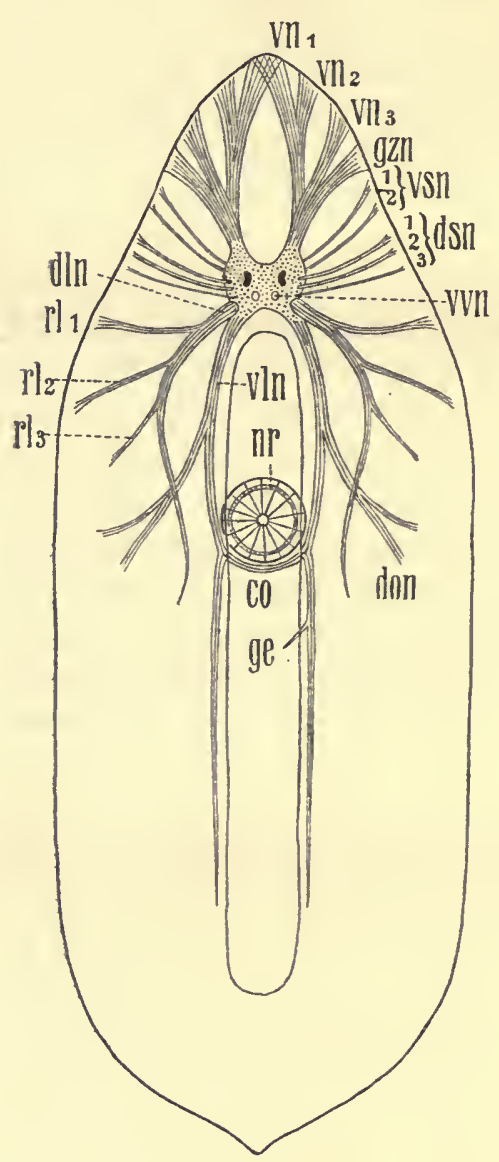

Abb. 129.

Ubersicht über das Nervensystem von Mesostoma ehrenbergi, von der Rückenseite gesehen. Erklärung der Bezeichnungen im Text. Von vorn ist nur die Ursprungsstelle angedeutet.
Hirnnerven, die bei schwacher Vergrößerung als einfache Stämme erscheinen, sich aus zwei übereinander liegende Fasergruppen zusammensetzen, deren jede sich in der Nähe der Kopfspitzen noch einmal spaltet und dann pinselartig in ihre einzelnen Nervenfäden auseinanderfällt. Die untere (ventrale) der beiden Fasergruppen $\left(\mathrm{vn}_{1},{ }_{2}\right)$ innerviert die mittlere Partie der Kopfspitze und ihre inneren Fasern $\left(v_{1}\right)$ durchkreuzen einander, was zur Folge hat,

1) Zur Sichtbarmachung der Nerven empfiehlt es sich die Tiere mit einem Gemisch von vier Teilen einer 3\% Kaliumbichromatlösung und einem Teil einer $1 \%$ Osmiumsäurelösung $z \mathfrak{u}$ konservieren (van Gehuchtensche Lösung), das auch die äuBere Körpergestalt vortrefflich erhält. Die konservierten Tiere lassen sich dann ohne weitere Färbung zu Totalpräparaten verarbeiten. Behandelt man die Tiere vorher noch mit einer $3 / 4$ bis $1 \%$ Höllensteinlösung (Golgi-Methode), so erhält man nicht selten eine vortreffliche Imprägnation des Hautnervenplexus (Abb. 128). 
daß das uns schon als empfindliches Tastorgan bekannte Vorderende mit beiden Hirnhälften in nervöser Verbindung steht. Die obere (dorsale) Fasergruppe versorgt dagegen die lateralen Abschnitte der Kopfspitze $\left(\mathrm{vn}_{3}\right)$ und die Gegend der sogenannten Grübchenflecke (gzn). Außer diesen Hauptstämmen existiert noch ein weiteres, allerdings sehr viel schwächeres, nach vorn ziehendes Nervenpaar (vvn), das von der Unterfläche des Hirns, dicht hinter den Augen, entspringt und das ventrale Epithel der Kopfspitze versorgt. Seitlich vom Gehirn werden die Muskeln und die Haut von fünf sehr zarten Nervenpaaren innerviert, von denen die beiden vordersten $\left(\mathrm{vsn}_{1},{ }_{2}\right)$ ventral, die drei anderen $\left(\mathrm{dsn}_{1-3}\right)$ dorsal aus dem Gehirn austreten.

Betrachten wir die Nervenversorgung des hinter dem Gehirn gelegenen eigentlichen Körpers, so stoßen wir hier zunächst jederseits auf die Wurzel eines mächtigen dorsalen Längsnerven (dln), dessen Durchmesser dem der uns schon bekannten ventralen Längsstämme an seiner Ursprungsstelle wenig oder gar nichts nachgibt. Er wendet sich zunächst in dorsolateraler Richtung, um die hier gelegenen Stäbchendrüsenpakete $\mathrm{zu}$ innervieren, und gibt alsdann einen starken Ast zur Seite $\mathrm{ab}\left(\mathrm{rl}_{1}\right)$; bis hierher ist er relativ leicht $z u$ verfolgen und auch schon von früheren Untersuchern beschrieben worden. Sein weiterer Verlauf wird dagegen durch die Rhammitendrüsen und ihre Ausführgänge stark verdeckt. Wie Frontalschnitte lehren, entsendet er noch zwei weitere Lateralnerven $\left(_{2}\right.$ und ${ }_{3}$ ) und biegt dann medianwärts gegen den Darm um, wo er nicht weit hinter dem Pharynx in einen feinen Fortsatz auszuläuft.

Auch die ventralen Längsnerven verlaufen nicht so einfach und unverzweigt, wie es den Anschein hat. Kurz vor dem Pharynx spaltet sich ein starker Faserzug ab, der teils zum Epithel, teils zu den Dotterstöcken (don) zieht. Dann schmiegen sich beide Stämme dem Schlundbulbus eng an und treten hinter demselben durch eine seit langem bekannte, starke, "postpharyngeale Kommissur" (co) miteinander in Verbindung. Weiter nach hinten geben sie Nerven zu den Geschlechtsorganen ab (ge) 
und verlieren sich dann in der Gegend des letzten Darmabschnittes, ohne daß ihre kaudale Endigung bisher genauer festgestellt werden konnte.

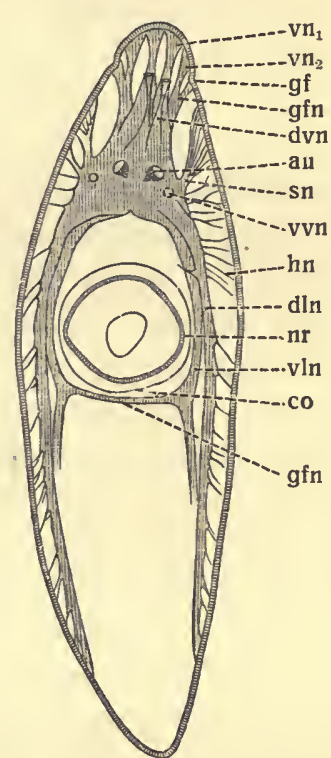

Abb. 130.

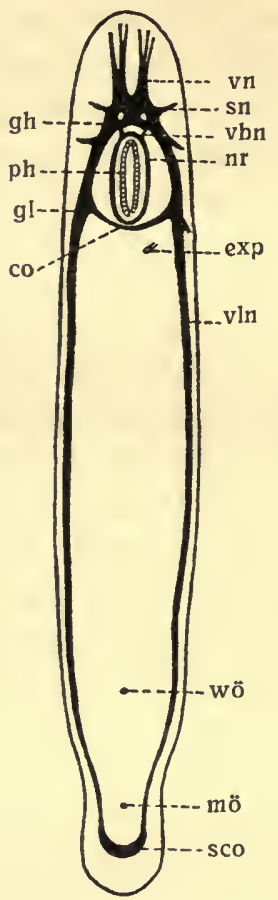

Abb. 131.

Abb. 130. Obersidit uber das Nervensystem von Mesostoma lingua. Abb. 131. Desgl. von Macrostomum appendiculatum.

au Augen; co Kommissur der ventralen Längsnerven (vln); din dorsale Längsnerven; dvn dorsale Hirnnerven; exp Exkretionsporus; gf Grïbchenfleck; gh Gehirn; gl gangliöse Anschwellung der ventralen Längsnerven; gfn Grübchenfleckennerv; hn Hautnerven; mö männlidhe, wö weiblidhe Gesdhledhtsöffnung; nr Nervenring d. Pharynx; sco Schwanzkommissur; sn laterale Hirnnerven; vbn Verbindungsnerv zwischen Hirn und pharynxnervenring; $v n, v_{1}, 2$ vordere Hirnnerven; vvn ventraler Hirnnerv (beide Figuren nad Luther).

Von verwandten Arten zeigt Mesostoma lingua im all gemeinen ähnliche Verhältnisse des Nervensystems (Abb. 130), doch sind die dorsalen Längsnerven ( $\mathrm{d} \ln$ ) noch weit kräftiger entwickelt als bei Mesostoma ehrenbergi. Anderen Formen dagegen, 
so z. B. den Macrostomum-Arten, fehlen diese Nerven ganz. Dafür sind hier die ventralen Längsnervenstämme bis zum Hinterende $\mathrm{zu}$ verfolgen und dort sogar durch eine besondere, mit Ganglienzellen belegte Kommissur verbunden ( $\mathrm{Abb} .131 \mathrm{sco}$ ). Die Ausbildung dieses "Schwanzganglions" hängt jedenfalls damit zusammen, daß in der Gattung Macrostomum das Hinterende als Haftscheibe entwickelt und infolgedessen besonders reich mit Muskeln und Drüsen ausgestattet ist (vgl. Abb. 135, S. 262).

Mehr als zwei hintere Längsnervenpaare besitzen die Rhabdocoelen nicht. Bei den Allöocoelen kommen dagegen $\mathrm{zu}$ den dorsalen und ventralen Stämmen noch ein oder zwei laterale Längsnervenpaare hinzu, was wiederum (vgl. S. 73) an die Verhältnisse bei den Tricladen erinnert. Zugleich bilden sich zwischen den einzelnen Längsnervenpaaren zahlreiche Kommissuren aus, die den Darm ringförmig umgreifen.

Außer den genannten Nervenstämmen findet sich wahrscheinlich überall ( $\mathrm{Abb} .129-131 \mathrm{nr}$ ) noch ein besonderer Nervenring im Pharynx, allerdings nur auf Schnitten nachzuweisen. Die Art seines Zusammenhanges mit dem übrigen Nervensystem ist nicht leicht zu ermitteln. Bei den Mesostoma-Arten wird sie wahrscheinlich durch feine, von den ventralen Längsstämmen abgehende Nervenfäden vermittelt, bei Macrostomum und ebenso auch bei Microstomum entsendet dagegen das Hirn direkte Verbindungsnerven zum "Schlundring" (Abb. $131 \mathrm{vbn}$ ).

\section{Histologie}

Da das Nervensystem der Rhabdocoeliden nur wenig scharf gegen das umgebende Gewebe abgegrenzt ist, findet man auf Schnitten durch das Gehirn ganz gewöhnlich Drüsenausführungsgänge, Parenchymstränge und Muskeln, die sich zwischen den Elementen seines Ganglienzellenbelages hindurchdrängen. Bei einzelnen Arten kann sogar die zentrale Punktsubstanz von Muskeln durchquert werden. Abgesehen von den hierdurch oder durch zufällige Kontraktionen hervorgerufenen Unregelmäßigkeiten ist die Anordnung der die Punktsubstanz umgebenden Ganglienzellen meist sehr regelmäBig. 
Bei Mesostoma ehrenbergi herrscht sogar eine strenge bilaterale Symmetrie, besonders in dem mittleren Teile des Gehirns, wo man vielfach für jeden Kern einer Ganglienzelle rechts einen entsprechend gelagerten auf der linken Seite findet. Es hängt dies mit der paarigen Anlage des Gehirns zusammen, auf die auch äußerlich noch die mediane Einschnürung hinweist.

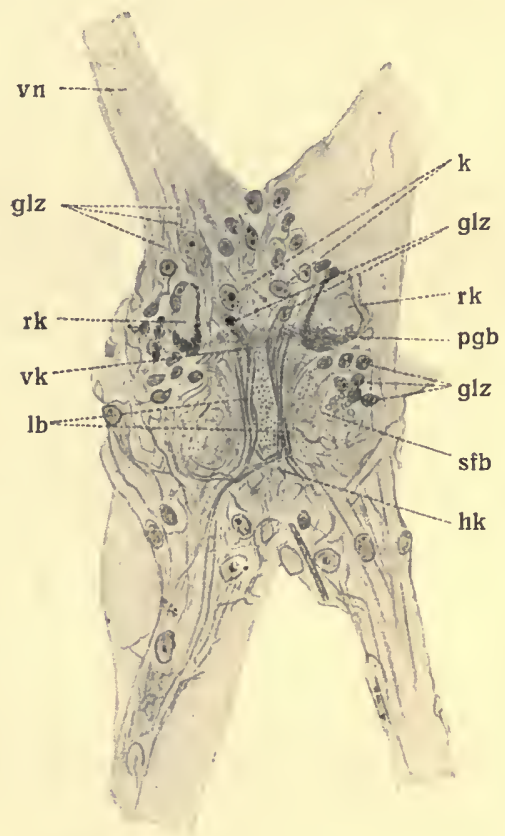

Abb. 132.

Frontalschnitt durch das Gehirn von Mesostoma ehrenbergi.

glz Ganglienzellen; k Kerne; vn vordere Nerven; rk Retinakolben; pgb Pigmentbecher; vk vordere Kommissur; hk hintere Kommissur; sfb seitlicher Faserballen; lb Längsbalken (nach Luther).

Das Gleiche gilt auch von der Punktsubstanz, in der man außer einer von queren Fasern gebildeten vorderen und hinteren Kommissur ein paar medianer, longitudinal verlaufender Stränge ("Längsbalken“) unterscheiden kann (Abb. 132 lb), die symmetrisch gelegene seitliche Faserballen voneinander scheiden (Abb. $132 \mathrm{sfb}$ ). Die Längsbalken setzen sich nach hinten in die ventralen Längsnerven fort, einzelne ihrer Fasern treten aber in der Nähe der hinteren Kommissur jeweils in den Längsnervenstamm der gekreuzten Seite über, bilden also ein „Chiasma“. 
Die Nerven, speziell die ventralen Längsstämme, gehen aus Zellsträngen hervor und sind auch im fertigen Zustande noch mit vereinzelten Ganglienzellen belegt. Reichlicher finden sich die Ganglienzellen an den durch kleine Anschwellungen ausgezeichneten Stellen, wo aus den Längsnerven eine Kommissur entspringt.

\section{Sinnesorgane}

Hugen Die Pigmentaugen der Rhabdocoelen lassen sich direkt mit dem Planaria torva-Typus der Tricladenaugen vergleichen, indem auch sie meist aus einer, selten aus zwei oder drei Sehzellen bestehen, deren distaler Teil als Stiftchenkappe, deren proximaler Abschnitt dagegen als feinfaseriger (oder spongiöser?) Retinakolben differenziert ist und sich in den Augennerven fortsetzt (Abb. 133). Der die Stiftchenkappe tragende Teil wird vom Pigmentmantel oder -becher umgeben, der von einer bis mehreren Zellen gebildet wird und ein in seiner Farbe sehr wechselndes Pigment enthält: außer dem gewöhnlichen schwarzen finden sich die verschiedensten Nuancen von braun (Tetracelis marmorosa), violett (Olisthanella splendida), schwarzblau (Mesostoma lingua), dunkel- bis karminrot (Rhynchomes. rostratum) und gelb, ja, die Farbe kann individuell und dem Standort entsprechend (tiefe oder seichte Gewässer) bei derselben Art wechseln.

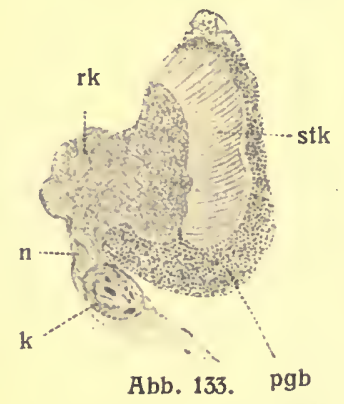

Bei verhältnismäßig wenigen Gattungen gänzlich fehlend, bei anderen nur gelegentlich und durch äußere Einflüsse ver-

Abb. 133. Schnitt durch das Auge von Mesostoma ehrenbergi. pgb Pigmentbecher; sik Stiftchenkappe; rk Retinakolben; n Nerv; k Kern (nach Luther).

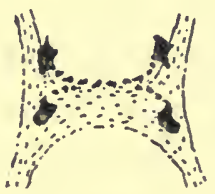

Abb. 134.
Abb. 134. Gehirn von Tetracelis marmorosa mit Augen. Die beiden Augenpaare stehen durch Pigmentstränge miteinander in Verbindung. 
schwindend, treten die Pigmentaugen meistens in der Zweizahl auf; doch können die Pigmentbecher auch so nahe aneinander rücken, daß sie nur einen unpaaren Flecken $z u$ bilden scheinen (einige Microstomum-Arten); umgekehrt wird bei anderen Formen ein Zerfall der zwei Augen in je zwei hintereinander liegende Teilaugen beobachtet, die aber meist noch durch Pigmentanastomosen miteinander in Verbindung bleiben (Castrella truncata, Abb. 112 au). Auch bei der in unseren süßen Gewässern vorkommenden, relativ seltenen, typisch vieräugigen Tetracelis marmorosa sind manchmal noch feine Stränge von pigmentkörnern zwischen den einzelnen Augen $\mathrm{zu}$ beobachten (Abb. 134).

Meist liegen die Augen vollkommen in die Gehirnsubstanz eingebettet, wie bei den Mesostoma-Arten (Abb. 132 pgb), selten nur gehören sie, wie bei Microstomum oder Alaurina dem Epithel an und werden dann entweder von den vorderen Hirnnerven oder von je einem Ast der ventralen Längsstämme innerviert. Bei Tetracelis marmorosa liegt nur das hintere Augenpaar cerebral, das vordere dagegen vor dem Gehirn, auf und etwas. einwärts von den oberen vorderen Hirnnerven (Abb. 134).

Die Augen der Allöcoelen unterscheiden sich von denen der Rhabdocoelen vornehmlich dadurch, daß ihre Pigmentbecher meist. in zwei bis drei Kammern zerteilt sind; außerdem sind der Pigmentbecheröffnung besondere Zellen vorgelagert, die als Linsenzellen bezeichnet werden. Ob letztere allerdings die damit angedeutete Funktion erfüllen, ist durchaus fraglich.

Ebenfalls als Organe des Lichtsinnes werden die hauptsächlich in der Gattung Stenostomum verbreiteten, aber auch bei: einzelnen Olisthanella- und Castrada-Arten vorkommenden. sog. "schüsselförmigen Organe" angesehen, Bildungen, die sich aus einem oder mehreren kleinen Kügelchen einer lichtbrechenden Substanz zusammensetzen und dem distalen Ende eines von der hinteren Gehirnhälfte abzweigenden Nerven aufliegen. Bau und Funktion dieser Organe sind aber zu wenig bekannt, als daß es. sich lohnte, näher darauf einzugehen. 
Statocysten

Statocysten, d. h. Organe des Gleichgewichtssinnes, kommen häufiger nur bei den im Meere lebenden Turbellarien vor. Sie sind hier allen Acoelen, sämtlichen Monocelididae und einer kleinen Anzahl anderer Arten eigen. Von den wenigen Süßwasserformen, bei denen sie sich finden, seien Otomesostoma auditivum und die Arten der Gattung Catenula genannt. Sie stellen von klarer Flüssigkeit erfüllte, kleine Bläschen dar (Abb. 104 sta, S. 220), die der vorderen Fläche des Gehirns anliegen oder in dieses eingebettet sind und einen seiner Hauptmasse nach aus kohlensaurem Kalk bestehenden, linsenförmigen Statolithen enthalten. Dieser wird vermutlich von einer plasmatischen Membran in der Schwebe gehalten, die von der inneren Wandung der Blase in diese hineinhängt. Bei den marinen Monocelididae sind an den Seiten der Statolithen zwei kleine sog. Nebensteinchen befestigt, in den Statocyten von Otomesostoma auditivum dagegen, wie es scheint, nicht. Uber die nervöse Versorgung der Statocysten ist noch nichts bekannt. Weder besondere Sinneszellen noch in sie eintretende Nervenfasern konnten bisher nachgewiesen werden.

Ubrige Sinnesorgane

Hautsinnes- und Tastorgane, Wimpergrübchen größeren Länge über das Wimperkleid hinausragende Geißeln, wie sie bei vielen Formen zu beobachten sind, zu Tastorganen gehören. Erst in neuerer Zeit ist es aber gelungen, etwas Näheres über den Bau dieser Organe zu erfahren und sie wirklich als "Tastgeißelzellen" zu erkennen.

Unter den Rhabdocoelen unserer süßen Gewässer sind besonders die verschiedenen Macrostoma-Arten zur Beobachtung dieser Organe geeignet (Abb. 135). Schon bei schwacher Vergrößerung zeigt sich hier die ganze Oberfläche der Tiere in unregelmäßigen Abständen mit weit vorragenden Tastgeißelgruppen besetzt, die in der Regel aus zwei bis neun einzelnen, aber so 
dicht zusammengeschlossenen Geißeln bestehen, daß die ganze Gruppe bei flüchtiger Betrachtung nur den Eindruck einer einzigen didken Geißel macht (tg). Häufig können alle Geißeln einer Gruppe

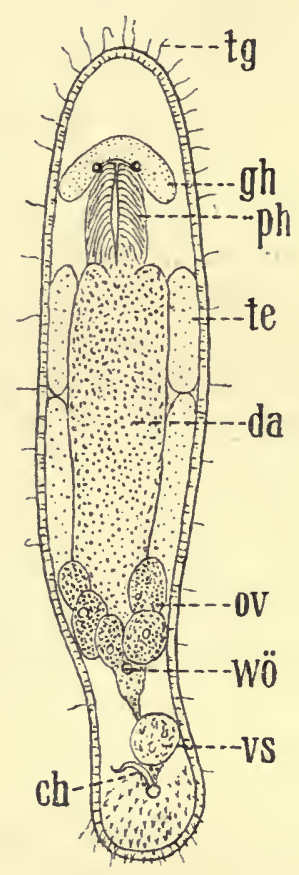

Abb. 135.

Macrostomum viride, Ubersicht der Organisation. di Chitinpenis; da Darm; gh Gehirn; ov Eierstodk; ph Pharynx; te Hoden ; $\operatorname{tg}$ Tastgeißeln; vs Vesicula seminalis; wö weibl. Geschlechts öffnung (nach Luther). gemeinsame Bewegungen ausführen, deren "peitschenartig hakiger" Charakter an die Bewegungen der Infusoriengeißeln erinnert. In anderen Fällen
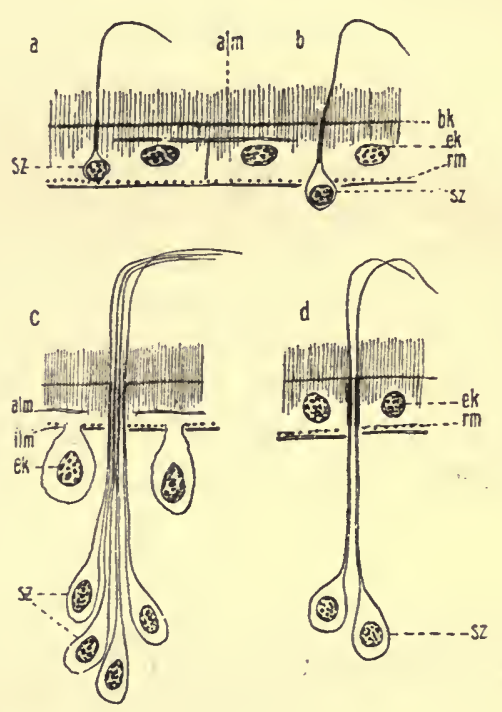

Abb. 136.

Tastgeißelzellen von palmenia, a, b; Childia c; $M$ acrost $0 \mathrm{mum}$ d.

alm äuBere, ilm innere Längsmuskelschicht; rm Ringfaserschidht des Hautmuskelschlauchs; bk Cilienwurzeln; ek Epithelzellenkerne; sz

Kerne der Sinneszellen (nach L u ther).

kann sich aber nur eine von den Geißeln der Gruppe, gewöhnlich die längste, unabhängig von den anderen bewegen. Jede dieser Geißeln sitzt einer Sinneszelle auf, die mit einem feinen, fadenförmigen Fortsatz das Epithel durdibohrt (Abb. 136 d), mit ihrem den Kern enthaltenden Zelleib aber ziemlich tief in das Parenchym 
versenkt ist. Interessant ist, daß, wie die Schnitte $a-c$ der $A b$ bildung 136 zeigen, bei anderen Formen alle Stadien der Auswanderung dieser Tastgeißelzellen aus dem Epithel und ihrer Verlagerung unter dasselbe $z u$ beobachten sind, ähnlich wie dies auch bei den Sinneszellen so vieler anderer Wirbelloser gefunden wird. Die Verbindung der Tastgeißelzellen mit dem Nervensystem ist bisher noch nicht ermittelt worden.

Daß man das stark bewegliche Vorderende der Rhabdocoeliden als Tastorgan auffaßt, besonders dann, wenn es $z \boldsymbol{u}$ einem Rüssel differenziert ist, ist schon des öfteren hervorgehoben worden. Streng genommen ist diese Bezeichnung aber nicht ganz gerechtfertigt, zumal da der Nachweis spezifischer Nervenendigungen daselbst gänzlich fehit. Es handelt sich hier eben nur um einen Sprachgebrauch, ebenso wie wir unsere Hand als Tastorgan zu bezeichnen pflegen, obwohl natürlich nicht ihr als Ganzes dieser Name zukommt, sondern nur den in ihrer Haut gelegenen Tastkörperchen.

Als letzte Kategorie von Hautsinnesorganen sind endlich noch die "Wimpergrübchen“ zu nennen, Bildungen, über deren Bau und Leistungen wir gleichfalls noch ganz ungenügend unterrichtet sind. Unter den Süßwasserformen sind sie bei Otomesostoma, Bothrioplana (Abb. $106 \mathrm{wg}$ ) usw., am häufigsten aber in der Gruppe der hysterophoren Rhabdocoelen anzutreffen, besonders bei den Arten der Gattungen Stenostomum und Microstomum. Sie bilden hier parige Grübchen zu beiden Seiten des vorderen, vor dem Gehirn gelegenen Körperabschnittes, die wahrscheinlich von einem eingesenkten Epithel ausgekleidet sind und von besonderen Hirnnervenästen innerviert werden. Bemerkenswerterweise finden sich am Kopfe mancher Mesostoma-Arten, besonders von Mes. lingua ( $\mathrm{Abb} .130 \mathrm{gf}$ ) in entsprechender Lage kleine Bezirke, wo das Epithel der Stäbchen entbehrt, dafür aber reich mit Nerven versorgt ist und bisweilen leicht eingezogen erscheint. Auch bei Mesost. ehrenbergi sind solche wimpergrubenähnlich differenzierte Stellen vorhanden und manchmal sogar als sehr 
deutlich hervortretende Einbuchtungen (Grübchenflecken) zu beobachten.

Unter den marinen Rhabdocoeliden finden sich statt der Wimpergrübchen häufig Wimperrinnen, die wohl als homologe Bildungen aufzufassen sind. $\mathrm{Zu}$ den wimpergrübchenähnlichen Organen werden ferner gewöhnlich auch unpaare Hautdivertikel gerechnet, die u. a. den in unsern Gewässern so ungemein häufigen Bothromesostoma-Arten zukommen. Es handelt sich hierbei um eine kleine Hauteinsenkung, die in der Mittellinie der Bauchseite etwas vor dem Munde gelegen und von zahlreichen cyanophilen Drüsen umgeben ist (Abb. $109 \mathrm{bl}, \mathrm{S}$. 225). Die Auskleidung des Blindsadks ist eine Fortsetzung des äußeren Wimperepithels und wird von den Ausführungsgängen der Drüsen durchbohrt. Uber Sinneszellen ist nichts bekannt; die Angaben über die Innervierung des Blindsacks gehen so weit auseinander, daß man es einstweilen als fraglich bezeichnen kann, ob es sich überhaupt um ein Sinnesorgan handelt.

\section{Biologie}

Bewegung

Schon in der Einleitung, als wir die Sammelmethoden besprachen (S. 15), mußte darauf hingewiesen werden, daß die Rhabdocoeliden eine größere Mannigfaltigkeit der Fortbewegungsarten zeigen als die Tricladen. Nur die größeren Formen, etwa aufwärts von 2-3 mm Länge, sind gleich jenen zum Gleiten auf einer Unterlage gezwungen. Alle kleineren Arten dagegen können mit Hilfe ihrer Wimpern frei durchs Wasser schwimmen. Aber auch die Jungen der größeren Rhabdocoelidenspezies sind so lange des Schwimmens mächtig, bis sie die oben angegebene Länge überschritten haben. Die Brut von Mes. ehrenbergi kann man in den ersten Stunden nach ihrer Geburt munter hierhin und dorthin das Wasser durchziehen sehen; erst nach einiger Zeit, je nach den Wachstums- 
und Ernährungsbedingungen schneller oder langsamer, geben sie das Schwimmen auf und gehen zum Kriechen über.

Diese Verschiedenheit in der Art der Fortbewegung und ihre Abhängigkeit von der Körpergröße erklärt sich daraus, daß der Schlag der zarten Wimpern nur zu einer beschränkten Kraftleistung fähig ist, und daher bei Tieren von einer gewissen Größe an nicht mehr ausreicht, um sie freischwebend durch das Wasser zu bewegen. Zwar wächst mit zunehmender Körpergröße auch die Kraft der Flimmerung, da die Zahl der Wimpern in gleichem Schritt mit der sich vergrößernden Körperoberfläche steigt. Aber weit rascher noch wächst gleichzeitig die Körpermasse und damit das Gewicht, das durch die Arbeit der Wimpern in Bewegung gesetzt werden soll. Wird beispielsweise ein Tier $10 \mathrm{mal}$ länger, so vergrößert sich seine Oberfläche und ebenso die Leistungsfähigkeit seiner Wimpern um das 100 fache; zugleich ist aber die Masse $1000 \mathrm{mal}$ so groß geworden, und die gleiche Wimperkraft hätte daher jetzt die 10 fache Arbeit $z u$ leisten. Es muß also schließlich der Zeitpunkt kommen, wo die Wimperkraft der aus der vergrößerten Körpermasse resultierende stärkeren Beanspruchung nicht mehr gewachsen, und die Folge wird sein, daß die Tiere dann vom Schwimmen zum Kriechen übergehen. Bei letzterer Fortbewegungsart wird die Arbeit, die nötig ist, um der Schwerkraft entgegenzuwirken, gespart, und es kann die ganze Energie des Wimperschlages zum Vorwärtstreiben des Körpers ausgenutzt werden.

Uber die Größe der Wimperkraft, welche die Turbellarien entwickeln können, sind direkte Messungen bisher nicht angestellt worden. Wohl aber hat man bei den Pantoffeltierchen (Paramaecium aurelia), allseitig bewimperten Infusorien von etwa $0,25 \mathrm{~mm}$ Länge, ermittelt, daß sie etwa das 9 fache ihres eigenen Körpergewichts im Wasser fortzubewegen vermögen. Hiernach würden also Tiere von ähnlicher Körperform und Bewimperung wie die Paramaecien, aber von 9 fach größerer Länge $(2,25 \mathrm{~mm})$ allenfalls noch imstande sein, sich frei schwebend im Wassser zu halten, bei weiterer Größenzunahme müßten sie aber 
notwendigerweise zu Boden sinken. Nun haben wir gesehen, daß die Rhabdocoeliden ebenfalls bei einer Länge von $2-3 \mathrm{~mm}$ das Schwimmen aufgeben und ihre Fortbewegungsart wechseln; es läßt sich daher vermuten, daß die Kraftleistung ihrer Wimpern un gefähr von derselben Größenordnung ist wie die der Infusorien.

Allerdings findet man nicht selten in der älteren Turbellarienliteratur und selbst noch in den neuesten Bestimmungswerken die Angabe, daß auch die großen Mesostoma-Arten, vor allem Mes. ehrenbergi zu schwimmen vermögen. Diese Mitteilungen beruhen jedoch sämtlich ${ }^{1}$ ) auf der unrichtig gedeuteten Beobachtung einer Erscheinung, die, obwohl auch bei den übrigen Turbellarien vorkommend, sich nirgends so ausgeprägt zeigt wie gerade bei den großen Mesostomen. Hält man ein Gefäß mit Mes. ehrenbergi an einem nicht $z u$ hellen Orte, so wird man nach einiger Zeit beobachten können, daß zahlreiche Individuen mitten im Wasser frei schweben, sich hierhin und dorthin drehen und wenden, oder auch langsam abwärts oder in die Höhe steigen. Und doch schwimmen sie ebensowenig, wie etwa ein Vogel, der im Theater über die Bühne schwebt, wirklich fliegt. Wie dieser an einem unsichtbaren Draht, so hängen auch unsere Würmer an einem unsichtbaren Faden, einem Schleimfaden, dem Absonderungsprodukt der "Spinndrüsen“ (Abb. 137), von denen früher (S. 213) die Rede war. Will man sich davon überzeugen, so braucht man nur die Spitze einer Nadel ins Wasser $z u$ tauchen, und dicht unter der Oberfläche nach dem Punkte zu bewegen, unter welchem in einigen Zentimeter Tiefe der Wurm sein Wesen treibt. Ist man an dieser Stelle angelangt, so er-

1) Eine Ausnahme bildet vielleicht Mes. tetragonum, dessen Körperoberfläche durch die Flossenbildung einen viel beträchtlicheren $\mathrm{Zu}$ wachs erfahren hat, als bei den anderen großen Hrten, und bei dem infolgedessen nicht nur die Wimperzahl, sondern auch die Schwebefähigkeit bedeutend gröBer sein muB. So mag es sein, daß diese Art wirklich schwimmen kann, wie vielfach angegeben wird. Hus eigener Erfahrung kann ich nichts darüber aussagen, weil sie mir bisher nicht lebend $z u$ Gesicht gekommen ist. 
kennt man an einer augenblicklichen Bewegung des Tieres, wann man den Schleimfaden berührt hat. Führt man die Nadel rasch weiter, so reißt der Faden $a b$, und der Wurm, der vermeintliche "elegante Schwimmer" so mancher Autoren, sinkt hilflos zu Boden, so krampfhaft er sich auch hin und her windet. Die Kraft seines Wimperschlages ist nidht imstande, ihn schwebend zu

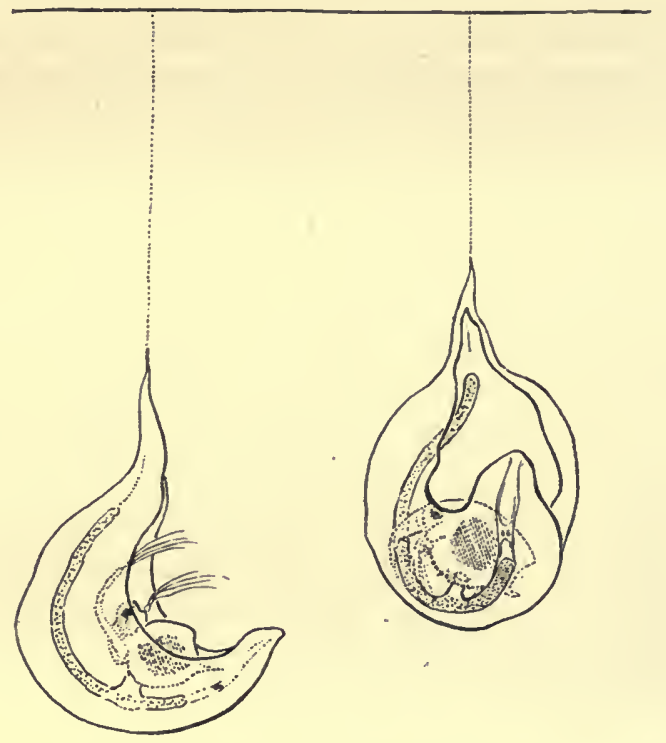

Abb. 137.

Zwei Individuen von Mesostoma ehrenbergi an ihren Spinnfäden von der Wasseroberflädhe herunterhängend; jedes der beiden Tiere hat ein Krebschen gefangen.

erhalten. Um aufs neue an die Oberfläche zu gelangen, muß der Wurm längs den Wänden des Gefäßes oder an einem Pflanzenstengel emporkriechen. Erst dann kann er sich wieder an einem Schleimfaden zum Schweben im Wasser herablassen.

Es gibt im Wasser wenig Tiere, die mit einer so hohen ${ }_{n}$ Spinnfähigkeit" begabt sind, wie Mes. ehrenbergi und seine nächsten Verwandten. Gleich den Spinnentieren auf dem Lande kann sich $M$ es. ehrenbergi nicht nur an seinem Faden herablassen, 
sondern an ihm auch wieder in die Höhe emporsteigen. Das zarte unsichtbare Seil macht den Zug der Schwerkraft unwirksam, und so genügt die Flimmerung, die Tiere aufwärts zu bewegen. An ihren Fäden hängend vollziehen die Würmer mit Vorliebe die $\mathrm{Be}$ gattung, wobei sie stundenlang unter ständigen, langsamen $\mathrm{Be}$ wegungen ihrer Körper miteinander vereint bleiben. Auch auf Beute lauern sie gern in dieser Stellung, den Schwanz nach oben, den Kopf nach abwärts gekehrt; und wenn in einem Gefäß zahlreiche Mes. ehrenbergi ihre Fäden gesponnen haben, so wirken diese gleich einem "mörderischen Netz". Man braucht nur eine Anzahl Daphnien in das Wasser zu bringen. Schon nach wenigen Sekunden hat jeder Wurm sich sein Opfer gefangen (Abb. 137).

Das Gleiten auf der Unterlage geschieht bei den größeren Mesostoma-Arten ganz ähnlich wie bei den Tricladen, wegen ihres geringeren spezifischen Gewichtes ${ }^{1}$ ) aber wohl ausschlieBlich durch die Kraft der Flimmerung. Wenigstens konnte auf Schnitt-

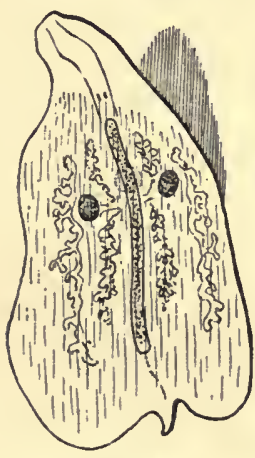

Abb. 138.

Ruhendes Mesostoma ehrenbergi mit d. Kopfende tastend.

präparaten nie etwas von jenen wellenförmigen Kontraktionen des Hautmuskelschlauches beobachtet werden, wie sie bei den Tricladen nachweisbar sind. Die Geschwindigkeit, mit der Mes. ehrenbergi vorwärts kriecht, ist etwa ebenso groß wie bei den Tricladen: 2 bis 2,5 mm pro Sekunde, sie bewegen sich also etwas mehr als doppelt so schnell wie die Weinbergschnecken auf dem Lande. Beim Kriechen zeigt der Körper gewöhnlich die in Taf. I, Abb. 4 wiedergegebene Haltung. In der Ruhe erscheint die hintere Körperhälfte verbreitert; bisweilen wird das Schwanzspitzchen geradezu in den übrigen Körper eingezogen, besonders wenn dabei das Kopfende leicht erhoben wird, um langsame Tastbewegungen auszuführen (Abb. 138).

1) Durch eine groBe Reihe genauer Messungen konnte das spezifische Gewidht von planaria lugubris gleid 1,05 bis 1,06 , das von Mes. ehrenbergi gleich 1,015 bis 1,02 bestimmt werden. 
Interessant ist, daß ebenso wie die Tricladen auch Mes. ehrenbergi unter der Einwirkung besonderer Reize eine andere Fortbewegungsart einschlägt, die es rascher vom Fleck bringt als das einfache Kriechen. Während aber die Tricladen zu diesem Zwedk nach Egelart "spannen“; geht Mes. ehrenbergi dabei ganz anders zu Wege; doch können wiederum die Egel als Vorbilder zur Beschreibung dieser beschleunigten Bewegungsart dienen. Wer je mit diesen Tieren $z u$ tun hatte, weiß nämlich, daß sie sich auch frei durchs Wasser "schlängeln " können, wobei sich ihr Körper möglichst lang ausstreckt und charakteristische Wellenbewegungen vollführt, die aber nicht wie bei den Schlangen in der horizontalen, sondern in der vertikalen Ebene verlaufen. Ganz ähnlich verfährt auch Mes. ehrenbergi (Abb. 139). Wird ein ein ruhig dahingleitendes Tier plötzlich etwas unsanft mit einer Nadel berührt - am besten in der Gegend des Gehirns, - oder erhält es von einem durch das Wasser tobenden Käfer oder dergl. einen StoB, so sieht man, wie es schleunig seinen Körper streckt und unter egelartigen Schlängelbewegungen $z u$ enteilen strebt. Auf diese Weise gelingt es dem Wurm, sich dicht über dem Boden schwebend rasch ein paar Zentimeter fortzubewegen, aber das. ist auch alles; sich höher zu erheben oder weiter zu entkommen, vermag er nicht. Seine zarte Muskulatur ermattet schon nach 10 bis 15 maligem Ablauf der Schlängelwellen, und kraftlos sinkt er alsbald $z u$ Boden. Wiederholt man den Reiz, so reagiert der Wurm erheblich

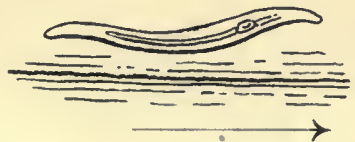

Abb. 139.

Mesostoma ehrenbergi "schlängelnd ". Der pfeil gibt die Be* wegungsrichtung an. schwächer und beantwortet ihn beim 3. oder 4. Mal nur noch mit einer schwachen Zuckung. Selbst starke Verletzungen können dann den Fluchtreflex nicht mehr auslösen.

Im Gegensatz zu den Tricladen, die auch bei ihrer beschleunigten Spannbewegung durchaus an den Boden gebunden bleiben, versucht also Mes, ehrenbergi, im Falle der Flucht sich unabhängig von der Unterlage fortzubewegen, wie es das auch in seiner Jugend vermochte. Während aber damals der 
Schlag der Wimpern ein regelrechtes Schwimmen ermöglichte, reicht jetzt die Kraft der Körpermuskulatur bei ihrer geringen Entfaltung nicht aus, die Tiere wirklich schwimmend fortzubewegen. Nichtsdestoweniger verdient aber doch gerade dieser "Versuch mit untauglichen Mitteln" besondere Beachtung, weil er uns die ersten Ansätze zu einer Schwimmbetätigung vor Augen führt, die in einer anderen Turbellariengruppe, bei den Polycladen, zu hoher Vollkommenheit ausgebildet ist. Auch diese Tiere kriechen normalerweise ganz wie die Tricladen, daneben vermögen aber viele Arten ausgezeichnet zu schwimmen. Ein Teil von ihnen (viele Leptoplaniden, Cryptocelis) vollführt dabei typische Schlängelbewegungen, wie sie oben beschrieben wurden; bei einem anderen Teil, besonders bei den großen, breiten Formen (Pseudoceriden, Prostheceraeus, Discocoelis, Stylochoplana u. a.), beschränken sich die undulierenden Bewegungen auf die Seitenteile des Körpers. Ihr Schwimmen, das sie außerordentlich behende durchs Wasser befördert, gleicht daher einem anmutigen Flattern, wie man es ähnlich auch bei den Flügelschnecken (Pteropoden) des Meeres beobachten kann.

\section{Ernährung}

Ernährungsweise. (Allgemeines)
Gleich den Tricladen leben die meisten Rhabdocoeliden von animalischer Nahrung, indem sie alle möglichen kleineren und größeren Tiere, soweit sie deren Herr werden können, verzehren. Es gilt dies indessen nicht für alle Arten. Vielmehr gibt es unter ihnen eine ganze Anzahl Spezies, in deren Darminhalt Reste von Algen, Diatomeen, Conferven und dergl. festgestellt werden konnten, die also pflanzliche Nahrung zu sich nehmen. Allerdings ist es fraglich, ob es sich dabei um reine Pflanzenfresser handelt. Denn wenn man auch bei manchen Formen, z. B. bei dem marinen promesostoma murmanicum, bisher nur vegetabilische Nahrungsobjekte beobachtet hat, so sind das doch nur gelegentliche Befunde, die nicht ausschließen, daß diese Tiere 
zu andern Zeiten etwa auch tierische Nahrung fressen. Sicher gibt es dagegen unter den Rhabdocoeliden eine ganze Menge Liebhaber von gemischter, bald tierischer, bald pflanzlicher Kost, wofür Stenostomum leucops und Macrostoma viride als Beispiele genannt seien. Ja es scheint sogar, daß manche Formen, die wie Mesostoma lingua und andere Typhloplaniden normalerweise Fleischfresser sind, gelegentlich auch pflanzliche Nahrung nicht verschmähen. Omnivor in diesem Sinne sind ferner audh die beiden in unsern Gewässern häufigen Microstomumarten. Für gewöhnlich gefräßige Räuber, die besonders auf kleine Crustaceen Jagd machen, kann man sie bisweilen ziemliche Massen bakterienreicher Schlamm- und Detritusteilchen verzehren sehen; auch mit leblosen, organischen Stoffen, wie Eigelb usw. lassen sie sich füttern. Ein Individuum mit ganz absonderlicher Beute, dem Bein einer Insektenlarve, das ihm noch zum Munde heraushängt, zeigt Abbildung 140.

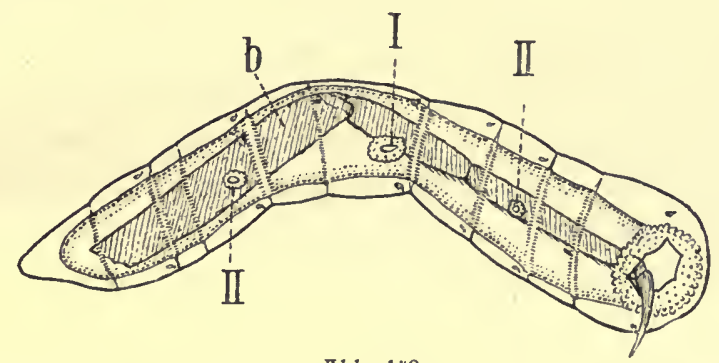

Abb. 140.

Microstomum giganteum mit Beute (Bein einer Ephemeridenlarve, b), nach einem

Totalpräparat. I und 11 pharynxanlagen der bei den beiden ersten Teilungen entstehenden Todterindividuen.

\section{Parasitismus}

daß die Rhabdocoeliden - und zwar sie allein unter den Turbellarien - zugleich auch ein größeres Kontingent parasitisch lebender Arten stellen. Die Zahl dieser Spezies beträgt nicht weniger als 27, und alle Formen des Schmarotzertums, vom gelegentlichen Raumparasitismus und Kommensalismus bis zum 
Ekto- und Entoparasitismus, haben unter ihnen Vertreter. In Anpassung an die parasitische Lebensweise haben diese Formen mancherlei Abänderungen des Körperbaues erfahren, am hochgradigsten die in der Leibeshöhle mariner Crustaceen schmarotzenden Fecampiiden, die im Alter sogar Mund und Darm zurüdkbilden. Sie müssen daher schließlich ihre Nahrung ganz ähnlich wie die Bandwürmer auf osmotischem Wege durch die Körperhaut hindurch aufnehmen.

\section{Symbiose mit HIgen}

Besonderheiten in der Ernährungsweise werden ferner auch durch die Vergesellschaftung mit einzelligen grünen (seltener braunen) Algen veranlaßt, die, wie wir schon früher hörten (Seite 205), zahlreiche Rhabdocoeliden und ebenso auch manche Acoelen einzugehen pflegen. Aller Wahrscheinlichkeit nach liefern dabei die Würmer den Algen Material zum Aufbau von Eiweißkörpern in Gestalt der stickstoffhaltigen Stoffwechselschlacken, die bei der Verdauung der yon ihnen gefressenen Nahrung übrig bleiben. Dagegen versorgen die Zoochlorellen ihrerseits die Würmer mit Sauerstoff und Kohlehydraten, und ersetzen bei den Hcoelen vielleicht auch das fehlende Exkretionsystem. In den meisten Fällen haben also beide Teile, Tier und Alge, aus diesem Zusammenleben Vorteile. Eine Ausnahme hiervon scheint jedoch Convoluta roscoffensis unter den Acoelen zu bilden, indem hier das Verhältnis zwischen Würmern und Zoochlorellen, das anfangs ganz normalen Charakter trägt, nach einiger Zeit in sehr eigenartiger Weise gestört werden soll. Man will nämlich beobachtet haben, daß die Tiere, sobald ihre Algen sich reichlich vermehrt haben und so zu ausgiebigen Nahrungsproduzenten geworden sind, dauernd auf die Aufnahme anderer Nahrung verzichten. Infolgedessen muß natürlich alsbald die Hauptquelle versagen, aus der die Algen bisher das Material zur Eiweißsynthese schöpfen konnten, und Stickstoffmangel eintreten, der dann wieder schwer auf die Würmer zurückfällt. Denn da sich der in den Zoochlorellen enthaltene, begrenzte Nahrungsvorrat nun nicht mehr in dem 
früheren Maße ergänzt, müssen die Tiere ihn allmählich aufgebrauchen und dann - da sie $\mathrm{zu}$ fressen verlernt haben unweigerlich Hungers sterben.

Im allgemeinen sind die Rhabdocoeliden indessen, wie schon gesagt, Tiere von räuberischer Lebensweise, deren Beute aus Infusorien und den verschiedenartigsten Würmern, vor allem aber aus kleinen Krebsen besteht. Manchen Arten dienen besonders Hydropolypen - und Moostierstöckchen als Weide. So leben auf den im Hafen von Neapel massenhaft wuchernden Kolonien der Bryozoe Bugula avicularia stets zahllose Individuen von Plagiostomum girardi, die von Zweig $z u$ Zweig kriechend ein Tier nach dem andern verzehren und an den leergefressenen Hüllen ihre Eier befestigen.

Nahrung von Mesostoma ehrenbergi
Mes. ehrenbergi soll nach den Angaben in der Literatur über einen recht "stattlichen Speisezettel “ verfügen. Von Würmern stehen darauf: verschiedene Oligochaeten (Naididen, Tubificiden, Lumbriculiden), sowie Rotatorien, von Krebsen: Vertreter aller Gruppen der kleinen Süßwasserentomostraken (Cladoceren, Copepoden, Ostracoden), ferner Fliegen- und Notonectalarven, sowie Wassermilben $(\mathrm{Hy}$ drachniden). Endlich sollen sie zu Zeiten auch die eigenen Jungen auffressen. In Wirklichkeit ist diese Liste aber viel zu umfangreich; von all den genannten Nahrungsobjekten kommen praktisch nur die Cladoceren, und zwar vorwiegend die Daphniden, sowie Stylaria lacustris und einige verwandte Naididen, ferner allerhand Rotatorien in Frage. Von den übrigen Formen werden einzelne bloß bei jeglichem Mangel anderer Nahrung angegriffen, etwa kleine Tubificiden oder Dipterenlarven, die andern aber gänzlich verschmäht. Wenn man Mes. ehrenbergi in kleinen Glasdosen, in denen sie sich bei Fütterung mit Daphnien monatelang halten lassen, nur mit Ostracoden und Copepoden zusammenbringt, so verhungern die Tiere trotz der reichlich vorhandenen Beute, und das gleiche ist der Fall, wenn man ihnen nichts als Hydrachniden oder Wasserwanzenlarven zum Fraß an-

Steinmann-Bresslau, Strudelwürmer. 
bietet. Die Autoren, die auch diese Tiere zu den Nahrungsobjekten von Mes. ehrenbergi rechnen, haben sich wohl durch die Beobachtung täuschen lassen, daß sich gelegentlich das eine oder andere Individuum in die Schleimfäden der Mesostomeen verwickelt und darin zugrunde geht. Gefressen werden sie aber nicht. Ebenso ist Kannibalismus, wenn er überhaupt vorkommt, eine Seltenheit. Bei den Zuchtversuchen, von denen später (S. 298, 299) die Rede sein wird, wurde die Aufeinanderfolge vieler Generationen und das Hufwachsen von Tausenden von Exemplaren, oftmals bei scharfem Hunger, zahlenmäßig genau kontrolliert; trotzdem wurden dabei nur ganz wenige Fälle beobachtet, wo der Verdacht, ein in Verlust geratenes Tier könnte von seinen Artgenossen gefressen worden sein, einigermaßen begründet war.

Daß bei der Ernährung von Mes. ehrenbergi die Copepoden keine Rolle spielen, hat vielleicht darin seinen Grund, daB diese Krebschen sich viel geschwinder bewegen als die Daphniden. Für die nur langsam sich fortbewegenden Ostracoden oder $\mathrm{Hy}$ drachniden kann dies indessen nicht zutreffen. Hier handelt es sich offenbar um ein regelrechtes Verschmähen solcher Nahrung in dem Sinne, daß entweder irgendwelche chemotaktischen Reize fehlen, die die Würmer zur Jagd auf die Krebse veranlassen könnten, oder daß umgekehrt von letzteren gewisse Reizwirkungen ausgehen, welche die Würmer abstoßen. Wahrscheinlicher von beiden Eventualitäten ist die letztere; wenigstens spricht dafür die Beobachtung, daß, wenn man in ein Gefäß mit hungernden Mes. ehrenbergi eine Anzahl Exemplare irgendeiner Cypris- oder sonstigen Ostracodenart bringt, die Würmer mit Fangbewegungen darauf reagieren, die Krebse aber, nachdem sie sie berührt haben, wieder loslassen. In einem Versuche wurden 3 ausgewachsene, sehr gefräßige Mes. ehrenbergi mit 20 Cypris in eine kleine Glasdose gesetzt. Nach 4 Tagen war der Darm der Würmer völlig leer, aber kein einziges der Krebschen gefressen, und auch nach weiteren 10 Tagen war die Situation unverändert, obwohl die Würmer durch den Hunger bereits sehr reduziert waren. 
Beutefang

Füttert man dagegen hungrige Mes. ehrenbergi mit Daphnien, so karın man sicher sein, schon nach wenigen Minuten jedes Exemplar mit dem Verzehren eines Krebschens beschäftigt zu finden. Auf die Hilfe, die den Würmern die von ihnen gesponnenen Schleimfäden beim Beutefang

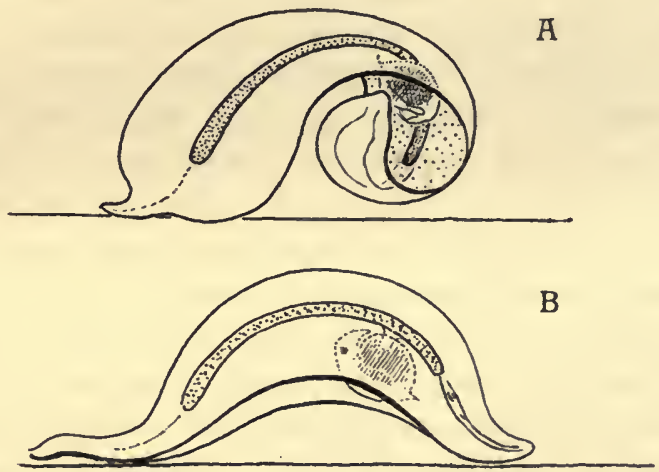

Abb. 141.

Mesostoma ehrenbergi : $A$ ein Krebschen fangend, B ein soldhes verzehrend.

leisten, wurde schon oben hingewiesen. Unbedingt notwendig ist diese Hilfe indessen nicht. Der Fütterungsversuch gelingt vielmehr mit derselben Sicherheit auch, wenn man die Würmer und Daphnien in einem mit frischem Wasser gefüllten Gefäß zusammenbringt. Sowie ein Krebschen in die Nähe eines Wurmes kommt, holt dieser mit seinem Kopfende zu einem kräftigen Schlage aus, und kaum hat er den Krebs berührt, so ist dieser gefangen. Mag er auch noch so sehr zappeln und sich wehren, er klebt an dem Vorderende des

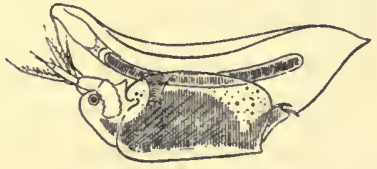

Abb. 142.

Junges Mesostoma ehrenbergi beim Verzehren einer Daphnie. Mesostoma fest, ohne daB es ihm gelingt, sich wieder zu befreien. Ist der Krebs im Verhältnis zum Wurm sehr groß, so kann er wohl noch ein Stück weit durch das Wasser rudern und letzteren dabei hinter sich herziehen. In den meisten Fällen bringt 
aber der Wurm sofort seinen Pharynx in Berührung mit der Daphnie und saugt sich an ihr fest. Ist dies geschehen, so löst sich die klebrige Masse, die den Krebs zuerst an dem Vorderende des Wurms anheftete. Ein Entkommen ist für ihn aber auch jetzt nicht möglich, umsoweniger, als das Mesostoma, wenn es seine Größe erlaubt, Vorder- und Hinterende über ihm zusammenbiegt und auch seine Seitenränder so um ihn faltet, $d a ß$ es den Krebs mit seinem Körper wie mit einer Glocke umhüllt (Abb. $141 \mathrm{~B}$, vgl. auch Abb. 137). Wehrt er sich noch immer, so versetzt ihm der Wurm rasch hintereinander ein paar Schläge oder Stöße mit der Kopfspitze (Abb. $141 \mathrm{~A}$ ) und schon nach wenigen Augenblicken ist die Daphnie ermattet und stirbt. Auf diese Weise können selbst jugendliche Würmer über Daphniden von solcher Größe Herr werden, daß man es kaum für möglich halten sollte. Ist der Krebs überwältigt, so bringt der Wurm seinen Schlundrüssel zwischen dessen zwei Schalenklappen und beginnt ihn auszusaugen (Abb. 142).

Was während der eben geschilderten, überaus charakteristischen Vorgänge im Einzelnen geschieht, ist bisher noch nicht mit Sicherheit festgestellt worden. Man hat früher und auch jetzt noch vielfach angenommen, daß die Rhabdoide beim Beutefang die Hauptrolle spielen. Diese Meinung trifft jedoch wohl nicht völlig zu. Zum Erhaschen der Beute dienen vielmehr aller Wahrscheinlichkeit nach die Spinndrüsen des Vorderendes, die sich durch ihre diffuse Anordnung (s. Abb. 99, S. 210) so auffällig von den längs der ventralen Mittellinie konzentrierten Spinndrüsen des übrigen Körpers unterscheiden. Dank dieser Gruppierung ist jede Stelle des Vorderendes, die mit dem Opfer in Berührung tritt, imstande, es festzuhalten. Nach dem Fang dürften cyanophile Drüsen in Tätigkeit treten, um das klebrige Spinndrüsensekret wieder $z u$ verflüssigen, und die Beute so für den Transport nach der Mundgegend frei zu machen. Außerdem müssen zur gleichen Zeit Stoffe ausgeschieden werden, welche die Beute lähmen oder vielleicht sogar töten. Hieran 
sind wahrscheinlich die Stäbchen beteiligt, wenigstens deutet hierauf die Tatsache hin, daß die Würmer gerade ihre rhabditenreiche Kopfspitze zu jenen eigenartigen Stößen benutzen, mit denen sie die vom Pharynx festgehaltenen Krebse endgültig zur Ruhe bringen.

Weichhäutige Tiere, wie Stylaria lacustris pflegt Mes. ehrenbergi ganz zu verschlucken, Daphnien dagegen saugt es immer nur aus, im Gegensatz zu Microstomum und den übrigen Arten mit Pharynx simplex, die dazu nicht fähig sind, und daher jedes Nahrungsobjekt ganz in sich aufnehmen. Bei der Durchsichtigkeit beider Tiere, des Krebses wie des Wurms, kann man leicht beobachten, wie der Pharynx des letzteren unter energischen Pumpbewegungen die ganze weiche Innenmasse des Daphnienkörpers in den eigenen Darm hinüber befördert, so daß schließlich nichts mehr übrig bleibt als die vollkommen leere Schale. Der ganze Aussaugeakt geht außerordentlich rasch vor sich, und dauert bei nüchternen Tieren, selbst wenn sie Daphnien, von respektabler Größe vor sich haben, nicht länger als 15 bis 17 Minuten. Eine solche Daphnie reicht im allgemeinen nicht zur Sättigung der Würmer aus, vielmehr pflegen sie schon 20 bis 30 Minuten nach der ersten Daphnienmahlzeit einen zweiten Krebs zu fangen und auszusaugen. Hungrige Tiere können hintereinander - innerhalb von 2 oder 3 Stunden -3 bis 4 Daphnien verspeisen und es an einem Tage auf 6 bis 8 Krebse bringen. In solchen starkgemästeten Tieren erscheint der Darm dann als ein prall gefüllter Sack mit weiter Lichtung und glatt konturierter relativ dünner, gespannter Wandung, dessen Querdurchmesser ein Viertel der Breite des ganzen Tieres betragen kann. Wenig später, oft schon nach einer Stunde sind aber bedeutende Veränderungen zu konstatieren: die Lichtung ist beträchtlich verengt, dafür die Darmwand dicker, dunkler pigmentiert und leicht gekräuselt, ein Zeichen dafür, daß die Nahrung von den Darmzellen zur weiteren Verarbeitung und Assimilation aufgenommen worden ist. Setzt man die Mästung einige Tage hindurch fort, so stellt sich jene Divertikelbildung ein, von der schon früher die Rede war (S. 229, Abb. 113). 
Über die Verdauungsvorgänge selbst sind an Rhabdocoeliden in neuerer Zeit keine Untersuchungen angestellt worden. Die Verhältnisse dürften jedoch im wesentlichen mit den bei den Tricladen beschriebenen übereinstimmen. Von historischem Interesse ist, daß die Tatsache der intrazellulären Verdauung von Metschnikoff (1878) zuerst bei Mes. ehrenbergi entdeckt wurde.

\section{Hunger}

Schon der Umstand, daß sich fast alle Arten unserer Süßwasserrhabdocoelen nur während relativ kurzer "Saisons", die Tricladen dagegen das ganze Jahr hindurch finden, weist auf die größere Abhängigkeit der ersteren von den äußeren Existenzbedingungen hin, unter denen, nächst der Temperatur, die Ernährungsverhältnisse die Hauptrolle spielen. Nahrungsmangel ist daher für sie ein viel bitterer Feind als für die Tricladen, und Hungerperioden, die letztere mühelos ertragen, räumen unerbittlich unter den Rhabdocoelen auf. Ausgewachsene, gutgenährte Exemplare von Mes. ehrenbergi von 12 und mehr Millimeter Länge werden schon durch zwei bis dreiwöchiges Fasten stark mitgenommen, sie verlieren ihre Transparenz und schrumpfen sichtlich zusammen. Vier Wochen und länger ertragen die Tiere den Hunger wohl nur noch unter den künstlichen $\mathrm{Be}$ dingungen des Experiments, wobei sie zu kleinen, kaum $3 \mathrm{~mm}$ langen undurchsichtigen, überaus hinfälligen Geschöpfen reduziert werden, die schon bei leiser Berührung zerfallen. Jene eigenartige Fähigkeit, Nahrungsmangel durch Einschmelzung innerer Organe zu kompensieren, die sich bei den Tricladen herausgebildet hat, geht Mes. ehrenbergi ganz ab. Natürlich schrumpft, wie das ganze Tier, so auch der Genitalapparat während des Hungerns zusammen. Aber seine Funktionsfähigkeit geht dabei durchaus nicht gänzlich verloren. Vielmehr können bisweilen selbst Tiere, die dem Hungertode schon ganz nahe scheinen, noch frische Dauereier produzieren. Tricladen und Rhabdocoeliden zeigen also eine ganz verschiedene Anpassung an Zeiten mit schlechten Ernährungsbedingungen. Während bei 
den einen die Geschlechtsorgane resorbiert werden, um eine Erhaltung des Individuums zu ermöglichen, bewahren sie sich bei den andern bis zuletzt ihre Leistungsfähigkeit, um die Erhaltung der Art zu sichern.

\section{Defäkation, Exkretion}

Rhabdocoeliden nichts besonderes $z u$ berichten. Soweit bekannt, liegen die Verhältnisse hier ganz ähnlich wie bei den Tricladen.

\section{Geschlechtliche Fortpflanzung}

Wenn man im August oder Anfang September Mesostoma ehrenbergi sammelt, werden in der Regel alle Exemplare so aussehen, wie es Abb. 4 der Tafel I veranschaulicht, d. h. sie werden sämtlich nur Dauereier produzieren oder sich $\mathrm{zu}$ deren Bildung vorbereiten. Dies ist schon mit bloßem Auge ohne weiteres daran $z \mathfrak{z}$ erkennen, daß die Hoden und vor allem die Dotterstöcke mächtig entwickelt sind (s. o. S. 242), während die Uteri ihre Längsschenkel noch nicht entfaltet haben, oder doch erst unter dem Druck der in sie eintretenden Eier entfalten.

\section{Begattung}

Die Eibildung findet nun bei diesen "Herbsttieren ", wie wir sie nennen wollen, normalerweise stets nach voraufgegangener wechselseitiger Begattung statt. Hält man eine größere Zahl der Würmer in einem Glasgefäß beisammen, so kann man den Vorgang jederzeit, tags wie nachts, häufig beobachten und zwar sowohl bei Individuen, die an ihren Spinnfäden im Wasser schweben, wie an solchen, die sich am Boden oder an den Wänden des Gefäßes befinden. Eingeleitet wird die Begattung durch eine Art Liebesspiel, das oft viertelstundenlang dauern kann. Die Tiere kriechen lebhaft um einander und betasten sich gegenseitig mit ihren Vorderenden die Genitalgegend, wobei der eine Partner seinen Rumpf glockenförmig zusammenkrümmt und der andere seinen Kopf in diese Wölbung schmiegt (Abb.143 A). Schließlich finden sich beide und vollziehen mit gegen- 
seitig in die Geschlechtsöffnung eingeführten Penes die Begattung, wobei sie bisweilen länger als eine Stunde miteinander gepaart bleiben. Ihre Lage zueinander ist dabei keineswegs konstant; nur in der Genitalregion sind die Leiber eng aneinandergepreßt, Kopf- und Schwanzenden sind dagegen beweglich. Man kann

H
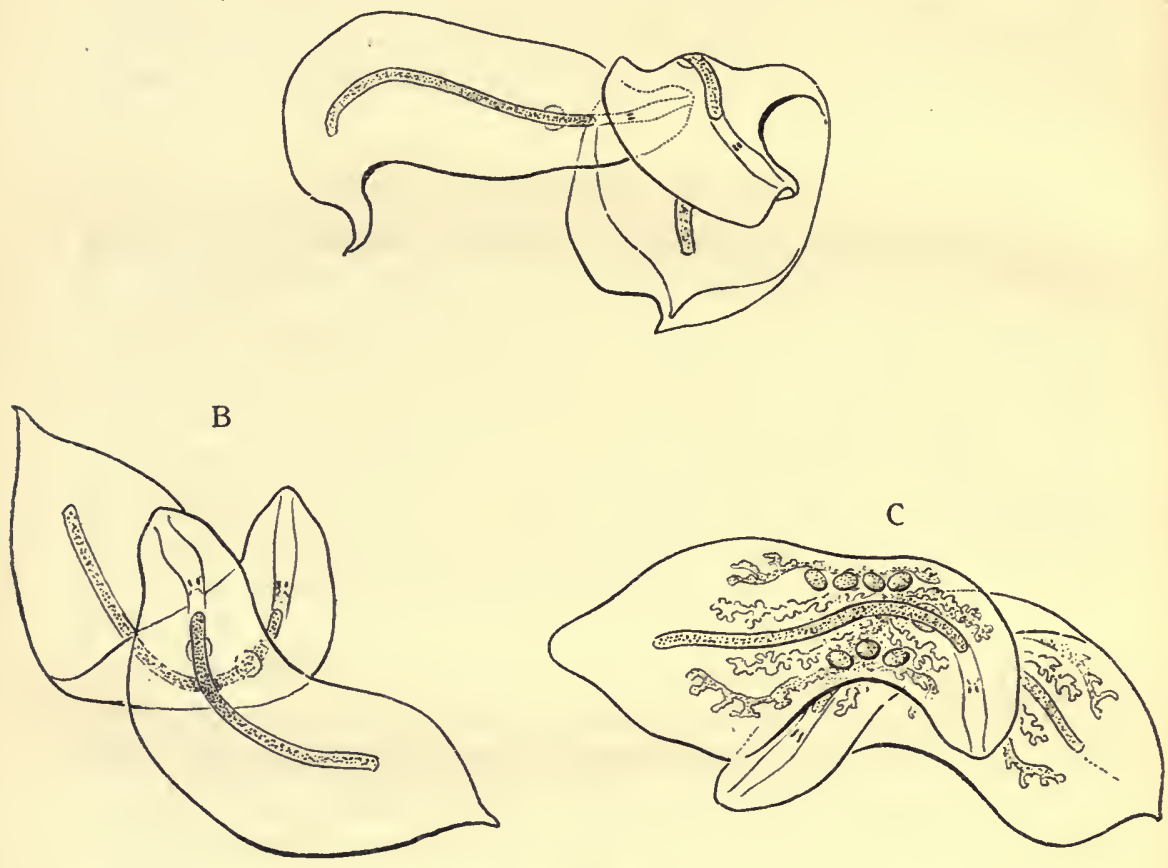

Abb. 143.

Mesostoma ehrenbergi : A Liebesspiel, B und C Begattung. Die Geschiechtsorgane sind nur in $C$ gezeichnet.

infolgedessen nicht selten beobachten, daß die kopulierenden Tiere ziemlich starke Drehungen umeinander ausführen, und bald die Kopfenden beide nach der gleichen ( $\mathrm{Abb} .143 \mathrm{~B}$ ), bald gegen einander gekreuzt, nach verschiedenen Richtungen ausstrecken (Abb. $143 \mathrm{C}$ ). Während der Begattung sind die Tiere nicht sehr empfindlich; man kann sie berühren, ohne daß sie voneinander 
ablassen. Durchreißt man die Spinnfäden, an denen ein kopulierendes Paar hängt, so bewegen sich die Würmer während des Sinkens lebhaft hin und her, setzen aber, am Boden des Gefäßes angelangt, ruhig die Kopula fort.

Nach der Begattung findet man das Sperma in der strotzend gefüllten Bursa copulatrix der beiden Tiere; bald darauf wird es portionenweise in das dem Ovidukt angeschlossene Receptaculum seminis befördert. Hier verbleiben die Spermien und besamen die Keimzellen, die auf dem Wege nach dem Ductus communis das Receptaculum passieren müssen. Da indessen die Tiere während der Eibildungsperiode wiederholt Begattungen vollziehen, ohne daß jedesmal vorher die im Receptaculum seminis enthaltene Samenmasse aufgebraucht ist, so muB angenommen werden, daß der Rest von Zeit zu Zeit nach außen geschafft wird, um Platz für das bei der neuen Kopula empfangene Sperma zu schaffen. Wie und wann das geschieht, ist bisher jedoch noch nicht beobachtet worden.

Bildung der Dauereier

Die Bildung der Eier findet im Genitalatrium statt, wohin sowohl die Keim- wie die Dotterzellen durch Vermittlung des Ductus communis gelangen. Gegenüber dem entsprechenden Vorgang bei den Tricladen sind dabei zwei bemerkenswerte Unterschiede $z \mathbf{z u}$ beachten. Einmal wird in jeder Eikapsel immer nur eine einzige Keimzelle mit den nach Hunderten zählenden Dotterzellen vereinigt, und zweitens wird die Substanz der Kapselschale, wie es scheint, ausschließlich von den Dotterzellen geliefert, ohne daß etwas der Grundsubstanz der Tricladenschale Ahnliches hinzutritt. Bei den. Herbsttieren von Mes. ehrenbergi ist daher die Eischale trotz ihrer relativ beträchtlichen Dicke homogen. Ihre Farbe erscheint dem Auge anfangs rein weiß, geht aber bald, - während die Eier aus dem Geschlechtsatrium in den Uterus geschoben werden - über gelb und orange in rot und dunkelbraun über (Tafel I, Abb. 4). Hand in Hand mit diesem Farbenumschlag vollziehen sich auffällige Veränderungen in der 
Konsistenz und Gestalt der Schale (Abb. 144). Die weiße Schale ist zunächst klebrig weich und nahezu kugelrund (a), während sie aber mit zunehmender Verfärbung erstarrt, stülpt sie sich wie

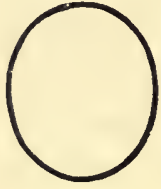

a

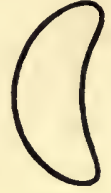

$b$

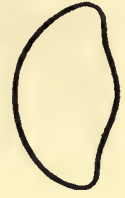

$c$

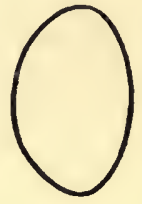

$d$

Abb. 144.

Gestaltveränderungen der Dauereier von Mesostoma ehrenbergi. Die UmriBzeichnungen veranschaulichen 4 aufeinanderfolgende Stadien. ein Gummiball einseitig ein, so daß ihr Durchschnitt konvex - konkav erscheint (b). Allerdings nur für kurze Zeit, denn bald danach erhält ihr Umriß die in Abb. 144 c gezeichnete Form und nimmt dann erst die bi konvexe, aber auf der einen Seite schwächer gewölbte Gestalt (d) an, die den fertigen Dauereiern eigen ist. Ihr größter Durchmesser beträgt alsdann etwa $0,45-0,5 \mathrm{~mm}$. Uber die Ursache dieser merkwürdigen Gestaltsveränderungen lassen sich nur Vermutungen aufstellen. Außere Einflüsse, Kontraktion der Eihälterwand oder Druck der Eier gegeneinander kommen nicht in Frage; denn da die Eier sich bei den Bewegungen der Tiere innerhalb der Uteri leicht verschieben und hin- und herdrehen, können sie kaum stärkeren Drudkwirkungen ausgesetzt sein. Möglicherweise spielen dabei Vorgänge innerhalb der Eier eine Rolle, etwa eine mit dem Zerfall der Dotterzellen einhergehende Flüssigkeitsabgabe, die dann später wieder $z$. T. ausgeglichen wird.

Während bei den Tricladen jeder Kokon bald nach seiner Bildung abgelegt wird, ist dies bei Mes. ehrenbergi nicht der Fall. Ei bleibt bei Ei im Mutterkörper, und erst durch dessen Zerfall nach dem Tode gelangen sie nach auBen, Bei guter Er nährung wird ungefähr alle 24 Stunden ein Ei gebildet, so daß ihre Zahl unter günstigen Umständen auf etwa 40-50 steigen kann (die höchste, aber nur einmal von mir beobachtete Zahl war 58). Zur Aufbewahrung der Eier dienen die beiden Uteri, die zu immer größerer Länge ausgedehnt werden. Im allgemeinen geschieht die Füllung der Uteri symmetrisch, wobei normalerweise 
das erste $\mathrm{Ei}$ in den rechten Uterusschenkel, also auf die Seite gelangt, auf der auch der Keimstock gelegen ist. Das zweite wird dann nach links hinübergeschoben, das dritte wieder nach rechts und so fort. In der Längsrichtung werden die Uteri für gewöhnlich so beansprudht, daß die beiden hinteren Schenkel des $\mathrm{H}$ stärker mit Eiern erfüllt und infolgedessen länger ausgezogen werden als die vorderen. Es hat dies darin seinen Grund, daß die Geschlechtsöffnung vor der Leibesmitte gelegen ist; zugleich bietet die hintere Körperhälfte mehr Raum zur Entfaltung der Uteruslängsschenkel als die vordere, die noch das Hirn und die davon ausstrahlenden, kräftigen Längsnervenstränge enthält.

Von dieser Regel sind aber zahlreiche Ausnahmen möglich. Manchmal beginnt die Füllung der Uteri nicht rechts, sondern auf der linken Seite; oder es werden von den Eihältern nur die vorderen, oder aber nur die hinteren Schenkel mit Eiern erfüllt. Nicht selten kommen endlich auch ganz asymmetrische Füllungszustände zur Beobachtung. Einen extremen Fall dieser Art bildete ein Ende Juli 1910 im Rheinwald gefangenes Exemplar, das 18 braunschalige Eier enthielt, die zwar gleichmäßig auf beide Eihälter verteilt waren, aber so, daß alle 9 Eier der rechten Seite im vorderen, die der linken Seite dagegen im hinteren Uterushorn sich fanden.

Wenn nun die Eier nach dem Tode des Muttertieres ins Freie gelangt und irgendwo zu Boden gefallen sind, so schlüpfen daraus nicht etwa, wie bei den Tricladen, schon nach wenigen Wochen Junge aus. Vielmehr bleiben sie, - die man deswegen mit Recht Dauer-, Latenz- oder auch Wintereier genannt hat, - unverändert liegen, einerlei ob die Wassertemperaturen um diese Zeit noch relativ hoch, oder bei frühzeitig einsetzender Kälte dem Gefrierpunkt nahe sind bringt. Nicht einmal Zufrieren der Gewässer oder ihr völliges Austrocknen vermag das in den Eiern schlummernde Leben $z u$ vernichten. Wenn im nächsten Jahre Schneeschmelze und Frühlingsregen den Grundwasserstand erhöht und die vorher ausgetrockneten Tümpel wieder mit Wasser gefüllt haben, dann bedarf es nur einer Reihe warmer Mai- oder Junitage, um die Brut der Dauereier zum Ausschlüpfen zu bringen. 
Bildung der Die Jungen, die aus diesen Eiern hervorgehen, Subitaneier verhalten sich nun aber, wenn sie herangewachsen sind und selbst wieder zur Fortpflanzung schreiten, ganz anders als ihre Eltern, wenn sie mit ihnen auch sonst in ihrem Körper bau durchaus übereinstimmen. Es ist daher zweckmäßig, sie gleich von vornherein durch einen besonderen Namen von jenen zu unter scheiden. Allerdings ist die von $A$. Schneider dafür eingeführte Bezeichnung "Wintertiere" nicht gerade sehr prägnant. Wir wollen sie aber hier beibehalten, da sie in der Literatur bisher überall zur Anwendung gelangt ist. Nur müssen wir uns darüber klar sein, daß es sich bei den Wintertieren nicht um eine im Winter lebende Generation handelt, sondern um die Tiere, die aus den Dauereiern nach ihrer Überwinterung hervorgehen.

Die Eigentümlichkeit der Wintertiere besteht nun darin, daß ihre Geschlechtsorgane, vor allem der männliche Apparat und die Dotterstöcke, auch unter den günstigsten Wachstumsbedingungen nicht jene voluminöse Entfaltung erlangen, die diese Organe bei den elterlichen Herbsttieren auszeichnete. Hoden und Vitellarien bleiben vielmehr klein und durchsichtig, ja das Kopulations organ ist überhaupt noch nicht fertig entwickelt, wenn die Tiere (bei einer Länge von etwa $4-5 \mathrm{~mm}$ ) mit der Eibildung beginnen. Es entseht infolgedessen eine ganz andere Eisorte, als es die Dauereier sind. Wiederum ist in jedem $\mathrm{Ei}$ nur eine Keimzelle vorhanden, aber es werden ihr jeweils nur wenige (40 bis 50 ) Dotterzellen von geringer Größe beigesellt, und diesen fehlen zudem alle jene Kügelchen und Tröpfchen von Nahrungsdotter und Schalensubstanz, die die Dotterzellen der Dauereier erfüllen. Die Eier - die man als Subitan oder Sommereier zu bezeichnen pflegt - sind daher winzig klein $(0,06$ bis $0,08 \mathrm{~mm}$ Durchmesser) und besitzen statt der dicken, braunen Schale der Dauereier nur ein äußerst zartes, vollkommen durchsichtiges Häutchen als Umhüllung (Abb. 146). Betrachtet man sie gleich nach ihrer Bildung bei stärkerer Vergrößerung unter dem Mikroskop, so kann man in jeder Keimzelle einen Spermafaden erkennen, eine Begattung kann jedoch nicht vorausgegangen sein, da der Penis 
der Tiere noch gar nicht funktionsfähig ist. Vielmehr liegt hier Selbstbefruchtung vor, dadurch herbeigeführt, daß vor $\mathrm{Be}$ ginn der Eibildung ein Quantum Samenmasse aus den eigenen Hoden des Tieres in das Receptaculum seminis übergeleitet wird.

Zum Unterschied von den Dauereiern werden die Subitaneier ferner in äußerst kurzer Zeit erzeugt. Innerhalb 24 Stunden ist die gesamte Anzahl, die ein Wurm überhaupt hervorzubringen vermag, fertig ausgebildet und ungefähr symmetrisch auf die beiden Uteruslängsschenkel verteilt. Dabei kann ihre Zahl die der Dauereier noch etwas übertreffen. Jedenfalls ist die größte bisher gefundene Subitaneierzahl 72 bei Dauereiern noch nicht beobachtet worden.

So rasch wie ihre Bildung erfolgt, so rasch geht auch die Entwicklung der Subitaneier vor sich, über die wir näheres in einem späteren Kapitel erfahren werden. Zugleich wachsen die Eier beständig, so daß sie schließlich ungefähr dieselbe Größe erreichen, die die Dauereier von Anfang an besitzen. Nach zwei bis vier Wochen - je nach den äußeren Bedingungen schneller oder langsamer - ist die Entwidklung beendet und jedes der Subitaneier enthält nunmehr einen jungen Wurm, der innerhalb der Eihülle langsam rotiert. Bald darauf sprengen die Jungen ihre Hüllen und schlüpfen aus, verbleiben aber gewöhnlich noch einige Stunden, bisweilen auch noch länger im Uterus des Muttertiers. Dann erst gelangen sie ins Freie, entweder in der Weise, daß sie die Uteruswand durchbrechen und durch die Gewebe des Muttertiers hindurch nach außen dringen oder per vias naturales, indem die Jungen, eines nach dem anderen, durch langsame Kontraktionen des Körpers aus den vorderen und hinteren Uterusschenkeln nach der Gegend der Geschlechtsöffnung hingeschoben und durch diese selbst nach außen geboren werden. Um dies interessante Schauspiel zu Gesicht zu bekommen, muß man allerdings über unverletzte Tiere verfügen, die nicht schon oft aus einem Gefäß ins andere transportiert oder anderen Insulten ausgesetzt gewesen sind. Bei Aquariumstieren pflegt man meist nur das Austreten der Jungen durch Risse der mütterlichen Leibeswand zu beobachten, 
im Freien dürfte aber wohl die Geburt der Tiere durch die Geschlechtsöffnung, ohne gröbere Verletzung der Mutter, das häufigere sein.

Mit diesem Zeitpunkt ist aber die Geschlechtstätigkeit der Wintertiere keineswegs $\mathrm{zu}$ Ende. Unmittelbar danach beginnt vielmehr eine neue Eibildungsperiode, die sich schon vorbereitet,

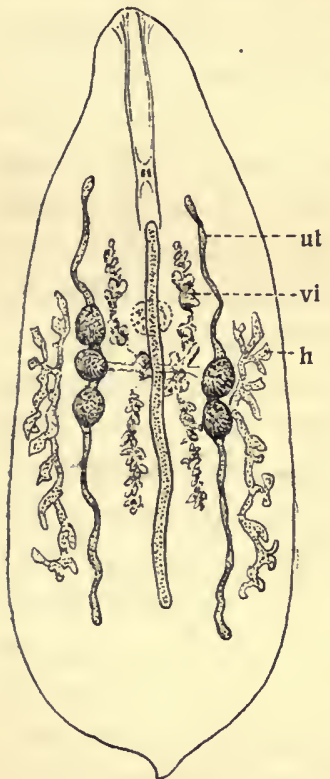

Abb. 145.

Wintertier von Mesostoma ehrenbergi nad d. Subitaneierlracht Dauereier produzierend. h Hoden; ut Uterus; vi Dolterstock. noch ehe die Subitaneierbrut vollends ausgeschlüpft oder zur Welt gebracht ist. Man bemerkt dies daran, daß in den Muttertieren Hoden und Dotterstöcke aufs neue zu wachsen beginnen und allmählich anschwellend mehr und mehr von ihrer Durchsichtigkeit einbüßen. Das geht so rasch, daß kurze Zeit nach der Geburt der jungen Subitaneier die Geschlechtsorgane ihrer Mütter ganz das Aussehen zeigen, wie wir es von den Herbsttieren kennen lernten. Ein durchgreifender Unterschied existiert indessen, der auf den ersten Blick die Vorgeschichte der Tiere verrät: während bei den Herbsttieren die Uteri erst unter dem Einfluß der sich entwickelnden Dauereier entfaltet werden, zeigen hier die langen, kollabierten Uterusschläuche auf jeder Seite zwischen Hoden und Vitellarien an, daß die Tiere bereits einmal trächtig gewesen sind (Abb. 145).

Der Entfaltung ihrer Geschlechtsorgane entsprechend beginnen die Tiere nunmehr nach voraufgegangener Begattung Dauereier $\mathrm{zu}$ bilden, ganz in derselben Weise, wie wir dies bereits von den Herbsttieren her kennen. So füllen sich ihre Uteri allmählich wieder; indessen wird die Zahl der Dauereier, die jetzt erzeugt werden, nicht ganz so hoch wie bei den Herbsttieren. Ins Freie gelangen sie gleich jenen erst nach dem Tod des Muttertiers.

Es ist bei den Wintertieren von Mes. ehrenbergi die 
Regel, daß die Dauereiproduktion erst nach beendigter Subitaneiertracht beginnt. Die beiden Eisorten kommen also normalerweise nicht nebeneinander in den Eihältern desselben Tieres vor. Nur wenn sich einmal das Ausschlüpfen der Jungen verzögert, können gelegentlich bereits die ersten Wintereier entstehen, ehe noch die Subitaneierbrut das Muttertier verlassen hat. Wer danach annehmen wollte, daß Dauer- und Subitaneier durcheinander erzeugt werden, würde aber gänzlich fehl gehen. Stets bilden die Subitaneier eine für sich vollkommen abgeschlossene Tracht, auf die erst nach einiger Zeit die Produktion der Dauereier folgt. Hat ein Individium erst einmal mit der Bildung der Dauereier begonnen, so vermag es unter keinen Umständen noch ein zweites Mal Subitaneier zu produzieren.

In dem seltenen Falle, daß die ersten Dauereier noch vor der Geburt der Sommereier auftreten, ist zugleich noch eine weitere Ausnahmeerscheinung zu beobachten. Weil zuletzt entstanden, liegen diese Dauereier in den Eihältern der Geschlechtsöffnung am nächsten und versperren also den ausgeschlüpften Jungen den Weg ins Freie. Trotzdem verlassen aber auch jetzt die Jungen unter normalen Verhältnissen den mütterlichen Körper nicht direkt durch Zerreißen seiner Gewebe, sondern auf natürliche Weise, indem nämlich vorher die ihnen im Wege liegenden Dauereier durch energische Geburtswehen nach außen geschafft werden. Unter diesen Umständen kommt es also einmal - was sonst bei Mes. ehrenbergi nie geschieht - zur Ablage von Dauereiern. Für die weiteren Dauereier, die die Muttertiere nach der Geburt der Jungen erzeugen, gilt das selbstverständlich nicht; sie werden vielmehr in der gewöhnlichen Weise innerhalb der Uteri aufgespeichert.

Aufeinanderfolge Wenn wir nun das Schicksal der aus den der Generationen Subitaneiern der Wintertiere ausgeschlüpften, von $A$. Schneider als "Sommertiere" bezeichneten Jungen verfolgen, so treffen wir da auf zwei Möglichkeiten des Verhaltens. Bei einem Teil von ihnen, gewöhnlich bei der Mehrzahl, erlangen die 
Geschlechtsorgane sogleich die Ausbildung, die wir vorher als typisch für die Herbsttiere kennen gelernt hatten; die Folge davon ist, daß die Tiere, ungeachtet ihrer Geburt im Hochsommer oder gar noch vor dessen eigentlichem Beginn, direkt Dauereier produzieren. Ein anderer Teil dagegen verhält sich genau wie die Wintertiere, indem er erst eine Tracht Subitaneier erzeugt, ehe er zur Bildung von Dauereiern schreitet. Die Subitaneier dieser Sommertiere entwickeln sich unter günstigen äußeren Bedingungen rasch und die aus ihnen hervorgehenden Jungen können wiederum entweder erst Subitan - und sodann Dauereier oder nur Eier der letzteren Sorte erzeugen. So können sich jährlich im Laufe der wenigen Monate, während deren die Art existiert, mehrere Generationen aufeinander folgen, ihre Anzahl ist jedoch je nach der Art der produzierten Eier recht verschieden, wie die beiden folgenden Schemata veranschaulichen:

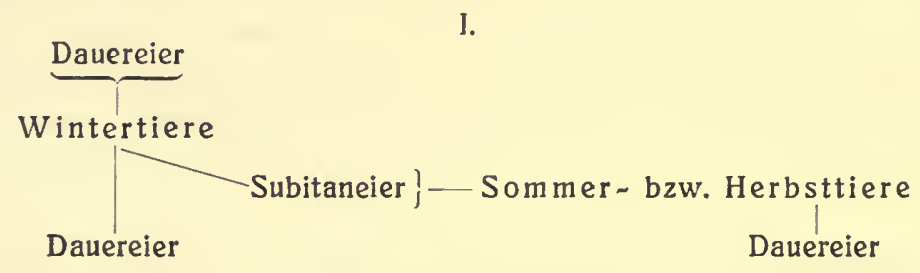

Wintertier

II. 
der Zyklus für das betreffende Jahr abgeschlossen ist. Verläuft die Entwicklung nach Schema II, so hängt die Gesamtzahl der Generationen davon $a b$, wie oft die Sommertiergenerationen sich wiederholen, ehe mit dem Erscheinen der Herbsttiere, die nur Dauereier produzieren können, der Jahreszyklus sein Ende nimmt. Eine solche Wiederholung ist nicht unbedingt nötig, vielmehr kann bei nur einmaligem Auftreten von Sommertieren die Gesamtzahl der Generationen sich auf drei beschränken. Andererseits kann die Zahl der Wiederholungen von zwei (wie in Schema II angedeutet) bis auf vier und die Gesamtzahl der Generationen danach bis auf sechs steigen. Letztere Zahl gibt das Maximum der Generationen an, die bei eigenen, längere Zeit hindurch Jahr für Jahr wiederholten Zuchtversuchen beobachtet wurde, aber nur in zwei unter vielen Hunderten von Zuchten. $\mathrm{Ob}$ eine solche Zahl in der Natur jemals vorkommt, ist allerdings sehr fraglich, da die sechste Generation in beiden Versuchen erst zu einer Zeit geboren wurde (s. die Stammbäume S. 298, 299), wo Mes. ehrenbergi längst nicht mehr im Freien vorkommt.

Biologische Bedeutung der Subitan- und Dauereier
Was hat es nun zu bedeuten, daß Mes. ehrenbergi - und ähnlich wie dieser Wurm verhält sich noch eine Anzahl anderer Typhloplaniden (Vertreter der Gattungen Typhloplana, Mesostoma, Bothromesostoma usw.) - zwei so verschiedene Arten von Eiern erzeugt?

In Beantwortung dieser Frage pflegte man früher die Dauereier als besondere Anpassungsbildungen aufzufassen, deren Bedeutung darin bestehen sollte, der Brut die Uberwinterung zu ermöglichen und ihr beim Austrocknen der Wohngewässer Schutz zu gewähren. Diese Annahme, die lange Zeit hindurch viele Anhänger zählte, trifft indessen nicht $z u$. Dauereier werden von allen Typhloplaniden gebildet. Subitaneier kommen dagegen nur bei einer relativ kleinen Zahl von Arten vor. Es können also höchstens die letzteren Eier aus den ersteren durch besondere Anpassung hervorgegangen sein. AuBerdem aber sind hart- und

Steinmann-Bresslau, Strudelwürmer. 
dunkelschalige Eier, die den Dauereiern der Typhloplaniden durchaus entsprechen, auch für zahlreiche marine Rhabdocoeliden typisch, wo von einem Schutzbedürfnis gegen Winterkälte oder Austrocknung nicht die Rede sein kann.

Man hat dann ferner versucht, die Entstehung der Subitaneier auf eine Art mimetischer Anpassung zurückzuführen, welche bezwedkt, die durchsichtigen Typhloplaniden den Blicken ihrer Feinde $z u$ entziehen. Gegen diese Annahme ist jedoch sofort einzuwenden, daß $u$. a. eine so prachtvoll transparente Form, wie Rhynchomesostoma rostratum, keine Subitaneier, sondern nur höchst auffällig dunkelrotbraun gefärbte Dauereier erzeugt, sowie daß schließlich ja auch die Subitaneier produzierenden Arten stets Dauereier bilden. Noch schlagender wird die Unhaltbarkeit dieser Deutung dadurch bezeugt, daß auch die Bothromesostoma-Arten Subitaneier hervorbringen, obwohl es für sie, bei ihrem undurchsichtigen Körper ganz bedeutungslos ist, ob die Eier gefärbt oder ungefärbt sind.

Ein dritter Erklärungsversuch geht endlich von der oben besprochenen Tatsache aus, daß die Subitaneier entstehen, noch ehe der Geschlechtsapparat seine volle Entfaltung erlangt hat. Von diesem Gesichtspunkt aus betrachtet scheinen alle Eigenschaften, durch die sich die Subitaneier von den Dauereiern unterscheiden, dazu beizutragen, die zu ihrer Entwicklung nötige Zeit zu verkürzen. Eine erste Zeitersparnis bedeutet es, daß die Subitaneier schon bei ganz jugendlichen Würmern auftreten, eine zweite, daß ihre Bildung, selbst wenn es sich um 50 oder 60 Stück handelt, innerhalb eines Tages vor sich geht. Weiterhin begünstigt die aus dem unreifen Zustande der Tiere resultierende geringe Dotterzellenzahl und -masse eine schnellere Entwicklung der Eier, ihre dünne Schale das rasche Ausschlüpfen der Jungen. Endlich wird auch durch den Fortfall der Wechselbegattung ein Zeitgewinn erzielt. Alles dies läßt also die Subitaneier als Bildungen erscheinen, die dazu dienen, der Art nach Eintreten der gūnstigen Jahreszeit eine möglichst rasche und möglichst große. Ausbreitung zu geben. $\mathrm{DaB}$ solche Einrichtungen für 
Tiere, die wie Mes. ehrenbergi und seine Verwandten alljährlich nur während weniger Wochen und Monate geeignete Existenzbedingungen finden, von großer Bedeutung sein müssen, liegt auf der Hand.

Die Richtigkeit dieser Deutung wird nun dadurch sehr wahrscheinlich gemacht, daß nicht überall die Unterschiede zwischen

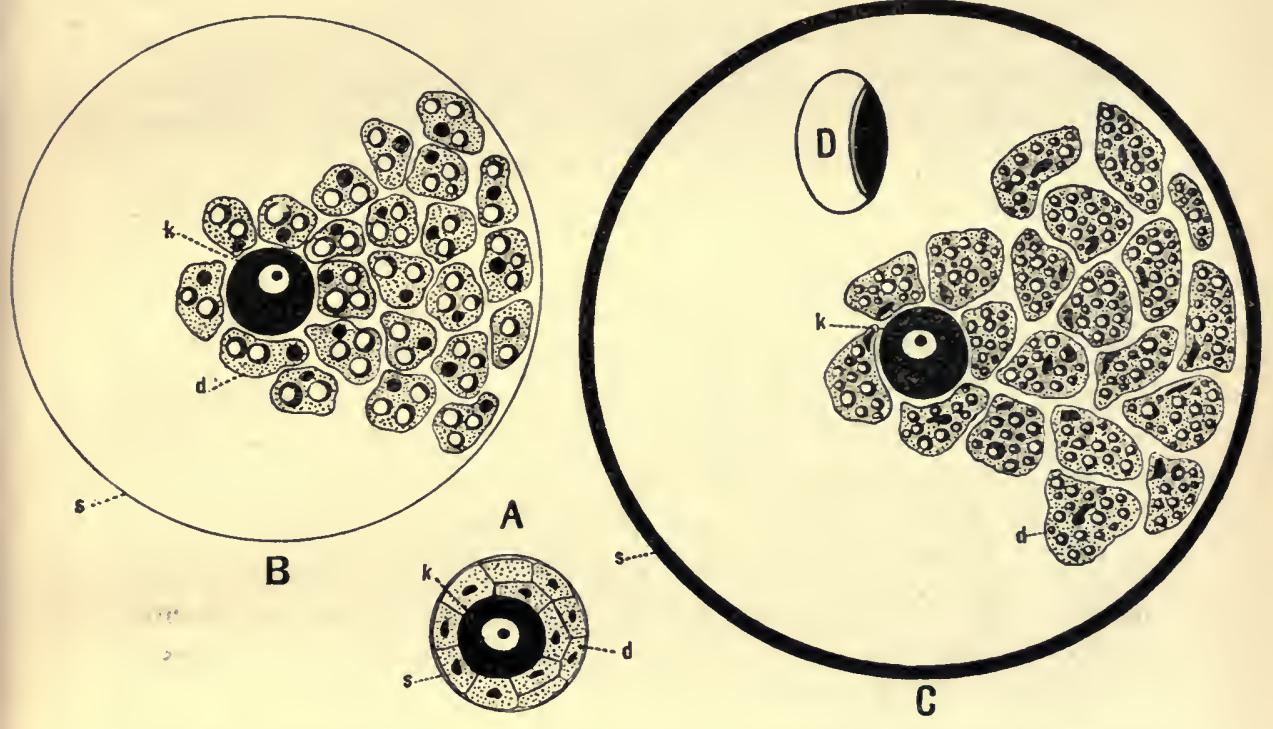

Abb. 146. Halbschematische Schnitte durch Mesostomideneler bei ungefähr gleicher VergröBerung gezeidinet.

A durch ein Subitanei von Mesostoma ehrenbergi; B durch ein Subitanei von Mesostoma lingua; $\mathrm{C}$ durch ein Dauerei von Mesostoma lingua; D Seiteransicht eines konkavkonvexen Wintereies von Bothromesostoma personatum.

$s$ Eischale, k Keimzelle, d Dotterzellen (in B und C nur zum Teil eingezeichnet).

Subitan- und Dauereiern so erheblich sind wie bei Mes. ehrenbergi. Während die Subitaneier der letzteren Art etwa 7-8 mal kleiner sind als die Dauereier, unterscheiden sie sich z. B. bei Mes. lingua ( $\mathrm{Abb} .146 \mathrm{~B}$ ), sowohl nach ihrer Größe wie nach der Zahl der in ihnen enthaltenen Dotterzellen nur verhältnismäßig wenig von den Dauereiern (C). Auch enthalten hier (B) die Dotterzellen, die im Dauerei $(\mathrm{C})$ mit kleineren und größeren 
Kugeln stark lichtbrechenden Dottermaterials vollständig erfüllt sind, ebenfalls je 2 oder 3 solcher verhältnismäßig großer Dotterkugeln, wogegen in den Subitaneiern von Mes. ehrenbergi $(A)$ eine derartige Dotteraufspeicherung noch so gut wie ganz fehlt. Die Subitaneier von Mes. lingua - und ebenso die Subitaneier von Mes. productum - stehen also zwischen den Subitaneiern von Mes. ehrenbergi und dessen Dauereiern ziemlich genau in der Mitte.

Eine noch größere Ähnlichkeit mit den Dauereiern zeigen sodann die Subitaneier von Bothromes. personatum. Hier stimmen die Dotterzellen beider Eisorten, was ihre Erfüllung mit Dotterkugeln betrifft, so weitgehend miteinander überein, daß außer einer geringen Größendifferenz eigentlich nur die verschiedene Beschaffenheit der Schale als morphologisches Unterscheidungsmerkmal zwischen Subitan- und Dauereiern übrig bleibt. Aber auch dieses letzte Merkmal erleidet hier noch eine gewisse Abstufung. Nach der Bildung der typischen, einen Durchmesser von 0,18 bis $0,2 \mathrm{~mm}$ besitzenden und mit einer vollkommen farblosen, äußerst zarten Schale versehenen Subitaneier produzieren die Tiere nämlich nicht direkt die durch ihre dicke braunrote Schale charakterisierten konvex-konkaven Dauereier (Abb. 146 D, größter Durchmesser 0,28 bis $0,31 \mathrm{~mm}$ ), sondern erzeugen vorher noch eine andere Sorte von Eiern, deren Schale bei einem Durchmesser von 0,23-0,24 mm nicht unerheblich dicker wie die der Subitan-, aber dünner ist als die der Wintereier, und eine gelbliche bis hellbräunliche Färbung besitzt. Die Entwidklung dieser eigentümlichen Eier verläuft vollkommen innerhalb der Muttertiere, wie bei den Subitaneiern, während sie sonst nach ihrem ganzen Bau mehr den Dauereiern ähnlich sind.

Aus diesem Verhalten erklärt es sich, daß man bei Bothromes. personatum ganz gewöhnlich Individuen antrifft, die gleichzeitig Subitaneier in verschiedenen Entwicklungsstadien, auBerdem jene gelbschaligen Eier und eventuell noch dazu Dauereier enthalten, während bei Mes. ehrenbergi, und ebenso bei Mes. lingua und productum, die verschiedenen Eisorten normalerweise nicht in demselben Individuum nebeneinander vor- 
kommen. Bei den letzteren Formen sind die Perioden derSubitanund Dauereierbildung zeitlich so weit voneinander getrennt, daß die zweite im allgemeinen nicht eher beginnt, ehe nicht die Jungen der ersten Periode geboren sind. Bei Bothromes. personatum dagegen gehen Subitan- und Dauereier nicht nur ihrem Bau nach allmählich ineinander über, sondern es werden auch die Subitaneier - statt auf einmal, wie bei den Mesostomaarten -in mehreren Schüben nacheinander erfolgen.

Wir können uns also die Subitaneier so entstanden denken, daß der Beginn der ersten Eibildung bei den verschiedenen Typhloplanidenarten allmählich in immer jugendlichere Stadien zurückverlegt wurde, in Stadien, in denen die Geschlechtsorgane die zur Erzeugung der typischen Eier - der Dauereier notwendige Reife noch nicht erlangt haben und daher Eier hervorbringen, die mit weniger Dottermaterial und schwächerer Schale ausgerüstet, eben Subitaneier darstellen. Bei Bothromes. personatum ist diese zeitliche Verschiebung noch so wenig bedeutend, daß bei Beginn der Subitaneierbildung die Dotterstöcke nahezu vollkommen ausgebildet und die Kopulationsorgane völlig entfaltet sind. Demzufolge sind die Subitaneier von den Dauereiern nur wenig verschieden und beide Eisorten gleichzeitig in denselben Individuen anzutreffen. Bei Mes. lingua und productum hat bereits eine weitergehende Verschiebung stattgefunden, wie sich aus den größeren Unterschieden zwischen Subitanund Dauereiern und aus ihrer Bildung in ganz getrennten Perioden zu erkennen gibt. Die Ausbildung des Penis gestattet aber, daß auch hier noch vor dem Erscheinen der ersten Subitaneier Begattungen stattfinden. Bei Mes. ehrenbergi dagegen beginnt die Bildung der Subitaneier so frühzeitig, daß sie aus den noch kaum entfalteten Vitellarien nur spärliches Dotterzellenmaterial beziehen; zugleich wird ihnen das Sperma infolge des unentwidkelten Zustandes der männlichen Kopulationswerkzeuge nicht mehr nach voraufgegangener Begattung, sondern durch Selbstbefruchtung zugeführt.

Die Entstehung der Subitaneier ist also die Folge eines ganz 
bestimmt gerichteten Entwicklungsprozesses, der bei den ausschließlich hartschalige Eier produzierenden Typhloplaniden beginnend über die durch Formen wie Bothromes. personatum, Mes. lingua und productum gekennzeichneten Etappen zu den bei Mes. ehrenbergi vorliegenden Zuständen geführt hat. Den AnstoB zu diesem Entwicklungsprozesse mögen zuerst vielleicht rein zufällige Geschehnisse gegeben haben, z. B. besondere Ernährungs- oder Witterungsverhältnisse oder anderweitige Umstände, die einen früheren Beginn der Eibildung veranlaßten. Mit Rücksicht auf den Vorteil - raschere Ausbreitung der Art den die Entstehung der Subitaneier mit sich brachte, wurden diese dann, obwohl sie im Grunde genommen im Vergleich zu den typischen Dauereiern unvollkommen ausgestattete Eier darstellen, im Laufe der Generationen nicht ausgemerzt, sondern im Gegenteil in ihrer Eigenart allmählich immer schärfer und schärfer ausgebildet.

Ursachen der verschiedenen Sexualität der Sommer-, Herbst- und Wintertiere
Können wir uns so ein Bild von der biologischen Bedeutung und der ersten Entstehung der Subitaneier machen, so erhebt sidh nunmehr die Frage, warum nur
ein Teil der Individuen von Mes. ehrenbergi und seiner Verwandten das Vermögen zur Erzeugung von Subitaneiern erlangt hat? Sehen wir doch jedes Jahr den Zyklus der aufeinanderfolgenden Generationen mit solchen Formen sein Ende nehmen, die, unfähig zur Subitaneiertracht, direkt Dauereier produzieren. Was sind die Ursachen, die eine solche Verschiedenheit der sexuellen Fähigkeiten bedingen? Es lohnt sich schon deswegen, auf diese Frage etwas näher einzugehen, weil wir damit Probleme streifen, deren Ergründung zurzeit auch in anderen Tiergruppen zahlreiche Forscher beschäftigt.

Von den Antworten, welche die Turbellarienforscher auf die eben gestellte Frage zu geben versucht haben, hat sich allerdings bisher keine als befriedigend erwiesen. Wenn z. B. angenommen wurde, daß Sommertracht (Bildung von Subitaneiern) Folge von Selbst- 
befruchtung, Wintertracht (Bildung von Dauereiern) dagegen Folge wechselseitiger Begattung sei, so ist leicht $z u$ beweisen, daß von einem solchen Einfluß der Befruchtungsweise auf die Eiqualität nicht die Rede sein kann. Selbstbefruchtung kommt ja nur bei den Wintertieren von Mes. ehrenbergi vor, während die Wintertiere von Mes. lingua, productum und Bothromes. personatum schon vor der Bildung der Subitaneier ganz regelmäßig kopulieren. Umgekehrt werden Dauereier nach Selbstbefruchtung gebildet, wenn man Individuen von Mes. ehrenbergi gleich nach der Geburt isoliert, im übrigen aber unter normalen Bedingungen aufzieht. Die Tiere treten dann zur selben Zeit wie ihre nicht isolierten Artgenossen in die Dauereitracht ein, ohne daß natürlich vorher eine Begattung stattfinden konnte.

Ebensowenig haltbar ist die Annahme, daß bei den Wintertieren die niedrige Frühlingstemperatur ein langsameres Reifen der Geschlechtsorgane und damit die Bildung von Subitaneiern veranlasse, bei den Sommer- bzw. Herbsttieren die zur Zeit ihrer Geburt herrschende größere Wärme und das dadurch bedingte schnellere Wachstum des Genitalapparates die direkte Produktion der Dauereier herbeiführe. Man braucht nur die auf S. 288 mitgeteilten Fortpflanzungsschemata $\mathrm{zu}$ betrachten, um zu erkennen, daß ein so direkter Zusammenhang zwischen den Jahreszeiten bzw. den ihnen eigentümlichen Temperaturen und der zu erzeugenden Eisorte nicht bestehen kann. Gelangen doch im Falle des Schemas II - besonders bei vierfacher Wiederholung der Sommergenerationen - vom Frühjahr an bis in den Herbst hinein Subitaneier zur Ausbildung.

Unzutreffend ist endlich auch noch eine dritte Hypothese, die nicht wie die beiden vorhergehenden Annahmen äußere Einwirkungen, sondern innere Ursachen für die Verschiedenheit der sexuellen Leistungen verantwortlich macht. Danach soll die Fähigkeit, Subitaneier zu produzieren, nur den Wintertieren eigen sein, von ihnen aber nicht auf die aus den Subitaneiern ausschlüpfenden Jungen vererbt werden; diese sollten vielmehr genötigt sein, zu dem ursprünglich allein für die Art typischen 
Fortpflanzungsmodus durch Dauereier zurüdkzukehren. Es ist klar, daß eine solche Annahme nur auf die Generationsfolge nach Schema I paßt. Gewiß ist diese häufig zu beobachten; Schema II lehrt aber, daß auch die Sommertiere - und sogar in mehreren Generationen hintereinander - Subitaneier erzeugen können.

Dieser Mangel einer befriedigenden Antwort nach den Ursachen, die den Fortpflanzungszyklus von Mes. ehrenbergi beherrschen, war es, der seinerzeit die Anregung zu jenen Zuchtversuchen gab, von denen schon oben (S. 274) die Rede war. Sie wurden in den Jahren 1909-1912 regelmäBig in sehr ausgedehntem Maße angestellt, und suchten $z u$ ermitteln, ob sich durch planmäßige Abänderung der verschiedenen äußeren Faktoren die Eiqualität beeinflussen läßt, oder ob die Zuchtresultate unabhängig von allen Modifikationen der äußeren Bedingungen durch innere Ursachen gesetzmäßig bestimmt sind. Das Ergebnis dieser Versuche, über das hier jetzt kurz berichtet werden soll, war, daß die Fortpflanzungsverhältnisse weder allein von äuBeren noch von inneren Ursachen reguliert werden. Zwar liegen dem sexuellen Verhalten der verschiedenen Generationen in erster Linie innere Faktoren zugrunde; diese selbst sind aber durch äußere Einwirkungen ihrerseits modifizierbar.

Das gesetzliche Walten innerer Faktoren zeigt sich zunächst darin, daß es nicht gelingt, die aus den Dauereiern ausschlüpfenden Wintertiere von der Bildung von Subitaneiern abzubringen und etwa zur direkten Produktion von Dauereiern zu veranlassen. Man kann die Jungen im Brutschrank bei Wärme bis zu $30^{\circ}$ aufziehen oder aber ihr Wachstum durch niedrige Temperaturen von $5-7^{\circ}$ wochenlang hintanhalten, man kann sie hungern lassen oder mästen, sie isolieren oder in Massen in geringem Wasserquantum zusammen züchten: immer wird man sie, wenn sie zur Eibildung schreiten, unweigerlich Subitaneier erzeugen sehen.

Innere Ursachen bewirken ferner unaufhaltbar, daß schließlich jeder Jahreszyklus mit dem Auftreten von Herbsttieren, die nur Dauereier hervorbringen können, sein Ende nimmt. Bei den 
Zuchtversuchen bildete es ein unter hundertfältiger Variation der Kulturbedingungen immer wieder aufs neue angestrebtes Ziel, durch Vermehrung der Zahl der Subitaneiergenerationen, die Zucht von einem Sommer in den andern fortzuführen. Aber vergebens. Schon Anfang Herbst, wenn Mes. ehrenbergi im Freien zu verschwinden beginnt, treten auch in den Zuchten die Subitaneier bildenden Tiere immer seltener auf (s. die Stammbäume auf S. 298, 299). Die meisten Kulturen sterben dann im Laufe des September oder Oktober mit Dauereier bildenden Individuen aus, einerlei unter welchen Bedingungen sie gehalten werden, und nur in wenigen, besonders günstigen Fällen gelingt es, sie weiter fortzuführen. Die Spätlinge werden aber immer mehr zu Kümmerformen und sind schließlich nicht mehr imstande, Subitaneier hervorzubringen. Wenn sie nicht schon vor Eintritt der Geschlechtsreife sterben, erzeugen sie lediglich Dauereier. Demgemäß nehmen die Kulturen im Dezember, spätestens im Januar ihr Ende.

$Z$ wischen die Generation der Wintertiere, die gesetzmäßig zuerst Subitaneier bildet, und die Generation der Herbsttiere, die nichts anderes als Dauereier produzieren kann, schiebt sich nun eine wechselnde Zahl $(0-4)$ Generationen Subitan- und Dauereier produzierender Sommertiere. Die Inkonstanz dieser Generationenzahl und die Möglichkeit durch Laboratoriumszucht das Auftreten der Herbsttiere bis in die 6. (vielleicht sogar in die 7.?) Generation - die in der Natur spontan nie vorkommen dürfte hinauszuschieben, läßt erkennen, daß hier jedenfalls äußere Einflüsse eine Rolle spielen. In welcher Weise die äußeren Faktoren dabei wirksam sind, hat sich aber bisher trotz aller Bemühungen noch nicht klar ermitteln lassen. Soviel ist sicher, daß einfache, grob sinnfällige Beeinflussungen durch Temperatur-, Ernährungs- oder chemische Einwirkungen usw. nicht in Frage kommen. Die Einwirkungen sind vielmehr allem Anschein nach komplexer Art und üben ihren Einfluß nur in einer kurzen "sensiblen" Periode aus. Näheres kann hier darüber indessen nicht mitgeteilt werden, da die Akten in dieser Angelegenheit noch nicht geschlossen sind. 
I

1 Exemplar am 15./VII. im Rheinwald mit S.E. gefangen. F.

\section{II}

19 Junge am 23./VII. geboren, auf 2 Kulturen verteilt

F. W. 9 Expl., 3 davon erzeugen S.E., Rest D.E.

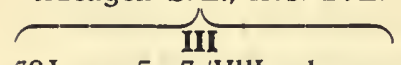

32 Junge, 5.-7./Vlli.geboren, auf 2 Kulturen verteilt

F. K.

23 Expl., 6 davon eralle er- zeugen D. E., zeugen $2+, 1$ Expl.mit

D. E.

000

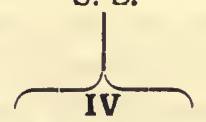

7 Junge, 29./VIIl. geboren. In W. gehalten, Fütterung der einzelnen Exemplare verschieden, trotzdem alle D. E.

000
H. W. 10 Expl., 4 davon erzeugen S. E., Rest D.E.

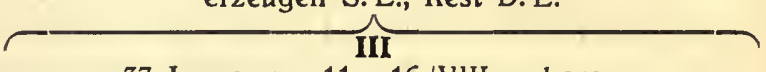

37 Junge, am 11.-16./VlII. geboren, auf 4 Kulturen verteilt
F.W.8Expl,
F. W.
H. W.
F. W.

5 erzeugen

S. E., Rest + , auch die 5 Jungen mit

S. E. starben

O 00

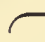

13 Expl., 12 erzeugen

D.E., 1 Expl.

S. E.

8 Expl., 4 erzeugen

D. E., Rest 8 Expl., alle erzeugen

D. E. S. E.

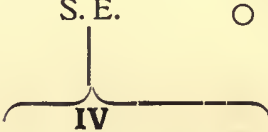

15 Junge, 1./1X. geboren, 2 Kulturen F. W. H. W. 5 Expl. 10 Expl. alle er 4 erzeugen zeugen D.E. D.E., 3†, O 0 O 3 Expl. (1 davon stirbt) S E.

18 Junge, 9. bis 10./IX. geboren, erzeugen trotz verschiedener Aufzucht, soweit sie geschlechtsreif werden, alle D. E.

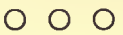

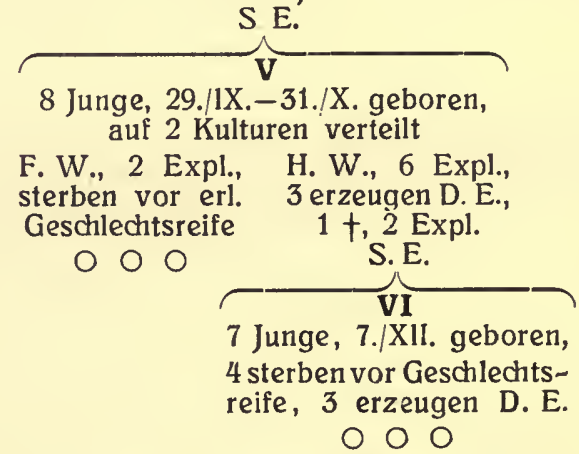

Stammbaum einer über 6 Generationen ausgedehnten Zucht von Mes. ehrenbergi aus dem Sommer 1911.

Da das Exemplar, mit dem diese Zucht beginnt, erst Mitte Juli im Freien gefangen wurde, ist es nicht ausgeschlossen, daB es sich bereits um ein Sommertier handelte. In diesem Falle würden dann sogar 7 Generationen aufeinander gefolgt sein. - S. E. bedeutet Subitaneier, D. E. Dauereier, F. Futter-, H. Hungerkultur, $\mathrm{K}$. Zucht in Temperatur unter $15^{\circ}, \mathrm{W}$. Zucht in Temperatur über $18^{\circ},+$ gestorben vor Eintritt der Geschlechtsreife. O Ende der einzelnen Kultur. 
I

1 Exemplar mit S.E., Mitte Mai 1912 aus D.E. geschlüpft, täglich F.

14 Junge, geboren 17./VI., erhalten bis 29./VI. tägl. F., an diesem Tage zeigen 8 Expl. S.E., die übrigen 6 D.E. -Tendenz, Die 8 Jungen mit S. E. werden am 29./V1. zu je 2 auf 4 Kulturen verteilt

2 Expl.

2 Expl.

2 Expl.

2Expl.(1dav.stirbt) mit S.E., tägl. F. mit S.E., alle 2 Tg. F. mit S.E., alle3Tg. F. mit S.E., alle 4 T. F.

\section{$\overbrace{\text { III }}$ \\ $7+17$ Junge, geboren 7./VlI., auf 2 Kulturen verteilt}

tägl. F., H.,

7 Expl., 17 Expl., 6 erzeug. $11 \mathrm{erz}$. DE., 1 D.E., 3t, S. E.

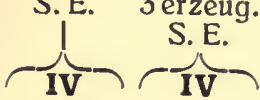

12 Junge, 14 Junge,

geboren geboren

27./VII., 30./VII.,

a. 2 Kul a. 2 Kul turen turen

(F. u. H.) (F. u. H.) verteilt, verteilt, alle erz. alle erz.

D.E. D. E.

D. O 00

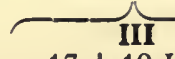

$17+10$ Junge, geboren 8.u.11./VII. teilt

tăgl. F.,

17 Ezpl., 10 Expl.,

15 erzeug. Zucht ver-

D. E., 2 unglückt

S. E.

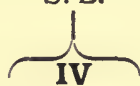

32 Junge,

geboren

$24 .-31$.

VII., auf 2 Kult.

(F. u. H.)

verteilt,

alle erz.

D. E.
O O 9 S.E.

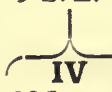

III

$21+13$ Junge, gebor. 10. u. 11./VII. auf 2 Kulturen verteilt

tägl. F. H., 21 Expl., 13 Expl., 8 erzeug. 3 erzeug. DE., 4 t, D.E., 5 t. 9 S.E. 5 S.E.
98 Junge, geboren

29./VII. auf

2 Kulturen verteilt

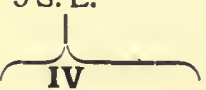

45 Junge, geb.

7.-18. VIII., auf 4 Kulturen mit verschied. Fütterg. vert., alle erz. D.E. O 00
tägl.F.49 Expl., H., 49 Expl., 48

45 erz. D. E., erzeugen 3 t, 1 Expl. S. E.

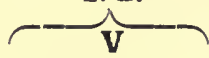

D. E., 1 Expl.

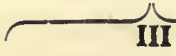

Junge, geboren am 11./VII., täglich $\mathrm{F}$., $1+, 9$ Expl. erzeugen S.E.

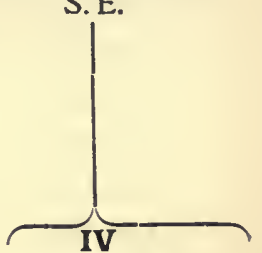

41 Junge, geboren 3.-9. VIII., auf 2 Kulturen

(F. und $\mathrm{H}$.) verteilt, alle erzeugen D.E.

21 Junge, geb. 3 Junge, geb. 11. 21./Vlil., in IX., als Hunger2 Kult. (F.u.H.), kulturgehalt., ab erzeugen alle 13./1X. in Wärme D. E. $\left(20-21^{0}\right)$,

$\bigcirc \bigcirc \bigcirc \quad 1$ Expl.D.E., 1 t, 1 Expl. S. E.

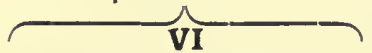

6 Junge, geb.17. X., wie vor. Kultur, 4 t, 2 Expl. D. E. 000

\section{Stammbaum einer über 6 Generationen ausgedehnten Zucht von} Mes. ehrenbergi aus dem Sommer 1912.

S. E. bedeutet Subitan-, D. E. Dauereier, F. Futter-, H. Hungerkultur (höchstens alle 3-4 Tage gefüttert), + gestorben vor Eintritt der Geschlechtsreife. O Ende der einzelnen Kultur. Die ganze Zucht wurde bis zur V. Generation in Zimmertemperatur gehalten. 
Neben äußeren Faktoren kommen aber für das Auftreten der Sommertiergenerationen sicherlich auch innere Ursachen in Betracht. Das lehrt schon die aus den Stammbäumen der vorigen Seite ohne weiteres abzulesende Tatsache, daß sich die unter gleichen Bedingungen gehaltenen Geschwister eines Wurfes hinsichtlich der Sommertracht fast niemals gleich verhalten. Schon die Individuen der zweiten Generation erzeugen nicht etwa sämtlich zuerst Subitaneier, sondern ein beträchtlicher Teil von ihnen schreitet - entsprechend Schema I (S. 288) - direkt zur Produktion von Dauereiern. ${ }^{1}$ ) Der Prozentsatz dieser wie Herbsttiere sich verhaltenden Jungen nimmt dann von Generation $z u$ Generation $z u$, so daß die meisten Kulturen in der 4. Generation nur noch Dauereier bilden und infolgedessen aussterben. Diese bei allen Zuchtversuchen immer wieder beobachtete Erscheinung beweist, daß bei den aus den Subitaneiern ausschlüpfenden Sommertieren eine Tendenz zur direkten Produktion von Dauereiern besteht. Kraft dieser durch innere Ursachen bedingten Tendenz würde die Fortpflanzung von Mes. ehrenbergi gemäß den in Schema I dargestellten Turnus verlaufen, wenn nicht - und hierbei sind jedenfalls äußere Einwirkungen mit im Spiele - das innere „Ursachengetriebe “ zeitweise in den Kurs nach Schema II "umgesteuert“ werden könnte.

Was hier über die Ursachen der zyklischen Fortpflanzungsänderungen bei Mes. ehrenbergi ermittelt wurde, ist nun deshalb von besonderem Interesse, weil es auffällig mit den neusten Ergebnissen der Sexualitätsforschung übereinstimmt, die beim Studium anderer Tierklassen erhalten wurden. In den Diskussionen über diese Fragen hatten sich bis vor kurzem - ebenso wie betreffs der Verhältnisse bei unseren Würmern - wesentlich zwei Gruppen von Anschauungen gegenüber gestanden, von denen die

1) Aus den beobachteten Zahlen, die in den verschiedenen Kulturen auBerordentlich schwanken, hat sich bisher keine Möglichkeit gezeigt, das Verhältnis der Subitan - und Dauereier produzierenden Jungen etwa mit Hilfe der Mendelschen Vererbungsregeln abzuleiten. 
eine äußere Einwirkungen wie Temperatur-, Nahrungs- oder chemische Einflüsse, die andere innere Ursachen - eine Festlegung auf bestimmte Vererbungslinien oder auf einen für die Art charakteristischen Fortpflanzungszyklus - als allein maßgebend annahm. Der Streit zwischen beiden Lagern war lange Zeit hindurch nicht zu schlichten gewesen, da hier wie dort Experimentatoren auf Beobachtungen hinweisen konnten, die allem Anschein nach richtig waren. Erst in den letzten Jahren fand sich dann die Lösung, die den Differenzen ein Ende machte: es konnte festgestellt werden, daß neben den inneren Faktoren, die in erster Linie die Eiqualität bestimmen, auch äußere Einwirkungen einen gewissen Einfluß besitzen. Aber auch im einzelnen besteht eine geradezu überraschende Parallelität zwischen den Verhältnissen bei Mes. ehrenbergi und Vertretern anderer Tierklassen. So gilt z. B. für die Wasserflöhe aus der Familie der Daphniden, daß die erste, aus den hier als Ephippien bezeichneten Dauereiern hervorgehende Generation jedes Jahr zunächst nur Subitaneier hervorbringt, einerlei unter welchen Bedingungen sie gehalten wird, und $\mathrm{da} B$ mit jeder folgenden Generation die Tendenz zur Produktion von Dauereiern zunimmt, bis deren Bildung schließlich nicht mehr aufzuhalten ist. Auf das sexuelle Verhalten der zwischen der ersten und der letzten Generation eines jeden Zyklus liegenden Generationen haben äußere Faktoren einen ziemlich bedeutenden Einfluß; die Zahl dieser Generationen kann daher experimentell beträchtlich gesteigert werden.)

In der eben skizzierten Form dargestellt erscheinen die Fortpflanzungsverhältnisse bei den Daphnien und bei Mes. ehrenbergi vollkommen identisch. Indessen besteht infolge der Getrenntgeschlechtlichkeit der Wasserflöhe der bemerkenswerte Unterschied, daß die aus den Dauereiern ausschlüpfenden Tiere ausschließlidi Weibchen sind, und die von ihnen produzierten Subitaneier sich daher parthenogenetisch oder - nach einer anderen Bezeichnungs-

1) Vgl. R. Wolteredk, Veränderung der Sexualität bei den Daphniden. Intern. Revue d. ges. Hydrobiologie Bd. IV 1911, S. 91 f. 
weise - agam entwickeln müssen. Männchen entstehen erst gegen Ende des Fortpflanzungszyklus, Befruchtung findet erst vor der Erzeugung der Dauereier statt. Die Frage nach den die Generationsfolge beherrschenden Momenten verquidkt sich daher hier mit der Frage nach den Ursachen der Bildung von Geschlechtstieren und weiter nach den Ursachen der Geschlechtsbestimmung. Demgegenüber liegen die Verhältnisse bei Mes. ehrenbergi viel einfacher. Die Zwittrigkeit der Tiere schließt hier von vornherein das Sexualitätsproblem in engerem Sinne aus, ebensowenig kommt es hier zum Auftreten von Parthenogenese. Vielmehr genügt es zur Förderung einer möglichst raschen Aufeinanderfolge der Generationen in . der Periode günstiger Lebensbedingungen, wenn an Stelle der wechselseitigen Begattung Selbstbefruchtung tritt.

Welch ungeheurer Vorteil für die Ausbreitung der Art Mes. ehrenbergi aus seiner Fortpflanzungsweise erwächst, ergibt sich ohne weiteres, wenn man sich die Zahl der Nachkommen vergegenwärtigt, die in einer Saison aus einem Muttertier hervorgehen. In den beiden Zuchten, deren Geschichte in den Stammbäumen auf S. 298, 299 dargestellt ist, wurden vermittelst der Subitaneier das eine Mal (1911) 143, das andere Mal (1912) sogar 382 Junge als Abkömmlinge je eines einzigen Individuums erhalten. Veranschlagt man weiter die Zahl der Dauereier, die jedes dieser Tiere schließlich erzeugt, nur auf 10 , so kommt man bei der Zucht aus 1912 auf fast 4000 überwinterungsfähige Keime. Was bedeutet gegenüber einer so gesteigerten Fruchtbarkeit die einfache, direkte Fortpflanzung durch Dauereier -, selbst wenn die Zahl dieser Eier bei einem extrem fruchtbaren Tier auf 100 anwachsen könnte! Man versteht danach, wie gerade die Rhabdocoelenarten, die es zur Ausbildung von Subitaneiern gebracht haben, weiteste Verbreitung zeigen und ihre Existenz selbst in Tümpeln fristen können, die alljährlich nur kurze Zeit mit Wasser gefüllt sind. 


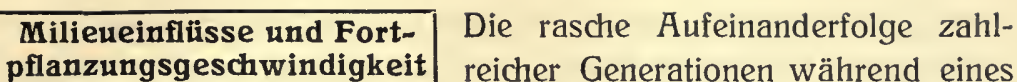
Sommers wäre natürlich nicht möglich ohne den großen Zeitgewinn, den die schnelle Bildung und Entwicklung der Subitaneier gegenüber der gewöhnlichen Fortpflanzung durch Dauereier mit sich bringt. Wie schon bekannt (s. S. 293), sind die Momente, die hierbei zusammenwirken: frühzeitiger Eintritt der Geschlechtsreife bei den Subitaneier erzeugenden Jungen, rasche Ausbildung der ganzen Sommertracht eines Individuums innerhalb eines Tages, Verzicht auf eine der Befruchtung vorangehende Kopula und große Entwicklungsgeschwindigkeit der Subitaneier. Eine wichtige Rolle hierbei spielen aber auch äußere Faktoren, besonders Ernährungs- und Temperatureinflüsse, insofern als durch Hunger und Kälte die Fortpflanzung in hohem Maße verzögert, durch reichliche Ernährung und Wärme dagegen beschleunigt wird. Daten, die den Einfluß dieser Faktoren erkennen lassen, erhält man schon bei einem Vergleich der in den Stammbäumen auf S. 298, 299 gemachten Angaben über die unter verschiedenen Bedingungen aufgezogenen Parallelkulturen. Hunger - oder Kältetiere bringen ihre Jungen erheblich später zur Welt als ihre unter günstigen Futter- und Temperaturbedingungen aufwachsenden Geschwister.

Daß die Ernährungsverhältnisse die schnellere oder langsamere Bildung und Entwicklung der Eier beeinflussen, ist ohne weiteres einzusehen. Zur Eiproduktion ist ein erheblicher Stoffund Energieaufwand erforderlich, der unter normalen Bedingungen durch Zufuhr eines genügenden Nahrungsquantums kompensiert wird. Hunger unterdrückt zwar die Eibildung bei Mes. ehrenbergi, wie wir schon gesehen haben (S. 278), nicht ganz, aber sie erfolgt später und die Zahl der produzierten Subitaneier wird gernger. In extremen Hungerkulturen kann sie sogar auf zwei, drei und vier sinken. Auch die Entwicklung der Eier geht alsdann viel langsamer vor sich. In einzelnen Fällen konnte beobachtet werden, daß die Entwicklung schließlich still stand; die Subitaneier zerfielen und wurden, wie es scheint, resorbiert. 
Wenigstens enthielten die Uteri nach einiger Zeit nur noch kleine Brocken einer körnigen Masse anstatt der Eier.

$\mathrm{DaB}$ auch die Temperaturverhältnisse ihren Einfluß auf die Bildung und Entwidklung der Eier jedenfalls durch Einwirkung auf den Stoffwechsel ausüben, findet sich schon im Tricladenteil dieses Buches erwähnt (S. 106). Wir wollen aber hier noch etwas näher darauf eingehen, weil die Beobachtungen, die sidh bei Mes. ehrenbergi darüber machen lassen, auf physiologische Erscheinungen von allgemeinerer Bedeutung hinweisen.

Stoffwechsel und Temperaturverhältnisse stehen deshalb miteinander in Zusammenhang, weil die Assimilationsvorgänge chemische Geschehnisse sind, und weil die Reaktionsgeschwindigkeit chemischer Prozesse sehr wesentlich durch die Temperatur beeinflußt wird. Zugleich besteht, wie die Chemiker durch Messung der Ablaufsgeschwindigkeiten zahlreicher Reaktionen bei verschiedenen Temperaturen abgeleitet haben, zwischen der Geschwindigkeitskonstante einer Reaktion und der Temperatur, bei der sie sich vollzieht, eine bestimmite Beziehung (gewöhnlich als van t'HoffArrheniussche Regel bezeichnet), die so formuliert werden kann, daß innerhalb des Bereiches mittlerer Temperaturen die Reaktionsgeschwindigkeit durch eine Temperaturerhöhung von $10^{\circ}$ etwa auf das Zwei- bis Dreifache gesteigert wird. Es hat sich nun weiter gezeigt, daß diese Regel nicht nur für die gewöhnlichen chemischen Vorgänge gilt, sondern auch für fermentative Prozesse und weiter für zahlreiche Umwandlungen, die in tierischen und pflanzlichen Organismen stattfinden. Natürlich liegen die Dinge hier viel komplizierter als bei den chemischen Vorgängen im Reagenzglase. Auch kommt immer nur der relativ kleinere Temperaturbereich in Frage, innerhalb dessen sich die Lebenserscheinungen der Organismen abspielen. Aber innerhalb dieser Grenzen findet man in sehr vielen Fällen, daß die Temperatur die Lebensvorgänge etwa in gleichem Maße beeinflußt wie den Ablauf einfacher chemischer Reaktionen. Daraus ergibt sich umgekehrt der Schluß, daß Prozesse, bei denen ein solcher Einfluß zu beobachten ist, im wesentlichen dhemischer Natur sind. 
Untersucht man nun die Einwirkungen der Temperaturen auf die Fortpflanzung von Mes. ehrenbergi, so erhält man stets Befunde von der Art, wie sie der nachstehende Bericht veranschaulicht:

\section{Versuch mit 36 Jungen, geboren am 22./VIII. 1910 von 2 Müttern aus Subitaneiern.}

Die Jungen werden zu je 18 auf 2 Kulturen verteilt, von denen die eine (W) auf dem Wärmeschrank bei $24-26^{\circ} 1$ ), die andere $(\mathrm{K})$ in einem Kühlraum bei $10,5-16^{0}$ ) gehalten wird. Beide Kulturen werden regel - und gleichmäBig reichlich mit Daphnien gefüttert. Dabei zeigen sich:

\begin{tabular}{l||c|c||c|c}
\hline & in Kultur $\mathrm{W}$ & in Kultur K & \multicolumn{2}{|c|}{$\begin{array}{c}\text { Dauer in Tagen ab 22./VIII. } \\
\text { in Kultur W }\end{array}$} \\
& & in Kultur K \\
\hline \hline $\begin{array}{l}\text { erste Exemplare } \\
\text { mit Subitaneiern }\end{array}$ & 27./VIII. & $1 . / \mathrm{IX}$. & 5 & 10 \\
\hline $\begin{array}{l}\text { erste Exemplare } \\
\text { mit Dauereiern }\end{array}$ & $30 . /$ VIII. & $9 . / \mathrm{IX}$. & 8 & 18 \\
\hline $\begin{array}{l}\text { erste Junge aus } \\
\text { Subitaneiern geb. }\end{array}$ & $4 . / \mathrm{IX}$. & $19 . / \mathrm{IX}$. & 13 & 28
\end{tabular}

Aus diesem Versuch - dem ähnliche in größerer Zahl an die Seite gestellt werden könnten - ergibt sich, daß die Beziehungen zwischen Temperatur und Fortpflanzungsgeschwindigkeit mit geradezu überraschender Genauigkeit der van t'HoffArrheniusschen Regel folgen. Sowohl die bis zum Eintritt der Geschlechtsreife für Subitan- oder Dauereier verfließende Zeit, wie die Entwicklungsdauer der Subitaneier selbst wird durch Erniedrigung der Temperatur um ca. $10^{\circ}$ ungefähr verdoppelt. Damit gewinnt also die Annahme, daß es sich hierbei um eine Einwirkung der Temperatur auf den Stoffwechsel handelt, größte Wahrscheinlichkeit.

Es liegt auf der Hand, daß die Beschleunigung der Entwicklung durch gute Ernährung und Wärme für die Ausbreitung

1) GröBere GleichmäBigkeit der Temperaturen konnte mit den vorhandenen Mitteln nicht erzielt werden. Indessen geben die mitgeteilten Zahlen die gröBten Schwankungen an, die gemessen wurden.

Steinmann-Bresslau, Strudelwürmer. 
und Erhaltung der Art sehr nützlich ist. Dank dieser Beschleunigung können in der günstigen Jahreszeit die Generationen rasch aufeinander folgen, und wenn bei großer Hitze die Gefahr des Austrocknens der Gewässer drohend naht, steigt damit zugleich die Chance, dieser Gefahr durch raschere Ausbildung der Dauereier wirksam zu begegnen. Die direkte Einwirkung der Milieueinflüsse auf die Fortpflanzungsgeschwindigkeit kombiniert sich also in sehr zweckmäßiger Weise mit jener indirekten Beeinflussung der zugleich von inneren Faktoren abhängigen Zahl der Sommergenerationen.

Als Anhang zu diesem Kapitel, das sich bisher fast ausschließlich mit Mes. ehrenbergi und seinen nächsten Verwandten beschäftigt hat, sollen nun noch in aller Kürze einige Angaben über die Fortpflanzungsverhältnisse bei anderen Rhabdocoeliden folgen. Bei der großen Mannigfaltigkeit, die gerade der Genitalapparat in unserer Gruppe zeigt, ist es klar, daß hier vielfach ganz andere Erscheinungen zu beobachten sein müssen als bei Mes. ehrenbergi. Zusammenhängende Untersuchungen darüber existieren jedoch bisher nicht und auch zuverlässige, kürzere Angaben sind verhältnismäßig selten. Zahlreiche interessante Fragen sind daher einstweilen nicht zu beantworten.

So herrscht z. B. fast völliges Dunkel darüber, in welcher Weise sich die vielen Arten, deren Kopulationsorgane mit komplizierten Stiletts und anderen aus systematischen Gründen viel studierten und daher morphologisch gut bekannten Chitingebilden bewaffnet sind, dieser eigenartiger Apparate bedienen. Ebenso über die Kopula bei solchen Formen, deren weiblicher Genitaltractus durch mehrere, bisweilen sogar dorsal gelegene offnungen nach außen mündet. $Z u$ untersuchen wäre ferner, in welchem Umfange Selbstbefruchtung verbreitet ist. Sicherlich dürften die meisten Rhabdocoelen, wenn sie isoliert aufgezogen werden, in der Lage sein, auch ohne voraufgegangene Begattung Eier zu bilden und zu besamen. Im allgemeinen kommt aber Selbstbefruchtung wohl nur in Ausnahmefällen vor; als Art, bei der 
sie - wenigstens für einen Teil der Eier - zur Norm geworden ist, dürfte Mes. ehrenbergi ziemlich vereinzelt dastehen.

Da bei den hysterophoren Rhabdocoelen noch keine Trennung zwischen Germarien und Vitellarien besteht, produzieren sie von den Eiern aller übrigen Rhabdocoeliden vollkommene verschiedene, endolecithale (s. S. 52) Eier, die leider bisher noch gar nicht näher studiert worden sind. Unter den Lecitophora bilden manche Arten Eikapseln, die nicht wie bei Mes. ehrenbergi nur eine, sondern mehrere Keimzellen enthalten. Von gewöhnlicheren Süßwasserformen seien als Beispiele hierfür nur Dalyellia viridis und Castrella truncata genannt; häufiger sind solche Arten dagegen im Meere. Die Zahl der Embryonen, die eine Eikapsel beherbergt, kann bis auf etwa ein Dutzend steigen (Plagiostomum girardi).

In einzelnen Fällen wird die Eikapsel ähnlich wie bei manchen Tricladen, mit einem Stiel versehen (Abb. 117); dieser kann bisweilen ziemlich lang werden und dann (Abb. 112) an die den Eiern vieler Trematoden eigentümlichen "Filamente" erinnern. Auch Deckelchen, die aufspringen, wenn die Jungen aus den Eikapseln ausschlüpfen, werden gelegentlich präformiert.

Daß die Fähigkeit, Subitaneier zu bilden, auf wenige, Mes. ehrenbergi nahe verwandte Arten beschränkt ist, wurde schon oben erwähnt. Weitaus die meisten Formen erzeugen nur eine Art von Eiern, deren Entwicklung meist außerhalb des Muttertieres vor sich geht. Die Ablage nach außen erfolgt vielfach, wie bei Mes, ehrenbergi, erst durch den Zerfall des Muttertieres nach seinem Tode. Die Eier werden daher $z u$ seinen Lebzeiten sämtlich bald im Uterus, bald im Parenchym aufgespeichert. Manche Arten setzen aber stattdessen die Eier einzeln nach außen ab. Bemerkenswert ist, daß sich nächstverwandte Spezies in dieser Beziehung verschieden verhalten können. Ein Beispiel hierfür bilden die Arten der Gattung Dalyellia (s. die Bestimmungstabelle). Die Eiablage wird von einzelnen Formen (Abb. 147) so bewerkstelligt, daß nach der Bildung der Eikapsel ihr anfangs noch zähflüssig-klebriger Stiel aus der Geschlechts- 
öffnung hervorgestülpt und mit seinem freien Ende an der Unterlage, auf der sich der Wurm gerade befindet, festgeklebt wird.

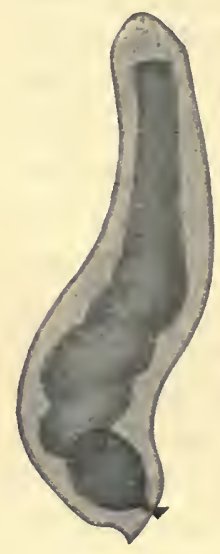

Abb. 147.

Plagiostomum gir ardi, einen Kokon ablegend.

Dann kriecht das Tier weiter und zieht sich auf diese Weise seinen eignen Geburtshelfer spielend - selbst den Kokon aus seiner Geschlechtsöffnung heraus.

Die Zahl der Eier, die gebildet werden, ist bei den verschiedenen Arten sehr wechselnd, über ihre Entwicklungsgeschwindigkeit ist wenig bekannt. Bei manchen Formen ist es nicht sicher, ob die Eier, die nach ihrer harten, braunen Schale und ihrer Entwicklung außerhalb des Mutterkörpers als Dauereier anzusehen sind, stets überwintern, ehe die Jungen ausschlüpfen. Es scheint vielmehr, als ob sie sich so rasch entwickeln können, daß in einem Jahre mehrere Generationen nacheinander auftreten. Jedoch fehlen genauere Beobachtungen darüber noch vollständig.

Ungeschlechtliche Fortpflanzung durch Querteilung

Ungeschlechtliche Fortpflanzung kommt unter den Rhabdocoeliden nur in der Gruppe der Hysterophora und zwar in den Familien der Microstomiden und Catenuliden vor. Besonders häufig ist der Vorgang bei den in unsern Gewässern so gewöhnlichen Arten der Gattungen Microstomum und Stenostomum $\mathrm{zu}$ beobachten; hier ist er daher auch am genauesten untersucht. Weniger bekannt sind die Verhältnisse, in den übrigen Gattungen (Catenula, Rhynchoscolex, Alaurina), die ungeschlechtliche Vermehrung zeigen. Doch handelt es sich dabei überall dem Wesen nach um mehrfache Querteilung verbunden mit ausgedehnter Regeneration der fehlenden Teile in den Tochterindividuen oder Zooiden, wie sie genannt werden.

Bei Microstomum beginnt die Teilung mit der Ausbildung einer queren Scheidewand zwischen Hautmuskelschlauch und Mus- 
kularis des Darms etwa in der Mitte des Körpers (Abb. 140, vor I), die den vorher einheitlichen Leibesraum des "Solitärtiers" in zwei Bezirke für die zukünftigen Tochterindividuen zerlegt. Im weiteren Verlauf des Teilungsprozesses entsteht dann an der Stelle des Septums eine ringförmige Einschnürung des Integuments, die allmählich tiefer und tiefer nach innen einschneidet, bis die Verbindung nur noch durch den Darm aufrecht erhalten wird. Dieser reißt dann schließlich durch und die Zooide sind frei.

Ehe dies geschieht, pflegen sich aber außer der ersten noch weitere Teilungen vorzubereiten. Zwei in der Mitte der beiden ersten noch miteinander zusammenhängenden Tochterindividuen auftretende Quersepten (Abb. 140, vor Il) machen aus dem ursprünglichen Solitärtier eine Kette von vier Zooiden, weitere Scheidewände in deren Mitte deuten auf einen dritten Teilungsschritt hin usf. So entstehen Kettenverbände von Zooiden, die sich, wenn ihr Zusammenhang lange aufrecht erhalten wird, aus 12,16 ja sogar 18 Tochterindividuen zusammensetzen können. So große Ketten - deren Länge bei Microstomum gigan teum $1 \frac{1}{2} \mathrm{~cm}$ und mehr erreichen kann - kommen aber nur unter besonders günstigen Verhältnissen zustande. Meist führen schon viel früher irgendwelche Anlässe von oft geringfügiger Natur - es genügt schon leichte Berührung - den Zerfall des Kettenverbandes in kleinere Stücke herbei. In der Regel trifft man daher nur Ketten von 6-8 Zooiden an. Ein gleichzeitiger Zerfall der Ketten in soviel Zooide, als in ihnen angelegt oder auch nur in soviel Zoide als in ihnen fertig ausgebildet sind, findet niemals statt. Immer geschieht der Zerfall durch wiederholte Zweiteilungen, deren Reihenfolge im allgemeinen dem Alter der Septen entspricht. Die Wunden, die jede dieser Teilungen mit sich bringt, heilen schnell.

Das Erscheinen der Quersepten, die das Solitärtier in eine Kette von Zooiden verwandeln, genügt allein natürlich noch nicht, um die Tochterindividuen lebensfähig zu machen. Hierzu sind vielmehr als Regenerationsprozesse sich darstellende Neubildungsvorgänge notwendig, durch welche die Teilstücke die Organi- 
sation ganzer Tiere erlangen. Diese Vorgänge vollziehen sich gleichfalls noch während des Zusammenhanges der Zooide im Kettenverbande ( $\mathrm{Abb} .140$ ). Es ist klar, daB sich die verschiedenen Tochterindividuen dabei ganz verschieden verhalten müssen. Während das vordere von je zwei Teiltieren, die durch ein Septum voneinander abgegrenzt werden, nur wenig $z \mathrm{u}$ regenerieren hat,

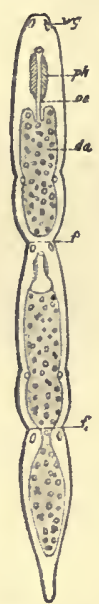

Abb. 148.

Stenostomum langi, Kette von 5 Zooiden, die durch Ringfurchen (f) gegeneinander abgesetzt sind. da Darm; oe Oesophagus; ph Pharynx; wg Wimpergrübchen (nach Keller aus v. Graff). muB das hintere vor allem Gehirn und Pharynx neubilden. Dies geschieht durch Zellen des Parenchyms, sog. "Bildungszellen", die durch rege Teilungen $z u$ beiden Seiten des Darms zunächst die paarige Gehirnanlage herstellen, aus der dann, unter gleichzeitiger Beteiligung der seitlichen Längsnervenstämme, das neue Zentralnervensystem hervorgeht. AuBerdem liefern die "Bildungszellen" auch das Material für eine unpaare, mediane Anlage, die den neuen Pharynx samt seinen Muskeln, Nerven und Drüsen entstehen läßt.

Die Teilungsvorgänge bei Stenostomum stimmen mit den eben geschilderten Prozessen im großen und ganzen überein, vor allem kommt es auch hier zur Ausbildung größerer, bis zu acht Zooiden umfassender Ketten. Ein wesentlicher Unterschied besteht jedoch insofern, als hier die Teilung nicht durch das Auftreten von Querscheidewänden, sondern durch die inneren Neubildungsvorgänge, in erster Linie durch die Anlage des Zentralnervensystems im hintern Teiltier eingeleitet wird. Uberhaupt fehlt die Septenbildung vollkommen. An ihrer Stelle entstehen nur ringförmige Einschnürungen des Integuments, die die einzelnen Zooide voneinander abgrenzen (Abb. 148).

Utber das Verhältnis der asexuellen Vermehrung dieser Würmer zur geschlechtlichen Fortpflanzung wissen wir noch sehr wenig. Es scheint als ob eine Art Generationswechsel besteht, 
indem nach einer unbestimmten Zahl währenó des Frühlings und Sommers durch Teilung erzeugter Generationen im Herbst eine sexuelle Differenzierung der Individuen stattfindet. Stets hört mit Eintritt der Geschlechtsreife die ungeschlechtliche Vermehrung auf. $\mathrm{Ob}$ dieselben Tiere, wie behauptet worden ist, nach der Sexualperiode in eine nochmalige Periode der Fortpflanzung durch Teilung eintreten können, ist nicht entschieden, ebensowenig in welchem Maße äuBere Bedingungen, wie Temperatur und Ernährung, diese Verhältnisse beeinflussen. $\mathrm{DaB}$ aber irgendwelche äußere Faktoren dabei wirksam sind, ist wohl sicher.

\section{Regeneration}

Wenn man von den Regenerationsprozessen absieht, die mit den eben besprochenen Teilungsvorgängen zusammenhängen, ist über Regeneration bei den Rhabdocoeliden bisher nichts Genaueres bekannt geworden. Einzelne Autoren geben zwar an, nach Zerschneidung der Tiere Regeneration beobachtet $\mathrm{zu}$ haben, bestimmte Mitteilungen darüber liegen jedoch nicht vor. Immerhin scheint das großartige Regenerationsvermögen, das den Planarien eigen ist, vielfach $z u$ der Ansicht geführt $z u$ haben, bei den Rhabdocoeliden müßten ähnliche Fähigkeiten vorhanden sein.

Mangel des Regenerationsvermögens bei Mes. ehrenbergi
Versuche an Mes. ehrenbergi haben indessen ergeben, daß wenigstens bei dieser Form keine Rede davon sein kann. Der Wurm eignet sich bei seiner Größe ausgezeichnet zu Regenerationsexperimenten, seine Durchsichtigkeit erlaubt zudem, den Erfolg der Operation und alle Vorgänge, die sich im Anschluß daran abspielen, genau zu kontrollieren. Auch sind an ihm mit Leichtigkeit Operationen auszuführen, die anderweit kaum möglich sind, z. B. die Exstirpation einzelner innerer Organe, des Gehirns oder des Genitalapparates. Alle diese Versuche ergaben indessen, daß niemals eine Regeneration stattfindet. Zwar heilt die Wunde, die durch die Operation gesetzt wird, fast immer rasch. Mehr als diese einfache Reparation des Schadens tritt aber 
im allgemeinen nicht ein. Höchst selten ist eine - auch dann aber nur ganz ungefähre - Wiederherstellung der äußeren Körperform zu konstatieren, wie z. B. die Ausbildung einer Art Schwanzspitze nach Amputation des Hinterendes. Wirklicher Ersatz eines entfernten Organs oder Organkomplexes konnte aber nie beobachtet werden.

So können Tiere, denen das Gehirn mit einem feinen Hohlmesser ausgestanzt wird, den Verlust dieses Organs in keiner Weise wieder gut machen. Die kleine Wunde ist zwar schon nach 24 Stunden vernarbt, und die Tiere kriechen alsdann im Wasser umher, als ob ihnen nichts geschehen wäre. Und doch tragen sie den Keim des Todes in sich. Wenn auch die meisten Bewegungen, wie es scheint, ohne das Vorhandensein des nervösen Zentralorgans ablaufen können, so doch nicht jene komplizierten Bewegungsmechanismen, die beim Beutefang und beim Fressen in Tätigkeit treten. Selbst wenn man die Tiere am 2. oder 3. Tage nach der Operation, ehe Entkräftung durch allzulanges Fasten eingetreten ist, mit reichem Futter zusammen bringt, vermögen sie nichts davon $z u$ sich zu nehmen, sie sterben daher schließlich Hungers. Das gleiche Schicksal wie derart enthirnte Tiere erleiden natürlich alle Individuen, denen das Vorderende mitsamt dem Hirn amputiert wird.

Ebensowenig wie das Gehirn kann der Pharynx regeneriert werden. Sein Verlust zieht daher gleichfalls die Unfähigkeit zur Nahrungsaufnahme und damit den Tod nach sich. Teilt man ein Tier durch einen Querschnitt zwischen Gehirn und Pharynx in zwei Stücke, so ist der hintere Abschnitt gehirn-, der vordere pharynxlos. Die Folge davon ist, daß beide Hälften schließlich zugrunde gehen, wenn sie unter günstigen Umständen auch oft noch tagelang vegetieren können. Wird der Schnitt dagegen hinter dem Pharynx geführt, so bleibt die vordere Hälfte leben und nur die hintere geht ein. $\mathrm{Ob}$ der Genitalapparat in dem vorderen Teilstück verbleibt oder nicht ist für dessen Existenz ohne Belang. Fehlt er, so bleibt das Teiltier steril, da eine Regeneration nicht stattfindet. Ist dagegen sein zentraler Teil noch 
vorhanden, wird die Geschlechtstätigkeit nicht unterbrochen. Die operierten Tiere fahren ruhig in der Eiproduktion fort, selbst wenn ihnen bei Führung des Operationsschnittes unmittelbar hinter der Geschlechtsöffnung der halbe Körper entfernt wurde. Auch für Verletzungen durch Längs- oder Schrägschnitte gilt das gleiche: Nicht auf die Größe des Verlustes kommt es an, sondern ob lebenswichtige Organe entfernt wurden oder nicht.

Man sieht, die Verhältnisse liegen bei Mes. ehrenbergi vollkommen anders als bei Planarien. Auf die Frage, warum das so ist, läßt sich einstweilen keine zureichende Antwort geben. Wissen wir doch auch nicht, warum die einen Planarien gut, die andern schlecht regenerieren. Nahe verwandte Formen können sich in dieser Hinsicht sehr verschieden verhalten, und es darf daher niemals von den regeneratorischen Fähigkeiten der einen Art ohne weiteres auf die einer anderen geschlossen werden.

\section{Natürliche Mißbildungen}

Da Mes. ehrenbergi das Regenerationsvermögen vollständig abgeht,

können bei ihm natürlich auch keine Doppelbildungen und Heteromorphosen erzielt werden. Wie sich in dieser Hinsicht die anderen Rhabdocoeliden verhalten, bleibt noch experimentell zu prüfen. Man kennt aber von ihnen eine ganze Anzahl natürlicher Doppelbildungen, die in Aquariumszuchten zur Beobachtung gelangten. Stets handelte es sich um Tiere, die

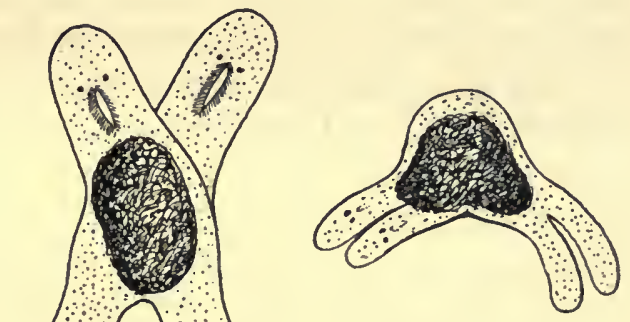

mit 2 Köpfen und 2 Schwänzen versehen waren (Abb. 149.) In allen Fällen, wo die Entstehung dieser Zwillingsformen ver- 
folgt werden konnte, zeigte sich, daß sie keine Verletzungsmißbildungen darstellten, sondern abnormen Vorgängen in den ersten Entwicklungsstadien ihren Ursprung verdankten. Wie auch beim Menschen bisweilen aus einem $\mathrm{Ei} Z$ Zwillinge (sog. eineiige Zwillinge) hervorgehen und unter besonderen Umständen teilweise miteinander verwachsen bleiben können - man denke an die berühmten "siamesischen Zwillinge ${ }^{u}$, so auch hier. Das Vorkommen von Doppelbildungen bei Rhabdocoeliden braucht also nicht ohne weiteres auf Regenerationsgeschehnisse hinzudeuten. Daß in der freien Natur solche Doppelbildungen im allgemeinen nicht zur Beobachtung gelangen, mag daher rühren, $\mathrm{daB}$ sie verborgener leben und sich langsamer bewegen als ihre normalen Artgenossen und wohl auch leichter als diese ihren Feinden zum Opfer fallen.

\section{Sinnestätigkeit}

Unser Bericht über die Sinnestätigkeiten der Rhabdocoeliden kann äußerst kurz gehalten sein. Spezielle Untersuchungen darüber existieren nicht, und das Wenige, was bekannt ist, entspricht im allgemeinen dem, was oben für die Tricladen ausgeführt wurde.

Auf Lichtreize hin zeigen die meisten Arten, und so auch Mes. ehrenbergi, Unterschiedsempfindlichkeit und negative Phototaxis. Eine Ausnahme hiervon machen vor allem die mit Zooxanthellen oder Zoochlorellen behafteten Arten, die positiv phototaktisch sind. Hier sind es aber jedenfalls die Algen, die diese Reaktion bestimmen. Sie brauchen das Licht für ihre assimilatorische Tätigkeit und veranlassen daher den Wurm, sich nach der Richtung des Lichteinfalls hin zu bewegen. Wirksam sind dabei wahrscheinlich kleine Schwankungen im Stoffwechsel der Algen, die als Reize auf den Wurm wirken. Die positiv phototaktische Reaktion ist besonders prompt bei den durch Zoochlorellen grünen Arten. - AuBer diesen Formen werden auch noch einige algenlose Arten als positiv phototaktisch beschrieben, die sich mit Vorliebe an der Wasseroberfläche aufhalten, wie 
Dalyellia armigera, Castrella truncata und Castrada armata. Es stimmt dies aber wohl nicht. In Versuchsaquarien suchten die meisten Individuen der genannten Spezies stets die dunkelsten Stellen auf; nicht das Licht, sondern ein besonders energisches Sauerstoffbedürfnis ist es, das diese lebhaft beweglichen Würmer an die Oberfläche treibt.

Während thermische und chemische Reize auf die Rhabdocoeliden in ähnlicher Weise wirken, wie auf die Tricladen, scheint Rheotaxis bei den meisten Arten nicht vorhanden zu sein. Strömungseinflüsse können ja auch im Leben von Bewohnern stehender Gewässer kaum eine Rolle spielen.

Uber die Bedeutung der Statozysten bei den Rhabdocoeliden liegen bisher Untersuchungen nicht vor. Besser unterrichtet sind wir dagegen über ihre Funktion bei den Acoelen, besonders bei Convoluta roscoffensis. Hält man diese Art in Gefäßen, so sammeln sich bei unbewegtem Wasser alle Tiere an der Oberfläche, bei der leisesten Erschütterung lassen sie sich dagegen sofort $\mathrm{zu}$ Boden sinken. Die Tiere sind also in ruhigem Wasser negativ, in bewegtem positiv geotaktisch. Zugleich läßt sich zeigen, daß diese Reaktion an die Anwesenheit der Statozyste gebunden ist: sie verschwindet sofort, wenn man die Tiere dekapitiert, oder wenn man durch rasche Verdünnung des Seewassers mit Regenwasser, die die Tiere im übrigen gut ertragen, eine Schädigung der feineren Struktur der Statozyste herbeiführt.

Feinde und Parasiten der Rhabdocoeliden

Die Gefahr, die Mes. ehrenbergi und den größeren Rhabdocoeliden von tierischen Feinden droht, ist, wie schon oben auch für die Tricladen angegeben, relativ gering. Es wird ihnen, so zarte und wehrlose Geschöpfe sie auch sind, im allgemeinen nur wenig nachgestellt. Indessen gilt dies nur für die großen ausgewachsenen Tiere. Die Jungen und ebenso die kleinen Arten fallen allen möglichen Wasserbewohnern, besonders größeren Crustaceen wie den Wasserkrebsen und Asseln, zum Opfer. 
Auch betreffs der Parasiten gilt ähnliches wie für die Tricladen. Besondere Erwähnung verdienen nur die sog. $\mathrm{Kri-}$ stalloide von Mes. ehrenbergi, die früher von manchen $\mathrm{Au}$ toren für aufgespeicherte Reservestoffe gehalten wurden, jetzt aber ganz sicher als Gebilde parasitischer Natur erkannt sind. Es handelt sich dabei um kugelige Zysten, deren plasmatischer Inhalt leicht Farbstoffe annimmt und gewöhnlich einen sehr dunkel sich tingierenden Kern enthält. Die feste, dicke Hülle der Zysten trägt hohe hyaline Leisten, die untereinander ein oft aus regelmäßigen, Vier-, Fünf- oder Sechsecken bestehendes Netzwerk bilden und so dem Ganzen das charakteristische Aussehen verleihen, auf das der Name Kristalloide hindeutet (Abb. 150). Die Zysten gehen aus amöboiden Jugendzuständen hervor und geben wahrscheinlich direkt wieder jungen

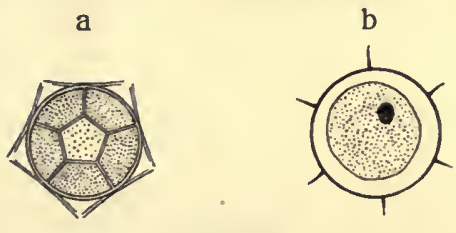

Abb. 150.

Kristalloide aus Mesostoma ehrenbergi, a Totalansicht, b Medianschnitt.

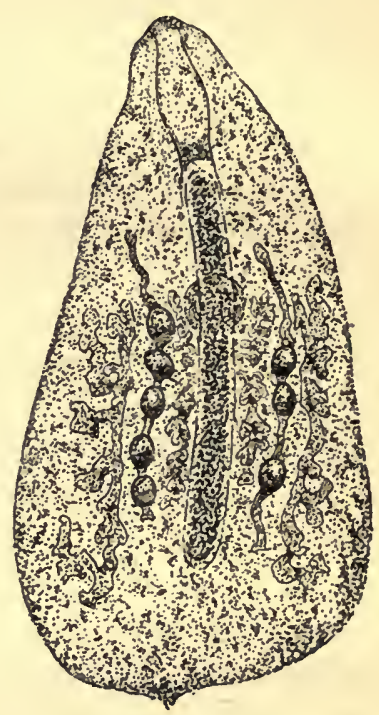

Abb. 151.

Mesostoma ehrenbergi, stark mit Kristalloiden infiziert, daher lrüb und undurchsichtig.

Amöben den Ursprung. Irgendwelche geschlechtliche Vorgänge, die etwa der Enzystierung vorangingen, sind nicht bekannt. Diesem Entwicklungsgange nach erinnern die Kristalloide am ehesten an die Haplosporidien, eine wenig erforschte Protistengruppe, deren $\mathrm{Zu}$ gehörigkeit zum Tier- oder Pflanzenreich noch zweifelhaft ist.

Die Infektion mit Kristalloiden tritt bei Mes. ehrenbergi Ende Sommers sehr häufig auf, der Weg, auf dem sie erfolgt, ist unbekannt. Zuerst werden einzelne Stellen befallen, die beim 
Kriechen der Tiere auf dunklem Grunde sofort als kleine weißliche Tafeln auffallen. Die Parasiten vermehren sich aber rasch und befallen nach und nach alle inneren Organe; die Tiere werden trüb und undurchsichtig (Abb. 151), stellen allmählich die Dauereibildung ein - bisweilen werden vorher einige taube Eier, die nur ein paar Dotterzellen enthalten, gebildet - und gehen schließlich an der fortschreitenden Zerstörung ihrer Gewebe zugrunde.

\section{Oekologie und Verbreitung}

Von einigen wenigen Prorhynchus-Arten abgesehen, die auch in feuchter Erde sich aufhalten können, leben die Rhabdocoeliden durchweg im Wasser. Rund 150 Spezies sind Meeres-, rund $200 \mathrm{SüBwasserbewohner.} Z u$ den letzteren stellen die Rhabdocoelen das Hauptkontingent, zu den ersteren die Alloeocoelen.

Unter den Meeresbewohnern sind ökologisch 2 Gruppen scharf voneinander $\mathrm{zu}$ unterscheiden: freilebende Formen und Parasiten. Uber die eigentümlichen Anpassungen im Körperbau, die die Schmarotzer auszeichnen, ist schon oben (S. 271) berichtet worden. Ihre Wirte sind Würmer, Krebse, Stachelhäuter und Mollusken. Die freilebenden Arten sind fast durchweg Küstenformen. Ihre Verbreitung ist noch lange nicht genügend erforscht. Aus Tiefen von über $25 \mathrm{~m}$ kennt man nur ganz wenige Vertreter.

Die Gliederung der Süßwasserbewohner nach Wohnorten ist nicht leidht, da manche Arten in Gewässern von recht verschiedenem Charakter leben können. Den natürlichen Verhältnissen dürfte noch am ehesten die Einteilung in 2 ökologische Hauptgruppen entsprechen:

I. Rhabdocoeliden temporärer Gewässer, Formen, die im Frühling ihre Hauptentwicklung haben und im Sommer, wenn die Gewässer auszutrocknen beginnen, verschwinden. 
II. Rhabdocoeliden konstanter Gewässer, die im Sommer oder das ganze Jahr hindurch in nicht austrocknenden Tümpeln und Wassergräben, in Seen und leichtfließenden Gewässern vorkommen.

Die Vertreter der ersten Gruppe leben vorzugsweise zwischen Pflanzen, unter Laub oder im Schlamm kleiner pfützen oder Gräben, die sich im Frühjahr für einige Wochen mit Wasser füllen ${ }^{1}$ ). Ihre Eier überwintern am Boden der ausgetrockneten $\mathrm{Ge}$ wässer, der sich bisweilen durch Humusschichten oder ihn bedeckende Lagen vermodernder Blätter eine gewisse Feuchtigkeit bewahren, bisweilen aber auch staubtrocken werden kann; sie lassen ihre Jungen frei, wenn sich für einige Zeit Wasser über ihnen ansammelt. Eine bestimmte Wärme des Wassers ist dazu nicht unbedingt erforderlich, wenn auch natürlich höhere Temperaturen, die sich besonders in kleinen, offen der Sonne ausgesetzten Wasserlachen tagsüber leicht einstellen, günstig wirken und weiterhin das Heranwachsen und Reifen der ausgeschlüpften Jungen bèschleunigen. Die Zeit des Verschwindens dieser Arten wechselt von Ort zu Ort, fällt aber häufig auf Anfang Juni oder Juli. Typische Beispiele sind: Dalyellia viridis, Phaenocora unipunctata und Opistomum pallidum.

Die Schärfe der Abgrenzbarkeit dieser Gruppe wird aber durch mancherlei Momente beeinträchtigt. So wird z. B. Phaenocora unipunctata manchmal auch in konstanten Gewässern gefunden. Das Gleiche gilt von Catenula lemnae, die vielfach in den gleichen temporären Wasserlachen wie Phaenocora unipunctata anzutreffen ist, anderwärts aber das ganze Jahr hindurch vorkommen kann; von dieser Art ist daher gar nicht zu entscheiden, ob sie in Gruppe I oder II einzuordnen ist. Weiter können die temporären Tümpel aud von solchen Formen bewohnt werden, die eigentlich zur Fauna konstanter Gewässer ge-

1) Solche regelmäBig austrocknenden Tümpel, die Phaenocora unipunctata, Catenula lemnae, Mesostoma ehrenbergi und Planaria vitta enthalten, existieren $z$. B. im Rheinwald bei Straßburg. 
hören, so von Gyratrix hermaphroditus und sogar von den großen Mesostoma-Arten. Letztere vermögen allerdings nur in günstig gelegene Tümpel einzudringen, die sich auf Temperaturen von $20^{\circ}$ und darüber erwärmen können, ohne doch vor etwa Monatsfrist auszutrocknen. In dieser Zeit können nicht nur die Wintertiere von Mes. ehrenbergi zur Dauereiproduktion übergegangen sein, sondern, wie wir oben gesehen haben (S. 305), auch die aus ihren Subitaneiern hervorgegangenen Jungen. In kälteren, temporären Gewässern ist die Existenz dieser Formen dagegen auf die Dauer nicht möglich. Es ist klar, daß hier die Art jedesmal zugrunde gehen muß, sowie das Austrocknen des Wohnwassers die Tiere noch während der Sommertracht trifft.

Unter den Vertretern der $z$ weiten Gruppe sind selbst wieder 2 Unterabteilungen $z u$ unterscheiden:

a) Sommerformen, die Mehrzahl aller Rhabdocoelen umfassend, deren Wohnsitze die konstanten Kleingewässer und die Uferregion größerer Seen bilden. Viele der hierher gehörigen Arten sind in ihrem Vorkommen streng an die betreffende Gewässergattung gebunden. Anderen dagegen gestattet ihre Anpassungsfähigkeit größere Freiheit in der Wahl des Wohnortes. Ein Teil von ihnen kann daher, wie schon bemerkt, in temporäre Gewässer übergehen oder sich in den tieferen Regionen der Seen ausbreiten. Doch bilden auch bei diesen Ubiquisten die zuerst genannten Lokalitäten das Hauptverbreitungsgebiet. Die Periode der größten Individuenzahl fällt bei ihnen in den Sommer (Juli, August). In rasch erhitzten Tümpeln und in der Ebene treten sie früher auf als in größeren Gewässern und im Hochgebirge; ebenso bewirken warme Sommer frühzeitigeres Erscheinen als kalte.

Zahlreiche Sommerrhabdocoeliden leben zwischen Pflanzen, u. a. alle grünen Typhloplana- und Castrada-Arten und von den größeren Formen Mesostoma ehrenbergi, tetragonum sowie Bothromesostoma personatum. Viele Arten treiben sich nicht nur zwischen Pflanzen umher, sondern gehen auch in den Schlamm der Bodenregion. Von den größeren Arten gehört 
hierher Mes. lingua, unter den kleineren Formen befinden sich gerade in dieser Gruppe ausgezeichnete Schwimmer, wie Gyratrix hermaphroditus und Strongylostoma radiatum; letztere Art wird daher nicht selten sogar planktisch angetroffen. Manche Formen scheinen das Schlammleben zu bevorzugen, wie z. B. Microstomum lineare. Sie bilden so die Brücke zu den echten Schlammbewohnern, unter denen besonders Prorhynchus stagnalis, Olisthanella truncula und Bothrioplana semperi genannt seien.

Wenn wir auch alle die zuletzt besprochenen Formen als "Sommerrhabdocoeliden " zusammenfassen, so ist doch dieser Name nur cum grano salis zu verstehen. Einzelne Arten widersprechen ihm direkt, insofern als sie in den konstanten Kleingewässern nicht erst im Sommer auftreten, sondern schon viel früher, oft schon Ende Februar und März. Hierher gehören Arten, die kaltes Wasser bevorzugen, wie Rhynchomesostoma rostratum, oder aber stark eurytherme Formen, wie Castrella truncata. Letztere ist mit Castrada armata eine der frühesten Rhabdocoelidenspezies, die bei Straßburg alljährlich in großer Individuenzahl erscheinen. Sie verträgt aber auch überaus hohe Temperaturen (bis $\mathrm{zu} 45^{\circ}$ nach der Angabe von Markow).

b) Perennierende Grundbewohner größerer Gewässer, an Orten lebend, wo sich die jahreszeitlichen Unterschiede nur wenig Geltung verschaffen können und daher nicht an den Sommer gebunden. Sie sind vor allem aus den großen Seen der Schweiz bekannt, wo für Plagiostomum lemani und Otomesostoma auditivum das Perennieren sidher nachgewiesen ist. Uber andere ähnlich lebende Formen (Castrada spinulosa, Trigonostomum neocomense) liegen entsprechende Angaben noch nicht vor, jedenfalls, weil nach ihnen bisher immer nur im Sommer gesucht worden ist.

Aus dem Gesagten geht hervor, daß die Rhabdocoeliden der Mehrzahl nach nicht gerade wählerisch in ihren Wohnorten sind. Es darf daher vermutet werden, daß sie auch unter ver- 
schiedenen klimatischen Verhältnissen leben können und also weite Verbreitung besitzen. Leider sind unsere Kenntnisse über die Rabdocoeliden ferner Länder noch sehr mangelhaft. Einigermaßen bekannt ist nur die Rhabdocoelidenfauna Nord- und Mitteleuropas; dagegen ist aus Italien, Spanien und den Balkanländern kaum eine Art mit Sicherheit festgestellt. Auch über amerikanische Formen sind unsere Kenntnisse nur gering, und noch viel weniger wissen wir über Vertreter der Rhabdocoeliden aus den Tropen oder den gemäßigten Gebieten der südlichen Halbkugel.

Immerhin steht für einige Formen bereits fest, daß sie als Kosmopoliten oder Weltbürger bezeichnet werden dürfen. So kennt man Mes. ehrenbergi aus Mittel- und Nordeuropa bis nach Sibirien, aus Innerasien, Nordamerika und Westindien, andere Arten des Genus Mesostoma, auch aus Ostafrika und Australien. Wahrscheinlich zeigen noch sehr viel mehr Gattungen ähnlich kosmopolitsches Verhalten.

Ihrer Verbreitung nach verdienen noch die perennierenden. Grundbewohner der Seen besonderes Interesse. Sie fehlen in Kleingewässern ganz oder fast ganz und treten dafür in den größeren Seen für gewöhnlich numerisch vor ihren ubiquistischen, ebenfalls in der Tiefenregion vorkommenden Genossen aus der Gruppe der Sommerrhabdocoeliden um so stärker hervor, je tiefer der Fundort unter dem Wasserspiegel liegt. Ihre Sonderstellung als typische Grund - oder Tiefenbewohner gegenüber jenen nur zufällig in die Tiefe gelangten Arten, die ihre Hauptentwicklung am Ufer haben, ergibt sich jedoch nicht nur aus dieser Verteilung im Wohngewässer und aus dem biologischen Verhalten (Perennieren), sondern auch aus ihrem systematisch abweichenden Charakter. Plagiostomum lemani gehört in eine sonst rein marine Gattung (ca. 20 Arten an den Meeresküsten Europas), wiewohl sie sich anatomisch von ihren marinen Verwandten nicht unwesentlich unterscheidet. Ahnliches gilt für die einzige Monocelidide des Süßwassers Otomesostoma auditivum, sowie für Trigonostomum neocomense.

Die genannten 3 Arten erscheinen als Fremdlinge unter den Steinmann-Bresslau, Strudelwürmer. 
übrigen Süßwasserrhabdocoeliden, und man hat daher die Vermutung ausgesprochen, daß sie sich zu Beginn der Postglazialzeit, während der Aussüßung der Meere durch die großen Schmelzwasserströme an das süße Wasser angepaßt haben. Sicherlich spricht mancherlei zugunsten dieser Vermutung, eine Entscheidung über ihre Richtigkeit ist jedoch zur Zeit unmöglich. Zur Vorsicht mahnt, daß in unsern Süßwässern noch ein weiterer Vertreter einer sonst typisch marinen Rhabdocoelidengattung, polycystis goettei, vorkommt, dessen Verbreitung (konstante Kleingewässer Süddeutschlands, Böhmens, Schottlands, in neuester Zeit ist auch eine Art aus Nordamerika beschrieben worden) mit Sicherheit jede Beziehung zur Eiszeit ausschließt. Ferner ist $z \mathrm{u}$ beobachten, daß einzelne Rhabdocoelidenarten (Gyratrix hermaphroditus, Macrostomum appendiculatum) sowohl im Meere wie im süßen Wasser vorkommen.

\section{Systematik}

Es würde über den Umfang, der diesem Buche zugemessen ist, weit hinausgehen, wollten wir hier die große Zahl der aus den süßen Gewässern Deutschlands und der angrenzenden Gebiete bekannten Rhabdocoeliden ebenso ausführlich besprechen, wie die viel weniger zahlreichen Arten der einheimischen Tricladen, oder sie auch nur so weit charakterisieren, als es zu ihrer sicheren Bestimmung nötig wäre. Auch dienen diesem Zwecke schon zwei andere Werke, die jeder, der sich eingehender mit der Systematik unserer Würmer beschäftigen will, doch zu Rate ziehen muB, nämlich 1. die 1909 erschienene Zusammenstellung der einheimischen Rhabdocoeliden in Brauers Süßwasserfauna Deutschlands durch von Graff, und 2. die von demselben Autor bearbeitete, soeben zur Ausgabe gelangte 35. Lieferung des "Tierreichs", die ausführliche Bestimmungstabellen, Beschreibungen und Literaturnachweise über alle bis 1911 gefundenen Rhabdocoelidenarten enthält. 
So wollen wir uns hier damit begnügen, den Leser soweit $z u$ führen, daß er ohne allzugroße Schwierigkeiten die Gattungszugehörigkeit etwa von ihm in unseren Süßwassern gefundener Rhabdocoeliden ermitteln und, falls es sich um eine der gewöhnlicheren Arten handelt, auch den Speziesnamen feststellen kann. In vielen Fällen wird es an der Hand der folgenden Tabelle schon bei Betrachtung des einfachen Quetschpräparates mit schwachen oder mittelstarken Linsen möglich sein, zu erkennen, um welche Gattung es sich handelt. Nur in den Familien der Dalyelliiden und Typhloplaniden werden hierzu stärkere Vergrößerungen notwendig sein und bei der zuletzt genannten Familie, wo schon die Unterscheidung einzelner Genera genaueres Studium der Verhältnisse des Genitalapparates erfordert, eventuell auch die Zuhilfenahme der Schnittmethode.

$\mathrm{Da}$ unsere Bestimmungstabelle ausschließlich mit Rücksicht auf ihre praktische Verwendbarkeit ausgearbeitet ist, führt sie direkt auf die Gattungen, ohne zugleich den übergeordneten Kategorien des Systems Rechnung zu tragen. Auch umfaßt sie, wie schon gesagt, nur die wichtigsten Genera, die in den süßen Gewässern Deutschlands und der Nachbarländer vorkommen. Wir müssen daher zum Verständnis der Stellung dieser Formen innerhalb der Rhabdocoeliden einen kurzen Uberblick über das System der ganzen Gruppe vorausschicken.

Eine Definition der Rhabdocoelida als Unterordnung der Turbellaria wurde schon in der Einleitung (S. 4) mitgeteilt. Sie zerfallen ihrerseits wiederum nach dem Bau des Darms, Parenchyms und Nervensystems in die zwei Sektionen der Rhabdocoela und Allöocoela, von denen die erstere zahlreiche, die letztere nur ganz wenige Vertreter im süßen Wasser besitzt. Um die Verschiedenheit des Aufenthaltsortes deutlich hervorzuheben, sind in der folgenden Ubarsicht die Gattungen, deren Arten ausschließlich im Süßwasser leben, fett, diejenigen, die sowohl Vertreter im Meere wie im süßen Wasser besitzen, kursiv, und diejenigen mit rein marinen Arten in gewöhnlicher Schrift gedruckt; Gattungen mit durchweg parasitisch lebenden Arten 
sind außerdem durch ein * gekennzeichnet. Die Gattungen sind durch die ganze Unterordnung hierdurch fortlaufend numeriert.

I. Sektion: Rhabdocoela, Darm ein einfacher, meist stabförmiger Sack mit oder ohne seitliche Divertikel, Parenchym in der Regel locker, oft mit großen Spalträumen, Nervensystem mit ein oder zwei Paaren hinterer Längsstämme. 17 Familien mit ca. 275 Arten, davon etwa $2 / 3$ im süßen Wasser, Rest marin; einige Arten leben auch in feuchter Erde, 27 Spezies sind Parasiten. Man unterscheidet zwei Subsektionen: in der einen (Hysterophora) sind die weiblichen Gonaden als Ovarien, in der andern (Lecitophora) als Germovitellarien bzw. Germarien und Vitellarien ausgebildet.

I. Subsektion: Hysterophora, mit Ovarien. Von den drei hierher gehörigen, 10 Gattungen mit etwa 60 Arten umfassenden Familien besitzen die beiden ersten einen Pharynx simplex, die dritte einen Pharynx compositus (variabilis?), Süßwasser- und Meerbewohner.

1. Fam.: Catenulidae, mit unpaarem Hauptstamm des Exkretionssystems. Fortpflanzung geschlechtlich und ungeschlechtlich.

Gatt.: 1. Catenula; 2. Fuhrmannia; 3. Stenostomum; 4. Rhynchoscolex.

2. Fam.: Microstomidae, Exkretionshauptkanäle paarig, nach der Art der Fortpflanzung in zwei Unterfamilien zerfallend:

a) Microstominae, mit geschlechtlicher und ungeschlechtlicher Vermehrung.

Gatt.: 5. Alaurina; 6. Microstomum;

b) Macrostominae, Fortpflanzung bloß geschlechtlich.

Gatt.: 7. Mecynostomum; 8. Macrostomum; 9. Omalostomum. 
3. Fam.: Prorhynchidae, nur eine Gattung im Süßwasser, einige Arten in feuchter Erde.

Gatt.: 10. Prorhynchus.

II. Subsektion: Lecithophora. Weibliche Gonaden, in einen Dotter und einen Keimzellen erzeugenden Abschnitt differenziert. 14 Familien mit 46 Gattungen und ca. 210 Arten, die sich nur geschlechtlich fortpflanzen. Man unterscheidet unter ihnen zwei Gruppen, je nachdem, ob ein in einer Scheide eingeschlossener Rüssel vorhanden ist oder nicht.

A. Liporhynchia, Rüssel fehlend, oder wenn vorhanden, einer präformierten Scheide entbehrend. 10 Familien, alle mit zusammengesetztem Pharynx, davon Fam. 1-4 mit Pharynx doliiformis, Fam. 5-8 mit $\mathrm{Ph}$. rosulatus, Fam. 9 mit $\mathrm{Ph}$. plicatus und die letzte mit rudimentärem, bei den erwachsenen Tieren ganz verschwindendem Pharynx.

1. Fam.: Graffillidae, ohne Vagina, Geschlechtsöffnung selbständig, mit zwei Germarien oder Germovitellarien (z. T. Parasiten mariner Mollusken).

Gatt.: 11. Vejdovskya; 12. Paravortex*; 13. Provortex; 14. Graffilla*.

2. Fam.: Dalyelliidae, ohne Vagina, Geschlechtsöffnung selbständig, Germarium unpaar, im männlichen Kopulationsorgan meist sehr komplizierte Chitingebilde. 57 Arten, mit einer Ausnahme durchweg Süßwasserbewohner.

Gatt.: 15. Dalyellia; 16. Castrella; 17. Didymorchis*;

18. Jensenia; 19. Phaenocora; 20. Opistomum.

3. Fam.: Anoplodiidae, mit Vagina, Geschlechtsöffnung selbständig. Durchweg Parasiten mariner Evertebraten (Sipunculiden, Holothurien, Seeigel).

Gatt. 21. Umagilla*; 22. Syndesmis*; 23. Anoplodium*; 24. Collastoma*. 
4. Fam.: Genostomatidae, Geschlechtsöffnung mit dem am hinteren Körperende gelegenen Munde kombiniert. Im Schalenraume mariner Krebse und Muscheln.

Gatt.: 25. Genostoma*; 26. Urastoma*.

5. Fam.: Byrsophlebidae, mit zwei Geschlechtsöffnungen.

Gatt.: 27. Maehrenthalia; 28. Byrsophlebs; 29. Typhlorhynchus*.

6. Fam.: Astrotorhynchidae, Geschlechtsöffnung einfach, Germarien paarig, Vorderende des Körpers ein unbewimperter, einstülpbarer Tastrüssel.

Gatt.: 30. Astrotorhynchus.

7. Fam.: Proxenetidae, Geschlechtsöffnung einfach, weibliche Gonaden paarig, ohne Tastrüssel.

Gatt.: 31. Proxenetes; 32. Promesostoma; 33. Paramesostoma.

8. Fam.: Typhloplanidae, Geschlechtsöffnung einfach, Germarium unpaar. Zahlreiche (ca. 80) Arten, mit zwei Ausnahmen durchweg Süßwasserbewohner. Man unterscheidet drei Unterfamilien, je nachdem, ob die Geschlechtsöffnung im hintersten Körperdrittel (Olisthanellini) oder davor gelegen ist, oder ob sich die Hoden ventral (Typhloplanini) oder dorsal von den Vitellarien finden (Mesostomatini).

a) Olisthanellini, Exkretionsendkanäle stets getrennt auf der Bauchfläche ausmündend.

Gatt.: 34. Olisthanella; 35. Typhloplanella; 36. Sphagnella; 37. Tauridella; 38. Taborella.

b) Typhloplanini, Nierenendkanäle in einen dem Munde aufgesetzten Becher oder in das Atrium genitale mündend.

Gatt.: 39. Strongylostoma; 40. Rhynchomesostoma; 41. Tetracelis; 42. Typhloplana; 43. Lutheria; 44. Castrada. 
c) Mesostomatini, Nierenendkanäle münden in einen dem Munde aufgesetzten Exkretionsbecher. Gatt.: 45. Mesostoma; 46. Bothromesostoma.

9. Fam.: Solenopharyngidae, der sehr lange Pharynx plicatus nach hinten gerichtet.

Gatt.: 47. Solenopharynx.

10. Fam.: Fecampiidae, durch Parasitismus in der Leibeshöhle mariner Crustaceen hochgradig umgebildet. Gatt.: 48. Fecampia*.

B. Kalyptorhynchia, mit einem muskulösen, in eine am Vorderende sich öffnende Scheide eingeschlossenen Rüssel. 4 Familien mit 8 Gattungen, sämtlich mit Pharynx rosulatus, der jedoch bei der ersten (Trigonostomidae) durch seine Gestalt und mit der Spitze nach vorn gerichtete Stellung an den $\mathrm{Ph}$. doliiformis erinnert.

11. Fam.: Trigonostomidae, Rüssel mit schwachem Muskelzapfen, Rüsselscheidenöffnung an der Ventralseite. Geschlechtsöffnung einfach.

Gatt.: 49. Hyporcus; 50. Trigonostomum; 51. Woodsholia.

12. Fam.: Polycystidae, Rüssel mit kräftigem Muskelzapfen, Rüsselscheidenöffnung am Vorderende, Geschlechtsöffnung einfach.

Gatt.: 52. Acrorhynchus; 53. Polycystis; 54. Phonorhynchus.

13. Fam.: Gyratricidae, Rüssel wohl entwickelt, Rüsselscheidenöffnung vorn. Zwei Geschlechtsöffnungen.

Gatt.: 55. Gyratrix.

14. Fam.: Schizorhynchidae, Rüssel distal der Länge nadh in zwei zangenartig gegeneinander bewegliche Hälften gespalten. Geschlechtsöffnung einfach.

Gatt.: 56. Schizorhynchus. 
II. Sektion: Alloeocoela, Darm bald unregelmäßig sackförmig, bald seitliche Divertikel tragend, bisweilen durch den Pharynx durchbrochen. Parenchym dicht, nur mit spärlichen Lücken. Hintere Längsnervenstämme in drei oder vier Paaren vorhanden und durch ringförmig den Darm umgreifende Kommissuren verbunden. Auch die Ausbildung der Protonephridien ist vielfach trikladenähnlich. 7 Familien mit 17 Gattungen und ca. 80 meist marinen Arten, unter denen man 3 Gruppen unterscheidet.

A. Holocoela, Darm ohne Seitentaschen, meist mit Pharynx variabilis. Ventral oder den Körper umgreifend häufig eine Wimperrinne. Geschlechtsöffnung einfach. 4 Familien mit 9 Gattungen.

1. Fam.: Halleziidae, mit zwei Ovarien.

Gatt.: 57. Hallezia.

2. Fam.: Pseudostomidae, mit zwei Germovitellarien.

Gatt.: 58. Pseudostomum; 59. Monoophorum; 60. Euxinia.

3. Fam.: Plagiostomidae, mit getrennten Keim- und Dotterstöcken. Pharynx nach vorn gerichtet, Mund vor Körpermitte.

Gatt.: 61. Plagiostomum; 62. Vorticeros; 63. Plicastoma.

4. Fam.: Allostomatidae, mit getrennten Keim- und Dotterstöcken. Pharynx nach hinten gerichtet, Mund im hinteren Körperdrittel.

Gatt.: 64. Enterostomum; 65. Allostoma.

B. Crossocoela, Darm seitliche Divertikel tragend. Mit

Pharynx plicatus und einer Statocyste, mit oder ohne paarige Wimpergrübchen. Germarien und Vitellarien getrenrit. 2 Familien mit 6 Gattungen.

5. Fam.: Monocelididae, mit 2 Geschlechtsöffnungen, mit oder ohne Bursa seminalis.

Gatt.: 66. Monocelis; 67. Myrmeciplana; 68. Archiloa; 69. Otomesostoma. 
6. Fam.: Otoplanidae, mit 1 Geschlechtsöffnung, ohne Bursa seminalis.

Gatt.: 70. Otoplana; 71. Bothriomolus.

C. Cyclocoela, Darm durch den Pharynx plicatus in einen vorderen und einen hinteren Ast zerlegt, die durch zwei seitliche Kommissuren verbunden werden. Ohne Statocyste, mit Wimpergrübchen, Geschlechtsöffnung einfach. 1 Familie mit 3 Gattungen.

7. Fam.: Bothrioplanidae.

Gatt.: 72. Bothrioplana; 73. Euporobothria.

Auf diese Übersicht lassen wir nun sogleich die zur Bestimmung der in Deutschland und seinen Nachbarländern vorkommenden Gattungen von Süßwasserrhabdocoeliden dienende Tabelle folgen. Wo die Gattungen nur eine Art besitzen, oder wo nur eine Art von ihnen erwähnenswert oder häufiger anzutreffen ist, wird in der Tabelle gleich deren Name genannt. Für die Gattungen, die mehrere gewöhnliche Spezies enthalten, sind dagegen besondere Artbestimmungsschlüssel ausgearbeitet, auf welche die in der Tabelle hinter den Genusnamen stehenden Seitenzahlen hinweisen. Die den Genusnamen vorangehenden eingeklammerten Zahlen entsprechen den Nummern der Gattungen in unserer systematischen Ubersicht, so daB also ihre Familienzugehörigkeit usw. ohne weiteres nachgeschlagen werden kann.

\section{Bestimmungstabelle der Gattungen (bzw. Arten)}

$\left\{\begin{array}{l}\text { Darm einheitlich (ohne oder mit Divertikeln) . . . } \\ \text { Darm durch den Pharynx in einen vorderen und einen } \\ \text { hinteren Abschnitt zerlegt, die durch } 2 \text { seitliche Kom- } \\ \text { missuren verbunden werden. }\end{array}\right.$

(72) Bothrioplana semperi (M. Braun) 
Vorderende mit einem muskulösen, in eine präformierte

2 Scheide eingeschlossenen Rüssel . . . . . . . . 3

Vorderende ohne einen solchen Rüssel . . . . . . 4

Das Hinterende enthält ein zum männlichen Kopulationsapparat gehöriges, scharf zugespitztes Chitinstilett von etwa Rüssellänge, das vorgestoßen und wieder zurück-

3 gezogen werden kann.

(55) Gyratrix hermaphroditus Ehrbg.

Kein derartiges Chitinstilett.

(53) Polycystis goettei Bresslau.

(Formen mehr oder minder durchscheinend, weißlich oder verschiedenartig gefärbt. Wenn infolge dunklen Pigments undurchsichtig, niemals $10 \mathrm{~mm}$ Länge erreichend.

4 Niemals mit Pharynx plicatus . . . . . . . .

Große (bis $15 \mathrm{~mm}$ ), undurchsichtige, dorsal, braunschwarz netzig pigmentierte Art mit Pharynx plicatus.

(61) Plagiostomum lemani (Forel und Du Plessis).

Gehirn mit einer Statocyste (nur 2 ziemlich seltene Arten) . . . . . . . . . . . . . . . . .

Keine Statocyste . . . . . . . . . . . . . .

Körper ein feines Fädchen, Vorderende mit einem durch eine Ringfurche abgesetzten Kopflappen, oft in ungeschlechtlicher Vermehrung.

6 (1) Catenula lemnae A. Dug.

Körperumriß blattförmig, Kopflappen fehlend, ohne ungeschlechtliche Vermehrung.

(69) Oto mesostoma auditivu m (Forel und Du Plessis).

(Pharynx ohne Pharyngealtasche ( $\mathrm{Ph}$. simplex), oft in un-

7 geschlechtlicher Fortpflanzung . Pharynx in einer Pharyngealtasche (Ph. bulbosus), ungeschlechtliche Fortpflanzung niemals vorkommend . 11

8 Hauptstamm des Exkretionsapparates unpaar, medio- 
2 seitliche, oft nur schwer wahrnehmbare Exkretionshauptstämme . . . . . . . . . . . . .

Vorderende ohne Rüssel.

(3) Stenostomum, s. S. 334.

9 Vorderende vor dem Munde einen -keulenförmigen Rüssel bildend.

(4) Rhyndhoscolex vejdovskyi Sekera.

Von der Ansatzstelle des Pharynx ein nach vorn sich erstreckender Darmblindsack, Hinterende verjüngt, Haut häufig mit Nesselkapseln. In ungeschlechtlichen Ketten bis zu 18 Zooiden.

(6) Microstomum, s. S. 334.

Ein präoraler Darmblindsack fehlt, ebenso Nesselkapseln; Hinterende $\mathrm{zu}$ einer Haftscheibe verbreitert, Fortpflanzung nur geschlechtlich.

(8) $M$ acrostomum, s. S. 335.

Mundöffnung am Vorderende des Körpers, mit ihr kombiniert die Offnung des mit einem Chitinstilett bewehrten männlichen Kopulationsapparates.

(10) Prorhynchus stagnalis M. Schultze.

Mundöffnung stets mehr oder weniger vom Vorderende entfernt

(Pharynx tonnenförmig ( $\mathrm{Ph}$. doliiformis), zur Körperlängsachse parallel oder nur wenig geneigt.

Pharynx rosettenförmig, ungefähr senkrecht zur Körperlängsachse stehend

(Pharynx am Vorderende des Darmes angegebracht und mit der Spitze nach vorn gerichtet; Mund im ersten Körperdrittel · · · · · · · · · · · ·

13 Pharynx von der Ventralfläche des Darms entspringend und mit der Spitze nach hinten gerichtet. Mund im letzten Körperdrittel.

(20) Opistomum pallidum O. Schm. 
(Geschlechtsöffnung im letzten Körperdrittel, die meist komplizierte Chitinbewaffnung des männlichen Kopulationsapparates außerhalb des Ductus ejaculatorius .

14 Geschlechtsöffnung vor der Körpermitte, meist dicht hinter dem Pharynx. Chitingebilde auf kleine Stacheln im D. ejaculatorius beschränkt.

(19) Phaenocora (Durostoma) unipunctata (Oerst.). Mit 2 nierenförmigen Augen. Penis ohne besondere Tasche für den Chitinapparat. Eier ungestielt. (15) Dalyellia s. S. 335.

2 Augen, deren Pigmentbecher sich aus je 2 nur durch eine feine (bisweilen fehlende) Brücke verbundenen Hälften zusammensetzen, so daß die Tiere bei schwacher Vergrößerung vieräugig erscheinen. Penis mit besond. Aussackung für den Chitinapparat: Eischale mit fadenförmigem Stiel.

(16) Castrella truncata (Abildg.).

Mündung der Exkretionskanäle hinter dem Pharynx in der Umgebung der Geschlechtsöffnung oder mit ihr

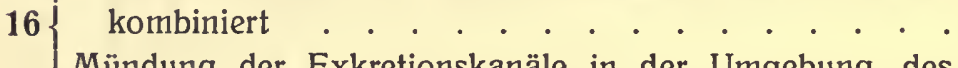

Mündung der Exkretionskanäle in der Umgebung des Mundes oder mit ihm kombiniert . . . . . .

(Die beiden Exkretionsendkanäle münden in das Genitalatrium. Vorderende des Körpers ein fernrohrartig einziehbarer Tastrüssel.

17 (40) Rhynchomesostoma rostratum (O. F. Müll.).

2 getrennte Exkretionsöffnungen auf der Bauchfläche in der Umgebung der Geschlechtsöffnung, Vorderende ohne Tastrüssel.

(34) Olisthanella (s. S. 336).

Geschlechtsöffnung im letzten Körperdrittel, Mund stets hinter der Körpermitte. Exkretionskanäle münden mehr oder minder nahe der Mundöffnung, aber doch von ihr getrennt. Durchweg augenlos . . . . . . 
(Geschlechtsöffnung im mittleren Körperdrittel, bisweilen mit der Mundöffnung kombiniert, die in der Regel vor

18 oder in, nur selten ein wenig hinter der Körpermitte gelegen ist. Exkretionskanäle öffnen sich in einem dem Munde aufgesetzten Becher. Mit oder ohne Augen .

Geschlechtsöffnung etwa in der Mitte zwischen Mund und Hinterende des Körpers . . . . . . . . .

Geschlechtsöffnung nahe der Schwanzspitze.

(36) Sphagnella lutheri Sekera.

Hoden vor der Geschlechtsöffnung.

(35) Typhloplanella bresslaui Sekera.

Hoden nach hinten von der Geschlechtsöffnung.

(38) Taborella hofsteni Sekera.

Hoden sackförmig, ventral von den Vitellarien. Männlicher Geschlechtsapparat oft mit Chitingebilden. Meist kleine Formen (nicht über 4,5 mm)

21 Hoden verschieden gestaltet, dorsal (bisweilen lateral) von den Vitellarien. Männlicher Geschlechtsapparat niemals mit Chitinbewaffnung. Kleine bis große $(15 \mathrm{~mm})$ Forme

Mit 2 Augen oder blind

22 Mit 4 Augen.

(41) Tetracelis marmorosa (O. F. Müll.).

(Der im Penisbulbus eingeschlossene Ductus ejaculatorius mit kleinen Chitinstacheln. 2 Augen.

(39) Strongylostoma radiatum (O. F. Müll.). Die meist vorhandene Chitinbewaffnung nie im Ductus ejaculatorius, sondern außerhalb des Penisbulbus. Mit einer Ausnahme (Castrada fuhrmanni) ohne Augen .

(Ohne Bursa copulatrix und Atrium copulatorium.

(42) Typhloplana viridata (Abildg.).

24 Mit Bursa copulatrix und Atrium copulatorium, die in verschiedener Weise bestachelt sein können

(44) Castrada s. S. 336. 
Ventraler Blindsack fehlt.

(46) Bothromesostoma, s. S. 338.

(45) Mesostoma, s. S. 337.

\section{Artbestimmungsschlüssel}

Gattung Stenostomum

Ohne deutlich abgesetzten Kopflappen. Durch den rein weißen Körper schimmert der Darm meist bräunlich hindurch. Lichtbrechende Organe schüsselförmig, je aus einigen 20 Kügelchen zusanımengesetzt.

St. leucops (A. Dugès).

Vorderende durch eine leichte Einschnürung in der Mundregion als Kopflappen abgesetzt. Körper durchsichtig, bisweilen mit einem Stich ins Bläuliche oder Grünliche. Lichtbrechende Organe kugelig, nicht aus mehreren Komponenten zusammengesetzt.

St. unicolor O. Schm.

Die erstere Art ist weitaus hăufiger als die zweite.

\section{Gattung Microstomum}

Am Hinterende ein mit Haftpapillen besetzter Schwanzanhang, präoraler Darmblindsack kurz. Länge der Solitärtiere $0,6-1,8 \mathrm{~mm}$, der aus maximal 18 Zooiden bestehenden Ketten bis $8 \mathrm{~mm}$.

$$
\text { M. lineare (Müll.). }
$$

Hinterende ohne Schwanzanhang und Haftpapillen, präoraler Darmblindsack nahe bis zur vorderen Körperspitze reichend. Länge der Solitärtiere $2-4 \mathrm{~mm}$, der Ketten bis $15 \mathrm{~mm}$.

M. giganteum Hallez.

Die letztere Art scheint nach den Angaben der Autoren seltener zu sein als die erstere. Sie tritt jedoch in Straßburg zu Zeiten an denselben Stellen wie jene ungemein häufig auf. 


\section{Gattung Macrostomum}

Das trichterförmige Chitinrohr des Penis einfach hakenförmig gekrümmt, Samen- und Kornsekretblase nur durch einen engen Kanal in Verbindung.

$M$. appendiculatum O.Fabr.(M. hystrix Oerst.).

Chitinrohr des Penis schwach S-förmig gekrümmt, Samenund Kornsekretblase breit miteinander verwadisen.

$M$. viride E. Bened.

Beide Arten sind oft miteinander verwechselt worden.

\section{Gattung Dalyellia (Vortex)}

(Große (bis $5 \mathrm{~mm}$ ), durch Zoodhlorellen grüne Arten, die bis 40 und mehr Eier enthalten können . . . . . 2

1 Kleine (nicht über $2 \mathrm{~mm}$ ) Arten, nie grün durch Zoochlorellen, nie mehr als $1 \mathrm{Ei}$ enthaltend . . . . . 3

Chitinapparat des Penis aus 2 durch einen Querbalken verbundenen Hauptstäben bestehend, die am Medialrande ihrer distalen Hälfte 13-14 kurze, leicht gekrümmte Stacheln tragen.

2 D. viridis (G. Shaw) bunden, jeder distal in eine große Anzahl gegliederler Endäste zerfallend, die an jedem Gliede abermals einen Stachel tragen.

D. scoparia (O. Schm.).

Chitinapparat besteht aus mehreren, kreisförmig angeordneten, isolierten oder quer miteinander verbundenen Stacheln .

Chitinapparat besteht aus 2 Hauptstäben, deren distale Endäste wieder bestachelt sein können

$4\left\{\begin{array}{c}\text { Chitinapparat aus } 4-6 \text { isolierten Stadieln. } \\ \text { D. cuspidata (O. Schm.). }\end{array}\right.$

49 Stacheln durch einen queren Halbring verbunden.

D. diadema Hofst. 


\section{$-336$}

(Beide Endäste tragen an ihrer inneren Seite 10-12 Stacheln . . . . . . . . . . . . . . . . . 6 Der eine Endast mit 5-10 Stacheln (davon der erste sehr lang), der andere unbestachelt. Zwischen beiden Endästen ein medianes, rinnenförmiges Chitinstück.
D. armigera (O. Schm.).

$6\left\{\begin{array}{l}\begin{array}{l}\text { Die Stacheln der Endäste alle ungefähr gleichlang. } \\ \text { D. hallezii (v. Graff). }\end{array} \\ \text { Je ein Stachel der Endäste wesentlich länger als die anderen. } \\ \text { D. picta (O. Schm.). }\end{array}\right.$

In dieser Tabelle sind diejenigen Arten aufgenommen, die in der Umgebung von Straßburg häufiger beobachtet wurden. Den Dalyellia-Arten im Aussehen sehr ähnlich ist die im Frühjahr oft massenhaft auftretende Castrella truncata.

\section{Gattung Olisthanella}

Pigmentbecher der Augen glattrandig. Begattungstasche ohne Nebenblasen. Größere Art $(1-3 \mathrm{~mm})$.

O. truncula (O. Schm.).

Augenpigment verästelt. Begattungstasche mit kleinen, ebenfalls Sperma enthaltenden Nebenblasen, kleinere Art $(0,8-2 \mathrm{~mm})$.

O. splendida (v. Graff).

Beide Arten sind noch nicht ausreichend studiert. Die, wie es scheint, bisher nicht sehr oft beobachtete O. splendida tritt bei Straßburg im Sommer zeitweise sehr häufig auf.

\section{Gattung Castrada}

(Das Atrium copulatorium zeigt außer der Bursa copulatrix keine blindsadkartigen Ausstülpungen . . . . . . 2

1 Atrium copulatorium mit einem oder zwei Blindsäcken . . . . . . . . . . . . . . 3 
(Ohne Zoochlorellen, Stiel der Bursa copulatrix im proximalen Teil ringförmig bestachelt. Große Art (bis 4,5 mm).
C. lanceola (M. Braun).

Durch Zoochlorellen grün, Bursa copulatrix mit erweiterter, Spermatophoren enthaltender Endblase und muskulösem, bestacheltem Stiel. Ductus ejaculatorius in 2 Aste gespalten, kleine Art (bis 1,5 mm).

C. hofmanni (M. Braun).

Atrium copulatorium mit einem dorsalen, großen, bestachelten Blindsack, durch Zoochlorellen grün.

C. viridis Volz.

2 dorsale Blindsäcke

(Durch Zoochlorellen grün, Blindsäcke, Bursa copulatrix und Atrium copulatorium fein bestachelt.

C. intermedia (Volz).

Ohne Zoochlorellen, in den sehr kleinen Blindsäcken des Atrium copulatorium auBer feinen Stacheln je ein großer Chitinhaken. $\quad$ C. armata (Fuhrmann).

Die Verbreitung der Castrada-Arten in Deutschland ist noch ganz unzureichend erforscht. Wahrscheinlich sind in unsern Gewässern bedeutend mehr Spezies, als in der vorstehenden Ubersicht genannt, häufig anzutreffen.

\section{Gattung Mesostoma}

Seitenkanten des Körpers in vier flossenartige Lamellen

Seitenflossen fehlen

(Mund und Geschlechtsöffnung durch einen Zwischenraum getrennt.

$M$. tetragonum (O. F. Müll.).

2 Mund und Geschlechtsöffnung miteinander kombiniert, Flossenkanten schwächer entwickelt.

M. craci (O. Schm.). 


\section{$-338$}

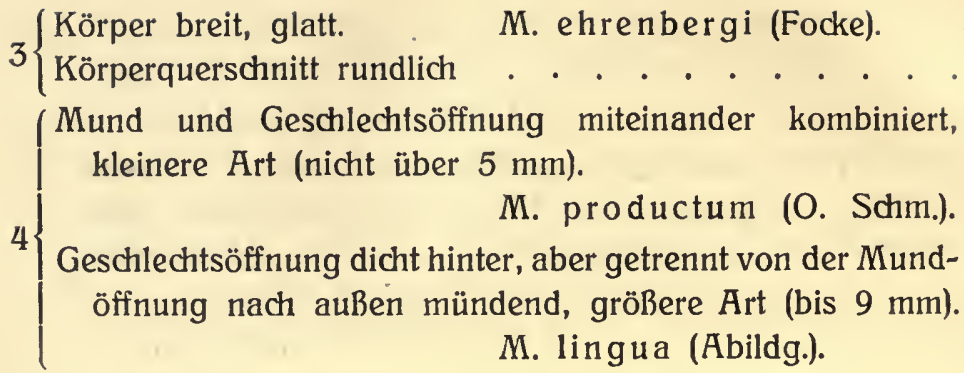

\section{Gattung Bothromesostoma}

Epithel enthält dunkle Pigmentkörner, Tiere daher kaffecbraun bis blauschwarz. B. personatum O. Schm.

Das Epithelialpigment fehlt, die Tiere nur durch den durchschimmernden Darminhalt gefärbt

B. essenii M. Braun. 


\section{Entwicklung und Stammesgeschichte der Turbellarien}

\section{Entwicklung}

\section{Geschlechtsprodukte}

Nachdem bereits in den anatomischen

Kapiteln (S. 53, 57 u. 236, 239) der Bau der Gonaden, in den biologischen (S. 101 u. 281 f.) die Eikapselbildung und -Ablage besprochen wurde, sollen hier noch kurz die Vorgänge Erwähnung finden, die sich vor der Befruchtung an den Geschlechtsprodukten abspielen.

Zwei durch ein Intervall getrennte Teilungen lassen aus je einer Samenmutterzelle (Spermatogonie) vier Samentochterzellen (Spermatozyten) entstehen, die sich durch Einschmelzung gewisser Abschnitte und Vergrößerung anderer zu den Samenfäden (Spermatozoen oder Spermien) umwandeln. Die Gestalt der Spermien wechselt in ziemlich weiten Grenzen; doch zeigen sie meist die Form dünner Fäden. Der Kern ist sehr lang gestreckt und verläuft meist durch den größten Teil des Samenfadens. Feine Geißeln bewirken die Fortbewegung.

Ebenfalls zwei Teilungen bewirken die Umwandlung der Eibildungszellen (Oogonien) zu den reifen Eiern. Hierbei wird - und das gleiche gilt auch für die Teilungen, welche die Samentochterzellen liefern - ein Teil der Kernsubstanz nach außen geschafft. Es geschieht dies deshalb, weil später bei der Befruchtung Samenfaden und Eizelle und vor allem ihre Kerne miteinander $\mathrm{zu}$ einer Einheit verschmelzen. Soll nun die Kernsubstanz und mit ihr die Masse der an sie gebundenen erblichen Anlagen - 
im befruchteten Ei und den daraus hervorgehenden Zellen des Nachkommentiers nicht größer sein wie bei der Mutter, so muß vor der Vereinigung der beiden Geschlechtszellen eine Halbierung der Erbmasse, eine Ausscheidung von Kernsubstanz erfolgen. Diese wird durch die beiden "Reduktions- oder Reifeteilungen" herbeigeführt. Der Vorgang spielt sich aber bei der Eireifung ganz anders ab als bei der Samenreifung. Durch jede der beiden Teilungen wird nämlich hier nur ein ganz kleines Gebilde, ein sog. Richtungskörperchen, abgeschnürt, das nachher zugrunde geht. Aus jeder Oogonie entsteht daher schließlich nur ein einziges $\mathrm{Ei}$.

Während bei den meisten Tieren dem Hinzutritt des Samens zum Ei die Reifung des letzteren vorausgeht, findet sie bei den Turbellarien in der Regel erst nach der Besamung statt. Fast überall, auch bei den Formen, die ihre Eier alsbald nach außen ablegen, spielt sich die Eireifung innerhalb des mütterlichen Körpers ab. Nur bei den Polycladen werden bisweilen die noch unreifen Eier zusammen mit einem oder zwei Spermien in einer Kapsel eingeschlossen nach außen abgegeben. Nach der Eireifung erfolgt die Vereinigung der reduzierten Kerne von $\mathrm{Ei}$ - und Samenzelle, die eigentliche Befruchtung, die also bei den meisten Strudelwürmern von der Besamung zeitlich getrennt ist.

Entwicklung der Tricladen

Die Eikapsel der Tricladen umschließt zur Zeit der Ablage mehrere (bis gegen 40) Ei- oder Keimzellen, von der Gestalt eines Rotationsellipsoides oder einer Kugel sowie Hunderte von Dotterzellen. Auf Schnitten durch die Kapseln werden daher späterhin mehrere Embryonen nebeneinander sichtbar. Die Keimzellen sind nackt und bis etwa 18 Stunden nach der Ablage noch ungeteilt. Die Zeit, während welcher die Würmer ihre Kapseln im Leib behalten, wechselt jedoch nicht unbedeutend, so daß die Ablage ein zweifelhaftes Kriterium für das Alter der Kapseln abgibt.

Die Entwicklung verläuft bei den Tricladen in sehr eigentümlicher Weise. Zunächst teilt sich die Keimzelle „äqual“ in 
eine Anzahl ungefähr gleichgroßer Teilzellen oder Blastomeren, ein bestimmt festgelegter Rhythmus der einzelnen Teilungsakte ist aber dabei nicht $\mathrm{zu}$ erkennen. Das ist darauf zurüdkführen, daß die Keimzellen alecithal sind, d. h. in ihrem Plasma keinen Dotter enthalten und daher von den umgebenden Dotterzellen auf osmotischem Wege ernährt werden müssen. Die Abhängigkeit der Blastomeren von diesen Nahrungsspendern stört einen regelmäßigen Ablauf der Teilungen, wie er für andere Tiergruppen typisch ist. Bei den Tricladen geht dies soweit, daß die Blastomeren nur kurze Zeit kettenartig miteinander zusammenhängen, dann aber sich trennen und in die Masse der Dotterzellen auseinander wandern, gleich als gingen sie, jede Teilzelle für sich, daselbst auf die Nahrungssuche. Die Dotterzellen zwischen den Blastomeren und in ihrer nächsten Umgebung schieben sich dabei immer dichter zusammen und zerfließen schließlich unter Aufgabe ihrer Zellgrenzen $z u$ einer einheitlichen Masse, einem sog. "Dottersyncytium".

In diesem Dotterbrei leben nun die einzelnen Zellen des Embryos für einige Zeit ziemilich selbständig. Dann aber sammeln sie sich wieder ungefähr in der Mitte desselben und schließen sich $z u$ einem rundlichen Zellhaufen zusammen. Aus diesem sog. "embryonalen Blastem " bilden sich darauf alle Organe, ohne daß man die Bildung einer sog. Gastrula und eine Sonderung von ${ }_{n}$ Keimblättern" beobachten könnte, die bei der Entwicklung der meisten andern Tiere eine so große Rolle spielen. Einzelne Blastomeren treten als Wanderzellen in das Dottersyncytium aus und bilden an dessen Peripherie ein feines Häutchen, das den ganzen Embryo umschließt und als provisorisches Ektoderm bezeichnet wird (Abb. $152 \mathrm{~A}$ ). Andere Wanderzellen scharen sich an einem Pol des Embryos zu einem kleinen rundlichen Komplex zusammen, der aus mehreren konzentrischen Zelllagen besteht. Während die mittlere der Schichten blasige oder faserige Struktur annimmt, tritt im Innern ein Lumen auf, das sich durch eine kleine Spalte im provisorischen Ektoderm nach außen öffnet (Abb. 153). Ungefähr gleichzeitig mit diesem Organ, das einen embryonalen Schlundrüssel (Embryonalpharynx) darstellt, ent- 
steht im Innern des Blastems ein kleiner mit dem Rüssellumen kommunizierender und von wenigen Zellen ausgekleideter Hohlraum, der provisorische Darm (Abb. $152 \mathrm{~A}$ ).

Der so gestaltete Embryo ändert nun seine Enährungsweise. Hatte er sich bisher darauf beschränkt, die in dem Syncytium enthaltene Dottermasse auszunützen, so beginnt er jetzt sich auch die das Syncytium umgebenden, noch nicht mit ihm verschmolzenen

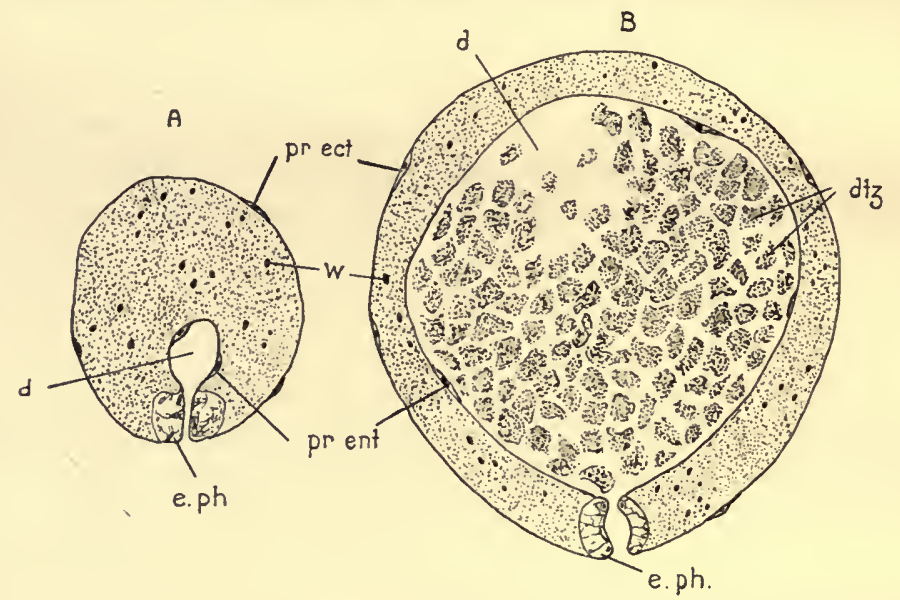

Abb. 152.

Medianschnitte durch $z$ wei Embryonen von Planarla gonocephala; $A$ vor, B wăhrend des Aufschludkens der Dotterzellen.

dtz Dotterzellen, e. ph Embryonalpharynx, pr ect provisorisches Ectoderm, pr ent provisorisches Entoderm, w Wanderzellen im Dottersyncytium.

Dotterzellen einzuverleiben. Es geschieht dies durch Schluckbewegungen des Embryonalpharynx, die große Mengen von Dotterzellen in den provisorischen Darm hinein befördern. Dieser wird dadurch gewaltig ausgedehnt und bewirkt seinerseits eine bedeutende Vergrößerung des Embryo, der zu einer ganz dünnwandigen Hohlkugel wird und große Dottermassen umschließt (Abb. 152 B).

Ist dieses Stadium erreicht, so beginnt der Embryo sich allmählich in den jungen, zum Ausschlüpfen reifen Wurm umzu- 
gestalten. Zunächst wird der jetzt funktionslos gewordene Embryonalpharynx zurückgebildet, und von ihm ganz unabhängig entsteht aus einer dichtbenachbarten Zellenanhäufung der definitive Schlundrüssel. Durch Hinzutritt von Wanderzellen bildet sich dann einerseits aus dem provisorischen Ektoderm die definitive Körperhaut, andrerseits aus dem provisorischen das definitive Darmepithel. Weiterhin gliedert sich der bisher einfache Hohlraum des embryo-

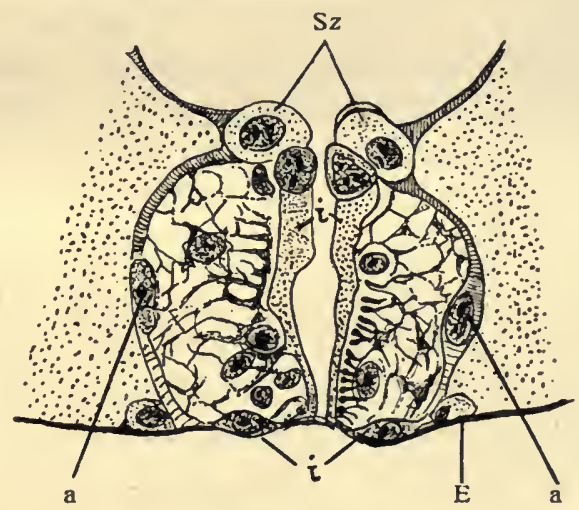

Abb. 153.

Embryonalpharynx (nach $M$ atthlesen).

(Längsschnitt) Sz sog. SchlieBzellen, a AuBenzellen, i Innenzellen (Lumenauskleidung), E provisorisches Ectoderm.

nalen Darms durch Einwachsen von Septen zum dreischenkligen Tricladendarm. Gleichzeitig wird der in ihm enthaltene Dotter ganz allmählich resorbiert. Dodı enthält auch der Darm der ausschlüpfenden Jungen noch reichlich Dotter. Aus dem Dottersyncytium mit seinen eingestreuten Wanderzellen wird das Parenchym, das zugleich den Ausgangspunkt für alle weiteren Organdifferenzierungen abgibt. Aus ihm entwickeln sich Nervensystem, Augen, Muskulatur und wahrscheinlich auch der Exkretionsapparat. Ferner entsteht aus dem Parenchym, wie wir bereits gesehen haben (S. 38), der Genitalapparat. Seine Bildung beginnt jedoch erst nach dem Ausschlüpfen der Jungen. Ebenso erhält erst nach diesem Zeitpunkt der Darm seine Divertikel, die sekundären und tertiären Verzweigungen (s. S. 42, Abb. 21). 
Die Embryonen sind beim Verlassen der Eikapseln den erwachsenen Planarien sehr ähnlich, jedoch gänzlich unpigmentiert und daher schneeweiß. Auch ist ihr Hinterende nur schwach entwickelt und der Rüssel liegt daher dem Schwanzende näher als bei den Erwachsenen. Dies hängt mit dem Fehlen des Kopulationsapparates zusammen.

Die Dauer der Embryonalentwicklung wechselt und ist von äußern Umständen, speziell von der Temperatur stark abhängig. Die Angaben, die in der Literatur hierüber zu finden sind, deuten auf eine beträchtliche Verschiedenheit bei den einzelnen Arten hin: vom Moment der Kapselablage bis zum Ausschlüpfen der Jungen können 10 Tage bis $1 \frac{1}{2}$ Monate verfließen.

Die Offnung der Kapseln erfolgt spontan; sie geschieht bei planaria torva durch Loslösung eines rundlichen, unregelmäßig konturierten Deckelchens. Bei den meisten andern bildet sich ein Längsriß, dessen Ränder sich einrollen. Die Jungen verlassen die Kapsel nicht gleichzeitig. Man findet bisweilen in bereits geöffneten Kapseln noch jüngere Embryonen.

Entwickiung der Rhabdocoeliden

Die Entwicklung der Rhabdocoeliden, besonders der Alloeocoelen klingt in manchen Punkten an die der Tricladen an, in anderen dagegen sind erhebliche Unterschiede vorhanden. Schon die Teilung der Keimzelle läßt dies erkennen. Die ersten Blastomeren sind nämlich bei den Rhabdocoeliden nicht gleichartig, sondern „inäqual“; es entstehen größere Teilzellen, sog. Macromeren und kleinere Micromeren. Dieser Unterschied verwischt sich aber im weiteren Verlauf der Teilungen, und schließlich findet man wie bei den Tricladen einen von Dotterzellen umgebenen rundlichen Haufen ungefähr gleichartiger Zellen, das embryonale Blastem.

Wie bei den Tricladen fehlt den ersten Teilungsvorgängen jeglicher Rhythmus, und auch hier ist den die Blastomeren umgebenden Dotterzellen die Verantwortung dafür zuzuschieben. Bei den Allöocoelen ist sogar $\mathbf{z u}$ beobachten, daß die Blastomeren 
zeitweise, wie bei den Tricladen, auseinander weichen (Plagiostomum girardi, Abb. 154).

Wesentlich verschieden ist dagegen die Art, wie der Embryo den Dotter aufnimmt. Weder ein die Dotterzellen schluckender Embryonalpharynx noch ein provisorisches Ektoderm noch ein provisorischer Darm werden bei den Rhabdocoeliden gebildet, sondern es treten, wenn die ersten Differenzierungsvorgänge im embryonalen Blastem beginnen, direkt die definitiven Organanlagen auf. Zunächst werden im Blastem 3 Zellenkomplexe sichtbar, von denen 2 die paarige Anlage des Gehirns darstellen, während die dritte den spätern Pharynx und den Genitalapparat liefert. Alsdann differenziert sich an der Bauchseite des Embryos die am meisten peripher gelegene Zellschicht $z u$ einem Epithel, das nunmehr als die Anlage der spätern Körperhaut den Dotter zu umwachsen beginnt und diesen damit in den Leibesbereich des zukünftigen Wurmes

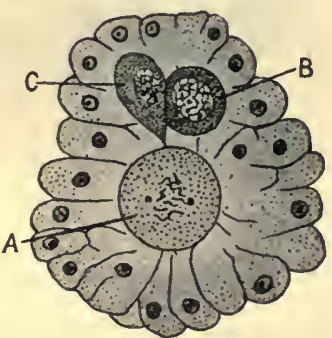

Abb. 154.

Schnitt durch ein Dreizellenstadium von Plagiostomum girardi. Die 3 Blastomeren (Macromer $A$ u. Micromeren B, C) rüdken innerhalb der sie umgebenden Dotterzellenmasse auseinander. einbezieht. Ganz zuletzt, nachdem sich vorher noch die beiden Hauptstämme des Exkretionssystems angelegt haben, entsteht der Darm, dadurch daß innerhalb der Dottermasse Spalträume auftreten und von bis dahin indifferent gebliebenen Zellen umwachsen werden. Der Rest der Zellen bildet das Parenchym des nunmehr zum Ausschlüpfen reifen Wurmes.

Während die Entwicklung im allgemeinen überall den hier geschilderten Verlauf nimmt, können sich im einzelnen gewisse Komplikationen und Abweichungen ergeben. So liefern die Dotterzellen bisweilen nicht nur das notwendige Nährmaterial zum Aufbau des Embryos, sondern noch eine ihn rings umschließende Zellhaut (Hüllenmembran der Subitaneier von Mesostoma ehrenbergi und der Eier von Paravortex cardii). Wie sehr das Vorhandensein einer größeren oder geringeren Dottermasse den 
Gang der Ontogenese beeinflußt, ergibt sich sehr deutlich daraus, daß zwischen der Enlwicklung der Subitaneier von Mes. ehren-

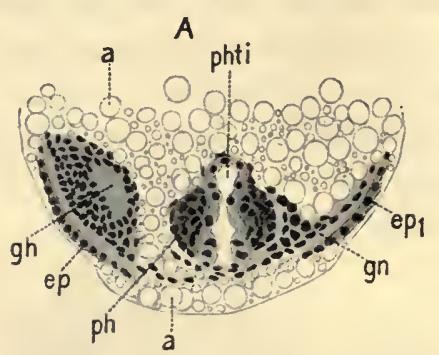

B

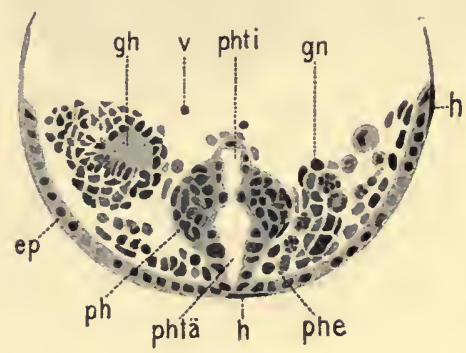

Abb. 155.

Sagittalschnitte durch zwei gleich weit entwidkelte Subitaneier (nur die ventrale Seite gezeidnet) von Bothromesostoma personatum ( $A)$ und Mesostoma ehrenbergi (B). An der Ventralseite von $A$ befindet sich noch Dottermasse (a); die Epidermis ist daher hier $z$ wischen $e p$ und $e p_{1}$ unterbrochen u. das Epithel des Pharynx (ph) folglich ohne Zusammenhang mit ihr entstanden. Das seiner Gestalt nad damit völlig ïbereinstimmende Pharyngealepithel (phe) von B ist dagegen aus einer Epidermiseinstïlpung hervorgegangen. ep Epidermis; gh Gehirn; gn Genitalanlage; h Hüllmembran; phtä Pharyngealtasche; phti Oesophagus; v Kern einer Dotterzelle.

da hier, wie wir schon wissen, einfache Eier gebildet werden. Leider ist über die Ontogenese dieser Formen noch gar nichts bergi und Bothromes. personatum charakteristische Unterschiede bestehen (Abb. 155). In den dotterarmen Subitaneiern von Mes. ehrenbergi wird $z$. B. die Auskleidung des Pharynx und der Schlundtasche von einer Einstülpung der Epidermis hergestellt; in den dotterreichen Subitaneiern von Bothromes. personatum - und ebenso verhalten sich die Dauereier von Mes. ehrenbergi - differenziert sich dagegen das Pharyngealepithel unabhängig von der Epidermis innerhalb des die Schlundanlage bildenden Zellhaufens. Man kann deutlich erkennen, daß hier zwischen Haut und Schlundanlage Dottermassen eingeschoben liegen, und damit eine epidermaleEntstehung des Schlundepithels verhindern.

Das bisher Gesagte gilt jedoch nur für diejenigen Rhabdocoeliden, die zusammengesetzte Eier produzieren, also für die Allöocoelen und die lecithophoren Rhabdocoelen. Bei den Hysterophora dagegen dürfte die Entwicklung aller Wahrscheinlichkeit nach wesentlich anders verlaufen, nach wesentlich anders verlaufen, 
bekannt, und zwar deshalb, weil sich ihrer Untersuchung große Schwierigkeiten entgegenstellen. Ein großer Teil der Hysterophoren vermehrt sich vorwiegend ungeschlechtlich, so daß geschlechtsreife Stadien nur schwer $z u$ erhalten sind, andere, wie die Macrostomiden und Prorhynchiden, die man häufiger in Geschlechtstätigkeit findet, haben die für den embryologischen Forscher äußerst unangenehme Gewohnheit, ungemein kleine Eier in spärlicher Zahl einzeln abzulegen. Und doch bedarf die Entwicklung dieser Formen dringend der Bearbeitung, weil sich daraus vielleicht die Antwort auf die bisher noch ungelöste Frage ergeben wird, wie die Rhabdocoeliden mit den übrigen Turbellarien, die sich durch einfache Eier vermehren, den Polycladen und Acoelen, zu verknüpfen sind.

\section{Entwidklung der Polycladen}

Bei den Polycladen werden die Eier gewöhnlich in Massen abgelegt, die durch ein gallertartiges Sekret zu oft ansehnlichen Ballen, Schnüren oder Platten vereinigt werden. Ihre Teilung verläuft äqual, wobei sich die Blastomeren in Kränzen anordnen, die durch horizontale Teilungsebenen voneinander getrennt werden. Die Zellenkränze verschieben sich in der Art, daß die Zellen jedes Kranzes in die Zwischenrãume des über und unter ihnen befindlichen Kranzes eingepaßt erscheinen (Spiraltypus der Teilung).

Bei der Teilung zerfällt das Ei zunächst in 4 Zellen (primäre Blastomeren). Diese liefern nacheinander durch drei aufeinanderfolgende Teilungen je 4 kleine Blastomeren (Micro- oder Ektomeren), aus denen die Wimperhaut des zukünftigen Wurmes hervorgeht. Aus Abkömmlingen des ersten Micromerenquartetts entwickelt sich außerdem das Zentralnervensystem, aus solchen des zweiten ein Teil des Parenchyms. Nach Abspaltung des dritten Micromerenkranzes schnüren die übrig gebliebenen Macromeren durch einen vierten Teilungsschritt ein neues Quartett kleiner Zellen (Entomeren) ab, die den Rest des Parenchyms und hauptsächlich die Auskleidung des Darms liefern. Letzterer entsteht 
zunächst als eine solide Zellenmasse, ohne daß, wie sonst zumeist im Tierreich, ein sog. Urdarm gebildet wird. Erst sekundär tritt zwischen den Zellen der Darmanlage eine spaltförmige Lichtung auf, die sich allmählich erweitert, bewimpert und durch Vorwuchern von Parenchymsepten verzweigte Gestalt annimmt. Inzwischen hat sich der Embryo gestreckt, abgeplattet und ist nun reif, aus der Eihülle auszuschlüpfen. Bei manchen Formen verwandelt er sich direkt in den jungen Wurm, bei andern bildet er vorher eine Anzahl Wimperlappen aus und schwimmt mit ihrer Hilfe als sog. Müllersche (mit 8 Lappen) oder Goettesche Larve (mit nur 4 Lappen) einige Zeit frei umher.

\section{Entwicklung der Acoelen}

Die Eier der Acoelen werden zu mehrereren gleichzeitig abgelegt und, obwohl jedes seine eigene Eihaut besitzt, noch durch eine zarte, durchsichtige Schleimhülle in einer gemeinsamen Eikapsel vereinigt. Ihr Teilungsrhythmus stimmt im großen und ganzen mit dem der

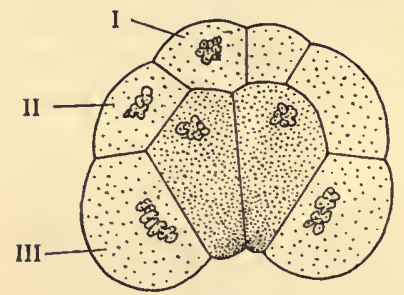

Abb. 156.

Medianschnitt durch eine Gastrula von Convoluta roscoffensis. I, II, IIl Blastomeren der drei ersten Ektomerenduette, dunkler punkliert die Macromeren. Polycladen überein, mit dem einzigen, sehr merkwürdigen Unterschiede, daß das $\mathrm{Ei}$ zuerst nicht in vier, sondern nur in zwei primäre Blastomeren zerfällt und daß infolgedessen statt Quartetten nur Duette von Micromeren gebildet werden (Abb. 156). Das äuBere Bild der Teilung wird natürlich dadurch wesentlich anders. Ein Urdarm wird ebensowenig wie bei den Polycladen gebildet, und da auch späterhin alle Entomeren dauernd flächenhaft aneinander grenzen, kommt es hier niemals zur Entwicklung eines Darmlumens. Die ganze Entwicklung geht äußerst rasch vor sich; schon ca. 24 Stunden nach der Eiablage kann der junge Wurm die Eihülle verlassen. Das kommt daher, weil die Eier sehr dotterarm sind. Etwas längere Zeit (5-6 Tage) nimmt die Polycladenentwicklung in Anspruch; die Eier enthalten hier aber auch mehr Dotter. 


\section{Stammesgeschichte}

Während sonst die Entwicklungsgeschichte häufig zum Verständnis der Stammesgeschichte führt, gibt sie uns bei den Turbellarien nur neue Rätsel auf. Auch die vergleichende Anatomie läßt uns an vielen Punkten im Stiche. Es wäre daher vielleicht das Richtigste, wenn unser Buch diese heiklen und strittigen Fragen überhaupt nicht anschnitte. Immerhin nehmen aber die Turbellarien im System als niederste Würmergruppe eine so prägnante und wichtige Stellung ein, daß wir doch kurz von den wichtigsten Theorien ihrer Abstammung sprechen müssen.

\section{Hbstammung der Turbellarien}

Schon über die Frage, welche Gruppe der Turbellarien als die primitivste aufzufassen sei, gehen die Ansichten weit auseinander. Eine Anzahl von Zoologen (unter Führung von v. Graff) betrachtet die Acoelen als ursprünglichste Formen und sucht ihre Vorfahren unter niedrigorganisierten Geschöpfen, deren Bau etwa dem der sog. "Planula"larven vieler Nesseltiere ähnlich gewesen sein dürfte. Andere (unter Führung von Lang) erblicken dagegen die Stammformen der Turbellarien in den Polycladen und suchen deren Anschluß an die Coelenteraten nicht bei den primitiven, sondern bei den am meisten spezialisierten Vertretern dieser Gruppe, den Ctenophoren oder Rippenquallen. Sie stützen sich dabei vorwiegend auf morphologische und biologische Verhältnisse, während für die Anhänger der ersteren Auffassung hauptsächlich entwicklungsgeschichtliche Gesichtspunkte in Betracht kommen.

Bei der Ableitung der Polycladen von den Ctenophoren wird in erster Linie auf gewisse kriechende oder seßhaft gewordene Rippenquallen aus den Gattungen Ctenoplana, Coeloplana und $\mathrm{Tjalfiella} \mathrm{hingewiesen,} \mathrm{die} \mathrm{mancherlei} \mathrm{Ahnlichkeit} \mathrm{mit} \mathrm{den}$ Turbellarien zeigen. Während ihre allgemeine Organisation die Tiere als echte Ctenophoren kennzeichnet, gleichen sie in ihrer plattgedrückten Gestalt und in ihrer an den Boden gebundenen Lebensweise den Polycladen. Dazu kommt die allgemeine Be- 
wimperung des Körpers, der Besitz einer Basalmembran und einer Hautmuskulatur, die bei den übrigen Ctenophoren nur angedeutet ist. Andere Übereinstimmungen, die teils weniger bedeutungsvoll, teils etwas problematisch sind, wollen wir hier bei Seite lassen.

Wie stellen wir uns hierzu?

Von den Anhängern der Langschen Theorie wird selbst zugegeben, daß die größere Hälfte der übereinstimmenden Eigenschaften auf Rechnung der kriechenden (bzw. sessilen) Lebensweise $\mathrm{zu}$ setzen ist. Es ist eine sehr häufig $\mathrm{zu}$ beobachtende Erscheinung, daß Tiere von ähnlicher Lebensweise und besonders von gleicher Lokomotion in ihrem Bau zahlreiche gleichartige Züge aufweisen, auch wenn sie verwandtschaftlich nichts miteinander zu tun haben. Dies gilt z. B. für die Fische und Walfische, oder für den Maulwurf unserer Gegenden (Talpa europaea) und den Beutelmaulwurf Australiens (Notoryctes typhlops). Besonders die beiden letzteren Formen zeigen im Zusammenhang mit ihrer grabenden Lebensweise eine geradezu überraschende Ahnlichkeit, obwohl sie sich unabhängig voneinander aus ganz verschiedenen Abteilungen des Säugetierstammes herausentwickelt haben. Gerade bei ihnen kann kein $Z$ weifel darüber bestehen, daß nicht Verwandtschaft (Homologie), sondern Konvergenz (Analogie), wie man diese Erscheinung nennt, vorliegt.

Die zahlreichen Ahnlichkeiten in der Organisation jener Ctenophorengattungen und der Polycladen bilden also an sich noch keinen zwingenden Beweis für ihre Verwandtschaft. Es kann sich vielmehr auch um Konvergenz infolge der ähnlichen Lebensweise handeln, und es fragt sich nun, welche von beiden Deutungen die richtige ist.

Schon Lang hatte darauf hingewiesen, daß das letzte Wort in dieser Frage die Entwicklungsgeschichte zu sprechen haben werde. Bei konvergenten Formen pflegt sich nämlich die Ahnlichkeit in der Organisation erst sekundär in den Endstadien der Ontogenese einzustellen, während in den Anfangsstadien deutliche Verschiedenheit herrscht. Ein schönes Beispiel hierfür bilden die Augen der Tintenfische und Wirbeltiere, deren erstaunliche Übereinstimmung 
bei den erwachsenen Tieren ebenso wohlbekannt ist, wie die total verschiedenen Verhältnisse, unter denen sie sich entwickeln. Zur Annahme einer Verwandtschaft ist dagegen nötig, daß zum mindesten der Ausgangspunkt der Formbildung hier und dort identisch ist. Die Ubereinstimmung braucht dabei nicht einmal dauernd erhalten zu bleiben, wenn sie nur wenigstens zu Beginn der Entwicklung vorhanden war. So bildet z. B. die dem Cilienkleid der Turbellarien homologe Bewimperung der als Miracidien bezeichneten Larven der Saugwürmer eins der wichtigsten Kriterien für die Verwandtschaft der Trematoden mit den Strudelwürmern, trotzdem sie in der Entwicklung rasch verloren geht und bei den erwachsenen Saugwürmern völlig fehlt.

Konnte man nun bis vor kurzem, solange über die Entwicklung jener bodenbewohnenden Ctenophorenarten nichts bekannt war, vom Standpunkte der Langschen Theorie aus hoffen, daß der Verlauf ihrer Ontogenese Züge enthalte, an die sich die Entwicklung der Polycladen werde anknüpfen lassen, so hat sich dies jetzt als trügerisch erwiesen. In jüngster Zeit erschienene Mitteilungen über die Entwicklung von Tjalfiella haben nämlich gezeigt, daß aus dem $\mathrm{Ei}$ dieser Form zunächst eine typische kleine Rippenqualle entsteht, die ihre Polycladenähnlichkeit erst sekundär erhält, wenn sie zum sessilen Leben übergeht. Bei den Polycladen finden sich dagegen während der Entwicklung keine Anklänge an ein Ctenophorenstadium, alle für sie charakteristischen Merkmale entstehen vielmehr ganz direkt. Die Ubereinstimmung von Tjalfiella mit den Polycladen - und ebenso wohl auch die von Coelo - und Ctenoplana - würde danach also auf Konvergenz beruhen, ${ }^{1}$ ) für die, wie wir eben sahen, gerade

1) Wenn auch in diesem Buch kein Platz für wissenschaftliche Polemik ist, so darf hier doch nicht unerwähnt bleiben, daB Mortensen, der Entdedker von Tjalfiella und ihrer Entwidklung, auf Grund seiner Beobachtungen den direkten Beweis für die Abstammung der Polycladen von den Ctenophoren erbracht $z u$ haben glaubt. Diese der hier vorgetragenen diametral entgegengesetzte Anschauung beruht darauf, daB Mortensen sein Urteil vornehmlich auf die von ihm sorgfältig studierten Ahnlichkeiten der erwachsenen Tjalfiellen mit den Polycladen stüłzt, die 
die sekundäre Herausbildung einer gewissen Ahnlichkeit der Form in den Endstadien bei prinzipiell verschiedenen Ausgangspunkten charakteristisch ist.

Wir prüfen nun die Gegenhypothese, die in den Acoelen die niedersten Turbellarien erblickt. Wenn man sich diesem Gedanken bisher meist verschlossen hat, so liegt das daran, daß man sich einer weitverbreiteten Anschauung (Haeckels Gastraeatheorie) zufolge die Stammform der vielzelligen Tiere gewöhnlich in Gestalt eines doppelwandigen Bechers vorstellte, in dem der sog. Urdarm den Hohlraum bildete. Bei der Darmlosigkeit der Acoelen müßte dagegen angenommen werden, daß ihre Ahnen einen solchen hohlen Urdarm nicht besaßen. Das hat gewiß etwas Befremdendes. Indessen veranschaulichen, von den parasitischen Mesozoen (Dicyemiden und Orthonectiden) ganz abgesehen, die schon mehrfach genannten Planulalarven mancher Nesseltiere solche Geschöpfe, denen (wenigstens in der ersten Zeit ihres Larvenlebens) eine Darmhöhle fehlt. Von solchen Formen könnte man theoretisch die Acoelen ableiten. Auch anatomische Merkmale sprechen für eine niedere Stellung der Acoelen in der Reihe der Turbellarien; denn es fehlt ihnen nicht nur der Darm, sondern auch das Exkretionssystem; am Genitalapparat sind eigene Kanäle zur Ausleitung der Geschlechtsprodukte meist noch nicht entwickelt; der Schlundrüssel ist überall ein Pharynx simplex, besonders primitiv gebaut ist ferner das Parenchym vieler Arten und endlich ihr Nervensystem. Alles dies liefert Belege dafür, die Acoelen als die den Turbellarienahnen nächststehende Gruppe anzusehen.

\section{Verwandtschaftsbeziehungen $z$ wischen den einzelnen Unter- ordnungen der Turbellarien}

worten, ohne daß zugleich auch die Frage nach den Verwandt-

Die Frage nach der Abstammung der Turbellarien läßt sich indessen nicht völlig beant- entwicklungsgeschichtlichen Momente, die für uns den Husschlag geben, dagegen stark zurüdktreten' läBt. Einen Vergleich der Müllerschen Polycladenlarven mit den jungen $\mathrm{Tjalfiellen}$ und ihre Deutung als Ctenophorenstadium halten wir für ausgeschlossen. 
schaftsbeziehungen der einzelnen Unterordnungen mit in Betracht gezogen wird. Denn je nachdem, ob man von den Acoelen oder von den Polycladen ausgeht, ergeben sich ganz verschiedene Möglichkeiten, den Stammbaum der 4 Unterordnungen aufzustellen, und es bleibt $\mathrm{zu}$ untersuchen, ob überhaupt eine dieser Möglichkeiten berechtigt ist.

Die Anhänger der Langschen Theorie nehmen gewöhnlich an, daß die Reihe: Polycladen-Tricladen-RhabdocoelidenAcoelen den Verlauf der Stammesgeschichte veranschauliche, und sie stellen sich dabei zugleich vor, daß entsprechend diesen 4 aufeinanderfolgenden Stadien eine Rückbildung des Darmes stattgefunden habe; aus dem verzweigten Darm der Polcyladen und Tricladen sei zunächst der einfache Stabdarm der Rhabdocoeliden hervorgegangen, und der Verlust des Lumens habe dann von hier aus den darmlosen Zustand bei den Acoelen herbeigeführt. Gegen diese Anschauung spricht nun aber zunächst die Entwicklungsgeschichte. Am Anfang und am Ende dieser Reihe stehen rein marine Formen mit einfachen Eiern, deren Teilung auffallend übereinstimmenden. Rhythmus zeigt, - und zwischen diesen sollen Gruppen vermitteln, die in großer Artenzahl zum Süßwasser- und Landleben übergegangen sind, sich durch zusammengesetzte Eier vermehren und einen Entwicklungsmodus zeigen, der von dem der Polycladen und Acoelen prinzipiell verschieden ist. Dazu kommt, daß man die Tricladen mit ihrer stark spezialisierten Ontogenese allenfalls von den Rhabdocoeliden ableiten kann, niemals aber umgekehrt. Ein weiteres Argument ist physiologischer Natur; es ist nicht einzusehen, wieso bei freilebenden Formen eine so hochgradige Rückbildung des Darms stattgefunden haben kann, wie angenommen werden muB, um bei den Acoelen das vollständige Fehlen dieses Organs zu erklären. Wären die Acoelen Parasiten wie die Bandwürmer oder wie Fecampia unter den Rhabdocoeliden, so wäre das Schwinden des Darms vielleicht verständlich; statt dessen leben sie aber frei im Meer als äußerst gefräßige Räuber. Außerdem ist sehr bezeichnend, daß die im erwachsenen Zustande darmlose 
Fecampia in der Jugend einen Darm besitzt, während er den Acoelen primär fehlt.

Es erscheint somit ganz aussichtslos, die Acoelen von den übrigen Gruppen abzuleiten und den Stammbaum in der oben angegebenen Weise zu konstruieren. Nehmen wir aber umgekehrt die Acoelen als Ausgangspunkt an, so ergeben sich bei dem Versuch, die übrigen Gruppen an sie anzuschließen, gleichfalls Schwierigkeiten, die zurzeit nicht überwunden werden können. Allerdings erscheint die Reihe hysterophore - lecithophore Rhabdocoelen - Allöocoelen - Tricladen durchaus natürlich, sowohl aus entwicklungsgeschichtlichen, wie aus anatomischen Gründen. In dieser Reihe vollzieht sich die Trennung der Ovarien in Germarien und Vitellarien, sowie die Umbildung des Pharynx simplex zu einem Pharynx compositus; zahlreich sind ferner die Merkmale, hinsichtlich deren sich die Allöocoelen als verbindendes Glied zwischen die Rhabdocoelen und Tricladen einschieben; endlich sei noch auf die schon früher erwähnte Tatsache aufmerksam gemacht, daß der Stabdarm von Mesostoma ehrenbergi durch reichliche Fütterung zur Divertikelbildung $z u$ veranlassen ist - was eine Möglichkeit andeutet, wie etwa aus einem einfachen ein verzweigter Darm entstanden sein könnte. Wie aber an diese Reihe die Acoelen und Polycladen anzuschließen sind, ist einstweilen nicht zu sagen. Der Gruppierungsmöglichkeiten sind mehrere; wir wollen aber, da es sich um reine Hypothesen handelt, die in der Literatur noch lange nicht so gründlich diskutiert worden sind wie die Langsche Theorie, davon absehen, sie hier $\mathrm{zu}$ besprechen. Wurde doch schon oben betont, daß es zurzeit noch an der wichtigsten Grundlage für ihre ersprießliche Betrachtung fehlt, an der Kenntnis der Entwicklung der hysterophoren Rhabdocoelen. Die Ontogenese dieser Formen mit ihren einfachen Eiern wird uns möglicherweise den Fingerzeig geben, wie die eine oder beide andern Gruppen mit ihr zusammenhängen und wie demgemäß der Stammbaum der Turbellarien $z u$ konstruieren ist. 


\section{Literaturverzeichnis}

Es werden nur die widitigsten Arbeiten, speziell zusammenfassende Werke und geschichtllch interessante Publikationen angeführt. $\mathrm{Da}$ für die Süßwassertricladen eine zusammenfassende Bearbeitung fehlt, wird hier das Literaturverzeichnis etwas ausfuhrlicher. Im übrigen sei anf v. Graff "Turbellaria" in: Dr. H. G. Bronns Klassen und Ordnungen des Tierreichs IV, Vermes Ic hingewiesen.

I. Arbeiten allgemeineren Inhaltes, die teils mehrere Unterordnungen, teils in diesem Buch nur nebenbei behandelte Gruppen (Acoela, Polycladida, Tricladida maricola und Tricladida terricola) betreffen

Baer, C. E. v., Beiträge zur Kenntnis der niederen Tiere Vİ. Uber Planarien. Nova Acta Acad. Caes. Leop. Car. Naturae Curios. Vol. XIII, 2, Bonn 1827. p. $690-730$.

Böhmig, L., Tricladienstudien I. Tricladida maricola. Zeitschr. f. wiss. Zool. Bd. LXXXI. 1906.

Dugès, Ant., Recherches sur l'organisation et les mœurs des Planariées. Annales des Sc. naturelles. Paris 1828. 1. sér., tom. XV, p. 139-182.

Ehrenberg, Chr. G. in: Hemprich und Ehrenberg, Symbolae physicae. Animalia evertebrata exclusis insectis recensuit Dr. C. G. Ehrenberg. Series prima cum tabularum decade prima. Berolini 1831.

Fabricius, O., Fortsaettelse af Nye Zoologiske Bidrag VI. Nogle lidet bekjendte og til deels nye Fladrome (Planariae) 1820. Kong. Danske Vid. Selsk. naturvid. og mathem. Abhandlingar II. Deel. Kjöbenhavn 1826.

Fuhrmann, O., Die Turbellarien der Umgebung von Basel. Revue Suisse de Zoologie. Tom. Il. 1894.

Graff, L. v., Die Organisation der Turbellaria Acoela. Mit einem Anhange über den Bau und die Bedeutung der Chlorophyllzellen von Convoluta Roscoffensis, von G. Haberlandt. 1891.

- Die Turbellarien als Parasiten und Wirte. Graz 1903.

- Monographie der Turbellarien II. Tricladida terricola (Landplanarien). Leipzig 1899. Fol. XIV u. 574 pag. mit Titelbild; 90 Textfig. u. Atlas von 58 z. T. kolor. Tafeln. 
Graff, L. v., Acoela, Rhabdocoela u. Alloeocoela des Ostens d. Vereinigten Staaten von Amerika. Mit Nachträgen $z u$ den "marinen Turbellarien Orotovas $\mathfrak{u}$. der Küsten Europas. In: Zeitschrift $\mathrm{f}$. wissensch. Zoolog. Bd. XCIX. 1911.

Hof sten, Nils v., Studien über Turbellarien aus dem Berner Oberland. Ztschr. f. wissensch. Zoolog. Bd. LXXX. Leipzig 1907. p. 391-654, tab. XXII-XXVII น. 8 Textfig.

Lang, H., Die Polycladen (Seeplanarien) des Golfes von Neapel und der angrenzenden Meeresabschnitte. Eine Monographie. Fauna und Flora des Golfes von Neapel $\mathfrak{u}$. d. angrenzenden Meeresabschnitte. Bd. XI. 1884.

Löhner, L., Zum Exkretionsproblem der Acoelen. In: Zeitschr. f. allgem. physiologie. 12. 1911.

Luther, A., Studien über acoele Turbellarien aus dem finnischen Meerbusen. In: Acta Soc. pro Fauna et Flora fennica. Vol. 36, Nr. 5. 1912.

Müller, O. F., Vermium terrestrium et fluviatilium, seu animalium infusorium, helminthicorum et testaceorum, non marinorum succincta historia. Vol. I, pars 2. Havniae et Lipsiae 1773. 40. p. 52-72.

- Zoologiae danicae prodomus, seu Animalium Daniae et Norwegiae indigenarum characteres, nomina, et synonyma imprimis popularium. Havniae 1776.

- Zoologia danica seu Animalium Daniae et Norvegiae rariorum ac minus notorum descriptiones et historia. Vol. I. Havniae 1788. Vol. II, 1788. Vol. III, 1789. Vol. IV, 1806.

Örsted, A. S., Entwurf einer systematischen Einteilung und speziellen Beschreibung der Plattwürmer, auf mikroskopische Untersuchungen gegründet. Kopenhagen 1844.

Uljanin, W., Turbellarien der Bucht von Sewastopol. Arbeiten der II. Vers. russ. Naturf. zu Moskau 1869. Tom. II. Abt. Zoolog. u. Physiol. Moskau 1870.

Vejdovsky, F., Zur vergleichenden Anatomie der Turbellarien (zugleich ein Beitrag zur Turbellarienfauna Böhmens). Ztschr. f. wiss. Zool. Bd.LX. Leipzig 1895. p.90-162, tab.IV-VIl. 4 Textfig.u.p.163-214, tab. VIII-X u. 1 Textfig.

Wilhelmi, J., Tricladen. Fauna und Flora des Golfes von Neapel und der angr. Meeresabschn. Bd. XXXII. Berlin 1909.

- Platodaria, Plattiere. In Lang: Handbuch der Morphologie III. Jena 1912. 


\section{SüBwassertricladen}

\section{Anatomie und Biologie}

Burr, A., Zur Fortpflanzungsgeschichte der SüBwassertricladen. Zoolog. Jahrb. Abt. f. System. Bd. XXXIII. Jena 1912.

Chichkoff, G., Recherches sur les Dendrocoeles d'eau douce (Triclades). In Arch. de Biologie. Tom. XII. Gand. 1892. p. 435-568, tab. XV-XX. Hesse, R., Untersuchungen über die Organe der Lichtempfindung bei niederen Tieren II. Die Augen der Plathelminthen, insonderheit der tricladen Turbellarien. Ztschr. f. wissensch. Zool. Bd. LXIl. 1897.

Jander, R., Die Epithelverhältnisse des Tricladenpharynx. Zoolog. Jahrb. Hbt. f. Anat. Bd. X. ${ }^{\bullet} 1897$.

Jijima, J., Untersuchungen über den Bau u. die Entwioklungsgeschichte der SüBwasserdendrocoelen (Tricladen). Ztschr. f. wissensch. Zoolog. Bd. XL. Leipzig 1884. p. 359-464, tab. XX-XXIII u. 3 Textfig.

Kennel, J. v., Untersudhungen an neuen Turbellarien. Zoolog. Jahrbücher. Abt. f. Anat. u. Ontogenie der Tiere. Bd. III. 1888/89.

1) Lang, P., Beiträge zur Anatomie und Histologie von Planaria polydhroa. Ztschr. f. wissensch. Zoolog. Bd. CV. 1913.

Micoletzky, H., Zur Kenntnis des Nerven- u. Exkretionsystems einiger SüBwassertricladen nebst anderen Beiträgen zur Anatomie von Planaria alpina. Ztschr. f. wissensch. Zoolog. Bd.LXXXVII. Leipzig 1907. p. 382-434, tab. XXI-XXIII.

Mrázek, $\mathrm{Hl}$., Utber eine neue polypharyngeale Planarienart aus Montenegro (Pl. montenigrina n. sp.). Sitzber. kgl. böhm. Ges.. d. Wissensch. 1903.

Stein mann, P., Untersudhungen an neuen Tricladen. Ztschr. f. wissensch. Zoolog. Bd. XCIII. 1909.

Stoppenbrink, F., Die Geschlechtsorgane der SüBwassertricladen im normalem und im Hungerzustande. Verh. Naturhist. Ver. preuB. Rheinlande 61. 1904.

Ude, J., Beiträge zur Anatomie und Histologie der SüBwassertricladen. Ztschr. f. wissensch. Zoolog. Bd. LXXXIX. 1908.

Wilhelmi, J., Untersuchungen über die Exkretionsorgane der SüBwassertricladen. Ztschr. f. wissensch. Zoolog. Bd. LXXX. 1906.

- Sinnesorgane der Aurikulargegend bei SüBwassertricladen. Zoolog. Anz. XXXIII. Leipzig 1908.

1) Diese während des Druckes der Monographie erschienene Arbeit macht es sehr wahrscheinlich, daB Planaria polydhroa mit Planaria lugubris identifiziert werden muB, resp. höchstens als eine Varietät gelten darf.

(Steinmann.) 


\section{Oekologie und Verbreitung}

Steinmann, P., Geographisches und Biologisches von Gebirgsbachplanarien. Arch. f. Hydrobiologie u. Planktonkunde. Bd. II. 1906.

Thienemann, Planaria alpina auf Rügen und die Eiszeit. X. Jahresber. der geogr. Ges. zu Greifswald 1905/1906. Greifswald 1907. p. 381-462. Mit 1 Tafel, 1 Ubersichtskarte und 1 Karte im Text.

- Der Bergbach des Sauerlandes. Faunistisch-biologische Untersuchungen. Revue d. Ges. Hydrobiol. u. Hydrogr. Biol. Suppl. IV, 2. 1912.

Voigt, W., Die Einwanderung der Planariaden in unsere Gebirgsbäche. Verh. naturhist. Ver. d. preuB. Rheinlande 53. 1896.

- Uuber die Wanderungen der Strudelwürmer in unsern Gebirgsbächen. Verh. naturhist. Ver. d. preuB. Rheinlande 61. 1904.

\section{Systematik}

Böhmig, L., Tricladida. In: Brauer: Die SüBwasserfauna Deutschlands. Heft 19. 1909.

Schmidt, O., Die dendrocoelen Strudelwürmer aus den Umgebungen von Gratz. Ztschr. f. wissensch. Zoolog. Bd. X. 1860.

Steinmann, P., Eine neue Gattung der paludicolen Tricladen aus der Umgebung von Basel (Polycladodes alba n. g., n. sp.). Verhandl. Naturf.-Ges. Basel. XXI. Basel 1910.

- Revision der schweizerischen Tricladen. Revue Suisse de Zoologie. Vol. XIX. Genève 1911. p. 175-234 mit 3 Textfig.

Weltner, W., Dendrocoelum punctatum Pallas, bei Berlin. Sitz.-Ber. kgl. preuB. Hkad. d. Wissensch. z. Berlin 1887.

\section{Rhabdocoelida}

\section{Anatomie und Biologie}

Bresslau, E., Plathelminthes. In: Handwörterbuch der Naturwissensch. Bd. VII. 1912.

Graff, L. v., Monographie der Turbellarien I. Rhabdocoelida. Bearb. u. herausgegeben mit Unterstützung der Kgl. Akad. d. Wissensch. zu Berlin. Leipzig 1882. Fol. XII u. 442 pag. mit 12 Holzschnitten und Atlas von $20 \mathrm{z}$. T. kolor. Tafeln.

Luther, A., Die Eumesostominen. Ztschr. f, wissensch. Zool. Bd. LXXVII. Leipzig 1904. p. 1-273, tab. I-IX, Textfig. 1-16.

- Zur Kenntnis der Gattung Macrostoma. Festschrift für Palmén, Nr. 5. Helsingsfors 1905.

Sekera, E., Monographie der Gruppe der Olisthanellini (Studien über Turbellarien, II), mit 2 Tafeln. In: Sitzungsber. der kgl. böhm. Ges. d. Wissensch, in Prag" 1911. 


\section{Oekologie und Verbreitung}

Brinkmann, August, Studier over Danmarks Rhabdocoele og acoele Turbellarier. In: Vidensk. Meddel naturh. Foren. Kobenhavn 1906. Hofsten, N. v., Neue Beobachtungen üb. d. Rhabdocoelen u. Alloeocoelen der Schweiz. Zoologiska Bidrag från Uppsala I. 1911.

- Revision der schweizerischen Rhabdocoelen u. Alloeocoelen. In: Revue Suisse de Zoologie. 20. Nr. 12. 1913.

\section{Systematik}

Graff, L. v., Turbellaria. In Brauer: Die SüBwasserfauna Deutschlands. Heft 19. Jena 1909.

\section{Entwicklung und Stammesgeschichte der Turbellarien}

Bresslau, E., Beiträge zur Entwicklungsgeschichte der Turbellarien. I. Die Entwicklung der Rhabdocoelen und Alloecoelen. In: Ztschr. f. wissensch. Zoolog. Bd. LXXVI. 1904.

- Die Entwicklung der Hcoelen. In: Verhandl. Deutsch. Zool. Ges. 1909. Hallez, P., Biologie, organisation, histologie et embryologie d'un Rhabdocoele parasite du Cardium edule L. Paravortex cardii n.sp. In: Archives de Zoologie experimentale et générale. Tom. IX, No. 7. 1909.

Lang, A., Der Bau von Gunda segmentata und die Verwandtschaft der plathelminthen mit Cölenteraten und Hirudineen. Mitteil. Zool. Station Neapel. Bd.1Il. Leipzig 1881. p. 187-252.

- Die Polycladen (Seeplanarien) des Golfes von Neapel und der angrenzenden Meeresabschnitte. Eine Monographie. Fauna und Flora des Golfes von Neapel u. der angrenzenden Meeresabschnitte, herausgeg. von der Zoolog. Station in Neapel. Bd. XI. Leipzig 1884.

Matthiesen, E., Ein Beitrag zur Embryologie der SüBwasserdendrocoelen. Ztschr. f. wissensch. Zoolog. Bd. LXXVII. Leipzig 1904. p. 274-361, tab. X-XliI, Textfig. 1-3.

Metschnikoff, E., Untersuchungen über die Entwicklung der Planarien. Notizen d. neuruss. Ges. d. Naturforscher zu Odessa. Bd. V. 1877. (Russisch.)

Mortensen, Th., Ctenophora. In: The Danish Ingolf-Expedition. Vol.5. 1912.

Surface, F. M., The Early Development of a Polyclad Planocera in quilina Wh. In: Proceedings of the Academy of nat. Sciences. Philadelphia 1907. 


\section{Erklärung im Text vorkommender Fachausdrücke}

A

Hbortiv $=$ nicht fertig ausgebildet. Acoela $=$ darmlose Turbellarien, Unterordnung der Turbellaria.

Acotylea = Polycladida ohne Saugnapf.

Adaption = Anpassung.

Adenal $=$ in Drüsen entstehend.

Adenochiren = Gruppen von Adenodactylen an gemeinsamem Stiel. Adenodactylen = fingerartige Drüsenorgane im Geschlechtsraum gewisser Landplanarien.

Heolididae $=$ Familie meerbewohnender Nadktschnedken.

Heolidier s. Aeolididae.

Hequale Teilung $=$ Eiteilung, welche gleichgroße Teilprodukte liefert.

Aeschna = Gattung der Libellen.

Agame Fortpflanzung $=\mathrm{F}$. ohne $\mathrm{Be}-$ fruchtung.

Akzessorisch = hinzutretend, hinzukommend.

Alecithal = ohne Dotter.

Allöocoela $=$ Sektion der Rhabdocoelida.

Amoebe $=$ Wechseltierchen.

Amoebenartig od. amoeboid $=$ wie ein Wechseltierchen, d.h. sich unter Formveränderung (Aussendung v. Fortsätzen) fortbewegend.
Analogie $=$ Ubereinstimmung in der Funktion.

Hnastomosen $=$ Querverbindungen. Animal = tierisch, anim. Funktionen: Empfindung, Bewegung; Gegensatz: vegetativ.

Antrum femininum $=$ selbständiger weiblicher Geschlechtsraum bei Arten mit getrennten Geschlechtsöffnungen.

Antrum masculinum $=$ selbständiger männlicher Geschlechtsraum bei Arten mit getrennten Geschlechtsoffnungen.

Atrium = Raum, Geschlechtsraum. Atrium commune $=$ gemeinsamer Geschlechtsraum, in densich männ liche u. weibliche Gänge öffnen. Atrium copulatorium $=$ Kopulationsraum, Abschnitt d. Atrium genitale. Atrium femininum $=$ weibliches $A$., in das sich nur d. weiblichen Gänge öffnen, Teil des.

Atrium genitale $=$ Geschlechtsraum. Atrium masculinum = männliches $A$., in das sich nur die männlichen Gänge öffnen, Teil des A. g.

Assimilation = Umwandlung von Nahrungssubstanz in Körpersubstanz des verdauenden Organismus. 
Aurikel = Ohrchen, bewegliche stumpfe Seitenlappen des Kopfes.

AuBenparasit $=$ dem Wirtstiere außen anhängender Schmarotzer.

Autochthon $=$ von alters her einheimisch.

Autotomie $=$ Selbstverstümmlung od. spontane Teilung.

Autotomieren $=$ sich spontan teilen.

\section{B}

Basalkörper $=$ in den Zellen des Wimperepithels gelegene, sehr feine Körperchen, die als Cilienwurzeln aufgefaBt werden.

Basalmembran $=$ an der Basis der Epithelzellen gelegene, strukturlose Haut.

Blastem $=$ embryonales Bildungsgewebe.

Blastomeren $=$ Teilungs- od. Furchungszellen, Teilprodukte des sich entwickelnden Eies.

Bilaterale Symmetrie $=$ spiegelbild liche Ahnlichkeit d. beiden Körperhälften.

Bipolar $=$ mit 2 Polen s. unipolar. Bryozoen $=$ die koloniebildenden an Polypenstöcke erinnernden ${ }_{n}$ Moostiere $^{4}$.

Bugula avicularia $=$ ein Moostierchen (Bryozoen).

Bulbus vergl. Penisbulbus.

Bursa copulatrix = Begattungstasche.

\section{C}

Carangiden $=$ Fische, die sich in der Jugend im Bereich von Quallen (Chrysaora) aufhalten.

Catenulidae $=$ Familie der Hysterophora.
Cerebral $=$ in der Gehirngegend.

Cestodes $=$ Bandwürmer.

Charawiesen $=$ Bestände der uferbe wohnenden Armleuchtergewächse. Chemoreception = Aufnahmechemischer Reize: riechen, schmecken. Chemotaxis $=$ Reaktion freier Organismen auf chemische Reize, indem eine Einstellung nach diesen Reizen erfolgt.

Chiasma $=$ Kreuzung (der Nerven).

Chitin $=$ stickstoffhaltige, widerstandsfähige Substanz, aus der z. B. der Panzer der Gliederfüßer sich aufbaut.

Chitincuticula $=$ Häutchen aus Chitin.

Chitinisiert $=$ mit Chitin versehen

Chitinös = aus Chitin bestehend, chitin-artig.

Cilien $=$ Wimpern (feinste schlagende Protoplasmafäden).

Cladoceren $=$ Abteilung der BlattfuBkrebse (Phyllopoden).

Cnidarier $=$ Nesseltiere.

Coelom = echte Leibeshöhle, ein zwischen Darm und Körperwand gelegener, von einer eigenen Zellhaut (Epithel) ausgekleideter Hohlraum.

Coeloplana $=$ kriechende Ctenophore s. Ctenoplana.

Copepoden $=$ SpaltfuBkrebse.

Cordylophora lacustris = eine süBwasserbewohnende Hydroidenart.

Cotylea $=$ Polycladen mit Saugnapf.

Cryptocelis = Gattung der Polycladen.

Ctenophoren $=$ Rippenquallen, höchstdifferenzierte Gruppe der Nesseltiere. 
Ctenoplana $=$ kriechende Ctenophore, mit Coeloplana $u$. Tjalfiella zusammen als Turbellarienvorfahr gedeutet.

Cuticula = strukturlose von Epithelzellen ausgeschiedene Haut.

Cyanophil = blau liebend, die sich mit Hämatoxylin blau färbenden Zellen und Gewebe.

Cyclopiden $=$ Familie d.Copepoden . Cypris = Gattung der Ostracoden. Cystid $=$ der becherförmige äußere Teil eines Einzeltieres einer Bryo zoenkolonie (Hautmuskelschlauch u. verkalkte Cuticula),vgl. Polypid.

\section{D}

Dalyelliidae $=$ Familie der Lecitho phora.

Daphnia $=$ Wasserfloh (niederer Krebs des Planktons).

Daphniden $=$ Familie der Wasser flöhe.

Defäkation $=$ Kotentleerung.

Deformation $=$ MiBbildung.

Degeneration $=$ Rüdkbildung.

Dekapitieren $=$ enthaupten.

Dendrocoela $=$ frühere Bezeichnung für die Turbellarien mit baumförmig verzweigtem Darm. Gegensatz: Rhabdocoela.

Dermal $=$ in der Haut gelegen.

Dicyemiden $=$ Familie d. Mesozoën.

Diffus = zerstreut; bei kleinen, sehr zahlreichen Elementen im Sinne von gleichmäBig ausgebreitet.

Dilatatoren $=$ Erweiterungsmuskeln.

Diptera $=Z$ weiflügler (Fliegen $u$. Mücken).

Discocoelis = Gattung der Polycladen.
Distal = entfernter gelegen als andere Teile. Gegensatz: proximal. Divertikel = die Verzweigungen des Darmes.

Dorsal = nach der Rückenseite gelegen od. verlaufend. Gegensatz: ventral.

Dorsolateral = vom Rücken nach den Seiten.

Dorsoventral = von der Rücken zur Bauchseite.

Dottersyncytium $=$ Dottermasse mit eingestreuten Kernen, entsteht durch Verschmelzung der Dotterzellen.

Dottertrichter $=$ Verbindungskanälchen zwischen Dotterstöcken und Eileiter.

Dredge $=$ ein speziell zum Fassen von Grundschlamm gebrauchtes Instrument, im wesentlichen ein GefäB, das dem Boden entlang geschleift wird.

Drüsengang $=$ unterster Teil des Eileiters, in welchen teilweise die Schalendrüsen münden.

Drüsenorgan $=$ muskulöses Hilfs organ des Geschlechtsapparates von penisartiger Gestalt.

Drüsensack, gestielter $=$ ein meist als "Uterus" bezeichneter Sack mit Stiel, der mit dem Geschlechtsraum in Verbindung steht.

Ductus communis = Gang für Geschlechtsprodukte, Dotter und Schalendrüsensekret.

Ductus ejaculatorius = Ausspritzkanal, durch den der Samen abgegeben wird.

Ductus genito-intestinalis $=$ Verbindungskanal zwischen Receptaculum und Darm. 
Ductus spermaticus = Samengang, Verbindungskanal $z$ wischen Bursa copulatrix und Receptaculum seminis.

Dytiscus = Gattung der Schwimmkäfer.

\section{E}

Ektoderm $=$ äuBeres Keimblatt.

Ektolecithale Eier $=$ Eier, die von Dotter umgeben sind, ohne selbst Dotter zu enthalten. Gegensatz: endolecithal vergl. auch alecithal.

Ektomeren, Micromeren $=$ welche bei inäqualer Teilung das Ekto derm liefern.

Ektoparasit $=$ AuBenschmarotzer.

Embryonalpharynx $=$ ein nur wäh rend der ersten Entwicklung der Tricladen auftretendes Schlundrohr, das zum Aufschludken von Dotterzellen dient.

Endolecithale Eier = Eier, die den Dotter in ihrem Plasma enthalten. Gegensatz: ektolecithal.

Entomostraken $=$ niedere Krebse.

Entoparasitisch $=$ innen schmarotzend.

Enzystierung $=$ Einkapselung, Ubergang in ein Ruhestadium unter Ausscheidung einer Schleimhülle, Zyste.

Eosin $=$ ein auf chemischem Wege gewonnener roter Farbstoff, der für die Untersuchung der Turbellarien wichtig ist.

Eosinophil = Eigensthaft gewisser Zellen und Gewebe, die sich bei Hämatoxylin - Eosinfärbung rot färben (s. erythrophil).

Ephemer = vergänglich.

Epidermis = Oberhaut, das aus dem
Ektoderm hervorgehende Körperepithel.

Epimorphose $=$ Regeneration durch Auswachsen neuen Materiales.

Epithel = Schicht aus zusammenhängenden Zellen.

Erythrophil $=$ eosinophil, ${ }_{n}$ rotliebend".

Eurytherm $=$ innerhalb weiter Temperaturgrenzen lebensfähig.

Exkretion = Ausscheidung der flüssigen Stoffwechselprodukte (Exkrete).

Exkretophorenzellen $=$ Zellen, welche bei fehlendem Exkretionssystem die Ausscheidung besorgen. Exstirpation = Husstechen od. Hus schneiden eines Organes.

Extrakorporell = auBerhalb desKör pers.

Extrapharyngeal $=$ auBerhalb des Pharynx gelegen.

Extrazellulär $=$ auBerhalb der Zelle.

\section{F}

Fecampiidae $=$ Familie der Lecitho phora.

Fibrillär $=$ faserig.

Fibrille $=$ feinste Faser.

Filament $=$ fadenförmiges Organ.

Fissiparität $=$ Teilungsfortpflanzung.

Flagellum $=$ GeiBel, ausstülpbare Ringfalte im Penis gewisser Tricladen.

Follikel = Schlauch oder Lappen einer Drüse.

Frontal $=$ in der Richtung derStirnebene, 1 zur Symmetriebene $u$. II zur Queraxe.

G

Gammariden $=$ Flohkrebse (Amphi poden). 
Gammarus $=$ verbreitete Gattung der Flohkrebse.

Ganglienzelle $=Z$., die besonders in den Ganglien vorkommt.

Ganglion $=$ Knoten, Anschwellung der Nervenstränge.

Gastrula $=$ Darmlarve,Entwicklungsstadium der meisten vielzelligen Tiere, in seiner typischen Gestalt einen doppelwandigen Becher darstellend.

Genitalporus $=$ Geschlechtsöffnung.

Genostomatidae $=$ Familie der Lecithophora.

Genus $=$ Gattung.

Geotaxis = Reaktion freier Organismen auf die Anziehungskraft der Erde, indem eine Einstellung in die Richtung der Schwerkraft erfolgt.

Germarium $=$ Keimstodk.

Germidukt $=$ Keimgang.

Germovitellarium = Geschlechtsdrüse, die in bestimmten Bezirken Keim-, in andern Dotterdrüse ist.

Gliazelle $=$ Stütz- od. Gerüstzelle des Nervensystems.

Goettesche Larve $=$ Larvenform d. polycladen.

Graffillidae $=$ Familie der Lecithophora.

Granuliert $=$ gekörnelt.

Gyratricidae $=$ Familie der Lecithophora.

\section{H}

Habitus $=$ das äuBere Aussehen. Hämatoxylin = Farbstoff aus Campecheholz bereitet, zur Färbung von Zellen und Geweben der Turbellarien vielfach gebraucht.
Hyalin = durdhsichtig oder durchscheinend. Gegensatz: opak.

Haplosporidien $=$ Abteilung der parasitischen Protisten.

Hermaphrodit $=z$ witterig.

Heteromorphose $=$ regenerative Bildung eines Organes, das dem entfernten nicht gleichwertig ist.

Histologisch = die Histologie, Lehre von dem mikroskopischen Bau der Gewebe und Zellen betreffend.

Holothurien $=$ Seewalzen, Abteil. der Stachelhäuter.

Homogen = gleichartig, ohne erkennbare Struktur.

Homologa $=$ homologe Teile.

Homologie = Ubereinstimmung in d. Herkunft. Gegensatz: Analogie. Hyaloide $=$ "Stäbchen" von glasartiger Beschaffenheit.

Hydrachniden $=$ Wassermilben.

Hysterophora $=$ Unterabteilung der Rhabdocoela.

\section{I}

Inäquale Teilung $=$ Eiteilung, welche ungleiche Teilprodukte liefert.

Integument $=$ Körperbedeckung. Interglazialzeit $=$ die Zwischenzeit zwischen zwei Vergletscherungsepochen.

Intersexualzeit $=Z$ wischenzeit $\mathbf{z w i}-$ schen zwei Geschlechtsperioden.

Interzellulär $=$ zwischen den Zellen gelegen.

Intrazellulär $=$ in den Zellen oder der Zelle gelegen.

Invers $=$ umgedreht.

Isolation=Isolierung, optische, Vereinzelung, Absonderung bestimm ter Lidhtstrahlen durch Abblendung der andern. 


\section{$\mathbf{K}$}

Kalyptorhynchia $=$ zusammenfassender Name für einige Familien der Lecithophora, die sich durch in eine Rüsselscheide eingeschlossenen Rüssel auszeichnen.

Kannibalismus $=$ das Auffressen von Artgenossen.

Kantendrüsen $=$ an den Rändern der Bauchseite von Planarien gelegene Drüsen, die den zur Fortbewegung nötigen Schleim liefern.

Kapillaren $=$ Haargefäße.

Keimlager $=$ eine Partie des Keim stocks, die aus unentwidkelten Eiern besteht.

Kokon od. Eikokon =Eikapsel, zahlreiche Eier und sehr viele Dotterzellen v. einer Schale umschlossen.

Kommensale $=$ Tischgenosse, Mitgenießer von Nahrung, der einem andern Geschöpf an- oder innewohnt, ohne ihm Schaden zu bringen.

Kommensalismus $=$ Tischgenossen schaft.

Kommissur $=$ Verbindungsstrang zweier Nervenstämme od. Gang lien.

Kontraktil $=$ zusammenziehbar.

Kontraktion $=$ Zusammenziehung.

Konvergenz $=$ das Ahnlichwerden ursprünglich verschiedener Organe und Organismen infolge gleicher Funktion, resp. Lebensweise.

Kopula $=$ Begattung.

Kopulant $=$ der Begattende.

Kopulationsapparat = Begattungs apparat.

Körnerdrüsen $=$ Drüsen mit körnigem Sekret.

Kosmopoliten $=$ Weltbürger.
Kristalloide $=$ Parasiten der Turbellarien (vielleidht Haplosporidien), welche die Form kleiner Kristalle zeigen.

Kubisch $=$ würfelartig.

L

Latenzeier $=$ Dauereier.

Lateral = seitlich (auBerhalb der Mittelebene) gelegen. Gegensatz: median.

Lecithophora $=$ Unterabteilung der Rhabdocoela.

Leptoplaniden $=$ Familie der polycladen Turbellarien.

Limnadophile $=$ reguläre Bewohner stehender Gewässer.

Limulus (Molukkenkrebs) = einzige noch lebende Gattung d. Schwertschwänze, auf deren Kiemen die Bdellouriden wohnen,

Litoral $=$ an der Küste lebend.

Lokomotion $=$ Ortsbewegung.

Lokomotorisch = die Fortbewegung betreffend.

Longitudinal $=$ der Länge nach an geordnet.

Longitudinalmuskeln = Längs muskeln.

Lumbriculiden $=$ Abteilung der Oligochaeten.

Lumen = lichte Weite, Hohlraum.

M

Makromeren $=$ groBeTeilungszellen. Makroskopisch = ohne VergröBerungsgläser sichtbar. Gegensatz: mikroskopisch.

Markstränge $=$ ventrale Längsnervenstämme, sofern sie Ganglien enthalten.

Maricola $=$ Sektion der Tricladida . 
Mazerieren $=$ loslösen weicherer Teile von härteren durch chemisch wirkende Stoffe.

Medial $=$ in der Richtung gegen die Medianebene gelegen. Gegensatz: lateral.

Median =in derMittelebene gelegen. Melia tessalata $=$ Krabbe, die $z u$ ihrem Schutz Seeanemonen mit herumträgt.

Mesenchym $=$ Parenchym.

Mesozoën = eine Gruppe, welche die niedrigsten vielzelligen Tiere umfaBt.

Microstomidae $=$ Familie der $\mathrm{Hy}-$ sterophora.

Mikromeren $=$ kleine Teilungszellen.

Mikroorganismus $=$ mikroskopisch kleines Lebewesen.

Mimetisch = nachahmend, der Umgebung gleichend.

Minotsche Körnerkolben $=$ kolbige Drüsenzellen des Darmepithels.

Mitose = Karyokinese mitotische od. indirekte Kernteilung, die Vorgänge bezeichnend, durch welche das Chromatin des .Kernes zu gleichen Teilen auf die Tochterkerne verteilt wird.

Mitotisch s. Mitose.

Molukkenkrebs s. Limulus.

Monstrosität $=$ MiBbildung.

Morphallaxis = Regeneration durch Umformung des alten Gewebes. Motorisch = bewegend, Bewegung hervorbringend.

Müllersche Larve $=$ Larvenform der polycladen.

Muscularis $=$ Muskelschicht.

Myoblast=Zellen, aus denen Muskelfasern werden, bisweilen wird der Name auch nur auf den auBer- halb der Faser gelegenen, kernhaltigen Abschnitt des Muskels bezogen.

\section{$\mathbf{N}$}

Naididen $=$ Abteilung der Oligochaeten.

Nematocysten $=$ Nesselkapseln, Organe zur Verteidigung und zum Beutefang; für die Cnidarier = Nesseltiere charakteristisch.

Nemertini $=$ Schnurwürmer.

Notonecta $=$ Rückenschwimmer, eine Wasserwanze.

Nutritiv $=$ ernährend.

\section{O}

Oekologie = Lehre von den Wohnorten und der Anpassung der Organismen an dieselben.

Oesophagus $=$ Speiseröhre, Verbindungskanal zwischen Mund $u$. Darm.

Oligochaeten $=$ die ${ }_{n}$ wenigborstigen" Gliederwürmer; zu denen z. B. auch der Regenwurm gehört. Omnivor = Allesfresser, genieBen tierische und pflanzliche Kost.

Ontogenese = individuelle Entwicklung. Entwicklung d. Keimes vom befruchteten Ei bis zur vollkommenen Ausbildung.

Oogonium $=$ Urei, Zelle, aus welcher durch Teilung Eizellen (Oozyten) hervorgehen.

Oozyten = Eizellen.

Opak = nicht durchscheinend, undurchsichtig. Gegensatz: hyalin. Optimum der Temperatur $=$ für das Gedeihen günstigste Temperatur. Orthonectiden $=$ Familie der Mesozoën.

Ostracoden $=$ Muschelkrebse. 
Ovarium $=$ Eierstock.

Ovidukt $=$ Eileiter.

\section{P}

Paludicola $=$ Sektion der Tricladida.

Papille $=$ Warze, Hügel.

Paramaecium aurelia $=$ Pantoffeltierchen (Wimperinfusorium).

parasitisch = schmarotzend.

Parasitismus $=$ Schmarotzertum.

Parenchym $=$ Körpergewebe.

Parthenogenese = jungfräulicheZeugung, Fortpflanzung durch Eier, die keine Befruchtung nötig haben.

Parthenogenetische Fortpflanzung s. Parthenogenese.

Partiell $=$ teilweise.

Pelagisch = im freien Wasser lebend.

Penis = der männliche Kopulations apparat.

Penisbulbus $=$ der vom Parenchym umfaBte rundliche od. zwiebelartige Teil des Penis.

Penispapille $=$ der frei in den Geschlechtsraum ragende Teil des Penis.

Penisscheide $=$ Verbindungskanal zwischen männlichem und weiblichem Geschlechtsraum.

Perennierend = das ganze Jahr vorkommend.

Peripherisch $=$ an der Peripherie gelegen.

Peristaltische Bewegung $=$ fortschreitende, wurmartige, zusammenziehende Bewegung, wie beim Darm der höhern Tiere.

Perivisceral $=u m$ die Eingeweide herum befindlich.

Perivisceralflüssigkeit $=$ die zwischen den Organen befindliche Flüssigkeit.
Perzipieren $=$ wahrnehmen, aufnehmen.

Phagozyten $=$ FreBzellen, Zellen, welche geformte Nahrung aufnehmen.

Phagozytose $=$ Tätigkeit der FreBzellen.

Pharynx $=$ Schlund, Rüssel, Saugrüssel.

$\mathrm{Ph}$. bulbosus $=$, zwiebelförmiger pharynx.

Ph. compositus $=$ zusammengesetzter Pharynx.

Ph. dolitiormis $=$ tonnenförmiger Pharynx.

$\mathrm{Ph}$. plicatus $=$ gefalteter Pharynx. $\mathrm{Ph}$. rosulatus $=$ rosenartiger Pharynx.

Ph. simplex $=$ einfacher Pharynx. $\mathrm{Ph}$. variabilis $=$ veränderlicher Pharynx.

Phototaktisch $=$ durch Phototaxis orientiert.

Phototaxis = Einstellung frei beweglicher Organismen in die Richtung der einfallenden Lichtstrahlen. Phylogenetisch = die Stammesgegeschichte betreffend.

pigment $=$ Farbstoff.

plankton $=$ Gesamtheit der im freien Wasser vorkommenden Organismen.

planula $=$ Larvenform vieler Nesseltiere.

Plasmatisch $=$ aus Plasma bestehend od. im Plasma gelegen.

Plathelminthes = Plattwürmer, umfassende Ordnungen der Turbellarien, Trematoden, Cestoden u. Nemertinen.

Plattenepithel $=$ Epithel, dessen Zellen breiter als hoch sind. 
Plexus $=$ Geflecht.

Polycladida $=$ Turbellarien mit viel ästigem Darm, Unterordnung der Turbellaria.

Polycystidae $=$ Familie der Lecithophora.

Polypharyngeal $=$ vielrũsselig.

Polypharyngie $=$ das Auftreten mehrerer Pharynge in einem Tier, "VielrüBligkeit".

Polypid = die polypenähnlichen, inneren Teile eines Einzeltieres einer Bryozoenkolonie (Darm und Tentakelkrone, vergl. Cystid).

Postembryonale Entwidklung $=$ Ent widklung nach dem Embryonalleben.

Postpharyngeal $=$ hinter dem Pharyux gelegen.

Präformiert $=$ vorgebildet.

Präovarial $=$ vor dem Eierstock gelegen.

Präpharyngeal $=$ vor dem Pharynx gelegen.

Procerodes $=$ eine Gattung der Meertricladen.

Prorhynchidae $=$ Familie der $\mathrm{Hy}$ sterophora.

Protonephridien $=$ ursprünglichstes, aus Kanälen bestehendes Exkretionssystem.

Protoplasma $=$ Ursubstanz, Trăgerin der Lebensvorgänge.

Protraktoren $=$ VorstoBmuskeln.

Prosteceraeus = Gattung der Polycladen.

Proximal $=$ näher gelegen (der Körperachse oder einem Zentrum) als andere Teile. Gegensatz: distal.

Pseudoceriden $=$ Familie der Polycladen.
Pseudometamerie - Scheinsegmentierung, die sich nur auf einzelne Teile bezieht.

Pseudorhabditen s. Rhabdoide.

Pteropoden $=$ die planktonbewoh nenden Flägelschnedken d. Meeres.

Punktsubstanz (Leydigsche) $=$ fein körnige Masse in den Anschwellungen (Ganglien) des Nervensystems, wahrscheinlich geknäulte Fasern.

\section{$\mathbf{R}$}

Radiärmuskeln $=$ von einem Zen trum ausstrahlende Muskeln.

Receptaculum seminis = Samen behälter, zur Aufnahme des frem den Samens.

Reduktion $=$ Rüdkbildung, Umwand lung differenzierter Elemente in einfache.

Reduktionsteilung $=$ eine bei der Samen - und Eientwidklung vor kommende Teilung, durch welche die Kernsubstanz auf die Hälfte reduziert wird.

Regenerant $=$ ein Organismus oder ein Teil eines Organismus der Fehlendes wieder ersetzt.

Regenerat $=$ der durch Regeneration neugebildete Körperbezirk.

Regeneration $=$ Wiederbildung von verlorenen Körperteilen.

Regulation $=$ durch Wachstums erscheinungen erfolgende Wiederherstellung der Form nach ein getretenen Störungen, speziell nach Regenerationen.

Reifeteilung s. Reduktionsteilung.

Resistent $=$ widerstandsfähig.

Resorbieren $=$ aufsaugen, verzehren. 
Reticulum = Netzchen, das netzartige Grundgewebe.

Retraktoren = Rüdkziehmuskeln.

Rhabditen s. Rhabdoide.

Rhabdocoela = Sektion der Rhabdocoelida, früher = Rhabdocoelida, Stabdarmturbellarien im Gegensatz zu d.Dendrocoela, den Baumdarmturbellarien.

Rhabdocoelida $=$ Unterordnung der Turbellaria: Turbellaria mit Stabdarm.

Rhabdoide = stabförmige Einschlüsse der Integumentzellen der Turbellarien; sie werden nach ihrer Beschaffenheit als Rhammiten, Rhabditen u. Pseudorhabditen unterschieden.

Rhammiten s. Rhabdoide.

Rheophil=normalerweise i. flieBenden Wasser lebend.

Rheotaxis = Reaktion freier Organismen auf Strömung, indem eine Einstellung in die Ridhtung der Strömung stattfindet.

Rhynchodemiden $=$ Familie der Landtricladen.

Rhynchodemus $=$ Gattung der Landtricladen.

Richtungskörperchen = kleine, wäh rend der Reifung vom Ei abgeschnürte kernhaltige Zellen.

Rotatorien $=$ Rädertiere.

\section{S}

Sagittal $=$ in der Richtung der Pfeilebene.

Segmental $=$ segmentweise angeordnet, sich in der Längsachse wiederholend.

Segmentierung $=$ Gliederung, Ausdruck für die Zusammensetzung

S te in ma n n-Bressla u, Strudelwärmer. aus reihenweise hintereinander geordneten "Segmenten ".

Sekret $=$ Absonderungsprodukt der Drüse.

Sekretion $=$ Absonderung d. Sekrete. Sensible Periode = Entwidklungsperiode, während welcher ein be-stimmter Reiz den Husfall einer Formbildung bedingen kann.

Septum $=$ Scheidewand.

Sipunculiden $=$ Gruppe eigenartiger mariner Würmer, Gephyreen.

Solitärtier $=$ einzellebendes Individuum (bei kettenbildenden Formen). Gegensatz: Kettenverband. Sperma $=$ Samen.

Spermatogonien $=$ Ursamenzellen oderSamenmutterzellen, aus denen durch Teilung die Spermatozyten hervorgehen.

Spermatophoren $=$ Samenkapseln. Spermatozoën $=$ Samenzellen.

Spermatozyten $=$ Teilungsprodukte der Samenmutterzellen; aus ihnen gehen die Samenzellen hervor.

Spermien $=$ Samenzellen.

Spezies $=$ Art.

Sphincter $=$ SchlieBmuskel.

Sporozoën = Sporentiere, parasitische Abteilung der Urtiere.

St ammzelle, Parenchymzelle mit ab gerundetem Plasmahof =ruhende Zelle, Bildungszelle, embryonale Zelle.

Statozyste $=$ bläschenförmiges Organ des Gleichgewichtssinnes.

Statolith = Gleichgewiohtstein; EinschluBkörper der Statocyste.

Stenotherm $=$ innerhalb enger Temperaturgrenzen lebensfähig.

Stereotaxis = im Sinne von Thigmotaxis (s. das.). 
Stiftchenkappe = Überzug der Sehzelle im Auge.

Stroma $=$ Grundgewebe, Gerüst.

Stylaria lacustris $=$ Oligochaet des SüBwassers.

Stylochoplana $=$ Gattung der Polycladen.

Subitaneier = Eier, die sofort, ohne ein vorangehendes Ruhestadium entwicklungsfähig sind.

Substanzinsel $=$ eine vom Gehirn umschlossene Partie von Körpergewebe.

Subterran $=$ unter der Erde.

Symbiose $=$ Gemeinschaftsleben mit gegenseitigem Nutzen.

Syncytial = Syncytium-artig.

Syncytium = ein Plasmabezirk mit vielen Kernen; durch Vermehrung der Kerne, in der Einzelzelle, od. durch Verschmelzung mehrerer Zellen.

\section{$\mathbf{T}$}

Tangentialmuskeln $=$ oberflächliche, 2 Punkte des Integumentes mit einander verbindende Muskeln.

Tentakel $=$ Fühlhorn, bewegliche pfriemliche od. kegelförmige Kopfanhänge.

Terminal $=$ endständig.

Terminalorgane $=$ Endorgane des WassergefäBsystems, sog. Wimpertrichter.

Teratologisd $=$ miBgebildet, krank haft.

Terricola $=$ Sektion der Tricladida.

Testis $=$ Hoden.

Tjalfiella $=$ festsitzende Ctenophore vergl. Ctenoplana.

Thigmotaxis $=$ Reaktion freier Organismen auf Berührung, indem ein Anschmiegen an die berührende Fläche eintritt.

Topographisch = auf die Lage be züglich.

Transplantation $=$ Überpflanzung eines losgetrennten Körperab schnitles an eine andere Stelle.

Transversal $=$ in der Querebene gelegen oder verl aufend.

Trematodes $=$ Saugwürmer.

Tridıodinen $=$ Wimperinfusorien, die meist auf andern Tieren leben (vergl. Hydralaus).

Tricladida $=$ Turbellarien mit dreischenkligem Darm. Unterordnung der Turbellaria.

Triton $=$ Gattung der Schwanzlurche.

Tuba = Muttertrompete, Anfangsstiel des Eileiters nächst dem Eierstock.

Tubificiden $=$ Ableilung der Oligochaeten.

Tunica propria $=$ eigene Haut, $z$. B. Abgrenzungshaut der Gonaden gegen das Parenchym.

Turbellaria $=$ Strudelwürmer, zerfallen in Acoela, Rhabdocoelida, Tricladida, Polycladida.

Typhloplanidae $=$ Familie der Leci thophora.

\section{U}

Ubiquisten $=$ Formen, die überall (ubique), d. h. an Fundstellen der verschiedensten Natur vorkommen.

Ulva $=$ marine Alge.

Unipolar $=$ mit einem Pol, unipolare Zelle $=Z$. mit einem Plasmafortsatz.

Uterus $=$ Eihälter. 
V

Vagina $=$ Scheide, Gang für die Hereinbeförderung von Sperma. Vakuolen = Bläschen, Hohlräume im Zellkörper.

Vakuolisiert $=$ mit Vakuolen durchsetzt.

Vas deferens $=$ Samengang.

Vas efferens = Samenkanal, feinstes Ausführkanälchen aus dem Hoden.

Vegetativ $=$ pflanzlich, von Funk tionen: Ernährung, Wachstum, Fortpflanzung. Gegensatz: animal.

Ventral = an der Bauchseite gelegen.

Vermes $=$ Würmer.

Vesiculae seminales $=$ Samenblasen, Behälter für den eigenen Samen. Vikarierend $=$ sich vertretend.

Vitellarium $=$ Dotterstock.
Z

Zerebralganglion $=$ Gehirnganglion.

Zirkulärmuskeln $=$ Ringmuskeln.

Zoochlorellen = grüngefärbte Algen, die mit Tieren in Symbiose leben. Zooid = Einzelwesen im Ketten verbande.

Zooxanthellen $=$ gelb oder braun gefärbte Algen, die mit Tieren in Symbiose leben.

Zyklische Fortpflanzung $=\mathrm{F}$, , bei welcher morphologisch oder bio logisch verschiedene Generationen abwechseln.

Zyklus $=$ Fortpflanzungskreis, das Hufeinanderfolgen der Generationen einer sich zyklisch fortpflan zenden Form vom Husgangspunkt an bis wieder $z u$ ihm zurück.

Zyste $=$ Schleimhülle, Kapsel siehe Enzystierung. 


\section{Register}

\section{H}

Acoela 4, 40, 69, 71, 74, 272, 315. Acoelenentwicklung 348.

Acrorhynchus 327.

- sophiae 218.

Adenochiren 69.

Adenodactylen 69.

Heolididae 211.

Aktive Verbreitung 154.

Hlaurina 260, 308, 324.

Allöocoelen 41, 228, 234, 245, 257, $260,317,323,328,346$.

Allostoma 328.

Allostomatidae 328.

Anastomosen des Darmes 41.

Anocelis coeca 83, 177, 181, 200.

Anoplodiidae 325.

Anoplodium 250, 325.

Antrum femininum 251.

- masculinum 251.

Archiloa 328.

Astrotorhynchidae 326.

Astrotorhynchus 326.

- bifidus 216.

Atrium femininum 250.

- genitale 243.

- masculinum 250.

Hufenthaltsorte 149.

Hugen 80, 259.

Hurikeln 85.

Aurikularsinnesorgan 84.
HuBenschmarotzer 95.

Hutotomie 107, 108.

\section{B}

Bachplanarienverbreitung $162 \mathrm{ff}$.

Bandwurmköpfe als Tricladenparasiten 149.

Basalmembran 32, 214.

Bauchmark 3, 73.

Bdellocephala 23, 36, 66, 67, 68, 69, $81,84,90,105,110,151,178,180$, 183, 185.

Bdelloura candida 175.

Bdellouriden 65, 95, 141, 153, 174, 175.

Befruchtung 340 .

Begattung 99, $279 f$.

Besamung 340.

Bestimmungstabelle $177 \mathrm{ff}$, $324 \mathrm{f}$.

Beutefang 90, 275.

Bewegung 86, 264.

Bildungszellen 37.

Bipalium kewense 150, 176.

Blastem, embryonales 341 .

Blastomeren 341.

Bothriomolus 329 .

Bothrioplana semperi 263, 320, 329.

Bothrioplanidae 329.

Bothromesostoma 247, 250, 252, 264, $289,290,326,334,338$.

- esseni 338. 
Bothromesostoma personatum 205, $224,225,291,292,293,294,295$, $319,338,346$.

Brackwasserbewohner 153.

Bryozoen 273.

Bugula avicularia 273.

Bursa copulatrix 244.

- seminalis 249.

Byrsophlebs 326.

Byrsophlebidae 226, 326.

\section{C}

Carangiden 213.

Castrada 248, 249, 251, 260, 319, $326,333,336$.

- armata $315,320,337$.

- hofmanni 249, 337.

- intermedia 337.

- lanceola 337.

- spinulosa 320.

- viridis 337.

Castrella 325.

- truncata 227, 248, 307, 315, $320,332,336$.

Catenula 261, 308, 324.

- lemnae 318, 330.

Catenuliden 234, 324.

Celloidinparaffin 12.

Cercyra hastata 175.

Cercyridae 175.

Chemische Reize 315.

Chemische Verhältnisse des Wohnmediums 142.

Chemismus der Umgebung als Regenerationsbedingung 118 .

Chemotaxis 143.

Chiasma 258.

Childia 262.

Chrysaora 213.

Cilien 26, 208.

Cladoceren 273.
Coelom 3.

Coeloplana 349, 351.

Collastoma 325.

Commensalismus 95 .

Conferven 270.

Convoluta 220.

- roscoffensis 272, 315, 348.

Copepoden 273, 274.

Cordylophora 212.

Crossocoela 328.

Cryptocelis 270.

Ctenophoren 349.

Ctenoplana 349.

Cyanophile Drüsen 39, 88, 276.

Cyclocoela 329.

Cypris 274.

\section{D}

Dalyellia 249, 307, 325, 332, 335.

- armigera 315,336 .

- cuspidata 335.

- expedita 248.

- diadema 335.

- hallezii 336.

- picta 336.

- scoparia 335.

- viridis $307,318,334$.

Dalyelliiden 214, 232, 325 .

Daphniden 274, 275, 276, 277.

Darm 46, 228.

Dauereibildung $281 \mathrm{f}$.

Defäkation 94, 279.

Dendrocoelum 89, 90.

- infernale $66,70,83,151,173$, 178, 180, 188.

- lacteum 66, 68, 69, 81, 82, 83, $91,99,100,102,105,110,116$ $145,146,151,152,153,154,161$ $178,180,184$.

- - var. bathycola 151 .

- mrazeki 66, 83, 173, 177, 180, 187. 
Diagonalmuskeln des Hautmuskelschlauches 34 .

Diatomeen 270.

Dicyemiden 352.

Didymorchis 208, 325.

Dilatatoren 218.

Discocoelis 270.

Divertikelbildung am Darm 277.

Doppelbildungen 123, 313.

Dorsalnerven 72.

Dorsoventralmuskeln 35, 215.

Drüsenorgan, muskulöses 65.

Ductus communis 243.

- ejaculatorius 238.

- genito-intestinalis 250 .

- seminalis 236.

- spermaticus 250 .

\section{E}

Ectomeren 347.

Eikapselablage 104, 105, 106.

Eikapselbildung 101, 102, 103, 104.

EiweiBglyzerin 13.

Embryonalpharynx 341.

Enterostomum 328.

Entomeren 347.

Epimorphose 119.

Ernährung 90, 270.

- als Bedingung der Regeneration 117.

Erythrophile Drüsen 39.

Euporobothria 329.

- bohemica 222.

Eurytherm 152.

Euxinia 328.

Excretophoren 235.

Exkretion 98, 279.

Exkretionsapparat 3, 46, 230.

Exkretionsbecher 225, 230.

Exkretionsporus 48.

Extrazelluläre Verdauung 93.

\section{F}

Fadenwürmer als Tricladenparasiten 149.

Farbe $21 \mathrm{f}$., $204 \mathrm{f}$.

Fasciola 6.

Fecampia 327, 353, 354.

Fecampiidae 327.

Feinde der Tricladen 148.

Filamente 307.

Fission 107 ff., 308.

Fliegenlarven 273.

Formregulation 118.

Fuhrmannia 324.

\section{G}

Ganglien 3.

Ganglienzellen 70, 258.

Gehirnganglion 71, 252.

Gelegenheitsparasitismus 95 .

Gelegenheitswanderungen 145, 154.

Genitalapparat 235.

Genitalporus 243.

Genostoma 204, 208, 326.

Genostomatidae 326.

Geotaxis 147, 315 .

Germarien 239.

Germidukt 240.

Germovitellarium 245.

Geschlechtliche Fortpflanzung 99, 279.

Gliagerüst 86.

Gliazellen 70.

Goettesche Larve 348.

Golgi 254.

Graffilla 325.

Graffillidae 325.

Grübchenflecke 264.

Gyratricidae 327.

Gyratrix 250, 327.

- hermaphroditus 210, 233, 249, $319,320,322,330$. 
H

Hämatoxylin Delafield 13.

Haftzellen 87.

Hallezia 328.

Halleziiden 245, 246, 328.

Hautdrüsen 213.

Hautmuskelschlauch 2, 33, 214.

Hautnervenplexus 71, 253.

Hautsinnesorgane 84, 261.

Herbsttiere $279 \mathrm{f}$.

Heteromorphosen 123, 126.

Histologie des Nervensystems 70, 257.

- der Regeneration 128.

Hoden 53, 236, 247.

Holocoela 328.

Hunger 96, 97, 278.

Hyaloide 210.

Hydrachniden 273.

Hydra viridis 205.

Hydropolypen 273.

Hyporcus 327.

Hysterophora 229, 233, 245, 246, $307,324,346$.

I

Jensenia 325 .

Inäquale Teilung 344.

Integument 25, 207.

Jod 11.

\section{$\mathbf{K}$}

Kaliumbichromat - Eisessiggemisch nach Tellyesniczky 18.

Kalyptorhynchia 203, 214, 226, 232, $233,327$.

Kannibalismus 274 .

Kantendrüsen 39 .

Kantenzellen 87.

Kapillaren des Exkretionsystems 46.

Kettenverband 309.

Klebzellen 31, 214.
Köder 143, 144.

Körnerkolben 93.

Körnerdrüsen 39, 238.

Körpermuskulatur 35, 215.

Kommissur 71, $255 \mathrm{f}$.

Kopfdarm 40.

Kopfdrüsen 39, 214.

Kopulationsorgan 238, 247, 248.

Kristalloide 316.

\section{$\mathbf{L}$}

Labriden 213.

Längsbalken des Gehirns 258.

Längsmuskeln des Hautmuskelschlauchs 33 .

Laichzeit $104 \mathrm{ff}$.

Landplanarien 79, 149, 176, 259.

Latenzeier 283.

Lecithophora 307, 324, 325, 346.

Leptoplaniden 270.

Leydigsche Punktsubstanz 71.

Licht als Regenerationbedingung 118.

Liebesspiel 279, 280.

Limnadophile 151.

Limulus 95.

Liporhynchia 325.

Lumbriculiden 273.

Lutheria 326.

\section{M}

Macromeren 344.

Macrostomum 223, 229, 234, 257, $261,331,335$.

- appendiculatum 256, 322, 335.

- viride 262, 271, 335 .

Maehrenthalia 326 .

Maricole 78.

Markstränge 74, 75.

Mecynostomum 324.

Melia tesselata 213.

Mesendiym 37. 
Mesostoma 257, 260, 263, 266, 289, $319,321,326,334,337$.

- craci 247.

- ehrenbergi $202 \mathrm{ff}$.

- lingua 215, 216, 247, 252, 256, 259, 291, 292, 293, 294, 295, 336.

- productum 214, 252, 292, 293, 294, 285, 338.

- tetragonum 202, 203, 247, 266, $319,337$.

Mesostomatini 326, 327.

Mesostomiden 215.

Mesozoën 352.

Micromeren 344.

Micropharynx parasitica 95, 175.

Microplana humicola 161, 176.

Microstominae 324.

Microstomiden 214, 324.

Microstomum 229, 233, 257, 260, $263,271,308,324,331,334$.

- giganteum 309, 334.

- lineare 212, 248, 320, 334.

Minimum der für Regeneration notwendigen Substanzmenge 122.

Minotsche Körnerkolben 46.

MiBbildungen, natürliche 129, 313.

Monoceliden 234, 261, 328.

Monocelis 202, 328.

Monophorum 328.

Morphallaxis 119.

Müllersche Larve 348.

Myoblast 33.

Myrmeciplana 328.

Macrostominae 324.

\section{$\mathbf{N}$}

Nahrung 92, 94, $273 \mathrm{f}$.

Naididen 273.

Nematocysten 211.

Nemertinen 252.

Nervensystem 70; 252.

Nesselkapsel 211.
Notonectalarven 273.

Notoryctes typhlops 350 .

\section{o}

Oekologie 149.

Oesophagus 228.

Olisthanella $231,260,326,332,336$.

- halleziana 247.

- splendida 259, 336.

- truncula $232,320,336$.

Olisthanellini 226, 231, 326.

Omalostomum 324.

Opistomum 325.

- pallidum 318, 331.

Oogonien 239, 338.

Organmuskeln 33, 36 .

Orthonectiden 352 .

Ostracoden 273, 274.

Otocelis rubropunctata 220 .

Otomesostoma 263, 328.

- auditivum 234, 261, 320, 321, 330.

Otoplana 329.

- intermedia 208.

Otoplanidae 329.

\section{p}

Palmenia 262.

Paramaecium aurelia 265.

paramesostoma 326.

Parasitismus 95, 149, 271, 317.

Paravortex 245, 246, 325.

- cardii 345.

Parenchym 3, 33, 35, 37, 219.

passive Verbreitung 157.

Penis 55f., $2 \bar{\jmath} 8$.

Peripherisches Nervensystem 77, 252.

Phaenocora 250, 325 .

- anophthalma 248.

- unipunctata $318,332$.

phagozyten 93.

Phagozytose 93.

Pliarynx 40, 42 f., 222 f. 
Pharynx bulbosus 224.

- compositus 222.

- doliiformis 227.

- plicatus 223, 224.

- rosulatus 224 .

- simplex 222.

- variabilis 228 .

Phonorhynchus 327.

- lemanus 233.

Phototaxis 133 ff., 314.

pigmentbecher 80 .

Plagiostomiden, 234, 328.

Plagiostomum 210.

- girardi 273, 307, 308, 345.

- lemani 234, 320, 321, 330.

Planaria albissima $66,179,182$, 197.

- alpina 9, 22, 42, 66, 74, 77, 78, $81,85,89,96,103,105,107,109$, $110,111,112,113,114,116,129$, $130,146,151,153,154,157,158$, 159, 162 f., 178, 181, 190.

- anophthalma 83.

- cavatica $66,83,151,162,173$, 177, 181, 196.

- fissipara 112, 113, 114.

- fusca 179, 182, 201.

- gonocephala 9, 20, 21, 25, 42, $66,69,74,77,78,79,81,82,83$, $84,85,91,100,102,103,105$, $107,108,109,110,111,112,113$, $114,116,119,122,142,145,146$, $151,152,153,158,162$ f., 178, 182, $185,192,342$.

- gracilis 130 .

- lugubris $42,66,69,81,85,91$, $99,100.103,105,110,116,122$, $126,138,144,146,151,161,179$, 182, 185, 194, 268.

- macrocephala 201.

- maculata 112, 113, 114, 117, 126.

- montenigrina 130.
Planaria polychroa $22,66,69,74$, $77,79,81,85,99,100,102,151$, $161,179,182,195$.

- subtentaculata 112, 113, 201.

- teratophila $86,110,130,131$.

- torva $42,66,81,83,85,116,117$, $146,151,153,161,179,181,185$, 196, 259, 344.

- unionicola 95.

- vitta $10,21,66,81,110,112$, $113,114,151,160,162,171,172$, $178,181,193,318$.

- vruticiana 179, 182, 201.

planula 352.

Plastische Rekonstruktion 14.

Plathelminthes 2.

plexus 71 .

plicastoma 328.

Polarität 127.

Polycelis $66,67,80,81,84,141$.

- cornuta 9, 21, 22, 42, 66, 74, $103,105,110,111,112,113,114$, $146,151,153,158,159,162$ ff., 179 , 183, 199.

- nigra $22,66,95,125,151,160$, $161,179,183,185,198$.

Polycladen 5, 69, 74, 250, 347.

Polycladodes alba 21, 66, 67, 68, $83,84,89,97,110,134,146,151$, $179,183,189$.

polycystidae 327 .

Polycystis 327.

- goettei $233,322,330$.

Polypharyngie 85, 130.

pomacentriden 213.

procerodes 95.

- dohrni 100, 101.

- lobata 101, 174, 175.

- segmentata (syn. P. lobata) 118.

- ulvae 85, 175.

Procerodidae 174.

Promesostoma 326. 
Promesostoma murmanicum 270.

Prohynchidae 325.

Prorhynchus 202, 252, 317, 325.

- applanatus 222 .

- hygrophilus 208.

- stagnalis 252, 320, 331.

prostheceraeus 270 .

protraktoren 218.

Provortex 246, 247, 325.

Proxenetes 326.

proxenetiden 226, 326.

Pseudoceriden 270.

Pseudorhabditen 29.

Pseudostomidae 328.

Pseudostomum 245, 246, 328.

Pteropoden 270.

Punktsubstanz 71, 258.

Querteilung 107, 308.

Quetschpräparate 14, 17.

\section{R}

Randnerven $72,78$.

Randzellen 31.

Receptaculum seminis 241 .

Reduktionen 128.

Reduktionsteilung 340.

Regeneration $115 \mathrm{ff} ., 310$.

Regenerationsdauer 117 .

Regenerationsgewebe 128 .

Regenerationsvermögen, verschiedenes der einzelnen Arten 116.

Reinwasserformen 152.

Retraktoren 217, 218.

Rhabditen 29.

Rhabdocoelidenentwidklung 344.

Rhabdoide 29, 276.

Rhammiten 29.

Rheophile 151.

Rheotaxis 145,315 .

Rynchodemus 79,84 .
Rhynchodemus bilineatus 161, 176.

- terrestris 150, 161, 176.

Rhynchomesostoma 251, 326.

- rostratum 203, 204, 216, 218, $231,259,290,320,332$.

Rhynchoscolex 308, 324.

- vejdovskyi 331.

Richtungskörperchen 340 .

Ringmuskeln d. Hautmuskelschlauchs 33.

Rotatorien 273.

Rüsselscheide 40.

\section{$\mathbf{S}$}

Sabussowia dioica 63, 175 .

Scariden 213.

Schalendrüsen $61,243$.

Schizorhynchidae 327.

Schizorhyndus 327 .

Schmutzwasserformen 152.

Schlundganglion, oberes und unteres 73.

Schlundkommissur 73.

Schlundring 257.

Schüsselförmige Organe 260.

Sdiwanzdarm 41.

Sdhwanzdrüsen 214.

Schwanzganglion 257.

Schwerkraft als Regenerationsbebedingung 118 .

Seetricladen 153, 174.

Sehkolben 82.

Sehnerven 77.

Selbstbefrudhtung 285.

Solenopharyngidae 327 .

Solenopharynx 327.

Solitärtiere 309.

Sommerlaicher 104.

Sommertiere $287 \mathrm{f}$.

Sorocelis 84 .

Sinnesnerven 77 .

Sinnesorgan 80, 259. 
Sinnestătigkeit $132 \mathrm{ff}$.

Spermatogonien 339.

Spermatophoren 248.

Spermatozyten 338 .

Spermien 330.

Speziesdiagnosen $183 \mathrm{ff}$.

Sphagnella 326.

- lutheri 333.

Spinndrüsen 213, 266, 276.

Spiraltypus der Teilung 347.

Sporozoen als Tricladenparasiten 149.

Stäbchen 29, 210.

Stäbchenstraßen 211.

Stammzellen 37.

Statocysten 261, 315.

Statolithen 261.

Stenostomum 245, 246, 260, 263, $308,310,324,331,334$.

- langi 310.

-- leucops 234, 255, 271, 334.

- unicolor 334.

Stenotherm 152.

Stereotaxis 147.

Stiftchenkappe 82.

Strickleiternervensystem 72.

Strongylostoma 326.

- radiatum 320, 333.

Stylaria lacustris 277 .

Stylochoplana 270.

Subitaneier $284 \mathrm{f}$.

Sublimateisessiggemisch 11 .

Sublimat-Salpetersäure 10.

Substanzinsel 74.

Symbiose mit Algen 272.

Syncoelidium 175.

Syncytium 37, 40.

Syndesmus 250, 325.

Synsiphonium 175.

$\mathbf{T}$

Taborella 326.

- hofsteni 333.
Talpa europaea 350.

Tangentialmuskeln 36, 215 .

TastgeiBelzellen 261.

Tastlappen 85 .

Tastorgane 261.

Tastrüssel $216 \mathrm{f}$.

Tauridella 326.

Teilungungsepidemien 107.

Temperatur als Bedingung der Regeneration 117.

Temperaturempfindlichkeit 141, 315 .

Tentakelbläschen 85 .

Tentakeln 85, 203.

Terminalorgan 47, 235.

Tetracelis 251,326 .

- marmorosa 259, 260, 333.

Thermische Reize 315.

Thigmotaxis 147 .

Tjalfiella 349, 351, 352.

Transplantation 128.

Trematoden 307.

Trichodinen als Tricladenparasiten 149.

Tricladenentwicklung 340 .

Trigonostomidae 327 .

Trigonostomum 327.

- neocomense 320, 321.

Tubificiden 273.

Typhloplana 259, 319, 326.

- viridata 333.

Typhloplanella 231, 232, 326.

- bresslaui 333.

Typhloplaniden $226,245,247,248$, $289,326$.

Typhloplanini 326 .

Typhlorhyndus 326 .

\section{U}

Umagilla 325.

Ungeschlechtliche Fortpflanzung 107, 308.

Unio 95. 


\section{$-380$}

Unpaardarm 41.

Unterschiedsempfindlichkeit $133 \mathrm{f}$. Urastoma 326.

Uteriporidae 174.

Uteriporus vulgaris 174.

Uterus 243.

\section{V}

Vagina 250.

van Gehuchtensche Lösung 254.

van t'Hoff-Arrheniussche Regel 304, 305.

Vasa deferentia 236.

Vejdovskya 325.

Verbreitung 154.

Verdauung 93.

- extrakorporelle 93.

- intrazelluläre 278.

Verdauungsapparat 39, 221.

Verschleppung 158.

Verschwemmung 157.
Vesicula seminalis 236, 238 .

Vitellarium $241 \mathrm{f}$.

Vortex 335.

Vorticeros 328.

Vorzeitige Regeneration 109.

\section{W}

Wimperorgane 235, 261, 263.

Wimpertrichter 47.

Wintereier 288.

Winterlaicher 104.

Wintertiere $284 \mathrm{f}$.

Woodsholia 327.

\section{Z}

Zenkersche Lösung 11.

Zerebralganglion 71 .

Zoochlorellen 205, 272, 314.

Zooiden 308.

Zooxanthellen 205, 314 . 





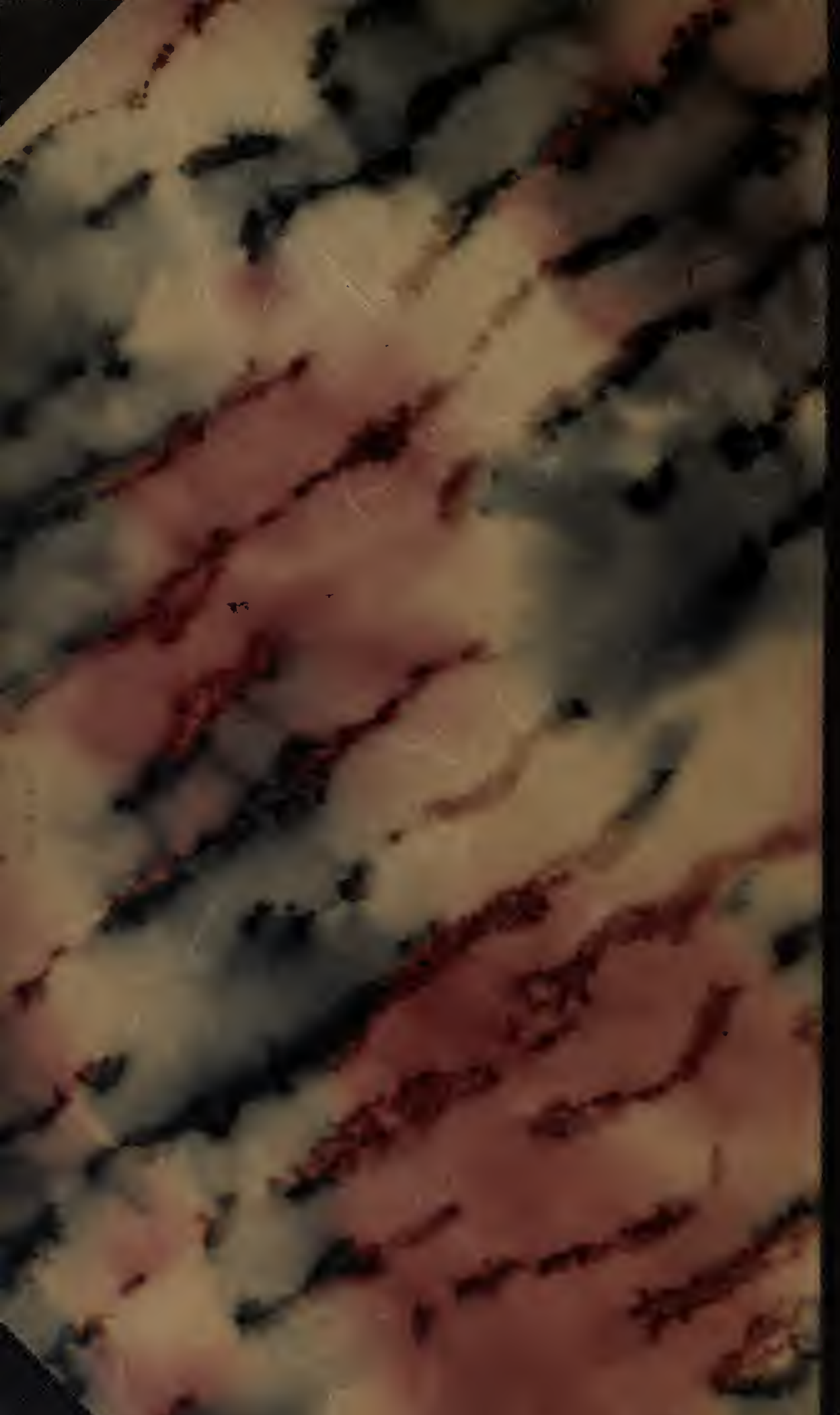

